\title{
TÓPICOS EM GESTÃO DA PRODUÇÃO VOLUME 5
}

\author{
Hélcio Martins Tristão \\ (organizador)
}

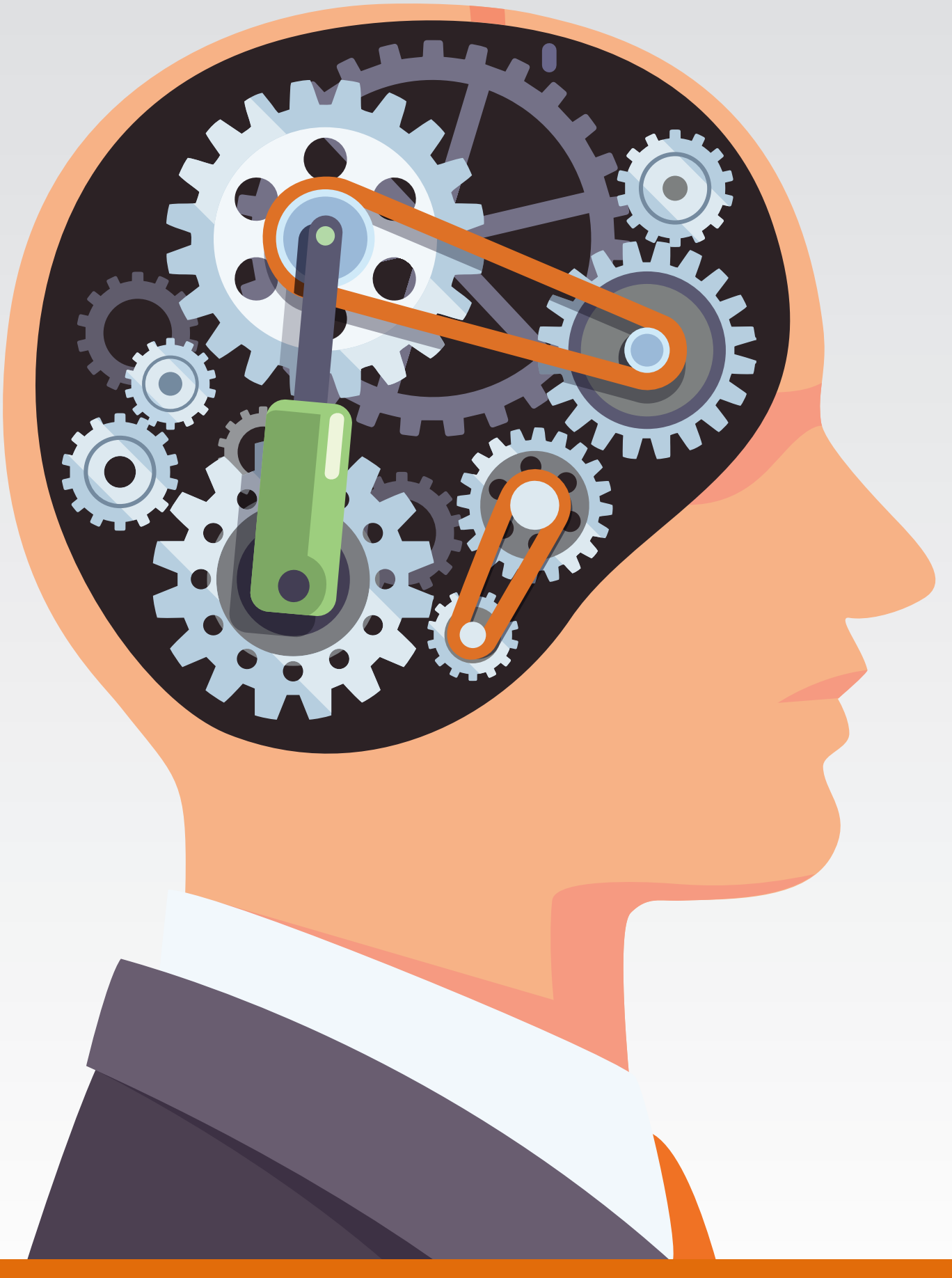

Editora Poisson 
Hélcio Martins Tristão

(organizador)

\title{
Tópicos em Gestão da Produção Volume 5
}

\author{
1르 Edição
}

Belo Horizonte

Poisson

2017 


\section{Conselho Editorial}

Dr. Antônio Artur de Souza - Universidade Federal de Minas Gerais Dra. Cacilda Nacur Lorentz - Universidade do Estado de Minas Gerais Dr. José Eduardo Ferreira Lopes - Universidade Federal de Uberlândia Dr. Otaviano Francisco Neves - Pontifícia Universidade Católica de Minas Gerais

Dr. Luiz Cláudio de Lima - Universidade FUMEC

Dr. Nelson Ferreira Filho - Faculdades Kennedy

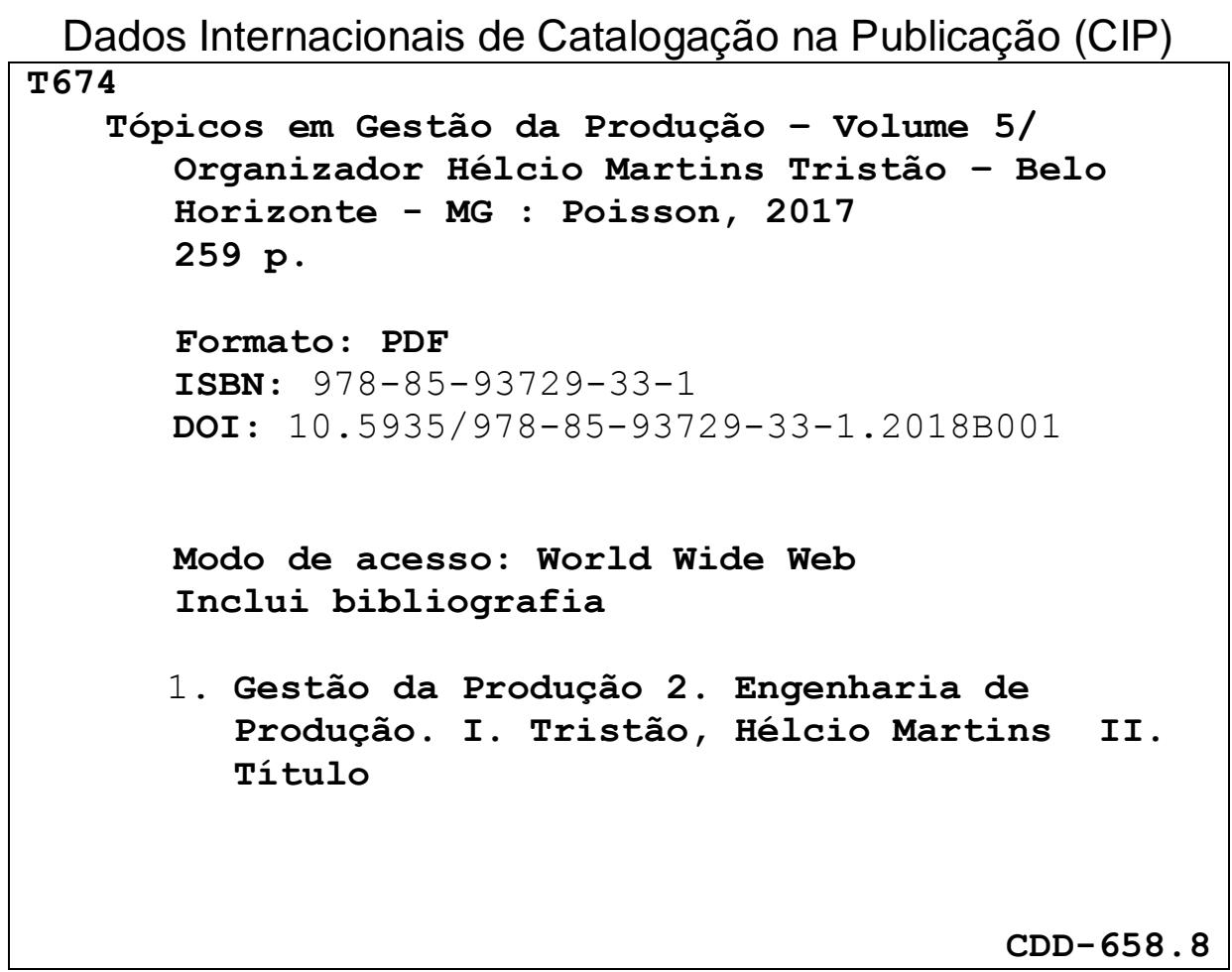

O conteúdo dos artigos e seus dados em sua forma, correção e confiabilidade são de responsabilidade exclusiva dos seus respectivos autores.

www.poisson.com.br

contato@poisson.com.br 
Apresentação

Na dinâmica da competitividade e efetividade da "Gestão da Produção" destacam- se cada vez mais tópicos inerentes à busca pela excelência em resultados econômicos e financeiros das organizações privadas e públicas.

Nesse escopo, este e-book apresenta contribuições da academia por meio de autores dedicados e com conhecimentos específicos que investigam, analisam métodos e aplicações, propõem soluções, desenvolvem formulações e abordam temas sobre: levantamento de estudos, análises e comparações de meios utilizados pelas organizações para o alcance de níveis de desempenho competitivos; da elaboração de propostas de soluções para problemas e melhoria do processo de gestão da produção, sejam eles voltados para a otimização dos recursos utilizados - tempo, recursos físicos e materiais, ou na formulação de instrumentos que permitam controle efetivo sobre - vendas, demandas e eliminação de fatores desnecessários para a produção de produtos e serviços.

Não obstante, ainda traz ampla abordagem de métodos, técnicas, modelos e impactos das novas tecnologias sobre as organizações e que permitem ao leitor ter um contato pragmático com resultados obtidos a partir do uso desses conhecimentos.

Assim, as contribuições inseridas nesse conjunto de abordagens corroboram tanto para acadêmicos quanto para profissionais dos setores privados e públicos, uma vez que não se limitam aos aspectos teóricos e conceituais, mas apresentam formas de integrar conhecimentos específicos dos "Tópicos Modernos da Gestão da Produção" com objetivos de melhoria dos resultados operacionais e da otimização na preservação e uso dos recursos produtivos.

Aos colegas acadêmicos, parceiros profissionais, editores, agradecimentos respeitosos e aos leitores desejo ótimas e profícuas leituras.
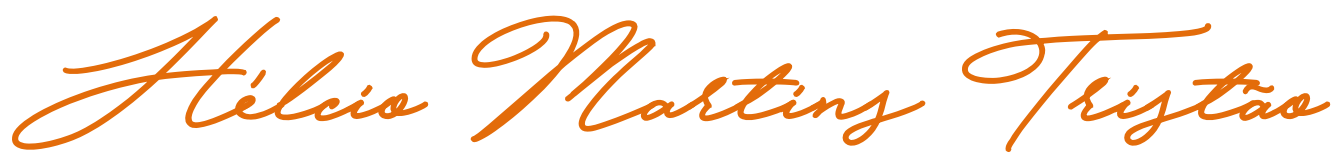


\section{SUMÁRIO}

Capítulo 1 - Escoamento de soja na região oeste da Bahia: um estudo

comparativo entre modais de transporte

Jovenilson Rocha de Oliveira, Meire Ramalho de Oliveira, Mayesk Alves Rocha, José Américo Fernandes de Souza, Éder Falcão

Capítulo 2 - Proporcionar a redução do tempo de Setup aplicado em uma indústria do Setor Gráfico

Luis Philippe do Carmo Moreira, Rafael Leandro da Silva, Vinnicyus Branco Morais Santos, Alessandro Marcio Martins Dias

Capítulo 3 - Proposta para implantação de ferramentas Lean em empresa de Design Gráfico de pequeno porte

Shirley Suellen Thesari, Renato Tonello, Marcelo Gonçalves Trentin, Dalmarino Setti, Flavio Trojan

Capítulo 4 - Redução do índice de perda de insumos com aplicação do método PDCA: estudo de caso em uma empresa de Manaus-AM Adriana Simas da Silva, Ariel Muniky dos Santos Brito, André Luiz Nunes Zogahib, Leandro Aparecido Leite

Capítulo 5 - Avaliação da percepção de riscos e perigos de acidentes dos operadores de logística

Gleison de Sousa Amorim, Kazuo Hatakeyama

Capítulo 6 - Controle de cadeias de suprimentos com incertezas de modelagem e de previsão de demanda: uma abordagem baseada no controle preditivo generalizado. Dayron Antonio Álvarez Rodríguez, Júlio Elias Normey-Rico, Rodolfo César Costa Flesch

Capítulo 7 - Proposta de melhoria na gestão de estoques em uma panificadora da região norte de Santa Catarina

Tamires Heidemann, Aldérico Silvio Gulini

Capítulo 8 - Análise de estoque em diferentes cenários produtivos utilizando modelo de dimensionamento de lotes e aplicando busca tabu

Talita Mariana Pinho Schimidt, Nathália Cristina Ortiz da Silva,Cassius Tadeu Scarpin, Alexandre Checoli Choueire Matheus Bazo do Nascimento

Capítulo 9 - Avaliação da produção científica do problema de programação em sistemas flowshop permutacional.

Kellen Dayelle Endler, Maria Teresinha Arns Steiner, Cassius Tadeu Scarpin, Bruno Henrique da Silva, Alexandre Checoli Choueiri

Capítulo 10 - Rede PERT/CPM em uma obra de construção civil: uma análise do caminho crítico e diversos componentes do processo 
Capítulo 11 - Problema de carregamento de múltiplos contêineres heterogêneos com restrição adicional de separação de itens: uma formulação matemática Cleder Marcos Schenekemberg, Cassius Tadeu Scarpin, José Eduardo Pécora Junior, Alexandre Checoli Choueiri, Deidson Vitorio Kurpel

Capítulo 12 - Sistemas especialistas nas organizações: um estudo bibliométrico Myller Augusto Santos Gomes, Eloni dos Santos Perin

Capítulo 13 - Análise da viabilidade econômica da implantação de uma indústria de blocos de concreto Letícia Lange de Macedo, Carina Lorenzon, Loreine Gabriele Martins da Silva Oliveira, Kamila Taira Paschoal Alves Corrêa, Camila Maira Viana Gonçalves

Capítulo 14 - Previsão de demanda em uma indústria de batata chips. Leticia Fernanda Pires Alves, Fabiane Avanzi Rezende, Rayane Carla Scheffer, Rony Peterson da Rocha

Capítulo 15 - Método ABC aplicado no transporte rodoviário de cargas

Dhiego Troquez, Cristiane Mallmann Huppes, Gabriela Borges Silveira, Robson Benedito Farias

Capítulo 16 - O impacto das novas tecnologias na gestão da produção:

estudo de caso em uma empresa de engenharia e construção.

Eliseu Afonso Soares, José Cícero Melo, Carlos Rodrigues Silva

Capítulo 17 - Mapeamento do processo produtivo como fator interveniente na competitividade organizacional.

Djosete Santos da Costa, leda Isabella de Lira Souza, Alice Dantas de Medeiros, Fernanda Maria de Oliveira Firmino, Rafaela Costa de Azevedo

Capítulo 18 - Alinhamento das prioridades competitivas nas estratégias das cadeias de suprimentos da Cisco e Nike - um estudo de múltiplos casos Délvio Venanzi, Haroldo Lhou Hasegawa, Orlando Roque da Silva

Capítulo 19 - Mapeamento de processos aplicado à organização do setor de patrimônio de uma instituição pública Juliano Ferreira Lima, Marcio Carvalho dos Santos

Capítulo 20 - Um estudo comparativo do desempenho das cadeias de suprimentos da indústria automobilística: o caso da Wolkswagen (RJ) e Mercedes Benz (SBC-SP)

Délvio Venanzi, Orlando Roque da Silva, Haroldo Lhou Hasegawa, Arnoldo José de Hoyos Guevara

Capítulo 21 - Análise multicritério da evidenciação ambiental das empresas do IBRX-100 uma aplicação do método T-ODA.

Mara Vogt, Larissa Degenhart, Nelson Hein, Adriana Kroenke 


\title{
CAPÍTULO 1
}

\section{ESCOAMENTO DE SOJA NA REGIÃO OESTE DA BAHIA: UM ESTUDO COMPARATIVO ENTRE MODAIS DE TRANSPORTE}

\author{
Jovenilson Rocha de Oliveira \\ Meire Ramalho de Oliveira \\ Mayesk Alves Rocha \\ José Américo Fernandes de Souza \\ Éder Falcão
}

Resumo: O agronegócio é responsável por uma significativa parcela do Produto Interno Bruto (PIB) nacional. Parte dessa contribuição advém da cultura da soja, uma das principais commodities agrícolas do país, também cultivada no Oeste do estado da Bahia. Esta cultura apresenta um novo ciclo de desenvolvimento, constituído por intensa transformação do espaço e uso de tecnologias agrícolas. Além da intensificação do processo produtivo, o escoamento é um fator estratégico. O objetivo deste artigo é comparar os modais rodoviário e rodoferroviário no escoamento da soja no estado Bahia, analisando aspectos como emissão de $\mathrm{CO} 2$, consumo de combustível, capacidade de carga e velocidade média, visando deste modo identifica as vantagens da implantação da Ferrovia de Integração Oeste -Leste (FIOL).

Palavras chave: Logística Agrícola, Ferrovia de Integração Oeste -Leste (FIOL), modais de transporte 


\section{INTRODUÇÃO}

O agronegócio, desde muito cedo, tem se tornado um dos pilares da economia nacional. No ano de 2014 o mesmo foi responsável por aproximadamente $22 \%$ do Produto Interno Bruto (PIB), correspondente a $R \$ 1,1$ trilhão, dos quais, as atividades agrícolas específicas representam 70\% desse montante (BRASIL, 2014). Em relação às exportações, a participação do agronegócio foi $50,3 \%$ das vendas externas totais do país, de US\$ 13,348 bilhões em fevereiro de 2016 (BRASIL, 2016). Estes índices demonstram a importância do agribusiness para a economia brasileira.

A nova dinâmica de mercado vigente culminou no desenvolvimento do agronegócio globalizado, com práticas modernas de gestão, em que há busca por controle de custos, planos de investimentos e práticas de novas técnicas de produção, tem se tornado cada vez mais comum, aumentando a competitividade global e a profissionalização das atividades do agronegócio (REZENDE; BARBOSA, 2012).

No que se refere à produção de grãos, mais especificamente a soja, os campeões de produção no Brasil são os estados de Mato Grosso, Paraná, Rio Grande do Sul, Goiás, Mato Grosso do Sul e Bahia. Na safra de 2014/2015 o Oeste baiano, onde praticamente quase toda a soja do estado da Bahia é produzida, gerou em torno de $4,5 \%$ da produção total de soja no país, cerca de quatro milhões de toneladas (MAPA, 2015).

Apesar da grande representatividade do setor agropecuário brasileiro, produzir alimentos em quantidades compatíveis com o crescimento da população mundial, bem como promover o desenvolvimento sustentável de produtos agrícolas, ainda caracteriza-se como um dos grandes desafios do agronegócio mundial. Sobretudo no que diz respeito à logística agrícola, que em sua maioria é ineficiente e paliativa às questões ambientais, utilizando-se muitas vezes de modais de transporte com altas taxas de emissão de gases estufa, que culmina no agravamento do aquecimento global.

No Brasil, o modal predominante é o rodoviário, principalmente nas regiões, nas quais o setor agropecuário é bem característico. No Nordeste não é diferente, porém a malha rodoviária ainda carece de boas condições de conservação (ABAG, 2015).

Neste contexto, Correia (2013) afirma que os custos logísticos de armazenagem e escoamento da produção acabam por elevar o preço da soja desenvolvida no oeste baiano, tornando-a menos competitiva no mercado de exportação.

Portanto, o objetivo desta pesquisa é realizar uma análise entre os modais rodoviários e rodoferroviários no escoamento da soja do oeste baiano, comparando os respectivos impactos ambientais, a produtividade e a análise da implantação da Ferrovia de Integração Oeste-Leste. A seguir, apresentar-se-á a fundamentação teórica sobre a temática em lide.

\section{REFERENCIAL TEÓRICO}

Apesar do cenário econômico de recessão vigente no Brasil, o agronegócio tem mantido firme sua participação no PIB, na geração de empregos e nas exportações, revelando-se um gigante na sustentação da economia (CNA, 2015).

O Brasil é um dos países de maior potencial produtivo de commodities do mundo, representado pela liderança na exportação de café, açúcar, álcool e sucos de frutas, de soja, carne bovina, couro, algodão e bioenergéticos. Parte desse resultado favorável deve-se ao desenvolvimento tecnológico ocorrido nas últimas décadas, resultando produtividade recorde em diversos produtos (OCDE FAO, 2015).

Nesse contexto, a produção e exportação de soja em grãos no Brasil têm aumentado vertiginosamente, contribuindo para o superávit da balança comercial brasileira e para a geração de divisas (NETO, 2015).

\subsection{A SOJA}

O melhoramento genético alcançado pelos institutos de pesquisas (EMBRAPA, ESALQ, IAC, etc.), proporcionou à soja passar de uma simples planta forrageira a cultura mais proeminente do agronegócio brasileiro, bem como, a oleaginosa mais comercializada nos dias atuais (KIIIHL, 2006). 
A produção de soja apresentou um crescimento expressivo a partir da década de 90, passando de 19,9 milhões de toneladas em 1990, para 81 milhões de toneladas em 2013, alçando o Brasil a condição de segundo maior produtor e exportador do mundo (NETO, 2015).

Espera-se que o Brasil tenha em 2016 uma área plantada de soja próxima a 33 milhões de hectares, representando um crescimento de 3\% em relação à safra 2015. E a Bahia, com o maior crescimento percentual dentre os estados produtores, deverá plantar em torno de 1,6 milhão de hectares, um crescimento de 13\% em relação à safra de 2015 (CNA, 2015).

Todavia, há um paradoxo entre o crescimento da produção agrícola brasileira e a logística para o seu escoamento. A ineficiência logística afeta a competitividade internacional das exportações, principalmente para produtos com baixo valor agregado, como é o caso da soja em grão. Os gargalos no escoamento da soja, juntamente com as deficiências na capacidade de armazenagem, reúnem os dois grandes fatores de estrangulamento do agronegócio brasileiro (NAVES, 2007).

\subsection{O ESCOAMENTO DA SOJA PELOS MODAIS RODOVIÁRIO E FERROVIÁRIO}

Possuir um setor agropecuário expressivo não é suficiente para garantir o abastecimento do mercado interno e a produção de excedente. As grandes dimensões do território nacional dificultam a integração e desenvolvimento econômico das diversas regiões do país, aumentando assim a necessidade de meios de transporte cada vez mais eficientes. A existência de modais de transporte que atendam exigências da produção agrícola é um fator determinante para a competitividade do agronegócio no mercado mundial (ROCHA, 2006).

Dentre os principais modais de transporte de cargas pesadas em longas distâncias no território brasileiro, destacam-se os modais: rodoviário e o ferroviário. O modal rodoviário tem sido a preferência na movimentação de pessoas e bens no Brasil, com a maior participação (61\%) na matriz de transportes de cargas, seguido pelos modais ferroviário (20,7\%), aquaviário (13,6\%), dutoviário $(4,2 \%)$ e aéreo $(0,4 \%)$ (CNT, 2015).

O transporte rodoviário é caracterizado pela flexibilidade nas operações logísticas, podendo atuar na distribuição de mercadorias desde a origem até o destino final, configurando-se como um transporte "porta-a-porta", sem a necessidade de transbordo (ROCHA, 2006). Já o transporte ferroviário tem como principal característica à capacidade de transportar grandes volumes de mercadorias por longas distâncias a um custo mais baixo se comparado ao modal rodoviário (CAIXETA et al., 1998).

A escolha de um modal depende da capacidade da carga e da distância a ser percorrida, conforme pode ser observado na Figura 1 (FLEURY et al., 2000).

Figura 1 - Comparativo entre os modais Rodoviário e Ferroviário

\begin{tabular}{|c|c|c|c|c|c|c|}
\hline & $\begin{array}{c}\text { Abaixo de } \\
0,5 t\end{array}$ & $0,5-4,5 t$ & $4,5-13,5 t$ & $13,5-27 t$ & $27-40 t$ & $\begin{array}{c}\text { Acima de } \\
40 t\end{array}$ \\
\hline \multicolumn{7}{|l|}{$\begin{array}{c}\text { Abaixo de } \\
180 \mathrm{~km}\end{array}$} \\
\hline \multicolumn{7}{|l|}{$160-320 \mathrm{~km}$} \\
\hline \multicolumn{7}{|l|}{$320-480 \mathrm{~km}$} \\
\hline \multicolumn{7}{|l|}{$480-500 \mathrm{~km}$} \\
\hline \multicolumn{7}{|l|}{$800-1600 \mathrm{~km}$} \\
\hline $\begin{array}{c}1600-2400 \\
\mathrm{~km}\end{array}$ & Rod & fário & COMI & [I Ċ̃̃ O & \multicolumn{2}{|c|}{ Ferroviário } \\
\hline $\begin{array}{l}\text { Acima de } \\
2400 \mathrm{~km}\end{array}$ & & & & & & \\
\hline
\end{tabular}

Fonte: Fleury et al. (2000) 
Da Figura 1 é possível inferir que para as menores distâncias e pesos, o modal rodoviário é o mais indicado, enquanto que para maiores distâncias e maiores cargas, o ferroviário ganha maior espaço, coexistindo uma região de competição entre os dois modais, como demonstrado na região sombreada.

O modal rodoviário é responsável por transportar mais da metade da produção de soja do Brasil, apesar de um caminhão transportar cerca de 150 vezes menos soja do que uma composição ferroviária, e possuir desvantagens inerentes, tais como maior poluição ambiental e maior consumo de combustível (HIIJAR, 2006). Somados a isso, CNT (2015) aponta que o Brasil tem prejuízo anual de $\mathrm{R} \$ 3,8$ bilhões somente com a exportação desses grãos devido às condições das rodovias, em especial à deficiência de pavimentação. A pesquisa ratificou ainda que $57,3 \%$ da extensão total das rodovias avaliadas apresentaram algum tipo de deficiência (pavimento, sinalização ou geometria da via), sendo que 6,3\% encontram-se em estado péssimo, 16,1\% estado ruim e 34,9\% regular - Figura 2.

Figura 2 - Classificação do Estado Geral das Rodovias Brasileiras

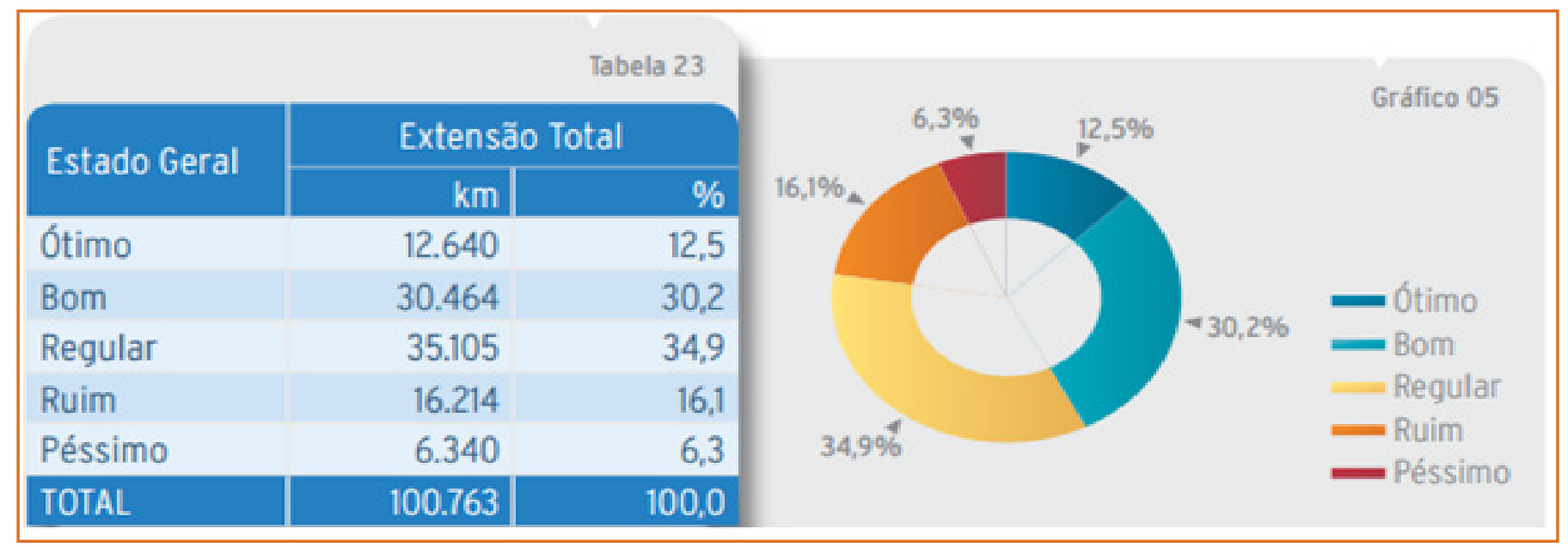

Fonte: CNT (2015)

Não obstante, essa ausência de infraestrutura rodoviária implica na elevação dos custos de operação, uma vez que a constância na manutenção dos veículos, as avarias com os pneus e o aumento do consumo de combustível, entre outros, são consequências do inadequado estado de conservação dessas estradas.

\subsection{OESTE DA BAHIA E O ESCOAMENTO DA SOJA}

O Oeste baiano está localizado no limite ocidental da Bahia, área que permaneceu preservada por ser avaliado como um território de reserva. A área de estudo é formada por dezessete municípios, totalizando uma extensão territorial de $114.873 \mathrm{~km}^{2}$, ou 20\% de todo território baiano (FERNANDES, 2010).

As particularidades do clima, solo e luminosidade são favoráveis a diversas culturas como soja, milho, algodão e café irrigado. A soja é a principal cultura agrícola desta região, com uma área cultivada de $58,8 \%$, o que representa $4,8 \%$ da produção brasileira e $58 \%$ da produção nordestina (AIBA, 2014).

A soja destinada às indústrias utiliza como rota de escoamento a BR 242, em $100 \%$ dos casos, enquanto a soja para exportação utiliza essa mesma rota para escoamento em $80 \%$ dos fluxos (AIBA, 2015). Os embarques do grão acontecem cada vez mais nos próprios portos do Estado, principalmente o da capital, Salvador. Em 2013, mais de 94\% do total exportado foi escoado por esta via. O Porto de Ilhéus correspondeu em 2013 uma canalização em torno de 4\% das saídas da produção, com o que, somando as de Salvador, concentra quase todo o movimento exportador da soja 
oriunda do Oeste da Bahia (AIBA, 2014).

\subsection{O PROJETO DA FERROVIA DE INTEGRAÇÃO OESTE-LESTE (FIOL)}

O objetivo geral da construção da Ferrovia Oeste-Leste é a substituição do modal rodoviário pelo ferroviário para aumentar a eficiência de trocas de cargas vindas do Oeste para o Centro e o Leste do país (ALMEIDA et al., 2010), conforme Figura 3.

Figura 3 - Representação da FIOL.

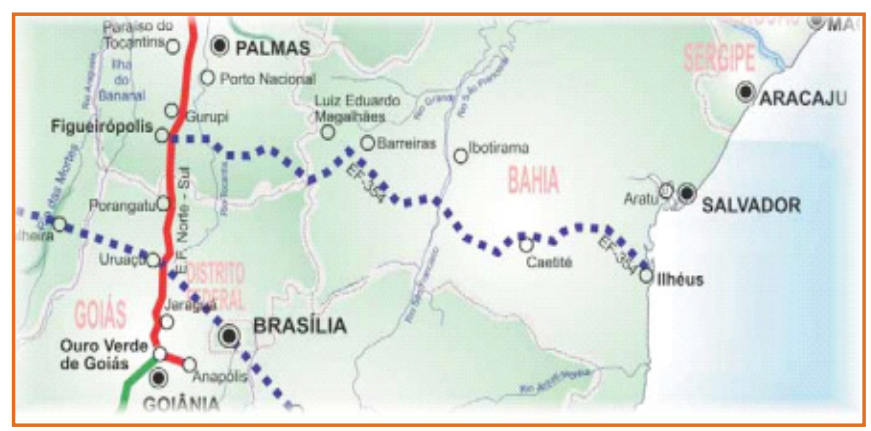

Fonte: RIMA (2009)

A Integração Oeste - Leste conectará as cidades de
Ilhéus (BA) à Figueirópolis (TO). O percurso total é de 1526 km de extensão, passando por um dos principais polos industriais de extração de minério de ferro, álcool e produção de grãos do Brasil. O projeto é coordenado e realizado pela estatal VALEC Engenharia, Construção e Ferrovias S.A.

A ferrovia dinamiza o escoamento de commodities produzidos no Norte, Centro e Nordeste do país, oferecendo uma nova alternativa logística com custos reduzidos e maior qualidade aos produtos destinados tanto ao mercado interno quanto à exportação (ALMEIDA et al., 2010).

Com o aumento da produção de grãos no oeste baiano, a ferrovia também oferece benefícios para o escoamento da produção de soja. Portanto, a ferrovia transportará os minérios de ferro extraídos no polo industrial de Caetité e os diferentes tipos de grãos produzidos no oeste baiano (OLIVEIRA et al., 2013).

A seguir tem-se a estrutura das etapas de construção da ferrovia - Figura 4. 


\begin{tabular}{|c|c|c|}
\hline \multicolumn{3}{|c|}{$01^{a}$ ETAPA - Entre llhéus e Barreiras } \\
\hline Lotes, extensão e cidades do trecho & $\begin{array}{l}\text { Valor do contrato } \\
\text { em R\$ milhões }\end{array}$ & $\begin{array}{l}\text { Execução da obra } \\
\text { até junho de } 2013\end{array}$ \\
\hline $\begin{array}{l}\text { Lote } 01 \text { - } 125 \mathrm{Km} \text { - Parte do terminal de llhéus, onde ficará o terminal de descarga } \\
\text { geral com capacidade estimada entre } 5 \text { e } 68 \text { milhões de toneladas }\end{array}$ & 575 & $7,75 \%$ \\
\hline Lote 02 - 125Km - Itagibá a Jequié & 650 & $18,7 \%$ \\
\hline Lote 03 - 115Km - Jequié a Tanhaçu & 403 & $41,9 \%$ \\
\hline $\begin{array}{l}\text { Lote } 04 \text { - 178km - Tanhaçu a Caetité - Instalação de Pólo Industrial voltado para a } \\
\text { industria de mineração - produção estimada em } 25 \text { milhões de toneladas/ano. Em } \\
\text { Brumado haverá um Pólo Industrial que vai transportar Magnetita, minério de ferro } \\
\text { e cargas gerais, com capacidade para } 29 \text { milhões de toneladas/ano; }\end{array}$ & 740 & $23 \%$ \\
\hline Lote 05 - 164km - Vai até as margens do Rio São Francisco; & 720 & Zero \\
\hline Lote 05 A - 2,9km - Ponte sobre o Rio São Francisco & 135 & Zero \\
\hline $\begin{array}{l}\text { Lote } 06 \text { A - } 159 \mathrm{~km} \text { - Até Correntina - Será instalado o terminal multimodal do } \\
\text { sudeste da Bahia com interligação entre a ferrovia e outros modais e fará o } \\
\text { carregamento de grãos, etanol e farelos; }\end{array}$ & 576 & Zero \\
\hline $\begin{array}{l}\text { Lote } 07 \text { A - } 161 \mathrm{~km} \text { - Até São Desidério. Barreiras erá abrir o Terminal Intermodal do } \\
\text { Oeste da Bahia que vai atuar no transporte de grãos, farelos, álcool e algodão; }\end{array}$ & 536 & Zero \\
\hline
\end{tabular}

Fonte: Almeida et al. (2010)

Segundo Oliveira et al (2013) a obra custará $R \$ 6$ bilhões, dos quais cerca de $R \$ 4$ bilhões ficará para os trechos do estado da Bahia. O projeto começou a ser realizado em 2010 e está atrasado em dois anos, com aumento de orçamento aproximado a $\mathrm{R} \$ 2$ bilhões do planejado e previsão de conclusão para 2018 (BORGES, 2015).

\section{METODOLOGIA}

Este trabalho caracteriza-se como uma pesquisa básica, bibliográfica, qualitativa e exploratória. Além disso, tem por objetivo comparar os modais rodoviário e rodoferroviário tomando como base o escoamento da produção de soja do município de Luís Eduardo Magalhães até o Porto de Salvador por rodovias, e do mesmo local de origem até o Porto Sul em IlhéusBahia, utilizando rodovia e ferrovia. Para fins do estudo, será utilizado o atual modelo de transporte empregado e uma comparação com a integração de modais em construção pela FIOL.

Visando uma comparação sustentável, alguns indicadores foram selecionados e estão expostos no Quadro 1. 
Quadro 1 - Indicadores para comparação dos modais

\begin{tabular}{|c|c|}
\hline INDICADOR & DESCRIÇÃO \\
\hline Emissão de $\mathrm{CO} 2$ & Quantidade de CO2 liberada durante o percurso. \\
\hline Consumo de Combustível & Quantidade de combustível consumido nas rotas supracitadas. \\
\hline Tempo & $\begin{array}{l}\text { Período de tempo para o escoamento do grão com a utilização de um } \\
\text { único modal e também pela multimodalidade (rodoviário + ferroviário). }\end{array}$ \\
\hline Quantidade de transporte & $\begin{array}{c}\text { Número de carretas para o modal rodoviário, e o número de vagões } \\
\text { necessários para a malha ferroviária. }\end{array}$ \\
\hline
\end{tabular}

\subsection{CONTEXTUALIZAÇÃO DO PROBLEMA}

Luís Eduardo Magalhães (LEM) é uma cidade localizada na região Oeste da Bahia, com população estimada em 79.162 habitantes, com economia pautada no agronegócio - destaque para a produção de grãos, sobretudo a soja (IBGE, 2015).

Estima-se que na safra de 2013-2014, a produção foi de aproximadamente 3.319 mil toneladas do grão, sendo que mais da metade do que fora produzido, teve o mercado exterior como cliente final. Em paralelo, cerca de $94 \%$ do volume exportado fora destinado ao Porto de Salvador (SSA), evidenciando sua importância para desenvolvimento e integração logística na região, conforme Tabela 1 (AIBA, 2014).

Tabela 1 - Dados referentes à safra 2013-2014

\begin{tabular}{|l|l|l|}
\hline $\begin{array}{l}\text { Produção } \\
\text { (Ton) }\end{array}$ & \multicolumn{1}{|l}{$\begin{array}{l}\text { Quantidade } \\
\text { Exportada (Ton) }\end{array}$} & $\begin{array}{l}\text { Exportação pelo } \\
\text { Porto de Salvador } \\
\text { (Ton) }\end{array}$ \\
\hline 3.319 mil & $1.578 \mathrm{mil}$ & $1.471 \mathrm{mil}$ \\
\hline
\end{tabular}

Fonte: AIBA (2014)

O escoamento dessa produção se deu pelo modal rodoviário (atual sistema de transporte utilizado pelos produtores). A rota utilizada para esse fim pode ser observada na Figura 5.
Figura 5 - Rota entre LEM e SSA

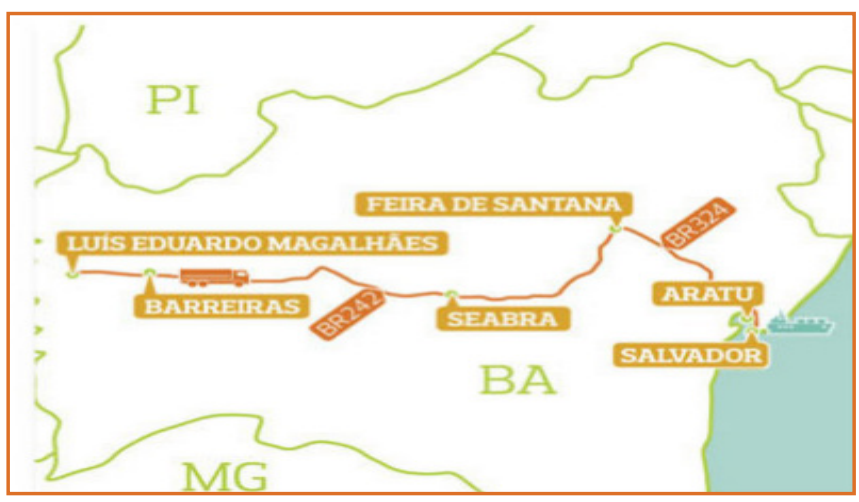

Fonte: Google Imagens (2015)

Esse trecho tem uma extensão de aproximadamente 950 quilômetros e é interligado pela BR 242 e BR 324, conectando a região produtora até o Porto de Salvador. Segundo Fraga (2013), a média de tráfego diário na BR-242 é de 1.100 caminhões, para o escoamento da produção e entrega de insumos agrícolas. Durante a safra de soja, o número é de 3.000 carretas por dia, culminando em congestionamento desta rodovia e em uma maior incidência de acidentes. Ademais, os altos custos com o atual modal acaba impactando negativamente no preço da commodity, no lucro dos produtores e principalmente no cenário ambiental.

Desde o ano de 2010 iniciou-se a construção da Ferrovia de Integração Oeste Leste, como possível solução para os eventuais problemas mencionados e potencial de diversificação do modal a ser utilizado. Tal ferrovia ligará a cidade de Barreiras, localizada a 90 quilômetros de Luís Eduardo Magalhães, ao também em construção, Porto Sul (Illhéus- Bahia). A distância entre esse trecho será de aproximadamente 1022 
quilômetros (VALEC, 2014).

Para realizar a comparação entre os modais considerouse os valores de exportação da Safra de soja de 20132014, que o novo Porto de llhéus (Porto Sul) seja capaz de atender toda a demanda de escoamento dessa produção e que o futuro sistema de transporte seja composto pela integração da malha rodoviária (entre LEM e Barreiras) e ferroviária (Barreias e Ilhéus). A seguir, tem-se a Tabela 2, com as comparações entre os modais.

Tabela 2 - Comparação entre os modais

\begin{tabular}{|c|c|c|c|}
\hline Sistema & Modal & Distância (Km) & Total (Km) \\
\hline Atual & Rodoviário & 950 & 950 \\
\hline Futuro & $\begin{array}{l}\text { Rodoviário- } \\
\text { Ferroviário }\end{array}$ & $\begin{array}{l}30 \\
1022\end{array}$ & 1052 \\
\hline
\end{tabular}

\section{RESULTADOS E DISCUSSÃO}

Nesta seção serão evidenciados os dados quantitativos que diferenciam e classificam os modais rodoviário e ferroviário. A Tabela 3 apresenta os dados de referência para a emissão de $\mathrm{CO}_{2}$, o consumo de combustível, a capacidade de cada carga e a velocidade média (MORAIS et al, 2013).

\section{Tabela 3 - Dados de Referência}

\begin{tabular}{|lllll|}
\hline Modal & $\begin{array}{l}\text { Emissão } \\
\text { de CO2 } \\
(\mathbf{k g} / 1000 \\
\left.\mathrm{TKU}^{*}\right)\end{array}$ & $\begin{array}{l}\text { Consumo de } \\
\text { Combustivel } \\
(\mathrm{L} / 1000 \mathrm{TKU})\end{array}$ & $\begin{array}{l}\text { Capacidade } \\
\text { Carga (Ton) }\end{array}$ & $\begin{array}{l}\text { Velocidade } \\
\text { média } \\
(\mathrm{Km} / \mathrm{h})\end{array}$ \\
\hline Rodoviário & 116 & 96 & 35 & 80 \\
Ferroviário & 34 & 10 & 70 & 25 \\
\hline
\end{tabular}

Fonte: Ministério do Transporte, adaptado de Morais et al (2013)

*Toneladas por Km útil

Para efetuação dos cálculos do sistema atual (malha rodoviária) tomou-se o valor da distância entre o trajeto de LEM e SSA, presentes na Tabela 2, bem como o valor do volume de exportação da soja pelo porto de Salvador, presente na Tabela1. A partir dos dados expostos acima, obtiveram-se os seguintes resultados:
Tabela 4 - Análise dos dados referentes ao modal rodoviário

\begin{tabular}{|llll|}
\hline Modal & $\begin{array}{l}\text { Emissão } \\
\text { de CO2 } \\
(\mathbf{k g})\end{array}$ & $\begin{array}{l}\text { Consumo de } \\
\text { Combustivel } \\
\text { (L) }\end{array}$ & $\begin{array}{l}\text { Tempo Estimado } \\
\text { por Viagem (h) }\end{array}$ \\
\hline Rodoviário & $1,62 \times 108$ & $1,34 \times 108$ & 11,88 \\
\hline
\end{tabular}

Tabela 5 - Análise dos dados referentes ao modal a ser implantado (Rodoferroviário)

\begin{tabular}{|llll|} 
Modal & $\begin{array}{l}\text { Emissão } \\
\text { de CO2 } \\
(\mathbf{k g})\end{array}$ & $\begin{array}{l}\text { Consumo de } \\
\text { Combustivel } \\
\mathbf{( L )}\end{array}$ & $\begin{array}{l}\text { Tempo estimado } \\
\text { por viagem }(\mathbf{h})\end{array}$ \\
\hline Rodoviário & $1,53 \times 107$ & $1,27 \times 107$ & 1,13 \\
\hline Ferroviário & $5,11 \times 107$ & $1,50 \times 107$ & 40,88 \\
\hline Total & $6,64 \times 107$ & $2,77 \times 107$ & 42,01 \\
\hline
\end{tabular}

Diante o exposto, pode-se constatar a discrepância entre a emissão do dióxido de carbono pelo sistema atual (Rodoviário) e o futuro modelo (Rodoferroviário). São mais de 95 milhões de quilos de $\mathrm{CO}_{2}$, quase $41 \%$, que seriam poupados de ser lançados na natureza, caso a integração dos modais já estivesse pronta. Seriam necessárias cerca de 600.000 árvores da Mata Atlântica, durante um período de 20 anos para neutralizar essa diferença de emissão, de acordo com estudos da Universidade Estadual de São Paulo e do Instituto Totum (CRISPIM, 2013).

Além disso, a diferença entre o consumo de combustível também é exorbitante. $\mathrm{O}$ atual modelo consome cerca de 106 milhões de combustível a mais do que no modelo a ser implementado. Neste caso dever-seia também considerar além do valor do combustível economizado, a depreciação de veículos, custos com manutenção, mão de obra direta, pedágios, entre outros.

Quanto ao indicador tempo, o valor gasto por cada viagem no modal rodoferroviário, seria 3,5 vezes maior que na malha exclusivamente rodoviária. Não obstante, vale ressaltar que foram consideradas situações perfeitas, na qual não houvesse paradas ao longo do trajeto, o que não é permitido legalmente (Lei no 12.619/2012), que prevê tempo de descanso de 30 minutos a cada quatro horas de viagem. Outros fatores que afetariam o tempo de viagem são as condições atuais da rodovia, congestionamentos existentes no período de safra, dentre outros fatores que aumentaria 
significativamente o tempo médio da viagem.

Em paralelo a isso, tem-se que a capacidade de carga do modal ferroviário é bem superior ao do rodoviário. Estima-se que para o escoamento dessa produção seria necessário cerca de 42.029 carretas e apenas 21.015 unidades de vagões de trem. Além disso, um trem comporta cerca de 80 vagões, havendo necessidade de 263 trens ou viagens para transporte da carga, reforçando ainda mais as vantagens competitivas deste modal.

\section{CONCLUSÃO}

Com base nos indicadores utilizados, verificouse que a utilização do modal rodoviário não é a alternativa mais eficiente para o escoamento da soja produzida no oeste baiano, uma vez que a utilização deste modal encarece o produto, prejudicando a sua competitividade no mercado.

Além disso, a implantação da ferrovia Oeste-Leste (FIOL) em substituição ao transporte rodoviário mostrou-se que irá impactar positivamente na redução de emissão de CO2, no consumo de combustível, e no número de viagens realizadas. Em decorrência da utilização da malha ferroviária, mesmo em sistema de integração, aliviaria o desenvolvimento do tráfego e proporcionaria melhores condições para o fluxo de veículos.

Não obstante, analisar a movimentação da soja produzida no oeste baiano por outras alternativas de transporte, além do estudado, rodoferroviário, é imprescindível para agregar valor ao commodity, e alcançar índices cada vez mais competitivos no mercado.

\section{REFERÊNCIAS}

[1] ALMEIDA, C. C. M.; SOUZA, T. S.; SANTANA, C. R. M. O traçado da Ferrovia de Integração Oeste-Leste (FIOL) e os impactos sócios-espaciais no município de TanhançuBA. Universidade Estadual do Sudoeste da Bahia. Vitória da Conquista, 2010.
[2] ABAG. Associação Brasileira do Agronegócio. Logística e Competitividade no Agronegócio Brasileiro. São Paulo, 2015. Disponível em: <http://www.abag.com.br/ media/20150807---relatOri0---c0mite-IOgistica---abag.pdf>. Acesso em 16 de fevereiro de 2016.

[3] AIBA. Associação de Agricultores e Irrigantes da Bahia . Revista AIBA Rural, Editora Gazeta Santa Cruz. Barreiras, 2015. Disponível em:< http://aiba.org.br/wp-content/ uploads/2015/09/Aiba-Rural-ed-02-WEBok.pdf>. Acesso em 16 de fevereiro de 2016.

[4] _Anuário da Região Oeste da Bahia - Editora Gazeta Santa Cruz. Barreiras, 2014. 112 p. Disponível em: <http://aiba.org.br/wp-content/uploads/2014/06/OESTE-DABAHIA-2014.pdf>. Acesso em 16 de fevereiro de 2016.

[5] BRASIL. Ministério da Agricultura. Notícias. 2014. Disponível em: <http://www.agricultura.gov.br/comunicacao/ noticias/2014/12/produto-interno-bruto-da-agropecuariadeve-ser-de-rs-1-trilhao>. Acesso em 17 de abril de 2016.

[6] BRASIL. Ministério da Agricultura. Notícias. 2016. Disponível em: <http://www.agricultura.gov.br/comunicacao/ noticias/2016/03/exportacoes-do-agronegocio-crescemquase-37porcento-em-fevereiro>. Acesso em 17 de abril de 2016

[7] BORGES, A. Obra da Ferrovia Oeste-Leste terá atraso de 5 anos. O Estadão, São Paulo, 2015. Disponível em: <http://economia.estadao.com.br/noticias/geral,obra-daferrovia-oeste-leste-tera-atraso-de-5-anos--imp-,1783912>. Acesso em 16 de fevereiro de 2016.

[8] CAIXETA FILHO, J. V. (Org.) et al. Competitividade no agribusiness: a questão do transporte em um contexto logístico. Piracicaba, FEALQ, 1998. Relatório técnico referente ao convênio FEALQ - Fundação de Estudos Agrários Luiz de Queiroz / FIA - Fundação Instituto de Administração, apoiado pelo IPEA - Instituto de Pesquisa Econômica Aplicada.

[9] CNA. Confederação da Agricultura e Pecuária do Brasil. Balanço 2015/ Perspectivas 2016. Brasília, 2015. Disponível em: $\quad<$ http://www.canaldoprodutor.com.br/sites/default/ files/01\%20Balanco2015\%20Perspectivas2016_panorama_ economico_0.pdf>.Acessado em 11 de fev. de 2016.

[10] CNA. Confederação da Agricultura e Pecuária do Brasil, CNA. Balanço 2015/ Perspectivas 2016. Panorama Cadeias Produtivas/ Cereais, Fibras e Oleaginosas. Brasília, 2015. Disponível em:< http://www.canaldoprodutor.com.br/sites/ default/files/02\%20Balanco2015\%20Perspecti vas2016_ panorama_cadeiasProdutivas.pdf>. Acessado em $11 \mathrm{de} \mathrm{fev.}$ de 2016.

[11] CNT. Confederação Nacional do Transporte. Pesquisa CNT de rodovias 2015: relatório gerencial. Brasília, CNT, 2015. Disponível em: <http://pesquisarodoviascms.cnt.org. br//Relatorio\%20Geral/PESQUISA_CNT2015_BAIXA.pdf>. Acessado em 13 de fev. de 2016. 
[12] CORREIA, M. V. A Logística Territorial: O Caso Do Pólo Produtor De Grãos Do Oeste Baiano. Trabalho de Conclusão de Curso, Universidade Federal Da Bahia, Faculdade De Economia. Salvador, 2013.

[13] CRISPIM, M. Cada árvore da Mata Atlântica chega a retirar 163 kg de gás carbônico da atmosfera. Diário do Nordeste, 2013; Disponível em : < http://blogs.diariodonordeste.com. $\mathrm{br} /$ gestaoambiental/mudancas-climaticas/cada-arvore-damata-atlantica-chega-a-retirar-163-kg-de-gas-carbonico-daatmosfera/> . Acessado em 01 de fev. de 2016.

[14] FERNANDES, R. C. Oeste Baiano: Da Agricultura Familiar à Agroindústria. 2010.

[15] FLEURY, P. F. et al. Logística Empresarial: a perspectiva brasileira. São Paulo: Atlas, 2000. 372 p.

[16] FRAGA, A. De olho no horizonte. Globo Rural, 2013. Disponivel em: <http://revistagloborural.globo.com/Revista/ Common/O,,ERT311901-18283,00.html>. Acesso em 16 de fevereiro de 2016

[17] HIJJAR, M. Logística, Soja e Comércio Internacional. Centro de Estudos em Logística (CEL), 2006. Disponível em: <http://www.centrodelogistica.com.br/new/fs-public.htm>. Acessado em 16 de fev. 2016

[18] IBGE. Instituto Brasileiro de Geografia E Estatística. Cidades 2015. Disponível em: < http://cidades.ibge.gov.br/ xtras/perfil. php?codmun=2919>. Acessado em: 01 de fev . de 2016.

[19] KIIHL, R. A. DE S. Como recolocar a "locomotiva" nos trilhos? Visão Agrícola, Piracicaba, v.5, p.4-7, jan/jun. 2006.

[20] MAPA. Ministério da Agricultura e Abastecimento, 2015. Projeções do Agronegócio, Brasil 2015/15 A 2024/25, Projeções De Longo Prazo. Disponível em: <http:// www.agricultura.gov.br/arq_editor/PROJECOES_DO_ AGRONEGOCIO_2025_WEB.pdf>. Acesso em 16 de fev. de 2016.

[21] MORAIS, C.G et al. Estudo de caso: escolha do sistema modal para o escoamento da soja com origem em Lucas do Rio Verde (MT) e destino no porto de Santos (SP) minimizando os impactos ambientais. 2013. Disponível em: < http://www.anpet.org.br/ssat/interface/content/autor/ trabalhos/publicacao/2013/201_AC.pdf>. Acessado em: 01 de fev. de 2016
[22] NAVES, I. A remoção dos estoques públicos através do CN: uma análise sob a ótica da logística do agronegócio. Dissertação de mestrado em agronegócios. Universidade Federal de Mato Grosso do Sul/Universidade de Goiás/ Universidade de Brasília. Brasília/DF, 2007.

[23] NETO, J. G. M. O Mercado de Exportação de Soja e os Portos Brasileiros. Minas Gerais, 2015. Disponível em: < http://www.antaq.gov.br/portal/pdf/Artigos/20150123_ Artigo_Jose_Goncalves_Moreira_Neto.pdf>. Acessado em 13 de fev. de 2016

[24] OCDE-FAO. Perspectivas Agrícolas 2015-2024. Disponível em: https://www.fao.org.br/download/ PA20142015CB.pdf. Acesso em 17/04/2016

[25] OLIVEIRA, C. H.; METTIG, D. H. G.; SOUZA, L. A.; SOUZA G. J. A FIOL e a logística territorial baiana: fragmentação e limitações. RDE, Revista de Desenvolvimento Econômico. Ano XV, no 28, dezembro de 2013, Salvador-BA.

[26] RESENDE, J.; BARBOSA, L. A.. Profissionalização no agronegócio - Do campo ao mercado. Mercado \& Negócios, v. 32, n. 102012 .

[27] RIMA - Ferrovia de Integraçao Oeste-Leste (EF - 334) entre Figueirópolis (TO) e Ilhéus (BA), 2009.

[28] ROCHA, E. A. Comparação entre os modais ferroviários e rodoviários no transporte de soja, da região centro oeste ao porto de santos. Monografia, Faculdade de Tecnologia da Zona Leste. São Paulo, 2006. Disponível em: < http:// daroncho.com/tcc/tcc61-eliel.pdf>. Acessado em 09 de fev. de 2016

[29] VALEC-Engenharia, Construção e Ferrovia. Ações e programas VALEC. 2014. Disponível em:< http://www.valec. gov.br/acoes_programas/>. Acessado em 10 de fev. de 2016 . 


\title{
CAPÍTULO 2
}

\section{PROPORCIONAR A REDUÇÃO DO TEMPO DE SETUP APLICADO EM UMA INDÚSTRIA DO SETOR GRÁFICO}

\author{
Luis Philippe do Carmo Moreira \\ Rafael Leandro da Silva \\ Vinnicyus Branco Morais Santos \\ Alessandro Marcio Martins Dias
}

Resumo: A busca por melhoria contínua dos processos e por produtos que atendam um mercado cada vez mais exigente em termos de qualidade fazem com que as empresas desenvolvam e apliquem ferramentas da engenharia de processos para resolver as não conformidades e/ou melhorar os processos produtivos. Além de desenvolver produtos com qualidade superior, com propósito de evitar desperdícios, reduzir custos e tornarem-se mais competitivas no mercado. Entre estas práticas estão às utilizações das técnicas, que são ferramentas para se organizar e buscar sempre resultados melhores. Mediante a esse conceito de melhoria contínua a Empresa $\mathrm{X}$, a qual produz etiquetas e rótulos autoadesivos no segmento gráfico, apresenta uma problemática de processos no setor produtivo gerando um alto índice de desperdícios de tempo no seu processo de acerto de máquina, devido a falta de uma análise bem estruturada do seu processo. Com o intuito de melhorar e diminuir os desperdícios de tempo utiliza-se as ferramentas de analise de processos nesta empresa, visando a melhoria da produtividade de produtos produzidos pela mesma, além de buscar a causa raiz dos problemas e propondo ações para reduzir o lead time durante o processo de setup.

Palavras chave: Engenharia de processos. Ferramentas de processos. Melhoria contínua. Setup. 
A liderança no mercado é caracterizada pela grande competitividade entre pequenas, médias e grandes empresas, e de suas necessidades em se adaptarem a esse novo padrão de concorrência. Tais empresas trazem como fator importante a adequação a uma manufatura eficaz e sem desperdícios, reduzindo custos e evitando gastos com processos despreparados e pouco robustos.

Consequentemente, para alcançar ou manter a liderança, as empresas são obrigadas cada vez mais a otimizarem os seus processos produtivos, utilizando a padronização das etapas, reduzindo o tempo ocioso de todos os colaboradores, utilizando todos os recursos de maquinário e garantindo as atualizações tecnológicas necessárias além de monitorar os processos dos concorrentes de forma que a mantenha favorecida perante as exigências do mercado.

A grande diversidade de produtos associado á necessidade de retorno ágil das emprsas à frequente necessidade de uma produtividade alta e constante num cenário global competitivo, faz-se imprescindível a adoção de práticas para diminuir e distinguir os desperdícios existentes no arranjo produtivo.

Entre esta prática estão a utilização das metodologias de padronização e otimização de processos produtivos, que em suma é baseada nos conceitos de melhoria continua, que é uma ferramenta com objetivo de estruturar e alcançar incessantemente melhores proveitos. O tempo é o melhor indicador quanto a evidência dos resultados esperados sobre a competitividade. Exerce de forma macro o reconhecimento dos desperdícios presentes na empresa com objetivo de eliminar as perdas, quer seja em processos produtivos já efetivados ou mesmo em estágio de projeto, novos produtos, mantenimento de máquinas, etapas administrativas e organizacionais.

O processo produtivo consiste em um sistema interativo, porém padronizado, de intervenções que são de forma sinérgica vinculadas no modelo variável e cujo objetivo é direcionar as condicionantes para que a ocorrência da transformação dos elementos seja conforme o especificado e com resultados devidamente de acordo com o esperado. Durante o processo o valor do produto é criado através dos implementos do mesmo, no qual a matéria-prima ou as entradas são transformadas em saídas, ou seja, no produto final acabado e com seu devido valor agregado.

- Existe grande necessidade de evidenciar os resultados das melhorias na otimização e padronização dos processos, através dos registros dos ciclos de tempo, entrega de produtos acabados no tempo exato, aumentos da lucratividade, e onde é adotado esse tipo de sistema de análise de processos, o grau de ritmo de crescimento necessita ser evidente para que a melhoria contínua dos mesmos sejam auto motivadoras para os acionistas investirem e dedicarem parte do capital em pesquisas e desenvolvimento produtivo dos processos.

\section{REVISÃO BIBLIOGRÁFICA 2.1 SETUP}

O setup é um termo usado na língua inglesa e em português pode significar instalar, estabelecer, preparar, montar, efetuar, apanhar, armar, inicializar, estabelecer-se. No âmbito de processos o setup é a forma como estão estruturadas as peças, ferramentas e aparelhos essenciais para um estabelecido posto de trabalho e também para qualquer fim específico. 0 setup pode ser também o tempo gasto por uma equipe ou por um indivíduo para finalizar algum tipo de tarefa.

O tempo gasto na troca de ferramentas em uma empresa industrial é de importância considerável e possui razões relevantes, pois aumentará o tempo de produção das máquinas, e como o seu custo é muito alto, a tendência é que os lotes de manufatura sejam grandes, exigindo que o estoque seja maior que o ideal para suprir toda a demanda.

Os estudos sobre o SETUP e a Troca Rápida de Ferramentas (TRF), iniciaram devida uma análise da utilização de uma prensa, que por sinal ouve uma perda enorme quando foram trocar suas matrizes, e, descobriram que ali não havia o parafuso específico para sua troca, logo surgiu o termo SETUP. A redução do tempo gasto em SETUP é condição necessária para 
diminuir o custo unitário de preparação. Tal redução é importante por três razões (CARPINETTI, 2010):

- 1- o custo do setup é muito alto, e os lotes de fabricação tendem a ser grandes, e aumenta o investimento em estoques.

- 2- são as técnicas mais simples de troca de ferramenta que diminuem a possibilidades de erros nas regulagens das máquinas.

- 3o com a redução do tempo de SETUP, aumentará o tempo de operação dos equipamentos.

Com tudo isto se teve a idéia de ser divididas em grupos ou etapas de processos:

- SETUP Interno: Este procedimento pode afirmar que é o maior custo, pois ele só é feito quando o equipamento está parado, ou seja, não está produzindo.

- SETUP Externo: Este pode se dizer que é um procedimento com menor valor agregado, pois ele permite que o procedimento seja executado com o equipamento em movimento.

Um exemplo grosseiro é uma máquina que faz usinagem geral em uma peça e leva 3 horas para executar sua tarefa, neste intervalo, o operador já deixou a próxima peça toda preparada para entrar em processo. Na primeira peça, este tempo de preparação era aproximadamente 40 minutos, então - que ocorreu neste caso foi uma troca de SETUP Interno pelo SETUP Externo. Mas para que ocorra esta alteração espontaneamente tem que haver um grande comprometimento entre funcionário e empresa, porque se for um funcionário que não dê a mínima pelo fato de ganhar alguns minutos ou até mesmo alguns segundos, esta empresa seja ou não uma forte candidata, estará fora do mercado, não pela sua incompetência de fazer seus produtos, mas sim pela falta de competitividade com seus concorrentes, agilidade de fabricação dos mesmos, falta de competir em novos horizontes externos, como, lançamentos de novos produtos, melhoria no prazo de entrega e melhoria contínua de seus produtos e serviços (SHINGO, 1996).

\subsection{ARRANJO FÍSICO}

O arranjo físico de um processo de produção empenha-se com a posição física dos implementos a serem transformados. Segundo Slack (2009), os arranjos físicos podem ser ordenamos como: celular, por produto, posicional e por processo. No arranjo físico posicional o implemento a ser transformado fica irremovível no sistema, por sua vez os instrumentos e colaboradores se movem quando precisa fornecer uma flexibilidade considerável em analogia aos resultados produtivos.

Normalmente gera uma unidade exclusiva do produto. No arranjo físico por processo as exigências e necessidades do implementos a serem transformados que formam o sistema de processos resolvem em relação ao arranjo físico. Os equipamentos de utilização mais comum são permanentes e a matéria-prima, a mão de obra e o produto se movem, condicionando a manufatura de diversos gêneros de peças finais. Tal modelo de arranjo físico necessita de muitas analises no processo operacional da sistemática e em relação com o arranjo físico por produto revela uma condição produtiva menor.

O arranjo físico celular é o que os implementos a serem transformados, iniciando na realização, são pré-estabelecidos para circular para uma parcela exclusiva no setor operacional (ou célula) no entanto os recursos gerais a serem transformados precisam seguir as exigências prescritas.Após o processamento na célula, os implementos modificados conseguem continuar para outra unidade celular (SALCK 2009). Em tal tipo de arranjo físico os equipamentos ficam parados, o produto se move e o deslocamento de material é menor, representa uma maleabilidade media e uma taxa produtiva.

O arranjo físico por produto inclui encontrar os implementos produtivos a serem transformados e observando a melhor adaptação do implemento que é transformado.Os implementos produtivos são difundidos ordenadamente em seqüência, pela ocorrência da padronização e da considerável quantia manufaturada, a flexibilidade é menor em consideração as alterações do resultado.Os equipamentos e 
colaboradores ficam estáticos enquanto há o deslocamento de produtos e materiais, com a taxa produtiva e classificado como alto. Em referencia aos modelos de processos tais se repartem em: projetos, lote ou batelada, continuo, massa e jobbing. Processos de projetos são aqueles que com produtos não muito comum, consideravelmente especificados. O espaçamento de tempo necessário para realizar o projeto ou trabalho é consideravelmente longo. Entretanto, volume baixo e variedade alta constituem os atributos deste processo. As tarefas incluídas na realização do produto advêm do modelo e do projeto de produto demandado, entretanto já não são especificados condicionando alterar-se no processo produtivo. Normalmente todos os implementos da organização são direcionados para um projeto de cada vez, no qual o processo é executado geralmente por demanda de encomenda (SLACK 2009).

O processo de jobbing: consta com uma gama de alta variedade e baixos volumes, no qual cada produto precisa compartilhar os implementos da execução com demais produtos. Os processos de jobbing geram mais elementos e utilidades menores do que os processos por projetos, no entanto, um e outro nível de freqüência são baixos. No lote ou batelada a execução é frequenciada, gerando uma estabelecida quantia de produtos equivalentes, entretanto o "lote" fica em processamento.

A magnitude do lote difere desde certas unidades até grandes quantias chegando a toneladas de produtos em função do tempo.O sistema de processos em lotes consegue ser fundamentado em uma variedade mais extensa de um grau de volume e gama do que outros modelos (SLACK 2009). Processos de massa são os que geram valores em considerável volume e uma gama relativamente afunilada.No entanto é essencialmente uma execução em massa que por diversas formas o produto não interage com o sistema necessário de produção (SLACK, 2009). Processos contínuos realizam em volumes até então mais consideráveis e possuem uma gama também mais baixa que a produção em massa.Geralmente executam por um tempo ainda mais considerável. Em determinadas situações são consideravelmente contínuos na direção de que os produtos inseparáveis e gerados em um sistema ininterrupto (SLACK, 2009).

\section{MÉTODO PROPOSTO}

A metodologia aqui utilizada foi a qualitativa descritiva. Os dados necessários para o estudo de caso podem ser obtidos em seis fontes distintas, "documentos, registros e arquivo, entrevistas, observação direta, observação participante e artefatos físicos" (YIN, 2005, p. 109).

Os dados para a pesquisa em questão foram obtidos através de documentos cedidos pela empresa e também através do método de observação participante a realizar-se pelos integrantes desta pesquisa que mapearam o processo de setup da máquina do setor de tipografia através do fluxograma e realizaram a identificação das melhorias.

Para calcular o tempo de reposição das peças foi utilizado o cronômetro YP2151da marca Technos e, para medir a distância foi utilizada uma trena de 30 $\mathrm{m}$ da marca Megaforth. Foi também utilizada uma calculadora Fx-82 ms da marca Casio para calcular a média, o desvio padrão, e conversão de unidades.

\section{RESULTADOS \\ 4.1 MAPEAR O PROCESSO DE SETUP NA MÁQUINA DE TIPOGRAFIA}

O processo de troca rápida de ferramentas funciona quando a Ready do Brasil para produzir etiquetas, no setor de tipografia, precisa fazer o setup da máquina para iniciar a produção de um lote de produtos diferente do anterior.

A troca rápida de ferramentas é feita pelo próprio operador da máquina, que antes de iniciar o setup, já recebe a Ordem de Serviço (OS) que Ihe informa a demanda de etiquetas para determinado lote. $\mathrm{Na}$ mesma OS também está incluso o tempo necessário para a realização do setup para o referido lote.

O processo de troca de ferramentas na máquina de tipografia está representado no fluxograma, conforme demonstra a Figura 1. 
Figura 1 - Fluxograma do processo de troca de ferramentas na máquina da tipografia

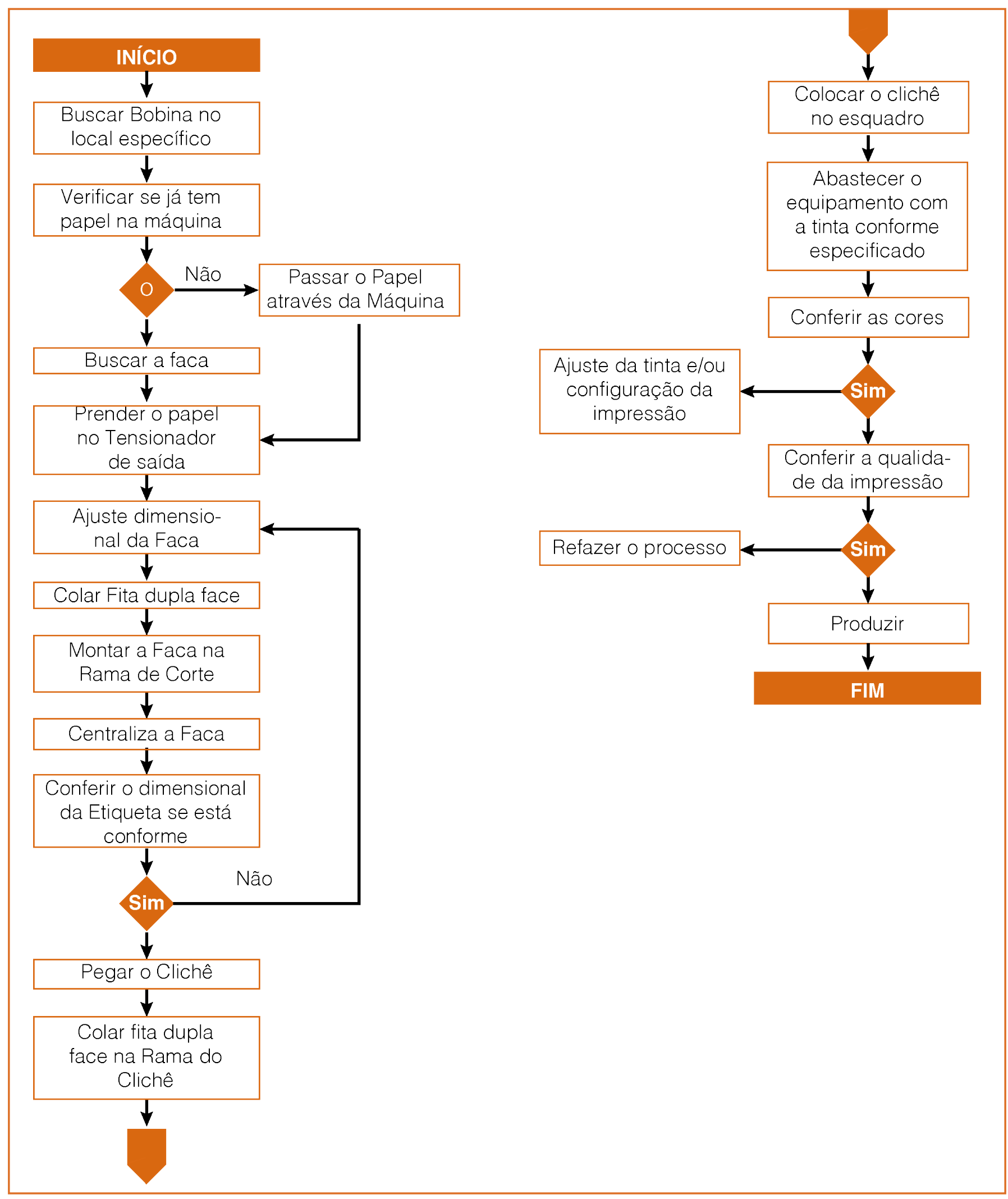

Fonte: Os autores (2015).

Ao iniciar a troca de ferramentas para produzir um novo lote, o operador vai buscar a bobina no deposito de papel. O próprio operador abri a máquina e verifica se a mesma já tem papel para fazer a emenda, logo após 
busca a faca para realização do corte e para prender o papel no tensionador de saída o mesmo é introduzido por toda extensão da máquina, utilizando o paquímetro para conferir o dimensional da faca, logo após faz a colagem da fita dupla face. O operador encaixa a faca na máquina para monta-la na rama de corte, liga a máquina para conferir se a faca está centralizada e conferi o dimensional da etiqueta com a escala de aço. O operador vai buscar o clichê na ferramentaria e logo após cola a fita dupla face na rama do clichê, encaixa e conferi se o clichê está centralizado. Busca a tinta no laboratório de tintas e abastece conforme a escala.
O operador liga a máquina e verifica se a impressão e a faca estão centralizadas, conferi as cores com a escala após o ajuste e verificar se a impressão está borrada ou se há falhas de centralização.

Conforme demonstra a Figura 2 e embasados no referencial teórico os pesquisadores utilizaram o mapa de processos para possibilitar a identificação dos pontos do processo que poderia ter um melhor aproveitamento do tempo ou até mesmo eliminar determinada atividade.

Figura 2 - Tempo necessário em cada etapa do processo de Tipografia

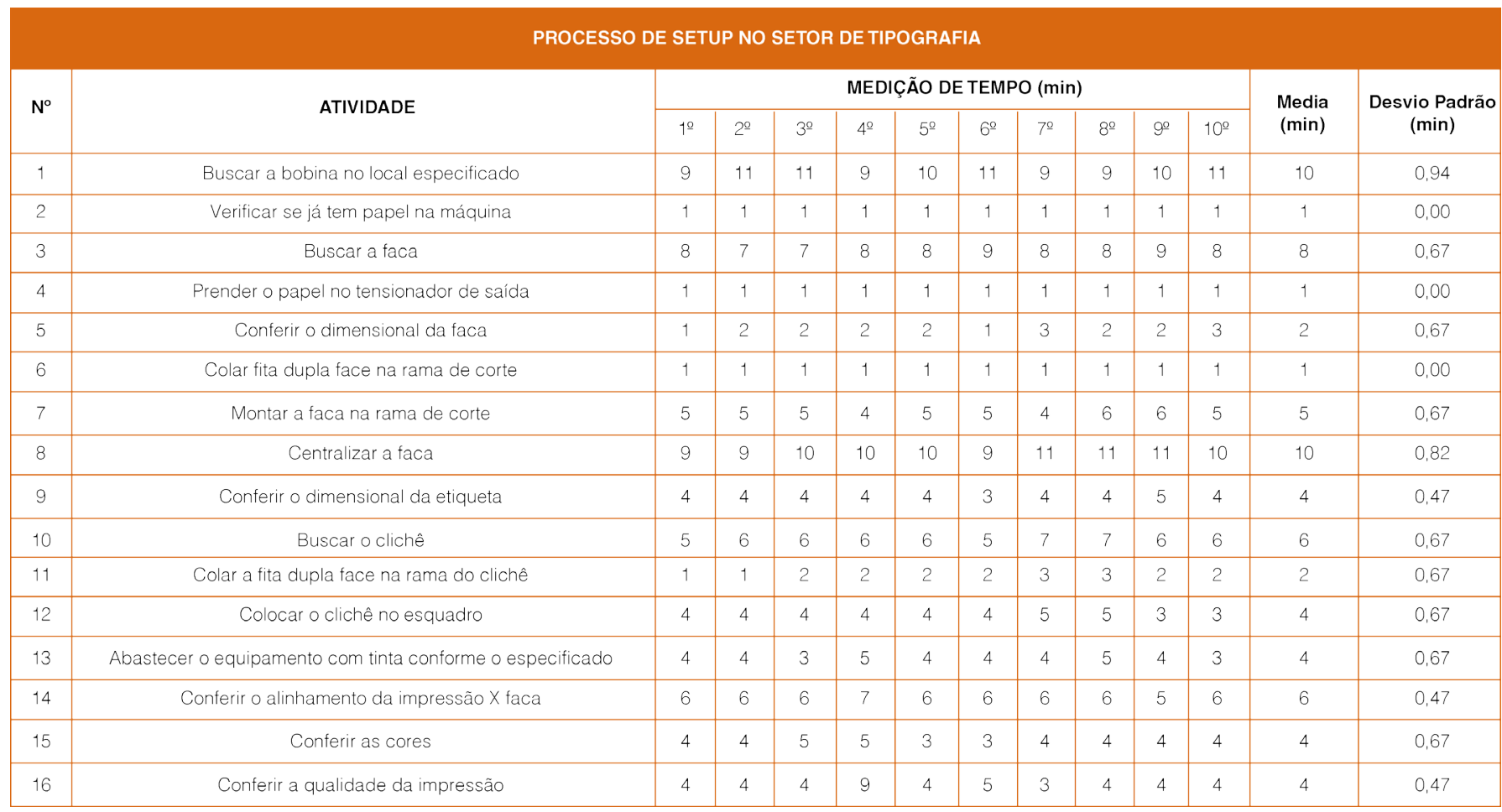

Fonte: Os autores (2015).

Ao iniciar a troca de ferramentas para produzir um novo lote, o desvio padrão máximo estipulado pelo setor de qualidade foi de 1 minuto, o operador vai buscar a bobina no depósito de papel, que está a 50 metros e conforme as medições realizadas, o mesmo gastou em media 10 minutos para realizar esta etapa do processo com o desvio padrão aceitável de 0,94 minutos. O próprio operador abriu a máquina e verificou se a mesma já tem papel para fazer a emenda e necessitou de 1 minuto em media para realizar essa etapa. lote atual, a mesma fica aguardada no almoxarifado e o operador gastou 8 minutos, percorrendo 50 metros até o local com o desvio padrão aceitável de 0,67 minutos. E para prender o papel no tensionador de saída o mesmo gastou em media 1 minuto, onde o mesmo é introduzido por toda extensão da máquina, utilizando o paquímetro para conferir o dimensional da faca, gastando 2 minutos em media nessa etapa com o desvio padrão aceitável de 0,67 minutos. Logo após faz a colagem da fita dupla face, que na media necessitou de 1 minuto.

Logo após, buscou a faca de corte especifica para o 
O operador encaixa a faca na máquina para montá-la na rama de corte, gastando em media 5 minutos, liga a máquina para conferir se a faca está centralizada, gastando em media 10 minutos até encontrar a centralização adequada com o desvio padrão aceitável de 0,82 minutos, e em media gasta 4 minutos para conferir o dimensional da etiqueta com a escala de aço com o desvio padrão aceitável de 0,47 minutos. O operador vai buscar o clichê na ferramentaria que está a 30 metros da máquina de tipografia, e o mesmo gasta 6 minutos em media para buscar o clichê com o desvio padrão aceitável de 0,67 minutos e logo após cola a fita dupla face na rama do clichê com uma media de 2 minutos para executar esta etapa com o desvio padrão aceitável de 0,67 minutos, encaixa e confere se o clichê está fixo no esquadro, até ajustar o mesmo foi necessário uma media de 4 minutos com o desvio padrão aceitável de 0,67 minutos. Buscar a tinta no laboratório de tintas que fica a 10 metros e abastecer conforme a escala, durante a execução foi necessário quatro minutos em media com o desvio padrão aceitável de 0,67 minutos.

O operador ligou a máquina e verificou se a impressão e a faca estão centralizadas e o ajuste adequado, o mesmo gastou em media 6 minutos com o desvio padrão aceitável de 0,47 minutos, após conferir se as cores estão conformes com a escala, em media gastou-se 4 minutos com o desvio padrão aceitável de 0,67 minutos, após o ajuste e verificou a impressão se está borrada ou se há falhas de centralização onde foi necessário uma media de 4 minutos com o desvio padrão aceitável de 0,47 minutos.

Conforme demonstra a Figura 3 e embasados no referencial teórico os pesquisadores utilizaram o mapa de processos para possibilitar a identificação dos pontos do processo que poderia ter um melhor aproveitamento do tempo ou até mesmo eliminar determinada atividade.

Figura 3 - Processo de setup no setor de tipografia.

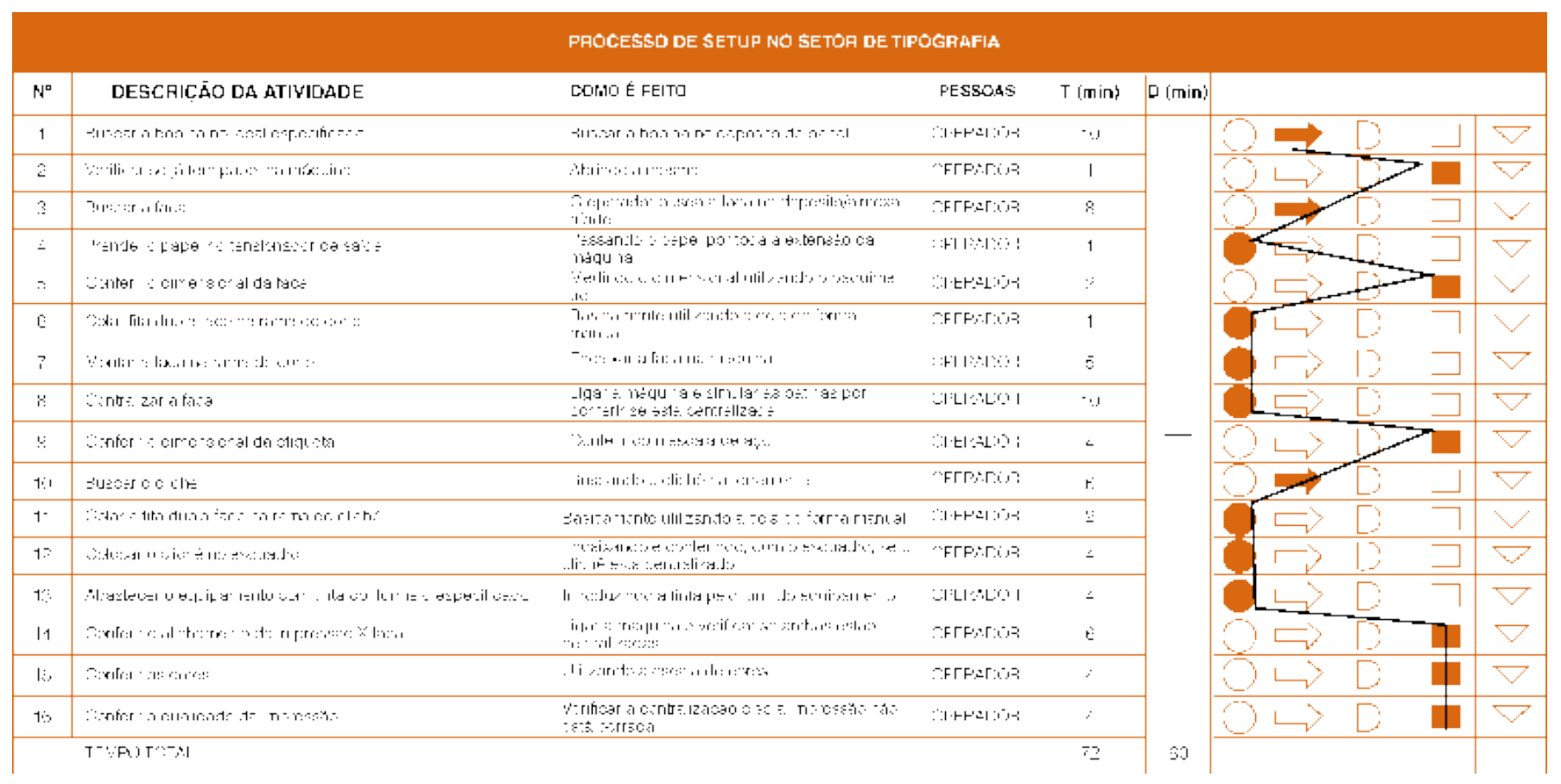

Fonte: Os autores (2015).

Ao iniciar o processo de SETUP no setor de Tipografia, a etapa de buscar a bobina no depósito de papel é realizada pelo próprio operador da máquina e de acordo com o mapeamento do processo é classificada como uma fase de transporte, o mesmo gastou em media 10 minutos para realizar esta etapa do processo. O próprio operador abre a máquina e verifica se a mesma já tem papel para fazer a emenda, 
que é classificada como inspeção, e necessitou de 1 minuto em media para realizar essa etapa. Logo após, buscou a faca de corte especifica para o lote atual, a mesma fica aguardada no almoxarifado e o operador gastou 8 minutos, percorrendo 50 metros até o local, identificado como Transporte.

E para prender o papel no tensionador de saída o mesmo gastou em media 1 minuto, onde o mesmo é introduzido por toda extensão da máquina, definido com uma etapa de operação, utilizando o paquímetro para conferir o dimensional da faca, gastando 2 minutos em media nessa etapa que é classificada como de inspeção, logo após, executou uma etapa de operação ao fazer a colagem da fita dupla face, que na media necessitou de 1 minuto. O operador encaixa a faca na máquina para montá-la na rama de corte, gastando em media 5 minutos, e liga a máquina para conferir se a faca está centralizada, gastando em media 10 minutos até encontrar a centralização adequada, ambas as fases são consideradas de "operação", na etapa classificada com inspeção gasta em media 4 minutos para conferir o dimensional da etiqueta com a escala de aço.

O operador, nesta fase de transporte, vai buscar - clichê na ferramentaria que está a 30 metros da máquina de tipografia, e o mesmo gasta 6 minutos em media para buscar o clichê e logo após cola a fita dupla face na rama do clichê com uma media de 2 minutos para executar esta operação, encaixa e confere se o clichê está fixo no esquadro, até ajustar o mesmo foi necessário uma media de 4 minutos, sendo esta uma etapa de operação. Busca a tinta no laboratório de tintas que fica a 10 metros e abastece conforme a escala e durante a execução foram necessários quatro minutos em média, fase de Transporte. O operador liga a máquina e verifica se a impressão e a faca estão centralizadas e até o ajuste adequado o mesmo gastou em media 6 minutos, após confere se as cores estão conforme a escala, em media gastou-se 4 minutos, após o ajuste e verifica se a impressão está borrada ou se há falhas de centralização onde foram necessários uma media de quatro minutos, , ambas as fases são consideradas como de "inspeção".

\subsection{DESCREVER O ARRANJO FÍSICO ATUAL DO SETOR DE TIPOGRAFIA}

No atual arranjo físico do setor de tipografia, a área de delimitada por paredes em seu perímetro, possui uma mesa retangular no qual sobre a mesma está a máquina tipográfica, e enfrente está o banco no qual é o posto de trabalho do operador. Conforme informado no item anterior, também faz parte da rotina do operador, durante a etapa de Setup, percorrer um trajeto de 50 metros até o almoxarifado.

Figura 4 - Arranjo físico do setor de tipografia.

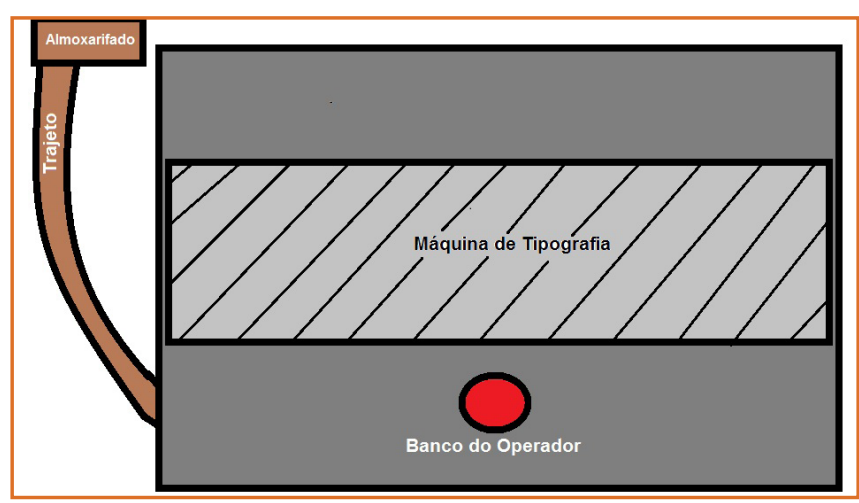

\subsection{MELHORIAS PROPOSTAS}

4.3.1 MELHORIA PROPOSTA PARA AS ETAPAS N ${ }^{\circ} 1$ E 3 (BUSCAR A BOBINA NO LOCAL ESPECIFICADO E BUSCAR A FACA)

Ao invés do operador no momento do Setup, deixar de executar o processo para ir buscar a bobina percorrendo 50 metros para ir até o almoxarifado, propusemos a alternância no arranjo físico do setor de tipografia, no qual a mesa com a máquina tipográfica foi para o fundo da área de trabalho e o banco do operador tambem foi proporcionalmente transferido para ficar de frente para a máquina, com tais alternancias no arranjo físico, será possivel a colocar um armário para armazenar as ferramentas necessárias durante a realização do Setup. 
Figura 5 - Novo arranjo físico do setor de tipografia.

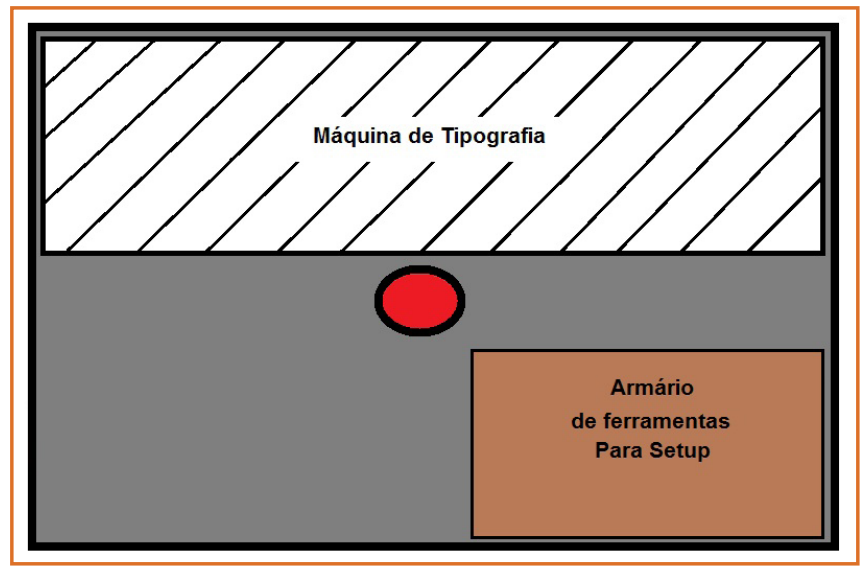

A área de trabalho no setor de tipografia, possui 5 metros de largura com 6 de cumprimento totalizando $30 \mathrm{~m}^{2}$. A mesa no qual está a maquina de tipografia possui 2 metros de largura e 5,7 de cumprimento totalizando $11,4 \mathrm{~m}^{2}$. O banco do operador possui $0,25 m^{2}$. A área livre dentro do setor de tipografia é $18,35 \mathrm{~m}^{2}$, o armário de ferramentas para setup, possui 2 metros de largura e 2,5 metros de cumprimentos totalizando $5 \mathrm{~m}^{2}$, e sua localização será no angulo inferior a mesa de trabalho, não gerando impedimentos quanto a circulação do operador dentro do ambiente. Conforme identificado no mapeamento de processos, duas das três etapas que demandam maior tempo, serão consideravelmente reduzidas, as etapas $01 \mathrm{e}$ 03 (buscar a bobina no local especificado e buscar a faca, respectivamente) que possuem uma media de 10 e 8 minutos, respectivamente, para serem executadas, será necessário apenas 1 minuto, para cada etapa, no qual o operador pega os materiais necessários dentro do armário de ferramentas. Da mesma forma, mais uma etapa que não é considerada como critica, mas também terá seu tempo reduzido é a etapa 10, onde o colaborador não precisará gastar 6 minutos para ir buscar o clichê, pois o mesmo já estará no armário localizado dentro da sala de operação tipográfica, e será necessário somente 1 minuto para execução desta etapa.

Figura 6 - Resultado da mudança no arranjo físico

\begin{tabular}{|l|c|c|c|c|}
\hline & Etapa 1 $(\mathrm{min})$ & Etapa 3 $(\mathrm{min})$ & Etapa 10 $(\mathrm{min})$ & Tempo total \\
\hline Arranjo fisico atual & 10 & 8 & 6 & 24 \\
\hline Arranjo fisico proposto & 1 & 1 & 1 & 3 \\
\hline Diferença de tempo & \multicolumn{4}{|c}{} \\
\hline
\end{tabular}

Com o novo arranjo físico o processo de setup da máquina de tipografia, terá uma redução em 21 minutos. O tempo total que é de 72 minutos irá para 51 minutos, se enquadrando no tempo padrão determinado pelo setor de qualidade que é de no máximo 60 minutos.

\section{CONCLUSÕES}

Por meio do presente estudo verificou-se todo o processo produtivo da Empresa $\mathrm{X}$, propiciando uma visualização ampla do sistema de produção, que de forma descritiva possibilitou a verificação da real utilidade que cada etapa do processo da empresa.

Ao estratificar e analisar todo o processo de setup no setor de tipografia, os autores desta pesquisa puderam evidenciar através da mensuração do tempo, a real necessidade de cada etapa, e verificaram também que, $38 \%$ do tempo consumido no processo, estão vinculados diretamente a somente $18 \%$ das etapas do processo de setup no setor de Tipografia da Empresa $\mathrm{x}$.

Conclui-se que, através dos dados levantados, destacaram-se várias oportunidades de melhorias no processo de setup, mas como prioridade os autores sugerem três melhorias que podem ser feitas em curto prazo e sem que a empresa tenha que investir nenhum capital financeiro, e com as análises, a Empresa X pode futuramente alterar o processo produtivo, melhorando assim, o processo de setup. 


\section{REFERÊNCIAS}

[1] CAMPOS, Vicente Falconi. TQC. Controle de Qualidade Total no estilo Japonês. 3. ed. São Paulo: Bloch, 1999.

[2] CARPINETTI, L. C. R., Gestão da qualidade: conceitos e técnicas. São Paulo: Atlas, 2010.
[3] SHINGO, S. Sistema toyota de produção: do ponto-devista de engenharia de produção. Porto Alegre: Bookmann, 1996.

[4] YIN, R.K. Estudo de caso: planejamento e métodos. 3. ed. Porto Alegre: Bookman, 2005.

[5] SLACK, N. Administração da Produção. São Paulo: Atlas, 2009 


\title{
CAPÍTULO 3
}

\section{PROPOSTA PARA IMPLANTAÇÃO DE FERRAMENTAS LEAN EM EMPRESA DE DESIGN GRÁFICO DE PEQUENO PORTE}

\author{
Shirley Suellen Thesari \\ Renato Tonello \\ Marcelo Gonçalves Trentin \\ Dalmarino Setti \\ Flavio Trojan
}

Resumo: A eficiência das operações e da produção nos processos industriais está fortemente ligada a um ambiente produtivo classificado, organizado, sistematizado e padronizado, e essas características precisam ser mantidas ao longo do tempo. Desde que começou a ser desenvolvido, após a Segunda Guerra Mundial, o modelo de produção Lean, idealizado na montadora japonesa Toyota, chamou a atenção e passou a ser implantado por milhares de empresas em todo mundo. Esse estudo se utiliza da filosofia desenvolvida no Leanmanufacturing para cumprir o seu objetivo de fornecer um modelo de implantação do programa 5S e de Procedimento Operacional Padrão - POP, oriundos do sistema lean. Estudos e resultados da utilização dessa metodologia em uma empresa de pequeno porte na área de design gráfico são também apresentados nesse trabalho.

Palavras chave: Lean, Programa 5S, Padronização. 


\section{INTRODUÇÃO}

Com a velocidade que o mundo se transforma, hoje é mais que necessário que o ambiente sempre esteja classificado, organizado, limpo e padronizado, e que esses atributos sejam mantidos ao longo do tempo. Para isso, a filosofia Lean e mais especificamente a sua ferramenta $5 S$ vem a contribuir satisfatoriamente nos diferentes ramos de empresas.

Design gráfico, segundo a Revista Guia do Estudante (2014), é um ramo que vem crescendo em todo Brasil devido ao surgimento de novas mídias e também pela necessidade de criação de novas mídias. As empresas de design gráfico criam, desenvolvem e executam projetos e sistemas que agregam textos e imagens em impressos e em meios eletrônicos, como web sites. Trabalham também criando novos produtos, ou reformulando os já existentes, de acordo com a necessidade e estratégia do cliente. A responsabilidade dessas empresas é grande, pois as mesmas transmitem a imagem, o conceito e a ideia do cliente através do visual, já que as duas das principais características do design são o compromisso com - público consumidor acima das preferências estéticas do designer. Ainda é o meio de estruturar a comunicação impressa de uma corporação ou de um profissional, trabalhando o relacionamento entre a imagem e o texto. Seus principais trabalhos são na criação de identidade corporativa (branding), design de embalagem (packaging design), design editorial, digital, web design, de interação de games, sinalética ou sinalização e tipografia. Além da comunicação visual como, por exemplo, monogramas, emblemas, escudos, símbolos artesanais e tudo que utiliza representação gráfica para transmitir uma mensagem (PANIZZA, 2004).

Assim, o objetivo da presente pesquisa é a elaboração de um modelo de implantação do método $5 \mathrm{~S}$ e da padronização das atividades realizadas por uma empresa de design gráfico de pequeno porte, como uma ferramenta para estruturação das atividades, organização e boa imagem da empresa perante o cliente.

Esse artigo está estruturado conforme se segue: após a introdução, a seção 2 apresenta o referencial teórico, que discorre sobre os conceitos e diretrizes para o estudo. Depois, na seção 3, é abordada a metodologia da pesquisa, que visa explicitar os caminhos metodológicos adotados. Por seguinte, na seção 4, o desenvolvimento do estudo feito a partir do caminho metodológico utilizado. Para então, na seção 5 apresenta as considerações finais obtidas a partir do estudo realizado.

\section{REFERENCIALTEÓRICO}

Um dos maiores desafios que as organizações enfrentam atualmente é o de se manterem competitivas à medida que as condições do ambiente de negócios se modificam e tornam-se mais complexas (ANDRADE, 2009). Deve-se ter como base, que o serviço é diferente do produto, pois é intangível, não pode ser armazenado ou inspecionado, não tem tempo médio de vida, envolve relacionamento entre pessoas e sua qualidade geralmente é subjetiva (MARTINS, LAUGENI, 2001).

Os métodos de gestão representam um conjunto de práticas disponíveis para uso no sistema de gestão das empresas, entre eles estão o Lean Manufacturing e o programa 5S (MARSHALL et al., 2008).

Desde que começou a ser desenvolvido, após a Segunda Guerra Mundial, o modelo de produção Lean ("enxuto" em português) da montadora japonesa Toyota, famoso por ajudar as corporações e eliminar desperdícios, busca também tornar enxutos os processos administrativos, não sendo de simplesimplementação, pois não é fácil visualizar os processos que envolvem bens intangíveis (CORREAA \&CORRÊA, 2008).

Os principais objetivos do sistema Lean é a criação de trabalho padronizado a fim de suavizar o fluxo de operações e eliminar etapas, e de forma geral, os desperdícios em um processo. Trabalhadores de todas as etapas produtivas são treinadosa identificar desperdícios e melhorar e padronizar sua etapa do processo (DAVID et al., 2010).

O método Lean tem sido usado com sucesso em 
estudos envolvendo serviços, como em Lean Service, Lean Office e Lean Health Care. Como por exemplo, para reduzir os custos dos testes de diagnósticos desnecessários (VEGTING et al., 2012); para melhorar a qualidade e reduzir custos em cirurgias (VLIET et al., 2010); melhor aproveitamento da sala de operação, a fim de aperfeiçoar o horário de trabalho de residentes em um hospital (WARNER et at., 2013); para reduzir e eliminar desperdícios no fluxo de valor de informações e conhecimentos (ROOS et al., 2011); melhorar o desempenho em termos de tempo de processamento, a qualidade do produto de software e redução das alterações em pedidos (PETERSEN et al., 2010); na detecção e eliminação de desperdícios em hotéis (VLACHOS et al., 2013); melhorar a eficiência e aumentar a rentabilidade e moral da equipe de acadêmicos em operação cirúrgicas (COLLAR et al., 2011), entre diversos outros.

A filosofia 5 S surgiu no final da década de 1950, no Japão pós-guerra, como parte do esforço empreendido em reconstruir o país. É um programa voltado para a mobilização dos colaboradores, através da implantação de mudanças no ambiente de trabalho, incluindo a eliminação de desperdícios, arrumação de salas e limpeza. As palavras que designam cada fase são oriundas do japonês: Seiri - organização, utilização, descarte; Seiton - arrumação, ordenação; Seisou - limpeza, higiene; Seiketsu - padronização; e, Shitsuke- disciplina (MARSHALL et al., 2008).

Os $5 S$ podem ser pensados como um método simples de organizar áreas de trabalho que enfatizem ordem visual, organização, limpeza e padronização, eliminando todos os tipos de desperdício relacionados à incerteza, à espera, à busca por informações relevantes e assim por diante. Ao eliminar o que é desnecessário e deixar tudo claro e previsível, a desordem é diminuída, os itens necessários estão sempre nos mesmo lugar e o trabalho se torna mais rápido e fácil (SLACK et al., 2002).

Para Werkema (2011), as vantagens de utilização dos $5 S$ é o aumento da produtividade, melhor atendimento aos prazos, redução de defeitos, aumento da segurança no trabalho, redução de material perdido e melhor capacidade para distinção entre condições normais e anormais de trabalho. Para Marshall et al. (2008) cita outras vantagens como a eliminação de estoques intermediários e documentos sem utilização; melhoria nas comunicações internas, nos controles e na organização de documentos, maior aproveitamento de espaços e layout, maior conforto e comodidade, melhoria do aspecto visual das áreas, mais limpeza dos ambientes, padronização dos procedimentos, economia de tempo e esforço, entre outras.

O Seiri diz respeito a separar o necessário do desnecessário, descartando o que não for útil. Seiton significa organizar o necessário, definindo um lugar para cada item. O terceiro S, o Seiso é limpar e identificar cada item. Seiketsu significa criar e seguir um padrão resultante do desempenho adequado dos três primeiros S. O último, o Shitsuke é estabelecer a disciplina para manter os quatro primeiros sensos ao longo do tempo (WERKEMA, 2011).

Em conjunto com a aplicação dos 5S, surgiu à necessidade da empresa ter um padrão na execução dos serviços. Segundo Werkema (2011), a padronização é o método usado para indicar os passos para execução de afazeres de um processo, de modo que os possam ser alcançados e mantidos. A autora ainda destaca que uma boa parte da variabilidade dos processos produtivos poderá ser evitada se as tarefas forem executadas da mesma forma, ou seja, se forem padronizadas entre equipes, o que contribuirá para melhoria de custos, qualidade, cumprimento de prazos e segurança.

Marshall et al. (2008) destaca que a padronização é de fundamental importância para as organizações, que a mesma foi responsável pelo sucesso da passagem de produção artesanal para em massa e está presente hoje com padrões universais de telecomunicações, combustíveis, pilhas e muito mais.

Devido à alta rotatividade de funcionários e poucos profissionais qualificados na crescente área de design gráfico e web, as empresas muitas vezes necessitam treinar os novos colaboradores, ou repetir diversas vezes o roteiro a ser seguido para execução de uma tarefa. Com um Procedimento Operacional Padrão (POP) e o fluxograma disponível, um novo funcionário 
terá um fácil entendimento das atividades e algumas de suas dúvidas, quanto à operação e rotina de trabalhos, esclarecidas de forma simples e rápida.

Um problema crítico identificado pelos gestores é o erro no salvamento e encaminhamento de arquivos. Etapas não são cumpridas e o tempo despendido em retrabalho é alto. De tal modo, com a padronização do serviço, algumas etapas da produção podem ser orientadas conforme o fluxograma a ser confeccionado, evitando dúvida, perda de tempo e erros ao executar determinada tarefa.

Fluxograma, de acordo com Marshall et al. (2008), é uma representação gráfica que permite uma fácil visualização dos passos de um processo, que apresenta a sequência lógica e de encadeamento de atividades e decisões, de forma a poder ter uma visão integrada do fluxo de um processo (técnico, administrativo ou gerencial), que permite a realização de análise crítica para a percepção de falhas e de oportunidades de melhoria.

Fluxogramas são diagramas de entrada-saída que dão uma visão geral útil do contexto do processo e de oportunidades de melhoramentos. O propósito é garantir que todas as diferentes etapas nos processos de fluxo estejam incluídas no processo de melhoramento, e que essas etapas estejam em sequência lógica (SLACK et al., 2002).

Ainda segundo Slack et al. (2002), os fluxogramas são importantes porque fornecem uma compreensão detalhada das partes do processo em que algum tipo de fluxo ocorre. Também porque o ato de registrar cada estágio do processo evidência fluxos mal organizados e o fluxograma destaca áreas e nelas problemas em que não existe nenhum procedimento para lidar com o as particulares circunstâncias.

Pode-se também, confeccionar um fluxograma do design gráfico, pois conforme Fernandes (2003) a criação ou design gráfico segue geralmente um caminho lógico, que não é o único, mas que é geralmente utilizado. Primeiramente formula-se 0 briefing, que consiste numa lista de dados que se inicia pelas solicitações e expectativas do cliente, incluindo dados sobre o mercado e as especificações técnicas do produto (tamanho, tipo de papel, recursos gráficos possíveis, etc.). O briefing é a garantia de não ser desviado o que é importante para o trabalho e deve-se digitar esses dados e enviar uma cópia ao cliente, para evitar que o trabalho não esteja de acordo com o que o cliente solicitou.

Depois da coleta de dados, passa-se para a criação em si, que é iniciada com diversos roughs, que são os primeiros esboços dos trabalhos. Nessa fase são desenhadas as estruturas gráficas das ideias para a organização de textos e de imagens, porém são apenas desenhos elementares.

Após a escolha da estrutura gráfica, inicia-se a elaboração do layout, ou seja, a simulação do impresso, para que possa suprir o aspecto final desejado em todos os detalhes. Pronto o layout, o mesmo deverá ser submetido à aprovação do cliente, para então iniciar a última fase do trabalho, a realização das artesfinais ou originais.

Originais e artes-finais são os elementos gráficos preparados de forma a possibilitar a reprodução gráfica do trabalho. Eles podem ser um arquivo de computador, um texto, uma ilustração, desenho, entre outros.

\section{METODOLOGIA}

O estudo tomou como base uma pequena organização, de multi-projetos na área de design gráfico, que segundo Taylor (2013) varia em tamanho e nos serviços que oferecem a seus clientes, podendo operar com uma base ampla e/ou multidisciplinar, ou se concentrarem setores específicos, como moda ou finanças.

Para a coleta dos dados, houve a necessidade de visita à empresa, já que segundo David et al. (2009) o pensamento Lean enfatiza identificar a causa raiz de um atraso ou problema, indo para o trabalhador e o local de trabalho para entender as demandas do trabalho. Deste modo, essa pesquisa se caracteriza também como pesquisa de campo, pois o objeto de 
estudo é abordado em seu meio ambiente próprio, ou seja, a coleta de dados é feita nas condições naturais em que os fenômenos ocorrem, sem a intervenção ou manuseio do pesquisador (SEVERINO, 2007). Para Miguel et al. (2012) o estudo de campo é a presença de dados de campo, sem estruturação formal do método de pesquisa.

A empresa em que foi realizado o estudo é do setor de design gráfico, e oferece os serviços de criação de projetos gráficos para publicações, catálogos, embalagens, rótulos, web sites, vídeos para TV e internet, fotos, jornais, revistas, livros, panfletos, anúncios e outdoors. Também cria logotipos e papelaria para profissionais dos mais diversos setores, comerciais e industriais. Devido ao fato da empresa ser nova no mercado, com menos de um ano de atividades, ainda não possui ferramenta para gestão da produção.

Foram entrevistados os três sócios da empresa, devido os mesmos serem os disseminadores do conhecimento na organização, e os demais colaboradores ainda estarem aprendendo as atividades. Foram feitas entrevistas não estruturadas, onde informalmente foram questionados os principais problemas envolvendo a empresa, e quais seria necessário serem solucionados com maior urgência. Também houve a observação do local de trabalho durante cinco dias, 2 horas em cada dia.

Depois das entrevistas, e da avaliação geral da empresa, definiu-se que o trabalho seria realizado em quatro fases (ver Figura 1), algumas cumpridas sendo elas: pesquisa bibliográfica para embasar 0 estudo; confecção defluxograma de aplicação dos 5S; elaboração domodelo de Procedimento Operacional Padrão (POP); aplicação dos 5S.
Figura 1 - Caminho metodológico

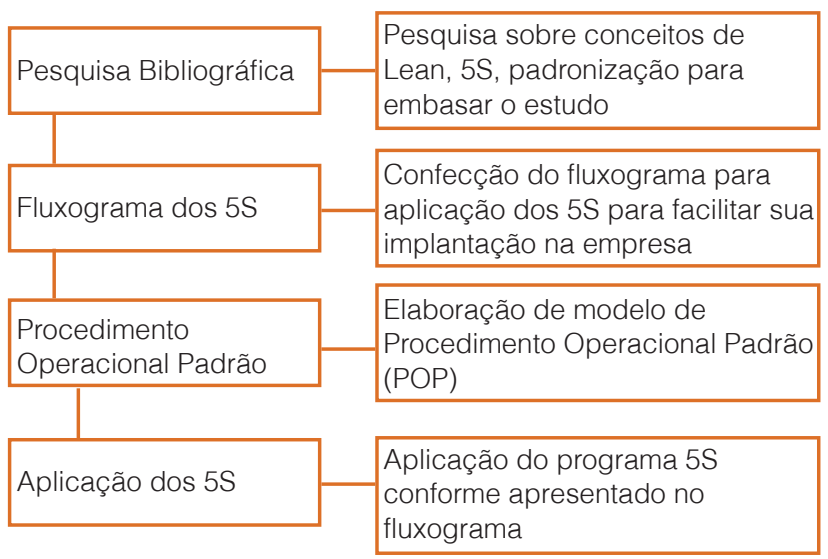

Fonte: Elaborado pelos autores

Para realizar a implantação dos 5S, o estudo utilizou de algumas fases como: Classificar, ordenar, limpar, padronizar e manter, conforme Figura 2.

Figura 2 - Etapas para implementação do 5S)

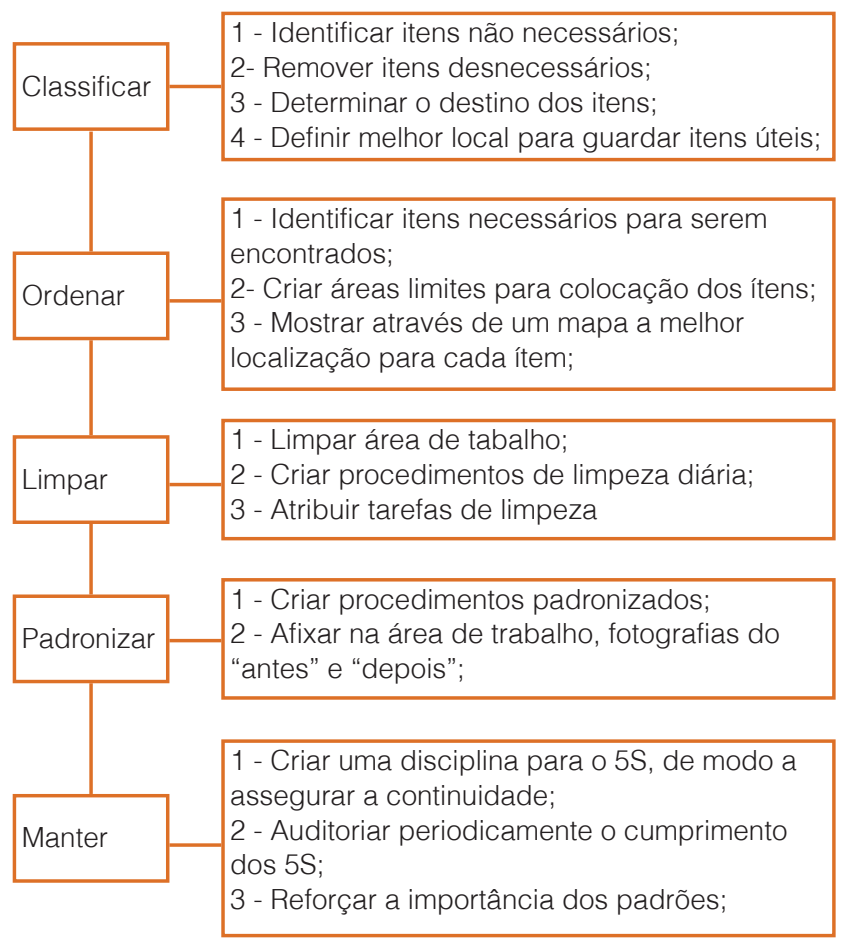

Fonte: Adaptado de Werkema (2011)

\section{DESENVOLVIMENTO}

Com base nas entrevistas e visitas à empresa, foi observado no local que, há perda de tempo em localizar ferramentas de trabalho, desorganização nas mesas e retrabalho por não ter um procedimento padrão a 
ser seguido. Em concordância com os proprietários foi proposta uma pesquisa de elaboração de um modelo de padronização e implantação do programa $5 S$ na empresa, que inclusive já era de conhecimento de um deles.

Como o objetivo principal da filosofia $5 \mathrm{~S}$, de acordo com Marshall et al. (2008), é mudar a maneira de pensar dos colaboradores, a fim de que procurem ter um comportamento melhor em toda a vida, profissional ou familiar, não seria possível implementar o programa em um único dia, nem em uma ação. Assim, foi sugerido aos gestores um fluxograma de implantação do método em etapas, conforme o relatado no referencial teórico.
Os cuidados a serem tomados com o uso dos $5 \mathrm{~S}$ foram evidenciados, conforme citados por Werkema (2011): o primeiro senso, o de classificar, deve ser cuidadosamente realizado, pois quanto melhor for o trabalho executado nessa etapa, mais fácil será a condução das próximas; o 5S deve fazer parte do trabalho de todas as pessoas da empresa e, por último, o sucesso do $5 \mathrm{~S}$ deve ser comemorado e amplamente divulgado.

O fluxograma para aplicação dos 5s contempla todas as etapas sugeridas no referencial teórico, e pode ser visto na Figura 3. 
Figura 3- Fluxograma de implantação Programa 5S

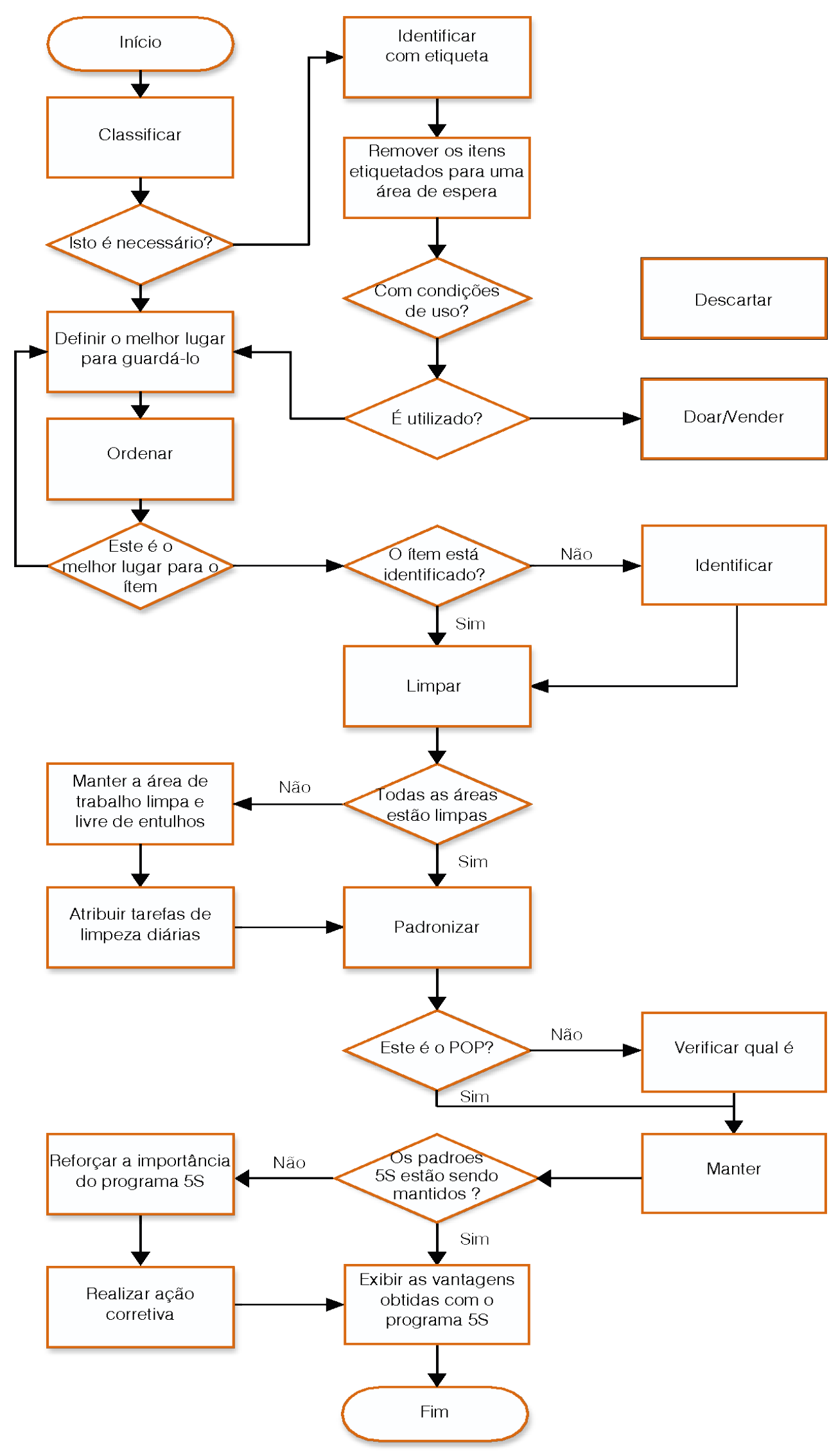

Fonte: Elaborado pelos autores 
Para o início da aplicação do programa dos 5S, foi selecionada uma sala da empresa de estudo. Nessa sala, os funcionários puderam observar a orientação de como fazer cada etapa, para que cada um pudesse repetir em seuprópriolocalde trabalho.

Primeiramente, foram utilizados os objetos constantes em cima da mesa de trabalho do exemplo, sendo julgados conforme o fluxograma: "Esse item é necessário?". Caso a resposta fosse positiva, deviase definir o melhor lugar para guardá-lo. Caso fosse negativa, devia-se etiquetar o objeto e colocá-los numa sala de espera. Os itens etiquetados deveriam responder a questão: "Com condições de uso?". Os sem condições de uso deviam ser jogados fora. Os com condição, deviam responder: "É usado?". Os itens não usados deviam ir para doação ou venda, e os usados, deveriam se juntar aos que estavam aguardando melhor lugar para guardá- los.

Classificados todos os objetos, a próxima etapa foi ordená-los, que começou com a questão: "Esse é o melhor lugar para esse item?", se não é, ele voltava para a etapa anterior de definir o melhor local para guardá-lo. Se sim, ele passava a pergunta: "O item está identificado?". Se não está, era colocada uma identificação, para então se juntar aos identificados, na etapa da limpeza.

Na limpeza, visualmente era identificado e respondido a questão: "Todas as áreas estão limpas?". Se a resposta fosse negativa, o procedimento era manter a área arrumada e livre de entulhos e então atribuir tarefas de limpeza diária, para então, as áreas limpas seguirem para o passo da padronização.

Na etapa da padronização a questãoa ser respondida era: "Esse é o procedimento padrão?". Se não fosse, deveria ser verificado qual o padrão e fazê-lo para então manter esse programa. Nessa etapa, devido a importância, foi explicado aos colaboradores sobre o Procedimento Operacional Padrão.

Dentro da padronização foram sugeridos os primeiros passos de acordo com Werkema (2011): Definir o processo a ser padronizado e gerar as tarefas repetitivas e os procedimentos básicos; Agrupar as pessoas envolvidas no processo, discutir os métodos utilizados e descobrir o melhor e mais simples procedimento operacional, e; Examinar e documentar o procedimento definido anteriormente, registrando as atividades em uma linguagem que todos os envolvidos possam entender, esse documento é denominado Procedimento Operacional Padrão (POP).

Diante do exposto, partiu-se para a confecção do modelo de procedimento operacional padrão (POP) sugerido. Como, segundo Marshall et al. (2008) a promoção da padronização e da consequente melhoria dos processos, bens e serviços se dá através da participação e comprometimento de todos os colaboradores, foram realizadas reuniões com os especialistas de cada processo para então a confecção do modelo de POP. O POP esclarece as eventuais dúvidas sobre qual procedimento seguir, servindo de ferramenta importante para novos colaboradores ou novas tarefas.

De acordo com Campos (1999) é essencial ter um bom sistema de padronização montado na organização e que sirva de referência para o seu gerenciamento. Montar os fluxogramas de tarefas da área de trabalho ajuda na padronização.

Deste modo, após a elaboração do procedimento operacional padrão, foi sugerido aos proprietários da empresa, a confecção de fluxogramas desses processos, para que fique mais simples para os novos colaboradores saber qual decisão devem tomar conforme cada opção apresentada.

Devido o estudo não propor a aplicação da padronização e o acompanhamento dos resultados, alguns passos deixaram de ser seguidos: Comunicar a existência do novo padrão a todos os envolvidos direta ou indiretamente a ele; Treinar todos os operadores e supervisores, de modo que eles executem exatamente aquilo que foi padronizado, sempre igual; e por último, a realização de auditorias periódicasnos processos para verificar a utilização dos Procedimentos Operacionais Padrão e aperfeiçoá-lo sempre que possível.

A última etapa do programa, o manter, ainda está em uso na empresa, uma vez que essa etapa é contínua. 
Foi esclarecida aos colaboradores a pergunta constante no fluxograma: "Os padrões $5 S$ estão sendo mantidos?". Se a resposta for negativa, deve-se reforçar a importância do programa $5 S$ e realizar ações corretivas. Caso seja positiva, é importante que sejam exibidas as vantagens obtidas através do programa. Foi sugerida também a fixação do fluxograma em área de trabalho (mural, quadro de recados) para possíveis consultas durante o período de adaptação.

\section{CONSIDERAÇÕES FINAIS}

Devido à grande competitividade existente em todos os setores empresariais, se faz cada vez mais necessário que as empresas repercutam boa imagem, limpeza e organização.

Com a finalidade de determinar as necessidades da organização em estudo, aconteceram diversas reuniões e contatos com os proprietários, onde foi definido que a necessidade primária da mesma era a implantação de um programa 5S. Dessa forma, o objetivo do presente estudo, a elaboração de um modelo de implantação do método $5 S$ foi alcançada através da elaboração de um fluxograma, onde os colaboradores da organização podem acompanhar passo a passo as etapas do programa, tirando eventuais dúvidas quanto o correto procedimento.

O segundo modelo proposto nos objetivos, o de padronização foi possível através de um Procedimento Operacional Padrão (POP), construído juntamente com os gerentes, para que o mesmo fosse de fácil entendimento e utilização. O POP teve e ainda terá papel importante em qualquer atividade que gerasse dúvida ao colaborador, evitando assim erros por não cumprimento de algum procedimento, ou procedimento feito de forma errônea.

Através do estudo, com a elaboração de fluxogramas para implementação dos $5 \mathrm{~S}$ e para o procedimento operacional padrão, a autora acredita que houve o enfatizado por Marshall et al. (2008), uma perspectiva concreta do que analisar e o que melhorar nos procedimentos e métodos da empresa, permitindo a análise crítica e consequente melhoria dos mesmos.
Sugere-se, no entanto, que os próximos estudos acompanhem a confecção do fluxograma para todas as atividades descritas nas fichas POP e os resultados obtidos a partir dessa aplicação, pois segundo Campos (1999) estabelecimento de fluxogramas é fundamental para a padronização e, por consecutivo para o entendimento do processo. Eles devem ser estabelecidos para todas as áreas da empresa, pelas pessoas que ali trabalham, de forma participativa, para que todos possam entender e fazer.

\section{REFERÊNCIAS}

[1] ANDRADE, E. L. de. Introdução à pesquisa operacional: métodos e modelos para análise de decisões. 4. ed. Rio de Janeiro: LTC, 2009.

[2] CAMPOS, V. F. TQC - Controle de Qualidade Total (no estilo japonês). Belo Horizonte: Editora de Desenvolvimento Gerencial, 1999.

[3] COLLAR, R. M.; SHUMAN, A. G.; FEINER, S.; McGONEGAL, A. K.; HEIDEL, N.; DUCK, M.;

McLEAN, S. A.; BILLI, J. E.; HEALY, D. W.; BRADFORD, C. R. Lean Management in Academic Surgery. Journal of the American College of Surgeons, Vol. 214, № 6, p. 928-936, 2012

[4] CORRÊA, H. L.; CORRÊA, C. A. Administração de produção e operações: manufatura e serviços: uma abordagem estratégica. 2. ed. São Paulo: Atlas, 2008.

[5] FERNANDES, A. Fundamentos de produção gráfica para quem não é produtor gráfico. Rio de Janeiro: Livraria Rubio, 2003.

[6] MARSHALL, I.; CIERCO, A. A.; ROCHA, A. V.; MOTA, E. B. Gestão da qualidade. 9. ed. Rio de Janeiro: Editora FGV, 2008.

[7] MARTINS, P. G.; LAUGENI, F. P. Administração da Produção. São Paulo: Saraiva, 2001.

[8] MIGUEL, P. A. C. (organização). Metodologia de pesquisa em engenharia de produção e gestão de operações. 2. ed. Rio de Janeiro: Elsevier: ABEPRO, 2012.

[9] DAVID, N.G.; VAIL G.; THOMAS, S.; SCHMIDT, N. Applying the Lean principles of the Toyota Production System to reduce wait times in the emergency department. CJEM Canadian Journal of Emergency Medicine; p. 50-57, 2010

[10] PANIZZA, J. F. Metodologia e processo criativo em projetos de comunicação visual. Dissertação apresentada ao mestrado em Ciências da Comunicação, da Escola de Comunicação e Artes, Universidade de São Paulo, 2004. 
[11] PETERSEN, K.; WOHLIN, C. Software process improvement through the Lean Measurement (SPI-LEAM) method. The Journal of Systems and Software, № 83, p. 1275-1287, 2010.

[12] REVISTA GUIA DO ESTUDANTE, Guia profissões: Design gráfico. Disponível em: http://guiadoestudan te.abril com.br/profissoes/artes-design/design-grafico-602419. shtml, acesso em: outubro de 2014.

[13] ROOS, C.; SARTORI, S.; PALADINI, E. P. Uma Abordagem do Lean Office para Reduzir e Eliminar Desperdícios no Fluxo de Valor de Informações e Conhecimentos. XXXI Encontro Nacional de Engenharia de Produção. Inovação Tecnológica e Propriedade Intelectual: Desafios da Engenharia de Produção na Consolidação do Brasil no Cenário Econômico Mundial. Belo Horizonte, 04 a 07 de outubro de 2011.

[14] SEVERINO, A. J. Metodologia do Trabalho Científico. 23. ed. São Paulo: Cortez, 2007.

[15] SLACK, N.; CHAMBERS, S.; JOHNSON, R. Administração da Produção. 2. ed. São Paulo: Atlas, 2002.

[16] TAYLOR, F. Como criar um portfólio. São Paulo: Gustavo Gili, 2013.
[17] VLACHOS, I.; BOGDANOVIC, A. Lean thinking in the European hotel industry. Tourism Management, № 36, p. 354-363, 2013

[18] VEGTING, I. L.; BENEDEN, M. V.; KRAMER, M. H. H.; THIJS, A.; KOSTENSE, P. J.;

NANAYAKKARA, P. W. B. How to save costs by reducing unnecessary testing: Lean thinking in clinical practice. European Journal of Internal Medicine, № 23; p. 70-75, 2012.

[19] VLIET, E. J. V.; SERMEUS, W.; GAALEN, C. M. V.; SOL, J. C. A.; VISSERS, J. M. H. Efficacy and

efficiency of a lean cataract pathway: a comparative study. The International Journal of Healthcare Improvement, № 19, p. $1-6,2010$.

[20] WERKEMA, C. Lean Seis Sigma: Introdução às ferramentas do lean manufacturing. 2. ed. Rio de Janeiro: Elsevier, 2011.

[21] WARNER, C. J.; WALSH, D. B.; HORVATH, A. J.; WALSH, T. R.; HERRICK, D. P.; PRENTISS, S.

J.; POWELL, R. J. Lean principles optimize on-time vascular surgery operating room starts and decrease resident work hours. Journal of Vascular Surgery, Lebanon, № 58, p. 1417 - 1422, 2013. 


\title{
CAPÍTULO 4
}

\section{REDUÇÃ̃o DO ÍNDICE DE PERDA DE INSUMOS COM APLICAÇÃ̃o DO MÉTODO PDCA: ESTUDO DE CASO EM UMA EMPRESA DE MANAUS-AM}

\author{
Adriana Simas da Silva \\ Ariel Muniky dos Santos Brito \\ André Luiz Nunes Zogahib \\ Leandro Aparecido Leite
}

Resumo: O gerenciamento de custos é fundamental para empresas que buscam elevar seus lucros e melhorar sua participação no mercado através da redução de preços e aumento das vendas. Desse modo, este estudo foi realizado em uma multinacional produtora de bebidas que possui em Manaus-AM duas linhas de produção responsáveis por fabricar cervejas e refrigerantes em latas. Observou-se que ambas causavam um elevado Índice de Perda de Latas (IPL) fabril, e que esse desperdício gerava um gasto monetário considerável à companhia. O objetivo deste artigo, portanto, foi reduzir a perda desses insumos com a aplicação da Metodologia PDCA. As etapas da pesquisa foram baseadas neste método. Após a identificação e observação do problema, fez-se a análise das causas fundamentais utilizando-se o Diagrama de Ishikawa e, posteriormente, priorizaram-se esses motivos com auxílio da Matriz GUT. Em seguida, foi concebido o plano de ação para bloqueio do problema, valendo-se de outra ferramenta da qualidade, o $5 \mathrm{~W} 2 \mathrm{H}$. Após a implantação das ações, verificou-se o decréscimo do IPL e dos gastos com latas desperdiçadas, os quais passaram a limitar-se às metas mensais estabelecidas pela organização. Compreendeu-se que o detalhamento do problema por meio do PDCA tornou possível a reversão do indicador para um patamar favorável. Ademais, constatou-se que, apesar da meta fabril de perda de latas (IPL) não ter sido alcançada em 2014, conseguiu-se estabelecer um cenário sustentável para o alcance da meta no ano de 2015, no qual se verificou relevante melhoria, inclusive no que diz respeito aos custos gerados por essas perdas.

Palavras chave: Redução, Desperdícios, Insumos, Custos, Índice de Perda de Latas, PDCA. 


\section{INTRODUÇÃO}

O gerenciamento dos custos fabris envolve a análise dos gastos realizados principalmente com mão de obra direta, materiais diretos, custos indiretos de fabricação e despesas. Todos esses sacrifícios financeiros são necessários para que empresas produtoras de bens e serviços alcancem os seus objetivos. Nesse contexto, a redução dos gastos com insumos de produção apresenta-se como um importante fator para melhoria da competitividade organizacional. Isso porque empresas que trabalham na redução dos custos de materiais diretos tendem a aumentar seus lucros ou mesmo praticar preços mais competitivos.

Assim, o estudo realizado refere-se ao Índice de Perda de Latas (IPL) praticado em uma empresa de bebidas multinacional, com filiais instaladas em Manaus, onde são produzidos refrigerantes em lata e PET, bem como cervejas em lata, garrafas de vidro e barris de chope. Nessa empresa, existem duas linhas de produção responsáveis pela fabricação de refrigerantes e cervejas em latas. A capacidade produtiva instalada dessas linhas é de aproximadamente $17.000 \mathrm{HI}$ de refrigerante e $98.000 \mathrm{HI}$ de cerveja por mês.

Ambas as linhas recebem insumos de diversas áreas fabris, principalmente do Armazém, responsável por armazenar as tampas e latas vazias (inputs) e os paletes de produto acabado (outputs). Ou seja, quando há produção programada ou em execução, latas vazias e tampas são envidas para as linhas. Do mesmo modo, na medida em que os paletes de latas cheias são formados, esses são encaminhados para o Armazém.

No momento em que há a conferência da produção, emite-se o Relatório de Fechamento, o qual descreve quanto de insumo foi enviado para a linha e quanto de produto acabado foi encaminhado para o Armazém. A ideia é que todas as latas conduzidas à linha voltem ao armazém com cerveja ou refrigerante e lacradas com tampas, de modo que não haja perda de material no processo de fabricação. Entretanto, não é dessa forma que acontece, pois muitas latas e tampas acabam sendo desperdiçadas durante a produção.

Nesse sentido, o IPL é calculado pela seguinte fórmula: $\left(\frac{\text { Latas perdidas durante a fabricação }}{\text { Latas enviadas para a linha }}\right) \times 0,7+\left(\frac{\text { Tampas perdidas durante fabricação }}{\text { Tampas enviadas para a linha }}\right) \times 0,3$

A quantidade de latas e tampas perdidas durante a fabricação é dada pela diferença entre as latas e tampas que foram enviadas para a linha como insumo e aquelas que viraram produto final conforme.

Partindo desse pressuposto, verificou-se que no ano de 2014, de janeiro a julho, o Índice de Perda de Latas acumulado estava em 0,97\% para uma meta anual de 0,60\%. Apenas em um desses meses (junho) a meta fabril foi alcançada, entretanto por motivos não sustentáveis, já que no mês seguinte o índice voltou a subir. O Gráfico 1 mostra os valores mensais e o acumulado anual (até o mês de julho) do IPL do ano de 2014 , sendo comparado às metas mensais e anuais da fábrica.

Além disso, o custo das perdas desse insumo até julho estava em torno de $\mathrm{R} \$ 97.352,57$, para uma meta anual de $R \$ 103.383,26$. Dessa maneira, os gastos com desperdícios de latas e tampas até o mês de julho ultrapassavam 94\% da meta anual. Esta situação pode ser observada no Gráfico 2. 
Gráfico 1 - Índice de Perda de Latas 2014

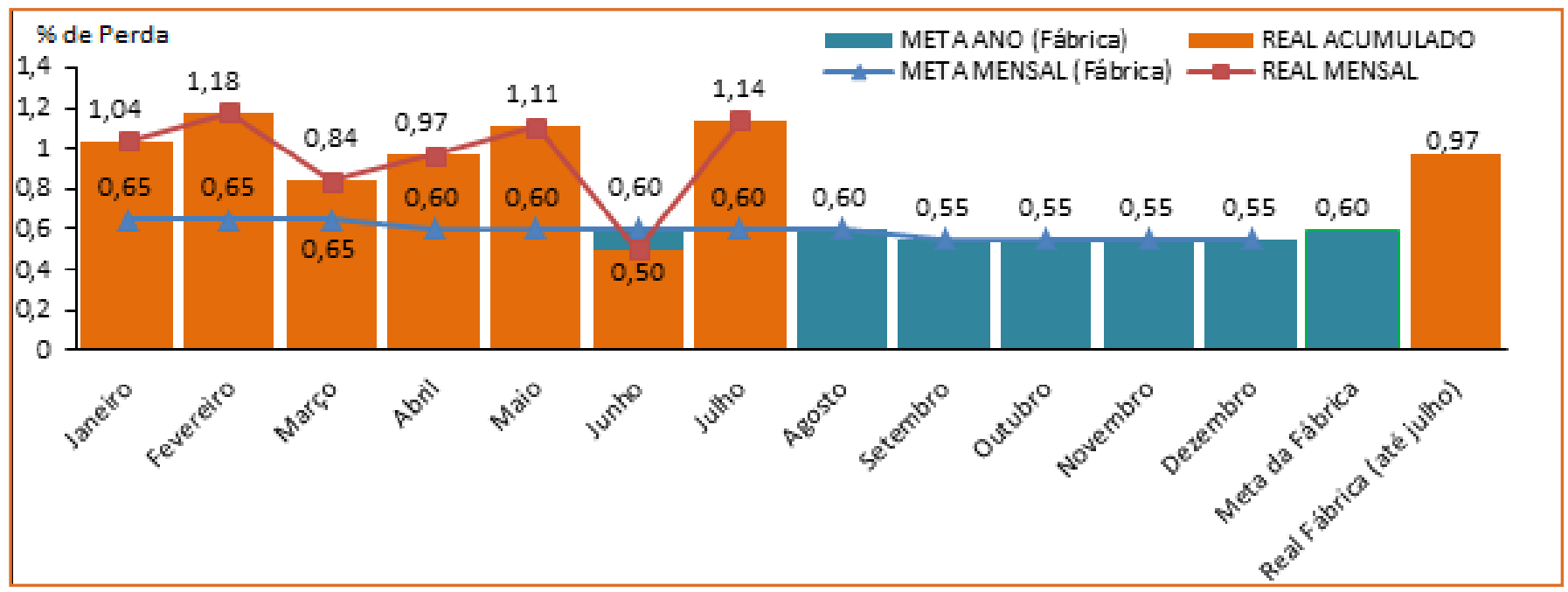

Fonte: Dados da Pesquisa, 2014.

Gráfico 2 - Custo da Perda de Latas 2014

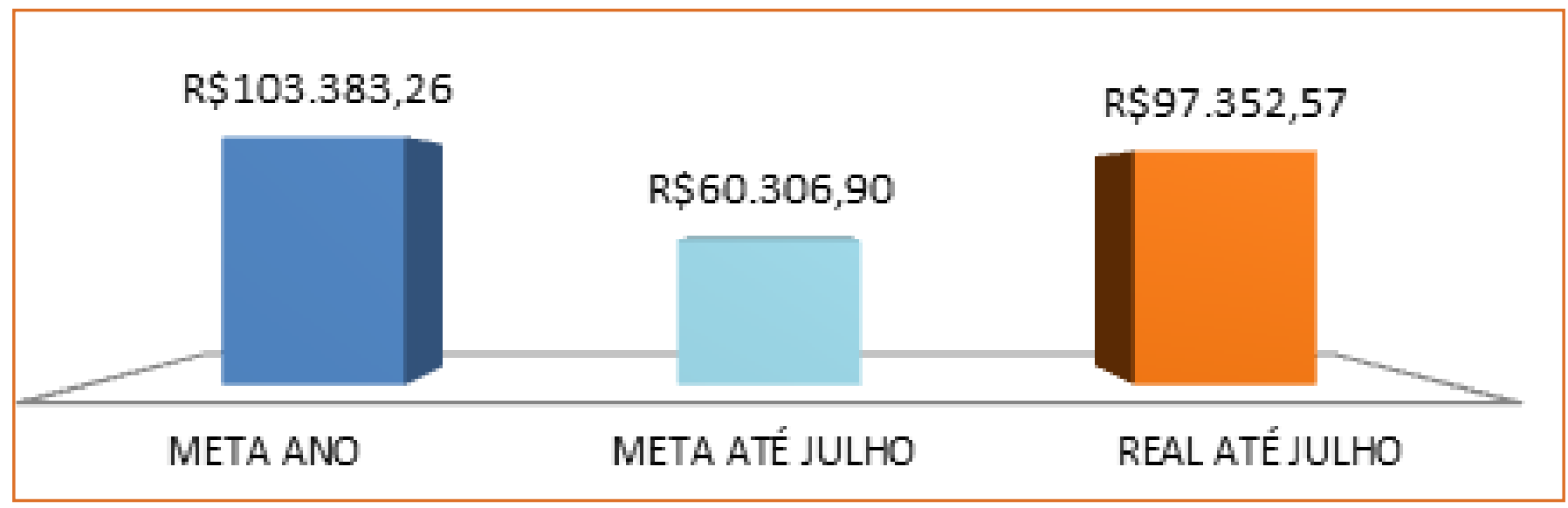

Fonte: Dados da Pesquisa, 2014.

A partir do problema apresentado, o objetivo deste trabalho foi reduzir o Índice de Perda de Latas com a utilização do Método PDCA. Buscou-se alcançar o índice de 0,77\% como resultado anual de 2014. Para isso, as metas mensais a partir de agosto passaram a ser 0,50\%, o melhor resultado da fábrica no ano, o qual foi alcançado no mês de junho.

Destaca-se, entretanto, que atingir 0,77\% no acumulado do ano não é suficiente para o atendimento da meta fabril $(0,60 \%)$, porém, aplicar a metodologia proposta para a efetiva realização do projeto torna viável a manutenção de indicadores favoráveis no ano seguinte.
Para alcançar o objetivo geral, este estudo teve como objetivos específicos: entender, com o auxílio de referenciais teóricos, a Metodologia PDCA; utilizar ferramentas da qualidade durante a identificação das causas fundamentais do problema e quando da concepção do plano de ação para bloqueá-lo; envolver gerência, supervisão e operação das linhas e do armazém quando da execução das atividades deste projeto.

\section{GESTÃO DE CUSTOS}

O gerenciamento de custos em todos os tipos de organização é essencial para o controle dos gastos e para a tomada de decisão. Diante dessa realidade, 
muitas empresas têm se amparado na Contabilidade de Custos para definir o que pode ser implementado para reduzir seus custos e despesas e aumentar seus lucros.

De acordo com Corbett (1997), a Contabilidade dos Custos emergiu no início do século XX com o propósito de gerar informações aos responsáveis pela gestão empresarial para que tomassem decisões capazes de aprimorar o desempenho das organizações.

Além disso, conforme Goldratt (1991), a redução dos custos na empresa deve ser tomada como principal medida de desempenho. O mesmo autor enfatiza que a diminuição dos custos em qualquer fragmento do sistema traz resultados de melhoria da rentabilidade da empresa, indicando que a Contabilidade dos Custos planeia a empresa como um aglomerado de atividades independentes, em que os recursos são igualmente fundamentais.

Nesse sentido, torna-se importante estudar quais os tipos de desperdícios podem existir dentro das organizações, de modo que sejam identificados e eliminados para que não gerem prejuízos de qualquer natureza às empresas.

\section{DESPERDÍCIOS}

A filosofia Lean Manufacturing ou Produção Enxuta, oriunda do Sistema Toyota de Produção, visa à eliminação de desperdícios e à agregação de valor ao cliente (WOMACK et al., 1991).

Para Ohno (1997) o genuíno melhoramento da produtividade de uma empresa desabrocha quando se é produzido com zero índice de desperdícios, pois esses consomem recursos, contudo não geram valor agregado. Além disso, a redução ou eliminação completa desses desperdícios aumenta gradativamente a eficiência de produção.

Do mesmo modo, Shingo (1996) afirma que qualquer empresa pode esforçar-se para eliminar as perdas. Unicamente quando a redução de custo se transfigura como o principal meio para manter ou ampliar lucros, a empresa será impulsionada para eliminar finalmente os desperdícios. Este autor classifica os desperdícios gerados como:

a) Desperdício de Superprodução: A superprodução consiste em produzir excessivamente ou cedo demais antes que o cliente precise. Produzir mais do que é imediatamente necessário para o próximo processo na produção é o maior originador de desperdício desencadeando outros como estoques, custos com energia, materiais obsoletos etc. (SLACK; CHAMBERS; JOHNSTON; 2002);

b) Desperdício de Estoque: Compreende-se em armazenamento em larga escala de produtos, entre processos, produtos finais, matéria primas etc. Considerado "dinheiro parado" dentro da filosofia Just in Time (JIT), os estoques são miras para eliminação (SLACK; CHAMBERS; JOHNSTON; 2002);

c) Desperdício de Transporte: Desperdício originado pela movimentação de produtos, peças, matéria primas etc. São as movimentações de materiais que não agregam valor ao produtos;

d) Desperdício de Movimentação: Distinto do desperdício de transporte, o desperdício de movimentação é com relação aos operadores durante a execução de suas atividades cotidianas. Um trabalhador muitas vezes pode parecer atarefado, contudo isso não significa que valor está sendo agregado ao produto. A simplificação de atividades é uma rica fonte de redução do desperdício de movimentação. (SLACK; CHAMBERS; JOHNSTON; 2002);

e) Desperdício de produzir itens defeituosos: Itens defeituosos geram desperdícios de matéria prima, de equipamentos e de tempo de armazenamento, aumentando assim os custos de produção e gerando retrabalhos sem agregar valor ao produto final;

f) Desperdício de espera: Ocorre quando há trabalhadores em estado ocioso, talvez assistindo máquinas trabalharem ou utilizando seu tempo com atividades que não agregam valor ao produto. O fluxo não contínuo de produção é o maior causador desse desperdício;

g) Desperdício de processos desnecessários: Algumas operações existem apenas em função de projeto ineficiente de componentes ou manutenção 
ruim, podendo ser analisadas e eliminadas (SLACK; CHAMBERS; JOHNSTON; 2002);

h)Desperdício de Capital Intelectual: Este desperdício consiste no não aproveitamento do capital intelectual da equipe dentro de uma empresa. De acordo com Carvalho e Souza (1999, p.2), "O Capital Humano é a capacidade, conhecimento, habilidade, criatividade e experiências individuais dos empregados e gerente transformando em produtos e serviços que são o motivo pelo qual os clientes procuram a empresa e não o concorrente".

\section{O CICLO PDCA}

A Gestão da Qualidade Total (no inglês "Total Quality Management") manifesta-se em uma gestão estratégica focalizada na importância da qualidade em todos os processos dentro da organização. Nesse sentido, Montgomery (2011) sustenta que "a melhoria efetiva da qualidade pode contribuir para o aumento da produtividade e redução dos custos".

Do mesmo modo, segundo Sashkin e Kiser (1994), quando as pessoas aprendem a utilizar as ferramentas da Qualidade Total, elas compreendem como controlar a variabilidade do sistema e isso é o caminho técnico para a melhoria contínua. Os mesmos autores asseguram ainda que "a administração da Qualidade Total funciona quando as pessoas usam as ferramentas básicas para manipular ou coletar dados a fim de analisar e resolver problemas".

Sendo assim, na década de 30, foi desenvolvido pelo americano Walter Shewhart o ciclo PDCA, porém o seu maior divulgador foi Deming, tornando-o mundialmente conhecido. A palavra PDCA é uma sigla oriunda da língua inglesa onde: P significa Plan (Planejamento), D significa Do (Execução), C significa Check (Verficação) e A significa Act (Ação) (MILET, 1993; BARRETO, 1999, apud NOGUEIRA, 1999).

O Ciclo PDCA é explicado por Werkema (1995, p. 17) como "método gerencial de tomada de decisões para garantir o alcance de metas necessárias à sobrevivência de uma organização". Nesse sentido, Mariani (2005) afirma que o método PDCA é aplicado pelas organizações para coordenar os seus processos e sistemas internos assegurando assim a conquista das metas estabelecidas, convertendo as informações em fator de condução das futuras decisões.

\subsection{ETAPAS DO CICLO PDCA}

As etapas do ciclo PDCA são abordadas por Marshall Junior (2006), da seguinte maneira:

\section{a) Etapa 1 - Plan (Planejamento):}

Fase onde os problemas são delimitados e as metas e objetivos são traçados. Durante esta etapa, algumas ferramentas da qualidade são utilizadas para auxiliar a tomada de decisões e ampliar o entendimento sobre os problemas a serem enfrentados dentro do processo. O Diagrama de Causa e Efeito ou Diagrama de Ishikawa, por exemplo, proposto pelo japonês Dr. Kaoru Ishikawa, em 1943, é descrito por Werkema (2006) como uma ferramenta utilizada para estudar e mostrar a conexão efetiva entre o processo e o resultado.

Este autor afirma que nos processos existem causas (fatores) que interferem num problema (efeito). Desta maneira, agrupando-se as causas a seis categorias (6M's - Máquina, Mão de obra, Método, Materias, Meio Ambiente e Medidas) pode-se encontrar a causa raiz da situação indesejada (WERKEMA, 2006).

Além disso, após a identificação das causas fundamentais do problema, devem-se priorizar aquelas que têm maior impacto sobre o indicador. Para isso, pode-se utilizar outra ferramenta da qualidade, a Matriz GUT. Gomes (2006) destaca a importância da Matriz de priorização GUT proposta por Charles H. Kepner e Benjamin B. Tregoe, em 1981. Esse autor retrata que a matriz GUT é uma ferramenta que esclarece a decisão na priorização de problemas e atividades. Depois de enumerar as causas para o problema estabelecido, a Matriz GUT viabiliza a quantificação das causas de acordo com a sua gravidade, urgência e tendência. Sendo assim, aos parâmetros são atribuídos um valor de 1 a 5 e a partir disso, é calculado o resultado $G$ $x \cup \times T$. Desta maneira é estabelecido a prioridade 
dos problemas a serem resolvidos ou ações a serem tomadas.

Para a definição das ações, momento crucial desta etapa, pode-se utilizar novamente uma ferramenta da qualidade como, por exemplo, o "5W2H". Este método quebra a ação em 7 pontos, sendo eles: What (o que fazer); Where (onde fazer); Why (por que fazer); Who (quem será o responsável); When (quando fazer); How (como fazer); How much (quanto custará). Desse modo, tem-se um plano de ações bem definidas e esclarecidas (WERKEMA, 1995).

\section{b) Etapa 2 - Do (Execução):}

Fase na qual se põe em prática o que foi planejado na fase anterior. Treinamentos sobre possíveis novos procedimentos, reuniões de acompanhamento devem ser viabilizadas regularmente, a fim de se fazer cumprir os objetivos delineados na primeira etapa do ciclo.

\section{c) Etapa 3 - Check (Verificação):}

Etapa onde as metas pré-estabelecidas são apuradas e os resultados alcançados são reavaliados, sendo comparado com a situação inicial. Nesta fase o uso de ferramentas de acompanhamento de atividades se faz necessário como a folha de verificação que é utilizada para simplificar a coleta e análise de dados, economizando assim tempo e disponibilizando uma visão mais ampla sobre as ações realizadas na etapa de execução das atividades para a melhoria do problema em análise. É uma ferramenta que concede dados onde as ações futuras devem ser baseadas de forma que a padronização das atividades sejam atendidas. (MARSHALL JR. et al 2007).

\section{d) Etapa 4 - Act (Ação/Padronização):}

A última fase do ciclo PDCA é onde ações corretivas são executadas para ajustar o que foi identificado como não conforme durante o processo. Nessa etapa também são tomada ações que garantam a prevenção dos resultados não esperados que talvez possam ter ocorrido durante o ciclo, para promover a continuidade das melhorias e manutenção do sistema.
Durante esse período, o $5 \mathrm{~W} 2 \mathrm{H}$ novamente pode ser utilizado. A ferramenta facilita a padronização de processos e mapeamento de atividades, auxiliando na elaboração de planos de ação e no estabelecimento de procedimentos relacionados e visualização de indicadores. (MARSHALL JR. et al 2007).

\section{PROCEDIMENTOS METODOLÓGICOS}

A natureza desta pesquisa é aplicada, pois desenvolve conhecimentos que têm aplicações práticas tanto na empresa investigada quanto em outras realidades fabris similares, que buscam a melhoria de indicadores de produtividade e eficiência de custos (SILVA E MENEZES, 2005). Além disso, quanto à forma de abordagem do problema, esta pesquisa é classificada como quali-quantitativa, pois ao mesmo tempo em que se observa e interpreta os fenômenos relacionados ao problema estudado, há a análise gráfica dos indicadores de perdas de insumos (SILVA E MENEZES, 2005).

Do mesmo modo, tem-se que, quanto aos fins, esta pesquisa caracteriza-se como descritiva por apresentar as características do fenômeno estudado e fazer correlações entre as variáveis que podem gerar o alto Índice de Perda de Latas; e explicativa por visar ao esclarecimento dos fatores que geraram o problema. Por outro lado, quanto aos meios, a pesquisa é bibliográfica e de campo, pois foram utilizados livros e artigos científicos para fundamentar o estudo e os dados da pesquisa foram coletados no local de ocorrência do problema (VERGARA, 2010).

Ademais, torna-se relevante citar que as técnicas empregadas foram a Pesquisa Documental e a Pesquisa Ação. Neste trabalho, foram utilizados arquivos particulares da empresa que continham informações diretas sobre o processo produtivo de refrigerantes e cervejas em lata. Da mesma forma, o pesquisador teve participação ativa na resolução do problema proposto (GIL, 2008; LAKATOS, MARCONI, 2010).

Quanto à interpretação dos dados, utilizou-se o método dedutivo. Este raciocínio utiliza a construção lógica para, a partir de teorias e leis gerais, chegar à 
previsão ou determinação de fenômenos particulares, denominada de conclusão (GIL, 2008; LAKATOS; MARCONI, 2010). Assim, o estudo pressupõe que o método PDCA contribui para resolução de problemas e geração de melhorias nos processos produtivos de empresas de bens e serviços. Por isso, aplicar essa metodologia à realidade da empresa de bebidas estudada ajudará a identificar as causas fundamentais do problema e as ações para o seu bloqueio.

\subsection{ETAPAS DA PESQUISA}

Neste estudo, a metodologia PDCA foi utilizada para nortear as etapas da pesquisa. Sendo assim, o primeiro passo foi a identificação do problema, momento no qual se verificou que o Índice de Perda de Latas estava consideravelmente superior à meta fabril, gerando gastos elevados com esse desperdício. Foi definido, portanto, conforme visto na parte introdutória, o problema que este trabalho buscou resolver.

Em seguida, foi feita a análise das causas fundamentais do problema abordado. Duas ferramentas foram utilizadas nesse momento: Diagrama de Ishikawa (ou de Causa e Efeito) e Matriz GUT. A primeira ferramenta analisou quais as causas relacionadas ao meio ambiente, aos materiais, às máquinas, às medidas, à mão de obra e aos métodos.

As causas apresentadas nesta ferramenta foram observadas nas linhas de produção e apontadas por operadores e supervisores, durante as reuniões de rotina, como os principais geradores do alto Índice de Perda de Latas.

Figura 1 - Diagrama de Ishikawa para o Índice de Perda de Latas

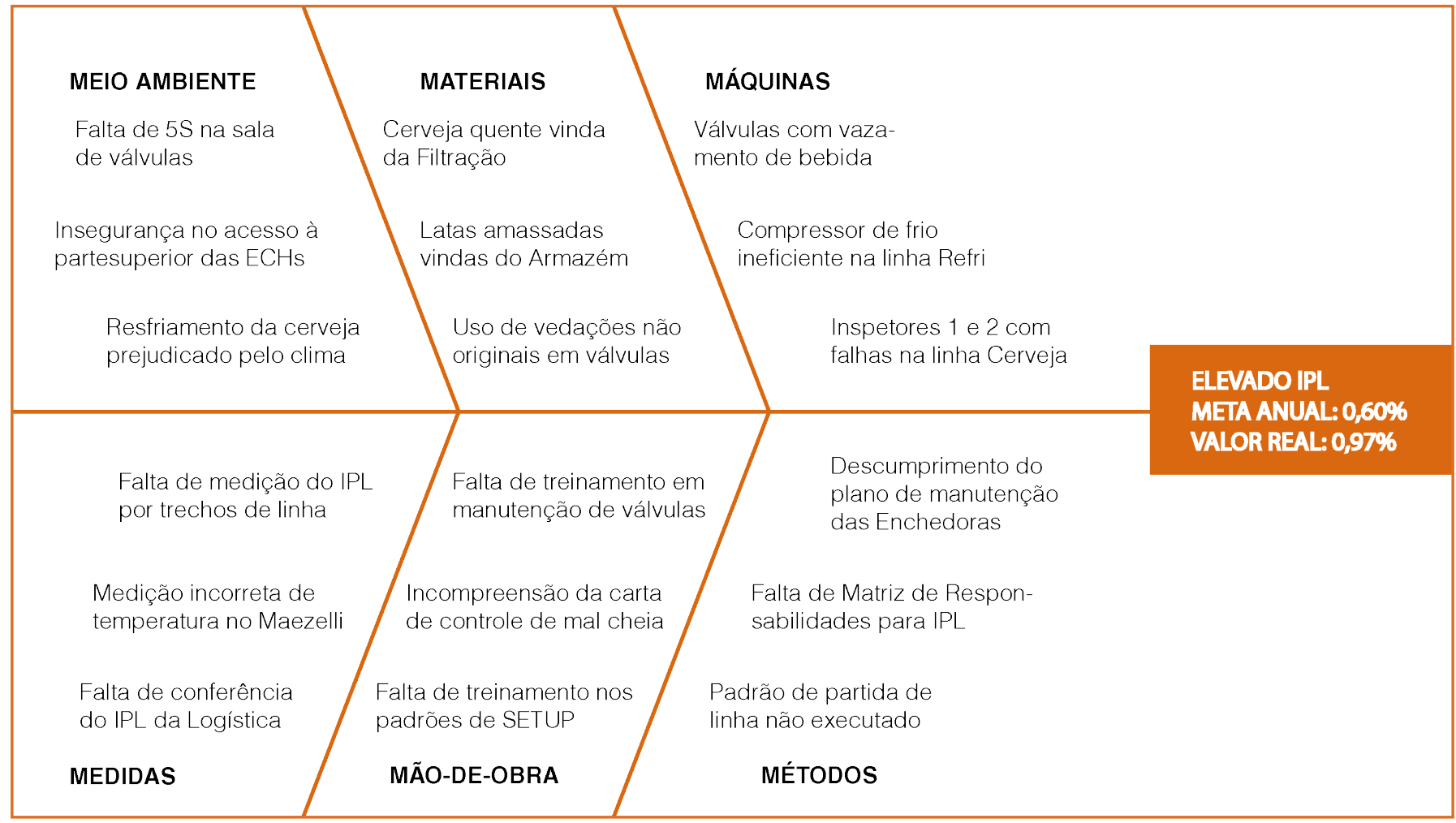

Fonte: Dados da Pesquisa, 2014.

A partir da determinação desses fatores, foi aplicada a Matriz GUT para priorizar as causas de modo que em seguida fossem tomadas as ações mais importantes para a resolução do problema. Cada causa foi 
pontuada de acordo com a sua Gravidade, Urgência e Tendência. Após isso, os índices foram multiplicados gerando a pontuação final.

De acordo a Matriz GUT apresentada na Tabela 1, a seguir, as 13 causas priorizadas (destacadas em negrito) correlacionam-se com os seguintes fatores: Máquinas, Métodos, Materiais, Mão de Obra e Medidas. Além disso, esses motivos obtiveram conceito igual e acima de 75 pontos e foram evidenciados para que a partir deles surgissem ações de bloqueio efetivo do problema estudado.

Destaca-se, ainda, que aquelas que alcançaram 125 pontos conectam-se principalmente aos aspectos de Máquinas, Métodos e Mão de Obra, removendose assim o prejulgamento de que o principal problema fabril está ligado sempre e somente ao mau funcionamento dos equipamentos industriais.
Quadro 1 - Matriz GUT para o Índice de Perda de Latas

\begin{tabular}{|c|c|c|c|c|}
\hline CAUSAS & G & $\mathbf{u}$ & $\mathbf{T}$ & TOTAL \\
\hline $\begin{array}{l}\text { Medição incorreta de temperatura no } \\
\text { Mazelli }\end{array}$ & 5 & 5 & 5 & 125 \\
\hline $\begin{array}{l}\text { Falta de treinamento em manutenção de } \\
\text { válvulas }\end{array}$ & 5 & 5 & 5 & 125 \\
\hline $\begin{array}{l}\text { Falta de treinamento nos Padrões } \\
\text { Operacionais de SETUP }\end{array}$ & 5 & 5 & 5 & 125 \\
\hline $\begin{array}{l}\text { Válvulas de enchimento das linhas com } \\
\text { vazamento de bebida }\end{array}$ & 5 & 5 & 5 & 125 \\
\hline $\begin{array}{l}\text { Compressor de frio ineficiente na linha de } \\
\text { refrigerante }\end{array}$ & 5 & 5 & 5 & 125 \\
\hline $\begin{array}{l}\text { Inspetores } 1 \text { e } 2 \text { descalibrados na linha de } \\
\text { cerveja }\end{array}$ & 5 & 5 & 5 & 125 \\
\hline $\begin{array}{l}\text { Falta de Matriz de Responsabilidades } \\
\text { para controle do IPL }\end{array}$ & 5 & 5 & 5 & 125 \\
\hline $\begin{array}{l}\text { Padrão Operacional de partida de linha } \\
\text { não executado }\end{array}$ & 5 & 5 & 5 & 125 \\
\hline $\begin{array}{l}\text { Descumprimento do plano de manutenção } \\
\text { das Enchedoras }\end{array}$ & 5 & 5 & 5 & 125 \\
\hline $\begin{array}{l}\text { Falta de medição do IPL por trechos de } \\
\text { linha }\end{array}$ & 5 & 5 & 3 & 75 \\
\hline $\begin{array}{l}\text { Falta de conferência da perda de latas da } \\
\text { Logística }\end{array}$ & 5 & 5 & 3 & 75 \\
\hline Cerveja quente vinda da área de Filtração & 5 & 5 & 3 & 75 \\
\hline Latas amassadas vindas do Armazém & 5 & 5 & 3 & 75 \\
\hline Falta de 5 S na sala de válvulas & 3 & 3 & 3 & 27 \\
\hline $\begin{array}{l}\text { Vedações das válvulas de enchimento } \\
\text { não-originais }\end{array}$ & 3 & 3 & 3 & 27 \\
\hline $\begin{array}{l}\text { Resfriamento da cerveja prejudicado pelo } \\
\text { clima }\end{array}$ & 3 & 3 & 1 & 9 \\
\hline $\begin{array}{l}\text { Desconhecimento do uso da carta de } \\
\text { controle de mal cheia }\end{array}$ & 3 & 3 & 1 & 9 \\
\hline $\begin{array}{l}\text { Insegurança no acesso à parte superior } \\
\text { das Enchedoras (ECHs) }\end{array}$ & 3 & 1 & 1 & 3 \\
\hline
\end{tabular}

Sendo assim, foi concebido o plano de ação com aquelas priorizadas na etapa anterior. Para isso valeu-se da ferramenta $5 \mathrm{~W} 2 \mathrm{H}$. Com o plano definido e aplicado, foi verificado se as ações efetivamente bloquearam o efeito (problema), ou seja, se o IPL e os gastos com a perda reduziram e se a meta foi alcançada. 
Quadro 2-5W2H para o IPL

\begin{tabular}{|c|c|c|c|c|c|c|}
\hline WHAT & WHERE & WHY & WHO & & HOW & $\begin{array}{l}\text { HOW } \\
\text { MUCH }\end{array}$ \\
\hline $\begin{array}{l}\text { Calibrar Mazelli da linha de } \\
\text { refrigerante }\end{array}$ & $\begin{array}{l}\text { Linha de } \\
\text { Refrigerante }\end{array}$ & $\begin{array}{l}\text { Medição incorreta de } \\
\text { temperatura no Mazelli } \\
\text { (Linha de refrigerante) }\end{array}$ & $\begin{array}{l}\text { Especialista } \\
\text { Técnico de } \\
\text { Mazelli }\end{array}$ & 07/08 & $\begin{array}{l}\text { Programando manutenção } \\
\text { conforme o Plano de } \\
\text { Manutenção (PM) do } \\
\text { Mazelli. }\end{array}$ & $\begin{array}{l}R \$ \\
2.768,53\end{array}$ \\
\hline $\begin{array}{l}\text { Treinar operação } \\
\text { da Enchedora em } \\
\text { manutenção de válvulas }\end{array}$ & $\begin{array}{l}\text { Linha de } \\
\text { Refrigerante e } \\
\text { de Cerveja }\end{array}$ & $\begin{array}{l}\text { Falta de treinamento em } \\
\text { manutenção de válvulas }\end{array}$ & $\begin{array}{l}\text { Especialista } \\
\text { Técnico de } \\
\text { Enchedora }\end{array}$ & 30/08 & $\begin{array}{l}\text { Treinando operadores dos } \\
3 \text { turnos das linhas durante } \\
\text { os PCMs do mês de agosto. }\end{array}$ & - \\
\hline $\begin{array}{l}\text { Treinar operação da } \\
\text { Enchedora nos Padrões } \\
\text { de Setup }\end{array}$ & $\begin{array}{l}\text { Linha de } \\
\text { Cerveja }\end{array}$ & $\begin{array}{l}\text { Falta de treinamento nos } \\
\text { Padrões de SETUP }\end{array}$ & $\begin{array}{l}\text { Especialista } \\
\text { Técnico de } \\
\text { Enchedora }\end{array}$ & 19/08 & $\begin{array}{l}\text { Treinando operadores dos } \\
3 \text { turnos durante o Setup } \\
\text { para } 269 \text { ml, com base no } \\
\text { Padrão de Setup. }\end{array}$ & - \\
\hline $\begin{array}{l}\text { Trocar orings e vedações } \\
\text { do conjunto de válvulas }\end{array}$ & $\begin{array}{l}\text { Linha de } \\
\text { Refrigerante e } \\
\text { de Cerveja }\end{array}$ & $\begin{array}{l}\text { Válvulas de enchimento } \\
\text { das linhas com } \\
\text { vazamento }\end{array}$ & $\begin{array}{l}\text { Operadores } \\
\text { de } \\
\text { Enchedora } \\
\text { do } 1^{\circ} \text { Turno }\end{array}$ & 18/09 & $\begin{array}{l}\text { Programando as trocas de } \\
\text { acordo com o PM. }\end{array}$ & $\begin{array}{l}\mathrm{R} \$ \\
86.491,16\end{array}$ \\
\hline $\begin{array}{l}\text { Realizar módulo } \\
\text { de manutenção no } \\
\text { compressor de frio }\end{array}$ & $\begin{array}{l}\text { Sala de } \\
\text { compressores } \\
\text { da Linha de } \\
\text { Refrigerante }\end{array}$ & $\begin{array}{l}\text { Compressor de frio } \\
\text { ineficiente na linha de } \\
\text { refrigerante }\end{array}$ & $\begin{array}{l}\text { Supervisor } \\
\text { de Utilidades }\end{array}$ & 17/08 & $\begin{array}{l}\text { Programando e realizando } \\
\text { o Módulo da linha de } \\
\text { acordo o PM. }\end{array}$ & $\begin{array}{l}R \$ \\
18.524,74\end{array}$ \\
\hline $\begin{array}{l}\text { Reativar Inspetor da saída } \\
\text { da Enchedora e Calibrar } \\
\text { Inspetor de Nível }\end{array}$ & $\begin{array}{l}\text { Linha de } \\
\text { Cerveja }\end{array}$ & $\begin{array}{l}\text { Inspetores } 1 \text { e } 2 \\
\text { descalibrados na linha de } \\
\text { cerveja }\end{array}$ & $\begin{array}{l}\text { Técnico } \\
\text { Heuft; } \\
\text { Especialista } \\
\text { de Inspetor } \\
\text { da fábrica }\end{array}$ & 23/09 & $\begin{array}{l}\text { Solicitando técnico externo } \\
\text { e peças para reativação e } \\
\text { calibração dos Inspetores. }\end{array}$ & $\begin{array}{l}R \$ \\
27.566,88\end{array}$ \\
\hline $\begin{array}{l}\text { Retreinar operação no } \\
\text { Padrão de Partida de Linha }\end{array}$ & $\begin{array}{l}\text { Linha de } \\
\text { Refrigerante e } \\
\text { de Cerveja }\end{array}$ & $\begin{array}{l}\text { Padrão de partida de } \\
\text { linha não executado }\end{array}$ & $\begin{array}{l}\text { Técnicos de } \\
\text { Qualidade } \\
\text { do } 1^{\circ}, 2^{\circ} \text { e } 3^{\circ} \\
\text { turno }\end{array}$ & 29/08 & $\begin{array}{l}\text { Treinando os operadores } \\
\text { com base no de Partida de } \\
\text { Linha. }\end{array}$ & - \\
\hline $\begin{array}{l}\text { Revisar as operações, } \\
\text { os materiais e os prazos } \\
\text { (periodicidade) das } \\
\text { manutenções contidas no } \\
\text { Plano da Enchedora }\end{array}$ & $\begin{array}{l}\text { Linha de } \\
\text { Refrigerante e } \\
\text { de Cerveja }\end{array}$ & $\begin{array}{l}\text { Descumprimento do } \\
\text { plano de manutenção } \\
\text { das Enchedoras }\end{array}$ & $\begin{array}{l}\text { Técnico de } \\
\text { Planejamento } \\
\text { de } \\
\text { Manutenção } \\
\text { das Linhas }\end{array}$ & 11/10 & $\begin{array}{l}\text { Revisando as Ordens de } \\
\text { Manutenção contidas no } \\
\text { PM Enchedora; Criando, } \\
\text { atividades para os itens } \\
\text { não contemplados pelo } \\
\text { plano; Inputando dados no } \\
\text { sistema. }\end{array}$ & - \\
\hline $\begin{array}{l}\text { Implantar Book de Controle } \\
\text { do IPL por trecho de linha } \\
\text { e analisar diariamente } \\
\text { os dados na Reunião de } \\
\text { Produtividade }\end{array}$ & $\begin{array}{l}\text { Linha de } \\
\text { Refrigerante e } \\
\text { de Cerveja }\end{array}$ & $\begin{array}{l}\text { Falta de medição do IPL } \\
\text { por trechos de linha; } \\
\text { Latas amassadas vindas } \\
\text { do Armazém. }\end{array}$ & Staff de & 09/08 & $\begin{array}{l}\text { Criando book de controle } \\
\text { de perdas por trecho e } \\
\text { treinando a operação para } \\
\text { utilizá-lo na rotina. }\end{array}$ & - \\
\hline $\begin{array}{l}\text { Reservar tanques } \\
\text { pequenos }(50 \mathrm{HI}) \text { para } \\
\text { passagem de cerveja da } \\
\text { filtração para a linha }\end{array}$ & $\begin{array}{l}\text { Linha de } \\
\text { Cerveja }\end{array}$ & $\begin{array}{l}\text { Cerveja quente vinda da } \\
\text { área de Filtração. }\end{array}$ & $\begin{array}{l}\text { Supervisor } \\
\text { de Filtração }\end{array}$ & 09/08 & $\begin{array}{l}\text { Incluindo na programação } \\
\text { dos tanques a reserva do } \\
\text { TQ1 para passagem de } \\
\text { cerveja da filtração para a } \\
\text { linha de produção. }\end{array}$ & - \\
\hline
\end{tabular}


A partir desta tabela, é possível verificar que das onze ações priorizadas apenas quatro demandaram investimentos, pois estavam relacionadas a melhorias e reestruturações em equipamentos fabris, bem como à vinda de técnicos especializados para a realização das manutenções necessárias.

Sendo assim, as ações relacionadas a treinamentos, alinhamento com outras áreas fabris (Logística e Filtração), desenvolvimento de books de controle e de matrizes de responsabilidades, bem como manutenções que dispunham de materiais e técnicos na localidade, foram programadas e realizadas no próprio mês de agosto.

Aquelas ações mais complexas, que demandaram técnicos externos e materiais específicos vindos de outros locais, assim como a atividade de revisão do plano de manutenção das enchedoras, foram programadas para os meses de setembro e outubro. Isso ocorreu, pois a sua realização requeria procedimentos específicos como autorização de pedido e inputação de informações em sistemas computacionais.

Dessa maneira, foram planejadas e executadas as ações delineadas com base na metodologia PDCA. Ao término do trabalho, as ações necessárias para melhoria e manutenção do comportamento favorável do indicador foram padronizadas.

\section{ANÁLISE DOS RESULTADOS}

A seguir é apresentado o Gráfico 3, que demonstra o resultado anual do IPL após a implantação da Metodologia PDCA, sendo comparado o índice real à meta estabelecida pela fábrica e à meta definida por esse projeto de melhoria.

Como pode ser observado, a partir do mês de agosto, quando oito ações foram implementadas nas linhas de produção, houve um decréscimo considerável no IPL fabril. Entretanto, nota-se que a meta mensal definida para o projeto só foi atingida no mês de novembro, quando foi alcançado o melhor índice do ano (0,24\%).

Verifica-se, além disso, que a meta anual do projeto de melhoria foi definida como $0,77 \%$, entretanto, o resultado anual da fábrica ficou em $0,78 \%$, ou seja, um centésimo acima do limite estipulado. Apesar disso, constatou-se que a tendência da reta passou a ser decrescente, o que significa que as ações definidas bloquearam efetivamente o problema, ajudando a reduzir o elevado Índice de Perda de Latas existente até o mês de julho.

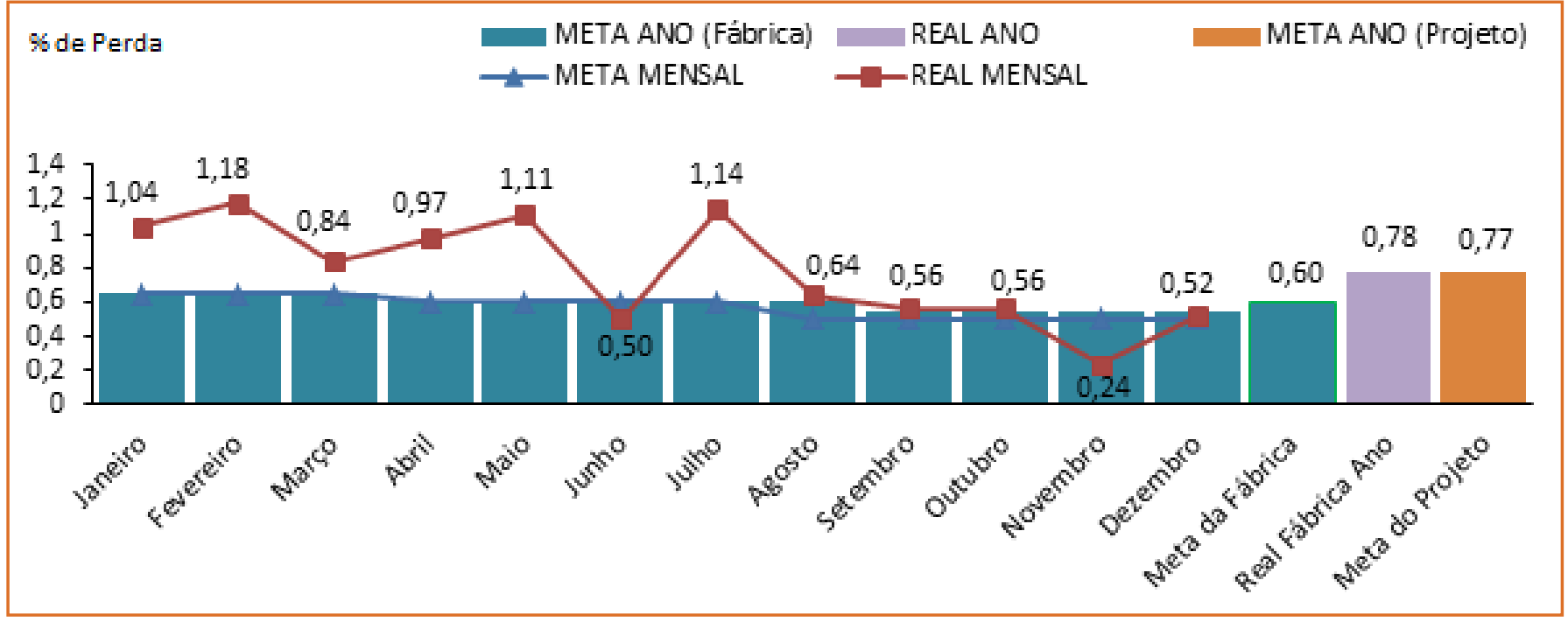


Como se reduziu o desperdício desses recursos, os esforços ou gastos para produzir refrigerantes e cervejas também reduziram, melhorando os resultados da organização.

Isso pode ser verificado no Gráfico 4, que apresenta os custos da perda de latas em 2014, comparando o primeiro semestre (janeiro a junho) ao segundo semestre (julho a dezembro), quando já havia a implementação das ações advindas do PDCA aplicado (exceto julho).

Gráfico 4 - Custo da Perda de Latas 2014

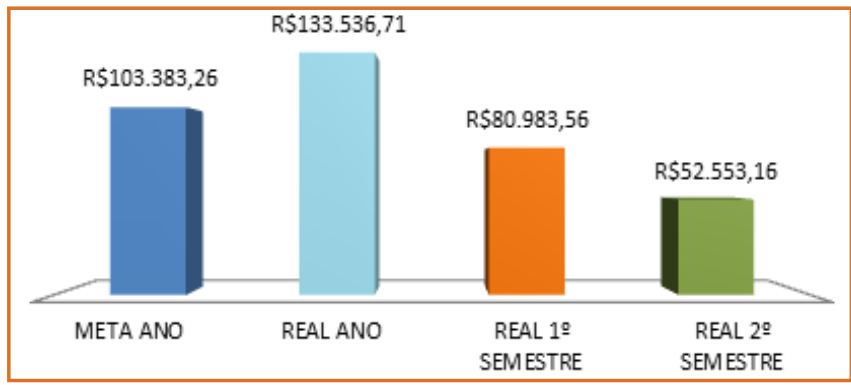

Fonte: Dados da Pesquisa, 2014.

Pode-se ressaltar, a partir do gráfico, que o resultado anual de custos não permaneceu dentro da meta fabril. Entretanto, comparativamente ao primeiro semestre, a segunda etapa do ano teve um gasto de aproximadamente $\mathrm{R} \$ 28.000,00$ a menos em perda de latas. Destaca-se, entretanto, que dentro do segundo semestre está incluso o mês de julho, último mês antes da implantação das ações de melhoria.

\section{CONCLUSÃO}

Neste trabalho, observou-se o processo de fabricação de refrigerantes e cervejas em latas em duas linhas de produção pertencentes a uma multinacional com filiais instaladas em Manaus. Esta empresa, assim como outras organizações que buscam aumentar a sua participação no mercado, preza pelo acompanhamento dos custos de fabricação dos seus produtos.

Observou-se, então, que o Índice de Perda de Latas (IPL), um dos principais indicadores de custos ligados à fabricação de bebidas desse tipo, estava consideravelmente acima da meta determinada pela filial. Para uma meta anual de no máximo 0,60\%, o índice se apresentava com $0,97 \%$ até o final do mês de julho de 2014, período no qual iniciaram-se os trabalhos para a implementação de ações de bloqueio do problema.

Para a execução deste projeto, foram seguidas as etapas do métodoPDCA, ferramenta da qualidade usualmente aplicada na busca da melhoria contínua. Sendo assim, após a identificação e observação do problema, realizou-se a análise das suas causas fundamentais a partir do Diagrama de Ishikawa. Para cada um dos 6M's propostos por essa ferramenta, foram mapeadas causas para a ocorrência do elevado IPL.

Após a composição do diagrama, verificou-se a necessidade de priorizar as causas listadas. Para isso, fez-se uso da Matriz GUT para, em seguida, gerar ações de reversão do problema. Construiu-se, desse modo, um plano de ação baseado na Matriz 5W2H.

Os principais "remédios" implantados foram: realização de treinamentos em padrões, de manutenção e de SETUP; revisão do plano de manutenção das enchedoras; confecção do book de controle do IPL por trecho de linha; definição da matriz de responsabilidades para atividades relacionadas à perda de latas; alinhamento com a área de Filtração para melhorar a temperatura da cerveja; e manutenções nos equipamentos-chave para o controle do indicador.

Os resultados obtidos com essas ações foram a redução do IPL a partir do mês de agosto, o que possibilitou o alcance de $0,78 \%$ de perda ao término do ano, e a queda dos custos com esse desperdício, ocasionando um segundo semestre com gastos consideravelmente inferiores àqueles da primeira metade do ano. Sendo assim, com a redução dos esforços financeiros para fabricar bebidas em latas, a empresa teve sua produtividade e eficiência melhoradas com a execução deste projeto.

Não obstante ao resultado de 2014 apresentar-se fora das metas fabris para o IPL e para os seus custos, destaca-se que a manutenção e a padronização das ações implementadas geraram um cenário 
consideravelmente positivo no ano seguinte. Em 2015, até o mês de abril (data da última coleta de dados), o Índice de Perda de Latas estava em 0,51\% no acumulado do ano. Do mesmo modo, os gastos com esse desperdício eram de $\mathrm{R} \$ 29.148,34$ para uma meta de $\mathrm{R} \$ 103.383,26$. Caso o resultado do primeiro quadrimente se repita nos dois próximos, apenas $84,5 \%$ da meta será gasto em perda de latas.

De fato, compreende-se que as ações executadas no ano anterior e padronizadas para contínua aplicação nos anos seguintes ocasionaram uma melhoria sustentável no IPL da fábrica de bebidas. Nesse contexto, pode-se averiguar que nos quatro primeiros meses de 2015 o índice estudado permanece dentro da meta mensal e consequentemente anual da empresa.

\section{REFERÊNCIAS}

[1] CARVAlHO, A. C. M., SOUZA, L. P. Ativos intangíveis ou capital intelectual: discussões da contradição na literatura e proposta para sua avaliação. Em: Prescpect. Cienc. Inf., Belo Horizonte, v.4, n.1, p.73-83,jan./jun. 1999.

[2] CORBETT NETO, T. Contabilidade de ganhos: a nova contabilidade gerencial de acordo com a teoria das restrições. São Paulo: Nobel, 1997.

[3] GIL, A. C. Métodos e técnicas de pesquisa social. 6. ed. São Paulo: Atlas, 2008.

[4] GOLDRATT, E. M. A síndrome do palheiro: garimpando informação num oceano de dados. São Paulo: Educator, 1991.

[5] GOMES, L.G.S. Reavaliação e melhoria dos processos de beneficiamento de não tecidos com base em reclamações de clientes. Rev. FAE, Curitiba, 2006.

[6] LAKATOS, E. M., MARCONI, M. de A. Fundamentos de metodologia científica. 7. ed. São Paulo: Atlas, 2010.
[7] MARIANI, C. A. Gestão pela qualidade e produtividade: curso de graduação em administração. Apucarana: Faculdade de Apucarana, 2005.

[8] MARSHALL JUNIOR, Isnard et al. Gestão da Qualidade. Rio de Janeiro. FGV, 2007.

[9] MONTGOMERY, D. C.; RUNGER, George C. Estatística aplicada e probabilidade para engenheiros. 2.ed. Rio de Janeiro: LTC, 2003

[10] NOGUEIRA, L. C. L. Gerenciando pela qualidade total na saúde. 2. ed. Belo Horizonte: Editora EDG, 1999.

[11] OHNO, Taichi. O Sistema Toyota de Produção. Além da produção em larga escala. Porto Alegre: Bookman, 1997.

[12] SASHKIN, M; KISER, K.J. Gestão da qualidade total na prática: o que é TQM, como usá-la.e como sustentá-la a longo prazo. Rio de Janeiro: Campus, 1994.

[13] SHINGO, S. O Sistema Toyota de Produção do ponto de vista da Engenharia de Produção. 2 ed. Porto Alegre, Bookman, 1996.

[14] SILVA, E. L., MENEZES, E. M. Metodologia da pesquisa e elaboração de dissertação. 4 ed. rev. atual. Florianópolis: UFSC, 2005, 138p.

[15] SLACK, N., CHAMBERS, S., JOHNSTON, R. Administração da Produção. 2 ed. São Paulo, Editora Atlas S.A, 2002

[16] VERGARA, S. C. Projetos e Relatórios de Pesquisa em Administração. 12. ed. São Paulo: Atlas, 2010.

[17] WERKEMA, M.C.C. As ferramentas da qualidade no gerenciamento de processos. Belo Horizonte, MG: Fundação Christiano Ottoni, Escola de Engenharia da UFMG, 1995.

[18] Ferramentas estatísticas básicas para o gerenciamento de processos. Belo Horizonte: Werkema Editora Ltda, 2006.

[19] WOMACK, James T; JONES, Daniel T., ROOS, Daniel. The Machine That Changed the World: The Story of Lean Production. Cap 2. Nova Iorque: Ed. HarperPerennial, 1991. 


\section{CAPÍTULO 5}

\section{AVALIAÇÃO DA PERCEPÇÃO DE RISCOS E PERIGOS DE ACIDENTES DOS OPERADORES DE LOGÍSTICA}

\section{Gleison de Sousa Amorim \\ Kazuo Hatakeyama}

Resumo: O objetivo deste trabalho foi avaliar o nível de percepção de riscos dos operadores de logística e aspectos do perfil desse trabalhador. A avaliação da percepção de risco e perigos permite aos empregadores e gestores de segurança a obterem indicadores e informações para o desenvolvimento de programas de segurança e campanhas de conscientização para redução e prevenção de acidentes. Com os resultados obtidos na pesquisa foram gerados indicadores que evidenciam que os operadores tem baixa percepção de risco em relação as suas atividades e a empresa possui deficiência no processo de capacitação dos trabalhadores e o ambiente de trabalho na logística é sobre pressão.

Palavras chave: Segurança do trabalho, Logística, Operador de Logística. 


\section{INTRODUÇÃO}

$\mathrm{Na}$ gestão dos processos e infraestruturas industriais, a eficiência da intralogística é essencial para a cadeia de suprimentos e sobrevivência das empresas. Segundo Ballou (2010) a logística é o processo de planejamento, implantação e controle do fluxo eficiente e eficaz de mercadorias, serviços e das informações relativas desde o ponto de origem até o ponto de consumo, com o propósito de atender às exigências dos clientes. No campo da logística empresarial, comuns são os estudos e pesquisas voltados para os processos operacionais, características e tecnologias de transporte, layout e área de armazenamento, Just in Time, custos de operação, programação e planejamento da produção, recebimento, distribuição e gestão de estoques.

A execução de atividades simultâneas e trabalhos em turnos são inerentes às operações intralogística das centrais de armazenamento e indústrias, e essas atividades propiciam anualmente a ocorrência diversificada de acidentes de trabalho que lesionam, incapacitam e matam trabalhadores.

Visando essa conscientização a presente pesquisa teve por objetivo avaliar e identificar a percepção de riscos e perigos de acidentes dos operadores de logística em uma empresa de armazenamento de produtos acabados.

\section{LOGÍSTICA}

Para Moura (2006) o papel da logística é fazer chegar à quantidade certa de mercadorias certas ao ponto certo, no tempo certo e ao mínimo custo. A logística constitui-se num sistema global, se inter-relacionando com diversos segmentos ou setores.

Nas indústrias e centrais de armazenamento a logística auxilia na minimização de custos e maximização de lucros, através da redução de custos com coletas e entregas, otimização de espaços físicos, atendimento de clientes no prazo, gestão de estoques de produtos acabados e matéria primas. Castiglioni e Minetto (2014) aponta que, um dos elementos mais importante da logística é o armazém, espaço físico destinado a guardar matérias-primas, produtos semiacabados e acabados.

A movimentação de materiais é uma tarefa que demanda grande empenho, e o uso de equipamentos adequados para o transporte de materiais pode contribuir a eficiência da execução da atividade. Os principais equipamentos utilizados na movimentação de materiais no armazém da empresa pesquisada são: Veículos Industriais e Embalagem:

Para a realização das operações na intralogística os principais agentes de transformação e concretização das atividades são os operadores de logística, armazenista ou operadores de movimentação e armazenagem de cargas. Esses profissionais, Paoleschi (2014) recepcionam, conferem e armazenam produtos e materiais em almoxarifados, armazéns, silos e depósitos. Fazem os lançamentos da movimentação de entradas e saídas e controlam os estoques. Distribuem produtos e materiais a serem expedidos.

\subsection{INTRALOGÍSTICA}

O termo é também conhecido como logística inbound, é a parte do processo da logística que realiza a movimentação interna, recebimento e armazenamento de materiais, alimentação, transporte e sequenciamento de linhas de produção, estocagem dos chamados produtos acabados e até o carregamento dos caminhões ou modais de produto acabados. Uma gestão eficiente dos processos produtivos e da logística desempenha um papel importante nos resultados e na redução de custos de indústrias e empresas, assim essas otimizam e padronizam os processos, ciclos e controles para ganho de tempo e ampliação de espaços físicos. O gerenciamento da intralogística permite a empresa a obter bons resultados, proporcionando reflexos positivos na logística externa, demonstrando aos clientes a eficiência no sistema logístico (PAOLESCHI, 2014).

A intralogística está interligada a logística externa, segundo Bowersox et al (2014) ela tem a finalidade de atender atividades primárias, ou seja, transportes, 
manutenção de estoques, processamento de pedidos, entre outros, pois são elas que contribuem com a maior parcela de custo total da logística e também pela sua importância para a coordenação e o cumprimento da tarefa logística.

\subsection{SEGURANÇA NO TRABALHO NA LOGÍSTICA}

A Segurança do Trabalho pode ser entendida como o conjunto de medidas adotadas, visando minimizar os acidentes de trabalho, doenças ocupacionais, bem como proteger a integridade e a capacidade de trabalho das pessoas envolvidas. (PEIXOTO, 2010). A segurança do trabalho é uma área do conhecimento humano que tem a finalidade de avaliar e identificar riscos e perigos para tornar os ambientes de trabalho seguros e saudáveis para os trabalhadores em todos os ramos de atividade econômica.

Ainda Peixoto (2010) no mundo moderno e competitivo, as relações entre empresas e colaboradores deixaram de ser consideradas simplesmente relações de trabalho e passaram a ter um enfoque mais amplo, implicando uma gestão total. Isto não só envolve compromissos financeiros, mas qualidade de vida $e$ de trabalho, passando, também, pela promoção da qualidade global que abrange ações sistemáticas na preservação do homem, do ambiente, da comunidade e da empresa.

Na logística a segurança do trabalho é fundamental em todas as suas ramificações, seja na logística externa no transporte rodoviário, marítimo e na intralogística na operação de equipamentos (empilhadeiras, paleteira elétricas, pontes rolantes), movimentação de carga mecânica e manual, carga e descarga de caminhões e estocagem de materiais.

O transporte dos materiais e matérias-primas, produtos em fabricação e produtos acabados sempre mereceu atenção por parte dos responsáveis pela gestão industrial, por ser assunto estreitamente ligado ao leiaute e à estrutura física do prédio e por ter implicações na produtividade, na qualidade, na segurança no local de trabalho e nos custos da operação (MARCHLINE, 2011).
$\mathrm{Na}$ intralogística os profissionais estão submetidos a jornadas exaustivas e condições inseguras de trabalho que são condicionadas pela sobrecarga de trabalho devido aos turnos de revezamentos e ausência de equipamentos apropriados para execução das operações que obriga os trabalhadores a executarem as atividades manualmente. Essas condições levam a inúmeros acidentes de trabalho como atropelamentos, queda de materiais e pessoas de prateleiras porta paletes, colisões de veículos industriais, prensagem e esmagamentos, queimaduras, choques elétricos, lombalgias, DORT-Doenças osteomusculares relacionados ao trabalho que causam lesões, fraturas e até morte.

As atividades logísticas são classificadas pelo CNAE do grupo 52 (Armazenamento e atividades auxiliares dos transportes), segundo o anuário estatístico de acidente do INSS (2012) entre 2010 e 2012 aconteceram 20.350 acidentes do trabalho e desses 1.822 ocorreram no estado de Santa Catarina. Os acidentes que ocorrem nas operações intralogística poderiam ser evitados e reduzidos se houvesse programas de segurança do trabalho que estimulassem a conscientização dos trabalhadores quanto aos riscos e perigos de suas atividades para a prevenção de acidentes.

Em contramedida para reduzir os riscos de acidentes do trabalho em ambientes logísticos e nas atividades de armazenagem e movimentação de materiais existe no Brasil a NR-11 estabelece requisitos mínimos para a movimentação Transporte, Movimentação, Armazenagem e Manuseio de Materiais, operação de equipamentos e veículos industriais, dimensionamento de áreas de armazenagem, capacitação e habilitação de trabalhadores.

A NR-11 estabelece requisitos mínimos, então somente seus requisitos não permite realizar a gestão eficiente de segurança do trabalho no ambiente logístico, pois seus requisitos não abrangem os aspectos comportamentais que são essenciais para evitar acidentes de trabalho. A consciência do comportamento seguro permite os trabalhadores a entenderem os riscos que estão expostos, assim pode adotar contramedidas e avaliar a riscos antes de iniciar as atividades para a prevenção de acidentes. 
Ressalta Tamayo e Paschoal (2003) o comportamento é percebido como sendo provocado e guiado por metas da pessoa, que realiza um esforço para atingir determinado objetivo. A maioria dos autores considera a motivação humana como um processo psicológico estreitamente relacionado com o impulso ou com a tendência a realizar com persistência determinados comportamentos. A motivação no trabalho, por exemplo, manifesta-se pela orientação do empregado para realizar com presteza e precisão as suas tarefas e persistir na sua execução até conseguir o resultado previsto ou esperado.

Enquanto o trabalhador não estiver motivado em realizar a segurança do trabalho para preservar a sua vida e integridade física não será possível efetivar a gestão eficiente da segurança nos ambientes de trabalho. Para isso acontecer deverão ocorrer mudanças físicas no ambiente de trabalho e na cultura dos trabalhadores e empregadores em prol da segurança, levando em consideração comportamento seguro.

Para Moura (2009) a mudança no local de trabalho pode beneficiar a redução ou prevenção de lesões, a redução do esforço dos funcionários através da diminuição das forças de elevação, de empurrar e de puxar materiais, a redução de fatores a eliminação aos gargalos de produção, das taxas de erros ou rejeições do uso de serviços médicos, indenizações por acidente de trabalho, excesso de atividade de funcionários, absenteísmo e retreinamento, e por fim aumento da produtividade, da qualidade dos produtos e dos serviços e da moral dos funcionários.

\section{PROCEDIMENTOS METODOLÓGICOS}

O objeto de estudo da pesquisa foram os operadores de logística da empresa, e foi aplicado um questionário com perguntas voltadas identificação das condições de trabalho, riscos da atividade, capacitação, experiências, acidentes de trabalho e uma ilustração de atividades com riscos e perigos para que os operadores identificassem que podem ser similares ao das suas atividades práticas executadas no armazém. Portanto, esse questionário serviu como uma importante ferramenta para identificar as deficiências e dificuldades dos trabalhadores em relação à segurança do trabalho nas operações logísticas.

Essa pesquisa é classificada como uma pesquisa básica estratégica e tem caráter exploratório com estudo de campo, sendo voltada ao levantamento de informações e dados com finalidade de compreender o nível de percepção de risco e perigos dos operadores logísticos. Para Gil (2002) a pesquisa exploratória tem como objetivo proporcionar maior familiaridade com o problema, com vistas a torná-lo mais explícito, esse tipo de pesquisa pode envolver levantamento bibliográfico e entrevistas com pessoas experientes no problema pesquisado.

A pesquisa no campo da logística em uma central de armazenamento de produtos acabados justifica-se por haver poucas pesquisas voltadas a segurança do trabalho, e permite obter conhecimento dos riscos e perigos inerente às atividades operacionais da logística. A questão que norteia a pesquisa é se os operadores de logística conhecem tem percepção de riscos e perigos das suas atividades.

O desenvolvimento da pesquisa foi realizado com os operadores logísticos de um armazém de produtos acabados de uma empresa de alimentos de Gaspar, SC. A empresa opera em 3 turnos de trabalho com 75 funcionários na logística operacional que recebem e armazenam materiais, controlam estoques e operam veículos industriais (rebocador e empilhadeiras). Dos três turnos de operação foi estudado somente o primeiro turno, e do universo de 75 funcionários a pesquisa foi realizada com a amostra de 35 funcionários com que atuam no setor produto acabado. Dos 35 questionários aplicados todos foram preenchidos, tendo 100\% de aceitação e respostas por parte dos funcionários abordados.

No questionário foi incorporado uma ilustração para que os trabalhadores identificassem os riscos para obter dados e assim avaliar o nível de percepção de risco e perigos em suas atividades no armazém de produtos acabados, em anexo. 


\section{ANÁLISE DOS RESULTADOS}

Indicadores de acidentes do trabalho são utilizados para mensurar a exposição dos trabalhadores aos níveis de risco inerentes à atividade econômica, permitindo o acompanhamento das flutuações e tendências dos acidentes e seus impactos nas empresas e na vida dos trabalhadores. Além disso, fornecem subsídios para o aprofundamento de estudos sobre o tema e permitem o planejamento de ações nas áreas de segurança e saúde do trabalhador (BRASIL, 2012).

Com os resultados da pesquisa foi possível obter indicadores importantes em relação a segurança do trabalho e aspectos do perfil dos operadores. Esses dados permitirão aos gestores de segurança e empregadores a terem parâmetros de riscos e perigos das atividades e características dos profissionais da área. Um dos itens pesquisados foi o sexo dos trabalhadores conforme gráfico 1 , e foi constatado que a maioria dos entrevistados são 53\% do sexo masculino e $47 \%$ do sexo feminino. A presença feminina está em áreas administrativas e de todos os entrevistados na área operacional apenas 15 mulheres executavam atividades operacionais. Assim demonstra que na área logística ainda é uma atividade masculina, mas há exceções, pois algumas mulheres exercem funções consideradas masculinas como a operação e empilhadeiras e transporte manual de cargas. No gráfico 2 é apresentado que 54\% dos operadores se declaram como brancos, e isso se comprova porque a cidade de Gaspar-SC foi construída a partir da colonização alemã e italiana e essas caraterísticas permanecem nos traços da população.

Gráfico 1 - Sexo

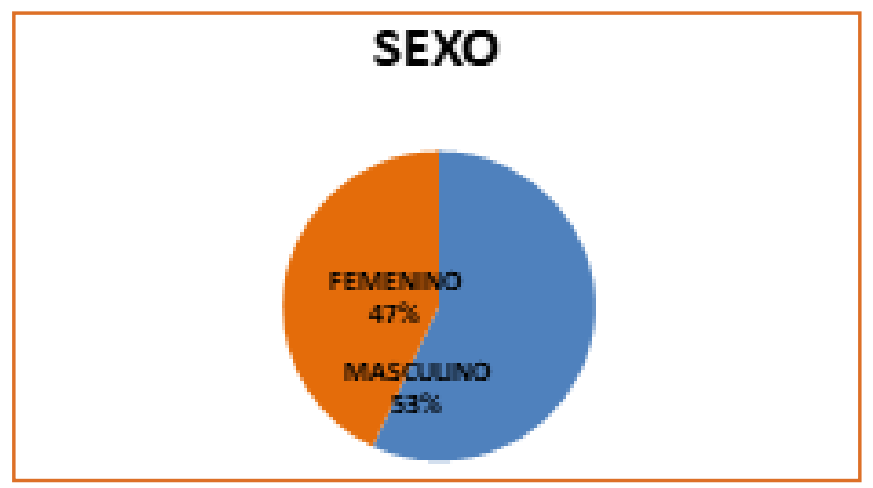

Fonte: autores (2015)
Gráfico 2 - Raça

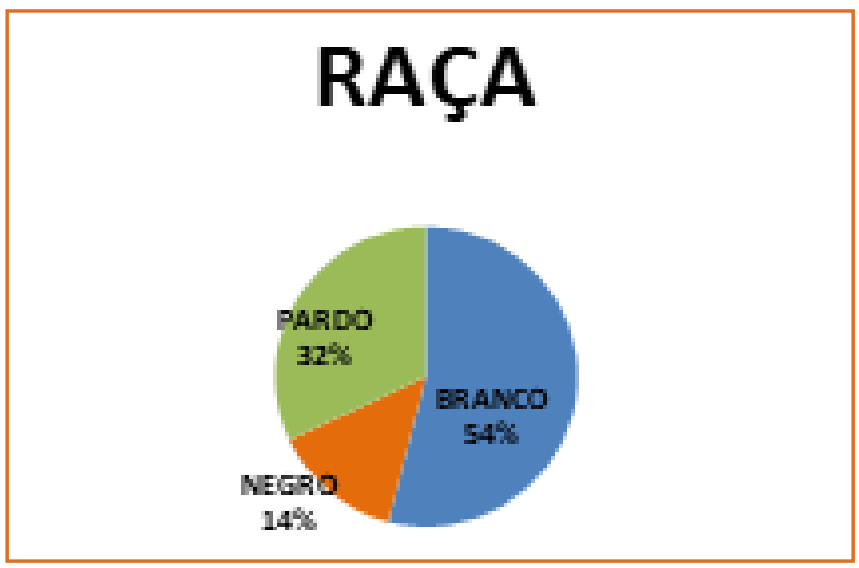

Fonte: Autores (2015)

Em relação ao estado civil dos operadores de logística é demonstrado no nos gráficos 3 que $46 \%$ são casados, $37 \%$ Solteiros, $9 \%$ separados $8 \%$ estão namorando, e no gráfico 4 descreve que 54\% possuem a idade de 18 e 25 anos.

Gráfico 3 - Estado Civil

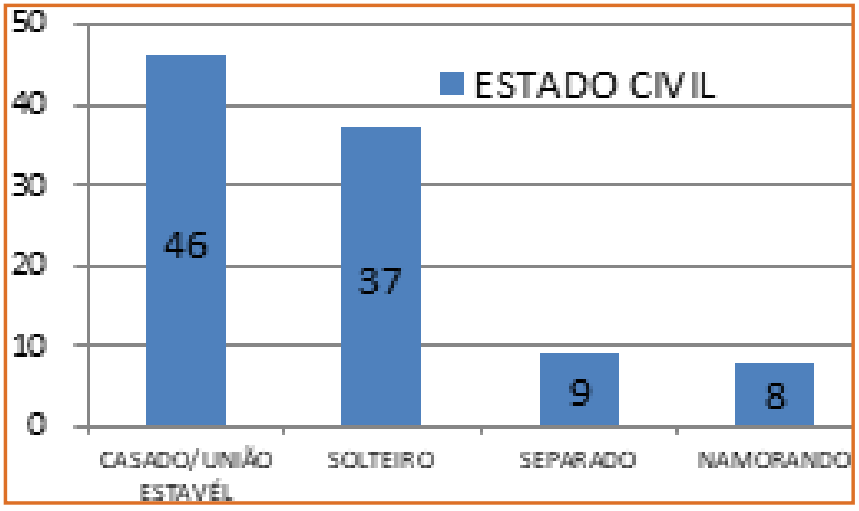

Fonte: Autores (2015)

Gráfico 4 - Média de Idade

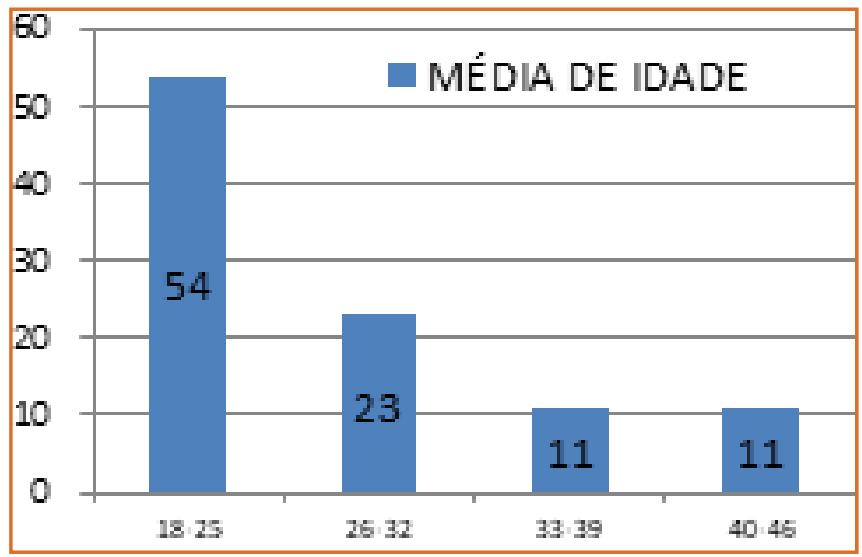

Fonte: Autores (2015) 
O grau de instrução dos trabalhadores foi identificado conforme o gráfico 5 que $60 \%$ possuem o ensino médio completo e estão lotados nas atividades operacionais, enquanto $40 \%$ estão nas funções administrativas por possuir curso técnico e ensino superior na área de logística. Relacionado ao grau de instrução outro indicador obtido e preocupante para a segurança do trabalho foi à capacitação e treinamento. Segundo $66 \%$ dos entrevistados (gráfico 6) existem deficiências no processo de capacitação, eles alegaram que receberam apenas a integração de segurança para inicio do trabalho e nunca receberam treinamentos periódicos ou cursos que especifiquem os riscos de operações de empilhadeiras e equipamentos.

Gráfico 5 - Escolaridade

\section{ESCOLARIDADE}

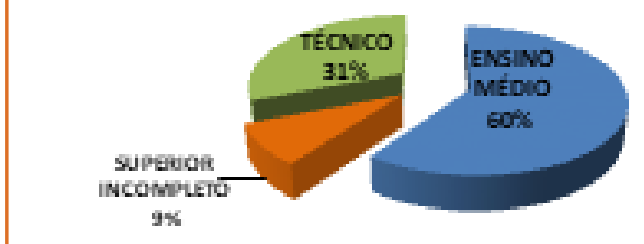

Fonte: Autores (2015)

Gráfico 6 - Treinamento e capacitação

\section{TREINAMENTO E CAPACITAÇÃO}

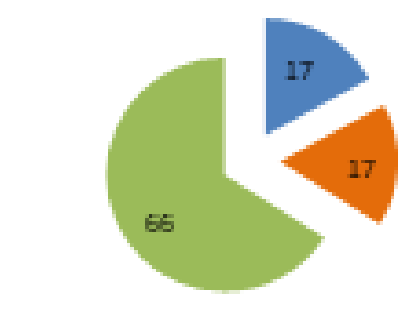

- OPCRACAO DE EMPPILHADERA - RICOS NA AREA DE LOGISTICA - INTEGRAC,AO
Outro fator pesquisado para avaliação do nível de percepção de risco foi o tempo de serviço do trabalhador no ramo da logística. No gráfico 7 foi evidenciado que 29\% dos trabalhadores possuem mais de 1 ano de atividade no ramo da logística e $31 \%$ já sofreram acidentes do trabalho na empresa pesquisada e empresas que trabalharam antes de entrar na empresa atual.

Gráfico 7 - Tempo de Serviço na logística

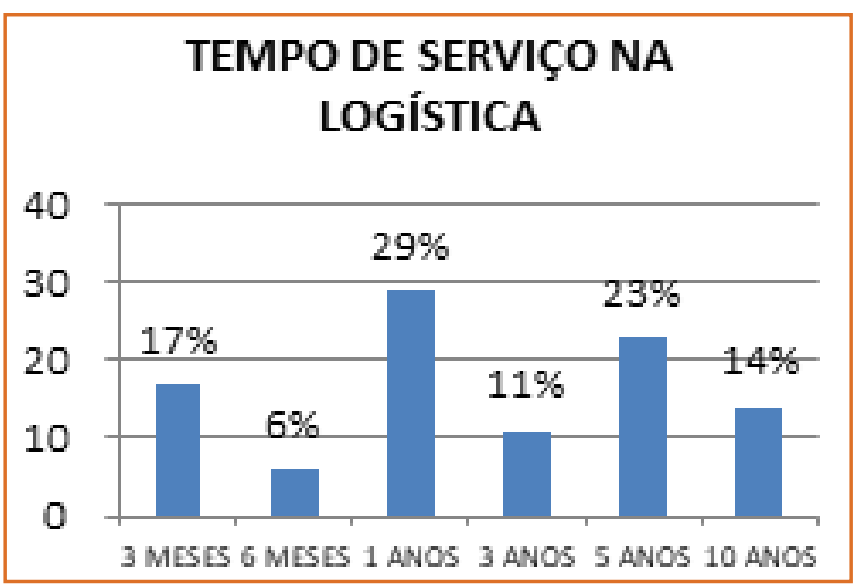

Fonte: Autores (2015)

Gráfico 8 - Acidentes de trabalho

\section{ACIDENTES DO TRABALHO}

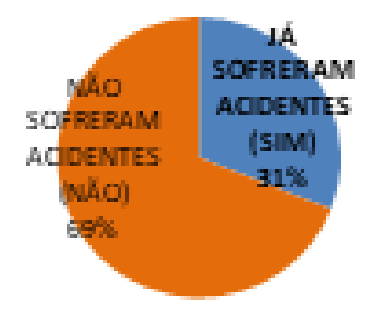

Fonte: Autores (2015)

O consumo de bebida alcoólica está no habito dos trabalhadores brasileiros e esse consumo causa impactos na saúde publica e no sistema produtivo das empresas, devido ao absenteísmo, acidentes no trabalho e no relacionamento interpessoal dos trabalhadores com colegas e família. Segundo Duailibi e Laranjeira (2007) o uso prejudicial do álcool é associado a mais de 60 tipos de doenças, incluindo desordens mentais, suicídios, câncer, cirrose, danos intencionais e não intencionais, comportamento agressivo, perturbações familiares, acidentes no trabalho e produtividade industrial reduzida. 
$\mathrm{Na}$ pesquisa realizada foi identificado conforme gráfico 9 que 51\% dos entrevistados consomem bebida alcoólica semanalmente, e isso mostra que esse consumo pode interferir nas atividades da área com o absenteísmo e a possibilidade da ocorrência de acidentes que podem ocorrer indiretamente por causa do álcool. Nas entrevistas 54\% os operadores de logística relataram que um fator importante na execução das suas atividades é a segurança do trabalho (gráfico 10), isso reflete que eles têm a consciência da importância da segurança no desempenho das suas atividades nos armazéns e depósitos.

Gráfico 9 - Consumo de Bebida Alcoólica

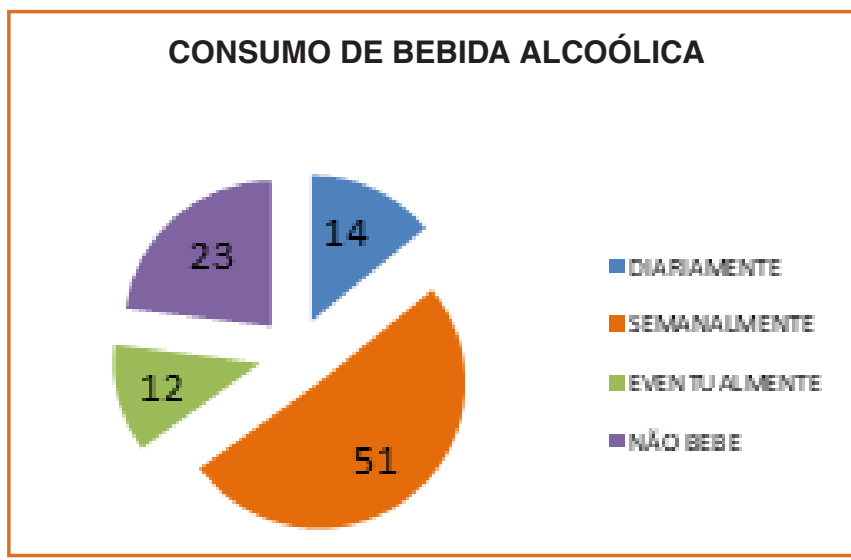

Fonte: Autores (2014)

Gráfico 10 - Fator Importante na Atividade

FATOR IMPORTANTE NA ATIVIDADE

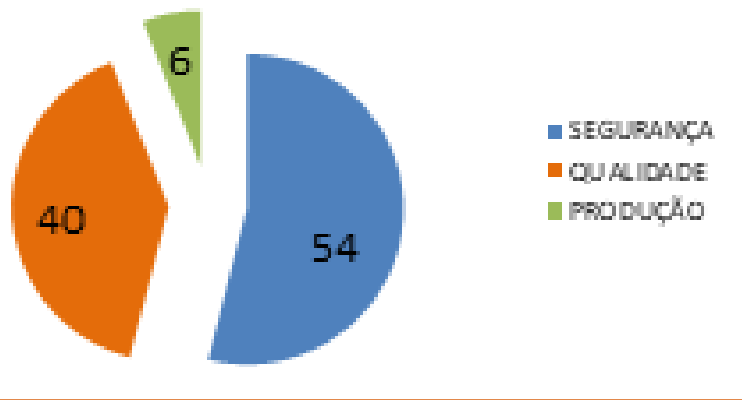

Fonte: Autores (2014)

Nas atividades que exercem na logística 53\% dos operadores consideram como bom às condições do ambiente de trabalho (gráfico 11), mas 66\% consideram que a pressão no trabalho (gráfico 12) é comum nesse ambiente.

Gráfico 11 - Condições do ambiente

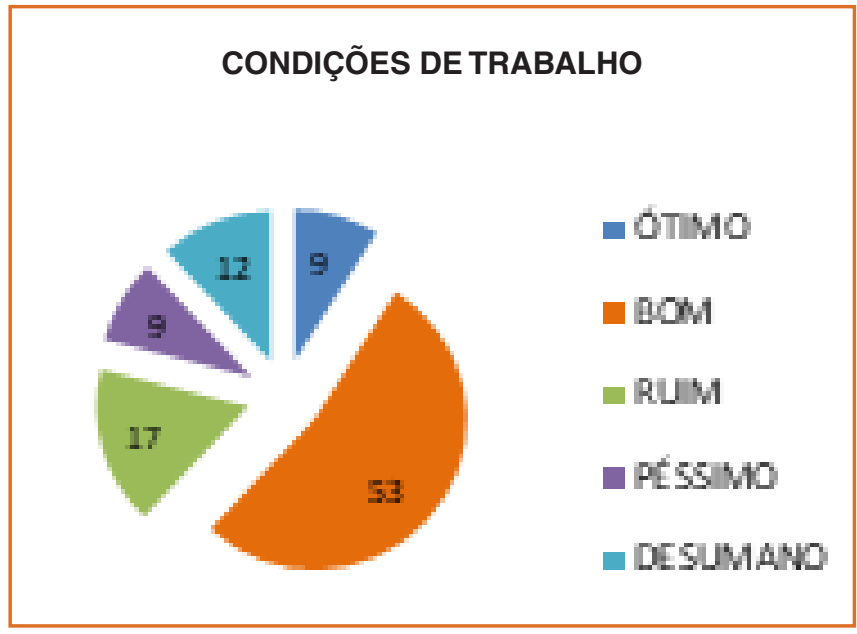

Fonte: Autores (2014)

Gráfico 12 - Situações comuns na logística

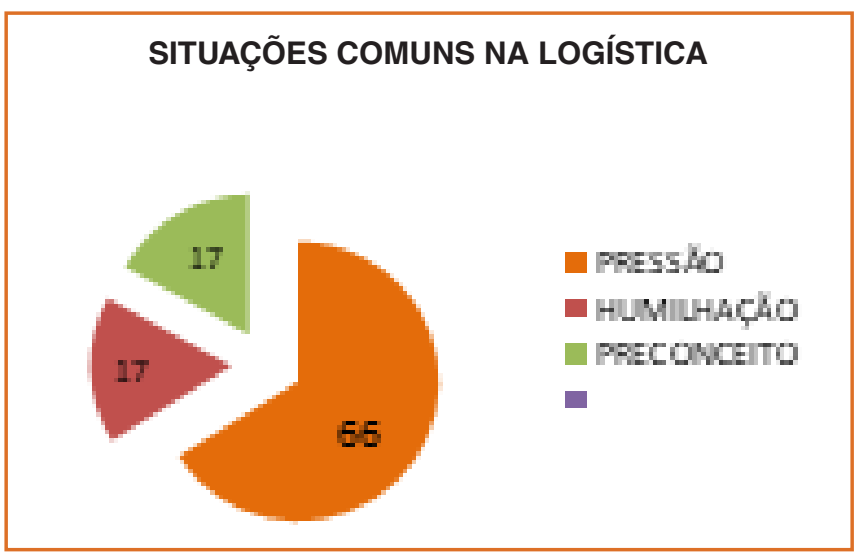

Fonte: Autores (2014)

Gráfico 13 - Riscos na area logística

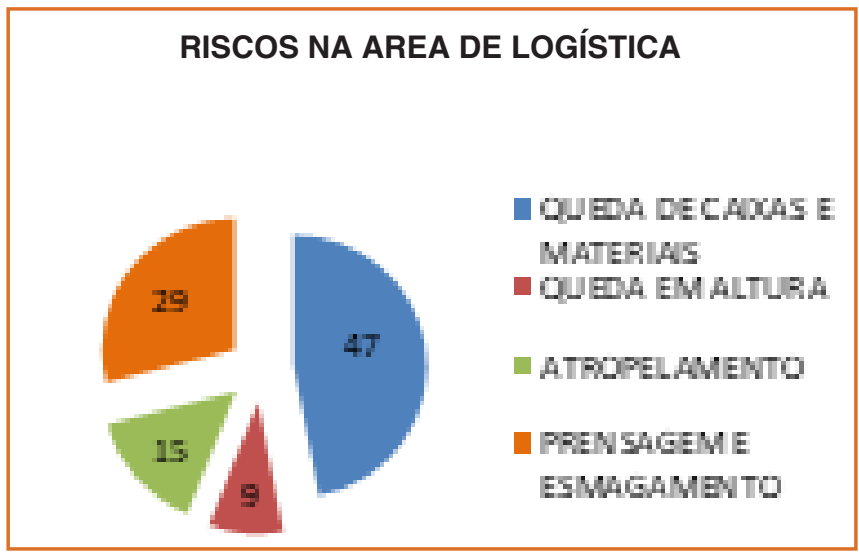

Fonte: Autores (2014)

$\mathrm{Na}$ avaliação da percepção de riscos dos operadores, eles consideraram que os riscos mais comuns na 
área de logística são atropelamentos, queda de caixas e materiais, queda de altura e prensagem e esmagamento. O maior risco que $47 \%$ dos operadores identificaram foi a quedas de materiais e caixas (gráfico 12) devido a constante movimentação de materiais, retirada de caixas dos portas paletes e carga e descarga de caminhões.

\section{CONCLUSÃO}

Os indicadores propostos não esgotam as análises que podem ser feitas para prevenção de acidentes, mas são indispensáveis para a determinação de programas de prevenção de acidentes e a consequente melhoria das condições de trabalho na empresa pesquisada e similares que possuem o mesmo processo produtivo. Na identificação de riscos na figura 3 que teve a finalidade de avaliar a percepção de risco dos trabalhadores do total de 50 riscos (gráfico 14), os operadores identificaram em média 10 riscos o que corresponde a $20 \%$ dos riscos descritos na ilustração. Isso demonstra que o processo de gestão e capacitação em segurança do trabalho possui deficiência e não existe uma sistemática para elevar no nível de percepção de risco e conscientização para a prevenção de acidentes do trabalho.

Gráfico 14 - Riscos na área Logística

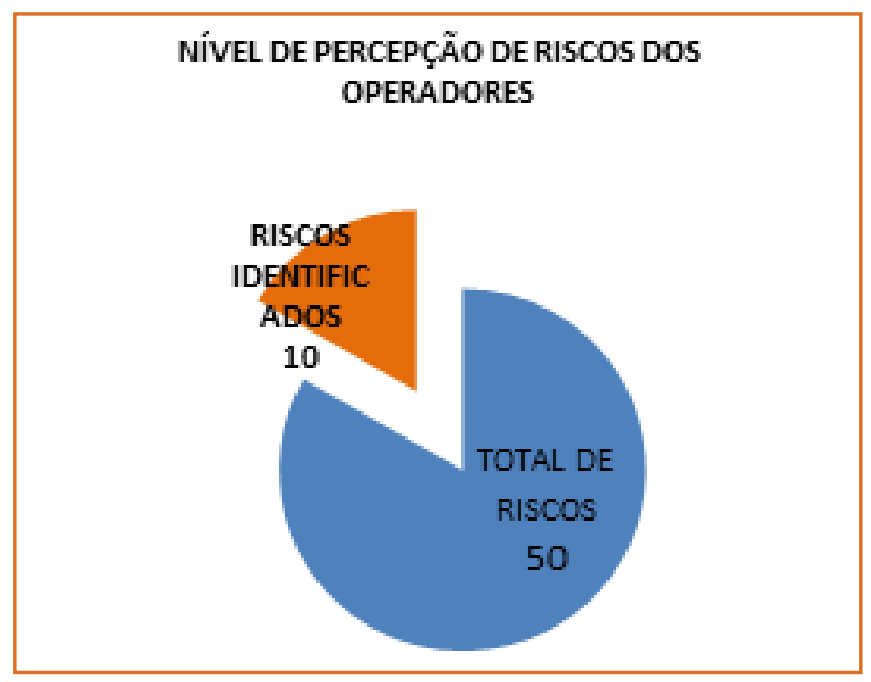

Fonte: Autores (2015)
Figura 2 - 50 riscos de acidentes

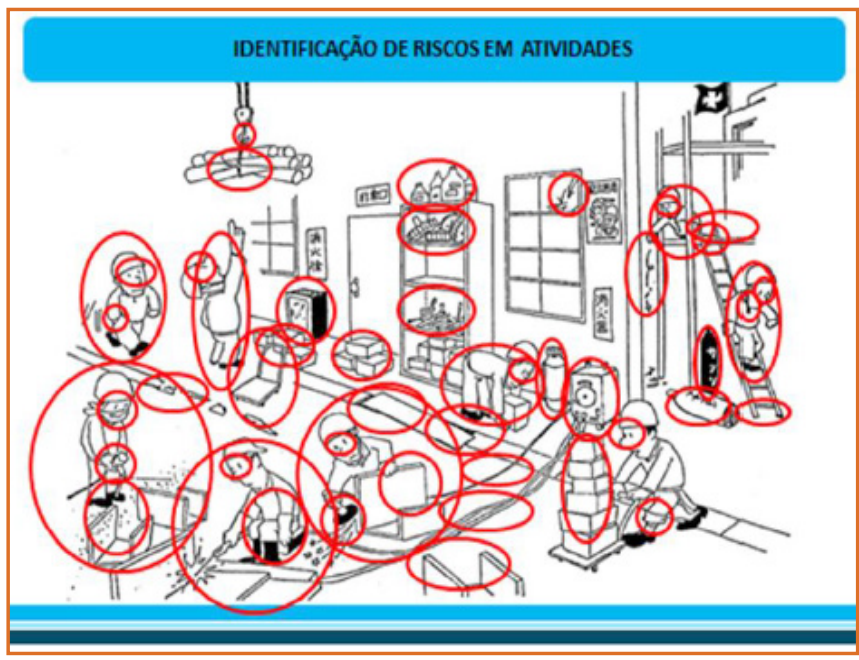

Fonte: Autores (2015)

Portanto, a pesquisa possibilitou a avaliação do nível percepção de risco dos operadores de logística, e pelos dados obtidos é possível verificar que falta capacitação periódica em relação a riscos de acidentes na logística e operação de empilhadeira, pressão no trabalho e a percepção de risco dos trabalhadores é baixa comparando com o total de riscos identificados na ilustração que tem aspectos similares aos que ocorrem na logística.

As informações levantadas na pesquisa abre um leque para novas pesquisas no campo da logística, principalmente no que diz respeito aos riscos e perigos da logística operacional, condições de trabalhos, educação, capacitação e eficiência na segurança no trabalho. As pesquisas em segurança do trabalho são importantes para a redução de acidentes e impactos na saúde publica que são decorrentes dos gastos com tratamento de acidentes e afastamentos do trabalho. Essas pesquisas contribuem para a melhoria das condições do trabalho em todos os ramos de atividades, principalmente nas atividades de movimentação de materiais que são responsáveis por mais de 20.000 acidentes por ano.

\section{REFERÊNCIAS}

[1] BALLOU, R. Logística Empresarial: transporte, administração de materiais e distribuição física. São Paulo: Atlas, 2010. 
[2] BOWERSOX, et al. Gestão da cadeia de suprimentos. 4. ed. Porto Alegre: Bookman, 2014.

[3] BRASIL, Anuário Estatístico de Acidentes do Trabalho. Ministério da Previdência Social. Brasília. 2012. Disponível em: http://www. previdencia.gov.br/estatisticas/aeps-2012anuario-estatistico-da-previdencia-social-2012/aeps-2012secao-iv-acidentes-do-trabalho/ Acesso em: 01 mai. de 2014.

[4] BUREAU, I.T. A sua saúde e segurança no trabalho: uma coleção de módulos. introdução à saúde e segurança no trabalho. Genebra. 2009. Disponível em: http://www.ilo.org/ public/portugue/region/eurpro/lisbon/pdf/pub_modulos2. pdf. Acesso em: 20 mai. De 2014

[5] CAStigliONI, J. A., MinetTO, R. Processos logísticos. São Paulo: Érica, 2014.

[6] DUAILIBI, S.; LARANJEIRA, R. Políticas públicas relacionadas às bebidas alcoólicas. Rev. Saúde Pública [online]. vol. 41 no.5 São Paulo. 2007. Disponível em: http:// www.scielo.br/pdf/rsp/v41n5/6462. pdf Acesso em: 15 mai. de 2014.

[7] GIL, A. C. Como elaborar projetos de pesquisa. 4. ed. São Paulo: Atlas, 2002.

[8] MACHLINE, C. Cinco décadas de logística empresarial e administração da cadeia de suprimentos no Brasil. Revista administração de empresa. vol.51, n.3. 2011. Disponível em: http://www.scielo.br/pdf/rae/v51n3/v51n3a03.pdf Acesso em: 18 mai. De 2014.
[9] Moura, B. C. Logística: Conceitos e Tendências. Lisboa: Centro Atlântico, 2006.

[10] MOURA, R. A Segurança intralogística: manuseio, embalagem, armazenagem, movimentação de materiais. São Paulo: IMAM, 2009. Disponível em: http://engenho.info/ revista/ed05/edartigos/artigo_01.pdf Acesso: 10 mai. de 2014.

[11] Novaes, A. G. Logística e Gerenciamento da Cadeia de Distribuição. Rio de Janeiro: Elsevier, 2007.

[12] PAOLESCHI, B. Estoque e armazenagem. São Paulo: Érica, 2014

[13] PAOLESCHI, B. Logística industrial integrada: do planejamento, produção, custo e qualidade a satisfação do cliente. ed. São Paulo: Erica. 2014

[14] PEIXOTO, N. H. Curso técnico em automação industrial: segurança do trabalho. 3. ed. UFSM. Santa Maria, 2010. Disponivel em: http://redeetec.mec.gov.br/images/stories/ pdf/eixo_ctrl_proc_indust/tec_autom_ind/seg_trab/161012_ seg_do_trab.pdf Acesso em: 20 mai. de 2014.

[15] TAMAYO, A.; PASCHOAL, T. A relação da motivação para o trabalho com as metas do trabalhador. Rev. adm. contemp. [online]. Rio de Janeiro. 2003. Disponível em: http://www.scielo.br/pdf/rac/v7n4/v7n4a03.pdf Acesso em: 15 mai. de 2014. 


\section{QUESTIONÁRIO TRABALHADORES LOGISTICA}

Prezado Companheiro de Classe: Este questionário năo é obrigatório, mas sua opiniāo é MUITO IMPORTANTE Năo precisa escrever seu nome no questionảrio. As informaçōes săo sigilosas e servirão para o trabalho cientifico de pesquisa que está sendo desenvolvido na Empresa. As respostas devem ser levadas em consideraçăo toda a sua vida e experiéncia no ramo logistico.

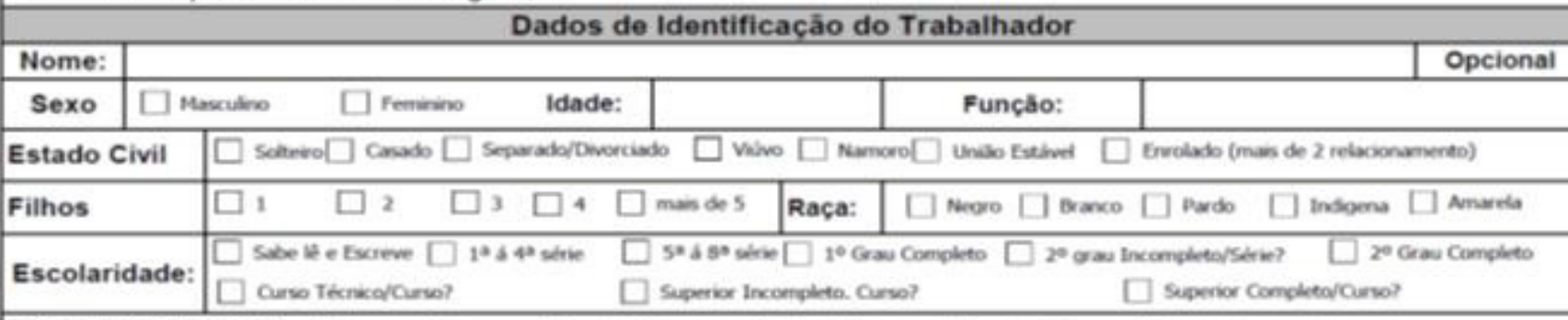

Tempo de Serviço em $\square$ menos de 3 meses $\square$ mais de 6 meses $\square$ Mus de 1 ano $\square$ mass de 3 anos $\square$ mais de 5 anos $\square$ mas de 10 anos logistica?

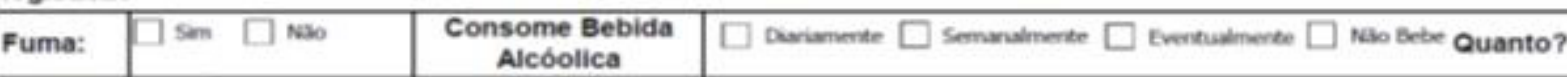

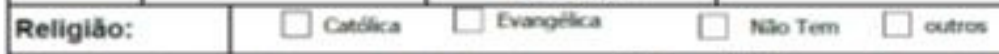

Ja Sofreu algum acidente de trabalho? $\square \mathrm{Sem} \square$ naso Ficou Afastado: $\square \mathrm{Sm} \square$ Naso

\begin{tabular}{l}
$\begin{array}{l}\text { Considera o ambiente de trabalho na ärea } \\
\text { logistica? }\end{array} \quad \square$ Como $\square$ bom $\square$ Rum $\square$ Akumo $\square$ Desumam \\
\hline
\end{tabular}

Qual o maior risco de acidente que voce $\square$ Abropelomerto $\square$ queda em Ahura $\square$ queda de caicas e Matmian $\square$ hrensapem esmapamento considera na área logisitca?

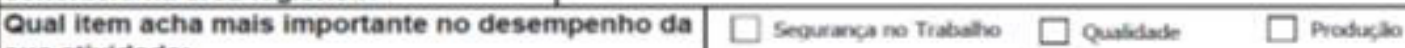
sua atividade:

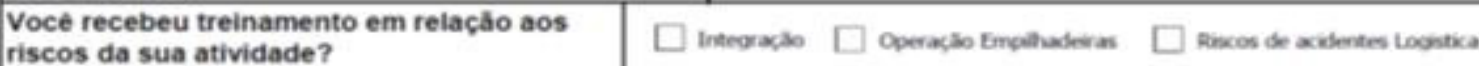

É realizado o DDS-Dialago diário de segurança

antes de iniciar as atividades?

Vocé realiza análise de risco antes de iniciar suas

atividades diárias? DDS/APR

Em sua Atividade vocé utiliza instruçào de trabalho

ou procedimento Operacional?

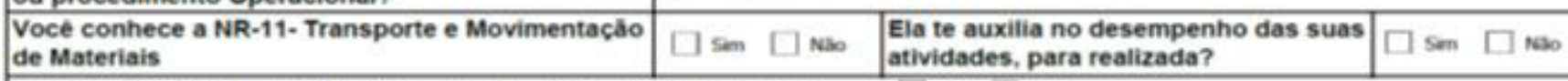

Gostaria de voltar a estudar ou receber qualificaçåo profissional?

$\square \mathrm{sm} \square \mathrm{Nbs}$

Qual desses fatores 6 comum na área logistica? $\quad \square$ Preconcento $\square$ mumilhaplo $\square$ Prembo no tratublo

IDENTIFIQUE ABAIXO OS RISCOS DE ACIDENTES QUE TEM NA FOTO

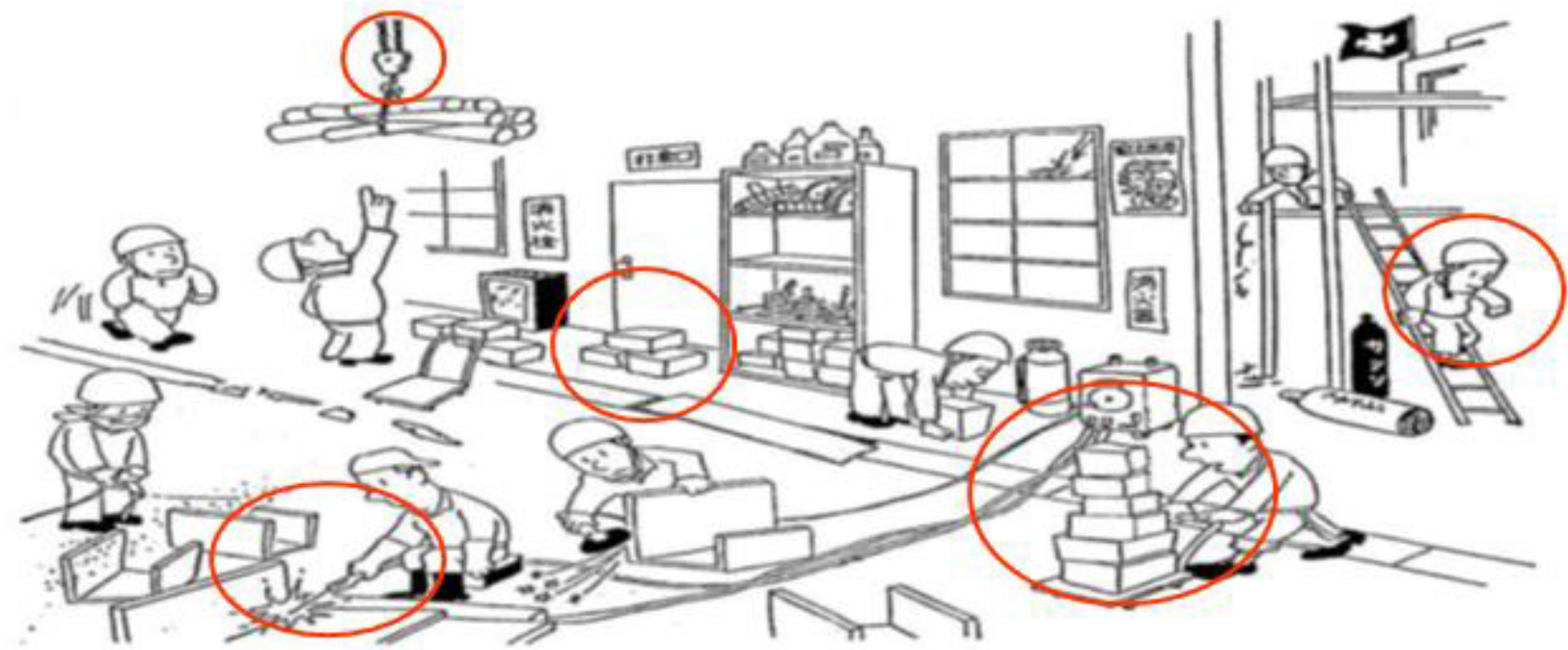

Total de itens identificados:

Total de riscos na figura:

AVALIADOR: 


\title{
CAPÍTULO 6
}

\section{CONTROLE DE CADEIAS DE SUPRIMENTOS COM INCERTEZAS DE MODELAGEM E DE PREVISÃO DE DEMANDA: UMA ABORDAGEM BASEADA NO CONTROLE PREDITIVO GENERALIZADO}

\author{
Dayron Antonio Álvarez Rodríguez \\ Júlio Elias Normey-Rico \\ Rodolfo César Costa Flesch
}

Resumo: Este capítulo apresenta uma estratégia de controle preditivo que permite tratar de forma eficiente as incertezas tipicamente presentes em cadeias de suprimentos. É aplicado o controle preditivo generalizado como base e são realizadas alterações na forma de realizar predições para tratar as incertezas de modelagem e de previsão de demanda, além de compensar o tempo morto. Resultados de simulação evidenciam como os algoritmos de controle preditivo empregados conseguem manter os níveis de estoque dentro da especificação e ao mesmo tempo atingir a demanda dos clientes. Em casos incertos, a versão modificada do controlador preditivo empregada é capaz de manter a estabilidade e um bom desempenho do sistema de malha fechada, o que não ocorre com a versão convencional do controlador preditivo generalizado.

Palavras chave: Controle preditivo baseado em modelos, tempo morto, cadeia de suprimentos. 


\section{INTRODUÇÃO}

Os primeiros sistemas de armazenagem sugiram com a necessidade da humanidade de garantir a sobrevivência em épocas de escassez. Em um primeiro momento, o objetivo era simplesmente estocar e consumir. Depois, além da questão da armazenagem propriamente dita, outros aspectos como perdas no sistema (devido a deterioração ou roubo) e garantia de abastecimento foram adicionados ao problema. Dessa forma, os primeiros passos para o gerenciamento de estoques estavam sendo dados. Com o crescimento populacional das cidades e o desenvolvimento da manufatura após o advento da revolução industrial, sistemas de estoques cada vez maiores se tornaram necessários para garantir o abastecimento e sua gestão tomou um impulso de grandes proporções (PACHECO, 2004).

No quadro econômico, não são apenas produtos que competem contra produtos, senão também cadeias de suprimento que concorrem com outras cadeias de suprimento (CS). Isso porque, ao eliminarem-se ineficiências dessas cadeias, podem-se economizar recursos, o que torna o produto final mais competitivo e rentável (SIMCHI-LEVI, et al, 2004). Uma CS eficiente traz grandes benefícios para a sociedade, uma vez que evita desperdícios e, por sua vez, reduz impactos ambientais causados pela produção excessiva (SCHWARTZ e RIVERA, 2010). As CS podem apresentar diferentes estruturas e sua complexidade pode variar dependendo do tipo de produto final, do tempo de produção, dos tempos de transporte, e também das variáveis envolvidas no processo de transformação das matérias primas (BENEDITO, 2006). Outro fator a ser considerado no estudo de uma CS é o nível de incertezas sob o qual a mesma opera, o que depende da variação da demanda. Para alguns mercados, é mais fácil conhecer ou estimar a demanda e seu comportamento no tempo, o que ajuda a manter preços e custos mais estáveis (ALOTHAM, et al, 2008). Esses conhecimentos tornam-se determinantes como suporte ao pessoal especialista em logística e operações da companhia. Pacotes de software e soluções de internet, tais como mySAP. com, permitem às empresas o acesso iterativo em tempo real a inventários, taxas de produção, previsões de vendas e outras informações disponíveis que ajudam na tomada de decisões e na implementação de estratégias para gestão dos estoques (BRAUN, 2001).

Para as indústrias em geral, torna-se cada vez mais difícil concorrer em escala global sem fortes estratégias de gerenciamento de estoque. Novas normas para gestão dos resíduos geram um foco renovado de qualidade, acrescentando obstáculos para alcançar certificações internacionais e adoção de paradigmas de alta qualidade (SUBRAMANIAM, et al, 2011). Portanto, as decisões de produção precisam ser rápidas e robustas frente às incertezas do mercado, porém otimizadas para atingir objetivos chave na CS. Esse cenário torna as CS sistemas ideais para a aplicação de técnicas de controle.

O uso de técnicas de controle para o problema de eficiência das CS tem crescido fortemente desde a segunda metade do século XX. Trabalhos nessa área incluem a modelagem de processos de CS usando analogia de fluidos através de comparações com sistemas de controle de nível em tanques acoplados (SCHWARTZ e RIVERA, 2010), bem como o controle desse sistema através de técnicas de malha fechada (NANDOLA e RIVERA, 2013). Inicialmente, começouse a utilizar a teoria de controle no estudo de CS a partir da aplicação de servomecanismos de tempo contínuo, manipulando a taxa de produção em um sistema simples que envolvia um único produto (HERBET, 1952). Posteriormente, estenderam-se essas ideias a modelos de tempo discreto para controle de inventario baseados nos conceitos da transformada z (VASSIAN, 1955). Na sequência, introduziu-se o modelo Forrester, que permitiu abordar problemas no âmbito de organização industrial. Seu amplo uso para ilustrar os problemas presentes nas CS facilitou e forneceu uma ferramenta poderosa para a utilização de técnicas de controle no gerenciamento de estoque (TOWILL, et al, 1992). No ano de 1992, aplicou-se pela primeira vez a teoria de controle preditivo em um problema de gerenciamento de inventário, com foco em um problema local de fabricação. Nesse estudo, Kapsiotis e Tzafestas (1992), tentaram compensar os prazos de produção, incluindo na função custo do controlador um termo de penalidade nos desvios da trajetória de referência. Posteriormente, muitos trabalhos surgiram com aplicação da teoria de controle 
preditivo em gestão de CS. Encoraja-se o leitor a ler os trabalhos de Sarimveis, et al (2008) e Subramaniam, et al (2012) para uma revisão mais detalhada da aplicação de técnicas de engenharia de controle para os problemas de CS.

De acordo com Al-Otham, et al (2008), o controle de CS visa minimizar custos de produção, minimizar excessos de armazenamento e minimizar as despesas de transporte, assim como satisfazer as demandas dos clientes, mantendo uma participação ativa no mercado. O problema de controle é manter o nível de estoque dentro de certos valores pré-determinados e, ao mesmo tempo, proporcionar um funcionamento economicamente ideal no processo de fabricação; em outras palavras, evitar mudanças rápidas no ritmo de produção e, ao mesmo tempo, evitar quantidades indesejáveis de estoque. O tempo morto aqui tem uma influência importante e é causado pelo tempo necessário para que os pedidos sejam processados e emitidos, como mostra a figura 1. Processos com essa característica de tempo morto significativo são difíceis de serem controlados usando controladores preditivos convencionais (NORMEY-RICO e CAMACHO, 2007), uma vez que a robustez desses sistemas de controle tende a ser baixa frente a incertezas na estimação do modelo e na estimação de demanda. Ainda, devido à quantidade de processos envolvidos, o processo como um todo tem um grande número de variáveis e dinâmicas complexas, o que gera dificuldades para o desenvolvimento de algoritmos de controle eficientes. Nesse cenário de complexidade no modelo e elevado tempo morto, propõe-se neste trabalho o uso de técnicas de controle preditivo baseado em modelo que incluem uma estrutura de compensação de tempo morto explícita no preditor, buscando aliar as vantagens do controle preditivo com a robustez necessária para aplicação prática. Como será mostrado, esses controladores podem ser configurados e ajustados para atingir bom desempenho e robustez em CS com tempo morto incerto.
Figura 1 - Tempos de produção e transporte em uma CS

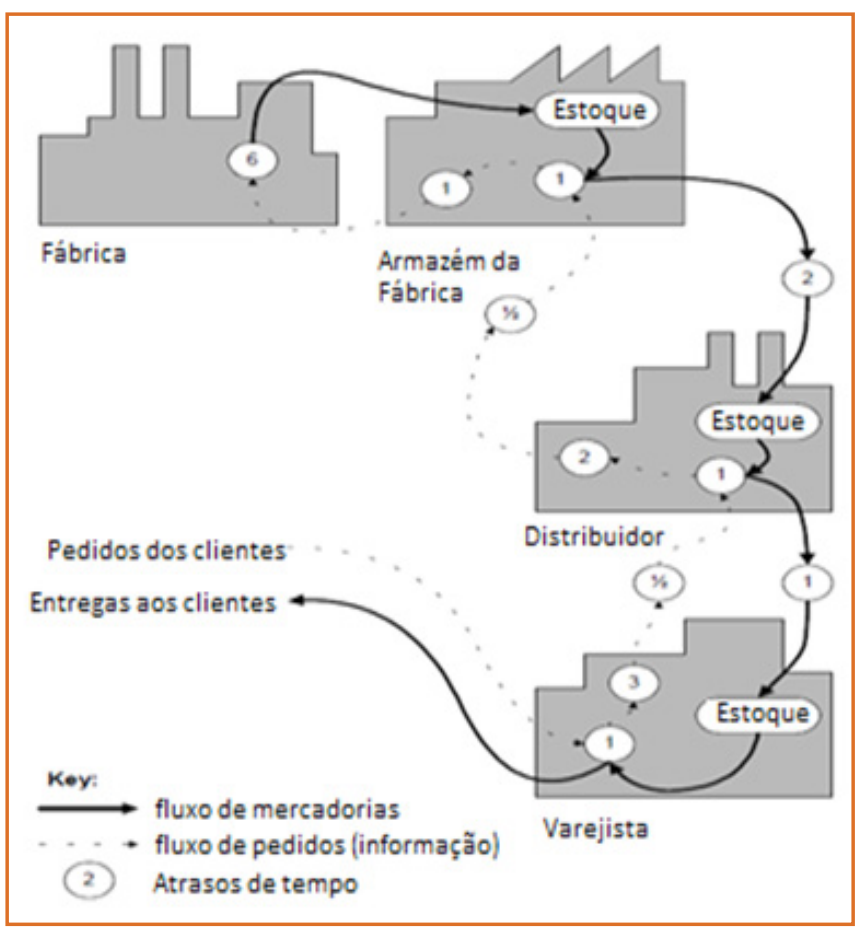

Este capítulo é dividido em cinco seções e uma lista de referências. Na seção 2 é descrita a rede de CS e desenvolve-se o modelo discreto para aplicação do algoritmo de controle. Na seção 3, apresenta-se a estrutura proposta para o problema de controle e compensação de tempo morto na CS. Resultados de simulação são apresentados na seção 4, mostrando o desempenho dos controladores. Por fim, apresentamse as conclusões e considerações finais.

\section{FORMULAÇÃO DO PROBLEMA}

Para clareza da apresentação, nesta seção é considerada uma CS para um só tipo de produto com um só nó em cada nível, mas o método pode ser estendido para um caso de múltiplos produtos e múltiplos nós. A topologia de CS apresentada na figura 2 tem o seguinte comportamento: a planta tem um tempo de produção de 5 dias e demora 2 dias para transportar o produto semi-acabado, após revisões de padrão de qualidade, até a área de embalagem. $\mathrm{Na}$ área de embalagem o produto pode demorar até 2 dias dentro do processo de acabamento final e leva-se 1 dia para entregá-lo no depósito. Finalmente, no depósito o produto leva 1 dia no processo de padronização e inclusão no estoque. Os pedidos demoram 1 dia para 
serem encaminhados após recebidos.

\subsection{MODELO DINÂMICO}

A matriz de transferência que representa as dinâmicas básicas características entre os fluxos de informação e material da CS está dada na equação (1). As equações escrevem o modelo de funções de transferência discreta que determinam as quantidades de produto semiacabado, $y_{1}(k)$, de produto embalado, $y_{2}(k)$, e de produto em depósito, $y_{3}(k)$, como função das variáveis manipuladas (pedidos), $u_{1}(k), u_{2}(k) e, u_{3}(k)$ e a perturbações no sistema (efeito da demanda), $q(k)$.

Figura 2 - Mapeamento de variáveis na CS

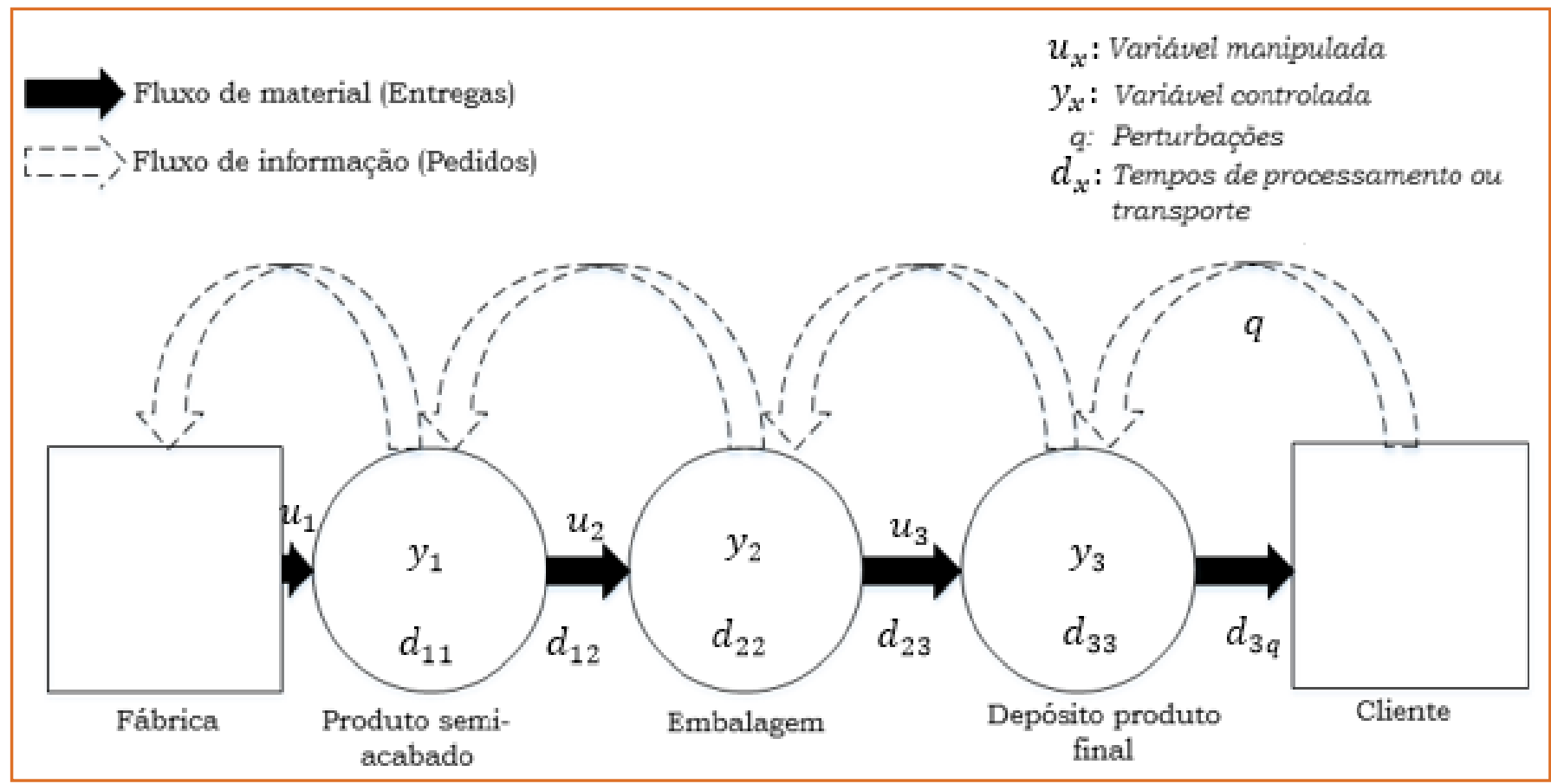

As decisões de pedidos e entregas são feitas em iguais períodos de tempo e para este trabalho escolheu-se um período . Considera-se, ainda, que a informação de pedidos entre os elos do processo conjunto de produção é feita instantaneamente.

$\left[\begin{array}{l}y_{1}(k) \\ y_{2}(k) \\ y_{3}(k)\end{array}\right]=\left[\begin{array}{ccc}\frac{z^{-1}}{1-z^{-1}} z^{-d_{11}} & \frac{-z^{-1}}{1-z^{-1}} z^{-d_{12}} & 0 \\ 0 & \frac{z^{-1}}{1-z^{-1}} z^{-d_{22}} & \frac{-z^{-1}}{1-z^{-1}} z^{-d_{23}} \\ 0 & 0 & \frac{z^{-1}}{1-z^{-1}} z^{-d_{33}}\end{array}\right]\left[\begin{array}{l}u 1(k) \\ u 2(k) \\ u 3(k)\end{array}\right]+\left[\begin{array}{c}0 \\ 0 \\ \frac{-z^{-1}}{1-z^{-1}} z^{-d_{3 q}}\end{array}\right][q(k)]$

\section{CONTROLE PREDITIVO BASEADO EM MODELO}

O controle preditivo baseado em modelo (MPC, do inglês Model Predictive Control) é uma estratégia de controle que usa uma lei de controle ótima baseada na minimização de um custo que considera a predição do comportamento futuro da saída do processo. O MPC usa um modelo explícito do sistema para predizer o comportamento das variáveis controladas nos instantes futuros de tempo, dentro de um horizonte definido. O objetivo é atingir o valor do controle ótimo considerando as restrições físicas ou econômicas do processo e levando as variáveis controladas a determinadas referências. O MPC usa uma estrutura como mostrada na figura 3 , na qual o modelo permite calcular as predições ao longo do horizonte que são usadas junto com as informações passadas e as saídas do processo para minimizar a função de custo considerando as restrições e trajetórias a serem seguidas. Apesar de o MPC calcular um vetor de controle futuro ótimo, ele trabalha sob o conceito de janela móvel, logo apenas o primeiro movimento de controle calculado é efetivamente aplicado ao processo e, como a cada amostra novas informações são coletadas do processo, o cálculo do controle é repetido em todo instante de amostragem, a fim de considerar os estados atualizados do sistema na definição da ação de controle. 
O enfoque preditivo usado na solução do problema de otimização e planejamento da produção visando atingir os níveis de inventário alvo, exige modelos adequados de predição e otimização. Ambos os modelos trabalham conjuntamente em um cenário de simulação que incorpora incertezas (mudanças não conhecidas na demanda), (PEREA LÓPEZ, et al, 2003). Assim, a cada período de amostragem, o modelo de predição calcula os níveis de inventário objetivo.

Figura 3 - Estrutura básica de um MPC

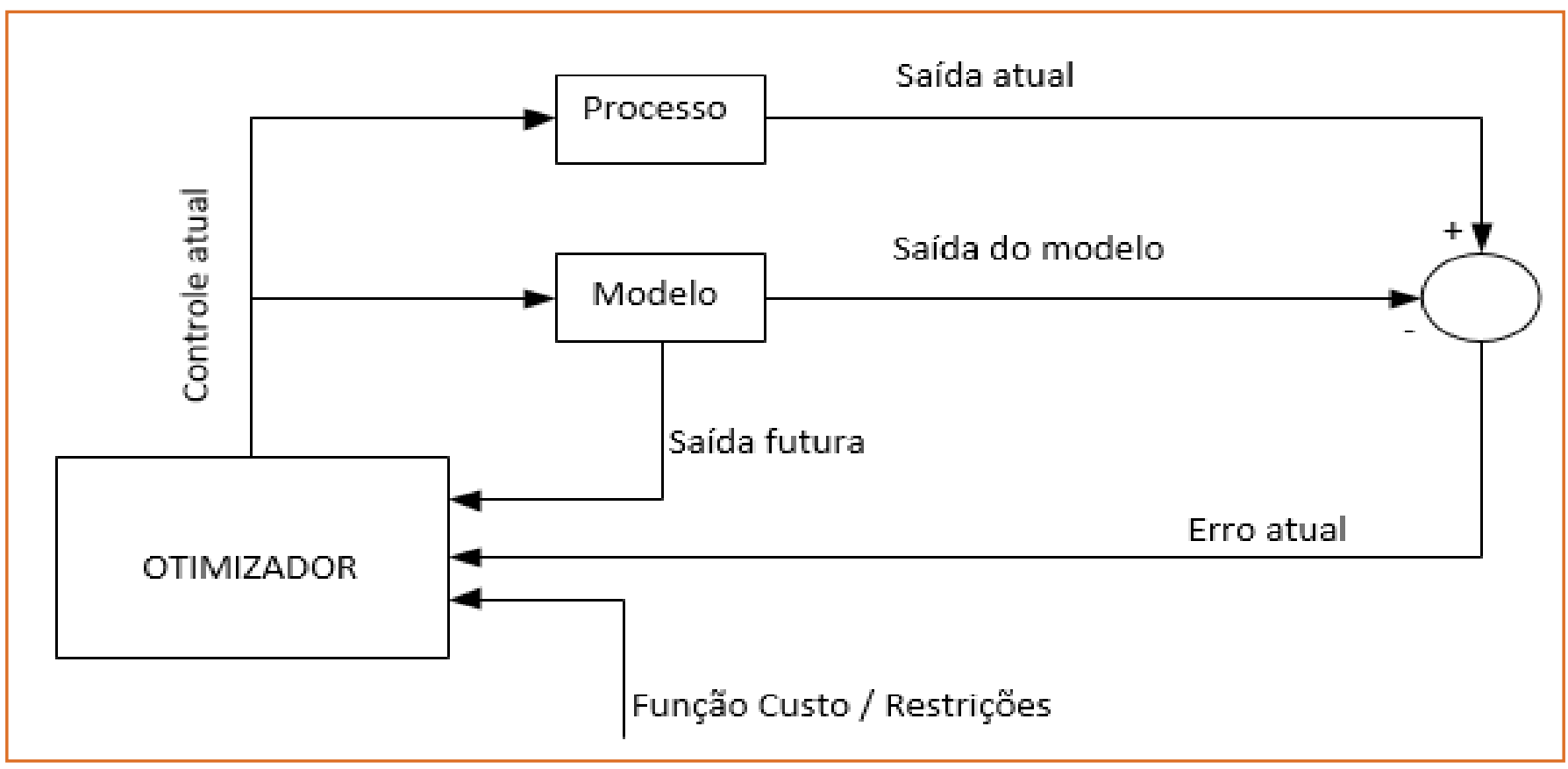

\subsection{MODELO DE PREDIÇÃO}

O modelo de predição usado pelo GPC considera também um modelo das perturbações não mensuráveis para o cálculo das predições no horizonte para cada uma das variáveis controladas (nível de estoque). Considerando perturbações não medidas modeladas por ruído branco integrado, as predições ótimas, $\boldsymbol{y}_{\boldsymbol{p} i}(\boldsymbol{k}+$ $t \mid k)$ são obtidas com um modelo na forma incremental do sistema definido na equação (2) e calculadas iterativamente considerando o horizonte de predição, $\boldsymbol{N}=\boldsymbol{N}_{2}-\boldsymbol{N}_{1} \cdot \boldsymbol{N}_{1}=d+1$, para sistemas com tempo morto.

$$
\Delta A_{i}\left(z^{-1}\right) y_{p_{i}}(k+t \mid k)=\sum_{j=1}^{N u_{x}} z^{-d_{i j}} B_{i j}\left(z^{-1}\right) \Delta u_{j}(k+t-1) ; t=N_{1} \ldots N_{2}
$$

$\boldsymbol{B}_{i j}\left(\mathbf{Z}^{-1}\right) \otimes \boldsymbol{A}_{i}\left(\mathbf{z}^{-1}\right)$ e são os polinômios característicos das funções de transferência do sistema. O GPC também pode incluir um modelo das perturbações medidas ou estimadas. No controle de CS, em algumas situações práticas a demanda pode ser conhecida em um determinado grau e alguns tipos de sinais determinísticos são usados para representá-la. É comum representar as oscilações diárias ou semanais da demanda como sinais senoidais, e variações lentas como rampas (NORMEY-RICO e CAMACHO, 2007). Caso a perturbação seja conhecida ou estimada, o modelo da perturbação pode ser definido como

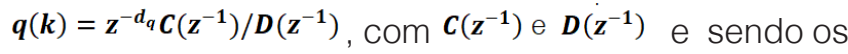
polinômios característicos que descrevem a dinâmica da perturbação.

\subsection{FUNÇÃO CUSTO}

A tarefa do controlador preditivo é calcular os vetores de controle, minimizando uma função custo específica. A função custo considerada aqui se mostra na equação (3). Ela considera a informação dos valores futuros dos estoques ou referências que se deseja atingir, $\boldsymbol{w}_{\boldsymbol{i}}(\boldsymbol{k}+\boldsymbol{t} \mid \boldsymbol{k})$, dentro de um horizonte de predição, e a variação das ordens de produção ao longo de um horizonte de controle, $\boldsymbol{N}_{\boldsymbol{u}}$. 
$J=\sum_{i=1}^{N y_{x}} \sum_{t=N_{1}}^{N} \alpha(i)\left[y_{p i}(k+t \mid k)-w_{i}(k+t \mid k)\right]^{2}+\sum_{j=1}^{N u_{x}} \sum_{t=1}^{N_{u}} \lambda(j)\left[\Delta u_{j}(k+t-1)\right]^{2}$

(3)

Em (3), $\quad \Delta \boldsymbol{u}_{\boldsymbol{j}}=\left(\mathbf{1}-\mathbf{z}^{-\mathbf{1}}\right) \boldsymbol{u}_{\boldsymbol{j}}$ são os incrementos de controle, $\boldsymbol{y}_{\boldsymbol{p}}(\boldsymbol{k}+\boldsymbol{t} \mid \boldsymbol{k})$ é o vetor com as predições ótimas t passos em frente da saída do sistema com a informação fornecida até o instante t. $\boldsymbol{N y}_{\boldsymbol{x}}$ e $\boldsymbol{N} \boldsymbol{u}_{\boldsymbol{x}}$ representam o número de entradas e saídas do sistema multivariável. $\boldsymbol{\alpha}(\boldsymbol{i})$ e $\boldsymbol{\lambda ( \boldsymbol { j } )}$ são as ponderações do erro de predição e dos esforços de controle, respectivamente. A função é minimizada para os horizontes de predição, $\boldsymbol{N}=\boldsymbol{N}_{\mathbf{1}}-\boldsymbol{N}_{2}$, e de controle, $\boldsymbol{N}_{\boldsymbol{u}}$ , definidos. Escolhendo os valores das ponderações pode-se dar mais importância ao seguimento de uma referência ou outra, além de ser possível definir quais variáveis manipuladas devem ser mais utilizadas para atingir os objetivos.

A estratégia de solução do problema consiste em escrever as saídas, $\boldsymbol{y}_{\boldsymbol{p} \boldsymbol{i}}(\boldsymbol{k})$, como função das entradas passadas e dos valores futuros do controle, $\boldsymbol{u}_{j}(\boldsymbol{k})$, assim como as informações prévias do nível dos estoques, as demandas atuais dos clientes e os pedidos para cada nó na CS. Desta forma, o problema de minimizar (3) tem como única variável independente o vetor de variações de controle futuro, $\Delta \boldsymbol{u}(\boldsymbol{k})$.

\subsection{PROBLEMA DE OTIMIZAÇÃO}

Para atingir requerimentos práticos na operação da CS, o problema de otimização precisa inserir algumas restrições nas variáveis do sistema. Para o caso, as equações (4), (5) e (6), escrevem os três tipos de restrição considerados a fim de garantir condições práticas de operação da CS:

Restrições nas variáveis de saída: definição dos limites de capacidade dos estoques,

$$
y_{\text {imin }}(k)<y_{i}(k)<y_{\text {imax }}(k) ; i=1 \ldots N y_{x}
$$

Restrições nas variáveis manipuladas: definição das capacidades de transporte de material,

$$
u_{\text {imin }}(k)<u_{j}(k)<u_{\text {imax }}(k) ; j=1 \ldots N u_{x}
$$

Restrições nos incrementos das variáveis manipuladas: definição das variações admitidas nas quantidades de material.

$$
\Delta u_{i m i n}(k)<\Delta u_{j}(k)<\Delta u_{\text {imax }}(k) ; j=1 \ldots N u_{x}
$$

Na presença de restrições, a minimização da função custo da equação (3) considerando o modelo de predição (2) é resolvida por meio de um algoritmo de programação quadrática, definido na equação (7).

$$
J=\min \frac{1}{2} \Delta u(k)^{T} H \Delta u(k)-\Delta u(k)^{T} b
$$

A matriz Hessiana, e o vetor gradiente, , são construídos a partir das diferentes equações de predição. A tabela 1, apresenta os limites físicos da operação da CS empregados nas simulações deste artigo.

Tabela 1 - Restrições de operação

\begin{tabular}{|l|l|}
\hline Parâmetro & Valor \\
\hline$y_{\text {imin }} \mid y_{\text {ima }}$ & {$[0 \mid 200]$} \\
\hline$u_{\text {imin }} \mid u_{\text {imax }}$ & {$[0 \mid 100]$} \\
\hline
\end{tabular}

\subsection{ESTRUTURA DTC NO GPC}

Vários estudos têm mostrado que quando se utilizam compensadores de tempo morto (DTC) explicitamente na estrutura de um GPC se conseguem algumas vantagens sobre o GPC tradicional quando o propósito é estabilidade e robustez em sistemas de controle de processos com tempo morto (NORMEY-RICO e CAMACHO, 2008a). Por exemplo, quando se utiliza um preditor de Smith filtrado (FSP, do inglês Filtered Smith Predictor) para calcular as predições até 0 tempo morto em vez do preditor ótimo inerente ao GPC, o controlador resultante é mais robusto e fácil de ajustar do que a solução tradicional (LIDIA, et al, 2009). Portanto, esse algoritmo, denominado DTC-GPC, é usado aqui para mostrar as vantagens no controle de 
CS sujeitas a elevados tempos mortos, perturbações e incertezas do sistema em conjunto com as restrições de operação. Para o caso, as predições $\boldsymbol{y}_{\boldsymbol{p}}(\boldsymbol{k}+\boldsymbol{t} \mid \boldsymbol{k})$ são calculadas em duas fases: predições de $\boldsymbol{t}=\mathbf{1}$ até $\boldsymbol{d}$ ( $\boldsymbol{d}$ é o tempo morto em amostras) usando a estrutura do FSP e predições de $\boldsymbol{t}=\boldsymbol{d}+\mathbf{1}$ até $\boldsymbol{N}_{\mathbf{2}}$ usando o preditor ótimo do GPC. Neste trabalho, o FSP usa as equações (8), (9) e (10).

$$
\begin{gathered}
y_{p}(k+t \mid k)=S(z) u(k)+F_{r}(z) y(k), \quad t=1 \ldots d \\
S(z)=G_{n}(z)\left[1-F_{r}(z) z^{-d}\right] \\
F_{r}(z)=\frac{f_{b 1} z+f_{b 0}}{(z-\beta)^{2}}
\end{gathered}
$$

A estrutura de predição, mostrada na figura 4, chama um otimizador para calcular o controle a partir da predição livre de tempo morto. Acrescenta-se mais um grau de liberdade na sintonia do controlador, o filtro $\boldsymbol{F}_{\boldsymbol{r}}(\mathbf{z})$ da equação (9). $\boldsymbol{G}_{\boldsymbol{n}}(\mathbf{z})=\mathbf{z}^{\mathbf{- 1}} \boldsymbol{B}_{\boldsymbol{i j}}(\mathbf{z}) / \boldsymbol{A}_{\boldsymbol{i}}(\mathbf{z})$ é o modelo rápido do sistema, ou seja, o modelo livre de tempo morto. Para dinâmicas de CS modeladas como processos do tipo integrador, $\boldsymbol{G}_{\boldsymbol{n}}(\mathbf{z})=\mathbf{1} / \mathbf{z}-$. A sintonia do filtro passa-baixas $\boldsymbol{F}_{\boldsymbol{r}}(\mathbf{z})$ para satisfazer condições de operação frente a perturbações do tipo degrau é descrita na equação (10), onde $\boldsymbol{f}_{b 0}=(\mathbf{1}-\boldsymbol{\beta})^{2} \boldsymbol{d}+\mathbf{2}(\mathbf{1}-\boldsymbol{\beta}), \boldsymbol{f}_{b 1}=(\boldsymbol{1}-\boldsymbol{\beta})^{\overline{2}}-\boldsymbol{f}_{b 0}, \quad$ e $\boldsymbol{\beta}$ é um parâmetro livre, ajustado utilizando especificações de robustez. O cálculo de $\boldsymbol{S}(\mathbf{z})$ visando garantir estabilidade interna do preditor, ou seja, visando cancelar internamente ao modelo de predição o polo $\mathbf{z}=\mathbf{1}$ em de $\mathrm{Gn}(\mathrm{z})$, se realiza usando as equações (11) e (12).

$$
S(z)=\frac{z^{-d}}{z-1}\left[z^{d}-\frac{f_{b 1} z+f_{b 0}}{(z-\beta)^{2}}\right]
$$

$S(z)=\frac{1}{(z-\beta)^{2}} Z^{-d}\left[Z^{d+1}+(1-2 \beta) z^{d}+\left(1-\beta^{2}\right) Z^{d-1}+\cdots+\left(1-\beta^{2}\right) Z+f_{b o}\right]$

\subsection{COMPENSAÇÃO ANTECIPATIVA}

O ação antecipada na compensação de perturbações mensuráveis apresenta resultados mais eficientes do que o controle realimentado. A principal razão é que ela fornece uma ação de controle antes que a perturbação tenha afetado a variável controlada. De fato, em algumas circunstâncias, é possível rejeitar totalmente o efeito das perturbações de carga a partir da ação antecipativa (GUZMÁN, et al, 2012). Em relação ao problema de CS, o controlador inclui os modelos das perturbações e usa também a previsão da demanda futura estimada segundo conhecimentos na tendência do mercado, o que permite incluir o modelo da perturbação na nova equação de predição, equação (13), fazendo o otimizador levar em conta o possível efeito no futuro e calculando uma ação de controle para compensá-lo.

$\Delta A_{i}\left(\mathrm{z}^{-1}\right) y_{p i}(k+t \mid k)=\sum_{j=1}^{N u_{x}} z^{-d_{i j}} B_{i j}\left(z^{-1}\right) \Delta u_{j}(k+t-1)+z^{-d_{q}} C\left(z^{-1}\right) \Delta q(k+t-1) ;$

Figura 4 - Estrutura do DTC-GPC com ação antecipativa para o caso restrito

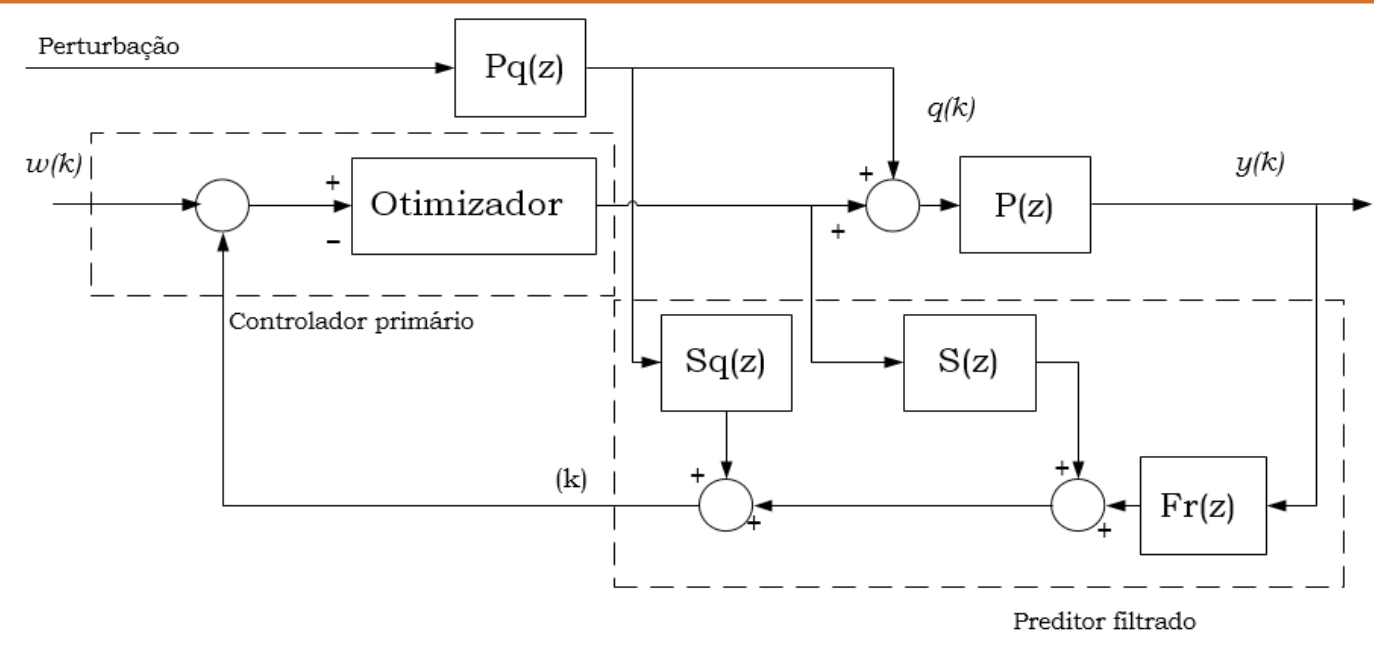


Com relação ao DTC-GPC operando com ação antecipativa, além de utilizar a equação (13) para o cálculo das predições, deve-se projetar mais um filtro no preditor correspondiente ao modelo da perturbação. $\mathrm{Na}$ figura 4, indica-se a estrutura de compensação antecipativa no DTC. Assim, o projeto $\boldsymbol{S}_{\boldsymbol{q}}(\mathbf{z})$ de deve cancelar os modos instáveis de $\boldsymbol{P}_{\boldsymbol{q}}(\mathbf{z})$ a fim de garantir estabilidade interna do preditor. A equação (14) formula o cálculo de $\boldsymbol{S}_{q}(\mathbf{z}) \cdot \boldsymbol{G}_{n q}(\mathbf{z})=\mathbf{z}^{-1} \boldsymbol{C}(\mathbf{z}) / \boldsymbol{D}(\mathbf{z})$ é o modelo rápido da perturbação. $\boldsymbol{F}_{\boldsymbol{q} r}(\mathbf{z})$ é o filtro projetado para assegurar uma correta rejeição das perturbações. O parâmetro $\boldsymbol{d}_{\boldsymbol{q}}$ é o tempo morto do modelo da perturbação $\boldsymbol{P}_{\boldsymbol{q}}(\mathbf{z})$. Deve ser comentado que, no caso geral, esta solução apenas funciona se os polos instáveis $\boldsymbol{P}_{\boldsymbol{q}}(\mathbf{z})$ de são também polos instáveis de $\boldsymbol{P}(\mathbf{z})$, o que sempre é o caso em uma CS, visto que a única dinâmica não estável do sistema é a integradora.

$$
S_{q}(z)=G_{n q}(z)=\left[1-F_{q r}(z) z^{-d q}\right]
$$

\section{RESULTADOS DE SIMULAÇÃO}

Para coordenação de uma CS deve-se determinar conjuntamente uma estrutura que estabeleça quando produzir e quanto produzir a cada amostra. É escolhida uma estrutura de controle centralizada ou global, que projeta só um controlador para otimizar as quantidades a serem fornecidas a cada dependência da CS, (BOSE e PEKNY, 2000). As decisões são tomadas a partir de dados conhecidos do sistema como uma totalidade (introduzindo a informação global do sistema) buscando atingir um objetivo comum, (FU, et al, 2014).

$\mathrm{Na}$ figura 5(a), são apresentados os resultados de simulação para a estratégia de controle GPC multivariável centralizada a partir dos modelos dinâmicos citados em (1). Mostram-se as variáveis de processo (quantidades de pedidos gerados) e as variáveis de controle (níveis de estoque). O controlador inclui os modelos da perturbação e usa também a previsão da demanda futura.

Figura 5 - Resultados com controle GPC: (a) desconsiderando erros na modelagem e na na previsão da demanda; (b) com erros na modelagem e na previsão da demanda.
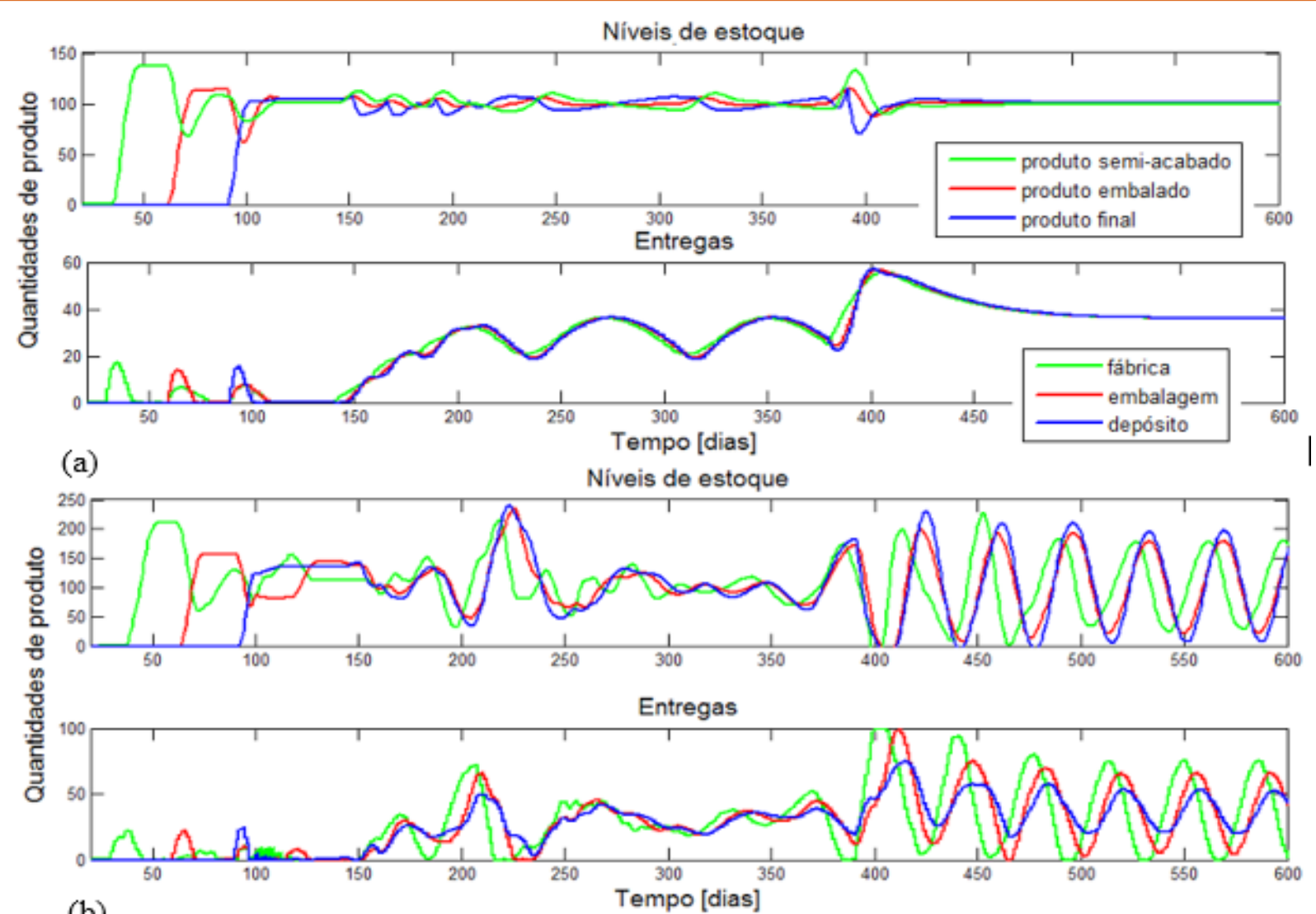

(b) 
O ajuste de parâmetros dos controladores é apresentado na tabela 2. Os horizontes de predição foram pensados para olhar até três meses para frente. Escolhou-se 90 dias para o nó de fábrica, 60 dias para o nó de embalagem e 30 dias para o nó correspondiente a produto terminado em depósito. Todos os horizontes excedem o total dos tempos mortos ao longo da CS. Para o primeiro nó, abrange-se uma maior quantidade de dias, exigido pela centralização das decisões, a fim de executar antecipações necessárias. A ponderação do esforço de controle, $\boldsymbol{\lambda}_{\boldsymbol{j}}$, foi definida para fixar um controle mais conservativo e evitar mudanças violentas nos estoques, reduzindo o efeito chicote (bullwhip effect) na CS. Considera-se 600 dias de operação para a cadeia de suprimentos. Nos primeiros 150 dias são inicializados os nós da CS para se manter em um nível fixo de inventário (setpoint), $\boldsymbol{w}_{\boldsymbol{i}}(\boldsymbol{k})=\mathbf{1 0 0}$ unidades de produto. Para o caso, foram desconsiderados erros na modelagem e no comportamento da demanda.

Tabela 2 - Parâmetros de sintonia
Apesar do bom comportamento no caso nominal, no momento de introduzir erro na modelagem para os modelos de simulação e controle é possível que não estejam garantidas condições de estabilidade e robustez no controlador. Para testar a resposta dos controladores frente a erros na modelagem, foi empregado o mesmo cenário de simulação e as mesmas configurações de ajuste do controlador mencionadas anteriormente. Foram inseridos 2 dias a mais no período de produção, 1 dia a mais dentro do processo de acabado final na área de embalagem e mais 1 dia no processo de padronização e inclusão no estoque do depósito, simulando demoras no processo estabelecido nos tempos de entrega definidos no modelo padrão de operação na CS. Finalmente, foi inserido um erro na previsão da demanda futura, tornando mais realista o comportamento do mercado na CS. A figura 6 mostra os perfis de demanda utilizados nas simulações.

\begin{tabular}{|l|l|}
\hline Parâmetro & Valor \\
\hline$N$ & {$[90|60| 30]$} \\
\hline$N_{u}$ & {$[10|10| 10]$} \\
\hline$\lambda$ & {$[300|300| 100]$} \\
\hline$\alpha$ & {$[1|1| 1]$} \\
\hline$\beta$ & {$[0,96|0,96| 0,96]$} \\
\hline
\end{tabular}

Figura 6 - Demanda real e previsão da demanda

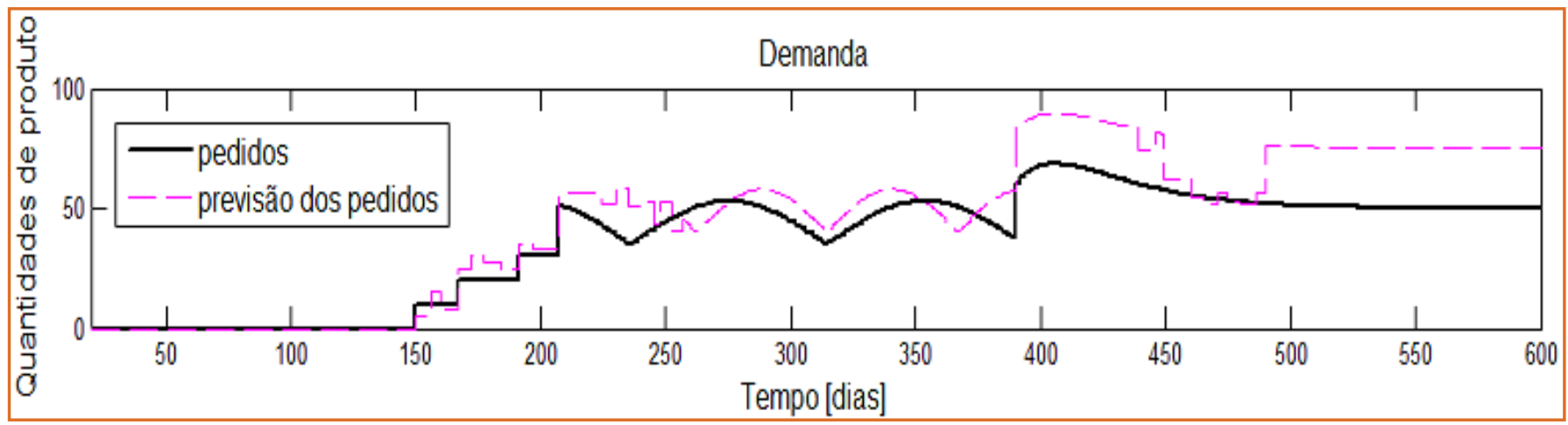

$\mathrm{Na}$ figura 5(b) é apresentado como o sistema age frente a erros. Pode-se observar como para a mesmo ajuste do controlador os erros inseridos deterioram o desempenho do controlador, apesar de inicialmente o controlador tentar manter os níveis de inventário. Observa-se claramente na figura $5(\mathrm{~b})$ que 
o controlador GPC não consegue atingir estabilidade. Esses resultados evidenciam o que foi anteriormente mencionado: algoritmos MPC baseados no preditor ótimo, apresentam problemas em dinâmicas com elevado tempo morto, caraterísticas típicas dos sistemas de CS. Para resolver o problema, o mesmo cenário é simulado usando agora o algoritmo DTCGPC com filtro ajustado de acordo com a tabela 2.

$\mathrm{Na}$ figura 7(a), são apresentados os resultados da simulação do projeto do controle centralizado empregando a estrutura DTC-GPC desconsiderando erros na modelagem e na previsão da demanda. Foi utilizado o mesmo cenário de simulação e os mesmos ajustes de parâmetros dos controladores, adicionando a sintonia do $\boldsymbol{\beta}$ escolhido para projetar os filtros, $\boldsymbol{F}_{\boldsymbol{r}}(\mathbf{z}), \boldsymbol{S}(\mathbf{z})$ e $\boldsymbol{S}_{\boldsymbol{a}}(\mathbf{z})$, dados pelas equações (10), (11) e (14). Assim, a figura 7(b) exibe os resultados da simulação para o controlador DTC-GPC em condição de erros na modelagem e na previsão da demanda. Evidencia-se como é mantida estabilidade do controlador. A figura 7(b) mostra como a metodolgia de controle preditivo com compensação de tempo morto e boa ferramenta para a solução de problemas em CS que operam sob incertezas na modelagem e na previsão de demanda . Foram inseridos os mesmos erros nos tempos de produção, embalagem e entrega no depósito considerados na simulação que deu origem ao caso apresentado na figura 5 , e os mesmos sinais de demanda apresentados na figura 6.

Figura 7 - Resultados com controle DTC-GPC: (a) desconsiderando erros na modelagem e na previsão da demanda; (b) com erros na modelagem e na previsão da demanda.

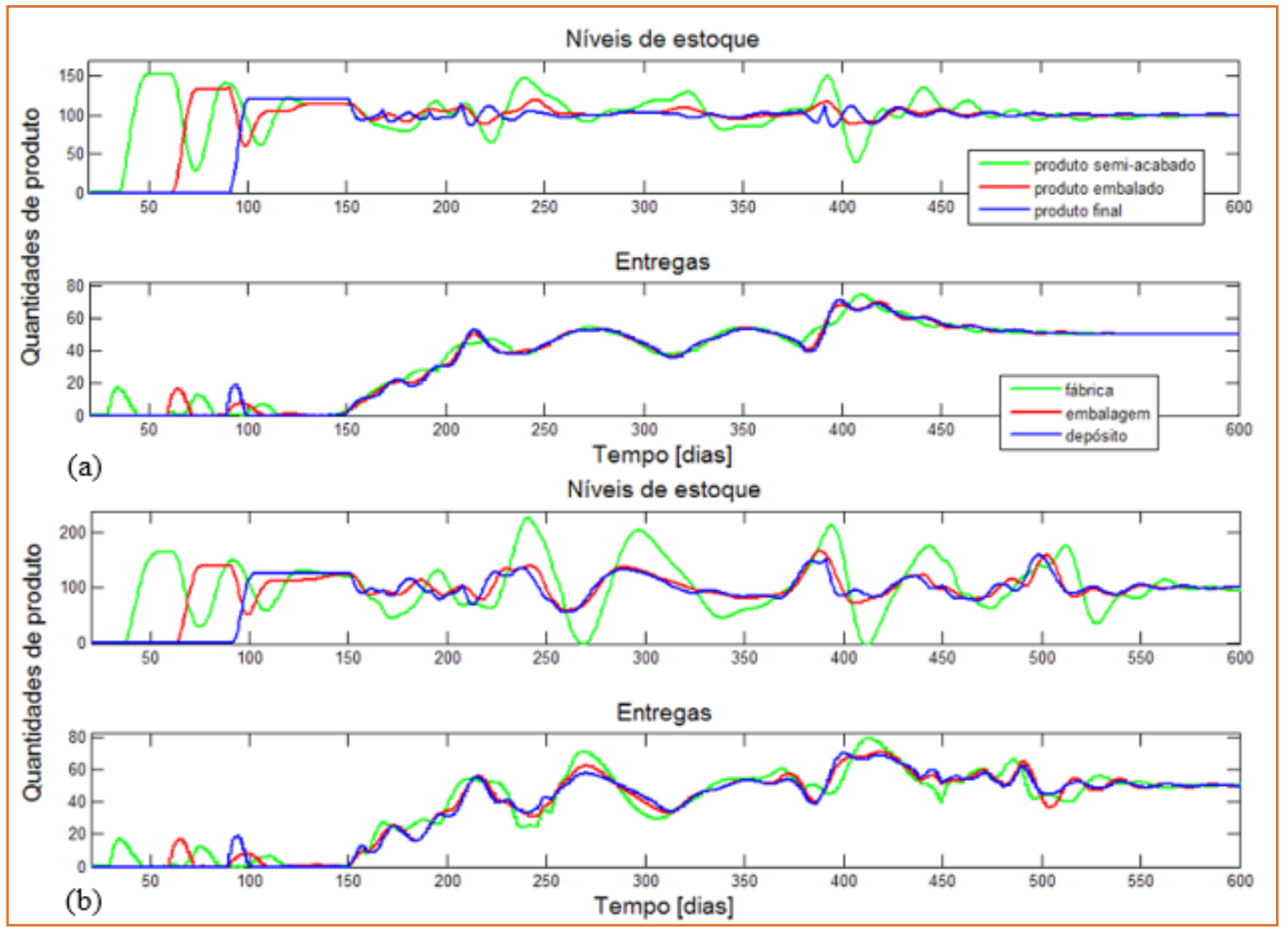

\section{5. CONCLUSÕES}

Este trabalho propõe um controlador preditivo com compensação explícita de tempo morto considerando uma estratégia de coordenação centralizada para resolver o problema de controle de inventários em uma 
CS. O controlador leva em conta restrições a fim de calcular as ações de controle ótimas, considerando as limitações físicas da CS proposta, como limites para o número de unidades em estoque e para os tamanhos dos pedidos. Quando o sistema é simulado considerando erros na modelagem e na estimação da demanda, mostra-se que a estrutura de compensação de tempo morto explícita permite manter estabilidade e um bom desempenho do controlador, o que não acontece com o GPC em sua estrutura convencional. Os resultados da simulação, em geral, apresentam um bom seguimento da trajetória de referência (níveis de estoque programados) e uma boa rejeição de perturbações (demanda do mercado).

\section{AGRADECIMENTOS}

Este trabalho recebeu auxílio financeiro da Coordenação de Aperfeiçoamento de Pessoal de Nível Superior (CAPES) e do Conselho Nacional de Desenvolvimento Científico e Tecnológico (CNPq), projetos número 311024/2015-7 e 305785/2015-0.

\section{REFERÊNCIAS}

[1] AL-OTHAM, W. LABADIDI, H. ALATIQI, I. AND AL-SHAYJI, K. Supply chain optimization of petroleum organization under uncertainty in market demands and prices. European Journal of Operational Research, Vol.189, p. 822-840, 2007.

[2] BENEDITO, E. SUBIAS, A. GRIÑÓ, R. AND U. P. DE CATALUNYA. INSTITUT D'ORGANITZACIÓ I CONTROL DE SISTEMES INDUSTRIALS. Descripción y análisis de los trabajos existentes sobre el efecto "bullwhip" y su tratamiento con técnicas de teoría de control. Institut d'Organització Control de Sistemes Industrials, 2006.

[3] BOSE, S. AND PEKNY, J. A model predictive framework for planning and scheduling problems: a case of consumer goods supplies chain. Computers and Chemical Engineering, Vol. 24, p. 329-335, 2000.

[4] BRAUN, M. Model-on-demand nonlinear estimation and model predictive control: novel methodologies for process control and supply chain management. Master's thesis, Arizona, 2001.

[5] CAMACHO, F. AND BORDONS, C. Model Predictive Control. Springer, 2004.
[6] D. FU, E. AGHEZZAF, AND R. KEYSER. A model predictive control framework for centralized management of a supply chain dynamical system. Systems Science and Control Engineering: An Open Access Journal, Vol. 2, p. 250 260, 2014.

[7] GUZMÁN, J. HÄGGLUND, T. AND VISIOLI, A. PID control in the third millennium (R. Vilanova and A. Visioli (eds.)). ch. Feedforward compensation for PID control loop. London: Springer, 2012

[8] HERBET, S. On the application of servomechanism theory in the study of production control. Econometrica, Vol. 20, p. 247-680, 1952.

[9] KAPSIOTIS, D AND TZAFESTAS, S. Industrial dynamics simulation models in the design of supply chains. Decision making for inventory production planning using model-base predictive control. Parallel and distributed computing in engineering systems, p.551-600, 1992.

[10] NANDOLA, N. AND RIVERA, D. An improved formulation of hybrid model predictive control with application to production-inventory systems. IEEE Transactions on Control Systems Technology, Vol. 21, p. 121-135, 2013.

[11] NORMEY-RICO, J. AND CAMACHO, F. Control of Deadtime Processes. Springer, 2007.

[12] NORMEY-RICO, J. AND CAMACHO, F. Dead-time compensators: A survey. Control Engineering Practice, Vol. 16, p. 407-428, 2008a.

[13] PACHECO, E. Usando dinâmica de sistemas para análise de algoritmos de reposição de estoque em ambientes produtivos. Master's thesis, Curitiba, 2004.

[14] PEREA LÓPEZ, E. YDSTIE, B. AND GROSSMANN, I. A model predictive control strategy for supply chain optimization. Computers and Chemical Engieering, Vol. 27, p. 1201-1218, 2003.

[15] ROCA, L. GUZMAN, J. NORMEY-RICO, J. BERENGUEL, M. AND YEBRA, L. Robust constrained predictive feedback linearization controller in a solar desalination plant collector field. Control Engineering Practice, Vol. 17, p. 1076-1088, 2009.

[16] SARIMVEIS, H. PATRINOS, P. TARANTILIS, C. AND KIRANOUDIS, C. Dynamic modeling and control of supply chain systems: A review. Computers and Research, Vol. 35, p. 3530-3561, 2007.

[17] SCHWARTZ, J. AND RIVERA, D. A process control approach to tactical inventory in production inventory systems. International Journal of Production Economics, Vol. 125, p. 111-124, 2010.

[18] SIMCHI-LEVI, et al. Managing the Supply Chain. McGraw-Hill, New York, 2004. 
[19] SUBRAMANIAM, K. RAWLINGS, J. MARAVELIAS, C. FLORES-CERRILLO, J AND MEGAN, L. Integration of control theory and scheduling methods for supply chain management. Computer and Chemical Engineering, Vol. 51, p. 4-20, 2012.

[20] TOWILL, M. NAIM, D. AND WIKNER, J. Industrial dynamics simulation models in the design of supply chains. International Journal of Physical Distribution and Logistics Management, Vol. 22, p. 3-13, 1992.
[21] VASSIAN, J. Application of discrete variable servo theory to inventory control. Operations Research, Vol. 3, p. 272-821, 1955. 


\title{
CAPÍTULO 7
}

\section{PROPOSTA DE MELHORIA NA GESTÃo DE ESTOQUES EM UMA PANIFICADORA DA REGIÃO NORTE DE SANTA CATARINA}

\author{
Tamires Heidemann \\ Aldérico Silvio Gulini
}

Resumo: Os estoques são importantes para as empresas e funcionam como amortecedores entre as flutuações na oferta e demanda e devem ser mantidos em quantidades necessárias para atender as necessidades da produção e dos clientes e por isso se faz necessária a sua eficiente gestão e controle. Neste sentido, o objetivo deste artigo é identificar como ocorre a atual gestão de estoques da panificadora da região norte de Santa Catarina para realizar uma proposta de melhoria para o processo de gerenciamento de estoques. Foi realizada uma pesquisa, através de dois questionários: um para o nível operacional e um para gerencial, com o intuito de identificar a percepção de ambos os níveis no que diz respeito à gestão de estoques da empresa. Foi obtido como resultado, que a atual gestão de estoques da empresa é boa, mas precisa ser aprimorada, visando à redução de custos e a disponibilidade de produtos para a produção e para os clientes. A proposta é baseada na classificação $A B C$ de estoques, que é uma ferramenta de controle e gerenciamento de estoques utilizada para identificar a classificação dos itens em A, B e C conforme sua importância, sendo que os de classe A são de importância alta, os de classe B de importância média e os de classe $C$ de pequena importância. Os itens do estoque da confeitaria da empresa foram classificados em A, B e C, para que fosse possível identificar os que necessitariam de maior gerenciamento e controle.

Palavras chave: Estoques, Gestão de estoques, Classificação ABC de estoques. 


\section{INTRODUÇÃO}

O ambiente organizacional está em constante transformação e evolução, e os gestores devem adaptar-se a estas mudanças, definindo suas estratégias, formulando seus objetivos para se adequar a gestão moderna e alcançar seu diferencial. A gestão eficiente e eficaz deve ocorrer em todas as áreas da empresa, e o foco deste estudo será a área de suprimentos, trazendo uma proposta de melhoria para a gestão de estoques da empresa estudada.

A administração de materiais envolve o planejamento, organização, direção e controle de todas as atividades ligadas à aquisição de materiais para a formação de estoques, desde o momento da compra até a distribuição do produto ao consumidor final. Nesse sentido, é importante ressaltar que deve haver uma boa gestão na área de suprimentos, pois esta área é a responsável pela compra dos materiais que serão transformados e vendidos, no caso das indústrias, ou apenas vendidos, em empresas comerciais.

A Panificadora situada na região Norte do Estado de Santa Catarina se enquadra nos dois casos, pois transforma matéria-prima em produtos acabados e vende-os e também compra produtos acabados para a venda na área de mercearia; sendo assim há a necessidade de aperfeiçoamento na gestão de estoques da empresa.

O objetivo do estudo é apresentar um modelo de gestão de estoques para a panificadora da região norte de Santa Catarina utilizando a curva $A B C$ de estoques, buscando assim, atender as necessidades e trazer benefícios à empresa estudada.

Para aperfeiçoar a gestão de estoques, foi realizada a classificação em A, B e C dos itens utilizados na confeitaria da empresa, pois este setor é o responsável pela maior parte dos custos em compras e também pelo maior faturamento. A empresa poderá utilizar os dados da classificação para poder dar maior atenção aos itens que devem ser mais controlados efetivamente: os de classe $A$.

Quanto à fundamentação do estudo, tem-se que o mesmo organiza-se da seguinte maneira: logística, administração de estoques e classificação ABC de estoques.

\section{LOGÍSTICA}

Na percepção de Viana (2002, p. 45) a logística "é uma operação integrada para cuidar de suprimentos e distribuição de produtos de forma racionalizada, o que significa planejar, coordenar e executar todo o processo, visando à redução de custos e o aumento da competitividade da empresa".

Bowersox \& Closs (2009, p. 19) salientam que "o objetivo da logística é tornar disponíveis produtos e serviços no local onde são necessários, no momento em que são desejados". Na visão de Christopher (2014), o objetivo final de qualquer sistema logístico é satisfazer os clientes. Deste modo, é necessário disponibilizar produtos e serviços no local certo e no momento certo com o propósito de atender as necessidades dos clientes.

Sendo assim, para ser considerada eficiente, a logística precisa ser capaz de disponibilizar bens e recursos, comprovando que consegue alcançar com efetividade os resultados propostos pela empresa. Mas, além de realizar a aquisição seguida de armazenagem e posterior entrega, o resultado esperado em todas as etapas, é que se comprove a eficácia da logística ao realizar suas tarefas. Tudo deve ser realizado com segurança, pontualidade e qualidade. O consumidor não quer apenas receber seu produto, ele necessita do produto na hora marcada e sem avarias ou defeitos (CAXITO et al., 2011).

\section{ADMINISTRAÇÃO DE ESTOQUES}

Conforme colabora Arnold (2014, p. 247), "a administração de estoques é responsável pelo planejamento e controle do estoque, desde o estágio de matéria-prima até o produto acabado entregue aos clientes".

O principal objetivo da gestão de estoques segundo Gonçalves (2004), é assegurar que a demanda seja atendida ou a produção seja suprida no tempo e na quantidade desejada e sua performance é mensurada pelo grau de atendimento à demanda. Por isso é 
de grande importância que a gestão de estoques seja realizada com eficiência e eficácia, para que a empresa sempre possa atender sua produção e seus clientes.

Sendo assim, pode-se afirmar que "o gerenciamento de estoque é um fator que deve ser integrado ao processo logístico para que os objetivos de serviço sejam alcançados" (BOWERSOX \& CLOSS, 2009, p. 229).

\subsection{ESTOQUES: DEFINIÇÃO E FUNÇÕES}

Na visão de Chiavenato (2005, p. 67), estoque "é a composição de materiais - MP's, materiais em processamento, materiais acabados, PA's - que não é utilizada em determinado momento na empresa, mas que precisa existir em função de futuras necessidades".

É necessário manter estoques para suprir a produção e aos clientes. É o que afirma Viana (2002, p. 144) quando cita que "os estoques são recursos que possuem valor econômico, os quais representam um investimento destinado a incrementar as atividades de produção e servir aos clientes".

De acordo com o que trata Chiavenato (2005, p. 68) as principais funções do estoque são garantir o abastecimento de materiais à empresa, minimizando os efeitos de atraso no fornecimento de materiais e riscos de dificuldade no fornecimento; proporcionar economias de escala por meio da compra ou produção em lotes econômicos, pela flexibilidade do processo produtivo ou pela rapidez e eficiência no atendimento às necessidades.

A partir do que foi abordado, pode-se ressaltar que para a maioria das empresas é necessário possuir estoques, mas os mesmos devem ser administrados da melhor maneira para minimizar custos.

\subsection{CUSTOS DE ESTOQUES}

Conforme colabora Gonçalves (2004, p. 54), "embora o estoque de materiais seja indispensável para um perfeito funcionamento do processo de produção e das vendas de produtos, ele tem um custo".
O custo se desdobra em vários componentes e, dependendo do enfoque utilizado pela organização, ele pode ter objetivos conflitantes para as diversas áreas da administração. Por exemplo, para o setor financeiro, o estoque tem um custo que representa um capital imobilizado na forma de materiais. Já na ponta de consumo, a existência de estoques é justificada pela demanda do produto e neste caso é importante manter estoques para não perder vendas ou clientes (GONÇALVES, 2004).

Na percepção de Deus et al. (2014), as empresas possuem como propósito dimensionar de maneira adequada as necessidades de estoques em relação à demanda, às oscilações do mercado, às negociações com os fornecedores e à satisfação do cliente, para que os recursos disponíveis sejam otimizados e que os estoques e seus custos, sejam minimizados.

Chiavenato (2005) salienta que valor investido em estoques geralmente é muito alto e por isso há grande necessidade de uma administração cuidadosa dos mesmos. Sendo assim, devido aos estoques gerarem vários custos à organização, eles devem ser dimensionados da melhor maneira possível.

\subsection{DIMENSIONAMENTO DOS NÍVEIS DE ESTOQUES}

$\mathrm{Na}$ visão de Cioato \& Reis (2012), seja qual for a estratégia da empresa quanto a manter ou não estoques, ou qual o nível que os mesmos devam ter, o que deve ser considerado como foco principal, é que este seja classificado e dimensionado de forma a garantir um nível de atendimento satisfatório ao cliente.

O dimensionamento dos níveis de estoques fundamenta-se na previsão do consumo dos materiais. A previsão do consumo ou previsão da demanda estima quanto de determinado material será consumido ou necessário durante determinado período de tempo (CHIAVENATO, 2005).

Na determinação dos níveis de estoque, pode-se citar como ferramenta o sistema dos máximos-mínimos, que na percepção de Chiavenato (2005) é utilizado quando 
há dificuldade de determinar o consumo ou quando ocorre variação no tempo de reposição. Tempo de reposição é o tempo gasto desde o momento em que se verifica a necessidade de reposição do estoque até a chegada do material fornecido no almoxarifado da empresa.

O sistema dos máximos-mínimos, segundo Chiavenato (2005) consiste em estimar os estoques máximo e mínimo para cada item, em função de uma expectativa de consumo previsto para determinado período. O estoque deverá variar entre os limites máximo e mínimo. A partir daí o ponto de pedido (PP) é calculado de acordo com o tempo de reposição do item (IR).

Para representar o sistema dos máximos-mínimos utiliza-se a chamada curva dente de serra, conforme o gráfico a seguir, representado na figura 1. Na abscissa está o tempo decorrido para o consumo $(T)$, geralmente em meses, e na ordenada está a quantidade ( $Q$ ) em unidades de material em estoque no intervalo de tempo (CHIAVENATO, 2005).

Figura 1 - Sistema dos máximos-mínimos

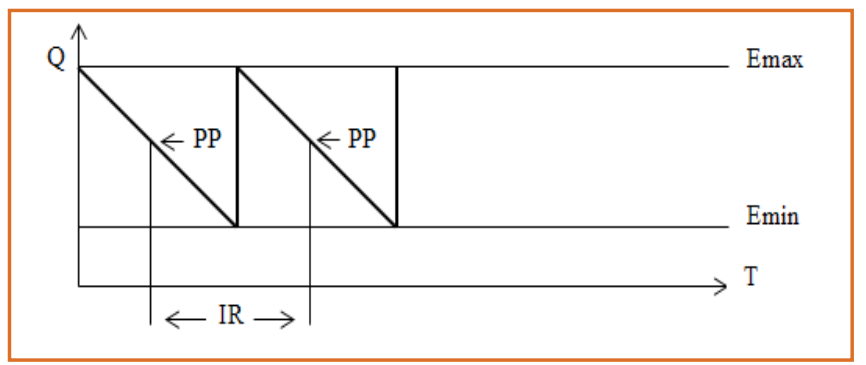

Na percepção de Moreira (2015, p. 455), "O gráfico dente de serra mostra a evolução da quantidade em estoque de um item ao longo do tempo".

\subsection{CONTROLE DE ESTOQUES}

Os estoques consistem em subsídios primordiais para o andamento do processo produtivo das empresas, para o eficaz desempenho de suas atividades, para o atendimento das necessidades de seus consumidores e também para o alcance dos objetivos desejados, destacando-se, desta forma, a importância de ações eficazes para o seu controle (DEUS et al., 2014).
Conforme trata Chiavenato (2005, p. 77) "um dos desafios da Administração de Materiais está em planejar e controlar os estoques para tentar mantê-los em níveis adequados de dimensionamento ou então reduzi-los sem afetar o processo produtivo e sem aumentar os custos financeiros".

Os estoques não podem ser muito grandes, pois implicam em desperdício e capital investido desnecessariamente, nem podem ser muito reduzidos, já que envolvem riscos de falta de materiais, e consequentemente, paralisação da produção e não atendimento aos clientes (CHIAVENATO, 2005).

O próximo capítulo aborda sobre uma ferramenta que é utilizada na gestão e controle de estoques: a curva $\mathrm{ABC}$ de estoques.

\section{CLASSIFICAÇÃO ABC DE ESTOQUES 4.1. PRINCÍPIO DE PARETO}

Vilfredo Pareto, economista, sociólogo e engenheiro italiano (1848-1923), em 1897, ao estudar a distribuição de renda entre a população do sistema econômico onde vivia, descobriu determinada regularidade na distribuição de renda de alguns países, estabelecendo um princípio, no qual o maior segmento da renda nacional concentrava-se em uma pequena parte da mesma renda. Pareto obteve vários dados sobre o número de pessoas que possuíam diferentes faixas de renda e a partir dos dados obtidos, ele traçou um gráfico, conhecido como princípio de Pareto (VIANA, 2002).

O surgimento do princípio de Pareto, de acordo com Chiavenato (2005), ocorreu quando Vilfredo Pareto, um sociólogo italiano, explicava que $20 \%$ da sociedade era responsável por $80 \%$ da riqueza nacional, enquanto os outros $80 \%$ era responsável por $20 \%$ dessa riqueza. Com os materiais, isto ocorre com a mesma proporção, já que 20\% dos materiais são responsáveis por $80 \%$ do capital investido em estoque, enquanto $80 \%$ dos materiais correspondem a $20 \%$ do capital investido. Sendo assim, o gestor deve dar maior atenção aos $20 \%$ dos materiais mais importantes. 
Na visão de Caxito et al. (2011), a classificação ABC ou gráfico de Pareto ou ainda gráfico 80-20 foi criada pelo italiano Vilfredo Pareto, no final do século XIX, para verificar o comportamento da distribuição de renda da população. Desde então passou a ser utilizada como um instrumento para inspecionar e controlar todos os itens de estoque de determinado sistema de operações.

\subsection{CURVA ABC DE ESTOQUES}

"A maioria das empresas mantém um grande número de itens em estoque. Para se ter um controle melhor a um custo razoável, é útil classificar os itens de acordo com sua importância" (ARNOLD, 2014, p. 266). A classificação ABC pode ser utilizada para realizar o controle de estoques de acordo com a importância dos itens mantidos em estoque.

No entendimento de Tubino (2000, p. 108), "a classificação $A B C$, ou curva de Pareto, é um método de diferenciação dos estoques segundo sua maior ou menor abrangência em relação a determinado fator, consistindo em separar os itens por classes de acordo com sua importância relativa".

De acordo com o que expõe Chiavenato (2005), a classificação $A B C$, também denominada Curva de Pareto é utilizada no planejamento e controle de estoques e baseia-se no princípio de que a maior parte do investimento em materiais concentra-se em um pequeno número de itens.

O principal objetivo da classificação $A B C$ é "identificar os itens de maior valor de demanda e sobre eles exercer uma gestão bem mais refinada, especialmente porque representam altos valores de investimentos e seu controle mais apurado vai permitir grandes reduções nos custos dos estoques" (GONÇALVES, 2004, p. 136).

\subsection{A UTILIZAÇÃO DA CURVA ABC NO CONTROLE DE ESTOQUES}

De acordo com Tubino (2000, p.108), "no âmbito da administração de estoques, a classificação $A B C$ mais utilizada é a obtida pela demanda valorizada (quantidade de demanda vezes o custo unitário do item)".

$\mathrm{Na}$ visão de Arnold (2014), o princípio ABC aplicado à administração de estoques estabelece uma relação entre a porcentagem de itens e a porcentagem do investimento realizado em estoques, sendo que:

- Classe A: cerca de 20\% dos itens correspondem a aproximadamente $80 \%$ do investimento realizado em estoques;

- Classe B: cerca de 30\% dos itens correspondem a aproximadamente $15 \%$ do investimento realizado em estoques;

- Classe C: cerca de 50\% dos itens correspondem a aproximadamente $5 \%$ do investimento realizado em estoques.

Conforme Chiavenato (2005) a classificação ABC divide os estoques conforme a sua quantidade, ou o seu valor monetário em três classes: classe $\mathrm{A}$, classe B e classe $\mathrm{C}$.

A classe A é constituída de poucos itens (de 15\% a $20 \%$ do total de itens) que são responsáveis pela maior parte dos investimentos em estoques (cerca de 80\%). São os poucos itens mais importantes e que devem receber uma atenção individualizada, devido ao seu grande valor monetário (CHIAVENATO, 2005).

A classe B é "constituída por uma quantidade média de itens (35\% a $40 \%$ do total de itens) que representam aproximadamente $15 \%$ do valor dos estoques. São os itens intermediários, que têm relativa importância no valor global dos estoques" (CHIAVENATO, 2005, p. 79).

"A classe C representa o grupo de menor valor de consumo e maior quantidade de itens, portanto financeiramente menos importantes, que justificam menor atenção no gerenciamento" (VIANA, 2002, p. 66).

A figura 2 representa a curva $A B C$ de estoques, com 
as respectivas divisões em região $A$, região $B$ e região C.

Figura 2 - Curva de Pareto ou curva ABC ou curva 80-20

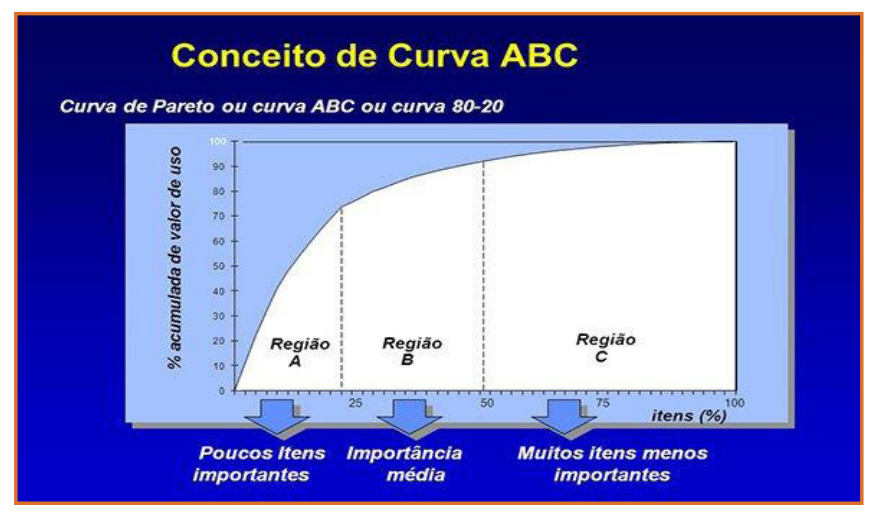

Conforme tratam Caxito et al. (2011) o gráfico de Pareto, também conhecido como curva $\mathrm{ABC}$ ou gráfico 80-20 apresenta uma aplicação bem simples e pode ser elaborado a partir dos seguintes passos:

a) 1- passo: relacionam-se todos os itens que foram consumidos em determinado período;

b) $2^{\circ}$ passo: para cada item é registrado o preço unitário e o consumo no período considerado;

c) 3o passo: para cada item, calcula-se o valor do consumo, que é dado pelo preço unitário multiplicado pelo consumo;

d) 4o passo: registra-se a classificação do valor do consumo (1 para o maior valor, 2 para o segundo maior valor, e assim por diante);

e) 5o passo: ordenam-se os itens de acordo com a classificação;

f) 6o passo: para cada item, lança-se o valor de consumo acumulado, que é igual ao seu valor de consumo somado ao valor de consumo acumulado da linha anterior. g) $7^{\circ}$ passo: para cada item, calcula-se o percentual sobre o valor total acumulado, que é igual ao seu valor de consumo acumulado dividido pelo valor acumulado total e multiplicado por cem.

A seguir, será exemplificado os passos que devem ser seguidos para a elaboração da curva $A B C$ de estoques em uma empresa $X$, seguindo a abordagem de Caxito et al. (2011).

O quadro 1 evidencia o primeiro passo, onde são relacionados os itens que foram consumidos no período (1) e o segundo passo: para cada item foi determinado seu consumo anual (2) e seu preço unitário (3).

Quadro 1 - Dados do estoque da empresa X

\begin{tabular}{|l|l|l|}
\hline Item (1) & $\begin{array}{l}\text { Consumo Anual } \\
(\mathbf{K g})(\mathbf{2})\end{array}$ & \multicolumn{2}{l|}{ Preço unitário (R\$) (3) } \\
\hline 1 & 55 & $\mathrm{R} \$ 1.800,00$ \\
\hline 2 & 16,5 & $\mathrm{R} \$ 9.600,00$ \\
\hline 3 & 100 & $\mathrm{R} \$ 12.600,00$ \\
\hline 4 & 66,5 & $\mathrm{R} \$ 2.400,00$ \\
\hline 5 & 83,5 & $\mathrm{R} \$ 600,00$ \\
\hline 6 & 65 & $\mathrm{R} \$ 16.300,00$ \\
\hline 7 & 55 & $\mathrm{R} \$ 900,00$ \\
\hline 8 & 50 & $\mathrm{R} \$ 1.500,00$ \\
\hline 9 & 78 & $\mathrm{R} \$ 3.000,00$ \\
\hline 10 & 33,5 & $\mathrm{R} \$ 2.400,00$ \\
\hline
\end{tabular}

Fonte: Primária (2015)

No quadro 2 serão demonstrados os demais passos que são utilizados para a elaboração da curva $A B C$ de estoques. Na coluna de percentual acumulado (\%), os percentuais em cor laranja representam os itens de classe A, em cor azul os de classe B, e em cor verde os de classe $\mathrm{C}$. 
Quadro 2 - Dados para montagem da curva ABC de estoques

\begin{tabular}{|c|c|c|c|c|c|c|c|}
\hline Ordem & Item & $\begin{array}{l}\text { Consumo } \\
\text { Anual (A) }\end{array}$ & Preço unitário (R\$) (B) & $\begin{array}{l}\text { Investimento total } \\
\text { (A) } \times \text { (B) }\end{array}$ & $\begin{array}{l}\% \text { do } \\
\text { item }\end{array}$ & $\begin{array}{c}\text { Valor do Investimento } \\
\text { Acumulado (R\$) }\end{array}$ & $\begin{array}{c}\text { Percentual } \\
\text { Acumulado (\%) }\end{array}$ \\
\hline 1 & 3 & 100 & $\mathrm{R} \$ 12.600,00$ & $\mathrm{R} \$ 1.260 .000,00$ & 39,06 & $\mathrm{R} \$ 1.260 .000,00$ & 39,06 \\
\hline 2 & 6 & 65 & $R \$ 16.300,00$ & $R \$ 1.059 .500,00$ & 32,85 & $R \$ 2.319 .500,00$ & 71,91 \\
\hline 3 & 9 & 78 & $\mathrm{R} \$ 3.000,00$ & $\mathrm{R} \$ 234.000,00$ & 7,25 & $\mathrm{R} \$ 2.553 .500,00$ & 79,17 \\
\hline 4 & 4 & 66,5 & $\mathrm{R} \$ 2.400,00$ & $\mathrm{R} \$ 159.600,00$ & 4,95 & $\mathrm{R} \$ 2.713 .100,00$ & 84,11 \\
\hline 5 & 2 & 16,5 & $\mathrm{R} \$ 9.600,00$ & $\mathrm{R} \$ 158.400,00$ & 4,91 & $\mathrm{R} \$ 2.871 .500,00$ & 89,02 \\
\hline 6 & 1 & 55 & $\mathrm{R} \$ 1.800,00$ & $R \$ 99.000,00$ & 3,07 & $\mathrm{R} \$ 2.970 .500,00$ & 92,09 \\
\hline 7 & 10 & 33,5 & $\mathrm{R} \$ 2.400,00$ & $\mathrm{R} \$ 80.400,00$ & 2,49 & $\mathrm{R} \$ 3.050 .900,00$ & 94,59 \\
\hline 8 & 8 & 50 & $\mathrm{R} \$ 1.500,00$ & $\mathrm{R} \$ 75.000,00$ & 2,33 & $\mathrm{R} \$ 3.125 .900,00$ & 96,91 \\
\hline 9 & 5 & 83,5 & $\mathrm{R} \$ 600,00$ & $\mathrm{R} \$ 50.100,00$ & 1,55 & $\mathrm{R} \$ 3.176 .000,00$ & 98,47 \\
\hline 10 & 7 & 55 & $\mathrm{R} \$ 900,00$ & $R \$ 49.500,00$ & 1,53 & $R \$ 3.225 .500,00$ & 100 \\
\hline \multicolumn{4}{|l|}{ TOTAL } & $\mathrm{R} \$ 3.225 .500,00$ & & & \\
\hline
\end{tabular}

Fonte: Primária (2015)

A partir das informações contidas no quadro 2, pode-se elaborar a curva $\mathrm{ABC}$ de estoques, que está representada na figura 3. No gráfico, o eixo das abscissas $(\mathrm{x})$ representa os itens em estoque e o eixo das ordenadas $(\mathrm{y})$ representa o investimento total acumulado.

Figura 3 - Curva ABC de estoques da empresa $X$

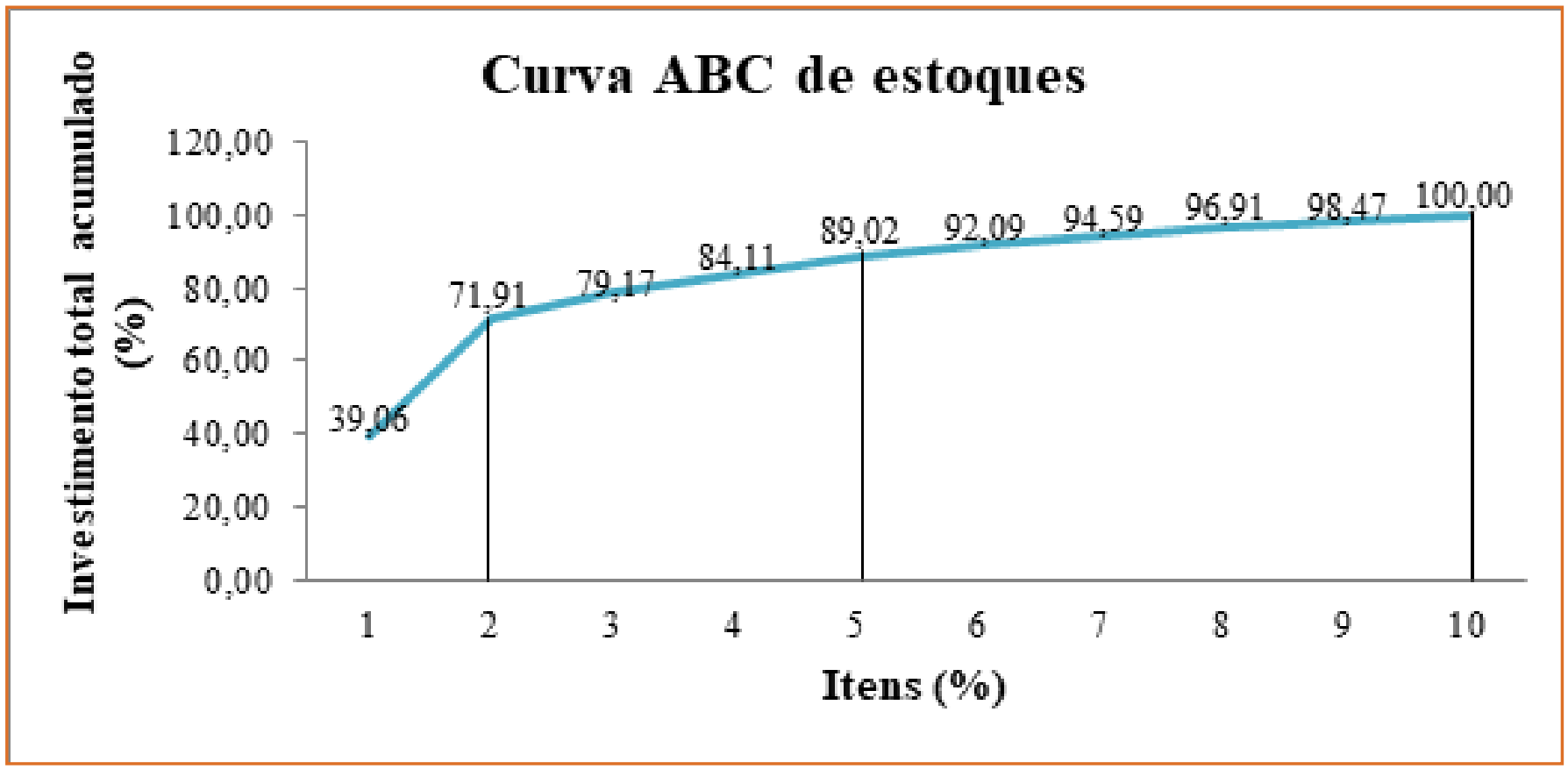

A partir da curva $\mathrm{ABC}$ de estoques, pode-se montar o quadro 3, que auxilia na análise dos dados do gráfico representado pela figura 3 . 
Quadro 3 - Análise dos resultados da curva ABC de estoques

\begin{tabular}{|c|c|c|c|c|}
\hline Classe & $\begin{array}{l}\mathrm{N}^{0} \text { de } \\
\text { itens }\end{array}$ & $\begin{array}{l}\% \text { de } \\
\text { itens }\end{array}$ & $\begin{array}{l}\% \text { do } \\
\text { faturamento }\end{array}$ & Itens em estoque \\
\hline A & 2 & $20 \%$ & $71,91 \%$ & 3 e 6 \\
\hline B & 3 & $30 \%$ & $17,11 \%$ & 9,4 e 2 \\
\hline C & 5 & $50 \%$ & $10,98 \%$ & $1,10,8,5$ e 7 \\
\hline Total & 10 & $100 \%$ & $100 \%$ & - \\
\hline
\end{tabular}

Fonte: Primária (2015)

No entendimento de Caxito et al. (2011), o estoque dos itens da classe A, devido ao seu valor, devem ser rigorosamente controlados, e o estoque de segurança destes itens devem ser mantidos em pequenas quantidades, já que possuem valor agregado relativamente alto. $\mathrm{O}$ estoque dos itens de classe $\mathrm{C}$ devem ter controles simples, podendo ter estoques de segurança maiores, pois o custo de armazenagem destes itens é baixo. Já os itens de classe B devem estar em situação intermediária.

Pode-se dizer que a classificação $A B C$ é de grande importância para o controle de estoques de uma empresa, pois através da classificação dos itens do estoque em classe A, B e C, podem ser identificados os itens que devem receber maior atenção em seu gerenciamento.

\section{METODOLOGIA}

Com a finalidade de atender aos objetivos do trabalho é necessária a realização de uma pesquisa para fundamentar a proposta de melhoria na empresa. Conforme colabora Gil (1991, p. 19), pesquisa "é o procedimento racional e sistemático que tem por objetivo proporcionar respostas aos problemas que são propostos".

Para o desenvolvimento deste estudo, será realizada uma pesquisa de abordagem qualitativa, tendo como método de investigação o estudo de caso de caráter descritivo.

Na percepção de Yin (2001, p. 23), o "estudo de caso como estratégia de pesquisa compreende um método que abrange tudo - com a lógica de planejamento incorporando abordagens específicas à coleta de dados e à análise de dados".

Para realização da pesquisa, serão considerados como população todos os funcionários da panificadora da região norte de Santa Catarina, tanto em nível operacional quanto gerencial.

Neste estudo o instrumento de coleta de dados que foi utilizado é o questionário, que é definido como "a forma mais usada para coletar dados, pois possibilita medir com melhor exatidão o que se deseja. Em geral, a palavra questionário refere-se a um meio de obter respostas às questões por uma fórmula que o próprio informante preenche" (CERVO \& BERVIAN, 2002, p. 48).

Para a realização da pesquisa foram elaborados e aplicados dois questionários com questões fechadas: um para os colaboradores e outro para os gestores, com o intuito de identificar a percepção das pessoas no nível operacional e estratégico da empresa, em relação à gestão de estoques.

\section{RESULTADOS E DISCUSSÃO}

Para melhor delinear os resultados obtidos na pesquisa, eles serão apresentados na seguinte sequência: análise do processo de gerenciamento de estoques da empresa e análise da pesquisa.

\subsection{ANÁLISE DO PROCESSO DE GERENCIAMENTO DE ESTOQUES DA EMPRESA}

O estudo foi realizado a partir da análise do setor de estoques da Panificadora da região norte de Santa Catarina. O setor foi escolhido devido a ocorrer algumas falhas no processo de gestão de estoques da empresa.

O estoque da empresa se apresenta com a seguinte divisão: confeitaria, panificação e mercearia. A análise foi realizada com base no estoque da área de confeitaria, pois o valor deste estoque é alto e por isto deve ser melhor gerenciado para reduzir os custos 
da empresa e também para que não ocorra excesso ou rupturas de estoque, o que acontece em alguns momentos.

Pode-se salientar que a empresa estudada não possui o dimensionamento e análise dos níveis de estoques e muitas vezes não se atenta às falhas que podem ocorrer, como: atraso nas entregas, aumento da produção devido a encomendas não previstas, ocorrendo assim, em alguns momentos, excesso ou ruptura de estoques. A gestão e controle de estoques são realizados por uma funcionária que faz o uso de poucas ferramentas que auxiliam na gestão de estoques.

Sendo assim, se faz necessária a construção e análise da curva $A B C$ de estoques da área de confeitaria, para classificar os itens conforme sua importância em classe $\mathrm{A}, \mathrm{B}$ ou $\mathrm{C}$ e dar maior atenção aos de classe $\mathrm{A}$, pois estes representam maior custo para a empresa, e em contrapartida maior faturamento. A análise dos resultados da curva $A B C$ de estoques serão representados no quadro 4 .

Quadro 4 - Análise dos resultados da curva ABC de estoques da Panificadora da região norte de Santa Catarina

\begin{tabular}{|l|l|l|l|} 
Classe & \multicolumn{1}{|l}{$\begin{array}{l}\mathbf{N}^{\circ} \text { de } \\
\text { itens }\end{array}$} & \multicolumn{1}{c}{$\begin{array}{l}\text { \% de } \\
\text { itens }\end{array}$} & \multicolumn{1}{l}{$\begin{array}{l}\text { \% do custo acumulado em } \\
\text { estoque }\end{array}$} \\
\hline A & 16 & $20 \%$ & $70,75 \%$ \\
\hline B & 25 & $30 \%$ & $21,32 \%$ \\
\hline C & 41 & $50 \%$ & $7,93 \%$ \\
\hline Total & 82 & $100 \%$ & $100 \%$ \\
\hline
\end{tabular}

Fonte: Primária (2015)

A partir da construção da curva $A B C$ de estoques, foram identificados os itens de classe $\mathrm{A}, \mathrm{B}$ e $\mathrm{C}$, podendo assim dar maior atenção aos 16 itens de classe $A$, pois os mesmos representam $70,75 \%$ dos custos do estoque da confeitaria. Sendo assim, a empresa deverá controlar os estoques destes produtos mais efetivamente, e deixar apenas a quantidade necessária ao atendimento de suas necessidades semanais, mantendo um baixo estoque de segurança; os 25 itens de classe $\mathrm{B}$ deverão ter controle intermediário e os 41 itens de classe $\mathrm{C}$ deverão ter um controle mais simplificado.

\subsection{ANÁLISE DA PESQUISA}

Foi realizada uma pesquisa de campo sobre a gestão de estoques da empresa através de dois questionários fechados: um gerencial, com 10 questões e um operacional com 11 questões. Serão salientadas e analisadas algumas questões de ambos os questionários. As questões das figuras 4 e 5 fazem parte do questionário gerencial e as questões das figuras 6 e 7 fazem parte do questionário operacional.

No questionário gerencial, foi avaliada a percepção dos donos no que diz respeito à gestão de estoques da empresa. Ambos os gestores consideram que a atual gestão de estoques é boa, mas que precisa ser aperfeiçoada para reduzir os custos em estoque, e que isto pode ser realizado através de um correto dimensionamento dos estoques e da classificação em A, B ou C dos itens em estoque conforme sua relativa importância.

Em relação à questão da classificação $A B C$ dos itens do estoque da empresa conforme sua importância, ambos os gestores identificaram a necessidade de classificá-los (veja a figura 4), pois assim a empresa poderá dar maior atenção ao gerenciamento e controle aos itens de classe $\mathrm{A}$, pois representam maior investimento, controlar de modo intermediário os de classe $\mathrm{B}$ e os de classe $\mathrm{C}$ podem ter um controle mais simplificado. 
Figura 4 - Importância da classificação ABC dos itens da empresa

Com a classificação $A B C$ de estoques, os itens são classificados conforme sua importância: os itens de classe A são de importância alta, os de classe B são de importância média e os de classe $\mathrm{C}$ são de pequena importância. Em sua opinião,

qual a importância de realizar a classificação dos itens da empresa?

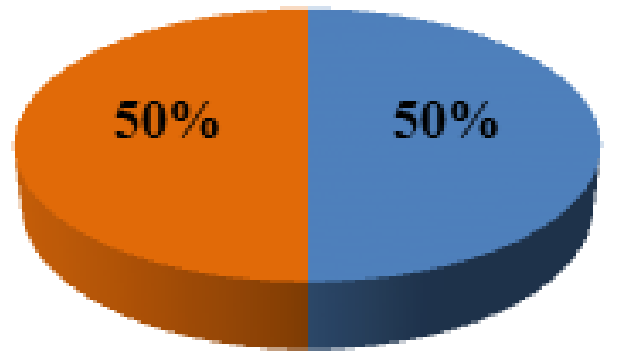

nÉ de extrema importância, para identificar os poucos itens que geram mais custos e devem receber uma maior atenção e para aprimorar a atual gestão de estoques.

"É de média importância, pois é necessário aprimorar a atual gestão de estoques.

mÉ de baixa importância, pois a gestão atual atende às necessidades da empresa.

No que diz respeito à questão da relevância de manter os estoques em níveis reduzidos e suficientes ao atendimento da demanda, os gestores classificam como relevante ou muito relevante (veja a figura 5), pois através do dimensionamento dos estoques, é realizada a identificação dos estoques de segurança, estoque mínimo, estoque máximo, intervalo de reposição e ponto de pedido, e assim os estoques estarão em níveis suficientes para atender a produção e aos clientes.

Figura 5 - Relevância de manter estoques em níveis reduzidos

\section{Qual a relevância de manter estoques em niveis reduzidos, mas que sejam suficientes para atender a demanda?}

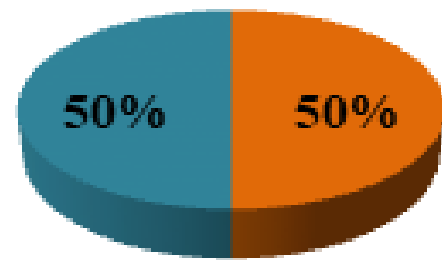

"É pouco relevante, não há necessidade de calcular os niveis de estoque.

nÉ relevante e os niveis de estoque devem ser calculados.

nÉ muito relevante e os niveis de estoque devem ser calculados e regularmente controlados.

No questionário operacional, foi analisada pelos funcionários, a gestão de estoques da empresa. A maioria dos funcionários também considera que a atual gestão de estoques é boa, mas que precisa ser melhorada para que não ocorra falta de matériaprima para a produção ou produtos para a venda, pois os mesmos, através das respostas do questionário, julgaram a importância de possuir estoques suficientes para atender a produção e aos clientes.

A grande maioria dos funcionários julga ser importante ter produtos para atender as necessidades dos clientes (veja figura 6), pois quando um cliente se direciona a empresa ele tem a necessidade de adquirir algo que a mesma oferece, e se o produto está em falta o mesmo não ficará satisfeito com a empresa e pode deixar de 
frequentá-la. Os mesmos salientaram que os clientes reclamam muito quando não encontram o produto que estavam dispostos a comprar.

Figura 6 - A venda é prejudicada quando há falta de produtos

\begin{tabular}{|l} 
Na sua percepção, a venda é prejudicada quando faltam produtos no \\
balcão, na prateleira ou freezers? \\
$6 \%$
\end{tabular}$\quad \begin{array}{r}\text { Sim, pois é importante ter sempre produtos } \\
\text { para atender as necessidades dos clientes. } \\
\text { não prejudica a venda. }\end{array}$

Apesar de haver falta de produtos na empresa casualmente, os funcionários acreditam que é necessário melhorar a gestão de estoques da empresa (veja figura 7), para que a mesma tenha sempre disponível matéria-prima para a produção e produtos para a venda, pois assim, sempre haverá produtos disponíveis para oferecer aos clientes, sejam eles de fabricação própria ou produtos da área de mercearia ou freezers.

Figura 7 - Necessidade de melhorar a gestão de estoques

\section{Você acha necessário melhorar o modo como são geridos os estoques para não haver falta de matéria-prima para produção ou produtos para a venda?}

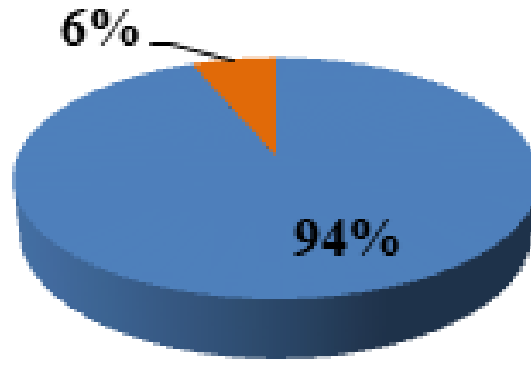

- Sim

não
A partir da análise da pesquisa, pode-se dizer, que a empresa possui um gerenciamento de estoques regular e que a gestão deve ser aprimorada, através da análise do dimensionamento de estoques, identificando o estoque de segurança, o estoque mínimo e o máximo, o intervalo de reposição e utilizar a curva $\mathrm{ABC}$ de estoques para o controle e gerenciamento dos mesmos.

\section{CONSIDERAÇÕES FINAIS}

Através do presente estudo, pôde-se perceber a grande importância da gestão dos estoques para uma empresa, pois a partir de uma boa gestão, a empresa sempre terá disponível matéria-prima para atender sua produção e produtos para satisfazer a necessidade de seus clientes.

Pôde-se identificar através da ferramenta de gestão de estoques Curva ABC, os itens do estoque da confeitaria conforme sua importância, dando possibilidades de a empresa poder gerenciar melhor seu estoque, através do controle dos estoques conforme sua classe, sendo que os de classe $A$ receberão maior atenção no 
gerenciamento, os de classe B terão gerenciamento intermediário e os de classe $C$ uma gestão simplificada.

A partir da pesquisa de campo, foi possível identificar a percepção dos gestores e dos funcionários da empresa em relação à gestão de estoques. De um modo geral, todos classificaram a gestão de estoques como boa, mas que necessita ser aperfeiçoada para reduzir os custos da empresa e para ter produtos disponíveis para atender a produção e aos clientes.

Os resultados obtidos pelo estudo da empresa e pela pesquisa possibilitaram o conhecimento de como é realizada a atual gestão de estoques da empresa estudada e quais ações e mudanças devem ser adotadas para que a gestão se torne mais eficiente e eficaz.

\section{REFERÊNCIAS}

[1] ARNOLD, J. R. Tony. Administração de Materiais: uma introdução. São Paulo: Atlas: 2014.

[2] BOWERSOX, Donald J; CLOSS, David J. Logística empresarial: o processo de integração da cadeia de suprimento. São Paulo: Atlas, 2009.

[3] CAXITO, Fabiano et al. Logística: um enfoque prático. São Paulo: Saraiva, 2011.

[4] CERVO, Amado Luiz; BERVIAN, Pedro Alcino. Metodologia científica. 5.ed. São Paulo:Prentice Hall: 2002.
[5] CHIAVENATO, Idalberto. Administração de materiais: uma abordagem introdutória. Rio de Janeiro: Elsevier, 2005.

[6] CHRISTOPHER, Martin. Logística e gerenciamento na cadeia de suprimentos. São Paulo: Cengage Learning, 2014.

[7] CIOATO, Micael Fabiano; REIS, Zaida Cristiane dos. Desenvolvimento Sustentável e Responsabilidade Social: as contribuições da Engenharia de Produção. Trabalho apresentado ao XXXII Encontro Nacional de Engenharia de Produção, Bento Gonçalves, 2012.

[8] DEUS, Cynthia Vargas de et al. O gerenciamento de estoques em uma empresa de pré-moldados de concreto. Trabalho apresentado ao IV Congresso Brasileiro de Engenharia de Produção, Ponta Grossa, 2014.

[9] GIL, Antônio Carlos. Como elaborar projetos de pesquisa. 3. ed. São Paulo: Atlas, 1991.

[10] GONÇALVES, Paulo Sérgio. Administração de materiais: obtendo vantagens competitivas. Rio de Janeiro: Elsevier, 2004.

[11] MOREIRA, Daniel Augusto. Administração da produção e operações. 2. ed. São Paulo: Cengage Learning, 2015.

[12] TUBINO, Dalvio Ferrari. Manual de planejamento e controle da produção. 2. ed. São Paulo: Atlas, 2000.

[13] VIANA, João José. Administração de materiais: um enfoque prático. São Paulo: Atlas, 2002.

[14] YIN, Robert K. Estudo de caso: planejamento e métodos. 2. ed. Porto Alegre: Bookman, 2001. 


\section{CAPÍTULO 8}

\section{ANÁLISE DE ESTOQUE EM DIFERENTES CENÁRIOS PRODUTIVOS UTILIZANDO MODELO DE DIMENSIONAMENTO DE LOTES E APLICANDO BUSCA TABU}

Talita Mariana Pinho Schimidt

Nathália Cristina Ortiz da Silva

Cassius Tadeu Scarpin

Alexandre Checoli Choueire

Matheus Bazo do Nascimento

Resumo: Este artigo trata do problema de dimensionamento de lotes no período $T=10$, sendo que este corresponde a 5 dias com dois turnos de trabalho ao dia. Aplicou-se a meta-heurística Busca Tabu à resolução deste problema e realizou-se uma variação do estoque inicial e final no intervalo de 0 a 500. O mesmo problema foi resolvido também pelo modelo matemático, para que fosse possível comparar a solução ótima. Foram criados três diferentes cenários, variando a penalidade por atraso, custo de estoque e custo de preparação do item e analisou-se em que situações esses parâmetros podem interferir no aumento ou diminuição do custo total. A Busca Tabu atingiu as soluções ótimas para todas as variações de estoque. A partir dos três diferentes cenários foi possível verificar que quando aumenta-se o custo de estoque e penalidade, o custo total aumenta na mesma proporção. Quando ocorre variação do custo de preparação do item, ocorre mudança de comportamento no gráfico das soluções ótimas, uma vez que este tem ligação direta com a decisão de produzir ou não em cada micro período.

Palavras chave: Dimensionamento de lotes, Busca Tabu, Variação de estoques. 


\section{INTRODUÇÃO}

As indústrias geralmente são estudadas como um sistema que transforma, via um processamento, entradas (insumos) em saídas (produtos). Este sistema é chamado sistema produtivo. Para que um sistema produtivo transforme insumos em produtos, ele precisa ser pensado em termos de prazos, em que planos são feitos e ações são disparadas com base nestes, para que, transcorridos estes prazos, os eventos planejados venham a se tornar realidade. De forma geral, podese dividir o horizonte de planejamento de um sistema produtivo em três níveis: o longo, o médio e o curto prazo (TUBINO D. F., 2009).

A longo prazo, os sistemas produtivos precisam montar um Plano de Produção cuja função é visualizar com que capacidade de produção o sistema deverá trabalhar para atender as especificações. Em médio prazo é desenvolvido o Planejamento Mestre da Produção, estabelecendo então um Plano Mestre de Produção (PMP). Segundo ARENALES et. al (2007), o PMP é um exemplo clássico de sistema de planejamento de quantidades de produção. Já a curto prazo, o sistema produtivo executa a Programação da Produção (TUBINO D. F., 2009). Neste sentido, de modo geral, um "bom" plano de produção é aquele que satisfaz as demandas sem atraso, respeita capacidade dos recursos disponíveis e minimiza custos.

Dentre as tomadas de decisões envolvidas, sendo estas a curto, médio e longo prazo, está a de estocar ou não certo produto por certo tempo, de acordo com os custos relacionados. O uso de estoques, seja de segurança ou de cobertura para atender à demanda média durante o lead time é extremamente importante porque possibilita um melhor nível de atendimento ao cliente e melhora a competitividade da empresa em relação aos concorrentes. No entanto, segundo Lenard e Roy (1995), a otimização do fluxo em uma organização é de vital importância, pois os estoques podem representar grande parte dos seus custos logísticos. Além disso, a produção tem um ritmo que não deve ser interrompido e o custo de manutenção dos estoques representa capital parado, que poderia estar sendo usado para outros fins.

Diante deste contexto, este artigo tem como objetivo resolver um problema de planejamento da produção referente ao dimensionamento de lotes, com a função objetivo de minimizar custos. O modelo matemático será resolvido analisando demanda, custo de estoque, custo de preparação do item, decisão de produzir ou não em cada micro período e penalidade por atraso. O mesmo problema será resolvido utilizando a meta-heurística Busca Tabu (BT) e a solução será comparada à solução ótima obtida através do modelo matemático exato, testando então a eficiência desta meta-heurística para este tipo de problema. A partir destes resultados será realizada uma análise da variação de estoque inicial e final, de acordo com três diferentes cenários para as duas soluções, visando à minimização dos custos totais em diferentes situações dentro da indústria.

\section{REVISÃO DA LITERATURA \\ 2.1 DIMENSIONAMENTO DE LOTES}

O problema de dimensionamento de lotes consiste em planejar a quantidade de itens a ser produzida em várias (ou única) máquinas, em cada período ao longo de um horizonte de tempo finito, de modo a atender a demanda, sujeito a restrições de limitação de capacidade, tendo como objetivo otimizar uma função, que pode ser, minimizar custos (ARENALES M. et al., 2000).

\subsection{BUSCA TABU}

Meta-heurísticas são técnicas usadas em situações que podem ser modeladas como problemas de maximizar (ou minimizar) uma função cujas variáveis tem certas restrições. A meta-heurística Busca Tabu (BT) foi inicialmente desenvolvida por Glover (1986) como uma proposta de solução para problemas de programação inteira. A partir de então, o autor formalizou esta técnica e publicou uma série de trabalhos contendo diversas aplicações da mesma. A experiência tem mostrado a eficiência da Busca Tabu na resolução de vários problemas de diferentes naturezas (GLOVER F., et. al., 1993) e atualmente pode-se afirmar que se trata de uma técnica definitivamente consolidada.

A busca tabu é uma meta-heurística baseada na noção de vizinhança, que guia um algoritmo de busca local na exploração contínua dentro de um espaço de 
busca. Diferente do que pode vir a ocorrer com outros procedimentos, a BT não é confundida pela ausência de vizinhos aprimorantes. Isso significa que o método evita retornar a um ótimo local visitado previamente, de forma a superar a otimalidade local e atingir um resultado ótimo ou próximo ao ótimo global (GLOVER F., et. al., 1997).

Partindo de uma solução inicial, que pode ser escolhida de acordo com algum dentre os vários critérios possíveis, a busca move-se, a cada iteração, para a melhor solução na vizinhança, não aceitando movimentos que levem a soluções já visitadas por permanecerem armazenadas em uma lista tabu. A lista permanece na memória guardando soluções já visitadas (tabu), durante um certo número de iterações (prazo tabu). (GLOVER F., et. al., 1997). Outra importante característica do método é que a solução final tem pouca ou nenhuma dependência da escolha feita para a solução inicial. Isso graças aos mecanismos implementados pelo método, que fogem de ótimos locais.

Esta meta-heurística requer a definição dos seus principais componentes, tais como o tipo de movimento que gera a vizinhança, o método de seleção da próxima solução, a característica a ser armazenada de cada solução, a regra de proibição, o número de iterações durante as quais um atributo continua proibido, o critério de liberação da proibição tabu e o critério de parada (WHITE et al., 2004).

\subsection{CRITÉRIO DE BOLTZMANN}

O critério de Boltzmann é utilizado como um critério de aspiração na resolução da metaheurística Simulated Anneling, que consiste em reproduzir o fenômeno físico do recozimento de metais, no qual o sólido cristalino é aquecido, e depois resfriado lentamente, até que se alcance o seu estado de energia mínima (HENDERSSON et al., 2003). O estado de mínima energia é obtido somente se a temperatura máxima (ou inicial) é suficientemente elevada e se o processo de resfriamento ocorre lentamente, uma vez que o fator redução desta deve estar entre 0,8 e 0,99.

No processo de resfriamento é realizada comparação entre o valor da função objetivo da solução perturbada com o valor da solução atual. Caso a solução perturbada obtenha valor melhor que a solução atual, esta passa a ser a solução atual e então a partir dela serão realizadas novas perturbações. Caso esta solução obtenha valor pior, ela ainda pode ser aceita pelo critério de Boltzmann, evitando que estagnese em ótimos locais. Esta solução é avaliada pela fórmula em que representa a diferença entre a solução perturbada e a solução atual, k é a constante de Boltzmann e T a temperatura. O processo de avaliação do critério de Boltzmann se inicia com a geração de um valor randômico, o qual pode ser fixo ou variável. Se esse valor randômico for menor do que o calculado pelo critério de Boltzmann, a solução perturbada deve ser aceita e, mesmo que seu valor seja pior que o encontrado anteriormente, ela deve ser a nova solução corrente. Se o valor do critério de Boltzmann não for aceito, a solução perturbada é descartada e a solução corrente atual continuará a ser a geratriz das novas perturbações (LAARHOVEN, P. et al., 1987).

A fase de geração de soluções se encerra quando: ou um número de perturbações é atingido, ou um determinado número de sucessos, que corresponde ao número de vezes que a solução perturbada avaliada foi aceita. Sendo que estes dois são os critérios de parada.

Faigle e Kern (1992) provaram a convergência do algoritmo Busca Tabu utilizando métodos desenvolvidos para o Simulated Anneling, propondo um algoritmo particular chamada probabilística busca tabu como uma metaheurística para auxiliar na orientação do Simulated Anneling. Na busca tabu probabilística as probabilidades de gerar soluções novas e aceitar "soluções candidatas" são definidas como funções quanto à um parâmetro de temperatura (como no simulated anneling), e as informações obtidas em iterações anteriores (como na busca tabu) (HENDERSSON et al., 2003).

\subsection{GESTÃO DE ESTOQUE}

Segundo Rosa et. al. (2010), a gestão de estoque percorre as tomadas de decisão em muitas organizações, sendo um tema bastante abordado no meio acadêmico e empresarial. 
A maior preocupação das empresas em relação à gestão de estoque está relacionada à necessidade de se garantir a maior disponibilidade de produto ao cliente final, com o menor custo possível, dada a pressão competitiva dos mercados (WANKE, P., 2012). No entanto, manter estoque também resulta em custos para a organização, o custo de manter em estoque está relacionado à armazenagem, seguro, deterioração, obsolescência e oportunidade de empregar dinheiro em investimentos. Existe também o custo associado à falta de estoque, sendo estes então diretamente ligados ao nível de serviço atingido.

Diante deste contexto, uma empresa que possui um gerenciamento eficiente de estoques, balanceia a disponibilidade de produto, o nível de serviço e os custos de manutenção (KREVER et al.,2003).

\section{METODOLOGIA}

\subsection{MODELO MATEMÁTICO}

O problema de dimensionamento de lotes abordado neste artigo envolve um único item, sem restrição de capacidade, em que a demanda pode ser atendida com atraso, sendo assim, atribui-se uma penalidade $\delta$ por unidade de demanda não atendida no período t. Considere os seguintes parâmetros:

$\mathrm{dt}=$ demanda no período $\mathrm{t}$;

$\mathrm{s}=$ custo de preparação do item;

$\mathrm{h}$ = custo unitário de estoque;

$\delta=$ penalidade por unidade de demanda não atendida;

Considere também as seguintes variáveis:

$\mathrm{xt}$ = quantidade do item produzida no período $\mathrm{t}$;

$I_{t}^{+}=$estoque do item no fim do período t;

$I_{t}^{-}=$falta (demanda não atendida) no período t;

$\mathrm{y}_{\mathrm{t}}=\left\{\begin{array}{l}1 \text { se o item é produzido no período t: } \\ 0 \text { caso contrário }\end{array}\right.$

A função objetivo, junto às restrições do modelo estão representadas nas equações de (01) a (06).

$$
\begin{aligned}
& \min \sum_{t=1}^{T}\left(s y_{t}+h I_{t}^{+}+\delta I_{t}^{-}\right) \\
& I_{t}^{+}-I_{t}^{-}=I_{t-1}^{+}-I_{t-1}^{-}+x_{t}-d_{t}, \quad t=1, \ldots, T
\end{aligned}
$$

$$
\begin{gathered}
\left(I_{0}^{+}=I_{0}^{-}=0, \quad I_{T}^{+}=I_{T}^{-}=0\right. \\
x_{t} \leq\left(\sum_{\tau=1}^{T} d_{t}\right) y_{t}, t=1, \ldots, T \\
I_{T}^{+}-I_{0}^{+}+\sum_{t=1}^{T} x_{t}=\sum_{t=1}^{T} d_{t}, \quad t=1, \ldots, T \\
\boldsymbol{x} \in R_{+}^{T}, I^{+} \in R_{+}^{T}, I^{-} \in R_{+}^{T}, y \in B^{T}
\end{gathered}
$$

O modelo exposto tem como função objetivo minimizar o custo total de produção do item durante o período total. É permitido atraso, podendo haver demanda não atendida em certos micro períodos como também pode-se estocar em alguns períodos, uma vez que, deve-se analisar o que minimizaria o custo total. Os fatores a serem analisados neste caso são: a decisão de produzir ou não no micro período t, produzir no micro período anterior mantendo assim um estoque para o próximo e gerando custo de estoque ou então não produzir em algum micro período, gerando atraso e consequentemente penalidade.

\subsection{APLICAÇÃO DA BUSCA TABU AO MODELO}

Para que fosse possível programar este modelo aplicando a BT em sua resolução, fez-se necessária a criação de regras e aplicação de um critério de aspiração. Considerou-se todos os parâmetros utilizados no modelo matemático e, além disso, uma solução inicial factível foi gerada para o problema.

A solução inicial $S_{0}$ foi gerada aleatoriamente, em forma de vetor para apenas um item a ser produzido de acordo com a variável $y_{t}$, que significa a decisão de produzir ou não um item no período t. A partir desta $S_{0}$, as trocas com a vizinhança foram realizadas em uma posição para cada iteração. A Figura 1 explica mais detalhadamente este procedimento.

Figura 1 - Procedimento de troca adotado para programar o modelo para BT.

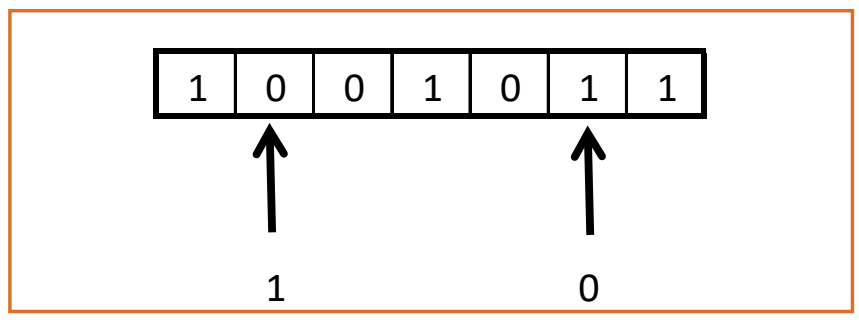

Fonte: Os autores (2015). 
A partir da solução inicial $\mathrm{S}_{0}$ gerou-se aleatoriamente um vetor com as quantidades produzidas em cada micro período $t$, considerando que ao final dos t períodos a distribuição da quantidade produzida em todos esses períodos somada com a variação dos estoques totalize o valor da demanda total de produção. Com base nessas informações iniciais, inicializa-se o processo da busca tabu, calculando-se a função objetivo a cada iteração, até que a meta-heurística atinja um valor ótimo global ou próximo deste.

Para que este processo aconteça de forma efetiva é necessário utilizar um critério que avalie as soluções "piores" que as anteriormente encontradas, evitando assim que se estagne em um ótimo local. Sendo assim, estabeleceu-se um Critério de Convergência Tabu baseado no Critério de Boltzmann, que ocorre conforme supracitado na sessão de revisão da literatura.

Adaptando-se a fórmula da temperatura inicial de Laarhoven et al. (1987), calculou-se o parâmetro de controle inicial $\left(\square_{0}\right)$, para que a partir deste decorresse as iterações.

Utilizou-se a seguinte fórmula:

$$
\alpha_{0}=-f\left(S_{0}\right) / \ln \xi_{0}
$$

Em que:

$f\left(S_{0}\right)$ : valor da função objetivo para a solução inicial randômica;

$\xi_{0}$ : valor empírico de referência, geralmente dado por 0,8 .

O parâmetro de controle inicial encontrado foi de $\alpha_{0}=1529060$, e a cada iteração este diminui de forma gradativa, sendo esta diminuição de $5 \%$.

A regra de rateio foi estabelecida de acordo com as possibilidades de atraso ou estocagem, e então é necessário que seja avaliado o que gera custo menor, analisando o custo de estoque e a penalidade por atraso. Sendo assim, pode ser que não se produza em alguns períodos, produzindo uma quantidade maior que a demanda em outros. Portanto, verifica-se a cada iteração qual é a melhor opção em cada caso.

Quando o custo de ruptura é maior ou igual ao custo de estoque, prefere-se que a redistribuição da quantidade produzida seja feita da seguinte forma:

a) Quando um item deixa de ser produzido em um período, a quantidade produzida neste período passa a ser produzida antes, quando possível. Caso não exista um item sendo produzido nos períodos anteriores, a quantidade é produzida, então, em um período posterior ao período da troca.

b) Quando um item passa a ser produzido em um período, a quantidade que será produzida neste período é dada pelo valor de um próximo período que possui uma quantidade maior do que a sua própria demanda, sendo que este valor é a diferença entre a quantidade produzida neste período e a sua demanda e o mesmo passa a ter a quantidade produzida igual a demanda própria. Caso não exista um item sendo produzido nos períodos seguintes, a quantidade é trazida, então, de um período anterior ao período da troca.

De modo análogo, obtém-se uma redistribuição quando o custo de ruptura é menor do que o custo de estoque.

A partir das trocas realizadas e da redistribuição ocorrida através da regra de rateio, recalcula-se a função objetivo e em seguida a mesma é analisada conforme supracitado na seção 2.3, e as soluções escolhidas vão para a lista tabu. As trocas permanecem nesta lista por apenas uma iteração.

\section{RESULTADOS E DISCUSSÕES}

O modelo matemático foi codificado na linguagem Visual Basic Studio 2012 em conjunto com o software de otimização CPLEX versão 12.4. O modelo em que se aplicou a Busca Tabu foi codificado na linguagem Visual Basic Studio 2012. Os testes computacionais foram realizados em um computador com processador Intel@ Core $^{\text {TM }}$ i5 3227 U $1.9 \mathrm{GHz}$, com 4 GB de RAM. 
Em ambos considerou-se o período $\mathrm{T}=10$, totalizando 5 dias com 2 turnos de trabalho ao dia. Tanto o estoque inicial quanto o final foram variados em um intervalo de 0 a 500 e foram realizadas 1000 iterações para cada uma destas variações.

\subsection{RESULTADOS COMPUTACIONAIS E ANÁLISE}

Em todas as variações de estoque realizadas a Busca Tabu atingiu a mesma solução ótima encontrada no modelo matemático. Além das variações de estoque, foram criados três diferentes cenários variando também o custo de estoque e penalidade por atraso.

\section{Sendo estes:}

- Cenário 1: Custo de preparação do item $(s)=100$

Penalidade por atraso $(\delta)=100$

Custo de estoque $(h)=100$

A Tabela 1 e Figura 2 representam os resultados referentes a este cenário. $O$ eixo $x$ representa 0 estoque inicial, o eixo y estoque final e as respostas são as soluções ótimas dadas pela meta-heurística e pelo modelo matemático.

Tabela 1 - Solução ótima quanto às variações de estoque: Cenário 1.

\begin{tabular}{|l|l|l|l|l|l|l|}
\hline$x / y$ & 0 & 100 & 200 & 300 & 400 & 500 \\
\hline 0 & 1000 & 11000 & 21000 & 31000 & 41000 & 51000 \\
\hline 100 & 1000 & 11000 & 21000 & 31000 & 41000 & 51000 \\
\hline 200 & 900 & 10900 & 20900 & 30900 & 40900 & 50900 \\
\hline 300 & 15800 & 25800 & 35800 & 45800 & 55800 & 65800 \\
\hline 400 & 37700 & 47700 & 57700 & 67700 & 77700 & 87700 \\
\hline 500 & 71600 & 81600 & 91600 & 101600 & 111600 & 121600 \\
\hline
\end{tabular}

Fonte: Os autores (2015)
Figura 2 - Gráfico das soluções ótimas encontradas para as variações de estoque do cenário 1.

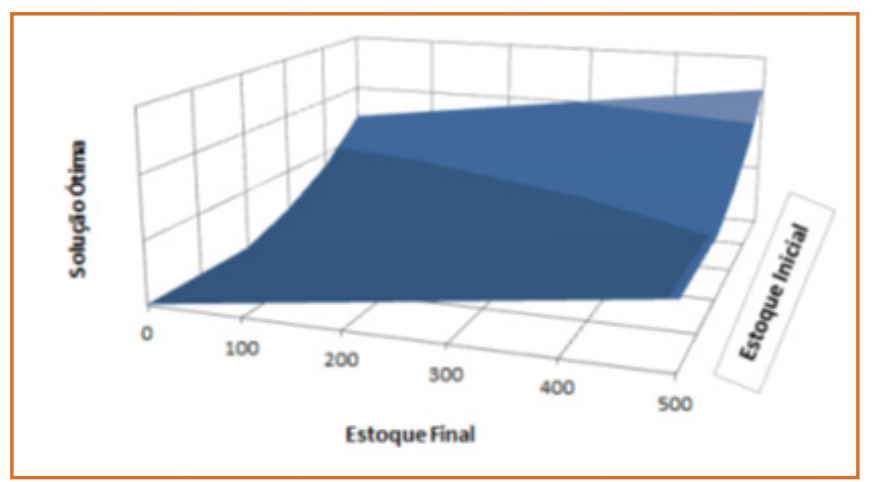

Fonte: Os autores (2015).

Cenário 2: Custo de preparação do item (s)=100 Penalidade por atraso $(\delta)=1000$ Custo de estoque $(h)=1000$

Tabela 2 - Solução ótima quanto às variações de estoque: Cenário 2.

\begin{tabular}{|l|l|l|l|l|l|l|}
\hline$x / y$ & 0 & 100 & 200 & 300 & 400 & 500 \\
\hline 0 & 1000 & 101000 & 201000 & 301000 & 401000 & 501000 \\
\hline 100 & 1000 & 101000 & 201000 & 301000 & 401000 & 501000 \\
\hline 200 & 900 & 100900 & 200900 & 300900 & 400900 & 500900 \\
\hline 300 & 15800 & 250800 & 350800 & 450800 & 550800 & 650800 \\
\hline 400 & 37700 & 470700 & 570700 & 670700 & 770700 & 870700 \\
\hline 500 & 710600 & 810600 & 910600 & 1010600 & 1110600 & 1210600 \\
\hline
\end{tabular}

Fonte: Os autores (2015)

Figura 3 - Gráfico das soluções ótimas encontradas para as variações de estoque do cenário 2 .

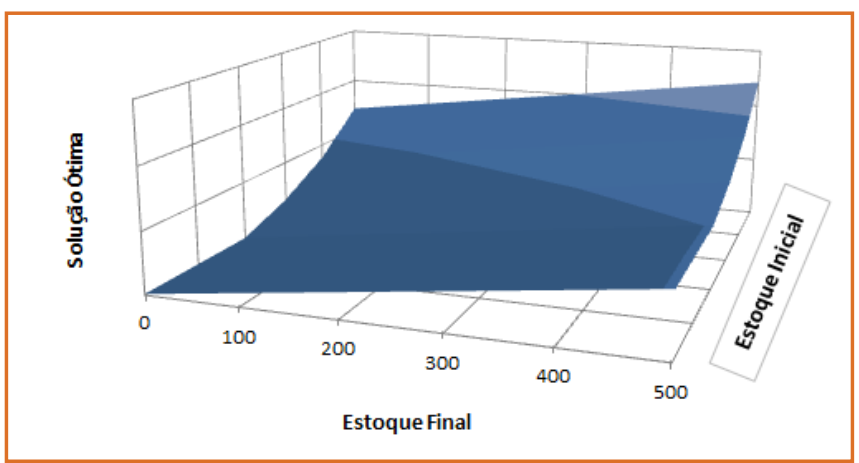

Fonte: Os autores (2015).

Cenário 3: Custo de preparação do item (s)=10000

Penalidade por atraso $(\delta)=100$

Custo de estoque $(h)=100$ 
Tabela 3 - Solução ótima quanto às variações de estoque: Cenário 3.

\begin{tabular}{|l|l|l|l|l|l|l|}
\hline$x / y$ & 0 & 100 & 200 & 300 & 400 & 500 \\
\hline 0 & 88000 & 98000 & 108000 & 118000 & 128000 & 138000 \\
\hline 100 & 88000 & 98000 & 108000 & 118000 & 128000 & 138000 \\
\hline 200 & 78000 & 88000 & 98000 & 108000 & 118000 & 128000 \\
\hline 300 & 88000 & 98000 & 108000 & 118000 & 128000 & 138000 \\
\hline 400 & 98000 & 108000 & 118000 & 128000 & 138000 & 148000 \\
\hline 500 & 122000 & 132000 & 142000 & 152000 & 162000 & 172000 \\
\hline
\end{tabular}

Fonte: Os autores (2015)

Figura 4 - Gráfico das soluções ótimas encontradas para as variações de estoque do cenário 3

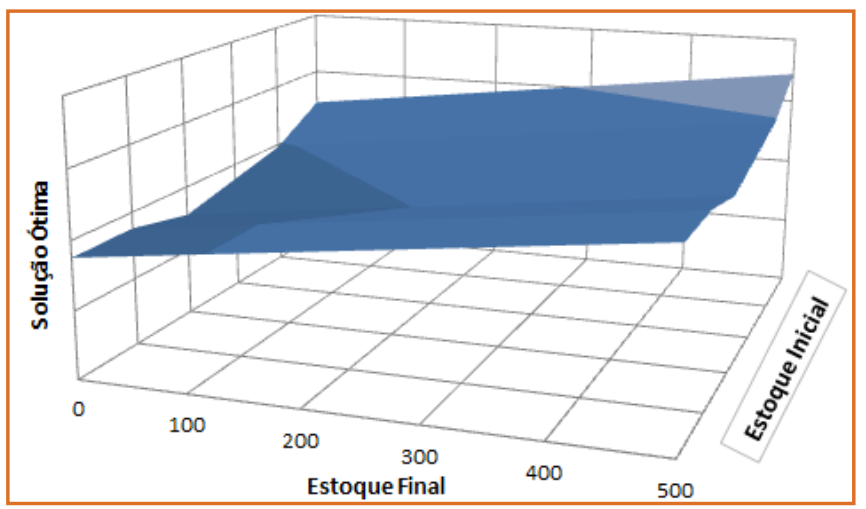

. Fonte: Os autores (2015).

No cenário 1 todos os parâmetros referentes à função objetivo possuem o mesmo custo. Já no cenário 2, houve um aumento do custo de estoque e da penalidade por atraso, sendo estes na mesma proporção. Enquanto no cenário 3 , os custos de estoque e penalidade permaneceram iguais ao cenário 1 e o custo de preparação do item aumentou expressivamente.

No segundo cenário, o custo de estoque e penalidade quando comparado ao primeiro é 10 vezes maior. Esta variação fez com que as soluções encontradas também aumentassem na mesma proporção, porém o gráfico gerado por estas manteve o mesmo comportamento.

No cenário 3 o parâmetro de custo de preparação do item recebeu um acréscimo alto em relação ao seu valor anterior, e os outros parâmetros se mantiveram conforme o cenário 1. Como pode ser observado, este cenário gerou um gráfico com comportamento diferente dos demais.
Em relação aos dois primeiros cenários de acordo com a variação dos estoques iniciais e finais, quando ambos são iguais a zero, não existem atrasos e não há estocagem, uma vez que se produz em todos os períodos a quantidade necessária para atender a demanda. Já quando o estoque inicial é diferente de zero, é produzido apenas o que é necessário para atender a demanda total, podendo não ocorrer produção em certos períodos uma vez que se tem estoque de segurança. Sendo assim, dentre todas as variações de estoque possíveis, a que gera custo total menor é quando se tem o estoque inicial igual a demanda do primeiro período e estoque final igual a zero. No caso em que o estoque final é diferente de zero, o valor que se deseja estocar é produzido apenas no último micro período.

Quando há uma grande variação do custo de preparação do item, como no cenário 3, pode-se encontrar casos em que existem atrasos e estocagem, uma vez que este custo influencia diretamente na decisão de produzir ou não em cada micro período, sendo que esta varia de acordo com as demandas. Neste caso, a solução de menor custo também é quando se tem estoque inicial igual a demanda $1 \mathrm{e}$ estoque final zero.

\section{CONSIDERAÇÕES FINAIS}

Foi resolvido neste artigo um problema de dimensionamento de lotes por meio de um modelo matemático exato e através da meta-heurística de vizinhança Busca Tabu. Com base na comparação realizada entre os métodos acima, verificou-se a eficiência da Busca Tabu para este tipo de problema, uma vez que a solução ótima foi atingida em todas as variações de estoque.

No primeiro cenário, observou-se que quando se tem o mesmo custo de estoque, penalidade por atraso e preparação do item, não gerou-se atraso e estoque, uma vez que se produz em todos os micro períodos a quantidade necessária para atender a demanda deste. Já quando aumentou-se o custo de estoque e penalidade, o valor da função objetivo aumentou na mesma proporção destes. 
No entanto, quando o custo de preparação do item teve um acréscimo considerável e os outros parâmetros foram mantidos como no cenário 1, houve mudança de comportamento no gráfico. O que indica que de acordo com o produto a ser fabricado, o custo de preparação e estocagem está diretamente relacionado à decisão de produzir, manter estoque de segurança ou atrasar a produção em determinada situação, sendo neste último caso preferível pagar penalidade quando esta não for tão alta se comparada aos outros custos.

\section{REFERÊNCIAS}

[1] ARENALES, M; ARAUjO, S.; Problema de Dimensionamento de Lotes Monoestágio com Restrição de Capacidade: modelagem, método de resolução e resultados computacionais. Pesquisa Operacional vol.20 no.2 Rio de Janeiro, 2000.

[2] ARENALES, M.; ARMENTANO, V.; MORABITO, R.; YANASSE, H., H. Pesquisa Operacional. Editora Campus/ Elsevier, Rio de Janeiro, 2007.

[3] BAHL, H.C.; RITZMAN, L.P.; GUPTA, J.N.D. Determining Lot Sizes and Resource Requirements: A Review. Operational Research Society of America, 35(3), p.329-345, 1987.

[4] FAIGLE, U.; KERN, W. Some convergence results for probabilistic tabu search.ORSA Journal on Computing, 4, 32-37, 1992.

[5] GLOVER, F.; LAGUNA, M. Tabu Search. Kluwer Academic Publishers, 1997.
[6] GLOVER, F.; LAGUNA, M. Tabu Search, Part II . ORSA Journal on Computing 2, 1993.

[7] HENDERSSON, D.; JACOBSON, S.H.; JOHNSON, A.W. The theory and practice of Simulated Annealing. Operations Research and Management Science, Vol. 57, 287-319, 2003.

[8] KREVER, M.; WUNDERINK, S.; DEKKER, R.; SCHORR, B. Inventory control based on advanced probability theory, an application. European Journal of Operational Research, v. 162, n. 2, p. 342-358, 2003.

[9] LAARHOVEN, P.J.M Van.; AARTS, E.H.L. Simulated Annealing: Theory and Applications. 1987.

[10] LENARD, J. D.; ROY, B. Multi-item inventory control: A multicriteria view. European Journal of Operational Research, v. 87, p. 685-692, 1995.

[11] ROSA, H.; MAYERLE, S. F.; GONÇALVES, M. B. Controle de estoque por revisão contínua e revisão periódica: uma análise comparativa utilizando simulação. Produção, v. 20, n. 4, dez. 2010.

[12] TUBINO, D. F. Planejamento e Controle da Produção: Teoria e Prática. São Paulo Atlas, 2009.

[13] WANKE, P. Quadro conceitual para gestão de estoques: enfoque nos itens. Gestão e Produção , v. 19, n. 4, p. 677687. São Carlos, 2012

[14] WHITE, G. M.; XIE, B. S.; ZONJIC, S. Using tabu search with longer-term memory and relaxation to create examination timetables. European Journal of Operational Research, v. 153, p. 90-91, 2004 


\title{
CAPÍTULO 9
}

\section{AVAliação da PRoduÇão Científica do PROBLeMa de PROGRAMAÇÃO EM SISTEMAS FLOWSHOP PERMUTACIONAL}

\author{
Kellen Dayelle Endler \\ Maria Teresinha Arns Steiner \\ Cassius Tadeu Scarpin \\ Bruno Henrique da Silva \\ Alexandre Checoli Choueiri
}

Resumo: A evolução das investigações nas diversas áreas de aplicação da Pesquisa Operacional pode ser impulsionada pela organização de dados da produção científica até o momento. O objetivo desse estudo consiste em analisar quantitativamente o que se produziu em relação ao problema de Programação em Sistemas de Produção Flowshop Permutacional. Tratou-se de um estudo de análise bibliométrica, através de dados da base ISI Web of Knowledge e seu tratamento pelos softwares Sitkis $®$ e Ucinet $₫$. Para a pesquisa utilizou-se as seguintes expressões-chave: "scheduling" ou "sequenciamento", e "Flow shop permutational" ou "permutation flow shop", gerando uma amostra constituída por 276 artigos. Ao final do estudo, apresentou-se resultados de estatística descritiva com a identificação dos autores, artigos e periódicos mais referenciados por estudiosos em todo o mundo. Além das principais redes de relacionamento de autores, citações e palavras-chaves. Tem-se neste trabalho, portanto, um importante aliado no desenvolvimento de novas abordagens sobre o tema.

Palavras chave: Programação da Produção, Flowshop Permutacional, Análise Bibliométrica. 


\section{INTRODUÇÃO}

Problemas de Produção são problemas clássicos de otimização discreta da Pesquisa Operacional. Problemas na área de produção em geral, são decompostos hierarquicamente em três níveis: estratégico, tático e operacional. Especificamente, no nível operacional, asprincipais decisões evolvidas são: Designação de tarefas a máquinas e Programação (Scheduling) das tarefas em cada máquina, isto é, a sequência de processamento das tarefas e o instante de início e término do processamento de cada tarefa (ARENALES, 2007).

Problemas de Programação da Produção (PPP) são tradicionalmente classificados de acordo com os sistemas de produção e por tipo de posicionamento do processo de produção onde ocorrem (BOIKO; MORAIS, 2009). Gigante (2010) os classifica em: Flow shop; Jobshop; Openshop; Flow shop permutacional; Máquina única; Máquinas paralelas; Jobshop com máquinas múltiplas; e Flow shop com máquinas múltiplas.

O presente trabalho trata especificamente do problema de programação de operações em ambiente Flow shop, que consiste em um assunto relevante para o dinâmico ambiente de produção atual. Para muitas situações, assume-se a premissa de que a ordem de processamento de tarefas é a mesma em todas as máquinas, tratando-se do caso específico do Flow shop permutacional (FSP), com $\mathrm{n}$ ! possíveis programações para $\mathrm{n}$ tarefas, foco desta pesquisa.

É fato que a programação da produção tem sido objeto de estudo altamente explorado pelas comunidades acadêmicas nas últimas décadas. Trata-se de uma das áreas com mais publicações em conferências e revistas especializadas. Todavia, trata-se também de uma das áreas onde há uma enorme distância entre a teoria e o que se consegue aplicar na prática. Apesar de ser considerada relativamente simples em termos de formulação e visualização do que é requerido, esta classe de problemas é por natureza muito complexa e de difícil resolução, em termos de obtenção da solução ótima (KAZAMA, 2011).
Tal constatação implica dizer que os PPP do cotidiano das empresas, por se tratar de problemas complexos, devem se basear em abordagens de soluções aproximadas, em detrimento de soluções exatas, obtidas com métodos heurísticos e meta-heurísticos, por exemplo. Com a evolução da capacidade computacional, cada vez mais, surgem métodos capazes de fornecer boas soluções, visto que apresentam melhor trade-off entre a qualidade da solução e o custo computacional.

O avanço científico nesse campo de estudo, portanto, deriva fundamentalmente do conhecimento disponível, fruto de interações entre pesquisadores ao longo do tempo. Conhecer a evolução dos métodos de solução, os principais estudiosos e a produção acadêmica de maior relevância pode colaborar significativamente para a melhor compreensão da teoria existente e identificação de tendências, lacunas e problemas que ainda não foram solucionados.

A partir dessa perspectiva, o objetivo da pesquisa é analisar a produção científica sobre PPP em Sistemas de Produção FSP de maneira quantitativa. A abordagem metodológica utilizada é de revisão sistemática da literatura, tendo como base a teoria bibliométrica e análise de redes.

Este artigo está estruturado em seis partes. Uma revisão bibliográfica que discute os principais conceitos (seção 2); Descrição do método de seleção da amostra de artigos e as técnicas de análise (seção 3); Resultados encontrados (seção 4); e, por fim, Considerações Finais, Limitações do trabalho e Sugestões para futuras pesquisas (seção 5).

\section{REVISÃO BIBLIOGRÁFICA}

A presente seção apresenta de forma abrangente o problema de programação da produção, seguido de sua aplicação ao Flowshop permutacional e, finalmente, de seus métodos de solução.

\subsection{O PROBLEMA DE PROGRAMAÇÃO APLICADO À FSP}

Do ponto de vista da Pesquisa Operacional, 
caracterizada por fornecer um ferramental matemático para a tomada de decisão, um Problema de Programação da Produção pode ser definido como "um problema de $\mathrm{n}$ tarefas $\{\mathrm{J} 1, \mathrm{~J} 2, \ldots, \mathrm{Jj}, \ldots, \mathrm{Jn}\}$ que devem ser processadas em $m$ máquinas $\left\{M_{1}, M_{2}, \ldots\right.$, Mk, ..., Mm\}" (TAILLARD, 1993).

O problema de programação Flow Shop é aquele no qual $\mathrm{n}$ tarefas devem ser processadas, na mesma seqüência, em um conjunto de m máquinas distintas. Um caso específico de programação Flow Shop, denominado permutacional, équandoem cadamáquina mantém-se a mesma ordem de processamento das tarefas. O objetivo é encontrar uma sequência, entre as $n$ ! possíveis, para o processamento das tarefas nas máquinas, de modo que alguma medida de desempenho previamente estabelecida seja otimizada (MOCCELLIN; NAGANO, 2007).

Os tempos de processamento necessários para as tarefas $\mathrm{i}$ serem realizadas nas máquinas $\mathrm{j}$ são representados por tij, onde $\mathrm{i}=1, \ldots \mathrm{n}, \mathrm{e} \mathrm{j}=1, \ldots, \mathrm{m}$. Os tempos de processamento são fixos, conhecidos previamente e não negativos. Baker (1974) lista várias premissas que são comumente feitas sobre esse problema:

- Cada tarefa i pode ser processada no máximo em uma máquina j por vez;

- Cada máquina j pode processar apenas uma tarefa i por vez;

- Após o início da operação, não são permitidas as interrupções;

- Cada operação tem no máximo uma precedente e uma sucessora, isto é, possuem fluxo unidirecional;

- Os tempos de setup são insignificantes e portanto podem ser ignorados;

- As máquinas estão continuamente disponíveis;

- Estoque em processo é permitido, entre outros.

Os PPP são de natureza combinatorial e enquadra-se na classe NP-hard (GAREY; JOHNSON; SETHI, 1979). Os métodos de solução dos PPP encontrados na literatura, segundo MacCarthy e Liu (1993), podem ser categorizados em:
1. Métodos ótimos (ou exatos): geram a melhor programação possível de acordo com o critério de desempenho adotado; e

2. Métodos heurísticos: geram uma programação de boa qualidade sem garantia de otimalidade em um tempo computacional aceitável.

3. Glover e Kochenberger (2003) incluem a esta classificação: Meta-heurísticas: procedimentos que coordenam estratégias de busca local de nível mais elevado, criando um processo para evitar mínimos locais, efetuando uma busca da solução mais robusta para um problema.

4. Boschetti et al. (2009) mais recentemente, ressaltam a utilização de: Métodos híbridos ou matheurísticas: algoritmos desenvolvidos por meio da interoperação de meta-heurísticas e técnicas de programação matemática. Esses métodos relacionados exclusivamente ao problema de programação Flow Shop serão tratados a seguir.

\subsection{MÉTODOS PARA SOLUÇÃO DO PROBLEMA DE PROGRAMAÇÃO FLOW SHOP}

Desde a década de 1960, um extenso esforço de pesquisa tem sido dedicado ao problema de programação Flow shop. No início, as pesquisas sobre Flow shop eram extremamente teóricas. Pesquisadores consideravam abordagens como, por exemplo, a de Programação Linear Inteira (MANNE, 1960), (SELEN; HOTT, 1986). Soluções Branch and Bound (LOMNICKI, 1965), (IGNAL; SCHRAGE, 1965), foram desenvolvidas para obter soluções ótimas do problema. Entretanto, tais técnicas não são eficientes em termos computacionais, em problemas de médio e grande porte. Assim, métodos heurísticos têm sido propostos, os quais, são classificados em dois grupos: métodos construtivos e melhorativos.

Os métodos heurísticos construtivos consistem em construir a solução de um problema a partir do zero, de forma incremental, a qual é adotada como solução final do problema (PALMER, 1965), (CAMPBELL; DUDEK; SMITH, 1970), (DANNENBRING, 1977), (NAWAZ; ENSCORE; HAM, 1983), (KALCZYNSKI; 
KAMBUROWSKI, 2008), (RAD; RUIZ;BOROOJERDIAN, 2009).

Heurísticas melhorativas partem de uma solução factível e procuram uma solução melhor dentro de uma vizinhança, definida geralmente por meio de permutações de posições das tarefas na sequência. Uma heurística clássica melhorativa pára quando não existe nenhum vizinho melhor que a solução corrente (ótimo local). Nesta categoria, destaca-se o trabalho de Dannenbring (1977).

Mais recentemente, foram desenvolvidos métodos de busca em vizinhança de maior complexidade, como o Busca Tabu e o Simulated Annealing que têm sido alvo de grande interesse na comunidade científica em função de aplicações bem sucedidas reportadas na literatura. Exemplos de aplicações dessas técnicas para o problema FSP são: (OSMAN; POTTS, 1989), (TAILLARD, 1990), (MOCCELLIN, 1995), (ZEGORDI; ITOH; ENKAWA,

1995), (NOWICKI; SMUTNICKI, 1996), (PARK; KIM, 1998), (MOCCELLIN; NAGANO,1998), (WODECKI; BO $\square Z E J K O, 2002),($ GRABOWSKI; WODECKI, 2004), (LAHA; CHAKRABORTY, 2009), (REN et al., 2011), (GAO; CHEN; DENG, 2013), (BARGAOUI; DRISS, 2014), (XIE et al., 2014).

Uma tendência de pesquisa de grande relevância refere-se ao desenvolvimento de métodos metaheurísticos híbridos utilizando Busca Tabu, Simulated Annealing e Algoritmo Genético, visando combinar essas técnicas, preservando suas características de ação "inteligente", de forma que o procedimento resultante seja mais eficaz do que seus componentes isoladamente. Trabalhos recentes podem ser citados: (GAO; CHEN; DENG, 2013), (XU et al., 2014), (MIRABI, 2014).

\section{METODOLOGIA}

A bibliometriaé definida como "atécnica de investigação que tem por fim a análise do tamanho, crescimento e distribuição da bibliografia num determinado campo do conhecimento". (PILKINGTON; MEREDITH, 2009). Salienta-se que a bibliometria desenvolveuse mediante a elaboração de leis empíricas sobre o comportamento da literatura (ARAÚJO, 2006). Nesse cenário, é importante citar as três leis básicas da bibliometria, para o melhor entendimento dos dados: Lei de Zipf que mensura a freqüência de ocorrência de palavras; Lei de Lotka que trata da produtividades de autores; e Lei de Bradford, referente a produtividade de periódicos (BUFREM; PRATES, 2005).

Para o desenvolvimento da presente pesquisa estabeleceram-se quatro etapas:

1) Constituição da fundamentação teórica da pesquisa - revisão de literatura sobre o Problema da Programação FSP (Seção 2) e Bibliometria (Seção 3.1);

2) Definição da amostra na base de dados do ISI Web of Knowledge (Seção 3.2);

3) - Organização e tratamento bibliométrico dos registros coletados (Seção 3.3); e

4) Análise e interpretação de resultados (Seção 4).

\subsection{DEFINIÇÃO DA AMOSTRA}

A amostra de artigos sobre problema de programação Flow shop foi definida a partir da escolha da base de dados, da identificação das palavras-chave, da seleção das áreas de pesquisas e da determinação dos anos de publicação, conforme ilustrado no 
fluxograma da Figura 1.

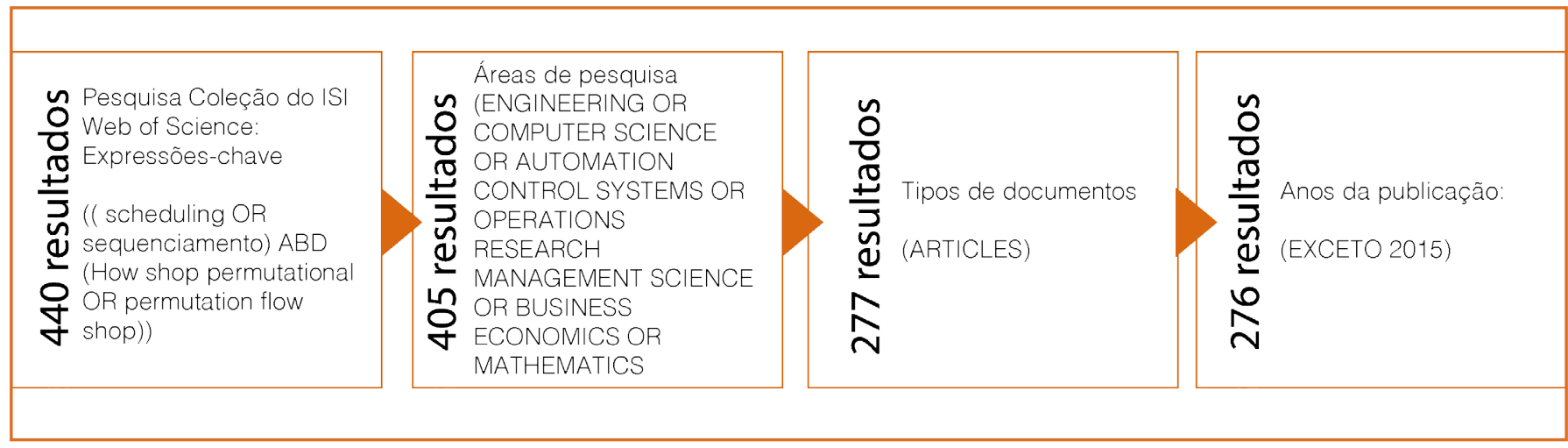

Figura 1 - Fluxograma do processo de definição da amostra Quanto à determinação da base de dados, optouse por utilizar a plataforma ISI Web of Knowledge, por incluir revistas com fator de impacto calculado no JCR (Journal Citation Report), além de fornecer um conjunto relevante de informações para a análise bibliométrica. O tratamento dos dados seguiu com o intuito de eliminar tipos de fontes que não correspondessem à áreas de pesquisa não relacionadas. Resultaram do esforço descrito 405 artigos.

Quanto à determinação do tipo de publicação - livros, patentes, artigos, anais de congressos, etc. - optouse por considerar apenas os artigos. Entende-se que a escolha é válida, pois artigos acadêmicos geralmente antecedem livros consagrados e são considerados fontes seguras para pesquisas por apresentar rigor metodológico para publicação.

A composição da amostra, então, foi concluída excluindo-se o ano de 2015, pelo fato de se desejar realizar uma busca de um ano completo, com 12 meses. Inicialmente a pesquisa retornou um total de 440 artigos, e após o refinamento resultou em uma amostra de 276 artigos a serem analisados.

\subsection{ORGANIZAÇÃO E TRATAMENTO BIBLIOMÉTRICO DOS REGISTROS COLETADOS}

O tratamento bibliométrico dos registros coletados é apresentado em duas etapas: estatística descritiva e análise de redes de relacionamento. A primeira, foi obtida através de tabelas e gráficos ilustrativos gerados através do software Microsoft Excel ${ }^{\circledR}$. Na segunda etapa, utilizou- se a ferramenta SITKIS $^{\circledR}$ (SCHILDT, 2002) para relacionar os dados de saída do banco de dados ISI Web of Knowledge (Web of Science), o programa UCINET ${ }^{\circledR}$ para codificar os relacionamentos e o NetDraw ${ }^{\circledR}$ (BORGATTI; EVERETT; FREEMAN, 2002) para ilustrar os diagramas de relacionamento.

\section{ANÁLISE DOS RESULTADOS}

Uma primeira análise descritiva das publicações procurou identificar tendências de crescimento ou decréscimo no interesse de desenvolvimento de estudos na área, classificando os artigos da amostra de acordo com o ano de publicação (Figura 2). Observouse que a primeira publicação relacionada com o tema data do ano de 1981, sendo que nos anos seguintes o volume de publicações apresenta um caráter cíclico com picos de volume de publicações nos anos 2007, 2011 e 2013, intercalados por períodos com menor volume de publicações.

Figura 2 - Evolução das publicações da amostra ao longo do tempo

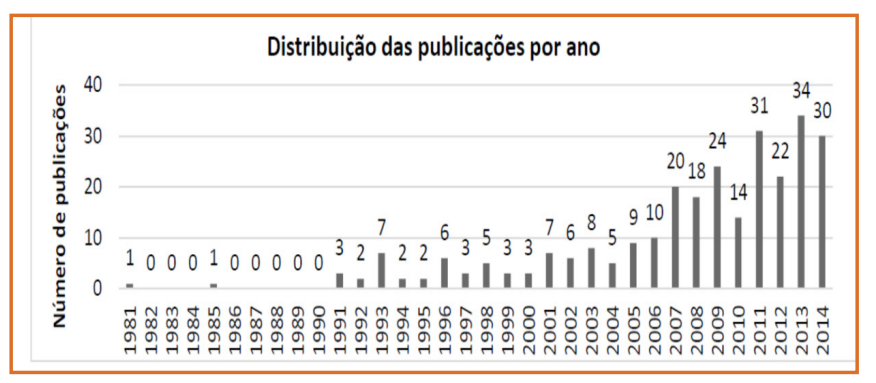

Uma segunda análise descritiva procurou avaliar 
a dispersão dos trabalhos, a fim de identificar os principais autores, países de origem e periódicos em volume de publicações, conforme indicado na Figura 3, Figura 4 e Figura 5.

Com relação à distribuição dos trabalhos por autor (Figura 3), a análise da amostra revelou uma dispersão considerável. Os autores com maior número de trabalhos são representados por um grupo constituído de 11 autores, com número de publicações na amostra acima de 5 artigos.

Figura 3 - Autores com maior número de publicações da amostra

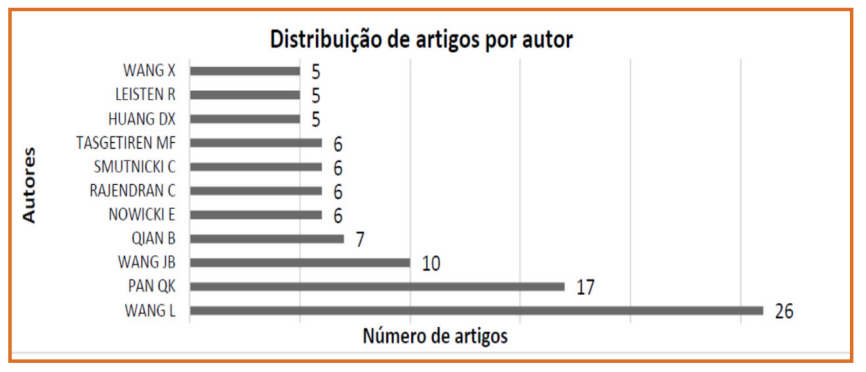

A estratificação das publicações por país de origem (Figura 4) demonstra um predomínio acentuado de publicações originárias da China, com publicação de 80 artigos, seguido dos Estados Unidos, com publicação de 40 artigos. A estratificação conta com todos os países da amostra com quantidade de publicações superior a seis artigos.

Figura 4 - Distribuição das publicações da amostra por país de origem

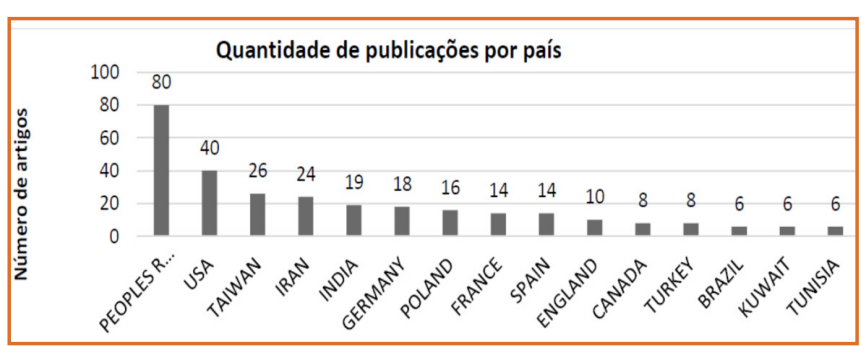

A distribuição dos artigos da amostra por periódico de publicação, encontra-se na Figura 5. Os 10 principais periódicos citados na Figura 5, são responsáveis por aproximadamente $64 \%$ da amostra.

Figura 5 - Comparativo da distribuição dos artigos pelas principais periódicos

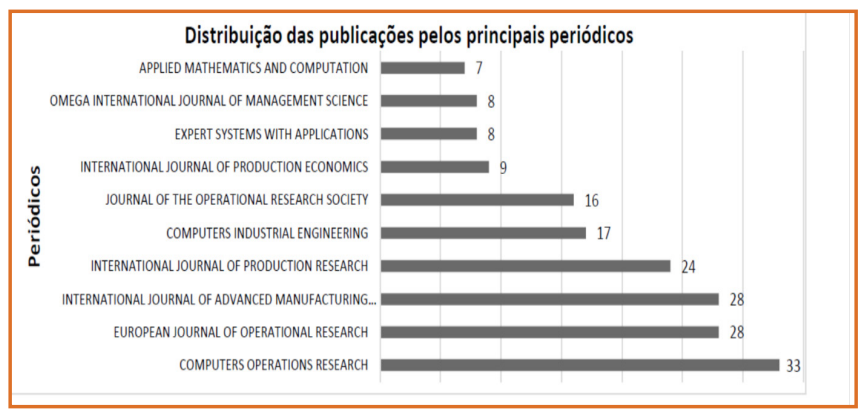

Os artigos com os maiores números de citações da amostra são apresentados na Tabela 1, juntamente com o fator de impacto de cada periódico. 
Tabela 1 - Publicações mais citadas da amostra

\begin{tabular}{|c|c|c|c|c|}
\hline Autores (Ano da Publicação) & Título da fonte & $\mathbf{F I}$ & TC & MA \\
\hline Taillard, E (1993) & EUROPEAN JOURNAL OF OPERATIONAL RESEARCH & 1,843 & 648 & 28.17 \\
\hline Nowicki, E; Smutnicki, C (1996) & EUROPEAN JOURNAL OF OPERATIONAL RESEARCH & 1,843 & 214 & 10.70 \\
\hline Liu, Bo; Wang, Ling; Jin, Yi-Hui (2007) & $\begin{array}{l}\text { IEEE TRANSACTIONS ON SYSTEMS MAN AND CYBERNETICS PART } \\
\text { B-CYBERNETICS }\end{array}$ & 3,781 & 118 & 13.11 \\
\hline $\begin{array}{l}\text { Pan, Quan-Ke; Tasgetiren, M. Fatih; Liang, } \\
\text { Yun-Chia (2008) }\end{array}$ & COMPUTERS \& OPERATIONS RESEARCH & 1.718 & 109 & 13.62 \\
\hline $\begin{array}{l}\text { Pan, Quan-Ke; Tasgetiren, M. Fatih; } \\
\text { Suganthan, P. N.; Chua, T. J. (2011) }\end{array}$ & INFORMATION SCIENCES & 3.893 & 108 & 21.60 \\
\hline Grabowski, J; Wodecki, M. (2004) & COMPUTERS \& OPERATIONS RESEARCH & 1.718 & 103 & 8.58 \\
\hline Ying, KC; Liao, CJ (2004) & COMPUTERS \& OPERATIONS RESEARCH & 1.718 & 95 & 7.92 \\
\hline Ben-Daya, M; Al-Fawzan, M (1998) & EUROPEAN JOURNAL OF OPERATIONAL RESEARCH & 1,843 & 94 & 5.22 \\
\hline Framinan, JM; Leisten, R (2003) & $\begin{array}{l}\text { OMEGA-INTERNATIONAL JOURNAL OF } \\
\text { MANAGEMENT SCIENCE }\end{array}$ & 3.190 & 88 & 6.77 \\
\hline Li, Bin-Bin; Wang, Ling (2007) & $\begin{array}{l}\text { IEEE TRANSACTIONS ON SYSTEMS MAN AND CYBERNETICS PART } \\
\text { B-CYBERNETICS }\end{array}$ & 3,781 & 76 & 8.44 \\
\hline
\end{tabular}

Na busca de identificação das bases teóricas sobre as quais a amostra de publicações foi desenvolvida, construiu-se uma rede de relacionamento entre os artigos da amostra e suas referências. O resultado dessa primeira análise está demonstrado na Figura
6. Há uma concentração clara em torno de duas referências específicas (TAILLARD, 1993; NAWAZ, ENSCORE e HAM, 1983) revelando certa influência nos trabalhos da área.

Figura 6 - Rede de relacionamento entre os artigos da amostra e suas referências

Nota: Os círculos representam os artigos da amostra inicial e os quadrados, suas referências, sendo que ambos foram citadas pelo menos 50 vezes.

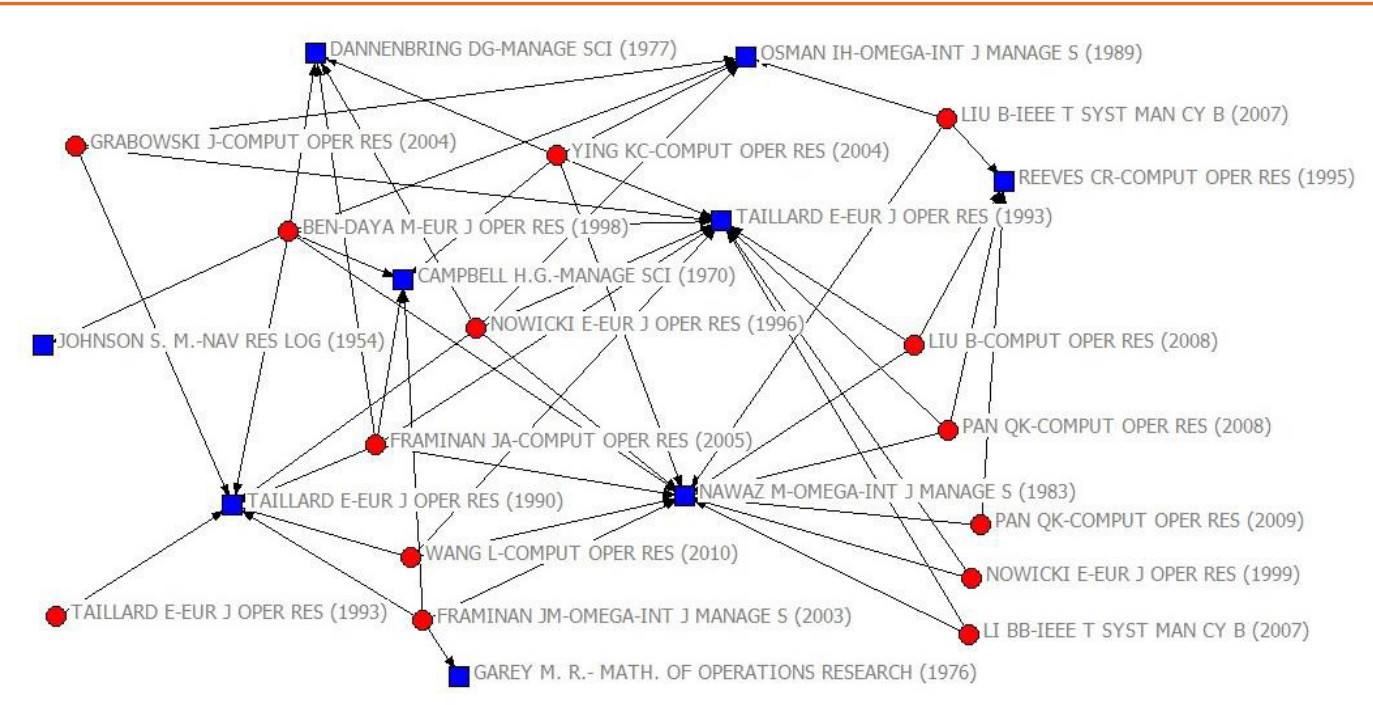

Fonte: Os autores 
A análise de cocitação (Figura 7) mede o grau de

documentos que os citam.

ligação entre dois ou mais artigos pelo número de

Figura 7 - Rede de cocitação

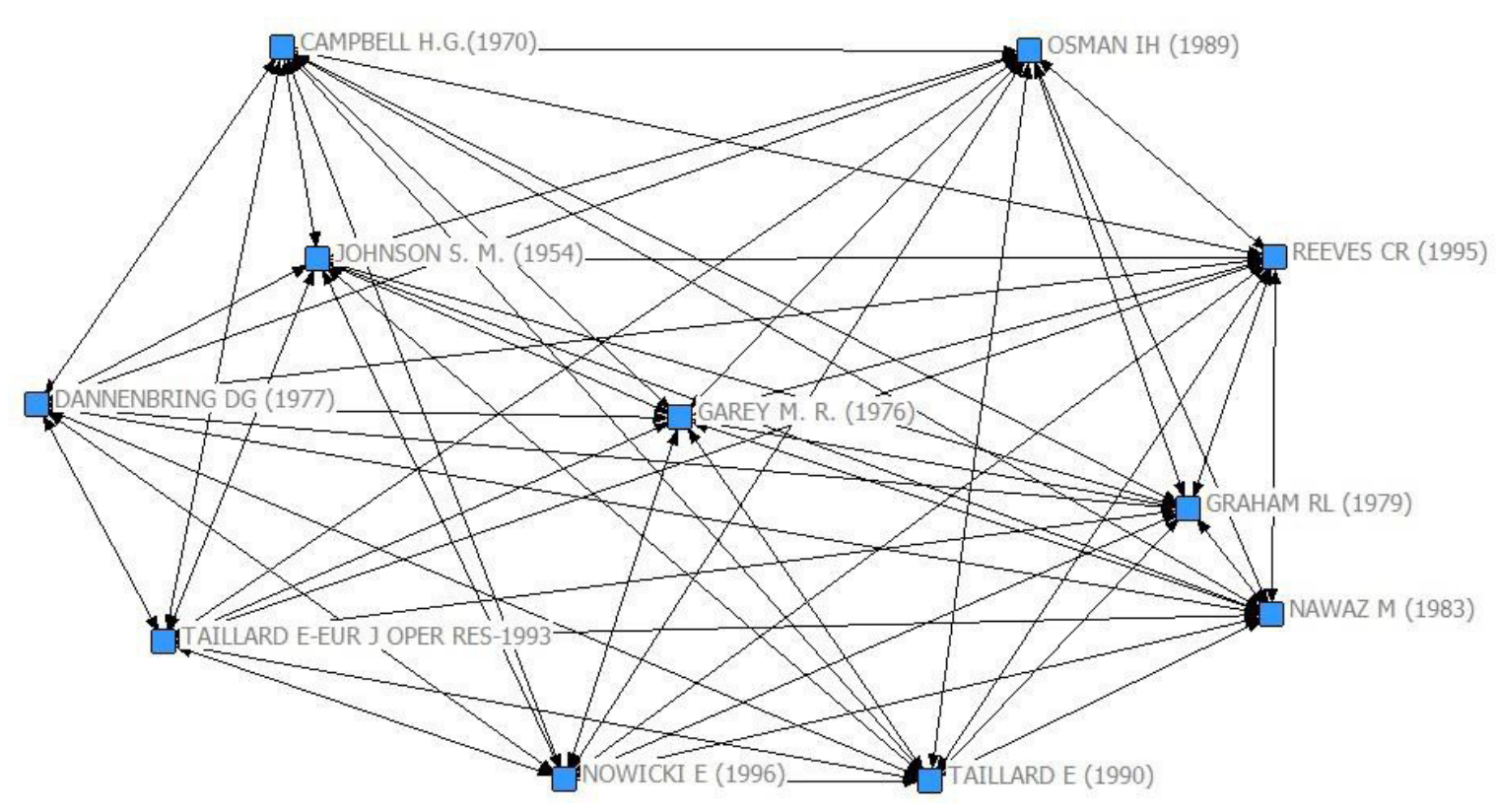

Nota: Os quadrados representam as referências dos artigos da amostra que foram citadas conjuntamente pelo menos 40 vezes.

Como última etapa da análise de redes, estabeleceuse uma relação de coocorrência das palavras-chave dos artigos da amostra (Figura 8). A fim de restringir a quantidade de dados e proporcionar uma visão mais nítida dos relacionamentos, o critério de corte consistiu em analisar as palavras-chave apenas dos artigos com mais de 30 citações.

Figura 8 - Rede de coocorrência de palavras-chave

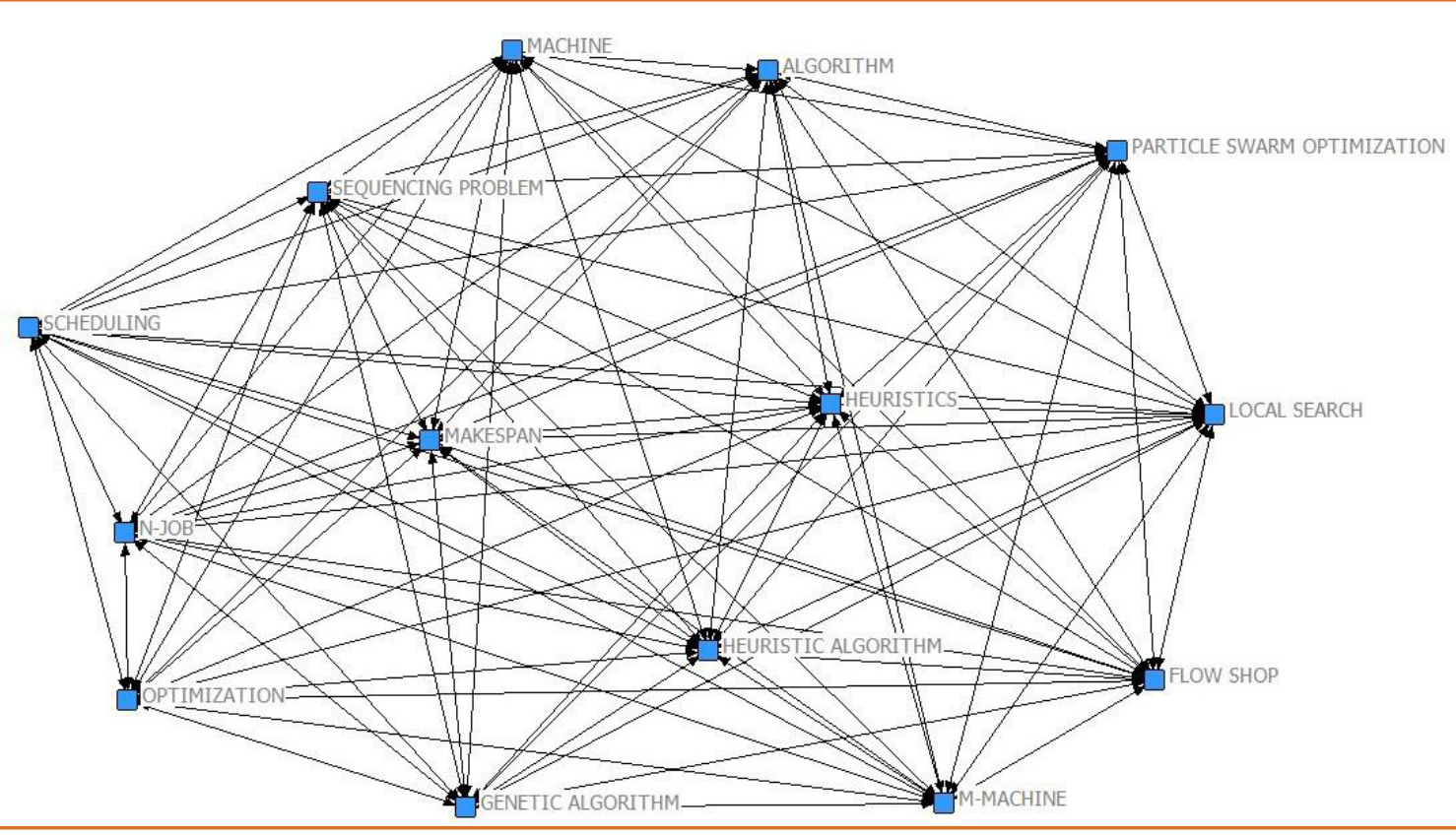

Nota: Os quadrados representam as palavras-chave dos artigos da amostra que foram citados conjuntamente pelo 
menos 30 vezes.

Essa análise contribuiu para uma identificação mais clara do inter-relacionamento dos principais temas. Por exemplo, uma das palavras que aparecem na rede é o "makespan", o que induz a associação do mesmo como a medida de desempenho mais utilizada em PPP em FSP. Ruiz e Maroto (2005), corroboram com ideia, afirmando que a minimização da duração total da programação é o critério mais comum reportado na literatura. Sendo que outra medida usual referese à minimização do tempo médio de fluxo (mean flow time), associado à redução do estoque em processamento.

Outra palavra-chave importante, consiste na "local search", ou seja, na "busca local". Entende- se, portanto, que a maior parte dos estudos referentes a programação da produção em ambiente FSP utilizase de heurísticas melhorativas para solução de problemas.

Destacam-se da mesma forma, as palavras-chave com referência a métodos de solução específicos, tais como "Particle Swarm Otimization" e "Genetic Algorithm", o que remete aos métodos que mais têm sido citados e estudados a fim de se resolver estes problemas de programação.

\section{CONSIDERAÇÕES FINAIS}

A organização de dados sobre a produção científica sobre o tema contribui sobremaneira para a consolidação do conhecimento disponível e para o desenvolvimento de novas visões econceitos. Faz-se necessário, contudo, mostrar algumas limitações do método e das fontes de dados que estão disponíveis para a construção deste trabalho.

A plataforma escolhida para esta investigação, ISI Web of Science, tem a predominância de publicações norte-americanas e em língua inglesa, não contemplando a produção acadêmica de muitos países, sobretudo aqueles em desenvolvimento. Sendo assim, publicações brasileiras, relevantes para o entendimento do problema de pesquisa no país, não necessariamente integram a amostra utilizada, e por consequência, não estão retratadas nos resultados.

Outra limitação, originada também no processo amostral, diz respeito ao tipo de publicações selecionado. O conhecimento que não tenha sido transformado em um artigo científico não foi levado em consideração nesta pesquisa. O que se sugere, então, é o desenvolvimento de uma investigação, cuja amostra seja constituída por artigos publicados no Brasil, ainda que não se considere outros veículos de publicação, mas que seja possível a identificação de autores e núcleos de pesquisa com produção relevante no país.

Outra sugestão de trabalho futuro, seria a avaliação bibliométrica e sistemática das publicações apenas dos últimos anos, a fim de se delimitar o que vem sendo publicado mais recentemente, evidenciando o real estado da arte. Uma avaliação sistemática da bibliografia, poderia ser realizada, classificandose os trabalhos por: métodos de solução; número de máquinas; tipo de função objetivo; critério de desempenho adotado; e restrições adicionais consideradas, por exemplo.

A maioria dos problemas reais de programação da produção é por natureza muito complexa e de difícil resolução, sendo que o estudo de funções objetivo bi e multi-critério; o desenvolvimento de metaheurísticas e matheurísticas; o estudo de setups independentes ou dependentes da sequência das tarefas e que adicionam restrições verificadas na prática dos ambientes de produção constituem-se em oportunidades evidentes para pesquisas futuras neste ambiente.

\section{REFERÊNCIAS}

[1] ARAÚJO, C. Bibliometria: evolução histórica e questões atuais. Pesquisa Brasileira em Ciência da Informação e Biblioteconomia, 2, 11-32, 2006.

[2] ARENALES, M.; ARMENTANO, V.; MORABITO, R. Pesquisa operacional: para cursos de engenharia, 2007.

[3] BAKER, K. R. Introduction to sequencing and scheduling. New York: John Wiley \& Sons, 1974. 
[4] BARGAOUI, H.; DRISS, O. B. Multi-agent Model Based on Tabu Search for the Permutation Flow Shop Scheduling Problem. Distributed Computing and Artificial Intelligence, 11th International Conference. Springer International Publishing, 519-527, 2014.

[5] BOIKO, T. J. P.; MORAIS, M. F. A atividade de programação da produção sobre a ótica da Pesquisa Operacional: uma abordagem teórico conceitual, Anais Encontro Tecnológico, Campo Mourão, Paraná, 2009.

[6] BORGATTI, S. P.; EVERETT, M. G.; FREEMAN, L. C. Ucinet for Windows: Software for social network analysis, 2002.

[7] BOSCHETTI, M. A.; MANIEZZO, V.; ROFFILLI, M.; RÖHLER, A. B. Matheuristics: Optimization, Simulation and Control. Lecture Notes in Computer Science, 5818, 171$177,2009$.

[8] BUFREM, L.; PRATES, Y. O saber científico registrado e as práticas de mensuração da informação. Ciência da Informação, Brasília, 34, n. 2, 9-25, 2005.

[9] CAMPBELL, H. G.; DUDEK, R. A.; SMITH, M. L. A heuristic algorithm for the $n$-job, $m$ - machine sequencing problem. Management science, 16, n. 10, 630-637, 1970.

[10] DANNENBRING, D. G. An evaluation of flow-shop sequence heuristics. Management science, 23, n. 11, 11741182, 1977.

[11] GAO J.; CHEN R.; DENG, W. An efficient tabu search algorithm for the distributed permutation Flow shop scheduling problem. International Journal of Production Research, 51, 3 ed., 641-651, 2013.

[12] GAREY, M. R.; JOHNSON, D. S.; SETHI, R. The Complexity of Flow shop and Jobshop Scheduling. Mathematics of Operations Research. 1, 117-129, 1976.

[13] GIGANTE, R. L. Heurística construtiva para a programação de operações flow shop permutacional. São Carlos, (2010). Dissertação (Mestrado) - Programa de Pós-Graduação em Engenharia de Produção e Área de Concentração em Processos e Gestão de Operações Escola de Engenharia de São Carlos da Universidade de São Paulo. São Carlos: USP, 2010.

[14] GLOVER, F.; KOCHENBERGER, G. A. Handbook of Metaheuristics. Kluwer Academic Publishers. Boston, 2003.

[15] GRABOWSKI, J.; WODECKI, M. A very fast tabu search algorithm for the permutation flow shop problem with makespan criterion. Computer \& Operations Research. 31, 1891-1909, 2004

[16] IGNALL, E.; SCHRAGE, L. E. Aplication of Branch and Bound Technique to some Flow- Shop Problem. Operations Research. 13, 400-412, 1965.
[16] KALCZYNSKI, P. J.; KAMBUROWSKI, J. An Improved $\mathrm{NEH}$ heuristic to minimize makespan in permutation Flow shop. Computers \& Operations Research. Amsterdam, 35, n. 9, 3001-3008, 2008

[17] KAZAMA, E. K. Heurísticas construtivas para programação de operações em sistemas de produção Flow shop permutacional: classificação de suas fases construtivas. 2011. 99 p. Trabalho de Conclusão de Curso - Escola de Engenharia de São Carlos, Universidade de São Paulo. São Carlos: USP, 2011.

[18] LAHA, D.; Chakraborty, U. K. An efficient hybrid heuristic for makespan minimization in permutation flow shop scheduling. The International Journal of Advanced Manufacturing Technology. 44, n. 5-6, 559-569, 2009.

[19] LOMNICKI, Z. A branch and bound algorithm for the exact solution of three machine scheduling problem. Operational Research. 89-100, 1965.

[20] MACCARTHY, B. L.; LIU, J. Adressing the gap in scheduling research: a review of optimization and heuristic methods in production scheduling. International Journal of Production Research. Londres, 31, n.1, 59-79, 1993.

[21] MANNE, A. S. The job-shop scheduling problem. Operational Research, 219-223, 1960, 2014.

[22] MOCCELLIN, J. V. A new heuristic method for the Permutation Flow-Shop Scheduling Problem. Journal of the Operational Research Society, 46, 883-886, 1995.

[23] MOCCELLIN, J. V.; NAGANO, M. S. Evaluating the Performance of Tabu Search Procedures for Flow Shop Sequencing. Journal of the Operational Research Society, 49, 1296-1302, 1998

[24] MOCCELLIN, J. V.; NAGANO, M. S. Uma propriedade estrutural do problema de programação da produção flow shop permutacional com tempos de setup. Pesquisa Operacional. 27, n. 3, 487-515, 2007.

[25] NAWAZ, M.; ENSCORE, E. E.; HAM, I. A Heuristic Algorithm for m-Machine, n-Job Flow- Shop Sequencing Problem. Omega, 11, 91-95, 1983.

[26] NOWICKI, E.; SMUTNICKI, C. A Fast Tabu Search Algorithm for the Permutation Flow- shop Problem. European Journal of Operational Research, 91, n. 1, 160-175, 1996.

[27] OSMAN, I. H.; POTTS, C. N. Simulated Annealing for Permutation Flow-Shop Scheduling. Omega, 17, n. 6, 551557, 1989.

[28] PALMER, D. S. Sequencing jobs through a multistage process in the minimum total time: a quick method of obtaining a near optimum. Operational Research, 101-107, 1965. 
[29] PARK, M. W.; KIM, Y. D. A Systematic Procedure for Setting Parameters in Simulated Annealing Algorithms. Computers \& Operations Research, 25, 207-217, 1998.

[30] PILKINGTON, A.; MEREDITH, J. The evolution of the intellectual structure of operations management - 19802006: a citation/co-citation analysis. Journal of Operations Management, 27, 185-202, 2009.

[31] RAD, S. R.; RUIZ, R.; BOROOJERDIAN, N. New high performing heuristic for minimizing makespan in permutation Flow shops. Omega: the Internation Journal of Management Science, Oxford, 37, n. 2, 331-345, 2009.

[32] REN, W. J., DUAN, J. H., ZHANG, F. R., HAN, H. Y., ZHANG, M. Hybrid Tabu Search

Algorithm for bi-criteria No-idle permutation flow shop scheduling problem. In: Control and Decision Conference (CCDC), 2011 Chinese. IEEE. 1699-1702, 2011.

[33] RUIZ, R.; MAROTO, C. A comprehensive review and evaluation of permutation Flow shop heuristics. European Journal of Operational Research, 165, 479-494, 2005.

[34] SCHILDT, H. Sitkis: Software for Bibliometric Data Management and Analysis. Helsinki Institute of Strategy and International Business. 6, 2002.
[35] SELEN, W. J.; HOTT, D. D. A Mixed-Integer Goal Programming Formulation of the Standard Flow-Shop Scheduling Problem. Journal of the Operational Research Society, 37, 1121-1128, 1986.

[36] TAILLARD, E. Some efficient heuristic methods for the flow-shop sequencing problem.

European Journal of Operational Research, 47, 65-74, 1990.

[37] TAILLARD, E. Benchmarks for basic scheduling problems. European Journal of Operational Research, 64, 278-285, 1993.

[38] WODECKI, M.; BOŻZEJKO, W. Solving the flow shop problem by parallel simulated annealing. In: Parallel Processing and Applied Mathematics. Springer Berlin Heidelberg, 236- 244, 2002.

[39] XIE, Z., ZHANG, C., SHAO, X., LIN, W., ZHU, H. An effective hybrid teaching-learning- based optimization algorithm for permutation flow shop scheduling problem. Advances in Engineering Software, 77, 35-47, 2014.

[40] XU, Y.; WANG, L.; WANG, S.; LIU, M. An effective hybrid immune algorithm for solving the distributed permutation flow-shop scheduling problem. Engineering Optimization, 46, 9 ed., 1269-1283, 2014.

[41] ZEGORDI, S. H.; ITOH, K.; ENKAWA, T. Minimizing Makespan for Flow Shop Scheduling by Combining Simulated Annealing with Sequencing Knowledge. European Journal of Operational Research, 85(3), 515-53, 1995. 


\title{
CAPÍTULO 10
}

\section{REDE PERT/CPM EM UMA OBRA DE CONSTRUÇÃO CIVIL: UMA ANÁLISE DO CAMINHO GRÍTICO E DIVERSOS COMPONENTES DO PROCESSO}

\author{
Isabela Costa Nery \\ Gustavo da Costa Rodrigues \\ Túlio Arnold Aguiar de Oliveira
}

Resumo: O setor da Construção Civil tem grande relevância para o desenvolvimento econômico do Brasil, uma vez que este ainda é carente de infraestrutura, sendo esse item responsável por empregar parte da população. Apesar da crescente demanda a mesma ainda atua de forma precária no país, de modo que grande parte dos projetos da construção civil encontram-se estagnados, em razão de gargalos, ou mesmo atrasos inerentes a entrega do serviço, onerando custos imprevistos à construtora como indenizações e perda de credibilidade no mercado da insatisfação dos interessados no projeto.

O presente trabalho vem com a proposta de aplicar a rede PERT/CPM em uma construtora e tem por objetivo de melhorar o tempo para a entrega do produto final, evitando possíveis inconveniências.

A metodologia a ser empregada conta com um levantamento de documentos utilizados para o planejamento e controle de obras disponibilizados pela empresa para posterior análise para a identificação das atividades gargalos, que devem ter um foco especial no projeto. Por fim, a técnica mostrada no trabalho é de importância para aqueles que pretendem atuar na área de controle de projetos, pois mostra-se eficiente para o mesmo, utilizando melhor o fator tempo.

Palavras chave: Construção Civil; Atrasos; Rede PERT/CPM; otimização; 


\section{INTRODUÇÃO}

A cadeia produtiva do setor da construção civil no Brasil é muito importante para o desenvolvimento econômico e social das cidades e apresenta grande potencial pela carência de infraestrutura do país, como obras de moradia, redes de esgoto e água, estradas, ferrovias e edifícios especializados.

Diante deste cenário da construção civil aquecida surge a necessidade das empresas se manterem competitivas no mercado tendo que investir no seu planejamento e controle da produção de obras para que não ocorram atrasos e prejuízos não sejam causados aos interessados do projeto. De acordo como afirma Pereira (2012), pois em um mercado em que se exige cada vez mais rapidez e agilidade, os prazos se tornam cada vez mais curtos e planejar estrategicamente se torna um diferencial na entrega de um empreendimento.

Esta pesquisa visa utilizar o método PERT/CPM que permite o a reorganização das etapas do projeto de acordo com suas dependências imediatas, com a montagem da rede e relacionamento entre os passos buscou-se a minimização do tempo de execução da obra de construção civil de uma casa térrea, analisando o caminho critico e outros componentes do processo.

\section{2. FUNDAMENTAÇÃO TEÓRICA}

\subsection{PESQUISA OPERACIONAL PARA A OTIMIZAÇÃO DO PROCESSO}

Os problemas de Pesquisa Operacional (existem desde longa data. Somente a partir da $2^{\underline{a}}$ Grande Guerra, todavia, passaram a ser tratados a partir de uma abordagem organizada, sendo organizados na forma de uma disciplina ou área do conhecimento (Ravindran et al., 1987). De acordo com Tiwari e Sandilya (2006), PO busca encontrar uma solução ótima para um determinado problema. Mas esta solução ótima não é apenas a que prevê o melhor resultado, mas a solução considerando vários outros aspectos, como restrições de tempo e custos.

Pode-se definir a Pesquisa Operacional como métodos matemáticos que podem objetivar a resolução de determinados problemas relacionados a diversos processos produtivos e até mesmo de serviço. Os modelos são constituídos de equações ou inequações que dão condições as mesmas e que somente serão manipuladas dentro de seus respectivos limites.

Silva et al. (1998) apresenta a Pesquisa Operacional como a utilização de um método de descrição de um sistema organizado, auxiliado por um modelo. De forma que experimentações do modelo levam a maneira ótima de operar o sistema. Através desses sistemas é possível, por exemplo minimizar custos e maximizar receitas e tais modelos quando solucionados e implementados são de essencial importância em indústrias e instituições afins,. A solução de problemas através da Pesquisa Operacional pode ser implementada através de um procedimento em sete etapas, conforme apresentado na figura abaixo (WINSTON, 1994): 
Figura 1 - Etapas para solução de problemas por meio do uso de Pesquisa Operacional:

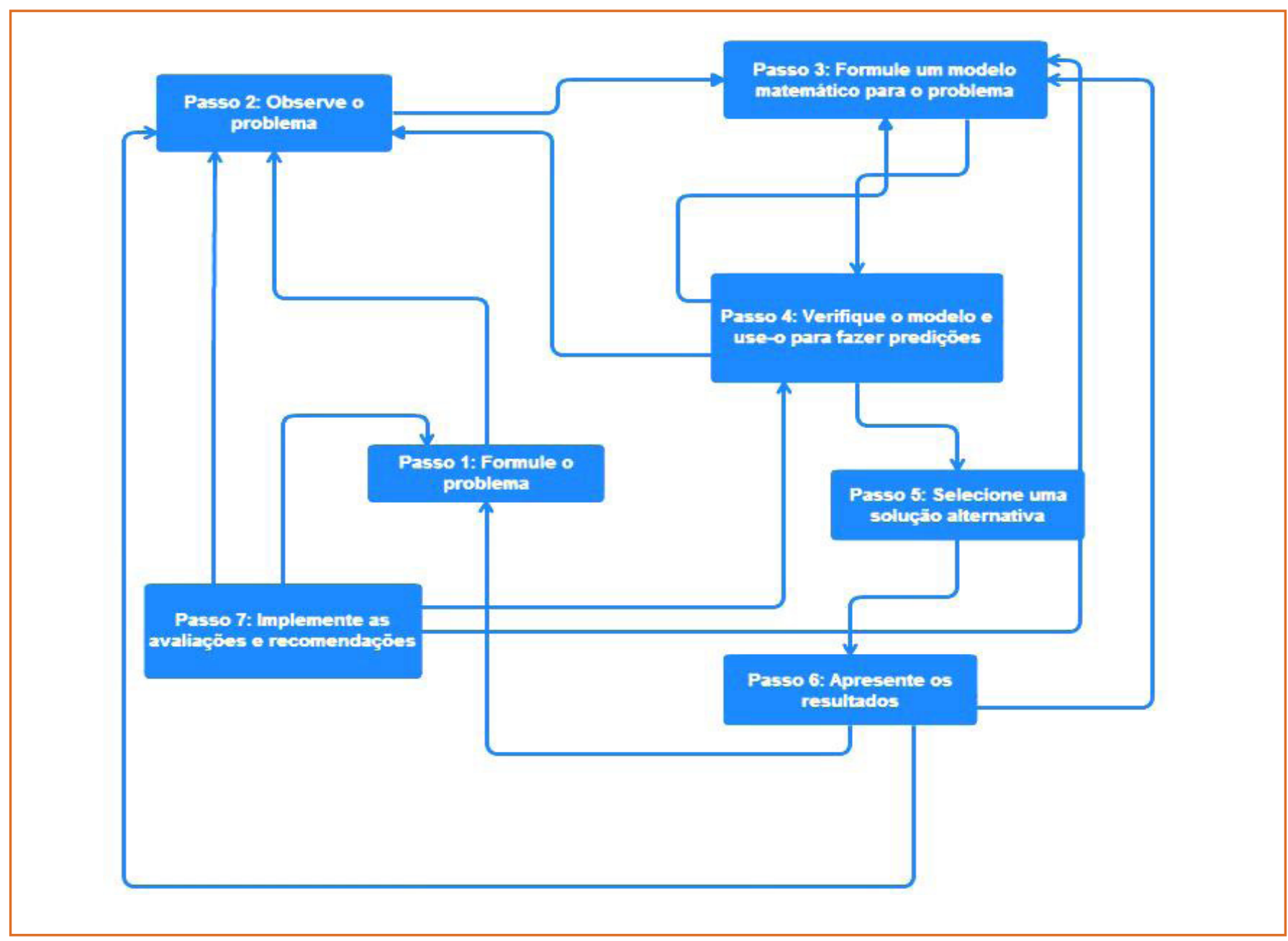

Fonte: Adaptado de Winston (1994)

A tomada de decisão (o processo de identificar um problema ou uma oportunidade e selecionar uma linha de ação para resolvê-lo) é um dos principais objetivos da pesquisa operacional. Quando estamos tratando do processo de otimização de planejamento de projetos podemos destacar algumas ferramentas de PO em especifico, conforme Davalos (2006) apresenta os mais importantes como sendo o PERT (Técnica de avaliação e controle de programas) e CPM (Caminho Crítico).

\subsection{PERT/CPM}

PERT/CPM é a integração de dois métodos para otimização de projetos, Em 1956, a Companhia Dupont de Nemours (EUA) desenvolveu o método CPM (Critical Path Method ou Método do Caminho Crítico) atraves de estudos para novas tecnicas de administração no setor de engenharia para o lançamento de novos produtos, enquanto o método PERT (Program Evaluation and Review Technique ou Técnica de Avaliação e Revisão de Programa) começou a ser utilizado pela Marinha dos EUA no início de 1959.

Para Moreira (2004), o planejamento através das técnicas Program Evalution and Review Technique (PERT) e Critical Path Metod (CPM) consiste em configurar o projeto através de um Diagrama de Rede onde se representam as atividades deste projeto e a ordem em que são efetuadas, tendo como objetivo definir o melhor programa possível de concepção/ fabricação de tal forma que os recursos sejam utilizados da melhor forma, evitando assim custos, desperdícios e atrasos de produção.

As atividades são representadas por setas que indicam 
as relações de correspondência entre os eventos ou acontecimentos importantes entre a operação, de modo que o conjunto mostre a seqüência entre todas as atividades do empreendimento que devem ser executadas. Junto de cada seta anota-se o nome e a duração e o custo estimado da atividade que ela representa (CUKIERMAN, 1978).

O quadro abaixo apresenta as características básicas para aplicação do método, Segundo Belchior (1974) apud Kienen (2000):

Quadro 1-Conceitos Básicos do Método PERT/CPM

\begin{tabular}{|c|c|c|c|}
\hline NOME & CONCEITO & $\begin{array}{l}\text { REPRESENTA- } \\
\text { ÇÃO GRÁFICA }\end{array}$ & EXEMPLO \\
\hline Projeto & $\begin{array}{l}\text { Conjunto de ações e } \\
\text { processos, envolvendo } \\
\text { recursos humanos, materiais } \\
\text { financeiros, etc., } \\
\text { organizados para a } \\
\text { realização de um objetivo, } \\
\text { concretamente definido, a } \\
\text { partir de uma situação inicial } \\
\text { conhecida ou } \\
\text { convencionada, chamada, } \\
\text { Operação Empreendimento }\end{array}$ & $\begin{array}{l}\text { Rede, diagra- } \\
\text { ma ou grafo }\end{array}$ & $\begin{array}{l}\text { Lançamento } \\
\text { de uma rede } \\
\text { de } \\
\text { abasteciment } \\
\text { o de águas }\end{array}$ \\
\hline Atividade & $\begin{array}{l}\text { É a identificação de uma } \\
\text { etapa de um projeto que } \\
\text { consome tempo e recursos, } \\
\text { estabelecida em nível } \\
\text { compativel ás necessidades } \\
\text { e possibilidades de sua } \\
\text { mensuração }\end{array}$ & $\begin{array}{l}\text { Em flechas ou } \\
\text { setas }\end{array}$ & $\begin{array}{l}\text { Serviço de } \\
\text { escavação }\end{array}$ \\
\hline Evento & $\begin{array}{l}\text { Início ou término de uma ou } \\
\text { mais atividades }\end{array}$ & Nó & $\begin{array}{l}\text { Início (ou } \\
\text { término) do } \\
\text { serviço de } \\
\text { escavação }\end{array}$ \\
\hline Atributo & $\begin{array}{l}\text { É toda característica } \\
\text { quantitativa específica de } \\
\text { uma atividade, indicando } \\
\text { qualquer dos recursos } \\
\text { necessários a sua efetivação } \\
\text { (exemplo: tempo, material, } \\
\text { mão-de-obra, equipamento, } \\
\text { etc) }\end{array}$ & $\begin{array}{l}\text { Em flechas ou } \\
\text { setas }\end{array}$ & $\begin{array}{l}3 \text { semanas } \\
\text { para } \\
\text { executar a } \\
\text { escavação }\end{array}$ \\
\hline
\end{tabular}

O uso do método PET/CPM traz consigo algumas vantagens dentre elas podemos citas: detalhamento das atividades, proporcionando suporte á decisão, Indicação de pontos criticos no projeto, proporcionam otimização de atividades podendo-as realizar de forma simultânea e maior visualização das atividades e como estão planejadas.

\section{METODOLOGIA}

A pesquisa desenvolveu-se fazendo uso dos documentos de planejamento da obra que foram disponibilizados pela construtora para a análise dos dados e informações necessárias para a construção da rede. Tais documentos correspondem aos de etapas da obra e suas necessidades e estimativas. 
Os dados que a empresa disponibilizou foram manipulados pelos pesquisadores juntamente com profissionais técnicos da construção civil para a construção da tabela e posteriormente da Rede Pert/ CPM.

4. Estudo de caso: Construção de uma casa térrea A empresa de construção civil utilizada para estudo de caso tem em seu acervo projetos de planejamento para casas térreas em quatro períodos diferenciados de acordo com a necessidade do cliente. Casas para 4, 6, 8 e 12 meses. Para o estudo foi escolhido o projeto da construção para 6 meses, uma estimativa de acordo com a construtora para 183 dias.

A documentação foi analisada e encontravam-se tarefas com atividades prioritárias sem necessidade, então elaborou-se uma tabela com as etapas nomeadas com duas letras aleatoriamente escolhidas para melhor visualização na rede PERT elaborada.

A duração para a execução da obra é de 183 dias, se cada atividade for realizada uma por vez. No entanto, existem atividades que podem ser realizadas simultaneamente, podendo com isso, reduzir a duração da execução da obra, trazendo resultados positivos para a empresa.

\subsection{MODELAGEM}

\subsection{FERRAMENTAS PARA EXECUÇÃO DA REDE} PERT/CPM

Para a construção da rede PERT/CPM é necessário a construção de uma tabela com as informações necessárias como representado no quadro abaixo: 
Quadro 2 - Tabela para Construção da Rede PERT/CPM

\begin{tabular}{|c|c|c|c|c|c|c|}
\hline $\begin{array}{c}\text { Atividade } \\
\text { (siglas) }\end{array}$ & Descrição & $\begin{array}{l}\text { Duração } \\
\text { (em dias) }\end{array}$ & $\begin{array}{c}\text { Atividades } \\
\text { Imediatamente } \\
\text { Antecessoras }\end{array}$ & $\begin{array}{c}\text { Atividades } \\
\text { Imediatamente } \\
\text { Posteriores }\end{array}$ & Início & Término \\
\hline SP & $\begin{array}{c}\text { Serviços } \\
\text { Preliminares }\end{array}$ & 12 & Nenhuma & FU & 0 & 12 \\
\hline FU & Fundações & 9 & $\mathrm{SP}$ & $\mathrm{FU}$ & 13 & 22 \\
\hline SE & Super Estrutura & 14 & $\mathrm{FU}$ & $V G$ & 23 & 37 \\
\hline AV & $\begin{array}{l}\text { Alvenaria de } \\
\text { Vedação }\end{array}$ & 8 & VG & $\mathrm{EQ}, \mathrm{IH}$ & 45 & 53 \\
\hline VG & Vergas & 6 & SE & AV & 38 & 44 \\
\hline $\mathrm{CB}$ & Cobertura & 8 & $\mathrm{IE}$ & PA & 54 & 62 \\
\hline $\mathrm{IH}$ & $\begin{array}{l}\text { Instalação } \\
\text { Hidráulica }\end{array}$ & 13 & AV & IE & 54 & 67 \\
\hline $\mathrm{IE}$ & $\begin{array}{c}\text { Instalação } \\
\text { Elétrica }\end{array}$ & 17 & $\mathrm{HH}$ & $\mathrm{CH}, \mathrm{CB}$ & 68 & 85 \\
\hline $\mathrm{CH}$ & $\begin{array}{c}\text { Chapisco e } \\
\text { Emboço }\end{array}$ & 18 & $\mathrm{IE}$ & TE & 86 & 104 \\
\hline TE & Teto & 8 & $\mathrm{CH}$ & $A C$ & 105 & 113 \\
\hline$E Q$ & Esquadrias & 7 & AV & VD & 54 & 61 \\
\hline PI & \begin{tabular}{|c|} 
Pisos- \\
Regulamentação
\end{tabular} & 9 & $\mathrm{IE}$ & AP & 86 & 95 \\
\hline$A C$ & $\begin{array}{c}\text { Acabamento da } \\
\text { Parede }\end{array}$ & 15 & TE & PT & 114 & 129 \\
\hline $\mathrm{AP}$ & $\begin{array}{l}\text { Acabamento } \\
\text { Piso }\end{array}$ & 9 & $\mathrm{Pl}$ & PT & 96 & 105 \\
\hline AÇ & $\begin{array}{c}\text { Louças, } \\
\text { aparelhos e } \\
\text { metais }\end{array}$ & 6 & VD, PT & PA & 153 & 159 \\
\hline PT & Pintura & 8 & $\mathrm{AC}$ & LÇ & 130 & 138 \\
\hline VD & Vidros & 6 & $E Q$ & LÇ & 62 & 68 \\
\hline PA & Paisagismo & 6 & CB, LÇ & LF & 160 & 166 \\
\hline \multirow[t]{2}{*}{ LF } & Limpeza Final & 4 & PA & Nenhuma & 167 & 171 \\
\hline & Total & 183 & & & & \\
\hline
\end{tabular}




\subsection{REDE PERT}

A rede foi elaborada com diferentes rotas de acordo com as dependencias das atividades.

Figura 2 - Rede PERT/CPM da obra

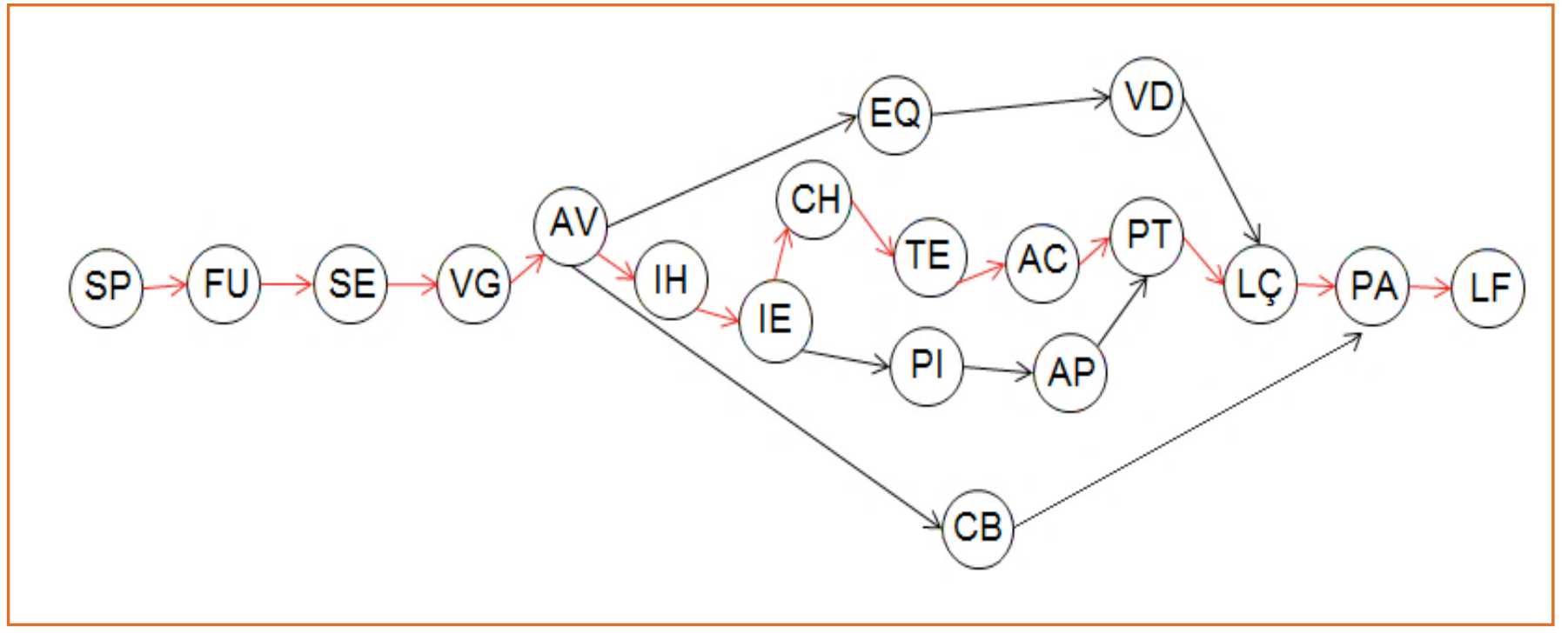

\subsection{CAMINHO CRÍTICO}

Quadro 3 - Identificação dos caminhos e seus comprimentos

\begin{tabular}{|c|c|}
\hline Caminho & Comprimento (dias) \\
\hline $\mathrm{SP}+\mathrm{FU}+\mathrm{SE}+\mathrm{VG}+\mathrm{AV}+\mathrm{EQ}+\mathrm{VD}+\mathrm{LC}+\mathrm{PA}+\mathrm{LF}$ & $12+9+14+6+8+7+6+6+6+4=78$ \\
\hline $\mathrm{SP}+\mathrm{FU}+\mathrm{SE}+\mathrm{VG}+\mathrm{AV}+\mathrm{IH}+\mathrm{IE}+\mathrm{CH}+\mathrm{TE}+\mathrm{AC}+\mathrm{PT}+\mathrm{LC}+\mathrm{PA}+\mathrm{LF}$ & $12+9+14+6+8+13+17+18+8+15+8+6+6+4=144$ \\
\hline $\mathrm{SP}+\mathrm{FU}+\mathrm{SE}+\mathrm{VG}+\mathrm{AV}+\mathrm{IH}+\mathrm{IE}+\mathrm{PI}+\mathrm{AP}+\mathrm{PT}+\mathrm{LC}+\mathrm{PA}+\mathrm{LF}$ & $12+9+14+6+8+13+14+9+9+8+6+6+4=121$ \\
\hline $\mathrm{SP}+\mathrm{FU}+\mathrm{SE}+\mathrm{VG}+\mathrm{AV}+\mathrm{CB}+\mathrm{PA}+\mathrm{LF}$ & $12+9+14+6+8+8+6+8=67$ \\
\hline
\end{tabular}

Na rede PERT/CPM podem-se identificar mais de uma rota do início até o fim do projeto. O comprimento (neste caso, em dias)éa soma das durações das atividades que compõem a rota. O caminho com maior comprimento, a segunda alternativa (SP+FU+SE+VG+AV+IH+ $\mathrm{IE}+\mathrm{CH}+\mathrm{TE}+\mathrm{AC}+\mathrm{PT}+\mathrm{LC}+\mathrm{PA}+\mathrm{LF})$ é o caminho crítico, uma vez que todos os demais caminhos deverão alcançar o nó até o fim antes do caminho crítico.

\subsubsection{CAMINHO CRÍTICO IDENTIFICADO}

A rota com as atividades gargalos foi identificada na rede pelas setas vermelhas, estas devem ter atenção redobrada dos responsáveis pela obra, uma vez que a não entrega das mesmas no período previsto, geralmente cominam no atraso de todo o projeto. 


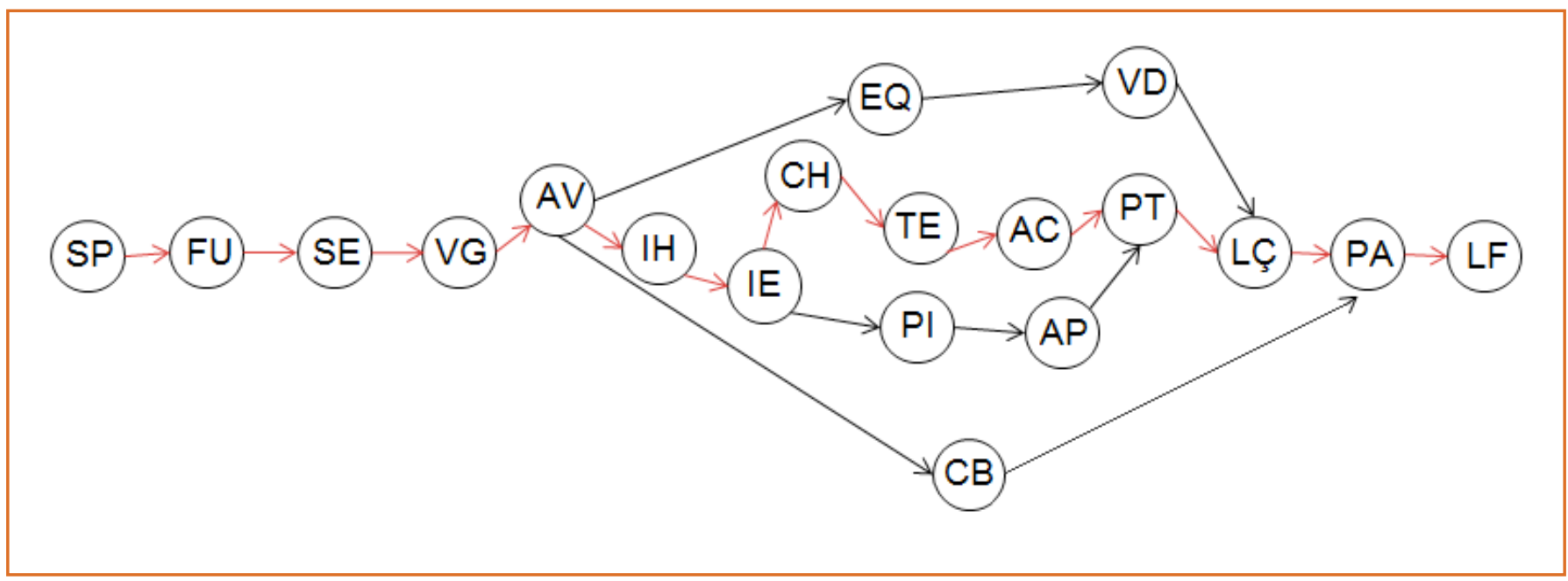

As atividades existentes nos outros caminhos não precisam necessariamente de tanta precaução como as atividades críticas, uma vez que as mesmas ainda tem um período denominado folga e se sofrerem algum atraso poderão ou não atrasar a duração do projeto.

\section{RESULTADOS}

Após análise foi observado que a construtora seguia etapas de maneira equivocada no que se diz respeito à importância do tempo para cada atividade. De acordo com a análise de documento e cronograma, o projeto tinha planejamento estimado para 183 dias, porém, após a modelagem com tabelas e a rede PERT/CTM, organizado de maneira a otimizar o tempo de execução das atividades fazendo uso de seus recursos disponíveis, no caso, mão de obra e tempo.

O caminho crítico da rede resultou em 144 dias, ou seja, há tempos o mesmo projeto foi executado com 39 dias além do necessário, de acordo com a rede que foi reorganizada com as dependencia das atividades disponíveis no documento de etapas do projeto.

\section{CONSIDERAÇÕES}

A modelagem da Rede PERT/CPM se mostrou bastante eficiente e útil para a execução e planejamento do projeto, dando uma nova visão para os responsáveis pela obra, mostrando principalmente que alguns passos podem ser dados sem mais precaução e outros com mais prudência. Puderam-se constatar as atividades gargalo e o foco do projeto se volta para as mesmas, buscando evitar atrasos e assim melhorando a eficiência no trabalho.

\section{REFERÊNCIAS}

[1] DÁVALOS, RICARDO VILLARROEL. Uma abordagem do ensino de pesquisa operacional baseada no uso de recursos computacionais. In: Encontro Nacional de Engenharia de Produção, 22., 2002, Curitiba. Anais. Curitiba, 2002.

[2] RAVINDRAN, A., PHILLIPS, D.T. \& SOLBERG, J.J. Operations Research, Principles and Practice, 2nd Ed.. New York: John Wiley, 1987.

[3] SILVA, E. M.; SILVA, E. M.; GONÇALVES, V.; MUROLO, A. C. Pesquisa Operacional: programação linear. 3 Ed. São Paulo: Atlas, 1998.

[4] TIWARI, NIRMAL KUMAR; SANDILYA, SHISHIR KUMAR. Operations Research. New Delhi: Pretice-Hall, 2006.

[5] WINSTON, W.L. Operations Research, Applications and Algorithm, 3rd Ed..Belmont (CA), Wadsworth Publishing Company, 1994.

[6] BELCHIOR, PROCÓPIO G. O.. Métodos de caminho crítico (PERT/CPM) na administração de projetos. Rio de Janeiro : Ed. Americana, 1974.

[7] CUKIERMAN, S. S..O modelo PERT/CPM aplicado a projetos . Rio de Janeiro : Rio, 1978.

[8] MOREIRA, D. A. Administração da Produção e Operações. São Paulo: Pioneira Thomson Learning, 2004.

[9] KIENEN, A. Protótipo de uma ferramenta de software baseada na metodologia PERT/CPM para o planejamento de projeto de desenvolvimento de sistemas. 2000. 74 p. Monografia (Bacharelado) - Universidade Regional de Blumenau. Blumenau, 2000. Internet. Disponível em: Acesso em: 17 de outubro de 2012. 
[10] PEREIRA, S.R.D.. Planejamento para o início de obras em edificações de múltiplos pavimentos - Universidade Federal de São Carlos. São Carlos, 2012.. 


\title{
CAPÍTULO 11
}

\section{PROBLEMA DE CARREGAMENTO DE MÚLTIPLOS CONTÊINERES HETEROGÊNEOS COM RESTRIÇÃO ADICIONAL DE SEPARAÇÃo DE ITENS: UMA FORMULAÇÃO MATEMÁTICA}

\author{
Cleder Marcos Schenekemberg \\ Cassius Tadeu Scarpin \\ José Eduardo Pécora Junior \\ Alexandre Checoli Choueiri \\ Deidson Vitorio Kurpel
}

Resumo: Neste trabalho apresenta-se uma proposta de resolução para o Problema de Carregamento de Múltiplos Contêineres Heterogêneos. Este problema consiste em empacotar caixas retangulares ortogonalmente e sem sobreposição dentro de contêineres, de modo a maximizar a ocupação do espaço disponível. Com base em propostas da literatura, este trabalho visa apresentar uma formulação matemática para o problema, por meio de um modelo de Programação Linear Inteira 0-1, que permite assegurar a separação de determinados itens em contêineres distintos. Embora comum em situações reais, esta restrição prática é raramente tratada em trabalhos correlatos. Testes computacionais com instâncias da literatura foram efetuados para avaliar os modelos gerados. Os resultados obtidos mostram que, apesar da formulação proposta se limitar a resolver problemas relativamente simples, a mesma descreve adequadamente as considerações tratadas.

Palavras chave: Formulação Matemática, Problema de Carregamento de Contêiner, Restrição de Separação de Itens. 


\section{INTRODUÇÃO}

Com a globalização econômica e o fluxo constante de mercadorias sendo transportada pelos mais variados modais e dispositivos de transporte, a otimização dos recursos disponíveis mostra ser um fator decisivo e, até mesmo, essencial na sobrevivência das organizações. O planejamento estratégico do transporte de matériasprimas e produtos acabados, ou ainda, a ausência de planejamento, pode impactar diretamente no custo associado às mercadorias destinadas aos consumidores.

Neste sentido, este trabalho visa contribuir com uma proposta de resolução para um tipo clássico de Problema de Corte e Empacotamento (PCE), conhecido como Problema de Carregamento de Contêiner (Container Loading Problem $\square$ CLP). O CLP engloba inúmeras aplicações práticas, tendo diferentes objetivos e restrições de carregamento. Para resolvê-lo, busca-se dispor caixas retangulares ortogonalmente dentro de contêineres, de tal modo que o volume (valor) da carga seja maximizado, ou em outros casos, que a quantidade de contêineres necessários para o carregamento seja minimizado.

Segundo Bischoff e Ratcliff (1995) um método de resolução para ser verdadeiramente útil para o CLP, deve levar em consideração, além dos objetivos primários, certas considerações práticas comumente encontradas em situações reais. Estabilidade da carga, restrição de limitação de peso dentro do contêiner, prioridades de envio, restrição de manuseio e separação de itens, são algumas das doze restrições elencadas pelos autores que podem ser incorporadas no carregamento da carga.

O objetivo deste trabalho é apresentar uma proposta de formulação matemática para o CLP, com base em um modelo de Programação Linear Inteira da literatura, capaz de considerar o carregamento de múltiplos contêineres e a restrição prática de separação de itens. Segundo Bortfeldt e Wäscher (2013), apesar do aumento significativo no número de publicações na literatura especializada, ainda há considerações práticas pouco ou raramente abordadas, como, por exemplo, a restrição prática tratada neste trabalho.

Algumas formulações matemáticas para o CLP podem ser obtidas na literatura. Por exemplo, pode-se citar Tsai, Malstrom e Kuo (1993), Mohanty, Mathur e Ivancic (1994), Chen, Lee, e Shen (1995), Hifi et al (2010) e Junqueira, Morabito e Yamashita (2012). Embora, cabe destacar que algumas destas abordagens se limitam quanto à consideração de exigências práticas. De modo alternativo aos modelos matemáticos, é comum encontrar outras metodologias de resolução para o CLP. Algoritmos heurísticos e metaheurísticos podem ser obtidos, por exemplo, em Gehring e Bortfeldt (1997), Pisinger (2002), Eley (2003) e Altarazi (2013). Da mesma forma, métodos exatos, de aproximação e de busca em árvore podem ser encontrados em Mizawa e Wakabayashi (1997), Martello, Pisinger e Vigo (2000), Oliveira e Morabito (2006) e Ren, Tian e Sawaragi (2011).

Este trabalho está organizado da seguinte forma: na seção 2, o problema de carregamento de múltiplos contêineres heterogêneos com restrição de separação de itens é brevemente explicado, juntamente com um modelo de Programação Linear Inteira para descrevêlo; na seção 3, apresenta-se um procedimento heurístico capaz de reduzir a complexidade da formulação proposta; na seção 4, os resultados computacionais obtidos na avaliação dos modelos são apresentados e analisados; finalmente, na seção 5 são apresentadas as principais conclusões alcançadas, bem como perspectivas para trabalhos futuros.

\section{FORMULAÇÃO MATEMÁTICA}

Nesta seção, inicialmente busca- se descrever brevemente o Problema de Carregamento de Contêiner. Em seguida, com base em um modelo da literatura, apresenta-se uma proposta de formulação matemática para o carregamento de múltiplos contêineres heterogêneos. Por fim, a consideração prática de separação de itens é formulada como restrição do modelo matemático proposto.

\subsection{DESCRIÇÃO DO PROBLEMA}

O CLP é um caso particular dos Problemas de Corte e Empacotamento. Os PCE's, como muitos dos problemas de natureza combinatória, abrangem uma variedade de problemas caracterizados por 
uma estrutura comum, que consistem em combinar unidades menores, denominadas itens (peças, caixas, entre outras) dentro de unidades maiores, chamadas de objetos (chapas, contêineres, entre outras), com a finalidade de otimizar certos objetivos prédeterminados. Esta combinação, dentro de suas mais variadas versões, pode determinar o padrão de corte de peças para composição de itens encomendados, como também o empacotamento de caixas em contêineres.

Genericamente, os Problemas de Carregamento de Contêiner, de acordo com a sua designação, podem ser divididos em dois tipos de subproblemas. Nos primeiros, denominados problemas de minimização das entradas, o espaço de armazenagem é suficiente para a alocação de todas as caixas, visto que o número de contêineres é irrestrito. Logo, busca-se minimizar o número de contêineres necessários para carregar todos os itens disponíveis. Já os demais, chamados problemas de maximização das saídas, o espaço de um número limitado de contêineres não é suficiente para armazenar todos os itens. O objetivo é, então, determinar um subconjunto de caixas que maximiza a utilização do volume dos contêineres ou valor associado à carga.

Uma classificação mais adequada para os CLP's pode ser obtida de acordo com a tipologia de Wäscher, Hau $\square$ ner e Schumann (2007) proposta para categorizar os PCE's. Os autores, por meio de combinações de critérios básicos, como dimensionalidade, variedade dos itens, variedade dos objetos, forma dos itens e tipo de designação (minimização ou maximização), classificam os mais variados tipos de PCE's, e consequentemente os CLP's, em problemas do tipo básico, intermediário e refinado.

Este trabalho aborda o carregamento de múltiplos contêineres distintos. Com base na tipologia de Wäscher, Hau $\square$ ner e Schumann (2007), este problema pode ser dividido em dois novos subproblemas de acordo com a variedade dos itens. O primeiro, chamado Multiple Heterogeneous Knapsack Problem (MHKP), visa empacotar um subconjunto de caixas fortemente heterogêneas em um conjunto de contêineres heterogêneos, isto é, contêineres não idênticos, tal que o valor (volume) total das caixas carregadas seja maximizado. Já o segundo, conhecido como Multiple Heterogeneous Large Object Placement Problem (MHLOPP), tem por objetivo empacotar um subconjunto de caixas fracamente heterogêneas em um conjunto de contêineres heterogêneos, tal que o valor (volume) total das caixas carregadas seja maximizado.

\subsection{MODELO MATEMÁTICO}

Em sua abordagem ao CLP, Junqueira, Morabito e Yamashita (2012) apresentam um modelo matemático baseado em Programação Linear Inteira para o carregamento de um único contêiner. Na sequência deste trabalho, por meio de adaptações, esta formulação matemática será estendida de forma a considerar o carregamento de múltiplos contêineres heterogêneos (não idênticos).

Considere tipos de contêineres com largura, comprimento, altura e disponibilidade (onde ), que devem ser carregados com tipos de caixas distintas. Cada caixa do tipo, , que pode ser alocada no interior de um dos contêineres do tipo, tem largura, comprimento, altura e volume (ou valor associado à caixa). Existe um total de caixas do tipo que podem ser arranjadas nos contêineres, logo, o problema é restrito quanto ao número de itens disponíveis para carregamento.

Figura 1 - Uma caixa do tipo i alocada no vértice (p, q, r) de um contêiner do tipo $\mathrm{k}$

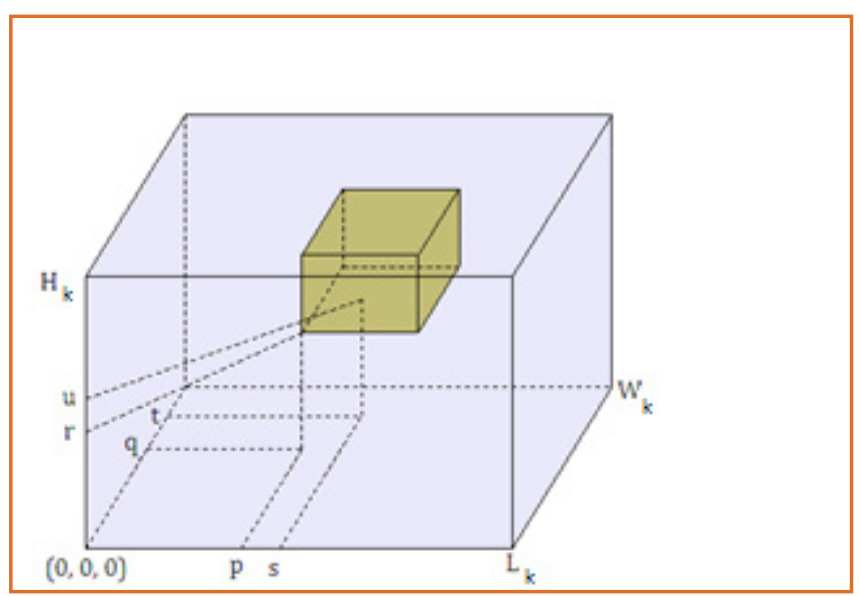

Tomando o sistema de coordenadas cartesiano, seja o vértice inferior frontal esquerdo de uma caixa qualquer 
no interior de um contêiner do tipo (veja Figura 1). Os conjuntos abaixo, adaptados de Junqueira, Morabito e Yamashita (2012), indicam as possíveis posições que uma caixa (onde ) pode assumir em relação às dimensões do(s) contêiner(es) do tipo. Ressalta-se que os itens possuem orientação fixa, isto é, a largura, comprimento e altura das caixas devem ser alocadas paralelamente às respectivas dimensões do contêiner designado, impossibilitando o movimento de rotação das caixas dentro dos contêineres.

$X_{k}=\left\{p \mid 0 \leq p \leq L_{k}-\min _{i}\left(l_{i}\right), \quad p \in \mathbb{Z}, \quad i=1, \ldots, m\right\}$

$Y_{k}=\left\{q \mid 0 \leq q \leq W_{k}-\min _{i}\left(w_{i}\right), \quad q \in \mathbb{Z}, \quad i=1, \ldots, m\right.$.

$Z_{k}=\left\{r \mid 0 \leq r \leq H_{k}-\min _{i}\left(h_{i}\right), \quad r \in \mathbb{Z}, \quad i=1, \ldots, m\right\}$

Considere ainda os conjuntos:

$$
\begin{aligned}
& X_{i k}=\left\{p \in X_{k} \mid 0 \leq p \leq L_{k}-l_{i}\right\} \\
& Y_{i k}=\left\{q \in Y_{k} \mid 0 \leq q \leq W_{k}-w_{i}\right\} \\
& Z_{i k}=\left\{r \in Z_{k} \mid 0 \leq r \leq H_{k}-h_{i}\right\}
\end{aligned}
$$

Embora os elementos dos conjuntos acima sejam restritos a valores inteiros, essa condição pode ser facilmente relaxada. As variáveis de decisão do modelo são do tipo binário, definidas da seguinte maneira:

$$
x_{i j k p q r}=\left\{\begin{array}{cc}
1, & \text { Se uma caixa do tipo } i \text { tem seu vértice inferior frontal } \\
- & \text { esquerdo no ponto }(p, q, r) \text { do } j-\text { ésimo contêiner do tipo } k, \\
0 & \text { tal que: } 0 \leq p \leq L_{k}-l_{i}, \quad 0 \leq q \leq W_{k}-w_{i}, \\
0, & 0 \leq r \leq H_{k}-h_{i}, \quad 1 \leq j \leq d_{k} ; \\
0 & \text { Caso contrário }
\end{array}\right.
$$

A seguir apresenta-se a formulação matemática para o problema com base no modelo de carregamento de um único contêiner de Junqueira, Morabito e Yamashita (2012). Por simplicidade, será mantida a notação original definida pelos autores. O modelo matemático para o Problema de Carregamento de Múltiplos Contêineres Heterogêneos, que será chamado de modelo base no decorrer deste trabalho, é obtido da seguinte maneira:

\section{Maximizar}

$$
Z=\sum_{k=1}^{c} \sum_{j=1}^{d_{k}} \sum_{i=1}^{m} \sum_{p \in X_{i k}} \sum_{q \in Y_{i k}} \sum_{r \in Z_{i k}} v_{i} \cdot x_{i j k p q r}
$$

Sujeito a

$\sum_{i=1}^{m} \sum_{\left\{p \in X_{i k} \mid s-l_{i}+1 \leq p \leq s\right\}} \sum_{\left\{q \in Y_{i k} \mid t-w_{i}+1 \leq q \leq t\right\}} \sum_{\left\{r \in Z_{i k} \mid u-h_{i}+1 \leq r \leq t\right\}} x_{i j k p q r} \leq 1$,

Onde $s \in X_{k}, t \in Y_{k}, u \in Z_{k}, \forall k=1, \ldots, c$ e $\forall j=1, \ldots, \mathrm{d}_{\mathrm{k}}$

$\sum_{k=1}^{c} \sum_{j=1}^{d_{k}} \sum_{p \in X_{i k}} \sum_{q \in Y_{i k}} \sum_{r \in Z_{i k}} x_{i j k p q r} \leq b_{i}, \quad \forall i=1, \ldots, m$

No modelo descrito por (8) - (11) , a função objetivo (8) visamaximizar ovolume(valor) das caixas empacotadas nos contêineres disponíveis. As restrições (9) garantem que duas ou mais caixas não se sobreponham, isto é, que não ocupem pontos internos em comum dentro de um mesmo contêiner. As expressões (10) impedem que caixas sejam carregadas além da disponibilidade máxima permitida. Por fim, em (11) define-se o domínio das variáveis de decisão.

\subsection{RESTRIÇÃO PRÁTICA DE SEPARAÇÃO DE ITENS}

Em muitos problemas práticos é frequentemente desejável que caixas de dois (ou mais) tipos sejam alocadas em contêineres distintos, por exemplo, produtos alimentícios e agrotóxicos. Embora com grande aplicabilidade em situações reais de carregamento de contêiner, esta restrição adicional não tem recebido muita atenção na literatura especializada. Segundo Bortfeldt e Wäscher (2013), apenas Eley (2003), por meio de um algoritmo heurístico, aborda esta exigência prática.

A proposta de formulação matemática apresentada neste trabalho visa assegurar a separação de diversos tipos de itens em contêineres distintos. Mais precisamente, garantir que para cada contêiner disponível seja empacotado no máximo um dos tipos de caixas do grupo de itens que se deseja separar.

Para isso, define-se um conjunto de tipos de caixas que devem ser separadas. Este conjunto, que será denotado por, é formado apenas pelos tipos de itens, entre os tipos disponíveis, que devem ser 
obrigatoriamente alocados em contêineres distintos. Cabe destacar que os demais tipos de caixas, isto é, que não pertençam ao conjunto, podem ser empacotadas simultaneamente nos contêineres disponíveis.

A formulação matemática da restrição prática de separação de itens é dada por:

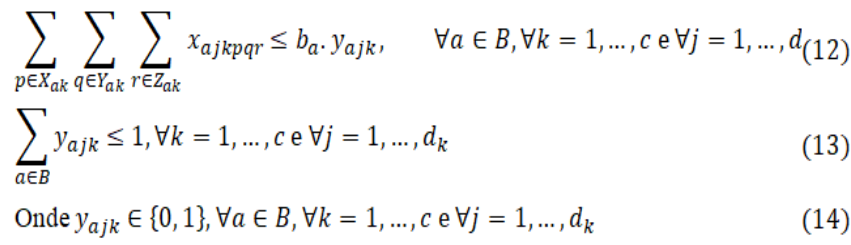

De acordo com (14), novas variáveis são definidas que, combinadas com (13), asseguram, por meio de (12) , que no máximo um tipo de caixa do conjunto pode ser carregado no $j$ - ésimo contêiner do tipo Observe que, como definido em (13), para o $j$ ésimo contêiner do tipo $k_{\text {. }}$, apenas uma variável binária pode assumir o valor unitário, sendo assim, indicando o único tipo de caixa do conjunto $B$ que pode ser alocada neste contêiner específico.

\section{ALGORITMO GERADOR DE NÚMEROS ÚTEIS}

A modelagem matemática apresentada na seção anterior, que descreve o modelo base e a restrição de separação de itens, foi formulada de acordo com os conjuntos de pontos candidatos a vértice das caixas, isto é, os conjuntos (1) - (6). . No entanto, uma vez que estes conjuntos possuam todas as possíveis posições que uma caixa pode assumir ao longo dos eixos de um contêiner, apenas problemas meramente realísticos podem ser resolvidos dentro de um limite de tempo aceitável. Junqueira, Morabito e Yamashita (2012) descrevem esta limitação da modelagem do problema, onde buscam minimizar a cardinalidade destes conjuntos por meio dos padrões normais e seções cônicas de Herz (1972) e Christofides e Whitlock (1977).

O Algoritmo Gerador de Números Úteis (AGNU) foi elaborado com base na heurística proposta por Carnieri, Mendoza e Gavinho (1994) para abordar o problema de corte bidimensional guilhotinado de chapas de madeira. Os autores apresentam um procedimento que permite a geração de apenas um grupo potencialmente útil de valores que devem ser avaliados como possíveis pontos de corte, eliminando pontos desnecessários na busca pela solução ótima. Este procedimento, em termos dos pontos gerados, é equivalente a metodologia utilizada por Junqueira, Morabito e Yamashita (2012), diferindo apenas no processo de geração dos valores.

Para descrever o algoritmo, considere um contêiner genérico do tipo $g$ com dimensões $\left(L_{g}, W_{g}, H_{g}\right)$, que deve ser carregado com tipos de caixas de diferentes tamanhos, ou seja, $\left(l_{i}, w_{i}, h_{i}\right)$, para $i=1, \ldots, m$. Em sua formulação original, o AGNU comporta apenas o caso unidimensional, sendo assim, o algoritmo deve ser reaplicado para cada dimensão específica de cada tipo de contêiner. Para efeito de apresentação, optouse pelo eixo $X$ do contêiner do tipo $g$, entretanto, os procedimentos descritos no algoritmo podem ser diretamente estendidos aos demais eixos do contêiner.

Figura 2 - Pseudocódigo do algoritmo gerador de números úteis

\begin{tabular}{|ll} 
Passo 1. & Calcule $\beta=\min \left\{l_{i}, i=1,2, \ldots, m\right\}$. Defina $X_{g}^{(m+1)}=F^{(m+1)}=\{0\}$, e faça \\
& $k=m$. \\
Passo 2. & Calcule $F^{(k)}=\left\{x+\varepsilon \cdot l_{k} \mid x \in X_{g}^{(k+1)}, \varepsilon=1,2, \ldots\right.$, e $\left.L_{g}-\left(x+\varepsilon . l_{k}\right) \geq \beta\right\}$. \\
Passo 3. & Faça $X_{g}^{(k)}=F^{(k)} \cup X_{g}^{(k+1)}$. Remova os números equivalentes de $X_{g}^{(k)}$. \\
Passo 4. & Se $k>1$, faça $k \leftarrow k-1$ e volte ao Passo 2. Caso contrário, pare. O conjunto \\
& $X_{g}^{(1)}$, ou simplesmente $X_{g}$, contém a lista dos números úteis do contêiner do \\
& tipo g gerados a partir do eixo $X$.
\end{tabular}


No pseudocódigo do algoritmo, descrito na Figura 2, o Passo 1 determina o menor comprimento entre todas as caixas disponíveis $(\beta)$, além disso, o primeiro número útil é definido como a coordenada nula do eixo $X$. No Passo 2, a partir da caixa do tipo $k$ e dos números úteis determinados, devem ser obtidos os pontos de vértices ao longo de $\mathrm{L}_{\mathrm{g}}$, adicionando $\mathcal{E}$ comprimentos de caixa $(\varepsilon=1,2, \ldots)$, desde que o tamanho remanescente do contêiner seja suficiente para posicionar uma caixa de menor comprimento $(\beta)$, obtido no Passo 1). Os números úteis obtidos são adicionados ao conjunto $X_{g}^{(k)}$, removendo os elementos repetidos (Passo 3). O critério de parada do algoritmo é satisfeito quando $\mathrm{k}=1$, onde o conjunto $X_{g}^{(1)}\left(X_{g}\right)$ é composto pelos números úteis do comprimento do contêiner.

Para exemplificar a aplicação do AGNU, considere um contêiner com dimensões $\left(L_{g}, W_{g}, H_{g}\right)=(20,15,15)$ , que deve ser carregado com três tipos de caixas: $\left(l_{1}, w_{1}, h_{1}\right)=(7,5,3),\left(l_{2}, w_{2}, h_{2}\right)=(5,6,5)$ e $\left(l_{3}, w_{3}, h_{3}\right)=(8,6,3)$.

Após a execução do algoritmo, os seguintes conjuntos de números úteis são gerados:

$X_{g}=\{0 ; 5 ; 7 ; 8 ; 10 ; 12 ; 13 ; 14 ; 15\}$

$Y_{g}=\{0 ; 5 ; 6 ; 10\}$

$Z_{g}=\{0 ; 3 ; 5 ; 6 ; 8 ; 10 ; 11 ; 12\}$

Em contrapartida, abaixo são apresentados os conjuntos gerados sem o uso do AGNU, isto é, pela definição (1) - (3):

$X_{g}=\{0 ; 1 ; 2 ; 3 ; 4 ; 5 ; 6 ; 7 ; 8 ; 9 ; 10 ; 11 ; 12 ; 13 ; 14 ; 15\}$

$Y_{g}=\{0 ; 1 ; 2 ; 3 ; 4 ; 5 ; 6 ; 7 ; 8 ; 9 ; 10\}$

$Z_{g}=\{0 ; 1 ; 2 ; 3 ; 4 ; 5 ; 6 ; 7 ; 8 ; 9 ; 10 ; 11 ; 12\}$

Com base na cardinalidade dos conjuntos (15) (17) e (18) - (20), fica evidente que um modelo gerado com o uso do AGNU, deve apresentar um número consideravelmente menor de restrições e variáveis binárias. No presente exemplo, a primeira formulação seria composta por variáveis binárias e restrições de não sobreposição, enquanto que, sem o uso do AGNU, este mesmo modelo seria formado por e, respectivamente. Desta forma, a utilização do AGNU na geração dos modelos pode levar a significativos ganhos de desempenho do método de solução empregado, visto que permite gerar modelos substancialmente menores.

\section{TESTES COMPUTACIONAIS}

Nesta seção são apresentados os resultados obtidos com os experimentos computacionais realizados. Os modelos foram gerados com base em um algoritmo em linguagem de programação Microsoft Visual Studio 2012@ (versão 11.0.50727.1) e o solver CPLEX@ Interactive Optimizer (versão 12.6.0.0), com parâmetros default, foi utilizado para resolvê-los. Os testes foram efetuados em um computador com sistema operacional Microsoft Windows 8 (64 bits), processador Intel@ CoreTM i5-4200U CPU @ 1,60HZ e memória RAM de 8GB. Um limite de tempo de segundos (24 horas) foi estabelecido para a execução dos testes.

Para avaliar os modelos os seguintes cenários foram considerados:

a) Cenário 1 (C-1): Modelo definido pelas expressões (8) - (11), gerado sem o uso do AGNU e sem restrição adicional;

b) Cenário 2 (C-2): Modelo definido pelas expressões (8) - (11), gerado com o uso do AGNU e sem restrição adicional;

c) Cenário 3 (C-3): Modelo definido pelas expressões (8) - (14), gerado com o uso do AGNU e com restrição adicional de separação de itens.

Os testes foram efetuados com os conjuntos de dados de Mohanty, Mathur e Ivancic (1994) conforme Tabela 1. 


\begin{tabular}{|c|c|c|c|c|c|c|c|c|c|c|c|}
\hline \multirow{2}{*}{$\begin{array}{l}\text { Conj. } \\
\text { de }\end{array}$} & \multicolumn{6}{|c|}{ Caixas } & \multicolumn{5}{|c|}{ Contêineres } \\
\hline & $i$ & $b_{i}$ & $l_{i}$ & $w_{i}$ & $\boldsymbol{h}_{\boldsymbol{i}}$ & $c_{i}$ & $k$ & $d_{k}$ & $L_{k}$ & $W_{k}$ & $\boldsymbol{H}_{k}$ \\
\hline \multirow{3}{*}{1} & 1 & 20 & 2 & 6 & 8 & 1,0 & 1 & 2 & 10 & 6 & 16 \\
\hline & 2 & 50 & 8 & 4 & 10 & 1,5 & 2 & 2 & 14 & 14 & 14 \\
\hline & 1 & 45 & 8 & 16 & 4 & 1,4 & 1 & 5 & 20 & 16 & 20 \\
\hline \multirow{4}{*}{2} & 2 & 60 & 8 & 8 & 8 & 1,0 & 2 & 5 & 24 & 12 & 16 \\
\hline & 3 & 50 & 8 & 12 & 12 & 1,2 & 3 & 5 & 20 & 8 & 16 \\
\hline & 4 & 25 & 12 & 4 & 4 & 1,0 & & & & & \\
\hline & 1 & 35 & 10 & 5 & 5 & 1,7 & 1 & 1 & 20 & 15 & 25 \\
\hline \multirow[t]{3}{*}{3} & 2 & 40 & 5 & 15 & 10 & 1,0 & 2 & 2 & 15 & 15 & 20 \\
\hline & 3 & 28 & 5 & 15 & 15 & 1,5 & 3 & 1 & 45 & 20 & 20 \\
\hline & 1 & 50 & 36 & 28 & 24 & 1,4 & 1 & 5 & 60 & 40 & 72 \\
\hline \multirow{2}{*}{4} & 2 & 60 & 40 & 32 & 20 & 1,0 & 2 & 5 & 40 & 36 & 52 \\
\hline & 1 & 25 & 15 & 20 & 25 & 2,5 & 1 & 3 & 35 & 30 & 20 \\
\hline \multirow[t]{3}{*}{5} & 2 & 30 & 10 & 15 & 10 & 1,0 & 2 & 3 & 35 & 35 & 40 \\
\hline & 3 & 40 & 20 & 25 & 35 & 2,0 & 3 & 2 & 35 & 25 & 40 \\
\hline & 1 & 28 & 18 & 10 & 8 & 2,0 & 1 & 2 & 24 & 20 & 24 \\
\hline \multirow[t]{3}{*}{6} & 2 & 37 & 12 & 14 & 10 & 1,2 & 2 & 5 & 18 & 16 & 20 \\
\hline & 3 & 30 & 6 & 10 & 8 & 1,6 & 3 & 2 & 30 & 20 & 30 \\
\hline & 1 & 15 & 7 & 4 & 10 & 1,2 & 1 & 1 & 20 & 15 & 29 \\
\hline \multirow[t]{5}{*}{7} & 2 & 12 & 3 & 5 & 11 & 1,0 & 2 & 1 & 17 & 12 & 24 \\
\hline & 3 & 20 & 6 & 9 & 12 & 1,5 & & & & & \\
\hline & 1 & 20 & 6 & 8 & 11 & 1,2 & 1 & 2 & 17 & 16 & 20 \\
\hline & 2 & 17 & 5 & 15 & 9 & 1,0 & 2 & 2 & 23 & 18 & 30 \\
\hline & 3 & 13 & 4 & 13 & 7 & 1,7 & 3 & 1 & 15 & 12 & 30 \\
\hline \multirow{3}{*}{8} & 4 & 24 & 12 & 13 & 8 & 1,3 & & & & & \\
\hline & 5 & 21 & 10 & 14 & 11 & 2,0 & & & & & \\
\hline & 6 & 80 & 8 & 2 & 4 & 1,0 & & & & & \\
\hline
\end{tabular}

\begin{tabular}{|c|c|c|c|c|c|c|c|c|c|c|c|}
\hline \multirow{2}{*}{$\begin{array}{l}\text { Conj. } \\
\text { de }\end{array}$} & \multicolumn{6}{|c|}{ Caixas } & \multicolumn{5}{|c|}{ Contêineres } \\
\hline & 1 & 18 & 10 & 13 & 11 & 1,8 & 1 & 1 & 40 & 22 & 26 \\
\hline \multirow{4}{*}{9} & 2 & 20 & 8 & 9 & 10 & 1,6 & 2 & 1 & 30 & 30 & 30 \\
\hline & 3 & 12 & 7 & 12 & 15 & 1,5 & 3 & 1 & 35 & 32 & 40 \\
\hline & 4 & 22 & 14 & 15 & 11 & 1,2 & & & & & \\
\hline & 1 & 50 & 2 & 4 & 16 & 1,2 & 1 & 2 & 24 & 16 & 8 \\
\hline \multirow[t]{3}{*}{10} & 2 & 70 & 2 & 8 & 16 & 1,5 & 2 & 1 & 16 & 16 & 16 \\
\hline & 3 & 80 & 8 & 2 & 4 & 1,0 & & & & & \\
\hline & 1 & 30 & 5 & 11 & 14 & 1,2 & 1 & 2 & 21 & 18 & 24 \\
\hline \multirow{4}{*}{11} & 2 & 28 & 9 & 12 & 10 & 1,8 & 2 & 1 & 19 & 15 & 26 \\
\hline & 3 & 37 & 7 & 13 & 17 & 1,3 & 3 & 1 & 23 & 20 & 27 \\
\hline & 4 & 23 & 10 & 10 & 8 & 1,1 & & & & & \\
\hline & 1 & 35 & 3 & 6 & 8 & 1,1 & 1 & 1 & 30 & 15 & 18 \\
\hline \multirow[t]{3}{*}{12} & 2 & 40 & 5 & 9 & 4 & 1,8 & 2 & 1 & 28 & 25 & 10 \\
\hline & 3 & 15 & 8 & 9 & 12 & 1,0 & 3 & 1 & 20 & 18 & 10 \\
\hline & 1 & 56 & 7 & 8 & 3 & 2,0 & 1 & 2 & 25 & 21 & 25 \\
\hline \multirow{2}{*}{13} & 2 & 28 & 12 & 11 & 4 & 1,2 & 2 & 2 & 18 & 15 & 9 \\
\hline & 1 & 25 & 4 & 8 & 6 & 1,8 & 1 & 2 & 30 & 24 & 12 \\
\hline \multirow[t]{3}{*}{14} & 2 & 32 & 10 & 12 & 6 & 1,9 & 2 & 2 & 20 & 20 & 10 \\
\hline & 3 & 45 & 14 & 14 & 9 & 1,3 & 3 & 2 & 18 & 16 & 30 \\
\hline & 1 & 25 & 6 & 6 & 9 & 2,2 & 1 & 2 & 28 & 14 & 18 \\
\hline \multirow{4}{*}{15} & 2 & 25 & 12 & 10 & 8 & 1,7 & 2 & 2 & 15 & 12 & 20 \\
\hline & 3 & 15 & 4 & 7 & 5 & 1,0 & & & & & \\
\hline & 4 & 20 & 7 & 9 & 11 & 1,9 & & & & & \\
\hline & 1 & 35 & 15 & 18 & 17 & 1,6 & 1 & 1 & 48 & 70 & 32 \\
\hline \multirow[t]{2}{*}{16} & 2 & 30 & 11 & 14 & 11 & 2,5 & 2 & 1 & 57 & 69 & 44 \\
\hline & 3 & 25 & 24 & 26 & 15 & 1,3 & 3 & 1 & 38 & 71 & 55 \\
\hline
\end{tabular}

Fonte: Mohanty, Mathur e Ivancic (1994)

Em todos os testes efetuados, a qualidade da solução obtida pode ser considerada: solução ótima, com gap nulo; solução não ótima, com gap não nulo e insuficiência de memória do computador para resolver o problema e, por fim, sem solução, sem gap e com insuficiência de memória do computador para compilar o modelo pelo solver CPLEX.

Onde o gap de otimalidade é obtido por: $g a p=\frac{(\text { melhor limitante obtido })-(\text { melhor valor obtido })}{\text { (melhor limitante obtido })} .100 \%$
Algumas suposições foram adotadas para a realização dos testes. O termo ${ }^{v_{i}}$ da função objetivo indica o valor associado à caixa do tipo $i(i=1, \ldots, m)$, que pode ser obtido por $v_{i}=c_{i} \cdot\left(l_{i} \cdot w_{i} \cdot h_{i}\right)$, onde $C_{i}$ representa o valor por unidade de volume. Para testar o cenário C-3, optou-se por separar as caixas do tipo 1 e 2 em contêineres distintos.

A Tabela 2 apresenta o número de variáveis binárias, restrições de não sobreposição e de separação de itens presentes em cada um dos modelos gerados para teste. A quantidade de restrições de limitação 
de caixas é equivalente ao número de tipos de itens disponíveis em cada conjunto de teste considerado. Desta tabela, cabe destacar que os modelos gerados sem o uso do AGNU apresentam valores mais elevados. Por comparação, percebe-se que o conjunto de teste
4 gerado de acordo com o cenário C-1 é composto por variáveis binárias, enquanto que este mesmo conjunto apresenta apenas variáveis no cenário equivalente, isto é, em C-2.

Tabela 2 - Número de variáveis e restrições em cada modelo, onde representa média e o desvio padrão

\begin{tabular}{|c|c|c|c|c|c|c|c|}
\hline \multirow[b]{2}{*}{$\begin{array}{l}\text { Conj. De } \\
\text { Testes }\end{array}$} & \multicolumn{2}{|c|}{ Cenário C-1 } & \multicolumn{2}{|c|}{ Cenário C-2 } & \multicolumn{3}{|c|}{ Cenário C-3 } \\
\hline & $\begin{array}{l}\text { Variáveis } \\
\text { Binárias }\end{array}$ & $\begin{array}{l}\text { Restrição } \\
\text { Não } \\
\text { Sobreposição }\end{array}$ & $\begin{array}{l}\text { Variáveis } \\
\text { Binárias }\end{array}$ & $\begin{array}{l}\text { Restrição Não } \\
\text { Sobreposição }\end{array}$ & $\begin{array}{l}\text { Variáveis } \\
\text { Binárias }\end{array}$ & $\begin{array}{l}\text { Restrição Não } \\
\text { Sobreposição }\end{array}$ & $\begin{array}{l}\text { Restrição de } \\
\text { Sep. de Itens }\end{array}$ \\
\hline 1 & 2.696 & 2.488 & 120 & 90 & 128 & 90 & 12 \\
\hline 2 & 36.945 & 28.535 & 1.010 & 660 & 1.040 & 660 & 45 \\
\hline 3 & 18.857 & 18.064 & 369 & 276 & 377 & 276 & 12 \\
\hline 4 & 137.060 & 93.550 & 90 & 45 & 110 & 45 & 30 \\
\hline 5 & 105.758 & 82.238 & 414 & 335 & 430 & 335 & 24 \\
\hline 6 & 44.793 & 25.671 & 444 & 229 & 462 & 229 & 27 \\
\hline 7 & 12.801 & 6.345 & 816 & 432 & 820 & 432 & 6 \\
\hline 8 & 51.756 & 29.064 & 15.176 & 10.380 & 15.186 & 10.380 & 15 \\
\hline 9 & 115.826 & 40.756 & 5.315 & 2.263 & 5.321 & 2.263 & 9 \\
\hline 10 & 4.635 & 6.375 & 544 & 640 & 550 & 640 & 9 \\
\hline 11 & 23.753 & 11.092 & 438 & 293 & 446 & 293 & 12 \\
\hline 12 & 13.175 & 9.478 & 928 & 664 & 934 & 664 & 9 \\
\hline 13 & 20.776 & 13.580 & 730 & 496 & 738 & 496 & 12 \\
\hline 14 & 24.800 & 15.386 & 706 & 474 & 718 & 474 & 18 \\
\hline 15 & 18.738 & 8.988 & 1.758 & 1.092 & 1.766 & 1.092 & 12 \\
\hline 16 & 445.624 & 210.220 & 6.904 & 4.140 & 6.910 & 4.140 & 9 \\
\hline $\bar{x}$ & $67.374,56$ & $37.614,38$ & $2.235,13$ & $1.406,81$ & $2.246,00$ & \begin{tabular}{|l|}
$1.406,81$ \\
\end{tabular} & 16,31 \\
\hline$\delta$ & $108.955,99$ & $53.026,33$ & $3.949,48$ & $2.605,27$ & $3.948,32$ & $2.605,27$ & 10,33 \\
\hline
\end{tabular}

Fonte: $\mathrm{O}$ autor

A Tabela 3 apresenta um sumário dos resultados obtidos após a realização dos testes. Nenhuma informação foi obtida para o conjunto de teste 16 do cenário C-1, visto que o modelo excedeu a memória do computador logo na leitura dos dados pelo solver CPLEX. Esta situação encontra-se identificada por "*" na tabela.
Uma breve análise mostra que dos testes efetuados, sendo exemplos para cada cenário considerado, apenas em dois casos a solução ótima (gap nulo) não foi alcançada dentro do limite de tempo especificado. Estas situações indicam um gap de e ocorrem no conjunto de teste dos cenários C-1 e C-2. Embora os modelos do cenário C-3 indiquem complexidade mais acentuada de resolução, visto que são compostos pelas mesmas restrições dos cenários C-1 e C-2 com o acréscimo da restrição de separação de itens, em todos estes exemplos a solução ótima foi alcançada. 
Tabela 3 - Resultados obtidos com os testes efetuados, onde representa média e o desvio padrão

\begin{tabular}{|c|c|c|c|c|c|c|c|c|c|}
\hline \multirow[b]{2}{*}{$\begin{array}{l}\text { Conj. de } \\
\text { testes }\end{array}$} & \multicolumn{3}{|c|}{ Cenário C-1 } & \multicolumn{3}{|c|}{ Cenário C-2 } & \multicolumn{3}{|c|}{ Cenário C-3 } \\
\hline & $\mathbf{Z}$ & gap & $\begin{array}{l}\text { Tempo } \\
\text { (seg.) }\end{array}$ & $\mathbf{z}$ & gap & $\begin{array}{l}\text { Tempo } \\
\text { (seg.) }\end{array}$ & $\mathbf{z}$ & gap & $\begin{array}{l}\text { Tempo } \\
\text { (seg.) }\end{array}$ \\
\hline 1 & 5.376 & - & 0,48 & 5.376 & - & 0,19 & 4.800 & - & 0,08 \\
\hline 2 & $70.438,4$ & - & 239,06 & $70.438,4$ & - & 2,09 & 70.080 & - & 2,48 \\
\hline 3 & $49.512,5$ & - & 406,83 & $49.512,5$ & - & 0,16 & $49.512,5$ & - & 0,16 \\
\hline 4 & 846.720 & - & $6.601,66$ & 846.720 & - & 0,05 & 846.720 & - & 0,11 \\
\hline 5 & 313.750 & - & $9.693,23$ & 313.750 & - & 0,08 & 313.750 & - & 0,09 \\
\hline 6 & 121.824 & - & 499,47 & 121.824 & - & 0,08 & 115.776 & - & 0,14 \\
\hline 7 & 12.522 & - & 32,30 & 12.522 & - & 0,13 & 12.396 & - & 0,16 \\
\hline 8 & $53.009,2$ & - & $1.765,2$ & $53.009,2$ & - & 111,55 & $52.662,8$ & - & 316,33 \\
\hline 9 & 112.338 & $0,8 \%$ & 81.167 & 112.338 & $0,8 \%$ & 11.884 & 107.532 & - & $1.852,42$ \\
\hline 10 & 11.264 & - & 0,56 & 11.264 & - & 0,03 & 11.264 & - & 0,13 \\
\hline 11 & $36.870,60$ & - & 190,56 & $36.870,6$ & - & 0,06 & $36.870,6$ & - & 0,22 \\
\hline 12 & 21.096 & - & 4,13 & 21.096 & - & 0,73 & 18.504 & - & 1,97 \\
\hline 13 & 34.656 & - & 22,88 & 34.656 & - & 2,80 & $27.014,4$ & - & 0,42 \\
\hline 14 & $61.588,8$ & - & 143,08 & $61.588,8$ & - & 0,11 & 59.472 & - & 1,56 \\
\hline 15 & 31.002 & - & 27,33 & 31.002 & - & 2,55 & 30.862 & - & 2,48 \\
\hline \multirow[t]{3}{*}{16} & * & * & * & 547.098 & - & 77,73 & 497.994 & - & 45,88 \\
\hline & $118.797,8$ & & $6.719,5$ & $145.566,5$ & & 755,1 & $140.950,6$ & & 139,04 \\
\hline & $208.076,3$ & & $20.086,4$ & $226.579,4$ & & $2.873,6$ & $221.898,9$ & & 448,9 \\
\hline
\end{tabular}

Fonte: O autor

Quanto ao tempo necessário para a resolução dos modelos temos que, no cenário C-1 o tempo médio decorrido foi de segundos, com desvio padrão de segundos. Já para os cenários C-2 e C-3, o tempo médio de resolução foi de segundos (com desvio padrão de ) e segundos (com desvio padrão de ), respectivamente. Destes valores cabe destacar que a restrição de separação de itens não impactou no tempo computacional de resolução, dado que o cenário C-3 obteve a menor média de tempo de resolução e, mesmo assim, a solução ótima foi encontrada em todos os modelos avaliados.

Figura 3 - Padrão de carga do conjunto de teste 12 gerado de acordo com o cenário C-2
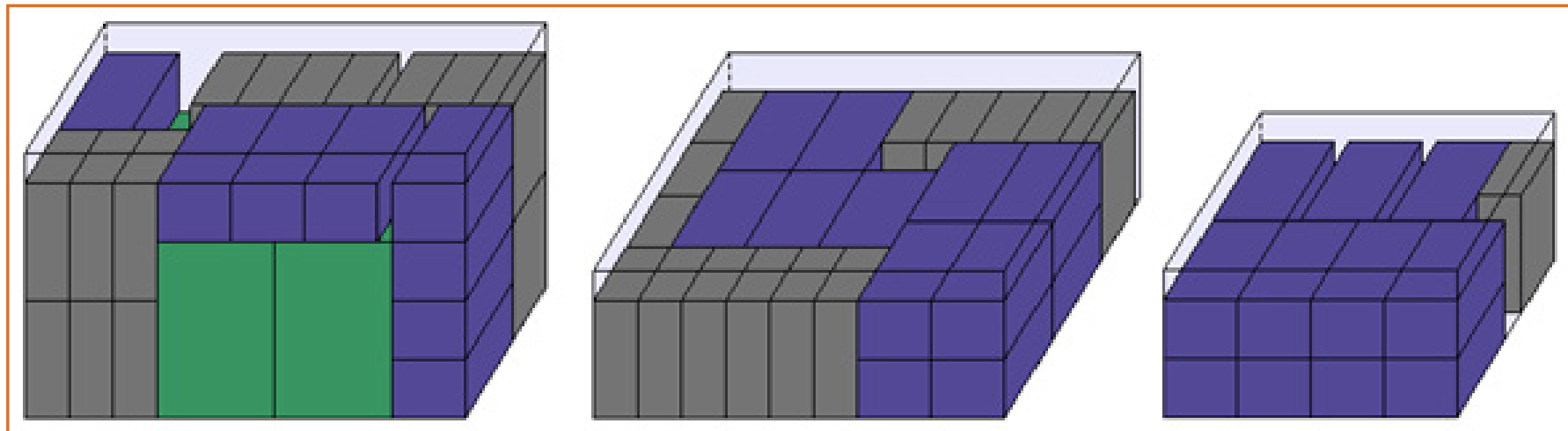

Outro ponto em destaque cabe ao uso do AGNU na geração dos modelos. Com base na Tabela 3, pode-se perceber acentuada diferença no tempo de resolução dos exemplos. Tomando os sete primeiros 
conjuntos de testes, percebe-se que nenhum modelo dos cenários C-2 e C-3 ultrapassa os três segundos de execução, enquanto que em C-1, apenas um exemplo foi resolvido nesta grandeza de tempo. Com destaque especial para o exemplo 5 deste cenário, que consumiu acima de segundos de execução.

As Figuras 3 e 4 ilustram, respectivamente, o padrão de carga obtido para o conjunto de teste gerado de acordo com os cenários C-2 e C-3. As caixas foram coloridas do seguinte modo: tipo 1 - cinza; tipo 2 - azul e tipo 3 - verde. Cabe lembrar que, para o cenário C-3, as caixas do tipo 1 e 2 devem ficar obrigatoriamente separadas em contêineres distintos.
O padrão de carga apresentado na Figura 3 foi obtido com alocação de 35 caixas do tipo 1, 40 caixas do tipo 2 e 03 caixas do tipo 3 , totalizando em . O primeiro contêiner da esquerda teve ocupação de 85,33\% do seu volume disponível, o segundo com $75,09 \%$ e o terceiro com $74 \%$, respectivamente. Já o padrão da Figura 4 é composto por 35 caixas do tipo 1, 40 caixas do tipo 2 e nenhum item do tipo 3 , totalizando em $Z=18.504$. . Os contêineres obtiveram ocupação de $53,33 \%, 72 \%$ e $80 \%$, respectivamente. Estes valores só reforçam o esperado, pois em modelos que consideram a restrição de separação de itens, em geral, devido ao acréscimo de exigência prática, tendem a obter um valor inferior de solução.

Figura 4 - Padrão de carga do conjunto de teste 12 gerado de acordo com o cenário C-3

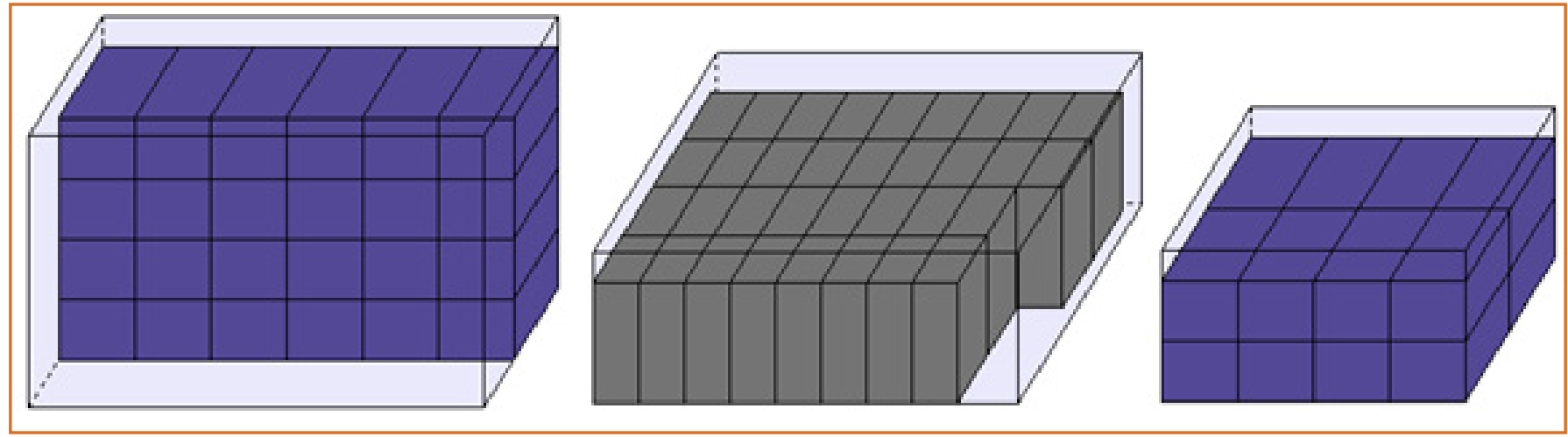

\section{CONSIDERAÇÕES FINAIS}

Neste trabalho foi apresentada uma proposta de formulação matemática para o problema de carregamento de contêiner, em especial, carregamento de múltiplos contêineres heterogêneos. Esta abordagem foi testada por meio do solver CPLEX, e embora limitada a resolver problemas de complexidade moderada, representou satisfatoriamente às condições tratadas.

A formulação matemática proposta, oriunda de uma adaptação do modelo apresentado por Junqueira, Morabito e Yamashita (2012), demonstra apresentar flexibilidade para a consideração de restrições práticas listadas por Bischoff e Ratcliff (1995). Apesar da modelagem apresentada neste trabalho abordar unicamente a restrição de separação de itens, podemse citar os trabalhos de Kurpel, Schenekemberg e Scarpin (2015), Junqueira, Morabito e Yamashita (2012) e trabalhos correlatos dos autores, como fonte de outras exigências práticas que podem ser diretamente acrescentadas ao modelo proposto.

Como indicado nos testes efetuados, o Algoritmo de Geração dos Números Úteis colaborou significativamente com a redução da cardinalidade dos conjuntos dos possíveis pontos de vértices dos itens, de forma a impactar diretamente na dimensão dos modelos avaliados. Este fator, como esperado, produziu significativos ganhos em termos de desempenho de resolução.

Os resultados computacionais obtidos mostram que a abordagem proposta é capaz de resolver, em tempo computacional aceitável, apenas problemas de complexidade moderada. No entanto, esta formulação pode servir de motivação para futuras pesquisas que explorem outros métodos de solução, como procedimentos heurísticos, metaheurísticos, métodos de relaxação, entre outros. 
Este trabalho pode ser utilizado, futuramente, como motivação para as seguintes pesquisas: explorar formas alternativas aos conjuntos, de modo a diminuir a cardinalidade e consequentemente a complexidade dos modelos; estender a formulação proposta para considerar os mais variados tipos de CLP's; expandir a modelagem para abordar restrições práticas não tratadas neste trabalho, como restrição adicional de manuseio, prioridades de envio e distribuição de peso dentro do contêiner e, por fim, testar combinações distintas de parâmetros para o solver CPLEX, visto que neste trabalho optou-se por parâmetros default.

\section{REFERÊNCIAS}

[1] ALTARAZI, S. A New Prioritizing-Stacking Heuristic Algorithm for the Inner-City Truck Loading Problem. International Journal of Business and Management. Vol. 8, n. 3, p. 1-7, 2013.

[2] BISCHOFF, E.E.; RATCLIFF, M.S.W. Issues in the Development of Approaches to Container Loading. Omega. Vol. 23, n. 4, p.377-390, 1995.

[3] BORTFELDT, A.; WÄSCHER, G. Constraints in Container Loading - A State-of-the-Review. European Journal of Operational Research. Vol. 229, n. 1, p.1-20, 2013.

[4] CARNIERI, C.; MENDOZA, G.A.; GAVINHO, L.G. Solution Procedures for Cutting Lumber into Furniture Parts. European of Operations Research. Vol. 73, p.495-501, 1994.

[5] CHEN, C.S.; LEE, S.M.; SHEN, Q.S. An analytical model for the Container Loading Problem. European Journal of Operational Research. Vol. 80, n.1, p.68-76, 1995.

[6] CHRISTOFIDES, N.; WHITLOCK, C. An Algorithm for Two-Dimensional Cutting Problems. Operations Research. Vol. 25, n. 1, p. 30-44, 1977.

[7] ELEY, M. A Bottleneck Assignment Approach to the Multiple Container Loading Problem. OR Spectrum. Vol. 25, n.1, p.45-60, 2003.

[8] GEHRING, H.; BORTFELDT, A. A Genetic Algorithm for Solving the Container Loading Problem. International Transactions in Operational Research. Vol. 4, n.5-6, p.401418, 1997.

[9] HERZ, J.C. Recursive Computational Procedure for TwoDimensional Stock Cutting. IBM Journal of Research and Development. Vol. 16, n. 5, p. 462-469, 1972.
[10] HIFI, M.; KACEM, I.; NEGRE, S.; WU, L. A Linear Programming Approach for the Three-Dimensional BinPacking Problem. Electronic Notes in Discrete Mathematics. Vol. 33, p. 993-1000, 2010.

[11] JUNQUEIRA, L.; MORABITO, R.; YAMASHITA, D.S. Three-Dimensional Container Loading Models with Cargo Stability and Load Bearing Constraints. Computer \& Operations Research. Vol. 39, n.1, p.74-85, 2012.

[12] KURPEL, V.K.; SCHENEKEMBERG, C.M.; SCARPIN, C.T. Um Modelo Matemático Exato para o Problema de Carregamento de Contêineres com Restrição de Carregamento Completo de Grupo de Itens. Revista Eletrônica Gestão e Saúde. Vol.6 (Supl.2), p.1014-1026, 2015.

[13] MARTELLO, S.; PISINGER, D.; VIGO, D. The ThreeDimensional Bin Packing Problem. Operations Research. Vol. 48, n.2, p.256-267, 2000

[14] MIZAWA, F.K.; WAKABAYASHI, Y. An Algorithm for the Three-Dimensional Packing Problem with Asymptotic Perfomance Analysis. Algorithmica. Vol. 18, p. 122-144, 1997

[15] MOHANTY, B.B.; MATHUR, K.; IVANCIC, N.J. Value Considerations in Three-Dimensional Packing - A Heuristic Procedure using the Fractional Knapsack Problem. European Journal of Operational Research. Vol. 74, n.1, p.143-151, 1994.

[16] OLIVEIRA, L.K.; MORABITO, R. Métodos Exatos baseados em Relaxações Lagrangeana e Surrogate para o Problema de Carregamento de Paletes do Produtor. Pesquisa Operacional. Vol. 26, n.2, p.403-432, 2006

[17] PISINGER, D. Heuristics for the Container Loading Problem. European Journal of Operational Research. Vol. 141, n. 2, p.382-392, 2002.

[18] REN, J.; TIAN, Y.; SAWARAGI, T. A Tree Search Method for the Container Loading Problem with Shipment Priority. European Journal of Operational Research. Vol. 214, n. 3, p.526-535, 2011

[19] TSAI, R.D.; MALSTROM, E.L.; KUO, W. Three Dimensional Palletization of Mixed Box Sizes. IIE Transactions. Vol.25, n.4, p.64-75, 1993.

[20] WÄSCHER, G.; HAU $\square$ NER, H.; SCHUMANN, H. An Improved Typology of Cutting and Packing Problems. European Journal of Operational Research. Vol 183, n. 3, p. 1109-1130, 2007. 


\section{CAPÍTULO 12}

\section{SISTEMAS ESPECIALISTAS NAS ORGANIZAÇÕES: UM ESTUDO BIBLIOMÉTRICO}

\section{Myller Augusto Santos Gomes}

Eloni dos Santos Perin

Resumo: A Inteligência Artificial é tema de abordagem em pesquisas de diversas áreas do conhecimento e com aplicação em vários ramos de estudos científicos, muitos ainda pouco explorados e entre eles os sistemas especialistas, foco de nosso estudo. Por sua abordagem interdisciplinar, o estudo das publicações de estudos organizacionais que utilizam sistemas especialistas para auxílio à tomada de decisões traz elementos importantes para a evolução e vantagem competitiva das organizações. Este artigo tem, portanto, a finalidade de identificar as principais publicações referentes a sistemas especialistas ou expert systems na área de ciências sociais. Para isso, investigou-se na base de dados Web of Knowlege, os trabalhos publicados entre o período de 1996 a 2015. Os dados foram analisados com auxílio de softwares de captura e organização dos dados, o Vosviewer e o Bibexcel, para identificar redes de autores, principais periódicos de publicação e as palavras chave referentes ao tema.

Palavras chave: Inteligência Artificial; Sistemas Especialistas; Organizações; Bibliometria. 


\section{INTRODUÇÃO}

O século XX foi palco da explosão tecnológica, a qual trouxe consigo uma gama de inovações, com novos modelos de gestão das organizações e novas formas de pensar e agir no mundo do trabalho.

As ações ficaram facilitadas pelo auxílio da tecnologia, o que trouxe também o desenvolvimento de uma nova área de estudos: a Inteligência Artificial. Esta área, alvo de interesse de pesquisadores de todos os campos de conhecimento, ainda é pouco explorada. Ela contempla diversos estudos, como o aprendizado de máquina, a robótica, as redes neurais, os sistemas especialistas e diversos outros campos.

Assim, este trabalho procurou identificar as principais pesquisas desenvolvidas na área de Inteligência Artificial, com foco em sistemas especialistas ou expert systems, para entender quais os principais pesquisadores, as áreas de pesquisa e os temas estudados. Portanto, o objetivo deste trabalho foi identificar os trabalhos desenvolvidos no campo do uso de sistemas especialistas, que visam melhorar a gestão e a inovação tecnológica nas organizações.

Considera-se que a grande quantidade de informação carrega implícitos "padrões de comportamento e outras características úteis para traçar cenários e antecipar tendências sobre aspectos sociais e econômicos da sociedade contemporânea" (RUAS e PEREIRA, 2014).

Como método, utilizou-se o estudo bibliométrico com o objetivo de mensurar o processo de transformação e aplicação do conhecimento. A pesquisa foi realizada na base de dados Web of Science, uma base considerada completa pelos pesquisadores na área de Ciências Sociais. Essa metodologia, que faz parte dos estudos cientométricos, objetiva fazer um levantamento dos trabalhos publicados em periódicos nacionais e internacionais, no tema de estudo.

\section{SISTEMAS ESPECIALISTAS}

No início dos anos de 1950 o desenvolvimento de software de computador começou com um foco em sistemas numéricos (PANDIT, 2013; IKRAN, QAMAR, 2015). A partir deste contexto, houve um crescimento expressivo de softwares, o marco do sistema especialista foi em 1970 na Universidade de Stanford, que desenvolveu um sistema especialista com objetivo de ajudar a diagnosticar a causa provável da infecção em pacientes e fornecer o tratamento recomendado.

Sua base de regra consiste em 450 regras o que poderia classificar vários tipos de infecções como a meningite. A partir desta experiência bem-sucedida, os criadores do sistema provaram que com um pouco de regras simples na forma de declarações em uma base de regras, era o suficiente para se lidar com um domínio complicado, mas com precisão no foco, devido sua estrutura de processamento de linguagem natural, processamento de símbolos, sistema baseado em regras e sistemas lógicos (IKRAN, QAMAR, 2015).

O processo de desenvolvimento de sistemas especialistas funcionais é sempre centralizada sobre a organização da base de conhecimento, este conhecimento é coletado e organizado, adquirido a partir do domínio do especialista em seguida, converte o conhecimento especializado em um formulário em linguagem computacional, neste momento o computador entende e salva os conhecimentos convertidos em uma base de conhecimento, compreendo dois aspectos: Engenharia do Conhecimento e a Engenharia de Software (KUSIAK, CHEN, 1988; PANDIT, 2013; IKRAN, QAMAR, 2015).

Com a base de conhecimento formulada e reconhecida pelo computador, os usuários digitam os fatos recolhidos, e o sistema através de sua interface com o usuário, salva os fatos na base de fatos. Finalmente, os usuários obtêm os resultados, recomendações e explicações a partir do processamento realizado pelo sistema (IKRAN, QAMAR, 2015).

Este cenário, o sistema especialista apresenta duas características:

1. Interações com o usuário frequente: Um sistema especialista coleta dados dos utilizadores, e formula os resultados finais com base nesses dados.

2. Base de conhecimento independente e dinâmica: A principal diferença de um sistema especialista a 
partir de um programa tradicional é o conhecimento que é independente, este, podendo ser modificado ou ampliado na medida que conhecimento evolui.

Caracterizado o sistema especialista, apresenta-se um conceito da seguinte perspectiva:

O sistema especialista é definido com aquele baseado em regras, que contém informações obtidas a partir de um especialista humano, e representa que a informação sob a forma de regras, sendo um corpo de conhecimentos especializados voltado ao processo de resolução de problemas, a fim de chegar a conclusão apropriada IKRAN, QAMAR, 2015).

No cenário evolutivo Ford (1985) destaca que o sistema especialista, uma consequência natural da inteligência artificial, sendo um programa de resolução de problemas que busca um bom desempenho em um especializado domínio do problema que requer conhecimentos específicos e habilidades distintas.

Durante a decada de 1980, os pesquisadores começaram a investigação da inteligência artificial em países como Estados Unidos, Jápão, assim como em muitos países da Europa, iniciaram o processo de investimentos nas áreas de sistemas de inteligência artificial e sistemas especialistas. Neste contexto, o objetivo da inteligência artificial é ampliar a aplicação de computadores para não somente realizar cálculos numéricos, mas também possuir um corpo de conhecimentos, e promover a sua utilização otimizando o trabalho humano (IKRAN, QAMAR, 2015).

A principal área de pesquisa da inteligência artificial inclui processamento de linguagem natural, processamento de símbolos, sistema baseado em regras e sistemas lógicos. O sistema especialistas funcionais é sempre centrado na organização de uma base de conhecimento ou base de regras (CHEN, 1998; IKRAN, QAMAR, 2015).

O objetivo destes sistemas é de processar o conhecimento de especialistas e promove uma tentativa de imitar a sua forma de pensar, intuito e habilidades distintas (FORD, 1985). Com desenvolvimento de controle baseado no conhecimento, os sistemas especialistas utiliza-se de técnicas para controlar o sistema de controle que podem automatizar algumas tarefas, atualmente desempenhadas por seres humanos especialistas em determinado conhecimento (LINKENS, CHEN, 1995).

Nesta perspectiva, os sistemas especialistas, tiveram suas primeiras aplicações no controle, com um comportamento off-line, desempenhado de forma passiva, podendo ser acompanhando por uma consultas e pela supervisão antes do processo de tomada de decisão. (LINKES, CHEN, 1995).

Em uma dimensão sociológica, Greenhalgh, Stones, Swinglehurst, (2014) realizam uma discussão, sobre as formas de captura da experiência profissional por meio de formalização e implementação do conhecimento impessoal, o sistema especialista em posse destes conhecimentos, pode-se moldar, monitorar, padronizar e tornar calculável o trabalho suportado.

Diederich, Ruhmann e May, (1987), reporta a o sistema especialista, como uma ferramenta para aquisição de conhecimento, onde, o nível de representação do conhecimento permite a integração de diferentes fontes de conhecimento e fornece a ferramenta de abertura aos métodos de elicitação, aonde é possível aproveitar a geração de base de conhecimento interativo.

Com o fornecimento de explicações semelhantes para o especialista humano, Pandit (2013) menciona que o sistema pode explicar porque várias perguntas estão sendo feitas, e como os dados foram obtidos. Com o sistema baseado em regras, o processo de interpretação acontece em duas etapas:

Condição, como parte antecedente;

Conclusão, como ação consequente.

A parte antecedente da regra representa os fatos ou condições que devem existir para a regra para disparar a etapa consequente, está, descreve os fatos que serão estabelecidos, ou a ação que será executada ou a conclusão que será feita, tornando todas as informações úteis (PANDIT, 2013). 
especialista, este é principalmente constituído por uma base de conhecimento ou base de regras, que consiste de fatos e regras, específicos do problema tratado, motor de inferência, é o ponto de partida pela busca de regras na base de conhecimento para virem a ser avaliadas. Mota e Mota (2011) em consonância, com a arquitetura utilizada, apresentase que o comportamento do sistema atua de forma independendente do problema em análise.

Figura 1- arquitetura do sistema especialista

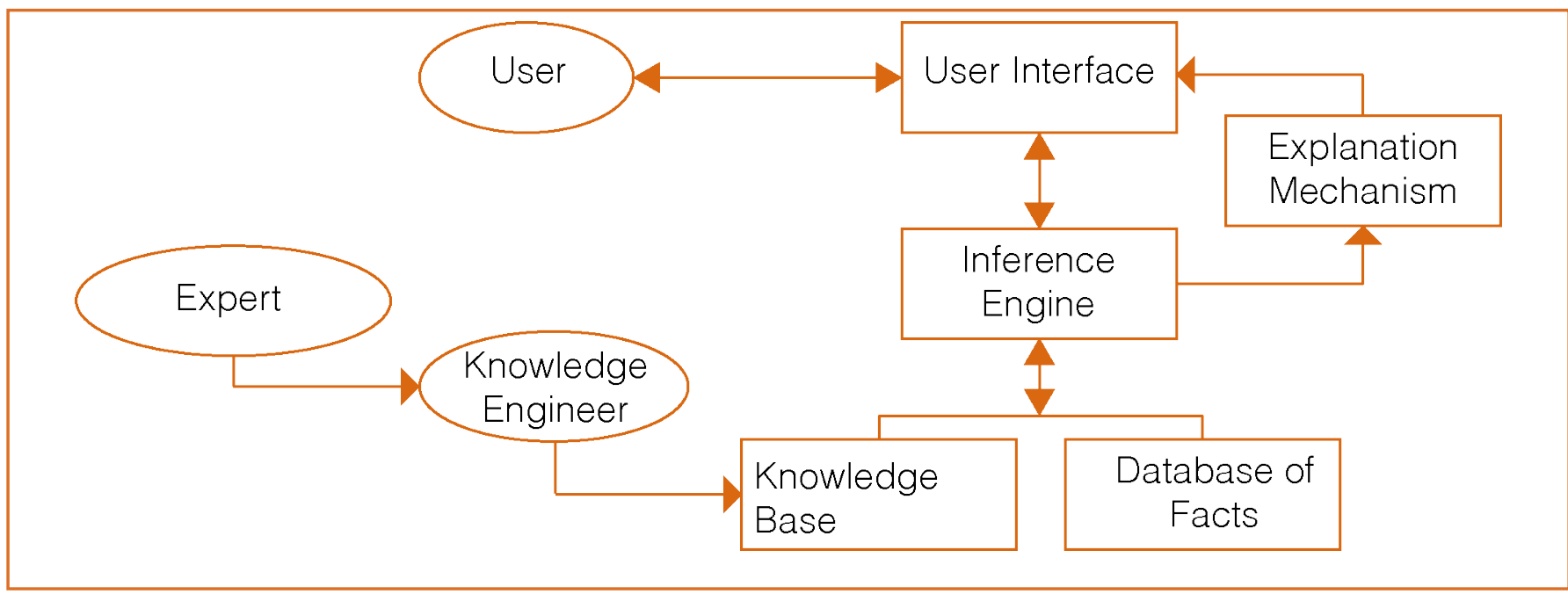

Fonte: Adaptado de Pandit, (2013)

O controle de uma base de conhecimento pode ser realizado por procedimentos independentes do problema em questão, como por exemplo, os procedimentos para determinar a sequência de execução da regra, formas de encadeamentos para frente e para trâs (KUSIAK, CHEN, 1998).

Com o sistema consolidado, Liker e Sindi, (1997) apontam que as intervenções específicas de gestão, pode ser somado pela metodologia para melhorar a aceitação da tecnologia. Exemplo, o gerente deve tomar decisões sobre se os limitados recursos disponíveis que deve ser gasto em treinamento para melhorar a confiança do usuário com a interface do sistema existente, ou na melhoria da interface do sistema, ou em uma campanha para educar os usuários sobre o que que vai acontecer aos seus empregos e competências, utilizando-se de forma tecnicamente sólida.

Conforme citado anteriormente, o sistema especialista são utilizados para solucionar problemas de diferentes áreas do conhecimento, sendo o determinante as regras utilizadas na base de conhecimento como a lógica binário que trata as afirmações, classificando como verdadeiras ou falas, a lógica nebulosa, difusa ou fuzzy que admite valores lógicos intermediários entre a falsidade e a verdade, definindo, uma área de pesquisa que traa das incertezas nos mais diversos tipos de problemas (SIMÕES e SHAW, 2007).

A inteligência artificial tem contribuido para o estado da arte em diversas áreas, como exemplo o reconhecimento de voz, tradução automática e a robótica, apesar deste enorme avanço, Pandit (2013), defende que, todos precisamos ser bem educados e inteligentes, para que possamos tomas decisões importantes, ecompreenderopapel dos programadores de inteligência artificial, para que possamos utilizar ferramentas como o sistema especialistas em nosso favor.

\section{PROCEDIMENTOS METODOLÓGICOS}

A pesquisa utilizou a bibliometria como instrumento de análise das publicações científicas do tema de Sistemas Especialistas. A bibliometria é definida por Pritchard (1969) como "todos os estudos que tentam 
quantificar os processos de comunicação escrita". Os estudos cientométricos tem sido bastante utilizados para compreender o campo das pesquisas científicas.

Hayashi (2013) traz a neo-bibliometria como ferramenta que vai além do estudo sobre produção e produtividade, mas a partir de seus indicadores pode chegar até uma abordagem teórica de seus pesquisadores. Para construção de indicadores bibliométricos a partir de dados coletados em base de dados, podem ser encontrados como registro de informações: autor, orientador, gênero, título do trabalho, nível (M/D), PPG, IES, região, linha de pesquisa, fomento, palavraschave, resumo.

Alguns indicadores bibliométricos padrão utilizados neste trabalho permitem realizar análise sobre autores, palavras-chave e instituições de pesquisa e publicação. A escolha deste trabalho foi identificar o número de artigos publicados por autor, os termos mais utilizados nos artigos e os principais periódicos de publicações na área de Sistemas Especialistas.

Para realizar este estudo primeiramente definiuse a expressão de busca "sistemas especialistas", utilizando o termo em inglês "expert systems". A base de dados escolhida para a pesquisa foi a Web of Knowledge, por ser uma das mais completas na área de Ciências Sociais.

Foi pesquisado o termo ("expert systems") e refinado por: domínios de pesquisa: (social sciences) and domínios de pesquisa: (social sciences or science technology ). A escolha deve- se a área de estudo dos pesquisadores.
Optou-se também por analisar os periódicos publicados entre os períodos de 1996 a 2015

Para a análise, considerou-se a primeira pesquisa na base, que filtrou trabalhos nas áreas de Social Sciences e trouxe um resultado de 587 trabalhos publicados. Para auxílio à análise, foram usados softwares disponíveis gratuitamente, para capturar, organizar e apresentar as informações, extraídas da base de dados de publicação científica, a web of Knowledge. Os softwares utilizados foram o VOSviewer, o Citespace.

\section{ANÁLISE DOS RESULTADOS}

Ao pesquisar o termo "expert systems", com filtro para a área de social sciences, a partir da extração de dados da base Web of Knowledge, obtivemos 587 artigos.

Identificaram-se as palavras mais usadas no Title e Abstract dos trabalhos de periódicos publicados no período de 1996, até o ano de 2015.

A pesquisa extraída das publicações do tema Sistemas Especialistas, passou pelo processamento e visualização das informações a partir dos programas VOSviewer, Bibexcel, Excel e Citespace.

A Figura 2, elaborada no software Vosviewer, mostra que a expressão expert system é a mais utilizada nos artigos, seguida de knowledge, rule, study, expert, process, decision, management, expertise, artificial inteligence e tecnology. Essa rede de palavras indica que as produções acadêmicas nessa área contém os sistemas especialistas no foco das pesquisas. 
Figura 2. Rede de palavras em Title e Abstract

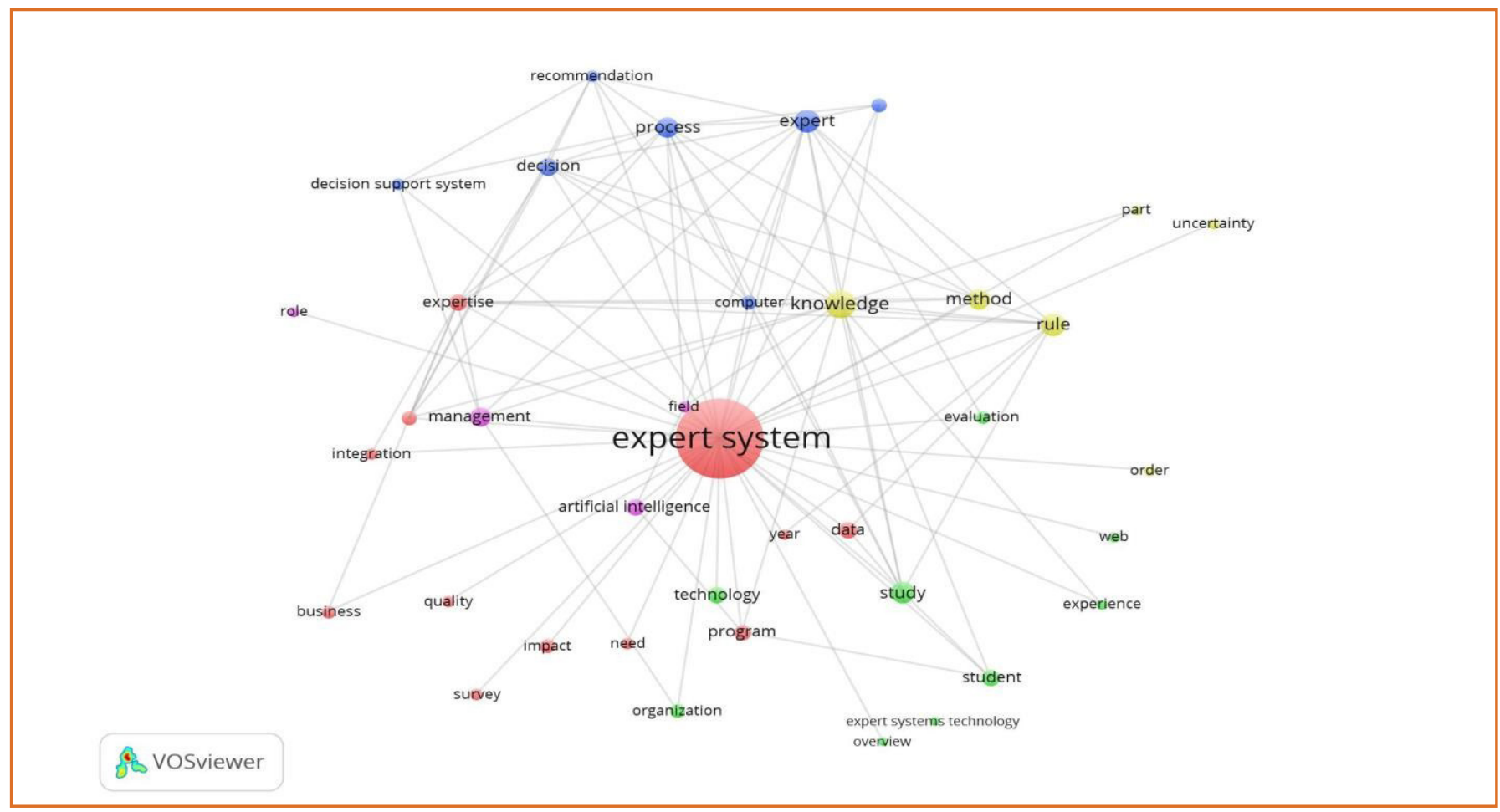

Os autores que mais publicaram aparecem com círculo maior na Figura 3, conforme dados extraídos da base de dados Web of Science e apresentados pelo Vosviewer, foram Edwards, J. S.; Okeefe, R. M.;
Oleary, D. E.; Fordyce, K.; Boritz, J. E.; Ram, S.; A Figura 3 foi construída considerando o número mínimo de três documentos publicados de um autor.

Figura 3. Autores e Co-autores que mais publicaram
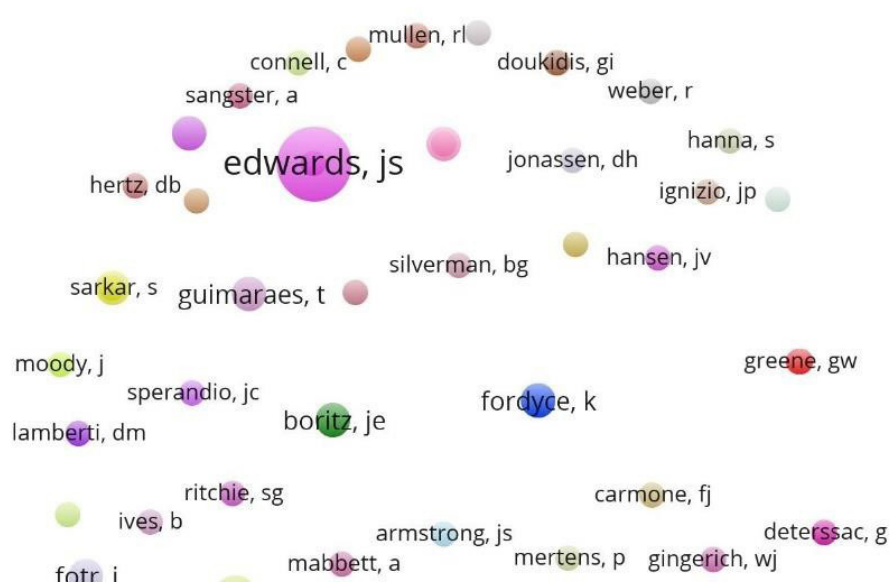
Os periódicos que contém número maior que três publicações estão relacionados na figura 4. A figura foi construída com o auxílio dos programas Bibexcel para tratamento das informações e visualizada através de gráfico construído no Excel. Dos cinco periódicos de maior concentração de publicações na área de expert systems, uma é americana (Interfaces) com Fator de impacto ou Journal Citation Reports - JCR 0,669, uma da Inglaterra (Journal of the Operational Research Society) com JCR 0.953 e três pertencentes a Elsevier, que possui bases no Reino Unido, Europa, USA (Information \& Management - JCR 1,865, European Journal of Operational Research - JCR 1,843 e International Journal of Man-Machine Studies - JCR 1,293).

Figura 4. Número de publicações por periódico

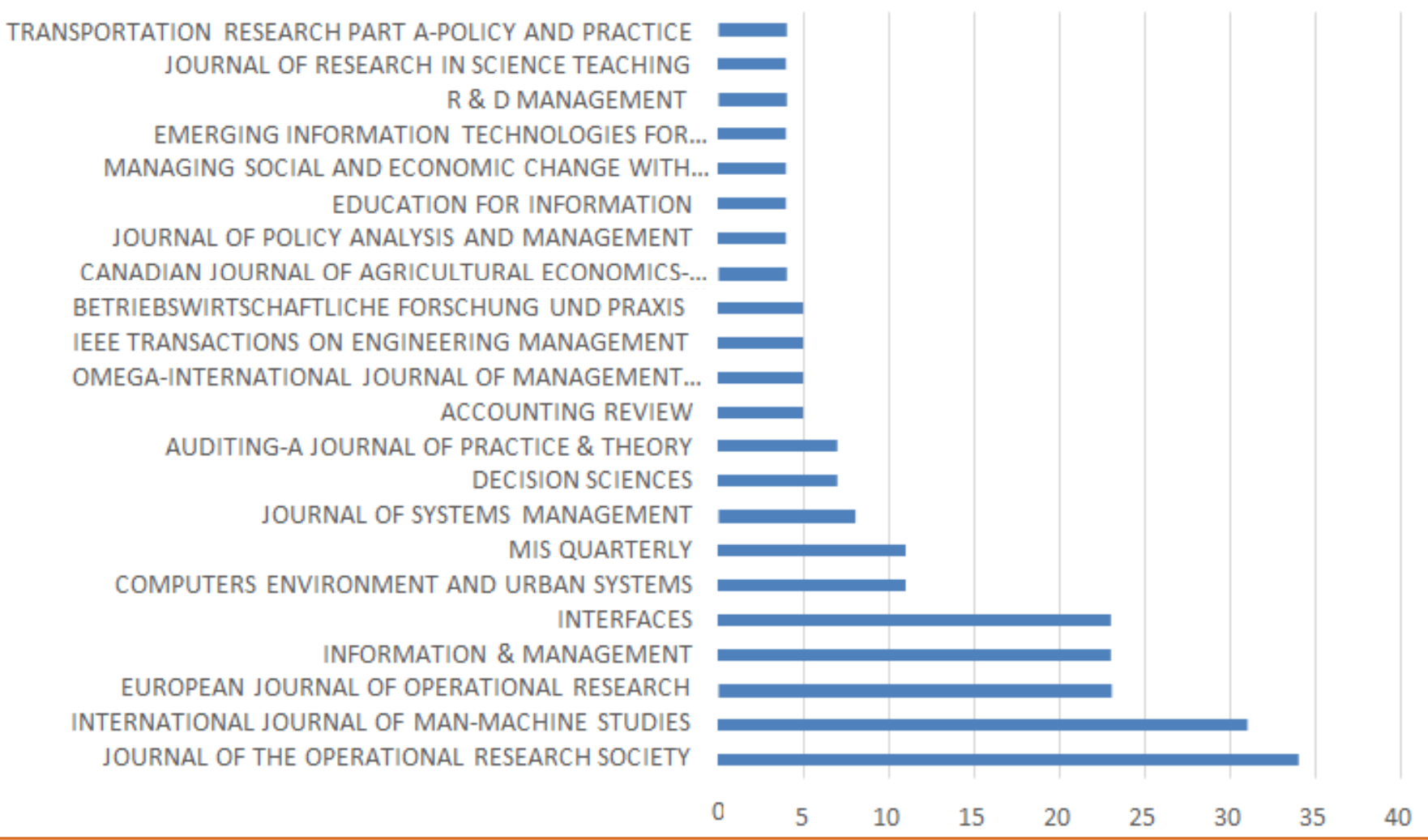

A Figura 5, extraída da base Web of Science, demonstra o número de publicações por ano compreendo o período de 1996 até 2015,neste cenário, é possível identificar uma desaceleração das publicações sobre o tema em questão.

Figura 5.Itens publicados por ano

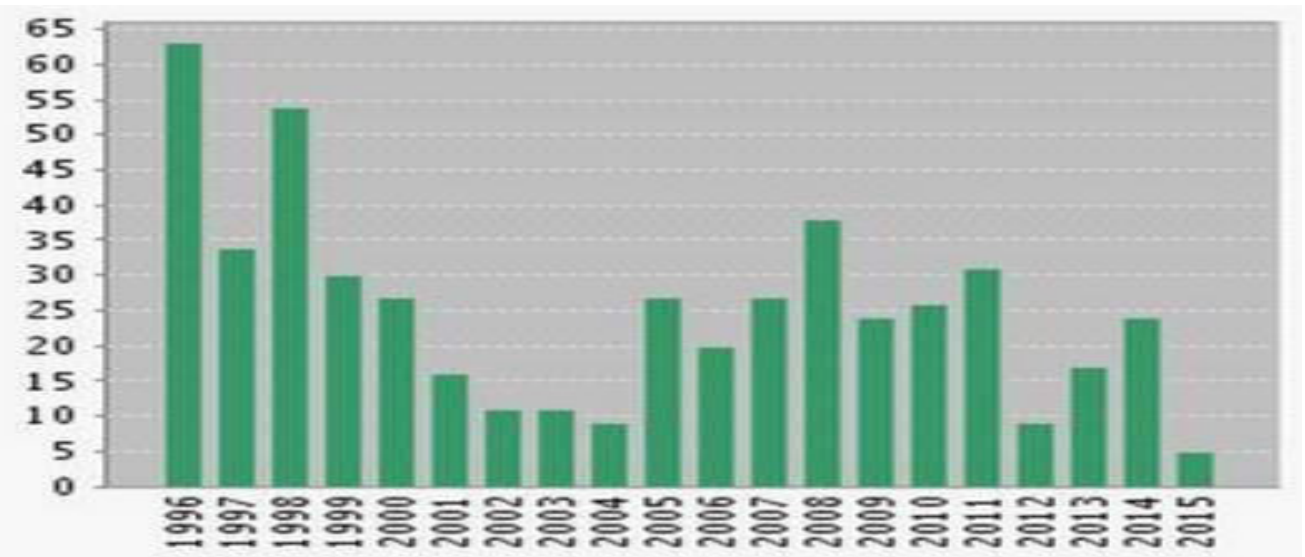




\section{CONSIDERAÇÕES FINAIS}

O objetivo deste trabalho foi realizar um estudo bibliométrico sobre os sistemas especialistas nas organizações, a proposta demostrou sua evolução e a natureza da literatura em relação ao tema. A análise das publicações permitiu estudar um vasto universo de conhecimento, buscando caracterizar os principais autores e co-autores, redes de palavras em títulos e abstract.

Identificados nos resultados um número expressivo de publicações, quantidade maior que 500 títulos em periódicos nas últimas três décadas. Foram identificados também os títulos de periódicos que publicaram no mínimo um artigo por ano e os países de origem.

Esta análise permitiu mapear descobertas interessantes:

a) Há um número considerável de publicações sobre os sistemas especialistas baseado em regras na base de dados Web of Science;

b) O termo pesquisado está em evidência e tem maior difusão nos continentes da América do Norte e Europa

c) Há ausência de títulos de periódicos brasileiros que publicaram no mínimo dois artigos por ano sobre o respectivo tema (período)

d) Entre os anos de 1996 a 2015, representou uma desaceleração das publicações a respeito do sistema especialista, entendemos que este resultado absorve os impactos do avanço tecnológico, que a área da ciência da computação tem passado durante este período.

Em relação à base de dados Web of Science, verificou-se que é uma importante ferramenta para os pesquisadores que escolherem por esta metodologia, pois fornece informações atualizadas com mais de 9.200 títulos de periódicos em nível internacional. Neste cenário, o sistema pode ser utilizado para uma pesquisa de alta qualidade, associando registros, buscando por autores relevantes ná área de interesse, por referência citada, recebendo avisos de publicação para assuntos, publicações ou autores, processando os resultados de uma busca e salvando-os ou com a opção de envio por email. Estudos futuros podem correlacionar autores e periódicos, análise do fator de impacto das citações e correlação entre instituições de pesquisa e autores.

Contudo, dada à importância do avanço da inteligência artificial, e consequentemente sua aplicação prática, os sistemas especialistas são aliados no processo de tomada de decisão em uma organização. Conclui-se que mais estudos nacionais deveriam ser realizados, com experiências empíricas, aumentando as publicações a fim de contribuir para umadisseminação maior do tema.

\section{REFERÊNCIAS}

[1] DIEDERICH, J; RUHMANN, I; MAY, M. KRITON: A knowledge-acquisition tool for expert systems. International Journal of Man-Machine Studies, v. 26, n. 1, p. 29-40, 1987.

[2] FORD, F. N. Decision support systems and expert systems: a comparison. Information \& Management, v. 8, n. 1, p. 21-26, 1985.

[3] GREENHALGH, T; STONES, R; SWINGLEHURST, D. Choose and Book: a sociological analysis of 'resistance'to an expert system. Social Science \& Medicine, v. 104, p. 210219, 2014.

[4] HAYASHI, M. Apontamentos sobre a coleta de dados em estudos bibliométricos e cientométricos. Filosofia e Educação, v. 5. n. 2. Out. 2013. Disponível em: < http:// periodicos.bc.unicamp.br/ojs/index.php/rfe/index> Acesso em: 05 set 2015.

[5] IKRAM, A; QAMAR, U. Developing an expert system based on association rules and predicate logic for earthquake prediction. Knowledge-Based Systems, v. 75, p. 87-103, 2015.

[6] KUSIAK, A; CHEN, M. Expert systems for planning and scheduling manufacturing systems. European Journal of Operational Research, v. 34, n. 2, p. 113-130, 1988.

[7] LIKER, J. K.; SINDI, A. A. User acceptance of expert systems: a test of the theory of reasoned action. Journal of Engineering and Technology management, v. 14, n. 2, p. 147-173, 1997.

[8] LINKENS, D. A.; CHEN, M. Expert control systems. Concepts, characteristics and issues. Engineering Applications of Artificial Intelligence, v. 8, n. 4, p. 413-421, 1995.

[9] LUISA, N.; MACEDO, F. Análise Bibliométrica sobre o desempenho. Enegep, 2012. 
[10] MOTA, A; MOTA, L. Especificação da iluminação no projeto de sistemas prediais de eletricidade utilizando um sistema especialista com regras nebulosas. Engevista. v. 13, n. 3, 2011.

[11] PANDIT, M. Expert system-A review article. International Journal of Engineering Sciences \& Research Technology, $v$. 2, n. 6 , p. 1583-1585, 2013
[12] RUAS, T. L.; PEREIRA, L. How to build Science, Technology, and Innovation Indicators using Web of of Science, Derwent World Patent Index, Bibexcel , and Pajek? Perspectivas em Ciência da Informação, v.19, n.3, p.52-81, jul./set. 2014.

[13] SIMÕES, M; SHAW, I. Controle e Modelagem Fuzzy- $2^{a}$ Ed. São Paulo. Edgar Blücher/FAPESP, 2007. 


\section{CAPÍTULO 13}

\section{ANÁLISE DA VIABILIDADE ECONÔMICA DA IMPLANTAÇÃ̃o DE UMA INDÚSTRIA DE BLOCOS DE CONCRETO}

\section{Letícia Lange de Macedo}

\section{Carina Lorenzon}

\section{Loreine Gabriele Martins da Silva Oliveira}

\section{Kamila Taira Paschoal Alves Corrêa}

\section{Camila Maira Viana Gonçalves}

Resumo: Antes de iniciar um projeto econômico é preciso realizar estudos para analisar a viabilidade econômica do mesmo a fim de diminuir os erros, seja este uma nova empresa ou até mesmo dentro de organizações já consolidadas no mercado. Com o intuito de encontrar tais resultados, existem métodos quantitativos que demonstram o quão atrativo e viável é a implantação do projeto. Para que isso ocorra, é preciso que os dados sejam colhidos corretamente para que os cálculos não apresentem resultados errôneos, provocando uma tomada de decisão arriscada ou equivocada pelo investidor. Dessa forma, este estudo tem o intuito de analisar a viabilidade econômica da implantação de uma fábrica de blocos de concreto. Primeiro foram coletados os dados necessários para a realização dos cálculos, como por exemplo, as estimativas de custos e demandas, e identificados os custos fixos e variáveis, a fim de estimar o montante do investimento. Com isso foi possível realizar a Demonstração do Resultado do Exercício, bem como o ponto de equilíbrio do projeto. Com tais dados foi possível utilizar os métodos de análise e de acordo com a literatura os resultados encontrados mostram que é viável a implantação do projeto.

Palavras chave: Engenharia Econômica, Análise de Investimento, Blocos de Concreto. 


\section{INTRODUÇÃO}

O setor de construção civil é um dos mais relevantes na economia brasileira e está em constante expansão no mercado, pois de acordo com o Sindicato da Indústria da Construção de Minas Gerais (SindusConMG, 2014), o crescimento do setor na última década foi de $52,10 \%$, o que representa um crescimento médio anual de $4,28 \%$. Com isso, a demanda por blocos cerâmicos para alvenaria de vedação é cada vez maior, fato que estimula novos empreendimentos neste ramo do mercado.

Porém, é importante à realização de estudos e análises de viabilidade econômica antes de qualquer investimento, seja ele em uma nova empresa em qualquer setor industrial, ou até mesmo dentro de empresas já consolidadas no mercado.

Para a realização dessas análises de investimentos existem métodos quantitativos que nos fornecem resultados seguros que permitem avaliar a atratividade e viabilidade econômica de projetos. Porém, o gestor que realizar a análise deve proceder com um estudo prévio sobre cada método e, também é importante que se tenha muito cuidado na coleta dos dados e na realização dos cálculos, para que um resultado errôneo não leve à uma tomada de decisão arriscada ou equivocada para o investidor.

Assim, o presente estudo tem o objetivo de analisar a viabilidade econômica na implantação de uma fábrica de blocos cerâmicos para alvenarias, através de estimativas de custos, demanda e demais fatores utilizados na metodologia.

\section{REVISÃO TEÓRICA}

\subsection{IMPORTÂNCIA DA ENGENHARIA ECONÔMICA}

A engenharia econômica envolve formular, estimar e avaliar os resultados econômicos, quando alternativas para realizar determinada ação estão disponíveis. Além disso, tem como vantagens: resolver problemas, analisar cada alternativa disponível e escolher a mais conveniente, comparar e otimizar as alternativas. Como o capital de um empresa é um fator limitado, a tomada de decisão de investimento dos fundos financeiros deve ser bem fundamentada, levando em conta uma combinação de fatores econômicos e não econômicos. Segundo Blank e Tarquin (2008), os engenheiros desempenham um papel importante nas tomadas de decisões, tendo como base suas análises, sínteses e esforções de projetos.

\subsection{CONCEITOS UTILIZADOS DA ENGENHARIA ECONÔMICA}

\section{Investimentos}

Segundo Strachoski (2011), investimento é todo desembolso realizado com o objetivo de obter algum lucro. Tanto uma criação de uma nova empresa como um novo projeto em uma empresa existente são considerados investimentos. Tomar uma decisão de investimento é totalmente complexa e difícil, pois como disse Braga (1995) "investimentos em novos ativos fixos têm efeitos sobre a vida da empresa e uma decisão inadequada poderá comprometer irremediavelmente o seu futuro." Assim deve-se fazer um complexo estudo das variáveis antes de tomar qualquer decisão de investimento.

\section{Custos fixos e Custos variáveis}

Os custos de um processo produtivo podem ser divididos em custos fixos e custo variáveis, levando em conta o valor total de custos dentro da unidade de tempo estabelecida e o volume de atividades. (REBELATTO, 2004)

- Custo fixo: São custos que, independente do volume de produção em um período, não alteram seus valores.

- Custo variável: Custos que variam de acordo com o volume de produtos/serviços produzidos em um período.

\section{Demonstração do resultado do exercício (DRE)}

A Demonstração do Resultado do Exercício (DRE) é um relatório contábil que apresenta as operações realizadas pela empresa em determinado período. Esse relatório deve ser elaborado juntamente com o balanço patrimonial. O DRE é fundamental para avaliar o desempenho da empresa e a eficiência dos gestores, 
pois esse tem como objetivo demonstrar o lucro líquido da organização por meio de confrontos entre receitas e despesas, gerando assim, informações de suma importância para a tomada de decisão.

De acordo com a legislação brasileira (Lei no 6.404 , de 15/12/ 1976, Lei da Sociedade por Ações), as empresas deverão discriminar na Demonstração do Resultado do Exercício os seguintes itens:

a. Receita bruta das vendas e serviços, as deduções das vendas, os abatimentos e os impostos;

b. Receita líquida das vendas e serviços, o custo das mercadorias vendidas e serviços prestados e o lucro bruto;

c. As despesas com as vendas, as despesas financeiras, deduzidas das receitas, as despesas gerais e administrativas, e outras despesas operacionais;

d. O lucro ou prejuízo operacional, as outras receitas e as outras despesas;

e. O resultado do exercício antes do Imposto de Renda e a provisão para tal imposto;

f. As

participações

ebêntures, empregados, administradores e partes beneficiárias.

\subsection{VIABILIDADE ECONÔMICA}

A viabilidade econômica de um projeto tem a função de avaliar ou prever o eventual êxito ou fracasso de um projeto. Para isso é realizado um estudo de condições esperadas de demanda do produto ou serviço ao longo da vida do projeto, para verificar se o retorno obtido será o que os investidores esperam e se o projeto será compensatório.

Para um resultado confiável da viabilidade econômica do investimento vários fatores devem ser analisado cuidadosamente. Segundo Woiler e Mathias (1996), devem ser analisados "a quantidade demandada, preço de venda, canais de distribuição (e a forma de estoque destes canais), descontos, etc. (...) análise de mercado um dos primeiros aspectos a serem considerados no projeto."

Outra questão importante a ser verificada e estudada é a localização do empreendimento, visto que a demanda varia de acordo com a região que está localizada o público alvo do negócio e a instalação em um local inadequado pode fracassar todo o projeto.

\subsection{ANÁLISE DE INVESTIMENTO}

Com o objetivo de evitar erros quanto aos investimentos a serem realizados, é fundamental que haja uma análise para avaliar as alternativas e escolher dentre estas, usando métodos quantitativos, a que mais se adequa à organização (SANTOS, 2001). Para Chiavenato (2004), os principais objetivos da análise de investimento é identificar e potencializar as oportunidades existentes, neutralizar as possíveis ameaças e descobrir como criar valor para o cliente a fim de gerar riqueza para a empresa.

Os métodos quantitativos que facilitam quanto a tomada de decisão par a empresa são: valor presente líquido, índice de lucratividade, taxa interna de retorno, o payback e o valor anual uniforme equivalente. São apresentados a seguir:

a) Valor do Presente Líquido - VPL: De acordo com Kassai (2000), este método é utilizado para demonstrar o valor do investimento medido pela diferença entre o valor presente das entradas do caixa e o valor presente das saídas, com a utilização de uma taxa de desconto. Tal valor é encontrado através da Equação 1 , e se o valor encontrado for positivo, significa que o investimento pode ser realizado, em caso contrário, não é vantajoso a implementação do mesmo.

$$
\left.\left.V P L=\mid \sum_{t=1}^{n} \frac{F C_{t}}{(1+K)^{t}}\right\rfloor-\mid I_{0}+\sum_{t=1}^{n} \frac{I_{t}}{(1+K)^{t}}\right\rfloor
$$

Sendo:

$F C_{t}:$ Fluxo de caixa de cada período;

$K$ : : Taxa de desconto;

$I_{0}$ : Investimento processado no momento zero;

$I_{t}$ : Valor do Investimento previsto em cada período subsequente. 
b) Índice de Lucratividade: Utilizado a relação entre as receitas e despesas do projeto, o Índice de Lucratividade é um indicador de aceitação ou rejeição de tal investimento (KASSAI, 2000). É expresso através da Equação 2, e se o resultado for positivo significa que o investimento pode ser realizado, caso contrário, não é vantajoso a implementação do mesmo.

$$
I L=\left\lfloor\sum_{t=1}^{n} \frac{\left(\frac{F C_{t}}{(1+k)^{t}}\right)}{I_{0}}\right\rfloor+\left\lfloor\sum_{t=1}^{n} \frac{I_{t}}{(1+K)^{t}}\right\rfloor
$$

Sendo:

k: Taxa de rentabilidade no período;

c) Taxa Interno de Retorno - TIR: O TIR avalia a rentabilidade de um investimento, representando a taxa de desconto necessária para igualar os fluxos de entrada e saída, num único momento (KASSAI, 2006). É através da Equação 3 que encontra-se tal índice, e caso o valor ultrapasse ou se iguale ao desejado pela instituição, o investimento é viável.

$$
\left\lfloor I_{0}+\sum_{t=1}^{n} \frac{I_{t}}{(1+K)^{t}}\right\rfloor=\left\lfloor\sum_{t=1}^{n} \frac{F C_{t}}{(1+K)}\right.
$$

d) Payback: O Payback é um método muito importante, pois demonstra o tempo necessário de recuperação depois de realizado um investimento. Caso este tempo de retorno seja muito longo, o investimento não é viável, pois devido a isso, o fluxo de caixa ficará comprometido por muito tempo.

Há dois tipos de Payback: o simples e o descontado. O Payback simples analisa o prazo de recuperação do capital investido sem remuneração, diferentemente do descontado, que faz a análise com a remuneração acrescentada. As equações 4 e 5 utilizadas neste método são demonstradas abaixo, e o projeto será viável caso o valnr de PRC. cøia mainr nı 1

$$
\begin{gathered}
P=\frac{F_{n}}{(1+i)^{n}} \\
P B C=\sum \frac{\text { Investimentos }_{n \rightarrow 0}}{\sum P_{n \rightarrow 0}}
\end{gathered}
$$

Sendo:

$P$ : Parcela no instante Inicial;

PBC: Payback e) Valor Anual Uniforme Equivalente (VAUE): Este método é utilizado em investimentos que se encontram em curtos prazos ou que o número de períodos sejam baixos. Este demonstrará uma série uniforme anual equivalente ao fluxo de caixa do investimento. Se o valor encontrado for menor que os fluxos de retorno, tal investime expresso atr.

$$
V A U E=\frac{P}{\frac{(1+i)^{n}-1}{(1+i)^{n} i}} \text { : }
$$
organização. É

\section{Sendo:}

i: Taxa mínima de atratividade

\section{METODOLOGIA}

\subsection{CARACTERIZAÇÃO DA PESQUISA}

A pesquisa se baseia nas bibliografias referentes ao assunto tratado, fundamentando o trabalho, sendo assim considerada uma pesquisa bibliográfica. Também pode ser classificada quanto ao conhecimento, sendo considerada uma pesquisa de desenvolvimento experimental. Para Gil (2009) pesquisas bibliográficas são usadas nos casos onde as informações são obtidas através de livros, artigos, entre outros já elaborados. Ainda segundo o autor, a pesquisa de desenvolvimento experimental busca, a partir de conhecimentos obtidos com pesquisas, analisar instalação ou produção para novos projetos.

Quanto ao objetivo da pesquisa, a mesma pode ser considerada exploratória, pois visa encontrar um resultado, levando-se em conta diversos fatores, com o auxilio de bibliografias, entrevistas e exemplos (GIL, 2009).

O uso de dados numéricos define a pesquisa como quantitativa. Para Fonseca (2002) as pesquisas podem ser consideradas quantitativas quando os dados usados representam a realidade da população, considerando a objetividade.

\subsection{PROCEDIMENTOS METODOLÓGICOS}

A análise de viabilidade econômica para o investimento 
em uma fábrica de blocos de concreto segue as etapas citadas na Figura 1.

\begin{tabular}{|c|}
\hline Escolha do projeto \\
\hline$\downarrow$ \\
\hline Definir itens necessários \\
\hline 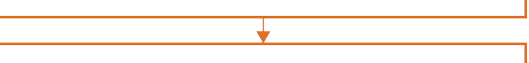 \\
\hline Coleta de dados \\
\hline \\
\hline $\begin{array}{c}\text { Identificar custos fixos e } \\
\text { variáveis }\end{array}$ \\
\hline $\begin{array}{l}\text { Definir montante do } \\
\text { investimento }\end{array}$ \\
\hline$\downarrow$ \\
\hline Elaboração do DRE \\
\hline 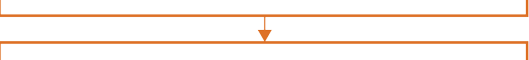 \\
\hline Calcular Ponto de Equilíbrio \\
\hline $\begin{array}{c}\text { Análise de viabilidade } \\
\text { econômica (Payback, VPL, } \\
\text { TIR, VAUE, IL) }\end{array}$ \\
\hline $\begin{array}{l}\text { Parecer sobre a viabilidade } \\
\text { do projeto }\end{array}$ \\
\hline
\end{tabular}

Figura 1 - Fluxograma com as etapas para a análise de viabilidade econômica

A definição dos itens necessários para a implantação da fábrica consistiu em pesquisas relacionadas a empresas do mesmo setor. Os valores foram estipulados com base na atual situação do mercado, sendo obtidos através do contato com fornecedores.

O volume de produção da fábrica foi calculado de acordo com a demanda da região, considerando também a capacidade de produção da máquina. A produção é relativa somente a blocos de concreto com

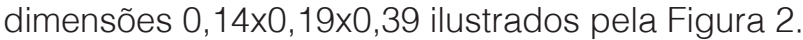

Figura 2 - Blocos de concreto com dimensões $0,14 \times 0,19 \times 0,39$

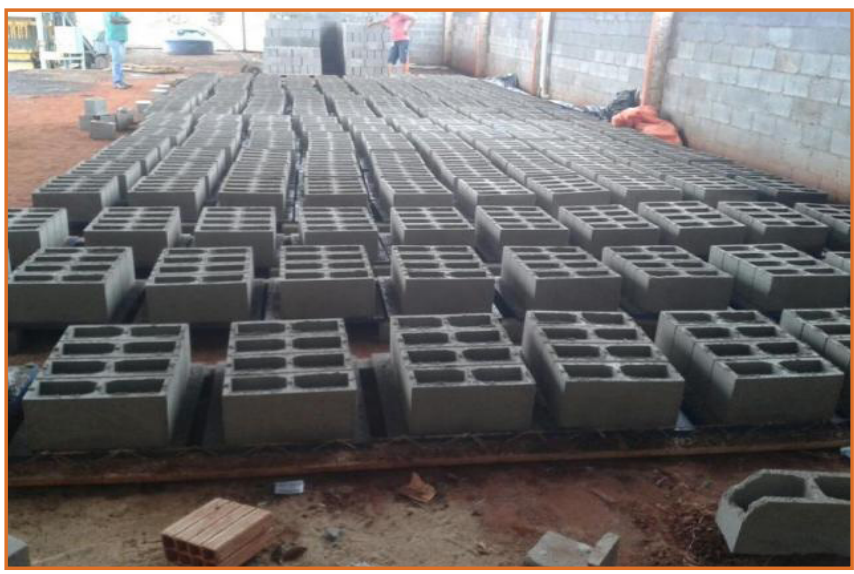

Através do volume da produção houve o levantamento dos investimentos necessários, sendo eles compra e reforma do terreno, aquisição dos equipamentos e do transporte. O total do investimento está contido na Tabela 1.

Tabela 1 - Valores dos investimentos para a fábrica de blocos de concreto

\begin{tabular}{|l|l|}
\hline Investimentos & \multicolumn{2}{l|}{ Valor } \\
\hline Terreno & $R \$ 275.000,00$ \\
\hline Reforma da infraestrutura & $R \$ \quad 25.000,00$ \\
\hline Caminhão & $R \$ 150.000,00$ \\
\hline Equipamentos & $R \$ \quad 90.000,00$ \\
\hline
\end{tabular}

Fonte: Elaborada pelos autores

O terreno foi escolhido de acordo com sua localização e o custo $x$ beneficio do mesmo com a área estipulada em $900 m^{2}$. A composição dos equipamentos consiste em uma vibro-prensa hidráulica, um misturador de concreto, uma esteira transportadora, sete fôrmas de várias medidas, dois carrinhos para retirada de blocos e mil tábuas de compensado, demonstradas na Figura 3. A capacidade da máquina escolhida é de 4.000 blocos diários. O transporte será realizado por um 
caminhão munck com capacidade de 15 toneladas, semelhante a Figura 4.

Figura 3 - Equipamentos usados em uma fábrica de blocos de concreto

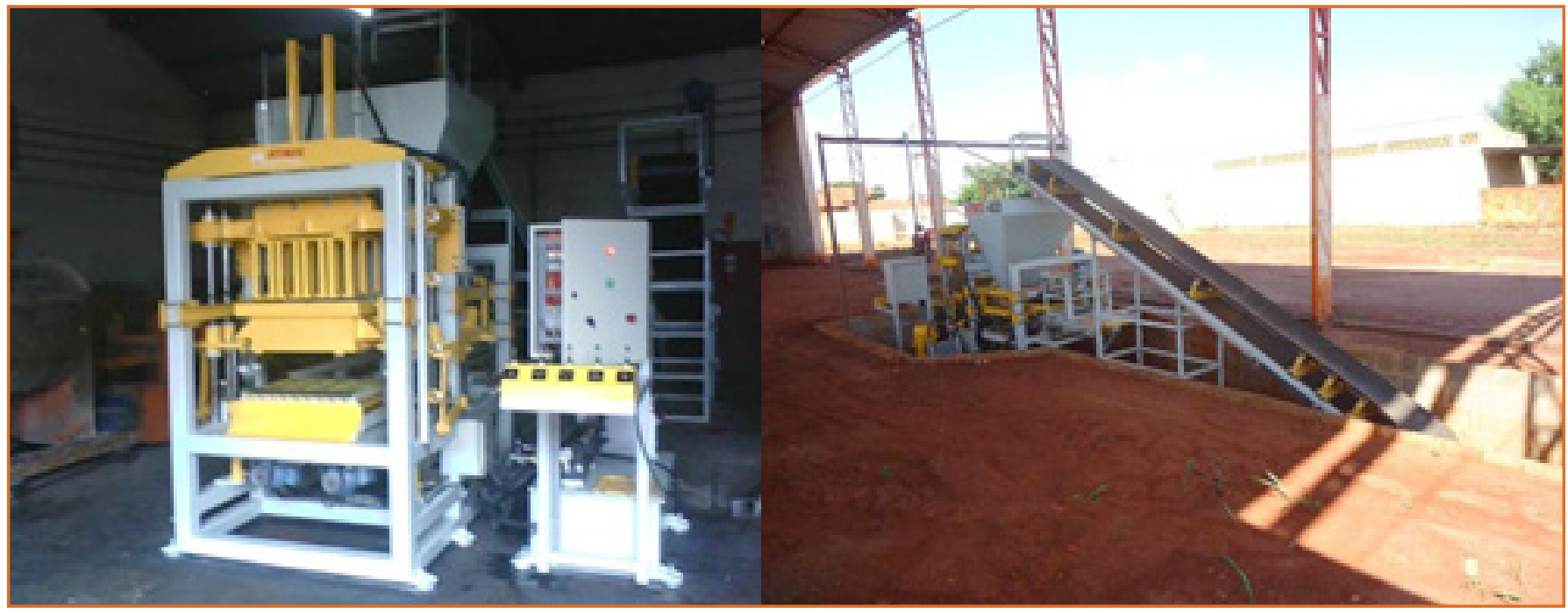

Figura 4 - Caminhão munck

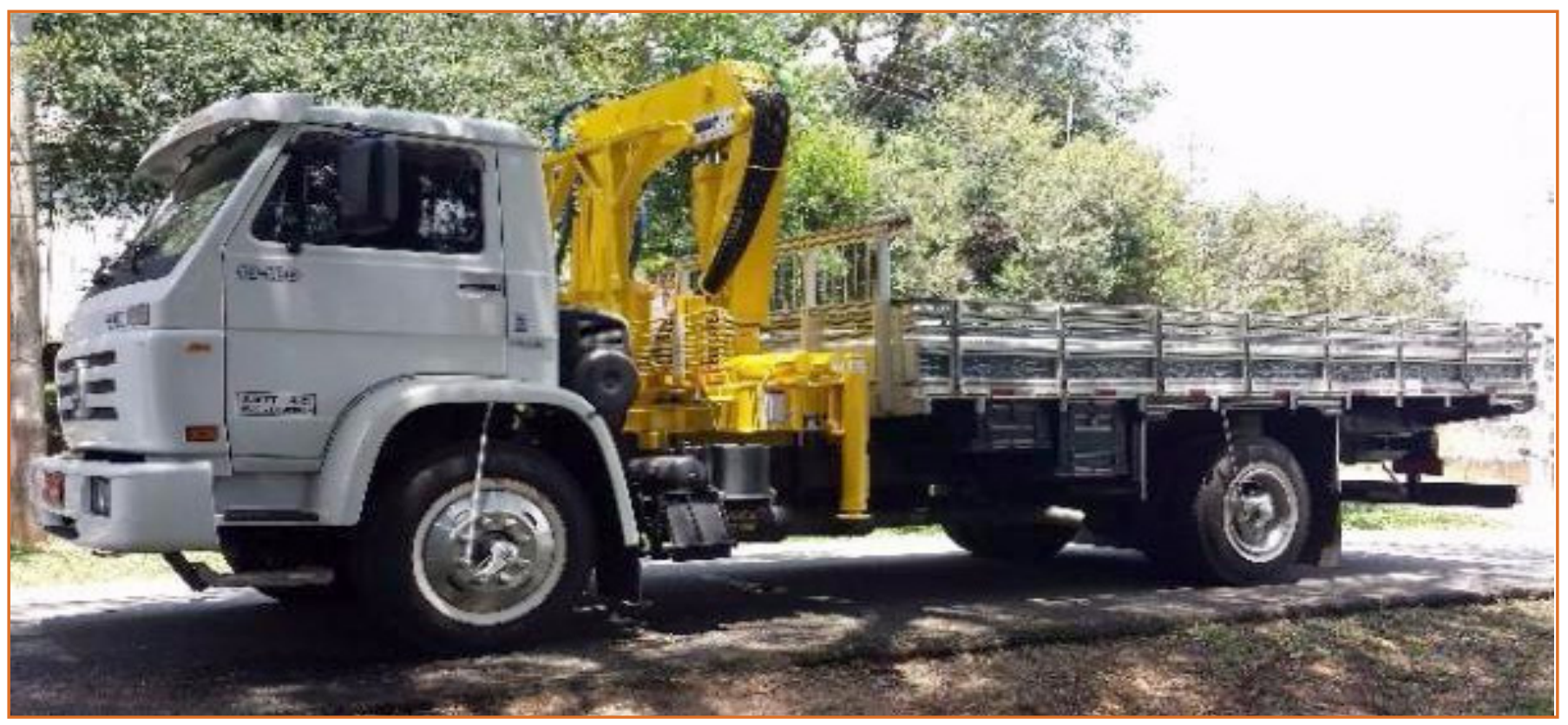

Os custos fixos englobam mão-de-obra, EPI e manutenção da fábrica. A quantidade de funcionários foi estimada de acordo com fábricas já existentes. Foram considerados dez funcionários incluindo produção e escritório. O salário foi calculado tendo como base o piso salarial da região envolvendo os encargos. Dos dez funcionários, seis compõe a produção. Portanto a quantidade de EPI's é estabelecida pelo tempo de vida útil do equipamento multiplicado pelo quadro de funcionários. Já o valor para a manutenção da fábrica foi encontrado em trabalhos e artigos relacionados ao estudo.
Os custos variáveis envolvem a matéria-prima, energia e embalagem. Como matérias-primas para a produção de blocos de concreto podemos citar: areia, cimento, pedrisco e água. A energia é calculada em relação ao consumo da máquina sendo acrescido um valor simbólico para o restante da fábrica. A embalagem do produto é composta por pallets e filme plástico strech. Para a determinação dos valores também foram analisadas tarifas e preços dos produtos.

O preço de venda foi estipulado de acordo com os valores médios usados por fábricas do mesmo setor. 
Sendo assim, o preço unitário considerado é de $R \$$ 2,30 .

Como já dito, a produção foi estipulada conforme a demanda da região. Para a formulação do DRE foi considerada a produção de 240.000 blocos no primeiro ano, e para os anos seguintes 480.000 blocos, analisando 5 anos de operação. Os impostos foram calculados com base no regime tributário Simples Nacional (2006), previsto em lei. A Tabela 2 contém os impostos que devem ser considerados e seus respectivos valores.

Tabela 2 - Impostos para pequenas empresas

\begin{tabular}{|l|l|}
\hline Impostos & $12 \%$ \\
\hline ICMS & $7,60 \%$ \\
\hline COFINS & $1,65 \%$ \\
\hline PIS & $6,60 \%$ \\
\hline \multirow{2}{*}{ IR* } & $8,60 \%$ \\
\hline \multirow{2}{*}{$\begin{array}{l}\text { * O valor do IR muda conforme a receita bruta acumulada, } \\
\text { assim a alíquota do primeiro ano é diferente das demais. }\end{array}$} \\
\hline
\end{tabular}

Fonte: Elaborada pelos autores

A análise de viabilidade econômica segue os passos citados na literatura, e conforme o resultado da mesma é verificado se o projeto é viável ou não. Para tanto foram utilizados os seguintes métodos: Payback (Simples e Descontado), VPL (Valor Presente Líquido), TIR (Taxa Interna de Retorno), VAUE (Valor Anual Uniforme Equivalente) e IL (Índice de Lucratitvidade). Para os cálculos, o valor da Taxa Mínima de Atratividade (TMA) considerado é de $10 \%$, sendo superior ao valor da poupança anual estimada em $6 \%$ a.a.

\section{RESULTADOS E DISCUSSÕES}

Com a soma de todos os investimentos necessários para inicio da produção de blocos de concreto, obtivemos o valor de $\mathrm{R} \$ 540.000$, composto pelos valores já descritos na Tabela 3.

Em relação aos custos de produção, após a coleta de dados foram obtidos os valores expostos na Tabela 3 , que inclui a soma total para os custos fixos e variáveis.

Tabela 3 - Custos totais para uma fábrica de blocos de concreto

\begin{tabular}{|c|c|c|c|c|c|}
\hline $\begin{array}{l}\text { Custos } \\
\text { Fixos }\end{array}$ & \multicolumn{2}{|c|}{ Valores (anual) } & $\begin{array}{l}\text { Custos } \\
\text { Variáveis }\end{array}$ & \multicolumn{2}{|c|}{$\begin{array}{l}\text { Valores/un. } \\
\text { (anual) }\end{array}$} \\
\hline $\begin{array}{l}\text { Mão de } \\
\text { obra }\end{array}$ & $\mathrm{R} \$$ & $156.000,00$ & $\begin{array}{l}\text { Matéria- } \\
\text { prima }\end{array}$ & $\mathrm{R} \$$ & 0,87 \\
\hline \multirow[t]{3}{*}{ EPI } & $\mathrm{R} \$$ & $1.086,00$ & Energia & $\mathrm{R} \$$ & 0,06 \\
\hline & $\mathrm{R} \$$ & $30.000,00$ & Embalagem & $\mathrm{R} \$$ & 0,05 \\
\hline & - & & Água & $\mathrm{R} \$$ & 0,03 \\
\hline TOTAL & $\mathbf{R} \$$ & $187.086,00$ & TOTAL & $\mathbf{R} \$$ & 1,01 \\
\hline
\end{tabular}

Fonte: Elaborada pelos autores

Com esses valores em mão tornou-se possível montar o DRE para cinco períodos do projeto em questão, que pode ser visualizado na Figura 5.

Figura 5 - Planilha de um DRE para uma fábrica de blocos 
de concreto

\begin{tabular}{|c|c|c|c|c|c|c|c|c|c|c|}
\hline DRE & & 2015 & & 2016 & & 2017 & & 2018 & & 2019 \\
\hline Receita bruta & $\mathrm{R} \$$ & $552,000.00$ & RS & $1.104 .000,00 \mathrm{~F}$ & $\mathrm{R} \$ 1$ & $1.104 .000,00$ & $R \$ 1$ & $1.104 .000,00$ & $R \$ 1$ & $1.104 .000,00$ \\
\hline Volume & & $240.000,00$ & & $480.000,00$ & & $480.000,00$ & & $480.000,00$ & & $480.000,00$ \\
\hline Preço & $\mathrm{R} \$$ & 2,30 & $\mathrm{R} \$$ & $2,30 \mathrm{~F}$ & & 2,30 & $\mathrm{R} \$$ & 2,30 & $\mathrm{R} \$$ & 2,30 \\
\hline Impostos sobre Receita Bruta & $R \$$ & $117.300,00$ & $R \$$ & $234.600,00 \mathrm{~F}$ & $R \$$ & $234.600,00$ & $R \$$ & $234.600,00$ & $\mathrm{R} \$$ & $234.600,00$ \\
\hline ISS e/ou ICMS e/ou IPI & $\mathrm{R} \$$ & $66.240,00$ & $\mathrm{R} \$$ & $132.480,00 \mathrm{~F}$ & $\mathrm{R} \$$ & $132.480,00$ & $R \$$ & $132.480,00$ & $\mathrm{R} \$$ & $132.480,00$ \\
\hline PIS & $\mathrm{R} \$$ & $9.108,00$ & RS & $18.216,00 \mathrm{~F}$ & $\mathrm{R} \$$ & $18.216,00$ & $\mathrm{R} \$$ & $18.216,00$ & $\mathrm{R} \$$ & $18.216,00$ \\
\hline Cofins & $\mathrm{R} \$$ & $41.952,00$ & RS & $83.904,00 \mathrm{~F}$ & $\mathrm{R} \$$ & $83.904,00$ & $\mathrm{R} \$$ & $83.904,00$ & $\mathrm{R} \$$ & $83.904,00$ \\
\hline Receita líquida & $\mathrm{R} \$$ & $434.700,00$ & $R \$$ & $869.400,00 \mathrm{~F}$ & $R \$$ & $869.400,00$ & $R \$$ & $869.400,00$ & $R \$$ & $869.400,00$ \\
\hline Custos do Produto Vendido & $\mathrm{R} \$$ & $420.823,93$ & $\mathrm{RS}$ & $664.561,87 \mathrm{~F}$ & $R \$$ & $664.561,87$ & $\mathrm{R} \$$ & $664.561,87$ & $\mathrm{R} \$$ & $664.561,87$ \\
\hline Custo fixo & $\mathrm{R} \$$ & $177.086,00$ & $R \$$ & $177.086,00 \mathrm{~F}$ & $\mathrm{R} \$$ & $177.086,00$ & $R \$$ & $177.086,00$ & $R \$$ & $177.086,00$ \\
\hline Custo variável & $\mathrm{R} \$$ & $243.737,93$ & $\mathrm{RS}$ & $487.475,87 F$ & $\mathrm{R} \$$ & $487.475,87$ & $\mathrm{R} \$$ & $487.475,87$ & $\mathrm{R} \$$ & $487.475,87$ \\
\hline Lucro Operacional + Lajirda & $\mathrm{R} \$$ & $13.876,07$ & RS & $204.838,13 \mathrm{~F}$ & $\mathrm{R} \$$ & $204.838,13$ & $R \$$ & $204.838,13$ & $\mathrm{R} \$$ & $204.838,13$ \\
\hline Depreciação & $\mathrm{R} \$$ & $1.500,00$ & RS & $3.000,00 \mathrm{~F}$ & $\mathrm{R} \$$ & $3.000,00$ & $R \$$ & $3.000,00$ & $R \$$ & $3.000,00$ \\
\hline Amortização e outros dedutíveis & $R \$$ & - & RS & - & $\mathrm{R} \$$ & - & $R \$$ & - & $\mathrm{R} \$$ & - \\
\hline Lucro antes dos juros e IR - Lajir & $R \$$ & $12.376,07$ & $\mathrm{RS}$ & $201.838,13 \mathrm{~F}$ & $R \$$ & $201.838,13$ & $\mathrm{R} \$$ & $201.838,13$ & $\mathrm{R} \$$ & $201.838,13$ \\
\hline Juros & $\mathrm{R} \$$ & - & $\mathrm{R} \$$ & - & $R \$$ & - & $\mathrm{R} \$$ & - & $\mathrm{R} \$$ & - \\
\hline Lucro antes IR - Lajir & $\mathrm{R} \$$ & $12.376,07$ & RS & $201.838,13 \mathrm{~F}$ & $R \$$ & $201.838,13$ & $\mathrm{R} \$$ & $201.838,13$ & $\mathrm{R} \$$ & $201.838,13$ \\
\hline Imposto de Renda & $\mathrm{R} \$$ & $816.82,00$ & $\mathrm{RS}$ & $17.358,08 \mathrm{~F}$ & $\mathrm{R} \$$ & $17.358,08$ & $\mathrm{R} \$$ & $17.358,08$ & $R \$$ & $17.358,08$ \\
\hline Lucro Líquido & $\mathrm{R} \$$ & $11.559,25$ & $R \$$ & $184.480,05 \mathrm{R}$ & $R \$$ & $184.480,05$ & $R \$$ & $184.480,05$ & $R \$$ & $184.480,05$ \\
\hline Lucro Líquido Acumulado & $R \$$ & $816.82,00$ & $\mathrm{R} \$$ & $196.039,30 \mathrm{P}$ & $\mathrm{R} \$$ & $380.519,35$ & $\mathrm{R} \$$ & $564.999,41$ & $\mathrm{R} \$$ & $749.479,46$ \\
\hline
\end{tabular}

Nota-se que os campos de amortização e juros na Figura 5, não possuem valores, já que não foram considerados empréstimos para o investimento na fábrica. Também percebe-se que o lucro líquido aumenta significativamente a partir do segundo ano de operação, pois o volume de produção é dobrado.

O valor da depreciação incluso na Figura 5 é referente ao cálculo da mesma através do método das unidades produzidas, que tem como base a capacidade total da máquina e o volume produzido no período, sendo a vida útil da máquina 10 anos.

Analisando o investimento pelo método do Payback Simples, é possível perceber que o retorno para o investimento inicial acontece no quarto ano de produção. Pelo método do Payback descontado obteve-se um valor igual a 0,996.

Já de acordo com o método do Valor Presente Líquido o índice VPL o valor encontrado foi de R $\$ 2.123,81$. Em relação a Taxa Interna de Retorno o valor da taxa é de
$10,13 \%$, maior que a taxa TMA considerada para os cálculos.

O Valor Anual Uniforme Equivalente obtido foi de -R\$ 142.450,64, e o índice de lucratividade foi de 1,116.

Os resultados obtidos por cada método podem ser encontrados na Tabela 4.

Tabela 4 - Resultados para análise de investimento em uma fábrica de blocos de concreto

\begin{tabular}{|l|l|}
\hline MÉTODO & RESULTADO \\
\hline PBC & 0,996 períodos \\
\hline VPL & $\mathrm{R} \$ 2.123,81$ \\
\hline TIR & $10,13 \%$ \\
\hline VAUE & $-\mathrm{R} \$ 142.450,64$ \\
\hline IL & 1,116 \\
\hline
\end{tabular}

Fonte: Elaborada pelos autores

Com os cálculos pelo método do Payback Simples 
identificou-se que o investimento inicial tem retorno no quarto ano de produção, indicando que o projeto apresenta baixo risco já que tal retorno é obtido dentro do período estipulado para a formulação do DRE.

Em relação ao Payback descontado o projeto pode ser considerado viável, pois o índice de PBC (0,996 períodos) é menor que um.

O valor presente líquido mostrou que quando subtraímos o valor do investimento da somatória do fluxo de caixa corrigido, o valor é de $R \$ 2.123,81$, ou seja, como o valor é positivo ele representa uma rentabilidade superior à mínima aceitável, sendo assim atrativo.

A taxa interna de retorno apresentou um valor de $10,13 \%$, que é maior comparada com o valor da TMA (10\%), sugere maior segurança para o projeto.

De acordo com o Valor Anual Uniforme Equivalente o investimento é viável por apresentar valor inferior aos fluxos de retorno. Para o investimento em um fábrica de blocos de concreto o VAUE é de -R\$142.450,64.

O índice de lucratividade para a análise em questão também indica que o investimento é viável, já que o valor de IL é igual a 1,116 (maior que um).

\section{CONCLUSÃO}

Para a análise de viabilidade econômica é crucial que as pessoas envolvidas obtenham todas as informações referentes ao projeto. É importante que seja estabelecido o valor do investimento e os custos gerados pela produção, para que o lucro líquido calculado ao final do DRE seja fidedigno a realidade.

Para a presente análise foi considerado um cenário no qual o volume de vendas aumenta $100 \%$ no segundo período, com um preço de venda de $\mathrm{R} \$ 2,30$ por bloco, retornando assim uma receita bruta de $R \$$ $552.000,00$ no primeiro ano e de $R \$ 1.104 .000,00$ nos demais anos, indicando que a empresa é de pequeno porte. O custo total gerado pela produção no primeiro ano de $R \$ 420.823,93$ e de $R \$ 664.561,87$ nos anos seguintes. O lucro líquido obtido no primeiro ano foi de $\mathrm{R} \$ 11.559,25$ aumentando para $\mathrm{R} \$ 184.480,05$ nos próximos anos, valores essenciais para o cálculo de análise de investimentos.

Ao término, com base nos índices e metodologias analisadas no cenário, pode-se considerar o investimento atrativo por resultar em valores dentro dos padrões considerados viáveis.

\section{REFERÊNCIAS}

[1] BERNARDI, Luiz Antonio. Manual de Empreendedorismo e Gestão: Fundamentos, Estratégias e Dinâmicas. São Paulo: Atlas, 2003.

[2] BLANK, L., TARQUIN, A. Engenharia Econômica. 6 ed. São Paulo-SP: MC Graw Hill, 2008.

[3] CHIAVENATO, Idalberto. Empreendedorismo: dando asas ao espírito empreendedor. São Paulo: Saraiva, 2004.

[4] KASSAI, José Roberto; KASSAI, Sílvia; SANTOS, Ariovaldo dos; ASSAF NETO, Alexandre. Retorno de Investimento: Abordagem Matemática e Contábil do Lucro Empresarial. São Paulo: Atlas 2000.

[5] MATHIAS, W., WOILER, S. Projetos. São Paulo: Atlas, 1996.

[6] REBElAtTO, D. Projeto de investimento: Com estudo de caso completo na área de serviços. Barueri -SP: Manole, 2004

[7] SANTOS, Edno Oliveira de. Administração Financeira da Pequena e Média Empresa. São Paulo: Atlas, 2001. 


\title{
CAPÍTULO 14
}

\section{PREVISÃO DE DEMANDA EM UMA INDÚSTRIA DE BATATA CHIPS}

\author{
Leticia Fernanda Pires Alves \\ Fabiane Avanzi Rezende \\ Rayane Carla Scheffer \\ Rony Peterson da Rocha
}

Resumo: A batata é um alimento que é consumido em muitos países e dentre os tipos de maneira que é consumida há a batata industrializada, ou seja, a batata chips. Para que as indústrias saibam ao certo quanto devem produzir deste tipo de alimento, elas necessitam de uma previsão de demanda para que tenham sua matéria-prima no momento e com quantidade correta. Por isso, o presente trabalho tem como objetivo realizar a previsão de demanda utilizando uma técnica quantitativa de previsão, a partir do histórico de vendas de uma indústria do ramo alimentício, e posteriormente analisar os resultados obtidos nesta previsão e comparar a demanda real com a previsão fornecida. Os métodos de abordagem utilizados foram o qualitativo e quantitativo. A pesquisa classifica-se quanto aos fins como descritiva e quanto aos meios como pesquisa bibliográfica e estudo de caso, dos tipos tradicional e virtual. A coleta dos dados de previsão de demanda foi realizada em uma indústria de médio porte localizada no Estado do Paraná. Nota-se que a demanda prevista se aproxima da demanda real e que fazendo as análises do MAD, este foi menor que a somatória do erro, mostrando assim, que a técnica sazonalidade simples apresenta boa aceitação com os dados coletados.

Palavras chave: Método Quantitativo, Planejamento e Controle da Produção, Sazonalidade Simples. 


\section{INTRODUÇÃO}

A batata é um alimento originário do Peru que foi levado para a Europa no século XVI por espanhóis e hoje é cultivada por diversos países e consumida por bilhões de pessoas (PEREIRA, 2011). No Brasil, este alimento começou a ser produzida no final do século XIX, quando imigrantes europeus começaram seu cultivo, uma vez que o clima brasileiro era muito favorável para a produção (PEREIRA, 2011).

Segundo dados da Associação Brasileira de Batatas (ABBA), a produção de batata no Brasil em 2010, foi de 3.459.183 toneladas (ABBA, 2011). No estado do Paraná, na safra de 2012, foram plantados 28.690 hectares totalizando a produção de 769.322 toneladas, um rendimento de 26, 82 quilos por hectares (SEAB, 2013).

A partir da batata é possível fabricar diversos alimentos, entre eles estão à batata industrializada e comercializada como batata frita no formato chips, na qual possui corte circular e é consumida como aperitivos e lanches (GOMES et al., 2005).

Para as indústrias que produzem a batata chips saber ao certo quanto devem produzir, é necessário que acompanhem a demanda de seu produto através de previsões de demanda, que tem por finalidade fornecer informações sobre a demanda futura, para que possa ser realizado um planejamento antecipado que garanta os recursos necessários, no momento certo e com qualidade desejada (QUEIROZ; CAVALHEIRO, 2003).

A previsão de demanda é muito importante no sistema produtivo, visto que as informações obtidas por essa previsão permitem que responsáveis deste setor antevejam o futuro e assim, planejam suas ações adequadamente (TUBINO, 2009).

Sendo assim, o presente trabalho tem como objetivo realizar a previsão de demanda utilizando uma técnica quantitativa de previsão, a partir do histórico de vendas de uma indústria do ramo alimentício, e posteriormente analisar os resultados obtidos nesta previsão $e$ comparar a demanda real com a previsão fornecida pela técnica que melhor se adequa ao comportamento dos dados utilizados.

\section{REFERENCIAL TEÓRICO}

\subsection{PREVISÃO DE DEMANDA}

A previsão de demanda é a base para o planejamento estratégico das empresas, tendo a partir disso, condições para realizar os planos de capacidade, de fluxo de caixa, vendas, produção e estoque, entre outros (TUBINO, 2009).

Os métodos de previsão apresentam características comuns entre si, sendo essas a utilização da demanda passada como base para a previsão da demanda futura e os resultados da demanda prevista pelos diferentes métodos não serem exatos, havendo a possibilidade de erro devido aos fatores aleatórios que a previsão de demanda não consegue abranger (MANCUZO, 2003).

É possível obter a previsão a partir de vários métodos, porém alguns fatores devem ser levados em consideração (MANCUZO, 2003), sendo eles:

i) Disponibilidade de dados, tempo e recursos: Existem métodos mais sofisticados que necessitam de profissionais que tenham domínio para trabalhar com os modelos, além dos computadores quando se trabalha com grande variedade de produtos.

ii) Horizonte de previsão: Alguns métodos apresentam melhores resultados quando utilizados em previsões de longo prazo, como anos, e outros em períodos mais curtos, como meses, semanas ou dias.

As técnicas de previsão estão subdivididas em dois grupos, as técnicas qualitativas e as quantitativas (TUBINO, 2009).

As técnicas qualitativas são aquelas em que a previsão é realizada de forma subjetiva pelos previsores ou especialistas, com base em suas intuições, conhecimentos e experiência. (REID; SANDERS, 2002). Existem diversos tipos de técnicas qualitativas de previsão, sendo os mais comuns a opinião dos executivos, pesquisa de mercado e método Delphi (REID; SANDERS, 2002).

As técnicas quantitativas utilizam a modelagem matemática e exigem dados quantificáveis para 
fazerem as previsões, gerando a mesma previsão exata a partir do mesmo conjunto de dados (REID; SANDERS, 2002). Essas técnicas estão divididas em técnicas de séries temporais e técnicas causais, definidas por Reid e Sanders (2002) como:

i) Técnicas de séries temporais: Parte do princípio de que as informações necessárias para realizar uma previsão estão presentes em uma série temporal dos dados, que consiste em observações em intervalos de tempo durante certo período. As ténicas de séries temporais podem ter comportamentos com tendência, sazonal ou cíclico, sendo que para cada um destes comportanemtos existe uma técnica específica;

ii) Técnicas causais: Pressupõem que a variável que se deseja prever é relacionada com outras variáveis do ambiente, sendo necessário saber de que forma estas estão se relacionando e utilizar essas informações obtidas para prever o futuro.

Para a realização do trabalho será utilizado a ténica de séries temporais com sazonalidade, visto que o comportamento dos dados obtidos se adequa à essa técnica.

\subsection{TÉCNICA PARA PREVISÃO DA SAZONALIDADE}

A sazonalidade consiste em variações da demanda em intervalos regulares de tempo, havendo uma razão para ocorrência e posterior repetição deste comportamento (TUBINO, 2009). Refere-se às variações razoavelmente regulares a curto prazo, relacionadas a fatores como clima, feriado e férias (STEVENSON, 2001).

Uma maneira simples de considerar a sazonalidade é utilizar o último dado da demanda no período sazonal e assumi-lo como previsão (TUBINO, 2009).

A sazonalidade de uma série temporal é expressa a partir do valor do desvio padrão dos valores reais em relação ao valor médio da série, sendo este de variação acima e abaixo da média, denominado de índice de sazonalidade (STEVENSON, 2001).
No caso da sazonalidade simples, consiste em obter o índice de sazonalidade para cada período analisado e aplicá-lo sobre a previsão da média em cada um desses períodos (TUBINO, 2009).

O índice de sazonalidade pode ser caculado pela razão da Média do Período pela Média do Período Global, conforme descrito por Gaither e Fraizer (2002, p. 69-70).

Após calcular o índice de sazonalidade para todos os períodos do ciclo sazonal, a previsão de demanda consiste em reaplicar o índice sazonal do período a ser previsto sobre a demanda média (TUBINO, 2009), como mostra a equação 1.

$$
\begin{aligned}
& D \cdot \text { Prev. }=D \cdot M \text { édia }+D \cdot \text { Média }(I S-1) \\
& D \cdot \text { Prev. }=D \cdot M \text { édia }+D \cdot \text { Média }(I S-1)
\end{aligned}
$$

(1)

Onde:

D. Prev: Demanda prevista;

D. Média: Demanda média; e

IS: Índice de sazonalidade.

O conhecimento das variações sazonais é um fator importante para o planejamento e programação de vendas no varejo e para o planejamento da capacidade de sistemas que dão suporte a cargas de pico (STEVENSON, 2001).

\subsection{MANUTENÇÃO E MONITORAMENTO DO MODELO}

Após ter decido a técnica de previsão a ser utilizada é necessário realizar o acompanhamento do desempenho das previsões e verificar a sua validação, sendo este realizado pelo cálculo do erro da previsão, que consiste na diferença entre o valor real da demanda e o valor previsto (TUBINO, 2009).

Uma forma de acompanhar o desempenho da técnica utilizada é verificar o comportamento do erro acumulado, o qual deve tender a zero, visto que espera-se que a técnica gere valores acima e abaixo 
dos reais para assim se anularem (TUBINO, 2009).

O erro médio da previsão pode ser calculado conforme a equação 2 e o desvio padrão médio MAD conforme a equação 3 (ZAN; SELLITTO, 2007).

$$
\begin{aligned}
& E_{t}=\text { D.real }- \text { D. Prev }{ }_{t}
\end{aligned}
$$

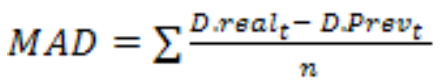

Onde:

$E_{t} E_{t}$ : Erro de previsão para o período t;

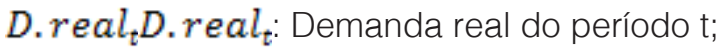

D. Prev ${ }_{t}$ D. Prev : $_{\text {: }}$ Demanda prevista do período t; n: Número de períodos.

\section{METODOLOGIA}

Os métodos de abordagem utilizados foram 0 qualitativo e quantitativo. A pesquisa para o estudo classifica-se quanto aos fins como descritiva, pois descreve-se as principais questões relacionadas a previsão de demanda e, quanto aos meios como pesquisa bibliográfica e estudo de caso, dos tipos tradicional e virtual.

Para a realização da revisão de literatura, foram feitas buscas nos anais do Conbrepro (Congresso Brasileiro de Engenharia de Produção), Enegep (Encontro Nacional de Engenharia de Produção), Simpep (Simpósio de Engenharia de Produção), limitando-se as buscas a partir do ano de 2010, com as palavraschaves, previsão de demanda, planejamento e controle da produção.

A coleta dos dados de previsão de demanda foi realizada em uma indústria de médio porte localizada no Estado do Paraná

\section{REVISÃO DE LITERATURA}

Foram encontrados 30 trabalhos na qual apresentaram outras técnicas de previsão de demanda, conforme segue: Alencar et al. (2010 a), Alencar et al. (2011 b), Alves et al. (2014), Andrade (2013), Assumpção et al. (2013), Azevedo (2011), Barbosa (2014), Benitez et al. (2014), Brandão, R. et al., (2012), Brandão, N. et al. (2012), Cavalheiro; Campos (2014), Ferreira et al. (2013 b), Fontana; Guerreiro (2010), Freitas et al. (2014), Gonçalvez; Negrão; Paiva, (2014), Kanezawa et al. (2014), Martins; Werner; Librelato (2011), Moro (2014), Oliveira; Carvalho (2013), Paiva; Negrão (2014), Pinheiro; Viana; Castro et al. (2013), Pinto (2014), Redante; Lanzer; Valentina (2013), Sampaio; Ribeiro et al. (2013), Santana et al. (2014), Silva et al. (2014), Silva; Silva; Porto (2014), Souza et al. (2013), Veiga et al. (2014) e Wanderley; Silva; Santos (2010).

Foi realizada uma seleção dos artigos e apresentados no Quadro 1, o objetivo de cada um e a técnica utilizada.

Quadro 1 - Análise dos trabalhos encontrados, com seus respectivos objetivos e técnicas utilizadas.

\begin{tabular}{|lll|}
\hline Referência & Objetivo do trabalho & Técnica utilizada \\
\hline (ALVES et al., 2014) & $\begin{array}{l}\text { Realizar a previsão de demanda a partir de uma técnica } \\
\text { quantitativa, com os dados históricos de uma empresa do } \\
\text { ramo alimentício }\end{array}$ & Média móvel exponencial \\
\hline & $\begin{array}{l}\text { Apresentar uma aplicação de previsão de demandas em } \\
\text { uma loja de autopeças da cidade de Belém a fim de que a } \\
\text { organização tenha um maior controle de previsão de suas } \\
\text { vendas e reposição de estoques }\end{array}$ & $\begin{array}{l}\text { Média exponencial ponderada, média móvel e } \\
\text { média móvel ponderada }\end{array}$ \\
\hline (AZEVEDO, 2011) & $\begin{array}{l}\text { Realizar um estudo de previsão de demanda de } \\
\text { movimentação de Diesel, Gasolina e Álcool, no Terminal } \\
\text { Petroquímico de Miramar, utilizando abordagem de séries } \\
\text { temporais e de séries causais }\end{array}$ & $\begin{array}{l}\text { Suavização exponencial dupla, suavização } \\
\text { exponencial simples, média móvel simples, } \\
\text { multiplicativo sazonal, aditivo de Holt-Winters, } \\
\text { multiplicativo de Holt-Winters, regressão }\end{array}$ \\
\hline BARBOSA, 2014) & $\begin{array}{l}\text { Padrão, ARIMA e SARIMA. } \\
\text { Determinar quando e quanto pedir de produto através da } \\
\text { aplicação de ferramentas de tomada de decisão, como a } \\
\text { previsão de demanda e controle de estoque }\end{array}$ & $\begin{array}{l}\text { Método de decomposição das séries } \\
\text { temporais }\end{array}$ \\
\hline (FONTANA; GUERREIRO & & \\
\hline
\end{tabular}




\begin{tabular}{|c|c|c|}
\hline Referência & Objetivo do trabalho & Técnica utilizada \\
\hline $\begin{array}{l}\text { (OLIVEIRA; CARVALHO, } \\
\text { 2013) }\end{array}$ & $\begin{array}{l}\text { Utilizar de métodos quantitativos de previsão de demanda } \\
\text { para auxiliar na tomada de decisão e manter níveis de } \\
\text { estoques de insumos reduzidos }\end{array}$ & $\begin{array}{l}\text { Média móvel, exponencial móvel e regressão } \\
\text { linear com sazonalidade }\end{array}$ \\
\hline (PINTO, 2014) & $\begin{array}{l}\text { Analisar e descrever a atual técnica de previsão de } \\
\text { demanda para o planejamento de compras de um hospital } \\
\text { oncológico e propor a utilização de uma técnica de previsão } \\
\text { de demanda de curto prazo e mais adequada ao hospital, } \\
\text { a fim de diminuir o capital de giro investido e balancear os } \\
\text { níveis de estoques }\end{array}$ & $\begin{array}{l}\text { Suavização exponencial, média móvel } \\
\text { ponderada, média aritmética, média dos } \\
\text { mínimos quadrados e decomposição }\end{array}$ \\
\hline $\begin{array}{l}\text { (REDANTE; LANZER; } \\
\text { VALENTINA, 2013) }\end{array}$ & $\begin{array}{l}\text { Analisar se a previsão dos especialistas e da venda real } \\
\text { de outras famílias de produtos, melhora a acurácia das } \\
\text { previsões }\end{array}$ & Regressão Linear Simples \\
\hline $\begin{array}{l}\text { (SAMPAIO; RIBEIRO et } \\
\text { al., 2013) }\end{array}$ & $\begin{array}{l}\text { Propor um modelo de previsão de demanda para uma } \\
\text { empresa do setor salineiro, para os anos de } 2011 \text { até } 2020 \text {, } \\
\text { em relação às vendas do sal de refinado de cozinha de } 1 \\
\text { Kg, com base nos dados históricos de demanda dos anos } \\
\text { de } 2013 \text { até } 2022\end{array}$ & $\begin{array}{l}\text { Técnica para previsão de sazonalidade com } \\
\text { tendência }\end{array}$ \\
\hline
\end{tabular}

Pode-se observar que há diversas técnicas de previsão de demanda utilizada em diversas áreas, com diferentes objetivos, sendo normalmente, empregadas várias técnicas em um mesmo trabalho, para uma avaliação de qual se adequa melhor a determinada situação.

\section{ESTUDO DE CASO}

De acordo com o site da empresa, esta começou atuando no ramo alimentício em 1991, na cidade de Terra Boa, interior do Estado do Paraná. Ao dar início a empresa adquiria salgadinhos de milho embalado para a comercialização, com o nome Naturitos, sendo que após algum tempo, foram adquiridos os primeiros equipamentos e a empresa começou a fabricar seus próprios produtos.

No ano de 2001, junto à produção de salgadinhos, a empresa deu início a fabricação de biscoitos com a marca Maria Clara, e hoje conta com uma grande variedade de salgadinhos e biscoitos à base de milho e trigo e com a terceirização de alguns produtos como a batata frita e biscoitos wafer. Na cidade de Engenheiro Beltrão, a empresa contém uma unidade, denominada Mais Sabor, com a produção de batata chips sendo nos sabores natural, churrasco, cebola, frango à passarinho e costelinha de porco.

A empresa conta com fornecedores de batata, gordura, gás e papelão, sendo estes vindos do Paraná e São
Paulo, Bahia, Londrina e Paraná, respectivamente.

Com o excelente trabalho que a empresa vem desempenhando, ela conta com parceiros e fornecedores renomados, matéria-prima de ótima qualidade, excelência profissional e inovação constante dos produtos, além de fazer parte do dia-adia da vida de milhares de brasileiros.

A Tabela 1 apresenta a demanda de vendas de batata chips natural da empresa em estudo, sendo que os dados obtidos abrande o período de Agosto de 2014 à Julho de 2015.

Tabela 1 - Demanda de vendas de batata chips natrual.

\begin{tabular}{|ll|}
\hline PERIODO & $\begin{array}{l}\text { DEMANDA DE VENDAS DE } \\
\text { BATATA CHIPS NATURAL } \\
\text { (Unidades de pacotes) }\end{array}$ \\
\hline Agosto de 2014 & 22.000 \\
\hline Setembro de 2014 & 24.000 \\
\hline Outubro de 2014 & 28.000 \\
\hline Novembro de 2014 & 31.000 \\
\hline Dezembro de 2014 & 26.000 \\
\hline Janeiro de 2015 & 30.000 \\
\hline Fevereiro de 2015 & 30.000 \\
\hline Março de 2015 & 28.000 \\
\hline Abril de 2015 & 24.000 \\
\hline Maio de 2015 & 26.000 \\
\hline Junho de 2015 & 31.000 \\
\hline Julho de 2015 & 29.000 \\
\hline
\end{tabular}


A partir dos dados da Tabela 1, foi gerado o gráfico da demanda de vendas de batata chips natural, a qual está representada na Figura 1.

Figura 1 - Gráfico de demanda de batata chips natural por mês.

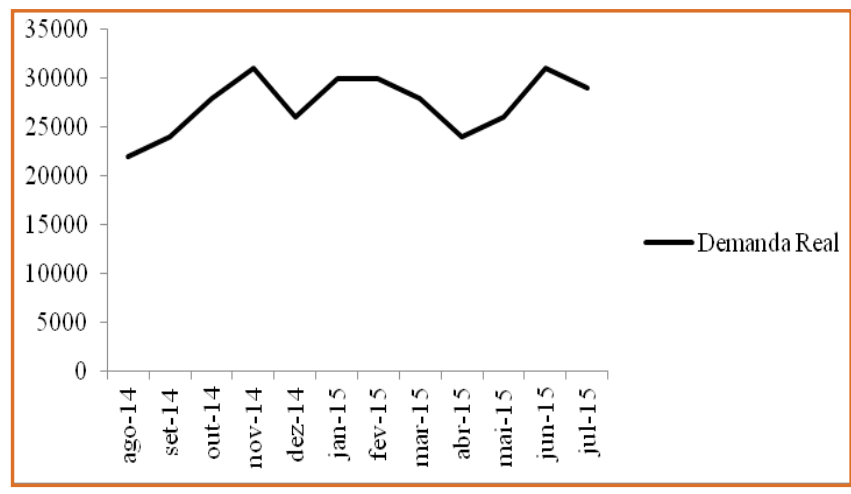

Observa-se pelo gráfico da Figura 1 que a demanda varia com ciclos de 4 períodos. Assim, com base nos estudos realizados na fundamentação teórica e com o gráfico gerado da demanda do produto em estudo, é possível realizar a previsão de demanda para os períodos correspondentes à Agosto de 2015 à Julho de 2016 e, posteriormente comparar os resultados obtidos da previsão com a demanda real, ou seja, o erro da previsão.

Para realizar o cálculo da previsão de sazonalidade simples, inicialmente calculou-se o índice de sazonalidade médio dos períodos, conforme descrito por Gaither e Fraizer (2002, p. 69-70), estando estes presentes na Tabela 2.

Tabela 2 - Índices de sazonalidade médios da demanda

\begin{tabular}{|ll|}
\hline IS MÉDIO & \\
\hline IS1 & 1,062662 \\
\hline IS2 & 0,890672 \\
\hline IS3 & 0,994366 \\
\hline IS4 & 1,054338 \\
\hline
\end{tabular}

A partir dos índices de sazonalidade e utilizando a equação (1) e (2), foi possível realizar a previsão de demanda e seus respectivos erros, conforme mostra a Tabela 3.

Tabela 3 - Previsão calculada com a técnica de sazonalidade simples.

\begin{tabular}{|c|c|c|c|c|}
\hline PERÍODO & DEMANDA MÉDIA & DEMANDA REAL & DEMANDA PREVISTA & ERRO \\
\hline Agosto/2014 & 27859,38 & 22.000 & 29605,1086 & $-7605,11$ \\
\hline Setembro/2014 & 27859,38 & 24.000 & 24813,5701 & $-813,57$ \\
\hline Outubro/2014 & 27859,38 & 28.000 & 27702,4254 & 297,5746 \\
\hline Novembro/2014 & 27859,38 & 31.000 & 29373,196 & 1626,804 \\
\hline Dezembro/2014 & 27859,38 & 26.000 & 29605,1086 & $-3605,11$ \\
\hline Janeiro/2015 & 27859,38 & 30.000 & 24813,5701 & 5186,43 \\
\hline Fevereiro/2015 & 27859,38 & 30.000 & 27702,4254 & 2297,575 \\
\hline Março/2015 & 27859,38 & 28.000 & 29373,196 & $-1373,2$ \\
\hline Abril/2015 & 27859,38 & 24.000 & 29605,1086 & $-5605,11$ \\
\hline Maio/2015 & 27859,38 & 26.000 & 24813,5701 & 1186,43 \\
\hline Junho/2015 & 27859,38 & 31.000 & 27702,4254 & 3297,575 \\
\hline Julho/2015 & 27859,38 & 29.000 & 29373,196 & $-373,196$ \\
\hline
\end{tabular}

Com os resultados obtidos na previsão de demanda da Tabela 3 e através da equação (3), foi possível fazer a análise e monitoramento da técnica adotada a partir do MAD, sendo encontrados os valores que estão presentes no Quadro 1.
Quadro 1: Monitoração da técnica adotada.

\begin{tabular}{|l|l|l|l|}
\hline \multicolumn{4}{|c|}{ TÉCNICA DE SAZONALIDADE SIMPLES } \\
\hline MAD & $4{ }^{\star}$ MAD & $\begin{array}{l}\text { ERRO (A } \\
\text { SOMATÓRIA) }\end{array}$ & MONITORAMENTO \\
\hline 2772,306 & 11089,23 & $-456,908$ & É menor que o erro \\
\hline
\end{tabular}


Como mostra o Quadro 1, a técnica de sazonalidade simples utilizada para realizar a previsão de demanda da batata chips natural atende ao critério de monitonamento, visto que o valor de $4^{*} \mathrm{MAD}$ calculado é menor que a somatória do erro.

A partir dos cálculos realizados para estimar a previsão de demanda, foi possível realizar o gráfico da Figura 2, na qual faz a comparação da demanda real com a previsão de demanda.

Figura 2 - Comparação da demanda real com a demanda prevista.

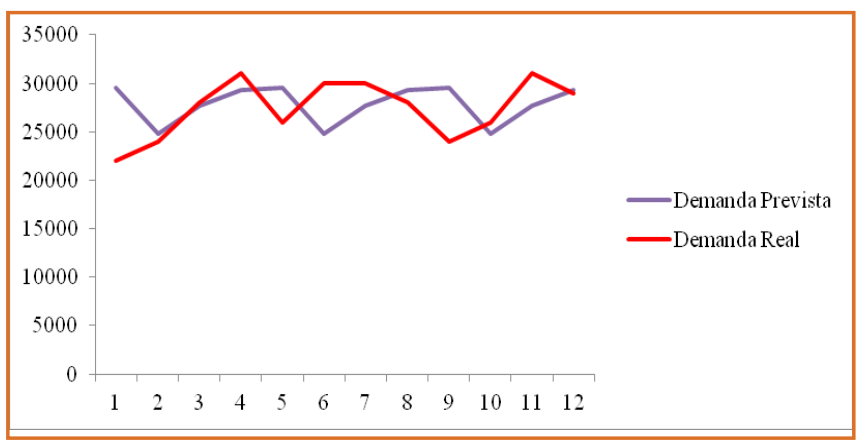

A partir das observações do gráfico da Figura 2, notase que a demanda prevista se aproxima da demanda real, mesmo que em alguns períodos da previsão apresente algumas falhas.

\section{CONSIDERAÇÕES FINAIS}

O estudo mostra a importância da previsão de demanda nas empresas, pois consiste em um meio pelo qual essas empresas podem prever o comportanento que suas vendas apresentarão no futuro e desta forma se preparar para conseguir atender toda a solicitação do mercado e, tendo disponível toda a matéria-prima na quantidade e no momento certo. Sendo assim, a previsão de demanda é fundamental para o setor de Planejamento e Controle da Produção, para que este execute de maneira correta todas as suas funções.

\section{REFERÊNCIAS}

[1] ABBA - Associação Brasileira Da Batata. Situação Real da Cadeira Brasileira da Batata. 2011.

[2] ALENCAR, E. D. M. et al. Alisamento exponencial no processo de previsão: estudo de caso baseado em demanda de navios no porto de Vila Conde. In: SIMPÓSIO DE ENGENHARIA DE PRODUÇÃO. Bauru. Anais... XVIII SIMPEP, Bauru, 2011.

[3] ALENCAR, E. D. M. et al. Análise comparativa entre modelos de alisamento exponencial para previsão de demanda: um estudo de caso no setor de hortaliças regionais de uma empresa supermercadista atuante em Belém do Pará. In: SIMPÓSIO DE ENGENHARIA DE PRODUÇÃO. Bauru. Anais... XVII SIMPEP, Bauru, 2010.

[4] ALVES, L. F. P. et al. Estudo de caso: utilização de um modelo quantitativo de previsão de demanda aplicado em uma agroindústria. In: CONGRESSO BRASILEIRO DE ENGENHARIA DE PRODUÇÃO. Ponta Grossa. Anais... IV CONBREPRO, Ponta Grossa, 2014.

[5] ANDRADE, W. R. Aplicação de modelo de previsão de demanda no tratamento de tuberculose na secretaria municipal de saúde da cidade de Marabá - PR. In: SIMPÓSIO DE ENGENHARIA DE PRODUÇÃO. Bauru. Anais... XX SIMPEP, Bauru, 2013

[6] ASSUMPÇÃO, R. C. et al. Aplicação de técnicas de previsão de demanda para projetar os dias de utilização de sondas de manutenção. In: ENCONTRO NACIONAL DE ENGENHARIA DE PRODUÇÃO. Salvador. Anais... XXXIII ENEGEP, Salvador, 2013.

[7] AZEVEDO, C. M. et al. Estudo de previsão de demandas aplicado à uma empresa de comércio de autopeças. In: SIMPÓSIO DE ENGENHARIA DE PRODUÇÃO. Bauru. Anais... XVIII SIMPEP, Bauru, 2011.

[8] BARBOSA, C. L. R. Estudo de previsão de demanda de movimentação de diesel, gasolina e álcool, no terminal petroquímico de miramar, utilizando abordagem de séries temporais e séries causais. In: ENCONTRO NACIONAL DE ENGENHARIA DE PRODUÇÃO. Curitiba. Anais... XXXIV ENEGEP, Curitiba, 2014

[9] BENITEZ, G. B. et al. Alinhamento da produção através de previsão de demanda. In: CONGRESSO BRASILEIRO DE ENGENHARIA DE PRODUÇÃO. Ponta Grossa. Anais... IV CONBREPRO, Ponta Grossa, 2014.

[10] BRANDÃO, N. B. et al. aplicação de gráficos de controle com limites móveis na modelagem da demanda de passageiros do aeroporto internacional de belém a partir da suavização exponencial de Holt-winters. In: ENCONTRO NACIONAL DE ENGENHARIA DE PRODUÇÃO. Bento Gonçalves. Anais... XXXII ENEGEP, Bento Gonçalves, 2012. 
[11] BRANDÃO, R. et al. Dimensionamento de um modelo de previsão de demanda para um empresa do ramo alimentício. In: SIMPÓSIO DE ENGENHARIA DE PRODUÇÃO. Bauru. Anais... XIX SIMPEP, Bauru, 2012.

[12] CAVALHEIRO, J. L.; CAMPOS, R. Aplicação de modelos de previsão de demanda em uma pequena empresa familiar de confecções. In: SIMPÓSIO DE ENGENHARIA DE PRODUÇÃO. Bauru. Anais... XXI SIMPEP, Bauru, 2014.

[13] FERREIRA, V. E. S. et al. Proposta de modelagem de um sistema de previsão de demanda em linguagem de programação Java. In: ENCONTRO NACIONAL DE ENGENHARIA DE PRODUÇÃO. Salvador. Anais... XXXIII ENEGEP, Salvador, 2013.

[14] FERREIRA, V. E. S. et al. Utilização de um modelo quantitativo de previsão de demanda para análise da demanda por concreto em uma empresa do Oeste Potiguar. In: ENCONTRO NACIONAL DE ENGENHARIA DE PRODUÇÃO. Salvador. Anais... XXXIII ENEGEP, Salvador, 2013.

[15] FONTANA, M.; GUERREIRO, K. M. S. Um estudo de caso da aplicação de ferramentas da tomada de decisão para atender à demanda futura e controle do estoque de uma PME. In: SIMPÓSIO DE ENGENHARIA DE PRODUÇÃO. Bauru. Anais... XVII SIMPEP, Bauru, 2010.

[16] FREITAS, J. F. Análise de demanda em uma empresa produtora de polpa de açaí, utilizando o modelo de média móvel simples. In: ENCONTRO NACIONAL DE ENGENHARIA DE PRODUÇÃO. Curitiba. Anais... XXXIV ENEGEP, Curitiba, 2014.

[17] GAITHER, Norman; FRAZIER, Greg. Administração da Produção e Operações. 8ª . Ed. São Paulo: Pioneira, 2002.

[18] GOlÇAlVES, M. C.; NEGRÃO, L. L.; PAIVA, M. H. P. Análise comparativa de modelos de previsão de demanda por meio de estudo de caso. In: SIMPÓSIO DE ENGENHARIA DE PRODUÇÃO. Bauru. Anais... XXI SIMPEP, Bauru, 2014.

[19] GOMES, C. A. O. Coleção Agroindústria Familiar: Batata Frita. 2005

[20] KANEZAWA, R. A. C. Utilização do método de Holt Winters para a previsão de vendas em uma casa lotérica. In: ENCONTRO NACIONAL DE ENGENHARIA DE PRODUÇÃO. Curitiba. Anais... XXXIV ENEGEP, Curitiba, 2014.

[21] MARTINS, V. M.; WERNER, L.; LIBRELATO, T, P. Previsões de demanda de alto- Um alantes em garantia: a contribuição da combinação de previsões. In: SIMPÓSIO DE ENGENHARIA DE PRODUÇÃO. Bauru. Anais... XVIII SIMPEP, Bauru, 2011.

[22] MAZUCO, F. Análise e previsão de demanda: estudo de caso em uma empresa distribuidora de rolamentos. 2003. 142 f. Dissertação (Mestrado em Engenharia com ênfase em Logística) - Escola de Engenharia, Universidade Federal do Rio Grande do Sul, Porto Alegra, 2003.
[23] MEDEIROS, F. S. B. et al. Previsão de demanda: um estudo de caso em uma empresa de comércio e prestação de serviços de Santa Maria - RS. CONGRESSO BRASILEIRO DE ENGENHARIA DE PRODUÇÃO. Ponta Grossa. Anais... I CONBREPRO, Ponta Grossa, 2011.

[24] MORO, M. F. et al. Previsão de demanda: uma aplicação do método de Holt Winters em uma indústria moveleira de pequeno porte. In: ENCONTRO NACIONAL DE ENGENHARIA DE PRODUÇÃO. Curitiba. Anais... XXXIV ENEGEP, Curitiba, 2014

[25] OLIVEIRA, U. M. B.; CARVALHO, F. L. S. Comparação de técnicas de previsão de demanda para controle de estoques de embalagem para computadores. In: ENCONTRO NACIONAL DE ENGENHARIA DE PRODUÇÃO. Salvador. Anais... XXXIII ENEGEP, Salvador, 2013.

[26] PAIVA, M. H. P.; NEGRÃO, L. L. L. Análise de métodos de previsão de demanda: aplicação na indústria cerâmica. In: ENCONTRO NACIONAL DE ENGENHARIA DE PRODUÇÃO. Curitiba. Anais... XXXIV ENEGEP, Curitiba, 2014.

[27] PEREIRA, A. S. A evolução da cultura da batata no Brasil. In: CONGRESSO BRASILEIRO DE OLERICULTURA, 51., 2011. Anais... Viçosa: Horticultura Brasileira, 2011.

[28] PINHEIRO, A. R.; VIANA, F. L. E.; CASTRO, E. A. L. aplicação de técnicas de previsão de demanda na indústria de confecções. In: ENCONTRO NACIONAL DE ENGENHARIA DE PRODUÇÃO. Salvador. Anais... XXXIII ENEGEP, Salvador, 2013.

[29] PINTO, K. A. C. O desafio do planejamento de compra em um hospital oncológico com foco em sua previsão de demanda: estudo de caso. In: SIMPÓSIO DE ENGENHARIA DE PRODUÇÃO. Bauru. Anais... XXI SIMPEP, Bauru, 2014.

[30] QUEIROZ, A. A.; CAVAlHEIRO, D. C. Método de previsão de demanda e detecção de sazonalidade para o planejamento da produção de indústrias de alimentos. In: ENCONTRO NACIONAL DE ENGENHARIA DE PRODUÇÃO, 23., 2003, Minas Gerais. Anais... ENEGEP, Minas Gerais, 2003.

[31] REDANTE, V.; LANZER, E. A.; VALENTINA, L. V. O. D. Previsão de demanda com incorporação de conhecimento passado de especialistas: um estudo de caso em uma indústria de motobombas. In: CONGRESSO BRASILEIRO DE ENGENHARIA DE PRODUÇÃO. Ponta Grossa. Anais... III CONBREPRO, Ponta Grossa, 2013.

[32] REID, R. D.; SANDERS, N. R. Previsões. In: REID, R. D.; SANDERS, N. R. Gestão de Operações. LTC, 2002. p. 141164.

[33] SAMPAIO, P. G. V.; RIBEIRO, H. D. S. Análise da demanda por sal refinado de cozinha: estudo de caso numa empresa Mossoroense. In: ENCONTRO NACIONAL DE ENGENHARIA DE PRODUÇÃO. Salvador. Anais... XXXIII ENEGEP, Salvador, 2013. 
[34] SANTANA, P. H. S. Estratégia de produção auxiliando no desenvolvimento de um produto a partir de resíduos do coco verde. In: SIMPÓSIO DE ENGENHARIA DE PRODUÇÃO. Bauru. Anais... XXI SIMPEP, Bauru, 2014.

[35] SEAB - Secretária de Agricultura e do Abastecimento. Produção Agropecuária: Área e produção agrícola no estado do Paraná e comparativo com o Brasil. 2013. Disponível em: <http://www.agricultura.pr.gov.br/>. Acesso em: 04 de jun. 2015.

[36] SILVA, R. B.; SILVA, F. S.; PORTO, A. G. Aplicação de técnicas quantitativas de previsão de demanda em uma indústria do setor alimentício. In: SIMPÓSIO DE ENGENHARIA DE PRODUÇÃO. Bauru. Anais... XXI SIMPEP, Bauru, 2014.

[37] SILVA, V. L. et al. Aplicação de técnicas de previsão de demanda em uma associação de materiais recicláveis localizada no estado do Paraná. In: CONGRESSO BRASILEIRO DE ENGENHARIA DE PRODUÇÃO. Ponta Grossa. Anais... IV CONBREPRO, Ponta Grossa, 2014.

[38] SOUZA, A. E. C. et al. Utilização do método Box- jenkins (ARIMA) na previsão de demandas de um produto de uma empresa de beneficiamento de açaí. In: ENCONTRO NACIONAL DE ENGENHARIA DE PRODUÇÃO. Salvador. Anais... XXXIII ENEGEP, Salvador, 2013.
[39] STEVENSON, W. J. Previsões. In: STEVENSON, W. J. Administração das Operações de Produção. LTC, 2001. p. 62-110.

[40] TUBINO, D. F. Planejamento e controle da produção: teoria e prática. São Paulo: Atlas, 2009.

[41] VEIGA, C. P. et al. Previsão de demanda no varejo de alimentos: uma comparação entre os modelos Holt-winters e ARIMA. In: ENCONTRO NACIONAL DE ENGENHARIA DE PRODUÇÃO. Curitiba. Anais... XXXIV ENEGEP, Curitiba, 2014

[42] WANDERLEY, L. C.; SILVA, D. L. R.; SANTOS, A. C. O. A eficiência do planejamento das necessidades de materiais na gestão da produção em uma indústria mineradora do estado do Pará. In: SIMPÓSIO DE ENGENHARIA DE PRODUÇÃO. Bauru. Anais... XVII SIMPEP, Bauru, 2010.

[43] ZAN, G. L.; SELLITTO, M. A. Técnicas de previsão de demanda: um estudo de caso tripo com dados de venda de materiais eletro-mecânicos. Gestão de produção, operações e sistemas, n.2, p. 95-106, jul./set. 2007. 


\section{CAPÍTULO 15}

\section{MÉTODO ABC APLICADO NO TRANSPORTE RODOVIÁRIO DE CARGAS}

\section{Dhiego Troquez}

\section{Gristiane Mallmann Huppes \\ Gabriela Borges Silveira \\ Robson Benedito Farias}

Resumo: O presente trabalho foi desenvolvido com um propósito de aprimorar a função de controle de custos e gestão empresarial, por meio de um estudo de caso com implantação do método de custeio ABC (Activity Based Costing) em uma empresa prestadora de serviços. Este método possui uma abordagem diferente no tratamento dos custos, utilizando direcionadores que identificam de que modo os serviços que consomem os recursos da organização. O sistema demonstrou versatilidade ao permitir ser aplicado com êxito no setor dos serviços. Portanto, ao longo do trabalho foi traçado um modelo baseado neste sistema de custeio, adequado às necessidades da empresa em estudo. O propósito desta pesquisa teve por fundamento a análise do custo das entregas realizadas pela empresa, norteando a metodologia de rateio para se chegar ao custo unitário de entrega. Os resultados do trabalho demonstraram a viabilidade do método de custeio $A B C$, mesmo em ambientes simulados, fornecendo uma importante ferramenta para a tomada de decisões e possibilidade de aplicação em empresas prestadoras de serviços.

Palavras chave: Custeio ABC. Atividades. Custos. Recursos. Serviços. 


\section{INTRODUÇÃO}

Os sistemas de custos emergiram com a finalidade de estruturar os gastos das empresas visando o equilíbrio da rentabilidade do negócio. Nos dias atuais, o enfoque dos custos é direcionado, principalmente, para dar suporte ao processo decisório permitindo que as organizações atinjam seus objetivos com maior eficiência e se possível, com o menor custo. Devido ao aumento dos inúmeros desafios econômicos que surgem, as organizações têm sido conduzidas a uma busca contínua para oferecer maior competitividade e qualidade no mercado atual. Kaplan e Cooper (1998, p. 248) afirmam que as empresas de serviços enfrentam os mesmos problemas gerenciais das indústrias para associar os custos dos recursos aos produtos ou serviços prestados.

As empresas de serviços, de uma maneira geral, também são compostas por atividades. Desse modo, o Custeio Baseado em Atividades - ABC (Activity Based Costing), o qual considera as atividades como as principais responsáveis pelo consumo dos recursos da empresa, pode representar uma importante ferramenta de controle de custos e suprimento das necessidades do setor empresarial de serviços. Nas ultimas décadas o setor de prestação de serviços tem se desenvolvido exponencialmente e chegam a representar a maior participação no Produto Interno Bruto em comparação com outros setores. Os serviços constituem "o grosso da economia de hoje, não só no Brasil, onde respondem por 55\% do Produto Interno Bruto (PIB), mas também no mundo" (LOVELOCK e WRIGHT, 2004, p. 5).

Nesse contexto, o presente trabalho tem intuito de aplicar o sistema de custeio ABC para uma prestadora de serviços. Para isso, elaborou-se um modelo de custeio baseado no conceito $A B C$, aplicado por meio de uma pesquisa exploratória do tipo de caso único. A entidade objeto de estudo é uma empresa de transportes de cargas, localizada na cidade de Dourados- MS, com dados referentes ao período de fevereiro de 2013 a janeiro de 2014. Com os dados e informações obtidas durante a pesquisa, o presente trabalho busca responder a seguinte questão: Como os gastos realizados por uma empresa de transporte são consumidos sob a ótica do Custeio ABC?
A importância de um estudo sobre o custeio ABC se justifica, pela sua aplicabilidade, onde é possível apurar o custo por atividade, tornando possível identificar as atividades que agregam e as que não agregam valores aos serviços, conforme explicam Ribeiro e Camacho (2008, p.38): "Ao identificar as atividades que não agregam valor é possível reduzir seus custos de maneira mais efetiva e, até mesmo eliminá-las, disponibilizando, assim, recursos para serem aplicados nas atividades que sejam essenciais e que agreguem valor".

\section{CUSTEIO ABC (CUSTEIO BASEADO EM ATIVIDADES)}

O método de Custeio Baseado em Atividades $A B C$ (Activity Based Costing) é considerado um dos métodos de custeio mais complexos. Entretanto, "contribui com maior número de informações aos gestores, pelo fato de considerar as atividades e não os produtos ou serviços como responsáveis pelo consumo dos recursos da empresa". (MUNARETTO; DIEDRICH, 2007, p. 73).Conforme Martins (2003, p. 305), o método de custeio $A B C$ pode ser visto "como uma ferramenta de analise dos fluxos de custos e, quanto mais processos interdepartamentais houver na empresa, tanto maiores serão os benefícios do ABC".

Segundo Player (1997, p. 3), o sistema ABC "é uma metodologia que mensura o custo e o desempenho de atividades que, por sua vez, são atribuídas aos objetos de custo, com base em seu uso". Nessa perspectiva, Ching (1995, p. 41) define o ABC, "é um método de rastrear os custos de um negocio ou departamento para as atividades realizadas e de verificar como estas atividades estão relacionadas para a geração de receitas e consumo dos recursos". Dessa forma, - ABC avalia o valor que cada atividade agrega para a performance do negócio ou departamento. Para Nakagawa (1994, p. 40), "trata-se de uma metodologia desenvolvida para facilitar a análise estratégica de custos relacionados com as atividades que mais impactam o consumo de recursos de uma empresa". E acrescenta que, "O ABC é um dado que poderá transformar-se numa poderosa ferramenta de 
alavancagem de atitudes das pessoas envolvidas no processo de mudanças de uma empresa".

A essência do sistema $A B C$ consiste em que as mudanças devem ser feitas nos fatores geradores de custos, influenciando-os, e não nos custos. O ABC é um método de custos que objetiva quantificar as atividades realizadas por uma empresa, aplicando vetores (direcionadores), para destinar as despesas de maneira mais realista aos serviços. Já nossistemas tradicionais, os custos indiretos são rateados para os produtos ou serviços, o que acarreta distorções e, consequentemente, poderá levar o gestor a tomar decisões equivocadas. Portanto, segundo Nakagawa (1994, p. 29), o sistema ABC "busca rastrear os gastos de uma empresa para analisar e monitorar as diversas rotas de consumo dos recursos diretamente identificáveis com suas atividades mais relevantes, e destas para os produtos e serviços". Seguindo esse entendimento Nakagawa (1994, p. 39) ainda afirma que "os recursos de uma empresa são consumidos por suas atividades e não pelos produtos que ela fabrica".

Uma atividade é uma tarefa discreta que uma organização executa para fabricar ou entregar um produto ou serviço. Para empregar o sistema de custeio $A B C$ primeiramente deve se identificar as atividades relevantes em cada setor, e para cada atividade faz necessário atribuir o respectivo custo e identificar o direcionador. Desse modo, identifica-se o custo e o desempenho de cada uma das atividades (HORNGREN; FOSTER; DATAR, 2000; MARTINS, 2003). Resumidamente, "O ABC rastreia as atividades mais relevantes da organização, identificando rotas de consumo dos recursos para, através dessa análise, planejar o uso eficiente e eficaz dos recursos utilizados pela empresa, otimizando seus resultados" (TOREJANI; PANOSSO, 2008, p. 24).

Segundo Martins (1998, p. 96), direcionador de custo é "o fator que determina o custo de uma atividade. Como as atividades exigem recursos para serem realizadas, deduz-se que o direcionador é a verdadeira causa dos custos". O autor ainda salienta a existência de dois tipos de direcionadores: direcionadores de recursos: identifica a maneira como as atividades consomem recursos e serve para custear as atividades, ou seja, demonstra a relação entre os recursos gastos e as atividades; direcionadores de atividades: identifica a maneira como os produtos "consumem" atividades e serve para custear produtos (ou outros custeamentos), isto é, indica a relação entre as atividades e os produtos.

De acordo com Nakagawa (1994, p. 81), a implementação do sistema ABC, implica nosseguintes passos: a) verificar no setor financeiro os itens que estão sendo classificados como custos indiretos e seus respectivos valores; b) segregar os custos entre aqueles que são consumidos pelas atividades destinadas à produção ou prestação de serviços daqueles destinados ao atendimento de clientes; c) separar os departamentos das áreas de suporte; d) separar os custos dos departamentos, transformandoos em centros de custos; e) identificar os centros de atividades que comporão a base do desenho do sistema ABC; f) identificar os direcionadores de custos relativos ao consumo de recursos pelas atividades; g) identificar os direcionadores de custos relativos à apropriação dos custos de atividades aos produtos ou serviços prestados; h) identificar os níveis de atividades; e i) escolher o número de direcionadores de custos.

As principais vantagens do $A B C$ se estabelecem em que esse método visa de minimizar as distorções provocadas por outros métodos de custeio, apurando o custo e auxiliando no processo de tomada de decisão, apresentando resultados mais precisos. Entretanto, como qualquer método de custeio, o ABC também expressa desvantagens e limitações como a complexidade da implantação e operação do sistema $A B C$, e alto custo de implementação e benefícios duvidosos (COGAN, 1999; KHOURY; ANCELEVICZ, 1999).

Para Ostrenga et. al (1997, p. 169), "o custeio baseado em atividades é tão aplicável à organização de serviços quanto à indústria". Tanto nas organizações de serviços como nas industriais, o propósito é tomar decisões gerenciais que tornem as organizações lucrativas e 
competitivas e as mantenham desta forma. "Embora o ABC tenha suas origens nas fábricas, atualmente, muitas empresas de serviços também estão obtendo grandes benefícios com o uso dessa abordagem"(KAPLAN e COOPER, 1998, p. 248). Os autores ainda destacam que, "as empresas de serviços têm exatamente os mesmos problemas gerenciais enfrentados pelas indústrias e que carecem do custeio baseado na atividade para associar os custos dos recursos que fornecem às receitas geradas pelos produtos e clientes específicos atendidos por tais recursos".

Conforme Berts e Kock (1995, p. 57), "uma organização de serviços que implanta o $A B C$ deve estar voltada para o mercado e focada na qualidade para saber se os serviços produzidos são considerados como valor agregado pelo cliente". Dessa maneira, devido ao desenvolvimento econômico e a extensão da competitividade, o setor passou a buscar novas alternativas em gerenciamento e gestão para que pudesse caminhar ao lado desse mercado cada vez mais exigente.

\section{METODOLOGIA DE IMPLANTAÇÃO DO MÉTODO $A B C$}

Para elaboração deste estudo, quanto aos objetivos, utiliza-se a pesquisa exploratória com a finalidade de proporcionar maiores informações sobre 0 assunto investigado (ANDRADE, 2002). Levando em consideração que objetivo deste trabalho é testar, verificar e demonstrar a apuração dos gastos em entidade do setor de serviços sobre a ótica do custeio $A B C$, adotou-se uma pesquisa empírica do tipo de caso único (RIBEIRO; CAMACHO, 2008, YIN, 2001). No que tange a abordagem do problema, optou-se pela análise qualitativa dos dados, onde segundo Beuren (2010, p.92) "as pesquisas qualitativa concebem-se análises mais profundas em relação ao fenômeno que está sendo estudado". Assim, após apuração dos custos sobre a ótica do ABC, elaborouse uma simulação de terceirização e de internalização das atividades.

\subsection{OBJETO DE ESTUDO}

O estudo foi realizado em uma empresa de transportes, localizada na cidade de Dourados Mato Grosso do Sul. Tal empresa tem cunho terciário, prestando serviços de redistribuição de mercadorias para empresas com venda sob encomenda. Os produtos distribuídos têm origem em empresas de cosméticos com fábricas nos estados de São Paulo e Minas Gerais. Estes produtos se referem aos pedidos realizados por consultoras (es) locais, que se encontram nas cidades de abrangência da empresa objeto da pesquisa.

As empresas de cosméticos têm contrato com a transportadora interestadual incumbindo-a da responsabilidade de coleta dos produtos na fábrica e entrega aos destinatários. A transportadora interestadual é então remunerada pelas empresas de cosméticos pelos serviços de transporte. Esta transportadora interestadual terceiriza o serviço de redistribuição por meio da empresa objeto de pesquisa, sediada na cidade de Dourados, tendo a seu cargo os processos de: recepção e guarda dos produtos no depósito da transportadora seguida de entrega das mercadorias no domicílio das(os) revendedoras(es). Davenport (1994, p. 7) escreve que "processo é uma ordenação específica das atividades de trabalho no tempo e no espaço, com um começo, um fim, e inputs e outputs claramente identificados: uma estrutura para a ação". A função da empresa prestadora de serviços de redistribuição tem início no momento da chegada das mercadorias no pátio da transportadora interestadual. A partir da chegada dos produtos na transportadora interestadual, a responsabilidade da empresa prestadora de serviços, objeto de pesquisa, compreende o seguinte processo: separação, roteirização, conferência e carregamento. A estrutura de pessoal que envolve os trabalhos é: 9 (nove) colaboradores em seu quadro de pessoal, sendo 3 (três) colaboradores com salários fixos desenvolvendo suas atividades nas instalações da empresa contratante; 1 (um) colaborador com salário fixo responsável por 1 (uma) das rotas de entrega que compreende 3 (três) cidades do estado do MS; 5 (cinco) colaboradores terceirizados que desenvolvem suasatividades na realização de entregas de 
mercadorias, dispondo de carro próprio, sendo estes responsáveis por 4 (quatro) rotas de entrega em 28 (vinte e oito) cidades deste estado.

\subsection{IDENTIFICAÇÃO E DESCRIÇÃO DAS ATIVIDADES}

Com base no processo atribuído à empresa, objeto de estudo, e por meio de observação direta,foram identificadas e divididas as atividades que seguem:

Atividades Internas:

a) Separação de Mercadorias: realizada por 3 funcionários. A estrutura física necessária compreende: uma empilhadeira manual e prédio da empresa transportadora interestadual.

b) Roteirização: realizada pelas pessoas envolvidas nas rotas. A execução compreende de tempo para ordenar as notas fiscais e selecionar pacotes.

c) Conferência de Mercadorias: a conferência é feita pelos 3 funcionários da empresa.

d) Carregamento: executada também pelos 3funcionários da empresa que se utilizam da empilhadeira manual.

Atividade Externa: Entrega estabelecida por rotas dispostas da seguinte maneira:

a) Rota $A$ : executada por 1 funcionário próprio e veículo da empresa. Consiste na entrega de mercadorias nas cidades de Ponta Porã, Antônio João e Itahum.

b) Rota B: Terceirizada. Entrega na cidade de Dourados.

c) Rota C: Terceirizado. Entrega nas cidades de Rio Brilhante, Prudêncio Thomaz, Itaporã, Montese e Pirapora.

d) Rota D: Terceirizada. Entrega nas cidades de Caarapó, Juti, Iguatemi, Itaquiraí, Eldorado, Coronel Sapucaia, Amambaí, Aral Moreira, Mundo Novo e Laguna Carapã.

e) Rota E: Terceirizada. Entrega nas cidades de Fátima do Sul, Deodápolis, Glória de Dourados, Ivinhema, Naviraí, Nova Andradina, Angélica, Vicentina, Batayporã, Anaurilândia, Jateí e Novo Horizonte do Sul.
As atividades internas estão diretamente relacionadas à quantidade de produtos a serem entregues, consequentemente, o tempo que os funcionários consomem na realização das tarefas aumenta ou diminui de acordo com o volume das cargas. Em relação ao volume de mercadorias e o tempo em que os funcionários estão ativos no edifício da transportadora, que variam conforme o período normal em que os funcionários dedicam, em média, 4hs/dia. E períodos de pico onde os funcionários dedicam o tempo integral da carga horária que é de 8hs/dia, estes períodos ocorrem uma vez ao mês e correspondem a uma semana do mesmo, devido ao ciclo de faturamento das fábricas dos cosméticos.

\section{ANÁLISE E DISCUSSÃO DOS DADOS}

Os custos da folha de pagamento são compostos pelos vencimentos básicos mais encargos sociais como INSS, FGTS, 13ํㅗㄴ salário e férias. Os serviços contratados correspondem aos custos com serviços contábeis e serviços de terceiros que são responsáveis pelas entregas nas rotas. Os gastos com a manutenção do veículo próprio da empresa utilizado na rota A, combustível, hospedagem e alimentação, foram inseridos na pesquisa por meio dos comprovantes de pagamento recolhidos pelo funcionário da empresa na realização de suas atividades de entrega. O cálculo do imposto sobre os serviços consiste na aplicação da alíquota de $6 \%$ sobre o valor bruto total dos serviços prestados devidamente registrados nas notas fiscais emitidas pela empresa em estudo. Este percentual se aplica devido ao fato da empresa estar enquadrada no regime tributário Simples Nacional.

A partir do levantamento das informações e dados utilizados na pesquisa, a soma dos os custos da empresa em estudo, compreendidos entre Fevereiro de 2013 e Janeiro de 2014, estão descritos na Tabela 1: 
Tabela 1 - Recursos financeiros da empresa

\begin{tabular}{|lll|}
\hline Gastos & Valor em R\$ & Consumo de recursos \\
\hline Folha de pagamento & $71.466,67$ & $15,69 \%$ \\
Serviços contratados & & \\
Honorários Contábeis & $6.000,00$ & $1,32 \%$ \\
Serviços de terceiros & $307.882,00$ & $67,59 \%$ \\
Despesas & & \\
Manutenção do veículo & $8.200,00$ & $1,80 \%$ \\
Combustível & $16.685,65$ & $3,66 \%$ \\
Hospedagem & $4.130,00$ & $0,91 \%$ \\
Alimentação & $6.271,55$ & $1,38 \%$ \\
Imposto & $34.840,96$ & $7,65 \%$ \\
Total & $455.476,83$ & $100 \%$ \\
\hline
\end{tabular}

Fonte: dados da pesquisa

\subsection{APLICAÇÃO DO ABC NAS ROTAS DE ENTREGA}

Através da pesquisa documental, fez-se um levantamento dos recursos consumidos para a execução das entregas de cada roteiro, possibilitando a construção da Tabela 2 que resume os gastos de todas as rotas.

Tabela 2 - Recursos financeiros das rotas.

\begin{tabular}{|c|c|c|c|c|c|}
\hline Gastos em R\$ & Rota A & Rota B & Rota C & Rota D & Rota E \\
\hline $\begin{array}{l}\text { Folha de } \\
\text { pagamento }\end{array}$ & 28586,67 & 10720,00 & 10720,00 & 10720,00 & 10720,00 \\
\hline \multicolumn{6}{|c|}{ Serviços contratados } \\
\hline $\begin{array}{l}\text { Honorários } \\
\text { contábeis }\end{array}$ & 1200,00 & 1200,00 & 1200,00 & 1200,00 & 1200,00 \\
\hline $\begin{array}{l}\text { Serviços de } \\
\text { terceiros }\end{array}$ & ------- & 49045,50 & 43420,00 & 84922,50 & 130494,00 \\
\hline \multicolumn{6}{|l|}{ Despesas } \\
\hline $\begin{array}{l}\text { Manutenção do } \\
\text { veículo }\end{array}$ & 8200,00 & ------- & ------- & ------ & ------- \\
\hline Combustível & 16685,65 & ------- & ------- & ------- & ------- \\
\hline Alimentação & 6271,55 & ------- & ------- & ------- & ------- \\
\hline Hospedagem & 4130,00 & ------- & ------- & ------- & -------- \\
\hline Imposto & 8276,81 & 4344,03 & 3727,44 & 7290,27 & 11202,41 \\
\hline Total & 73350,68 & 65309,53 & 59067,44 & 104132,77 & 153616,41 \\
\hline
\end{tabular}

Fonte: dados da pesquisa

A rota de entrega A, compreende o itinerário realizado por funcionário e veículos próprios da empresa destinados unicamente para esta função. Assim, um quarto dos custos com folha de pagamento identificados na Tabela $1(\mathrm{R} \$ 71.466,67)$ corresponde ao colaborador responsável por esta rota $(R \$$ $17.866,67)$ e os três quartos restantes ( $\mathrm{R} \$ 53.600,00)$, representam os outros três funcionários que estão à disposição de todas as cinco rotas de entrega. Sendo assim, o montante de $\mathrm{R} \$ 53.600,00$ será dividido pelas 5 rotas, constituindo o valor de $\mathrm{R} \$ 10.720,00$, da folha de pagamento, para as rotas A, B, C, D e E. Na rota $A$, a quantia de $R \$ 10.720,00$ é somada ao valor de $R \$$ 17.866,67, explicado acima, totalizando o montante de $R \$ 28.586,67$ na folha de pagamento dessa rota.

Na rota A, além dos gastos com folha de pagamento, são somadas as despesas com manutenção do veículo, combustível, hospedagem e alimentação, pois as demais rotas são terceirizadas, sendo tais despesas de inteira responsabilidade dos terceiros. O imposto do roteiro A corresponde à alíquota de $6 \%$ que incide sobre o valor de $R \$ 137.946,90$ sendo este, o faturamento auferido pela rota no período. Os serviços de terceiros representam o valor pago diretamente ao responsável da rota B. Este valor corresponde ao total de 23.355 entregas efetuadas na rota supra citada no período indicado. O montante pago, por entrega realizada, é de $R \$ 2,10$. Sendo que o imposto calculado toma por base o faturamento bruto da rota, ou seja, o valor de $R \$ 72.400,50$ auferidos na nota fiscal.

Todas as entregas realizadas nas rotas C, D e E, têm como valor $\mathrm{R} \$ 6,50$ pois são efetuadas fora da cidade de Dourados. A quantia de serviços de terceiros da rota C correspondem a 6.680 entregas, gerando assim, o montante de $R \$ 43.420,00$. Para o cálculo do imposto desta rota, tomou-se por base de cálculo o valor bruto de faturamento que é de $R \$ 62.124,00$. A rota $\mathrm{D}$ a quantia indicada em serviços é composta por 13.065 entregas efetuadas e cada uma custando $\mathrm{R} \$$ 6,50 para empresa objeto de estudo. Baseado no faturamento bruto, o imposto calculado incidiu sobre o montante de $\mathrm{R} \$ 121.504,50$.

Por fim, as entregas da rota $E$ correspondem a 20.076 entregas efetuadas no período em estudo. Sendo o imposto, calculado com base no faturamento bruto da rota de $\mathrm{R} \$ 186.706,80$. Ao agrupar os custos de todas as rotas em um gráfico, pode-se visualizar 
claramente a parcela de recursos consumida por cada rota em relação ao custo total.

Figura 1 - Recursos consumidos pelas rotas

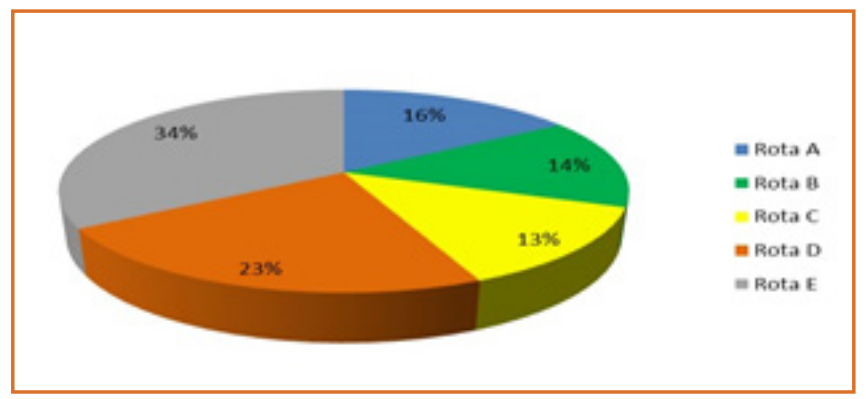

Fonte: Dados da pesquisa.

\subsection{ALOCAÇÃO DOS CUSTOS DAS ATIVIDADES AO OBJETO DE CUSTO}

A alocação dos custos das atividades de entrega das rotas para os objetos de custos é estabelecida através dos direcionadores de atividades. Os custos de entrega das rotas serão alocados com base no número de entregas executada pelo itinerário, permitindo desta forma, apurar o custo unitário de entrega em cada uma das rotas.

Tabela 3 - Alocação dos recursos aos objetos de custos.

\begin{tabular}{|llll|} 
Atividades & Direcionador & $\begin{array}{l}\text { Valor em } \\
\text { R\$ }\end{array}$ & $\begin{array}{l}\text { Valor } \\
\text { unitário em } \\
\text { R\$ }\end{array}$ \\
\hline Entregar Rota A & 14.833 entregas & $73.350,68$ & 4,94 \\
\hline Entregar Rota B & 23.355 entregas & $65.309,53$ & 2,79 \\
\hline Entregar Rota C & 6.680 entregas & $59.067,44$ & 8,84 \\
\hline Entregar Rota D & 13.065 entregas & $104.132,77$ & 7,97 \\
\hline Entregar Rota E & 20.076 entregas & $153.616,41$ & 7,65 \\
\hline
\end{tabular}

Fonte: dados da pesquisa

A princípio, nota-se que a rota $\mathrm{B}$ apresenta o menor custo unitário, isto porque o valor pago por entrega ao terceiro corresponde a $R \$ 2,10$. Uma vez que esta rota é realizada na cidade de Dourados, o deslocamento do terceiro é significativamente menor em relação ao feito pelas demais rotas, corroborando o valor unitário reduzido desta rota $\mathrm{B}$. Em outra análise, embora a rota $E$ tenha demonstrado um custo total maior que as rotas $C$ e $D$, dentre as rotas que custam inicialmente $\mathrm{R} \$$ 6,50 por unidade para a empresa, pode-se notar que o valor unitário final da rota $\mathrm{E}$ é menor que o das rotas $\mathrm{C}$ e $\mathrm{D}$. Portanto, nota-se que quanto maior for a quantidade de entregas destas rotas menor é o custo unitário dispêndio pela empresa na execução desta atividade.

Do mesmo modo, percebe-se que a rota $A$, que é realizada por funcionário e veículo próprios da empresa, apresenta um custo unitário muito abaixo das rotas C, D e E. Tal aspecto pode ser analisado por outra perspectiva, uma vez que o intuito do trabalho consiste em fazer análises baseadas nas informações levantadas e fornecer instrumento de pesquisa que auxilie na tomada de decisões para um gerenciamento consistente e bem amparado. Diante disto, foram elaboradas projeções de quanto seria o custo unitário da entrega se a rota A (própria da empresa) fosse terceirizada e, da mesma forma, se todas as rotas pudessem ser executadas por funcionários e veículos da empresa, viabilizando até mesmo, um caminho que pode futuramente, ser implantado na organização para enxugar custos e proporcionar maximização de ganhos.

\subsection{PROJEÇÃO DE TERCEIRIZAÇÃO DAS ROTAS}

Ao simular um ambiente terceirizado para a Rota A, é necessário realizar algumas adequações, tais como descartar os custos com o funcionário que executa as entregas e as despesas com combustível, manutenção do veículo, alimentação e hospedagem, já que todos estes gastos são de responsabilidade dos terceiros. 
Tabela 4 - Recursos consumidos pelas rotas (terceirizadas)

\begin{tabular}{|c|c|c|c|c|c|}
\hline Gastos em R\$ & Rota A & Rota B & Rota C & Rota D & Rota E \\
\hline Folha de pagamento & 10720,00 & 10720,00 & 10720,00 & 10720,00 & 10720,00 \\
\hline \multicolumn{6}{|l|}{ Serviços contratados } \\
\hline Honorários contábeis & 1200,00 & 1200,00 & 1200,00 & 1200,00 & 1200,00 \\
\hline Serviços de terceiros & 96414,50 & 49045,50 & 43420,00 & 84922,50 & 130494,00 \\
\hline \multicolumn{6}{|l|}{ Despesas } \\
\hline Imposto & 8276,81 & 4344,03 & 3727,44 & 7290,27 & 11202,41 \\
\hline Total & 116611,31 & 65309,53 & 59067,44 & 104132,77 & 153616,41 \\
\hline
\end{tabular}

Fonte: dados da pesquisa

A princípio, nota-se que o custo desta rota aumenta significativamente, demonstrando um acréscimo de 58,98\% em relação a situação real, em que o itinerário é cumprido por funcionário e veículo próprios da empresa. Os serviços de terceiros da rota $A$ correspondem a 14.833 entregas realizadas no período, sendo que o imposto corresponde ao faturamento bruto de $R \$ 137.946,90$. Inserida nessas circunstâncias de terceirização total de entregas, a empresa apresentaria um custo total de $R \$$ $498.737,46$ representando um aumento no consumo de recursos de $9,5 \%$.

\subsection{ALOCAÇÃO DOS CUSTOS DAS ATIVIDADES AO OBJETO DE CUSTO (TERCEIRIZADA)}

A alocação dos custos no âmbito simulado baseada no número de entregas, possibilita a determinação do custo unitário das entregas em cada rota. Inicialmente, percebe-se que ao terceirizar a rota $A$, o custo unitário quase dobra seu valor, demonstrando que a execução deste itinerário pela equipe da empresa gera mais receita do que a terceirização, dado que o custo unitário é consideravelmente menor.

Tabela 5 - Alocação dos recursos aos objetos de custos (terceirizada)

\begin{tabular}{|llll|}
\hline Atividades & Direcionador & Valor em R\$ & Valor unitário em R\$ \\
\hline Entregar Rota A & 14.833 entregas & 116611,31 & 7,86 \\
\hline Entregar Rota B & 23.355 entregas & 65309,53 & 2,79 \\
\hline Entregar Rota C & 6.680 entregas & 59067,44 & 8,84 \\
\hline Entregar Rota D & 13.065 entregas & 104132,77 & 7,97 \\
\hline Entregar Rota E & 20.076 entregas & 153616,41 & 7,65 \\
\hline
\end{tabular}

Fonte: dados da pesquisa

Diante disto, emerge uma última e promissora linha de raciocínio que consiste na simulação de um ambiente em que todas as rotas são realizadas por funcionários e veículos próprios da empresa. Desse modo, quais seriam as vantagens da internalização das rotas? Seria mais rentável para empresa? Para isto, realizouse uma projeção em que todos os custos incorridos na realização das entregas foram assumidos pela empresa.

\subsection{PROJEÇÃO DE INTERNALIZAÇÃO DAS ROTAS}

Para esboçar uma atmosfera simulada, faz-se necessário uma reformulação dos quadros de pessoal e ativos da empresa. Nesta perspectiva, haveria a necessidade de contratação de 8 funcionários; aquisição de 5 veículos. Neste novo ambiente, os valores de despesas de manutenção de veículos, combustível, hospedagem e alimentação serão baseados nos valores identificados na rota A, visto que esta permanecerá com seus dados originais, pois foram elencados com base na pesquisa 
documental. Dentro desta perspectiva, ao elencar os que resume a projeção analisada. recursos reais e projetados, foi elaborada uma tabela

Tabela 6 - Recursos consumidos pelas rotas (internalizadas).

\begin{tabular}{|c|c|c|c|c|c|}
\hline Gastos em R\$ & Rota A & Rota B & Rota C & Rota D & Rota E \\
\hline Folha de pagamento & 28586,67 & 28586,68 & 28586,67 & 28586,67 & 28586,67 \\
\hline \multicolumn{6}{|l|}{ Serviços contratados } \\
\hline Honorários contábeis & 1200,00 & 1200,00 & 1200,00 & 1200,00 & 1200,00 \\
\hline \multicolumn{6}{|l|}{ Despesas } \\
\hline Manutenção do veículo & 8200,00 & 8200,00 & 8200,00 & 8200,00 & 8200,00 \\
\hline Combustível & 16685,65 & 8342,83 & 8342,83 & 33371,30 & 33371,30 \\
\hline Alimentação & 6271,55 & ------- & 3135,77 & 6271,55 & 12543,10 \\
\hline Hospedagem & 4130,00 & ------- & ------- & 4130,00 & 8260,00 \\
\hline Imposto & 8276,81 & 4344,03 & 3727,44 & 7290,27 & 11202,41 \\
\hline Total & 73350,68 & 50673,54 & 53192,71 & 89049,79 & 103363,48 \\
\hline
\end{tabular}

Fonte: dados da pesquisa

A rota B compreende a entrega na cidade de Dourados, sendo desnecessária a despesa com hospedagem e alimentação do funcionário, uma vez que o mesmo reside nesta cidade. O montante consumido na manutenção do veículo será mantida para todas as rotas, posto que todos os veículos serão supostamente iguais. Esta rota apresenta sua variação apenas na despesa com combustível, posto que o veículo percorrerá toda a cidade de Dourados, fazendo uso da metade de combustível gasto na rota A, aproximadamente. Nota-se que o custo diminui significativamente, pois em situação real onde a rota é terceirizada, o custo total é de $R \$ 65.309,53$. Ao internalizar este itinerário observa-se uma redução de $22,41 \%$ no custo da rota.

O trajeto de entrega C é executado em cidades próximas de Dourados, o que permite o não tenha desembolso com hospedagem do funcionário. Contudo, os gastos com alimentação são necessários de serem contabilizados. As variáveis encontradas na rota C correspondem ao combustível e alimentação, posto que o trajeto percorrido é aproximadamente metade do percorrido na rota $A$. Da mesma forma, a alimentação representa metade do valor listado na rota $A$, pois a quantidade de entregas do itinerário C atinge aproximadamente a metade da rota $A$, possibilitando que o funcionário se ausente menos e, consequentemente, faça refeições fora de seu domicílio. Ao internalizar este itinerário observa-se uma redução de $14,21 \%$ no custo da rota.

No itinerário D os gastos com combustível desta rota correspondem aproximadamente ao dobro do consumido na rota $A$ devido à distância entre as cidades em que as entregas são efetuadas. Contudo, as despesas de alimentação e hospedagem encontram-se nas mesmas proporções do trajeto A, uma vez que os dois apresentam as mesmas condições de necessidade destas duas variáveis. Ao internalizar este itinerário observa-se uma redução de $14,49 \%$ no custo da rota. As alterações identificadas correspondem ao combustível consumido, pois a distância percorrida é aproximadamente o dobro em relação à rota $\mathrm{A}$. Da mesma maneira, os custos de hospedagem e alimentação representam o dobro do valor da rota $A$, pois devido ao volume de entregas e à distância do domicílio do funcionário há um grande acréscimo nas diárias e refeições despendidas pelo mesmo. Ao internalizar este itinerário observa-se uma redução de 32,71\% no custo da rota.

\subsection{ALOCAÇÃO DOS CUSTOS DAS ATIVIDADES AO OBJETO DE CUSTO (INTERNALIZADA)}

Ao alocar os recursos no ambiente simulado, foi tomado 
por base o número de entregas como direcionador, possibilitando assim, a determinação do custo unitário das entregas em cada rota, demonstrado na Tabela 7

Tabela 7 - Alocação dos recursos aos objetos de custos da internalização (simulada).

\begin{tabular}{|llll|} 
Atividades & Direcionador & $\begin{array}{l}\text { Valor em } \\
\text { R\$ }\end{array}$ & $\begin{array}{l}\text { Valor } \\
\text { unitário em } \\
\text { R\$ }\end{array}$ \\
\hline Entregar Rota A & 14.833 entregas & 73350,68 & 4,94 \\
\hline Entregar Rota B & 23.355 entregas & 50673,54 & 2,17 \\
\hline Entregar Rota C & 6.680 entregas & 53192,71 & 7,96 \\
\hline Entregar Rota D & 13.065 entregas & 89049,79 & 6,81 \\
\hline Entregar Rota E & 20.076 entregas & 103363,48 & 5,14 \\
\hline
\end{tabular}

Fonte: dados da pesquisa

Diante dos dados elencados, torna-se evidente a redução dos custos em todas as rotas, se estas fossem executadas por colaboradores e veículos da empresa, mesmo que aparentemente, o amplo aumento da folha de pagamento e gastos com os veículos possa gerar receio da parte dos administradores, o que realmente importa é a considerável diminuição dos gastos que resulta em crescimento da receita e consequentemente, dos lucros. Com o objetivo de análise e comparação, elaborou-se um gráfico comparativo da diferença entre o valor unitário das entregas no ambiente terceirizado e no internalizado, para facilitar a visualização de proporcionalidade entre as projeções realizadas.

Figura 2 - Diferença entre as projeções

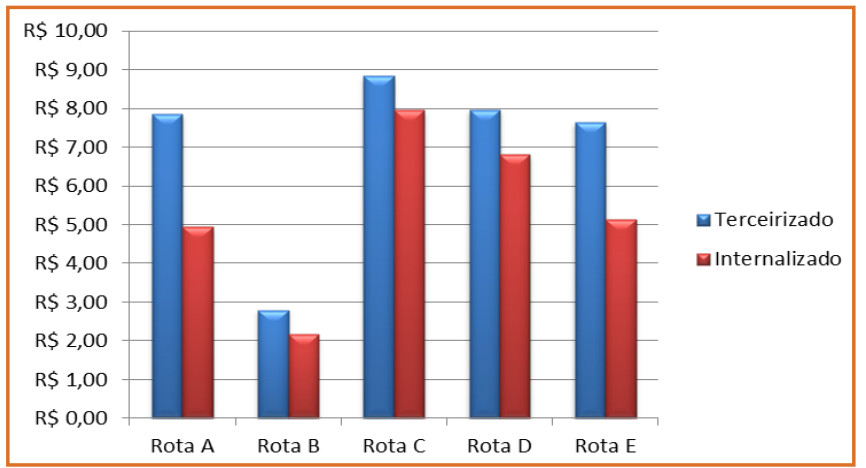

Dado que a rota $A$ já é executada normalmente pela empresa, entende-se que este itinerário está sendo efetuado da melhor maneira, posto que a organização deixe de gastar $\mathrm{R} \$ 2,92$ por entrega se o roteiro fosse terceirizado, representado uma economia de $37,15 \%$ no custo unitário. O itinerário B é realizado por terceiro, o que mostra que a empresa poderia enxugar cerca de $\mathrm{R} \$ 0,62$ por entrega, o que representa uma redução de 22,23\% nos custo desta rota. Também feito por terceiro, embora contenha o menor número de entregas dentre todas as rotas, o trajeto $\mathrm{C}$ poderia gerar uma economia de $\mathrm{R} \$ 0,88$ por entrega para a empresa, representando uma diminuição de 9,96\% de custo unitário.Se fosse executada pela empresa, este roteiro apresentaria uma economia de $\mathrm{R} \$ 1,16$ por entrega, o que representa $14,56 \%$ a menos no custo unitário. Por fim, a rota E representaria uma economia de $\mathrm{R} \$ 2,51$ por entrega, acarretando uma redução de custo unitário de $32,81 \%$ se fosse executado pela organização.

Portanto, fica evidente que a situação em que a empresa reduz o consumo de seus recursos significativamente, é ao internalizar todas as rotas, contratando mais funcionários e adquirindo veículos. Desta forma, ao comprimir os gastos há um aumento de receita e possivelmente um acréscimo dos lucros, que claramente é o objetivo de qualquer organização com fins lucrativos. O montante do custo total estimado, tanto na situação real da empresa quanto nas simulações de terceirização e internalização total das rotas está representado proporcionalmente, na Figura 2 que segue.

Figura 3 - Recursos consumidos pela empresa

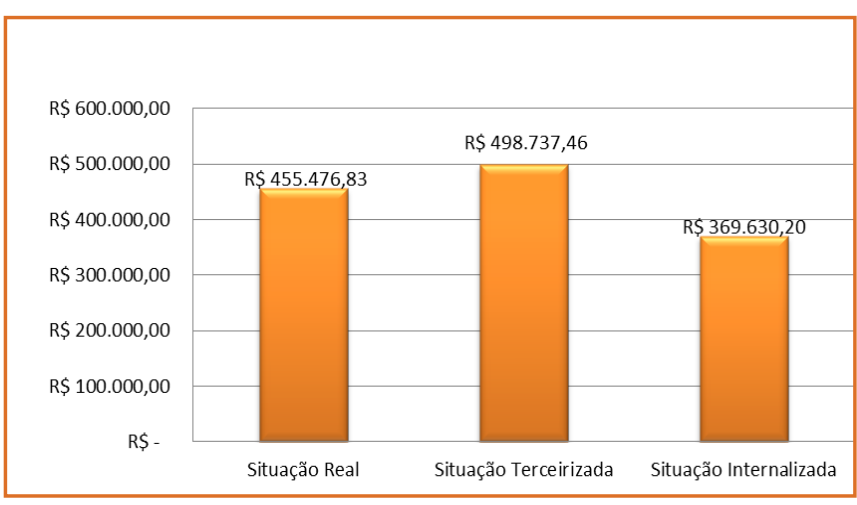

Fonte: dados da pesquisa

$\mathrm{Na}$ Figura 3, a situação real representa os recursos realmente consumidos pela empresa no decorrer do período em estudo. Percebe-se que, ao terceirizar a 
entrega em todas as rotas, há um aumento de 9,5\% no custo total, correspondente ao valor de $\mathrm{R} \$ 43.260,63$ que a organização passaria a gastar além do que já é dispêndio no ambiente normal. Portanto, ao internalizar todos os roteiros e executá-los por meio de funcionários e veículos próprios, a empresa poderia auferir uma economia de $\mathrm{R} \$ 85.846,63$ no período, cerca de 18,85\% menos do que na situação real. Ressalta-se que esta consideração de internalização, não apresenta informações do custo do capital que deverá ser investido, caso haja esta decisão.

\section{CONSIDERAÇÕES FINAIS}

Este trabalho teve como fundamento o levantamento de dados através de visitas, conversas informais, análise documental, pesquisa bibliográfica, que propiciou o desenvolvimento do modelo, discernindo as atividades fundamentais da empresa. Após determinar o custo da entrega realizada através do método de custeio, também foi possível aplicar o modelo em projeções simuladas da empresa em âmbitos diferentes, propiciando uma importante perspectiva de que o modelo não é útil apenas para rastrear os recursos consumidos, mas também para nortear a empresa à uma abordagem de gerenciamento que suprime os gastos na realização de suas atividades. Além de descrever, analisar e mapear as atividades, o modelo proporcionou ao gestor um diferente mecanismo para calcular o consumo de recursos, permitindo a identificação de elementos a ser controlados e a elaboração de estratégias para enxugar os custos. Os resultados da pesquisa permitiram elencar o custo total dos recursos consumidos pela empresa no período, correspondendo a $\mathrm{R} \$ 455.476,83$.

Este trabalho possibilitou a projeção de ambientes simulados em que a organização poderia terceirizar todas as rotas de entrega ou internalizá-las. A projeção terceirizada não demonstrou melhorias no consumo dos recursos, uma vez que o custo total neste ambiente simulado se elevaria para $R \$ 498.737,46$, representando aumento de 9,5\%. Entretanto, na projeção em que as rotas são internalizadas, haveria um enxugamento nos custos de $18,85 \%$ em relação a situação real da organização, onde esta, poderia auferir uma economia de $\mathrm{R} \$$ 85.846,63 reduzindo o custo total do período a $\mathrm{R} \$ 369.630,20$. Logo, através do sistema desenvolvido neste trabalho, a empresa teve acesso a um panorama em que ao internalizar a execução das entregas em todas as rotas, obteria uma significativa ampliação de seus ganhos, uma vez que o modelo demonstrou uma redução maciça dos gastos despendidos neste cenário. Porém, destacase que tais conclusões não levam em consideração o custo do capital dos investimentos e o retorno do mesmo, no caso das internalizações.

\section{REFERÊNCIAS}

[1] ANDRADE, Maria Margarida de. Como preparar trabalhos para cursos de pós-graduação: noções práticas. 5. ed. São Paulo: Atlas, 2002.

[2] BERTS, K. e KOCK, S. Implementation considerations for activity-based cost systems in service firms: the unavoidable challenge. Management Decision, v. 33, n. 6, p. 57-63, 1995.

[3] BEUREN, Ilse Maria; LONGARAY, André Andrade; RAUPP, Fabiano Maury; SOUSA, Marco Aurélio Batista de; COLAUTO, Romualdo Douglas; PORTON, Rosimere Alves de Bona. Como Elaborar Trabalhos Monográficos em Contabilidade: Teoria e Prática. São Paulo: Atlas, 2010.

[4] BEUREN, Ilse Maria; ROEDEL, Ari. O uso do custeio baseado em atividades: ABC (Activity Based Costing) nas maiores empresas de Santa Catarina. Revista Contabilidade \& Finanças, v. 13, n. 30, p. 7-18, 2002

[5] CHING, H. Y. Gestão Baseada em Custeio por Atividades - Activity Based Management. 1. ed. São Paulo: Atlas, 1995.

[6] COGAN, S. Custos e Preços - Formação e Análise. São Paulo: Pioneira, 1999

[7] DAVENPORT, Thomas H. Reeengenharia de processos: como inovar na empresa através da tecnologia da informação. Rio de Janeiro: Campus, 1994. 390p.

[8] HORNGREN, Charles T.; FOSTER, George; DATAR,Srikant M. Contabilidade de Custos. 9a. Edição. Rio de Janeiro: LTC, 2000.

[9] IUDÍCIBUS, Sérgio de. Introdução à teoria da contabilidade: para o nível de graduação. São Paulo: Atlas, 1999.

[10] KAPLAN, R. S. e COOPER, R. Custo e Desempenho Administre seus custos para ser mais competitivo. São Paulo: Futura, 1998. 
[11] KHOURY, C. Y. e ANCELEVICZ, J. A Utilização do Sistema de Custos ABC no Brasil. Revista de Administração de Empresas. São Paulo, v. 39, n. 1, p. 55-63, jan./mar. 1999.

[12] LOVELOCK, C; WRIGHT, L. Serviços: marketing e gestão. Tradução: Cid Knipel Moreira; revisão técnica Mauro Neves Garcia. São Paulo: Saraiva, 2004.

[13] MARTINS, E. Contabilidade de Custos: inclui o ABC. 6. ed. São Paulo: Atlas, 1998.

[14] _. Contabilidade de Custos. 9. ed. São Paulo: Atlas, 2003.

[15] MUNARETTO, Lorimar Francisco; DIEDRICH, Márcia. Custeio variável integrado ao custeio baseado em atividades: estudo de caso em indústria de embalagem para presentes. Revista Universo Contábil, v. 3, n. 1, p. 70-86, 2007.

[16] NAKAGAWA, M. ABC: Custeio Baseado em Atividades. 1. ed. São Paulo: Atlas, 1994.
[17] OSTRENGA, Michael, et. al. Guia da Ernst \& Young para Gestão Total dos Custos. 13 ed. Rio de Janeiro: Record, 1997.

[18] PLAYER, S. AL . ABM: Lições do campo de batalha. São Paulo: Makron Books, 1997.

[19] RIBEIRO, Edinéia Nicolau; CAMACHO, Reinaldo Rodrigues. Custeio ABC em entidades públicas: evidências de sua utilização em um centro municipal de educação infantil. Enfoque: Reflexão Contábil, v. 27, n. 1, p. 37- 52, 2008.

[20] TOREJANI, Hiolanda Nunes; PANOSSO, Alceu. Apuração dos custos em um pet shop pelo método de Custeio Baseado em Atividades. Enfoque: Reflexão Contábil, v. 27, n. 2, p. 21-38, 2008.

[21] YIN, Robert. K. Estudo de Caso: planejamento e método. p.31. Porto Alegre: Bookman, 2001. 


\title{
CAPÍTULO 16
}

\section{O IMPACTO DAS NOVAS TECNOLOGIAS NA GESTÃ O DA PRODUÇÃO: ESTUDO DE CASO EM UMA EMPRESA DE ENGENHARIA E CONSTRUÇÃ̃}

\author{
Eliseu Afonso Soares \\ José Cícero Melo \\ Carlos Rodrigues Silva
}

Resumo: Este artigo tem como propósito apresentar os impactos das novas tecnologias na gestão da produção do concreto usinado. Descreve o processo produtivo da empresa, identificando as possíveis inovações da empresa, como ocorre o processo e demonstrar as possíveis contribuições das novas tecnologias para gestão da produção. Para alcançar o objetivo proposto foi realizada investigação direta com o uso de fontes primárias, por meio de estudo de caso realizado em uma empresa do setor de engenharia e construções com ênfase na produção do concreto usinado, instalada no parque industrial no município de Paranaíba-MS. Utilizou-se da abordagem de pesquisa qualitativa, com método de pesquisa exploratória. A coleta de dados foi por meio de entrevistas, observações e análise em documentos. Concluiu-se que as novas tecnologias implementadas na organização ofereceram uma série de benefícios, como: acelerar o processo produtivo, oferecer um produto de maior qualidade, redução na utilização de mão-de-obra e reduziu o desperdício de matéria-prima.

Palavras chave: Concreto usinado. Gestão da produção. Inovação. 


\section{INTRODUÇÃO}

As inovações tecnológicas podem abranger tecnologias novas ou aperfeiçoar as existentes, um produto pode ser aprimorado, lapidado de acordo com a necessidade do seu uso. Diante deste aparato é que deparamos com tais características encontradas na empresa estudada, a J.C Grande Engenharia e Construções, que trabalha com um simples produto que foi modificado ao longo dos séculos, aperfeiçoado em termos de melhor desempenho e após muitas inovações possibilitou seu aprimoramento e uso nos diversos ramos da construção sendo um dos materiais essenciais.

A prática da inovação como estratégia permite que as empresas busquem constantemente evoluir produtos e serviços, e com isso garante seu espaço no mercado e vantagem na competição pela preferência do cliente. Quando uma empresa oferece um diferencial é possível observar o seu destaque as demais, essas mudanças organizacionais e o desenvolvimento de novos produtos fortalecem a sua estabilidade como percussora de inovação.

Apresentamos como problema de pesquisa quais os impactos das novas tecnologias na gestão da produção de uma empresa que produz concreto usinado tendo em vista que este tipo de inovação vem modificando o cenário do ramo de construções? O objetivo geral é Identificar o impacto das novas tecnologias empregadas na gestão da produção de concreto usinado da empresa J. C. Grande Engenharia e Construções, seqüencialmente especificar o processo produtivo da empresa, identificar as possíveis inovações da empresa e como ocorre o processo e demonstrar as possíveis contribuições das novas tecnologias para gestão da produção.

Esta pesquisa é importante, pois tem como objetivo esclarecer, definir e apresentar o papel das novas tecnologias na gestão da produção em uma empresa que produz concreto usinado, com o desígnio de proporcionar aos gestores da produção e aos proprietários de empresas desse segmento um maior conhecimento das inovações no setor, para aplicálas ou mesmo gerenciar a inovação de modo que os investimentos em novas tecnologias propiciem um maior retorno à empresa e aos clientes. A pesquisa é importante por oferecer aos pesquisadores da área da inovação e gestão da produção um material teórico que descreve o papel das novas tecnologias na gestão da produção.

O desenvolvimento dessa pesquisa é viável, pois apesar de existir vários estudos na área, ainda há lacunas que possibilitam contribuições por meio da a realização de novas pesquisas. É viável, por existir literatura disponível e por considerar que a relação custo-benefício é positiva, já que se trata de pesquisa de cunho acadêmico para desenvolver novos conhecimentos. Por outro lado os benefícios que a pesquisa proporcionará serão importantes, pois pretende contribuir para uma melhor compreensão por parte da comunidade acadêmica, a respeito das novas tecnologias na gestão da produção.

Este trabalho é oportuno, pois pretende esclarecer aos administradores sobre os impactos das novas tecnologias na gestão da produção que visa contribuir nas decisões de novas estratégias e inovações, demonstrando a importância dos conceitos descritos. O estudo, ainda é oportuno devido ao setor da construção civil ser considerado um setor que é visto como atrasado quando se trata de inovação, pois é um segmento em que as inovações são pouco expressivas. Esse setor apresenta problemas como o desperdício de materiais e de mão de obra.

\section{REFERENCIALTEÓRICO}

A seguir serão discutidas as teorias relevantes que darão o suporte necessário à pesquisa no que se refere à parte prática.

\subsection{INOVAÇÃO}

A inovação é um fator essencial que contribui para que as organizações se desenvolvam, tanto na elaboração de novos produtos, processos e formas de se administrar ou melhoramento dos mesmos. As inovações são constantes em empresas de grande porte, esses fatores são convertidos em vantagens competitivas, pois as grandes organizações se preocupam em desenvolver novos produtos para melhor atender seus consumidores (TIDD; BESSANT; PAVITT, 2008). 
É complexo de estabelecer um conceito de inovação, porém teóricos como Moreira e Queiroz (2007) a definem como um processo de inventar algo novo ou quando os produtos existentes são modificados algumas características e assim resulta numa versão melhorada desse produto, para melhor atender as necessidades do público-alvo.

A OCDE (2005) define que inovação é quando se introduz um novo produto (bens ou serviços) ou mesmo cria-se uma versão com um melhoramento significativo, as inovações também podem ocorrer em processos, em marketing, no modelo organizacional em uma organização ou ambiente de trabalho. A inovação pode ocorrer quando determinada empresa cria um produto ou desenvolve um melhoramento significativo em um produto. Pode-se considerar inovação a partir do momento que uma empresa utiliza uma nova tecnologia em seu ambiente interno, toda organização que investe em uma nova tecnologia está inovando.

É importante saber que no mundo ocorrem muitas mudanças tecnológicas, que são o resultado do grande numero de inovações. Com a utilização de um novo conhecimento e as situações experimentais que colaboraram para o rápido avanço tecnológico, esses efeitos deixaram o processo produtivo cada vez mais complexo e as mudanças tecnológicas oriundas das inovações em produtos e em processos tende a ser dinâmico, freqüente e interativo (ANPEI, 1993).

\subsubsection{TIPOS DE INOVAÇÃO}

A inovação ocorre quando é desenvolvido um produto novo ou um melhoramento no existente, ou seja, a inovação no produto deixa-o mais fácil de ser utilizado, menor, mais leve, oferecendo praticidade ao consumidor. A inovação em processos acontece quando surge um novo método de produzir algo ou quando é melhorado o existente, ou seja, com utilização de novas máquinas e equipamentos mais sofisticados resultam em uma maior produção em menos tempo, isso permite redução em gastos com a produção e melhorando qualidade do produto (OCDE, 2005).
As organizações que incorporaram algum tipo de inovação obtiveram melhores resultados, com o conhecimento por parte do nível gerencial/diretoria que adota a inovação em produtos. Com as novas tecnologias, as grandes corporações e as de base tecnológica investiram muito em pesquisa e desenvolvimento (P\&D), por seu alto custo é mais comum em grandes corporações e tem contribuído para o aperfeiçoamento de novos produtos/processos. O P\&D tem como objetivo aumentar o estoque de conhecimentos científicos e tecnológicos, por meio de cientistas e engenheiros é pesquisado e desenvolvido, o melhor método para se produzir e como criar um novo produto ou como será otimizado, por esse motivo requer um alto custo ao empreendedor (MOREIRA; QUEIROZ, 2007; ANPEI, 1993).

A inovação de marketing são modificações significativas na percepção do produto ou em sua embalagem e também na promoção do produto, esse tipo de inovação se preocupa em melhor atender as necessidades dos consumidores, abrindo novos mercados, ou posicionando o produto de uma empresa no mercado, com a finalidade de otimizar as vendas (OCDE, 2005).

A inovação organizacional consiste na introdução de um novo método de negociar ou de se relacionar com fatores externos a empresa, ou seja, a criação de novos métodos para administrar a organização, isso pode gerar a redução de gastos administrativos e redução do tempo em transações, deste modo criase melhorias nas praticas administrativas (OCDE, 2005).

Existe outra maneira de classificar a inovação que são: as inovações incrementais e as inovações radicais, a incremental é o tipo de inovação que apresenta um melhoramento significativo ou adaptações no produto. $E$ as inovações radicais são responsáveis por criar impactos na sociedade, como mudar a estrutura de um mercado e criar novos mercados para os novos produtos, onde os produtos substituídos pela inovação radical tornamse obsoletos (OCDE, 2005; TIDD; BESSANT; PAVITT, 2008). 


\subsection{GESTÃO DA PRODUÇÃO}

A função da produção está presente em diferentes tipos de organizações, não é variável, pois, é a mesma para qualquer tamanho de organização, no entanto, possuem conjuntos de problemas diferentes, a mudança são os objetivos traçados para atender os consumidores por meio de estratégias que melhorem o planejamento e o controle de produção. A administração da produção tem como objetivo gerenciar a produção e disponibilizar bens e serviços para as operações e produções. A parte responsável pela organização desta atividade é exatamente a função de produção existente em toda organização juntamente com a função de marketing e de desenvolvimento de produto/serviço. Todas essas estratégias em conjunto com as funções de apoio que são: função de recursos humanos, compras e engenharia/suporte técnico completam e sustentam esta função (SLACK; CHAMBERS; JOHNSTON, 2009).

De acordo com Slack et al. (2006) a administração da produção se refere às formas pela qual as organizações produzem bens e serviços. Tudo o que é produzido e chega até o consumidor é em razão do resultado final do trabalho de um gerente de produção, permitindo a disponibilização final de produtos e serviços dos quais nos tornamos dependentes. Sendo assim a Administração da produção nada mais é que a coordenação de todos os recursos por meio das funções administrativas para alcançar os objetivos enunciados envolvendo a tomada de decisão.

\subsubsection{IMPACTOS DA INOVAÇÃO NA GESTÃO DA PRODUÇÃO}

Baseado no paradigma atual emergente, a busca por novas tecnologias é fundamental para gerar as inovações, é uma prática que acelera o processo de mudança que otimiza o uso do tempo, como a redução de tempo na produção de bens, a produção aumenta consumo de bens, que pode acarretar em um efetivo negativo como a redução do ciclo de vida dos produtos (LEMOS, 1999).

Para Tigre (2006) a inovação tecnológica se faz uma ferramenta importante para $\mathrm{o}$ aumento da produtividade e competitividade nas empresas, como também para incentivar o crescimento econômico regional e dos países. O desenvolvimento consiste principalmente em um processo de qualidade de transformação da estrutura da produção através da intensificação do uso da informação e do conhecimento, incorporando novos produtos, agregando e processando valor à produção.

O mundo tem muitos exemplos de países que está conseguindo vencer o subdesenvolvimento por meio de investimentos em educação e tecnologia e também à entrada bem-sucedida em setores inovadores e dinâmicos da economia mundial. O desenvolvimento depende primordialmente de transformações que promova empregos de qualidade, criando novas formas de organização, atendendo as necessidades novas do consumidor e melhorando a própria maneira de viver. As corporações mais dinâmicas e lucrativas do mundo são aquelas mais inovadoras que criam seus próprios nichos e obtém de monopólios temporários por meio de patentes e segredos industriais, ao invés de competir em mercados saturados pela concorrência. A geração e apropriação da inovação, portanto, é um processo complicado e difícil que depende não só das qualificações e dos recursos técnico-financeiros de uma empresa, mas também do ambiente institucional no qual estar envolvida e do poder de negociação com fornecedores e clientes (TIGRE, 2006).

As inovações geralmente são introduzidas com o intuito e objetivo de reduzir custos, melhorar a qualidade ou aumentar a capacidade de produção.

Segundo Barbiere (1997), a fase de instalação de uma inovação tecnológica envolve a criação de ferramentas, obtenção e disposição dos recursos de manufatura, bem como a produção inicial, suporte comercial e outras atividades relacionadas às mais críticas do processo de inovação. A forma como uma empresa administra a sua área de produção pode facilitar ou não a realização dessas atividades que, em geral, representam a maior parcela de custos associados a este processo. A inovação que, introduz novidades importantes para a organização requer diversas atividades relacionadas com a produção, 
envolvendo equipamentos, materiais, pessoal, serviços de apoio, procedimentos e programas operacionais. Assim, o uso de instrumentos apropriados de gestão da produção favorece a realização de inovações tecnológicas importantes e facilita a entrada de melhorias no produto ou no processo. Um ambiente interno altamente motivado e com as habilidades necessárias para realizar a introdução de melhorias contínuas são as práticas de administração exigidas em todas as instâncias de inovação.

Ainda para o autor, a área produtiva de uma empresa tem um importante papel a desenvolver nos processos de inovação tecnológica, as inovações favorecem ao uso de instrumentos apropriados a gestão da produção facilitando as melhorias no processo produtivo.

\subsection{INOVAÇÃO NA PRODUÇÃO DE CONCRETO USINADO}

Desde a arquitetura monumental do Egito Antigo às grandes obras grego-romanas e seu aperfeiçoamento para o uso atual, todas as obras simples ou monumentais foram construídas a partir de uma substancia essencial na construção civil, o cimento. Este composto é um material cerâmico que, em contato com a água, produz reação exotérmica de cristalização dos produtos, obtendo resistência mecânica. É o principal material de construção civil, pois compõe varias etapas da construção e é utilizado como aglomerante composto de argila e calcário que elevado a certa temperatura se fundem e formam o clínquer, acrescido de gipsita se transforma em cimento (KAEFER, 1998).

Uma das formas para produzir o cimento é com emprego de caixas impermeáveis feitas no próprio canteiro de obra onde são misturados aos demais materiais com auxilio de ferramentas manuais, apesar de ser um método antigo é a realidade de parte das construções civis nos dias de hoje.

Com o avanço tecnológico a mecanização no ramo da construção civil tem alcançado outros patamares, a utilização de maquinários nas construções reduz a mão-de-obra, o desperdício de materiais e o prazo, facilitando a organização dos processos produtivos e o aumento da qualidade dos serviços. A mecanização é um processo generalizado, sendo que é necessário avaliar o custo beneficio que tais equipamentos possam oferecer (KAEFER, 1998).

A viabilidade da mecanização disponibiliza no mercado o uso de equipamentos como a betoneira uma máquina utilizada para misturar, consiste num tambor rotativo para misturar o cimento em grandes quantidades com os demais componentes de acordo com o tipo de obra em diversos fins e aplicações. A betoneira viabiliza uma rápida produção de concreto reduzindo o tempo de mistura que resulta na homogeneidade da fabricação de concreto.

Os Métodos convencionais/ou processos tradicionais, deverão sempre estar coesos em todos os estudos comparativos de preços e de vantagens. O uso de concretos produzidos no canteiro está disseminando dúvidas entre os construtores pelo detrimento de qualidade do produto final em comparação com o uso concreto usinado. Esta nova forma de preparar o concreto tem maior desenvolvimento tecnológico na produção, qualidade e aproveitamento, pois seu uso proporciona muitas vantagens. "O grande desafio da tecnologia de concreto atualmente parece ser aumentar a durabilidade das estruturas, recuperar estruturas danificadas e em entender o complexo mecanismo químico e mecânico dos cimentos e concretos" (KAEFER, 1998, pag.40).

O concreto usinado é produzido com aditivos que enriquece suas propriedades, apresentando maior durabilidade permitindo acatar as demandas decorrentes de construções modernas. A norma brasileira NBR 7212, para execução de concreto dosado em central, determina o tempo máximo de transporte, bem como o tempo que o concreto seja utilizado na obra. O concreto em suas diversas preparações depende da necessidade do seu uso na obra, por diversas questões a necessidade na forma de prepará-lo, em pequenas concretagens nos canteiros, betoneira ou concreto usinado o seu uso é fundamental na construção civil (ABNT, 2009). 


\subsection{A EVOLUÇÃO NA PRODUÇÃO DO CONCRETO}

Desde a arquitetura monumental do Egito Antigo, as grandes obras grego-romanas e seu aperfeiçoamento para o uso atual, todas as obras simples ou monumentais foram construídas a partir de uma substancia essencial na construção civil, o cimento. Este composto é um material cerâmico que, em contato com a água, produz reação exotérmica de cristalização dos produtos, obtendo resistência mecânica. É o principal material de construção civil, pois compõe varias etapas da construção e é utilizado como aglomerante composto de argila e calcário que elevado a certa temperatura se fundem e formam o clínquer, acrescido de gipsita se transforma em cimento (KAEFER, 1998).

Uma das formas para produzir o cimento é com emprego de caixas impermeáveis feitas no próprio canteiro de obra onde são misturados aos demais materiais com auxilio de ferramentas manuais, apesar de ser um método antigo é a realidade de parte das construções civis nos dias de hoje.

Com o avanço tecnológico a mecanização no ramo da construção civil tem alcançado outros patamares, a utilização de maquinários nas construções reduz a mão-de-obra, o desperdício de materiais e o prazo, facilitando a organização dos processos produtivos e o aumento da qualidade dos serviços. A mecanização é um processo generalizado, sendo que é necessário avaliar o custo beneficio que tais equipamentos possam oferecer (KAEFER, 1998).

A viabilidade da mecanização disponibiliza no mercado o uso de equipamentos como a betoneira uma máquina utilizada para misturar, consiste num tambor rotativo para misturar o cimento em grandes quantidades com os demais componentes de acordo com o tipo de obra em diversos fins e aplicações. A betoneira viabiliza uma rápida produção de concreto reduzindo o tempo de mistura que resulta na homogeneidade da fabricação de concreto.

Os Métodos convencionais/ou processos tradicionais, deverão sempre estar coevos em todos os estudos comparativos de preços e de vantagens. O uso de concretos produzidos no canteiro está disseminando duvidas entre os construtores pelo detrimento de qualidade do produto final em comparação com o uso concreto usinado. Esta nova forma de preparar o concreto tem maior desenvolvimento tecnológico na produção, qualidade e aproveitamento, pois seu uso proporciona muitas vantagens. "O grande desafio da tecnologia de concreto atualmente parece ser aumentar a durabilidade das estruturas, recuperar estruturas danificadas e em entender o complexo mecanismo químico e mecânico dos cimentos e concretos" (KAEFER, 1998, pag.40).

O concreto usinado é produzido com aditivos que enriquece suas propriedades, apresentando maior durabilidade permitindo acatar as demandas decorrentes de construções modernas. A norma brasileira NBR 7212, para execução de concreto dosado em central, determina o tempo máximo de transporte, bem como o tempo que o concreto seja utilizado na obra. O concreto em suas diversas preparações depende da necessidade do seu uso na obra, por diversas questões a necessidade na forma de prepará-lo, em pequenas concretagens nos canteiros, betoneira ou concreto usinado o seu uso é fundamental na construção civil (ABNT, 2009).

\section{MÉTODOS E PROCEDIMENTOS DE PESQUISA}

Para melhor desenvolvimento da pesquisa foi utilizado o método de pesquisa exploratório para facilitar a compreensão da realidade sobre os impactos das novas tecnologias na gestão de produção de concreto usinado, buscando conhecimentos reais através de experiências dos profissionais que integram o setor da construção civil (GIL, 2006).

Um dos pontos centrais desta pesquisa objetivou conhecer os impactos das novas tecnologias na gestão da produção do concreto usinado frente ao mercado de construções, utilizando a forma de abordagem qualitativa. O objetivo de pesquisa foi descritivo, para que não ocorresse interferência nos processos tampouco nos resultados (COLLIS; HUSSEY, 2005; COOPER; SCHINDLER, 2003; GIL, 2006).

O procedimento técnico adotado foi estudo de caso 
sendo os resultados discutidos através de comparações com os referenciais teóricos apresentados no decorrer da pesquisa. A técnica de coleta de dados foi entrevista, observação, documentos e registro de arquivos que foram acompanhadas e disponibilizadas pelo diretor administrativo da empresa. A técnica de análise dos dados foi análise de conteúdo para facilitar o entendimento dos resultados apresentados (YIN, 2005; RAMPAZZO, 2005; GIL, 2006).

\section{ESTUDODECASO NA EMPRESA JCENGENHARIA}

A entrevista foi realizada com o administrador, José Carlos Macedo Grande, sendo ele o Diretor Administrativo da Empresa J. C. Grande Engenharia e Construções, cuja função é a gestão da Concreteira e das obras. A empresa é classificada como de médio porte, localizada no parque industrial na cidade de Paranaíba/MS. Os produtos e serviços ofertados pela J C Grande Engenharia e Construções são o concreto usinado, e serviços de engenharia e construções em geral.

A empresa atua desde 1978 na cidade de Paranaíba com os serviços de engenharia e construção a construção civil, desde o início de suas atividades até o ano de 2003 a produção de concreto era manual. Como na cidade não existia uma empresa que oferecesse concreto usinado a empresa visionou uma oportunidade de negócio para investir nesse segmento com objetivo de atender a demanda tanto dos serviços de engenharia e construção da empresa quanto da população de Paranaíba-MS.

Em 2003 a empresa decidiu investir no segmento da produção de concreto usinado em Paranaíba-MS e assim criou a concreteira. Devido à falta do concreto usinado na cidade e por ser um concreto que oferece mais qualidade, e menor tempo de produção justificou o investimento no setor.

A empresa conta atualmente com 14 funcionários distribuídos em dois setores: 1) serviços construção e engenharia; 2) produção de concreto usinado. O gestor administrativo tem formação em engenharia civil, e atualmente está cursando um MBA em Gestão
Empresarial. As instalações físicas dos dois setores são em locais diferentes, a concreteira é localizada na Rua Orlando Colli n 570 Parque industrial Antônio Ovídio em Paranaíba-MS, e o escritório responsável pelo serviço de engenharia e construção é localizado na Rua Treze de Maio, ํㅡ36, no centro de ParanaíbaMS

\subsection{CARACTERIZAÇÃO DO AMBIENTE DE PESQUISA}

A pesquisa foi realizada numa empresa de médio porte localizada na cidade de Paranaíba/MS. A J. C Grande é uma empresa, que está aproximadamente há 37 anos atuando no mercado de engenharia e construções em Paranaíba/MS. Porém há 12 anos atua na produção de concreto usinado, tanto para atender os serviços de engenharia da empresa como os clientes de Paranaíba.

A empresa ingressou no setor da produção do concreto usinado em Paranaíba pelo fato de que não existia outra que oferecia esse produto e pela demanda existente devido ao crescente mercado no ramo da construção civil. Diante de tal necessidade foi feito um investimento neste setor que hoje abrange a cidade e demais cidades da região. O crescente mercado fez com que essa inovação tecnológica colocasse a empresa como percussora no setor e referência quanto à qualidade dos produtos oferecidos.

Atualmente a empresa JC Grande, é dividida em 2 (dois) setores, contando com a colaboração de 14 funcionários, e tendo como o produto de maior rentabilidade desta empresa a JC GRANDE Engenharia e Construção a produção do concreto usinado.

\subsection{PROCESSO DE PRODUÇÃO}

Os fornecedores da matéria-prima, como pedra e areia estão localizados em Paranaíba, já os fornecedores de cimento é o grupo Votorantim localizado em Itaú de Minas-MG e o composto aditivo utilizado na mistura do concreto são fornecidos por uma empresa do Rio de Janeiro- RJ. 
O processo inicia com chegada das matérias-primas areia e pedra, que é estocada em baias e o cimento a granel é armazenado em um equipamento chamado silo é um depósito metálico com o formato de cone e impermeável, esse cimento é mais resistente que cimento ensacado disponível no mercado, o silo da empresa tem uma capacidade de armazenar aproximadamente 75 toneladas.

A próxima etapa do processo, o balanceiro, o responsável por controlar as medida de matériaprima, define a quantidade de areia e pedra, é dosado, pois há uma receita para cada tipo de concreto, todo esse material é despejado em uma balança para ser pesado, em seqüência o material é liberado na esteira, e no fim da esteira é despejado no caminhão, o cimento que se encontra no silo por gravidade é depositado no caminhão, em seguida uma bomba despeja a quantidade exata de água e de aditivo utilizado na mistura, logo após o caminhão faz o processamento da massa para a produção, assim finaliza-se o processo e o mesmo caminhão realiza a entrega do concreto usinado nas obras.

\subsection{INOVAÇÃO NA GESTÃO DA PRODUÇÃO}

A adoção da inovação na produção do concreto usinado iniciou com o investimento em maquinários como: caminhões, esteiras transportadoras, balança, o silo de armazenagem a bomba de concreto, o laboratório de análise. O investimento no silo permitiu a empresa trabalhar com o cimento a granel que é mais resistente que o cimento ensacado. Com a adição dos ativos ao concreto diminuiu o tempo de secagem na obra, o que torna mais eficaz reduzindo o tempo e conseqüentemente os custos.

A empresa dispõe de um laboratório de pesquisa, que realiza atividades de análise da resistência do concreto para a própria empresa ou fornecido ao cliente se solicitado. O tempo de espera à entrega dos resultados parciais é de 7 dias e o resultado final é disponibilizado após 28 dias. No laboratório é testada a qualidade do cimento produzido, pois qualquer alteração na quantidade dos componentes afeta a resistência do produto acabado.
Para análise das amostras de concreto a empresa possui uma câmara úmida (um tanque com água), onde são depositados os corpos de prova (amostras do concreto), é registrado o lote a que pertence à amostra, dispõe informações como a data de fabricação, e número da nota fiscal. A amostra que a empresa recolhe dos seus produtos comercializados, para avaliar a resistência de cada concreto para descobrir se o concreto possui algum tipo de falha na composição. Logo abaixo é apresentada na figura 3 da câmara úmida onde são armazenadas as amostras.

\subsection{ANÁLISE DA PESQUISA}

O sistema produtivo da organização atenta-se a produzir seus bens e serviços de maneira eficaz e eficiente. A empresa trabalha com a produção por pedido do cliente, para tanto existe o controle dos recursos que serão direcionados para a produção, utilizam de técnicas da gestão da produção como o planejamento e controle de suas atividades produtivas para obter benefícios como menores custos de produção e um produto com uma qualidade superior (SLACK; JOHNSTON; CHAMBERS, 2009).

Ao realizar o estudo de caso foi identificado que a organização inova em produtos e processos, e foram introduzidas inovações incrementais procurando atender de maneira mais ágil a demanda dos clientes. A inovação de processos ocorre na empresa, pois foram implementados novos métodos de produzir com utilização de maquinas e equipamentos mais sofisticados ajudaram no aumento da produção, menor custo de produção em menos tempo. As inovações de produto e processos identificados na empresa apresentam características da inovação incremental, por ser realizada apenas adaptação nos produtos existente e nos processos essa inovação ocasionou em melhorias significativas nas formas de se produzir (OCDE, 2005; TIDD; BESSANT; PAVITT, 2008).

Como a inovação tecnológica é ferramenta importante para o aumento da produtividade e competitividade nas empresas, evidenciou que na empresa J. C. Grande Engenharia e Construções e as inovações 
adotas contribuiu para o aumento da sua capacidade produtiva, como também para a criação de novos produtos com uma qualidade superior ao demais ofertados no mercado (TIGRE, 2006).

A busca por informações e o conhecimento dos integrantes da alta administração da organização, colaboraram para adoção de estratégias com viés a inovação, e assim desenvolveram um produto novo para a população de Paranaíba-MS, pelo processo de produção ser mais ágil e o produto ser mais resistente agrega mais valor aos clientes (TIGRE, 2006; OCDE, 2005; BARBIERE, 1997).

As grandes empresas trabalham com estruturas de $P \& D$, que contribuiu para o desenvolvimento de produtos, a empresa dispõe de um laboratório de pesquisa, porem apenas são desenvolvidas atividades para o teste de resistência dos produtos ofertados aos clientes. Contudo observou-se que a empresa procura inovar por meio da buscar de informações sobre o setor, para aplicá-las na empresa, e assim ocorre a inovação (ANPEI, 1993; MOREIRA; QUEIROZ, 2007).

Com estudo de caso observou-se que a produção de cimento na organização antes do emprego das novas tecnologias, se produzia com o auxilio de ferramentas manuais, se tratava de atividades quem demandavam de muita mão-de-obra, ocorria o desperdício de materiais e o processo era muito demorado, apesar de esse método ser antigo é ainda a realidade de muitas obras (KAEFER, 1998).

Por isso cabe resultar que os avanços tecnológicos e mecanização no ramo da construção civil permitiram a empresa reduzir a mão-de-obra, evitar o desperdício de materiais, gerenciarem os processos produtivos de maneira eficaz bem como aumentou da qualidade dos produtos/serviços. E assim identificou-se que os equipamentos geram um custo beneficio maior em relação a outras maneiras de se produzir (TIGRE, 2006; KEAFER, 1998).

\section{CONSIDERAÇÕES FINAIS}

Este estudo teve como objetivo identificar o impacto das novas tecnologias empregadas na gestão da produção de concreto usinado da empresa J. C. Grande Engenharia e Construções. Foi identificado que o tipo de inovação existente na empresa são inovações em processos de forma incremental que resultaram em um novo produto. Do ponto de vista teórico, constatase que é fundamental a implementação de novas tecnologias de qualquer tipo, pois propicia ganhos as empresa como novos produtos/processos, e as empresas que não inovarem terão dificuldades para se manter no cenário atual.

Considera-se que as novas tecnologias implementadas na organização ofereceram uma série de benefícios como: acelerar o processo produtivo, oferecer um produto de maior qualidade, redução na utilização de mão-de-obra e reduziu o desperdício de matériaprima.

Os impactos gerados pelas novas tecnologias na gestão da produção foram um controle racional no uso da matéria-prima, redução de custos com mão-deobra, aumentou a capacidade produtiva da empresa. Esses benefícios permitiram a empresa planejar com mais precisão para atender as demandas constantes do setor da construção civil que se encontra em crescimento.

As novas tecnologias também contribuíram para uma menor exposição do trabalhador aos materiais tóxicos, como também a utilização de uma bomba que permite despejar o concreto em locais altos, desse modo assegura a saúde do trabalho e evita acidentes em obras.

Assim, concluiu-se que, a despeito do investimento necessário para a aquisição dos equipamentos e tecnologia, bem como o treinamento de mão-deobra, a inovação trouxe benefícios superiores ao investimento, mostrando-se positiva na relação custobenefício.

\section{REFERÊNCIAS}

[1] ABNT, Associação Brasileira de Normas Técnicas. NBR 7212, Execução de concreto dosado em central, 2009. Disponivel em: <http://www.construpac.com.br/pdf/ NBR7212.pdf>. Acesso em 05 de maio de 2015. 
[2] ANPEI. Indicadores empresariais de inovação tecnológica: resultados da base de dados ANPEI. Anpei, v. 7, dez. 1998.

[3] BARBIERI, José Carlos. A contribuição da área produtiva no processo de inovações tecnológicas. RAE-Revista de Administração de Empresas, v. 37, n. 1, p. 66-77, 1997.

[4] BRASIL, Ministério das Comunicações. Inovações tecnológicas. 15 de maio de 2012. Disponível em: <http://www.mc.gov.br/acoes-e-programas/inovacaotecnologica>. Acesso em: 01 de maio de 2015. COLLIS, Jill, HUSSEY, Roger. Pesquisa em Administração. 2 ed. Porto Alegre: Bookman, 2005.

[5] CONSTRUFACILRJ. Mistura e preparo do concreto: mecânica e manual. Rio de Janeiro: . 2009. Disponível em: <http://construfacilri.com/mistura-e-preparo-do-concreto/>. Acesso em: 23 de abr. de 2015.

[6] COOPER, Donald R.; SCHINDLER, Pamela S. Métodos de pesquisa em administração. 7. Ed. Porto Alegre: Bookman, 2003.

[7] DA SILVA, Edna Lúcia; MENEZES, Estera Muzkat. Metodologia da pesquisa e elaboração de dissertação. UFSC, Florianópolis, 4. edição, 2005.

[8] GIL, Antonio Carlos. Métodos e Técnicas de Pesquisa Social. 5. ed. São Paulo: Atlas, 2006. KAEFER, Luís Fernando. A evolução do concreto armado. São Paulo-Brasil, 1998.

LAKATOS, Eva Maria; MARCONI, Marina de Andrade. Fundamentos de metodologia científica. São Paulo: Atlas, 1993.

[9] LEMOS, Cristina. Inovação na era do conhecimento. Informação e globalização na era do conhecimento. Rio de Janeiro: Campus, 1999.

[10] MANUAL, DE OSLO. Diretrizes para coleta e interpretação de dados sobre inovação. Publicação Conjunta da Organização para Cooperação e Desenvolvimento Econômico (OCDE) e Gabinete Estatístico das Comunidades Européias, 2005.
[11] MEIRELLES, Anthero de Morais; GONÇALVES, Carlos Alberto. Projetos e relatórios de pesquisa em administração. São Paulo: Atlas, 2004.

[12] MENEZES, G.C. O; ROCHA, C.P.T. Estudo comparativo de custo entre concreto usinado e concreto produzido na obra em um prédio de 32 pavimentos localizado em BelémPA. Belém: Universidade da Amazônia, 2013. Disponível em http://www.unama.br/graduacao/engenhariacivil/ tccs/2013/estudo

$\% 20$ comparativo $\% 20$ de $\% 20$ custo $\% 20$ entre $\% 20$ concreto\%20usinado.pdf> . Acesso em: 23 de abril de 2015.

[13] MOREIRA, Augusto, QUEIROZ, Ana Carolina S. (coord.), Inovação organizacional e tecnológica. São Paulo: Thomson Learning, 2007.

[14] RAMPAZZO, Lino. Metodologia científica: para alunos dos cursos de pós-graduação e pós-graduação. 3. ed. São Paulo: Loyola, 2005

[15] SLACK, Nigel, CHAMBERS, Stuart, HARLAND, Christine, HARRISON, Alan, JOHNSTON, Robert. Administração da produção. [et al]: revisão técnica Henrique Corrêa, Irineu Glanesi. -1 ed. - 10. Reimpr. - São Paulo: Atlas, 2006.

[16] SLACK, Nigel. CHAMBERS, Stuart. JOHNSTON, Robert. Administração da produção. Trad. Henrique Luiz Corrêa. 3 ed. -São Paulo: Atlas, 2009.

[17] TEIXEIRA, A.C. Como é produzido o concreto usinado. São Paulo: equipe de obra. 2012. 1 p. Disponível em: <http://equipedeobra.pini.com.br/construcao-reforma/54/ artigo273683-1.aspx> .Acesso em: 23 de abril de 2015. TIDD, Joe e BESSANT, John e PAVITT, Keith. Gestão da Inovação. 3 ed. Porto Alegre: Bookman, 2008. TIGRE, Paulo. Gestão da inovação: a economia da tecnologia no Brasil. Rio de Janeiro: Elsevier, 2006.

[18] YIN, Robert K. Estudo de Caso: planejamento e métodos. Robert K. Yin; trad.Daniel Grassi. - 3. ed.-Porto Alegre: Bookman, 2005. 


\title{
CAPÍTULO 17
}

\section{MAPEAMENTO DO PROCESSO PRODUTIVO COMO FATOR INTERVENIENTE NA COMPETITIVIDADE ORGANIZACIONAL}

\author{
Djosete Santos da Costa \\ Ieda Isabella de Lira Souza \\ Alice Dantas de Medeiros \\ Fernanda Maria de Oliveira Firmino \\ Rafaela Costa de Azevedo
}

Resumo: O presente trabalho tem como objetivo avaliar, na perspectiva da teoria da administração da produção, a interveniência do mapeamento e análise do processo produtivo na competitividade organizacional. As organizações buscam alternativas para criar diferenciais competitivos e, assim, tornarem-se mais eficientes em seus processos e eficazes no alcance de seus objetivos. Neste sentido, o mapeamento e análise do processo produtivo tornam-se imperativos, pois, a partir disso, consegue-se conhecer profundamente as atividades inerentes ao processo identificando as variáveis internas que influenciam no seu desenvolvimento. Oportunamente vale ressaltar que as variáveis internas são aquelas as quais apresentam maiores possibilidades de controle e interferência por parte da empresa. Para o mapeamento e análise do processo produtivo são utilizados ferramentas e instrumentos conceituais e operacionais que contribuem para identificação de possíveis falhas no processo facilitando a obtenção de medidas corretivas e preventivas.

Palavras chave: Processo, Mapeamento e análise, Competitividade. 


\section{INTRODUÇÃO}

A busca por melhorias é constante por parte das empresas. Atualmente o diferencial competitivo das organizações está acontecendo nos detalhes, assim, a empresa que melhor conhecer os seus processos terá maiores chances de dominá-los e proporcionar as suas melhorias $e$ atender as expectativas $e$ necessidades dos seus clientes. Corroborando com isso Jacobs e Chase (2012) enfocam que "entender como os processos funcionam é essencial para garantir a competitividade de uma empresa. Um processo que não atende às necessidades de uma empresa prejudica cada minuto de sua operação".

A fim de atender ao objetivo geral desse trabalho, a tipologia metodológica se caracteriza quanto aos objetivos como uma pesquisa bibliográfica. (GIL, 2006)

Para realização da pesquisa inicialmente escolheuse o tema na área de Administração da Produção e Operações. Fez-se uma coleta teórica de diversos autores na área de Administração da Administração da Produção, mapeamento de processos e competitividade organizacional. As fontes foram consultadas em fontes primárias e secundárias. Depois de todo o material coletado elaborou-se fichamentos acerca de cada uma dessas temáticas. A partir desse instrumento analisou-se o objetivo do trabalho buscando interpretar as conexões teóricas que foram identificadas. Por fim, houve a fase da escrita desse artigo. (LAKATOS, 2001).

\section{OBJETIVO}

O objetivo do presente trabalho é avaliar, na perspectiva da teoria da administração da produção, a interveniência do mapeamento e análise do processo produtivo na competitividade organizacional.

\section{CENÁRIO COMPETITIVO E PROCESSO PRODUTIVO}

O nível de competição entre as organizações está assumindo patamares cada vez mais elevados e exigindo destas competências voltadas para a capacidade de adaptação e inovação. Assim, de acordo com Maranhão e Macieira (2004) "as pressões nas organizações geram dificuldades, mas também podem ser excelentes oportunidades para a gestão exemplar". Isto posto, a pressão competitiva elevada cria situações nas quais surgem oportunidades para o desenvolvimento de vantagens competitivas a serem exploradas pelas organizações. Considerando-se como oportunidade de melhoria da performance empresarial a utilização de ferramentas gerencias para auxiliar no diagnóstico do processo. Maranhão e Macieira (2004) destacam como uma das ferramentas a ser utilizada a gestão de processos, que fornece os instrumentos básicos para a gestão das organizações, que significa conhecer, fazer funcionar, avaliar, controlar e melhorá-las continuamente.

Para que a empresa possua condições de fazer uso da gestão de processo torna-se necessário entender o que vem a ser processo. Assim, Oliveira (2006) define processo como sendo "um conjunto estruturado de atividades sequenciais que apresentam relação lógica entre si, com a finalidade de atender e, preferencialmente, suplantar as necessidades e as expectativas dos clientes externos e internos da empresa". De uma maneira geral, o processo pode ser representado esquematicamente conforme a figura1.

Figura 1 - Modelo Geral do Processo. Adaptado de Maranhão e Macieira (2004)

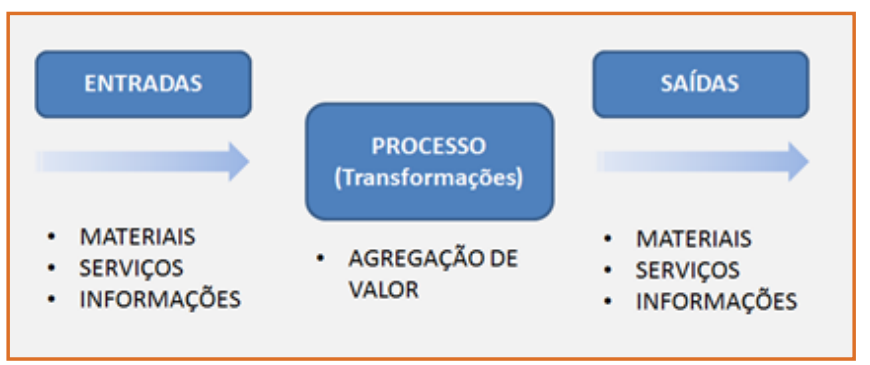

A definição de processo pode ter várias aplicações, desde a forma geral, exposta anteriormente, até a sistematização de atividades específicas. Além disso, os processos e os seus resultados impactam ou interferem nos objetivos estratégicos da organização, assim, os processos precisam estar inter-relacionados com o que é preconizado no planejamento estratégico da empresa.

Os objetivos estabelecidos pelo planejamentoestratégicodefinemosfocos que os processos administrativos devem 
alcançar; as políticas estabelecidas pelo planejamento estratégico definem os critérios e os parâmetros de sustentação para a estrutura decisória inerente à administração de processos; e as estratégias estabelecidas pelo planejamento estratégico definem as ações-focos para a aplicação dos processos. (OLIVEIRA 2006)

A figura 2 apresenta de forma esquemática a interligação existente entre os processos e o planejamento estratégico organizacional.

Figura 2 - Interligação dos processos com o planejamento estratégico.

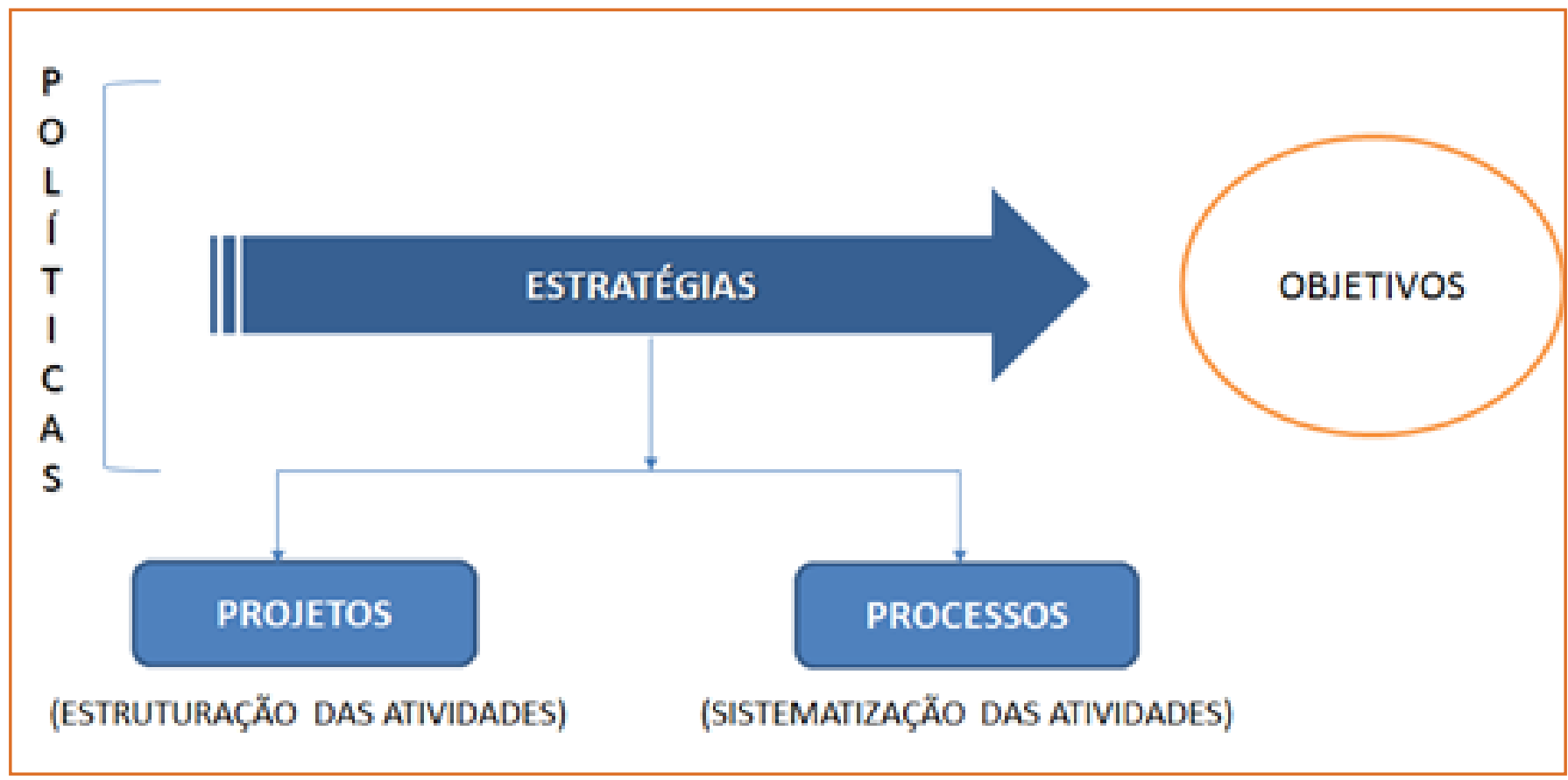

Fonte: Adaptado Oliveira (2006).

Assim, a gestão dos processos, adequada e alinhada com o planejamento estratégico, favorece a empresa no alcance dos resultados e metas estabelecidas.

\subsection{PROCESSO DE PRODUÇÃO}

Considerando os aspectos pertinentes a administração de produção, utiliza-se a definição de sistema de produção ou processo de produção quando se refere ao processo. De acordo com Moreira (1999), "Definimos sistema de produção como o conjunto de atividades e operações inter-relacionadas envolvidas na produção de bens (caso da indústria) ou serviços". Além disso, o autor ainda esclarece que o sistema de produção é uma entidade abstrata, porém extremamente útil para dar uma ideia da totalidade. O sistema de produção é composto, segundo Moreira (1999) pelos seguintes elementos:
- Insumos: são os recursos a serem transformados diretamente em produtos, como as matériasprimas, e mais os recursos que movem o sistema, como a mão de obra, o capital, as máquinas e equipamentos, as instalações, o conhecimento técnico dos processos, etc.

- Processo de conversão: em manufatura, muda o formato das matérias-primas ou muda a composição e a forma dos recursos. Em serviços, não há propriamente transformação: o serviço é criado. Em serviços, diferentemente da manufatura, a tecnologia é mais baseada em conhecimentos (know how) do que em equipamentos. Comparativamente, em geral, as atividades de serviços são mais intensivas em mãode-obra (pessoal) enquanto que as atividades industriais são mais intensivas em máquinas e 
equipamentos (capital físico).

- Sistema de controle: é a designação genérica que se dá ao conjunto de atividades que visa assegurar que programações sejam cumpridas, que padrões sejam obedecidos, que os recursos estejam sendo usados de forma eficaz e que a qualidade desejada seja obtida. O sistema de controle, pois, promove a monitoração dos três elementos do sistema de produção.

Vale ressaltar que o cerne do estudo deste trabalho é a busca de melhorias e aperfeiçoamento dos processos produtivos como forma de tornar a empresa apta a competir com os demais concorrentes. Assim, as organizações devem buscar incessantemente melhorias em cada um dos elementos que compõem o processo ou sistema de produção. Essas melhorias podem ser eliminando atividades que não agregam valor ao processo, como também, aperfeiçoando atividades que apresentam potenciais de otimização.

\subsection{INSTRUMENTALIZAÇÃO PARA OTIMIZAÇÃO DO PROCESSO PRODUTIVO}

O aperfeiçoamento do processo de produção deve seguir etapas. Segundo Martins \& Laugeni (2006), a melhoria dos processos se compõe de quatro estágios e um preliminar. Conforme os autores essas etapas são assim detalhadas:

- Estágio Preliminar: uma nova maneira de pensar. Nesse estágio, é importante ver as coisas sob todos os aspectos. As coisas objeto de análise devem ser relacionadas em quatro categorias: causa e efeito, oposição, similaridade e proximidade.

- Estágio 1: conceitos básicos para as melhorias. Devemos identificar claramente o problema. Em primeiro lugar, deve-se entender que sempre pode haver melhorias.

- Estágio 2: conceitos básicos para as melhorias. Como melhorar? Para que se tenha uma melhoria em um processo deve-se entendê-lo, e para isso recorre-se a representações gráficas e a modelos conceituais é o $5 \mathrm{~W} 1 \mathrm{H}$, que significa:
-What? ( o quê?): objeto;

-Who? (quem?): sujeito;

- Howm(como?): método;

-Where? (onde?): local;

-When? (quando?): tempo;

-Why? (por quê?): razão, objetivo, motivo.

Os autores recomendam que o "porquê" deve ser perguntado a cada um dos itens listados. Deseja-se descobrir as razões das coisas. Muitas vezes, questão é eliminar o processo e não apenas melhorá-lo ou aperfeiçoá-lo.

Vale ressaltar que neste estágio podem e devem ser utilizados outros instrumentos que facilitam a representação, como também, o entendimento do processo.

- Estágio 3: planejamento das melhorias. Os passos para que sejam obtidas as melhorias são: 1 envolvimento no problema, entender claramente e, mais sentir o problema.

- 2 - geração de ideias para a solução. É importante que o envolvimento com o problema seja separado da geração de ideias para resolvêlo.

Neste momento pode ser utilizada a diferenciação das atividades que por ventura agregam valor ao processo das que não agregam.

- Estágio 4: implementação das melhorias. Toda mudança (mesmo que seja para melhor) tende a causar problemas. Portanto, deve-se:

a. Entender o cenário ( e o cenário envolve principalmente pessoas e não somente máquinas);

b. Tomar diferentes ações para que a implantação gere os resultados esperados.

\subsubsection{PRINCIPAIS FERRAMENTAS UTILIZADAS NA MELHORIA DOS PROCESSOS}

Como evidenciado por Martins \& Laugeni (2006) no "Estágio 2" para melhorias do processo, pode-se 
fazer uso de outras instrumentos para registrar e/ou representar graficamente as atividades desenvolvidas no processo. Dentre os instrumentos mais utilizados para tal fim encontram o fluxograma, mapofluxograma, gráfico homem-máquina e diagrama de causaefeito. Segundo Moreira (1999), o fluxograma "é uma representação gráfica do que ocorre com o material, ou conjunto de materiais, incluindo peças e subconjuntos de montagem, durante um sequência bem definida de fases do processo produtivo". Assim, o fluxograma descreve as etapas e sequências de atividades ocorridas durante o processo. Para isso, o fluxograma faz uso de uma simbologia que representa cada uma das atividades. De acordo com Moreira (1999) a simbologia é a seguinte:

Figura 3 - Simbologia empregada no fluxograma.

\begin{tabular}{|c|c|c|}
\hline SIMBOLO & ATIVIDADE & DESCRIÇAO \\
\hline \multirow{5}{*}{$\Longrightarrow$} & Operação & $\begin{array}{l}\text { Considera-se que um objeto sofre uma operação quando ocorrer uma das } \\
\text { seguintes condições: a) alteram-se suas caracteristicas fisicas ou } \\
\text { quimicas; b) ele é montado ou separado em outro objeto; c) ele é } \\
\text { preparado para outro evento seguinte. }\end{array}$ \\
\hline & Transporte & $\begin{array}{l}\text { Toda vez que se desloca um objeto de um local para outro, ocorre um } \\
\text { transporte. }\end{array}$ \\
\hline & Inspeção & $\begin{array}{l}\text { A inspeção consiste em examinar um objeto, tanto para identificação, } \\
\text { como para contagem ou verificação de qualidade. }\end{array}$ \\
\hline & $\begin{array}{l}\text { Estocagem/ } \\
\text { armazenagem }\end{array}$ & $\begin{array}{l}\text { Ocorre quando um objeto é retido intencionalmente para uso posterior, } \\
\text { em instalações apropriadas ou não. }\end{array}$ \\
\hline & Demora/E spera & $\begin{array}{l}\text { Uma demora é uma retenção não intencional do objeto, ou seja, uma } \\
\text { retenção que não faz parte teoricamente do processo de produção, } \\
\text { impedindo o próximo passo no andamento do fluxo. }\end{array}$ \\
\hline
\end{tabular}

Fonte: Adaptado Moreira (1999).

O mapofluxograma é a representação do fluxograma na planta baixa da empresa onde ocorre o processo, utilizando a mesma simbologia presente no fluxograma. A partir do mapofluxograma é possível identificar espacialmente em que local específico determinada atividade do processo é realizada, assim, visualizase as distâncias percorridas e oportuniza analisar as possibilidades de aperfeiçoamento no layout utilizado (MARTINS \& LAUGENI 2006).

O gráfico homem-máquina conforme Moreira (1999) é uma representação que envolve um ou mais operadores, trabalhando em uma ou mais máquinas. A partir deste diagrama é possível identificar tanto as atividades realizadas isoladamente pelo operador como também aquelas realizadas pela máquina e as que são combinadas entre homem/máquinas e as esperas de um e de outro. Ainda de acordo com o autor pode-se determinar qual a proporção de tempo (em relação ao total da operação) em que o homem e a máquina encontram-se trabalhando ou esperando. Para Slack, Chambers e Johnston (2002), os diagramas de causa-efeito são um método particularmente efetivo de ajudar a pesquisar as raízes dos problemas. No diagrama de causaefeito são elencados os possíveis elementos que contribuem para ocorrência do efeito identificado, como por exemplo, em uma empresa onde se observa um elevado número de peças defeituosas são identificadas as prováveis causa do problema. Assim, são analisados aspectos relacionados com a mão-de-obra, matéria-prima, métodos, equipamentos, instalações, etc. Slack, Chambers e Johnston (2002) recomendam os seguintes passos para construção do diagrama causa-efeito:

- Passo 1 - Coloque o problema na caixa efeito.

- Passo 2 - Identifique as principais categorias para causas possíveis do problema. Embora qualquer categoria possa ser usada para os ramos centrais 
do diagrama.

- Passo 3 - Use a busca sistemática de fatos e discussão em grupos para gerar possíveis causas sob essas categorias. Qualquer coisa que possa resultar em um efeito que está sendo considerado deveria ser listada como causa potencial.

- Passo 4 - Registre todas as causas potencias no diagrama sob cada categoria, e discuta cada item para combinar e esclarecer as causas.

\section{IMPACTOS DO MAPEAMENTO E MELHORIA DO PROCESSO NO NÍVEL DE COMPETITIVIDADE}

O mapeamento do processo tem como principal finalidade possibilitar a identificação e análise das atividades que compõem o processo produtivo e, assim, promover as melhorias necessárias, sejam na busca de maximizar os impactos das atividades agregadoras de valor ou minimizar/eliminar as atividades não agregadoras de valor e os seus respectivos impactos no desempenho organizacional. Segundo Slack, Chambers e Johnston (2002), o desempenho das organizações podem ser avaliadas considerando cinco objetivos de desempenho, são eles: Custo, confiabilidade, flexibilidade, qualidade e rapidez. Neste sentido, torna-se factível avaliar o impacto das melhorias realizadas no processo produtivo sob a ótica dos objetivos de desempenho exposto pelos autores.

Figura 4 - Algumas medidas parciais de desempenho.

\begin{tabular}{|c|c|}
\hline Objetivo de Desemp & Algumas medidas Típicas \\
\hline Qualidade & $\begin{array}{l}\text { Número de defeitos por unidade } \\
\text { Nível de reclamação de consumidor } \\
\text { Nível de refugo Alegações de garantia }\end{array}$ \\
\hline Velocidade & $\begin{array}{l}\text { Tempo médio entre linhas } \\
\text { Escore de satisfação do consumidor } \\
\text { Tempo de cotação do consumidor Lead time de pedido } \\
\text { Frequência de entregas } \\
\text { Tempo de atravessamento real versus teórico } \\
\text { Tempo de ciclo }\end{array}$ \\
\hline Confiabilidade & $\begin{array}{l}\text { Porcentagem de pedidos entregues com atraso } \\
\text { Atraso médio de pedidos } \\
\text { Proporção de produtos em estoque } \\
\text { Desvio-médio de promessa de chegada } \\
\text { Aderência à programação }\end{array}$ \\
\hline Flexibilidade & $\begin{array}{l}\text { Tempo necessário para desenvolver novos produtos/serviços Faixa de produtos ou } \\
\text { serviços } \\
\text { Tempo de mudança de máquina Tamanho médio de lote } \\
\text { Tempo para aumentar a taxa de atividade Capacidade média/capacidade máxima } \\
\text { Custo por hora de operação } \\
\text { Tempo para mudar operações }\end{array}$ \\
\hline Custo & $\begin{array}{l}\text { Tempo mínimo de entrega/tempo médio de entrega } \\
\text { Variação contra orçamento } \\
\text { Utilização de recursos } \\
\text { Produtividade da mão-de-obra Valor agregado } \\
\text { Eficiência } \\
\text { Custo por hora de operação }\end{array}$ \\
\hline
\end{tabular}

Fonte: Adaptado Slack, Chambers e Johnston (2002).

A partir das variáveis listadas na figura 4, a organização pode proceder uma comparação com as demais empresas, sejam elas concorrentes ou não e, assim, obter um resultado relativo ao seu grau 
de competitividade, ou seja, saber se a mesma está qualificada para competir no mercado em condições satisfatórias ou não. Neste sentido, as medidas de desempenho podem contribuir no que diz respeito a avaliação da eficácia das ações de melhorias introduzidas no processo produtivo.

Destarte Jacobs \& Chase (2012), são estabelecidas algumas métricas que podem ser utilizadas para avaliar o desempenho do processo produtivo, são elas:

- Tempo de operação = tempo de preparação + tempo de execução

- Tempo de processamento = tempo médio para uma unidade passar pelo sistema

- Velocidade = tempo de processamento / tempo de valor agregado

- Tempo de ciclo = tempo médio entre a finalização das unidades

- Taxa de processamento $=1 /$ tempo de ciclo

- Eficiência = produção real / produção padrão

- Produtividade $=$ produto $/$ insumo

- Utilização = tempo ativado / tempo disponível

\section{CONSIDERAÇÕES FINAIS}

A criação e utilização de estratégias de produção que proporcionem o melhor desempenho competitivo da organização estão fazendo com que a empresa obtenha o máximo de informações possíveis sobre si mesma, no sentido de possibilitar conhecer profundamente todas as atividades desenvolvidas nos seus processos. Isto posto, o mapeamento e análise do processo produtivo é condição sine qua non para que a empresa possa ampliar seu autoconhecimento e promover as melhorias e performances esperados por seus stakeholders.

Atualmente, as organizações têm a disposição ferramentas capazes de mapear e analisar os seus processos tornando-os mais eficientes na utilização de recursos, sejam eles equipamentos, matérias-primas, mão-de-obra e capital, como também mais eficazes na obtenção dos resultados almejados. Entretanto, há ainda gestores que não despertaram para esta realidade e continuam realizando suas atividades de maneiras intuitivas e informais. Assim, tendem a obter melhores resultados as organizações que utilizarem estratégias de produção efetivas voltadas a compreender como criar ou agregar valor para os seus clientes (DAVIS, AQUILANO E CHASE. 2001).

Por fim, vale ressaltar que os processos devem estar intimamente interligados com os objetivos estratégicos organizacionais, pois, é por meio das atividades desenvolvidas nos processos que os objetivos estratégicos são alcançados. Assim, a postura da gestão da organização tem papel fundamental na determinação de uma cultura de aperfeiçoamento a partir do mapeamento e análise do processo produtivo.

\section{REFERÊNCIAS}

[1] CORRÊA, Henrique L.; CORRÊA, Carlos A. Administração de produção e operações. 3ed. São Paulo: Atlas, 2012

[2] DAVIS, Mark M.; AQUILANO, Nicholas J. CHASE, Richard B. Fundamentos da administração da produção. 3ed. Porto Alegre: Bookman Editora, 2001.

[3] GIL, Antonio Carlos. Como elaborar Projetos de Pesquisa. São Paulo: Atlas, 2006.

[4] JACOBS, Robert; CHASE, Richard B. Administração de operações e da cadeia de suprimentos. 13 ed. Porto Alegre: AMGH, 2012.

[5] LAKATOS, Eva M. Fundamentos de Metodologia Científica. 4. ed. São Paulo: Atlas, 2001.

[6] MARTINS, Petrônio G.; LAUGENI, Fernando Piero. Administração da produção. São Paulo: Saraiva, 2006.

[7] MARANHÃO, Mauriti.; MACIEIRA, Maria Elisa Bastos. O processo nosso de cada dia: modelagem de processos de trabalho. Rio de Janeiro: Qualitymark Ed., 2004.

[8] MOREIRA, Daniel Augusto. Administração da produção e operações. São Paulo: Pioneira, 1999.

[9] OLIVEIRA, Djalma de Pinho Rebouças de. Administração de processos: conceitos, metodologia, práticas. São Paulo: Atlas, 2006.

[10] SLACK, Niguel.; CHAMBERS, Stuart.; JOHNSTON, Robert. Administração da produção. 2 ed. São Paulo: Atlas, 2002.

[11]DE SORDI, José Osvaldo. Gestão de processos: uma abordagem da moderna administração. 2 ed. São Paulo: Saraiva, 2008. 


\section{CAPÍTULO 18}

\section{ALINHAMENTO DAS PRIORIDADES COMPEITIVAS NAS ESTRATÉGIAS DAS CADEIAS DE SUPRIMENTOS DA CISCO E NIKE UM ESTUDO DE MÚLTIPLOS CASOS}

\section{Délvio Venanzi \\ Haroldo Lhou Hasegawa \\ Orlando Roque da Silva}

Resumo: Nesses últimos anos a competição tem crescido significativamente no mundo industrial, provocando o surgimento de novos desafios e oportunidades na forma de organizar e gerenciar a produção. Nesse contexto, a gestão da cadeia de suprimentos (Supply Chain Management-SCM) tem emergido como uma nova e promissora maneira de obter vantagens competitivas no mercado, utilizando-se de cadeias ágeis, flexíveis e enxutas, embasadas nas prioridades competitivas e no alinhamento estratégico de suas cadeias. Por sua vez, os setores pesquisados apresentam um conjunto de fatores que facilitam uma gestão mais efetiva da cadeia de suprimentos, em razão, principalmente, da velocidade das inovações tecnológicas nos setores. Este artigo tem por objetivo básico apresentar uma análise geral da gestão da cadeia de suprimentos nesses setores (eletrônico e vestuário esportivo), com foco na cadeia de abastecimento e prioridades competitivas e o quanto essas cadeias estão alinhadas. O estudo teve o suporte de uma pesquisa conduzida nesses dois setores por representantes em destaque mundial que atuam no Brasil.

Palavras chave: gestão da cadeia de suprimentos, prioridades competitivas, alinhamento estratégico. 


\section{INTRODUÇÃO}

Face a globalização de mercados nos países, esta trouxe um cenário de intensa concorrência global. Empresas passaram a competir não mais localmente, mas rompendo fronteiras comerciais e territoriais. Hoje a competitividade já alcança grandes cadeias de suprimentos, principalmente as cadeias que são ágeis, flexíveis e enxutas, por exemplo: as empresas foco deste artigo, estão dentro desta classificação colocada. A disputa pelo share se aloja nas perspectivas da competência e do nível de disputa da cadeia de suprimentos em oferecer um nível melhor de serviço sem que o consumidor pague mais por isso. Alguns fatores contribuíram para esse cenário: melhoria dos processos de produção, em particular nos ambientes avançados de manufatura (TUBINO et al., 2007); da visão focada no produto ao atendimento responsivo de requisitos dos clientes (CHRISTOPHER, 2007); uso da tecnologia de informação no compartilhamento de processos (SKIPPER et al., 2008); integração intra e interempresarial (DONK et al., 2008) e complexidade na gestão dos arranjos (MORGAN, 2007),o emprego das prioridades competitivas na cadeia de suprimentos, entre outros.

Visando superar os desafios provenientes da acirrada competição e acompanhar a evolução no nível de exigência dos consumidores, as empresas passaram a formar arranjos para obter vantagens competitivas que dificilmente conseguiriam, se atuassem de maneira isolada das outras empresas. A cadeia de suprimentos representa um formato empresarial que se insere num contexto de grande complexidade, dado o grande número de interações trocadas entre os membros da cadeia, tornando a gestão mais difícil (MORGAN, 2007). Uma cadeia de suprimentos, para Mentzer et al. (2001), é um conjunto de três ou mais entidades diretamente envolvidas com o fluxo, a montante e a jusante, de produtos, serviços, finanças, e/ou informações da fonte ao consumidor. As dificuldades na gestão dessas relações podem se evidenciadas por diversos autores (TÖYLI et al., 2008).

De acordo com Lambert, Cooper e Pagh (1998), a cadeia de suprimentos representa todas as organizações com as quais a empresa líder de um arranjo interage direta ou indiretamente através de seus fornecedores e clientes. O conceito de logística integrada criado para integrar operações logísticas no âmbito interno da empresa estimulou o surgimento do conceito SCM (Supply Chain Management) ou gestão da cadeia de suprimentos. Pela análise da literatura não é possível identificar com certa precisão a origem do termo (COOPER et al., 1997; LAMBERT et al., 1998; PIRES, 2004)

Observou-se, entretanto, que os processos de negócios entre os participantes da cadeia de suprimentos necessitavam de integração. Essa integração foi buscada através do conceito SCM, com a finalidade de que os processos de negócios transacionados entre os membros da cadeia de suprimentos fossem compartilhados para melhorar o fluxo de produtos e materiais, da extração da matéria-prima, passando pela entrega do produto final ao cliente e acabando no fluxo de retorno de materiais e produtos retornáveis. Figueiredo (2001) comenta a influência da logística integrada para a integração externa relacionada à gestão dos fluxos de materiais e informações ao longo da cadeia (de fornecedores a clientes finais). Para Bowersox e Closs (2001), a logística integrada "é vista como a competência que vincula a empresa a seus clientes e fornecedores". Nesse sentido, o conceito SCM tem sido empregado para melhorar a eficiência na gestão da cadeia de suprimentos e aumentar o nível de serviço demandado por todos os atores do arranjo, incluindo fornecedores, consumidores, atacadistas, varejistas, operadores logísticos, clientes finais, plantas industriais, entre outros.

O incremento na eficiência de uma cadeia de suprimentos passa necessariamente pela análise do valor gerado entre os elos do arranjo. Nesse sentido, avaliar as cadeias de valor dos membros tem sido uma alternativa ainda pouco usada na gestão da cadeia de suprimentos, no entanto, pode tornar-se uma ferramenta valiosa para verificar se as competências centrais dos integrantes do arranjo estão alinhadas para gerar valor aos diversos stakeholders interessados. Segundo Novaes (2004), "a cadeia de suprimentos é formada por uma sequência de cadeias de valor, cada uma correspondendo a cada uma das empresas que formam o sistema". De acordo com Koh e Nam (2005), uma cadeia de valor é uma série de atividades pelas quais promovem o valor, com ênfase 
no planejamento e coordenação dos negócios para se obter o melhor desempenho. A literatura evidencia que geralmente a configuração de uma cadeia atende a poucos requisitos, que usualmente não estão conectados entre si. Todavia, algumas contribuições têm sido observadas no sentido de melhor configurar uma cadeia de suprimentos (COOPER et al., 1997; LAMBERT et al., 1998; CROXTON et al., 2001).

Outro elemento importante a ser verificado nas cadeias de suprimentos é o alinhamento estratégico com a estratégia de operações. O alinhamento estratégico, para Chopra e Meindl (2003), significa que as estratégias, competitiva e da cadeia, têm objetivos comuns. Para os autores o alinhamento estratégico diz respeito à compatibilidade entre prioridades advindas do cliente, satisfeitas pela estratégia competitiva, e às habilidades da cadeia de suprimento, criadas pelas estratégias da cadeia. O alinhamento estratégico deve ser confrontado com a cadeia de valor de cada membro-chave da cadeia de suprimentos. O objetivo é verificar se existem sincronia e complementação entre as competências centrais de cada membro-chave na geração de valor aos elos componentes da cadeia de suprimentos. Com o levantamento das cadeias de valor dos membros, é possível verificar se há a formação de um sistema de valor comprometido com a elevação do nível de serviço ao cliente final a um custo adequado.

O objetivo deste artigo é averiguar o alinhamento estratégico na cadeia de suprimentos das empresas pesquisadas, e comparar as prioridades competitivas com as áreas internas dessas empresas, no tocante à suporte a projetos de novos produtos (área de engenharia do produto), pontualidade, capacidade de produção, rapidez no tempo de ciclo (área de produção) e preço (área de suprimentos).

\section{REFERENCIAL TEÓRICO \\ 2.1 SUPPLY CHAIN MANAGEMENT (SCM)}

A Gestão da Cadeia de Suprimentos (Supply Chain Management - SCM) vem sendo utilizada como uma das ferramentas mais importantes na busca por maiores lucros e participação no mercado. (SIMCHILEVI; KAMINSKY, 2010). Segundo Lummus e Vokurka (1999), o interesse pelo assunto se intensifica a partir da década de 1990 devido a fatores como: a verticalização e maior especialização das organizações; aumento na competitividade nacional e internacional, permitindo ao consumidor maior liberdade na aquisição de um produto, e o potencial diferencial competitivo obtido através da SCM, proporcionando, entre outros, a redução nos custos e a maior agilidade de entrega.

A abordagem tradicional de relacionamento entre indústrias e seus fornecedores, baseado na competição, vem perdendo espaço para configurações baseadas na cooperação e nas alianças de longo prazo, que integram alguns dos conceitos do gerenciamento das cadeias de suprimentos. Estas novas configurações implicam em uma nova distribuição de responsabilidades, quase sempre acompanhadas de maior terceirização da produção de bens e da prestação de serviços. (NÓBREGA $J R, 2000)$. As organizações podem concentrar suas ações referentes à SCM através da compreensão da importância da cadeia de suprimentos; dos impactos gerados pelas novas tendências de mercado; do novo ambiente de negócios e da necessidade de reformulação da estratégia da empresa. (BUOSI; CARPINETTI, 2002).

De um ponto de vista total, SCM pode ser compreendida como uma área contemporânea, dentro do espaço da gerência do negócio, que considera a convergência de uma série de temas e de interesses de áreas tradicionais, tais como a gerência de produção, logística, compras e marketing. (PIRES, 2007). De acordo com Fabbe (2008), esta ressalta que, diferentemente da logística tradicional, a SCM envolve a coordenação de empresas gerencialmente independentes que buscam maximizar seus lucros individuais. Embora a performance global de uma cadeia de suprimento dependa da performance conjunta das empresas 
envolvidas, as metas operacionais individuais podem ser conflitantes e resultar em ineficiência para a cadeia como um todo.

Segundo Tan (2002), a SCM envolve a integração dos processos de negócios por meio da cadeia de suprimentos, abrangendo a coordenação de atividades e processos não apenas dentro de uma organização isolada, mas entre todas as que compõem a cadeia de suprimentos. A SCM baseia-se na idéia de que empresas devem estar estratégica e holisticamente integradas com os seus fornecedores e clientes. (PIRES, et al. 2001). Embora cada empresa da cadeia tenha seus clientes diretos, a cadeia como um todo, acumulada, agrega valor ao pacote que será entregue ao cliente final. Para Reichhart e Holweg (2008), a configuração de redes de suprimentos e as decisões relacionadas da cadeia foram mencionadas extensamente como fonte de vantagens competitivas potenciais. Para Kuehnle (2007), a melhor maneira de lidar com a dinâmica das redes de suprimentos é conhecer a natureza dessa dinâmica da cadeia, ao invés de se esforçar em superar os efeitos desta. Posteriormente, as operações devem se dedicar a realizar ações próativas de gerenciamento de redes com base na coordenação, diferenciação e reconfiguração das atividades. A coordenação está relacionada com os esforços para sincronizar o comportamento da cadeia de suprimentos e aumentar a sua eficiência; a diferenciação centraliza-se nos esforços para assegurar que as políticas adotadas pela cadeia de suprimentos estejam adequadas às necessidades competitivas de cada produto/ serviço do seu mercado; e a reconfiguração atua na mudança dos estágios de uma cadeia ou dos relacionamentos existentes entre eles.

\subsection{CLASSIFICAÇÃO DAS CADEIAS DE SUPRIMENTOS}

\subsubsection{CADEIAS DE SUPRIMENTOS ENXUTAS}

De acordo com Gattorna (2009), as organizações aplicam conceitos enxutos nos sistemas logísticos corporativos e no mais amplo domínio da gestão da cadeia de suprimentos. Os princípios enxutos se concentram na eliminação dos desperdícios de material, processo, tempo e informação. A cadeia enxuta é a cadeia na qual o baixo custo é alcançado assegurando-se que os clientes não sejam superatendidos. Os custos baixos são obtidos por meio de seus processos mais básicos, mas bem-feitos. As cadeias enxutas se os clientes não quiserem compartilhar suas projeções de demanda, naturalmente é necessário empurrar o produto usando as melhores previsões em um ambiente mais estável, portanto para se conseguir eficiência nessa cadeia há necessidade de colaboração dos fornecedores.

$\mathrm{Na}$ visão de Gattorna (2009), as cadeias enxutas estão inseridas num contexto em que os clientes frequentemente compram preços e utilizam múltiplas empresas na busca pelo suprimento estável e preço mais baixo. Mas ao adotar essa postura eles podem ser impessoais ou adversativos, com o desenvolvimento de pouca lealdade. Este é um mercado caracterizado por um estilo muito transacional, no qual a informação é poder e ocorre pouco ou nenhum compartilhamento entre compradores evendedores. Paraosfornecedores, é um mercado difícil e implacável, com clientes tão sensíveis ao preço que as empresas que as empresas não têm praticamente nenhuma oportunidade de diferenciar sua proposição de valor. Para competir em tais condições, necessita ter o produtor mais barato e sustentar essa vantagem ao longo do tempo, usando todas as técnicas e estratégias disponíveis.

Para Vachon (2009), o melhor caminho para servir o mercado guiado pelo baixo custo e confiabilidade é por meio de uma configuração enxuta da cadeia de suprimentos. O foco principal está em operações eficientes que ofereçam maior volume e menor variedade, e em sua maioria que produzam bens e serviços baseados em previsões. É o ambiente operacional MTF (Make-To-Forecast - Produção Sob 
Previsão). Segundo Vachon (2009), clientes servidos por cadeias enxutas, beneficiar-se-ão com a produção e a logística de baixo custo, alcançadas por meio de uso de todas as sinergias, integração, sincronismo, troca de informações, compartilhamento de knowhow, entre os elos e economias de escala disponíveis. Há a vantagem em prever a demanda de forma mais precisa. Essas cadeias têm como característica central a reprodução de processos padronizados. Dessa forma, as cadeias enxutas de baixo custo e confiáveis podem ser projetadas e operadas para fornecer a eficiência, a previsibilidade e o baixo custo tão almejado pelos clientes. Em ambiente operacional onde os clientes exigem altos níveis de responsividade em condições imprevisíveis às cadeias enxutas podem ser inadequadas.

\subsubsection{CADEIAS DE SUPRIMENTOS ÁGEIS}

Para Gattorna (2009), as cadeias ágeis tem como foco serem rápidas e alinharem-se com os clientes exigentes. Frequentemente, a alta responsividade requer a habilidade de prever a capacidade com precisão em vez de prever qual será o próximo produto de sucesso e estar preparado para passar para uma produção de alta prioridade quando chegar o momento. O comportamento de compra dominante dos clientes de uma cadeia ágil é de demanda e reposta rápida. São cliente que exigem do modelo de negócio uma resposta rápida para condições imprevisíveis de fornecimento e demanda.

Na visão de Stevenson (2009), a cadeia ágil é uma cadeia de fluxo oscilante, pois a demanda tem surtos durante condições de mercado imprevisíveis e de grande variedade. As capacidades de MTO (Make-To-Order- Produção sob Encomenda) ou ATO (Assemble-to-order- Montagem sob Encomenda) são críticas por uma resposta rápida às exigências do cliente. A alta responsividade não pode ser atingida por um custo mínimo; clientes têm de fazer escolhas, caso contrário eles se tornam inadministráveis e não lucrativos. Essas cadeias respondem rapidamente e com alta prioridade, em condições imprevisíveis de suprimentos e demanda.
O sucesso dessas cadeias é o resultado de uma combinação de processos e técnicas específicos dentro de um modo de pensar do negócio voltado à responsividade. Técnicas como o fornecimento estratégico e a manufatura postergada têm um papel central nesse aspecto, pois tudo tem que estar alinhado para se obter um resultado rápido e um custo eficiente. Há também a necessidade de habilidades nas atividades enxutas em módulos e ter capacidade de reconfigurar de maneira que forneçam as respostas desejadas. Quanto aos processos que motivam e sustentam as cadeias ágeis, estes são principalmente combinações de processos-padrão e modulares, pois esta é a chave para conter custos e ao mesmo tempo, atender ás urgências de serviços em curtos períodos. Uma outra característica importante de acordo com Stevenson (2009), nas cadeias ágeis, é fundamental desenvolver e manter um modelo de otimização de rede, pois melhoram muito a qualidade das decisões tomadas no nível executivo integradas com as empresas participantes desse processo, buscando um alinhamento entre a empresa, clientes e fornecedores.

\subsubsection{CADEIAS DE SUPRIMENTOS TOTALMENTE FLEXÍVEIS}

Jagjit (2008) define as cadeias totalmente flexíveis, as que conseguem responder com rapidez e flexibilidade situações inesperadas impostas pelo mercado. Estas são desenhadas para encontrar soluções pra os problemas com muita rapidez, independente se requer pensamentos criativos das áreas internas, comportamentos inovadores por parte da empresa e um custo elevado internamente, o negócio está disposto a encarar essa situação. Esses clientes procuram soluções inovadoras em seus produtos e a empresa tem que estar preparada com seus elos para responder rapidamente às necessidades destes clientes especiais.

As cadeias são configuradas em torno dos princípios de diminuição do risco e mobilização que fornecem responsividade máxima de maneiras distintas durante períodos curtos, pois o objetivo central é atender a demandas não programadas e não planejáveis com soluções rápidas, eficazes e centradas nos 
clientes, que geralmente não estariam disponíveis em circunstâncias normais. Quanto ao desenho organizacional que caracteriza essa cadeia, a maior ênfase é colocada em inovação e em auto-suficiência, o trabalho é cooperativo entre as partes.

\subsection{ESTRATÉGIA DE OPERAÇÕES}

Sob a ótica do planejamento estratégico, a Estratégia de Operações é uma estratégia funcional e, portanto, deve promover sustentação à estratégia competitiva. Dado o fato de os elementos que compõem o sistema produtivo serem concebidos para atingir determinados fins e realizar determinadas tarefas, estratégias competitivas diferentes poderão exigir configurações distintas do sistema de produção. Neste sentido, cada tipo de estratégia demanda certas tarefas da produção e especifica determinados objetivos, os quais são conhecidos por "prioridades competitivas" e foram inicialmente identificados por Skinner (1969) como sendo produtividade, serviço, qualidade e retorno sobre investimento.

Uma forma eficaz de alinhar a capacidade dos recursos produtivos com as necessidades de mercado é apresentada por Hill (1989). Hill (1989) contribuiu bastante para a área de estratégia de operações ao explicitar a interface entre as operações e o marketing, afirmando que as operações poderiam contribuir para os esforços estratégicos da empresa, apoiando as diversas maneiras pelas quais os produtos ganhariam pedidos de forma melhor que os competidores e desenvolvendo políticas de escolha de processo e design de infra-estrutura que estivessem de acordo com critérios ganhadores de pedidos. Para fazer isso, as operações teriam que estar envolvidas em todo o processo estratégico, explicando as implicações das decisões tomadas e influenciando o processo estratégico para beneficiar o negócio como um todo, ou seja, teria que haver um debate entre as diferentes áreas da organização, principalmente entre marketing e operações, pois, desta forma, a estratégia de operações resultante estaria alinhada com a estratégia de marketing da empresa e, o que é mais importante, com os objetivos corporativos da organização.
As prioridades competitivas também chamadas de objetivos de desempenho constituem as diretrizesmestras para posicionar a manufatura perante todos os grupos sociais que tenham vínculos de interesse na organização. Dı'az-Garrido (2008), numa recente pesquisa de empresas na Espanha, concluiu que as empresas pesquisadas adotam como prioridades competitivas as conhecidas na literatura mundial (custo, qualidade, flexibilidade, confiabilidade, velocidade, inovação), mas com uma novidade: a inclusão da prioridade competitiva proteção ambiental.

O desempenho da empresa se refere aos aspectos observados no âmbito externo (visão do cliente) assim como no âmbito interno (fatores que servirão de base para o desempenho externo). Os aspectos qualidade, velocidade, confiabilidade, flexibilidade e custo são apontados por Slack et al. (2002) como os elementos básicos da competitividade. O critério qualidade representa vantagem competitiva para as empresas por meio de produtos com alto desempenho, isentos de erros, e com características que os outros competidores não conseguem oferecer (GARVIN, 1987). Qualidade influenciará outros fatores competitivos, tais como em confiabilidade (pois reduz a probabilidade de faltar o produto e aumenta a estabilidade e a eficiência da organização) e em custos (pois promove menos desperdício de material, menos tempo perdido para correção, menos confusão, menos irritação) (SLACK et al., 2002). A flexibilidade pode ser subdivida em dois grupos: variedade de produtos e flexibilidade de volume. Normalmente, empresas de pequeno porte irão competir na flexibilidade de variedade de produtos, pois significa dizer que elas podem atender pedidos fora dos padrões e que podem tomar a frente na introdução de novos produtos (LAUGEN, BOER E FRICK 2005). Flexibilidade terá um efeito em outros fatores competitivos, tais como velocidade, custos, e confiabilidade, visto que operações flexíveis adaptamse rapidamente às circunstâncias mutantes e não interrompem a produção (SLACK et al., 2002).

A velocidade refere-se à diminuição no tempo de entrega de um determinado produto ou serviço solicitado pelo cliente externo. Para alcançar este fator competitivo é preciso diminuir o tempo no processo da manufatura, o que irá beneficiar a empresa e sua 
operação deixando-a mais enxuta e mais produtiva (KRAJEWSKI, 2008). A diminuição do tempo no processo de manufatura trará também uma maior satisfação do consumidor, maior confiabilidade e conseqüentemente redução dos custos na manufatura (SLACK et al., 2002). A confiabilidade é atingida ao se cumprir os prazos de entrega de produto ou serviço ao consumidor final. Está diretamente ligada a velocidade de entrega, que significa fazer as coisas em tempo para que esses recebam os bens ou serviços honrados em contrato (DEVARAJ; HOLLINGWORTH; SCHROEDER, 2004).

Os consumidores só podem julgar a confiabilidade de uma operação após o produto ou serviço ter sido entregue. Ao selecionar o serviço pela primeira vez, o cliente não terá qualquer referência do passado quanto à confiabilidade do fornecedor, entretanto no decorrer do tempo, a confiabilidade poderá assumir a posição de fator mais importante do que qualquer outro critério em um vínculo de fornecimento (CHASE, et al, 2006). O custo é normalmente um dos principais objetivos da produção (HAYES; PISANO, 2008). O foco da gestão de operações, como um todo, é na redução dos custos totais de produção (SLACK et al, 2002). Mesmo as empresas que concorrem no mercado, utilizando outros objetivos de desempenho para atrair seus clientes terão interesse em manter seus custos baixos. Tentar obter uma vantagem de custo não significa que a empresa estará oferecendo produtos de baixo valor ou baixa qualidade (HEIZER; RENDER, 2004).

\section{DESCRIÇÃO DOS SETORES PESQUISADOS}

\section{$3.1 \mathrm{CISCO}$}

A Cisco é uma empresa cuja $80 \%$ das transações comerciais são efetuadas na internet, e esta é apenas uma pequena parcela do total. A Cisco adquire empresas que detém tecnologia de ponta e as integra com rapidez a seus sistemas. Ela também vende soluções de rede, não apenas componentes, a seus clientes. Isto exige coordenação de hardware, software e componentes de serviços em inúmeras operações de vendas.
A capacidade de fornecer estes serviços e de integrar vem do sistema de empresa única da Cisco. Este sistema é a espinha dorsal de todas as atividades da empresa, conectando clientes, funcionários, fabricantes de chips, distribuidores de componentes, fabricantes contratados, empresas de logística e integradores de sistemas. Estes autores conseguem trabalhar como se formassem uma única empresa, porque todos dependem das mesmas fontes de dados de um mesmo website. Todos os fornecedores da Cisco vêem a mesma demanda e não dependem apenas de suas próprias previsões baseadas nas informações que fluem de diversos pontos na cadeia de suprimentos. Sua liderança tecnológica surgiu primeiro com o software de operação desenvolvido para rotear grandes quantidades de dados de um computador para o outro, usando microprocessadores especialmente desenhados para tanto. Suas capacidades operacionais têm origem em seu sistema on-line de gerenciamento da cadeia de suprimentos, um dos mais ágeis e flexíveis.

\subsection{NIKE}

A Nike é a maior empresa de footwear (tênis e afins) e vestuário esportivo do planeta, presente em cerca de 140 países. A sua qualidade é baseada na performance e na confiabilidade dos tênis, vestuário e do equipamento, no desenvolvimento de novos produtos, no preço, na identidade de marca através de ações de comunicação e marketing, e na sustentação de ralações junto aos consumidores. As principais atividades da empresa envolvem design, pesquisa e desenvolvimento de produtos e marketing. É fundamental para uma corporação do porte da Nike se valer de marcas registradas e patentes, o que acontece em mais de 100 países. O intuito é se diferenciar da concorrência e agregar valor aos produtos desenvolvidos e comercializados pela companhia, principalmente em decorrência dos gastos com $\mathrm{P} \& \mathrm{D}$, design e marketing.

Em termos de produção, a maior parte dos vestuários Nike é fabricada fora dos EUA, concentrados, principalmente nos seguintes países: Bangladesh, China, Hong Kong, Índia, Indonésia, Malásia, 
México, Paquistão, Filipinas, Sri Lanka, Taiwan e Tailândia, onde se obtém um custo de mão de obra muito inferior ao dos EUA. Para dar unidade a todo o empreendimento da Nike, existem sistemas de informação que coordenam cada etapa dessas extensas atividades e uma infra-estrutura logística capaz de juntar os componentes no momento certo, e também, de gerenciar o fornecimento de produtos acabados para o mercado global. É importante que ambos sejam suficientemente flexíveis para dar conta da constante inovação de produtos, matéria-prima e processo, permitindo que a companhia lance, a cada ano no mercado, mais de 300 novos modelos de tênis. No entanto, essa massacrante taxa de inovação implica altos níveis de estoque de produtos acabados, se as previsões de venda não se tornarem reais, os produtos não se transformarão em vendas.

A estratégia global da Nike é centralizada e planejada na matriz da corporação, no Nike Campus, no Oregon/ EUA e é baseada no conceito de valorização de imagem de marca-branding. A Nike vende atitude, não produtos. E a atitude propagada pela Nike extravasa $\mathrm{O}$ mundo esportivo, passando por todos os setores da empresa: Produção, Pesquisa \& Desenvolvimento, Responsabilidade Social, Estrutura Física, Marketing. Quanto á Pesquisa \& Desenvolvimento Pesquisa \& Desenvolvimento: a corporação tem enfatizado sua preocupação com a melhora da performance dos atletas pelo domínio de know-how tecnológico. Em relação ao Marketing, a Nike percebeu que propaganda é a matéria-prima dos seus produtos, e busca criar conceitos associados ao espírito Nike na mente do consumidor. Toda a atitude descrita acima e difundida pela corporação é fundamental na formação de uma imagem de marca que associa a Nike com tecnologia esportiva, paixão pelo esporte e responsabilidade social. Para propagar os conceitos estabelecidos pela estratégia global da companhia, a empresa agrupa países em função de sua similaridade e tenta criar, preferencialmente, produtos com demanda universal dentro de nichos específicos e segmentados de mercado. Esta macro-segmentação permite que se identifique e defina os consumidores, tornando a abordagem - approach - junto ao público alvo mais efetiva pela utilização de elementos que combinam informações demográficas, de atitudes e de estilo de vida. Isto é causa da estratégia de comunicação global que possibilita a veiculação de anúncios conceituais, onde a parte textual é ínfima, a sonoridade da trilha importante para causar a ambientação para a plena compreensão da idéia passada e, o mais relevante, a base da comunicação é a simbologia imagética (iconização).

Verifica-se então que a tecnologia da informação favorece a existência de formas organizativas de rede e surgem outras denominações como organização virtual". Robbins (2000, p.190), descrevendo sobre novas formas de estrutura, define a organização virtual, organização em rede ou modular, como "uma organização pequena, de núcleo, que terceiriza as funções empresariais maiores", é altamente centralizada, com pouca ou nenhuma departamentalização, esta forma estrutural permite que cada projeto disponha de pessoal com talento mais adequado a atender suas demandas, minimizando as despesas burocráticas e reduzindo os riscos e custos de longo prazo porque não existe longo prazo - uma equipe é feita para determinado período e depois desmontada. Segundo este autor, as grandes organizações, como Nike, Reebok e Dell Computer, utilizam a estrutura virtual, geralmente o fazem para terceirizar a fabricação.

\section{METODOLOGIA DE PESQUISA}

A estratégia de pesquisa adotada foi o estudo de caso, pois investiga fenômenos contemporâneos inseridos em algum contexto da vida real, quando as fronteiras entre fenômeno e contexto não são muito claras e são utilizadas múltiplas fontes de evidência. Dado em que se ambiciona verificar, empiricamente, o desempenho das cadeias de suprimentos das três empresas de diferentes setores baseados no alinhamento estratégico de cada empresa. A escolha desta abordagem está em concordância com as proposições de Yin (1994), pois se deseja "investigar um fenômeno atual dentro do seu contexto real, quando as fronteiras entre o fenômeno e o contexto não são claramente definidas e utilizando-se várias fontes de evidência". A pesquisa de campo, tendo sido realizada por meio de estudos de caso, utilizou-se de um método qualitativo, de 
pesquisa descritiva (ou exploratória), o fator decisivo que conduziu à escolha da pesquisa exploratória foi o fato do tema ser recente, importante e diferenciado na literatura.

Segundo Lazzarini (1997), os métodos denominados qualitativos caracterizam-se por um foco maior na compreensão dos fatos que propriamente na sua mensuração. Foram conduzidas entrevistas semiestruturadas, nos modelos de negócios estudados, seguindo-se um roteiro previamente formulado a partir da revisão bibliográfica, incluindo um protocolo de pesquisa. A escolha dessas empresas nos respectivos setores, deve-se principalmente aos extremos de suas configurações e estratégias nas cadeias de suprimentos e o foco nas prioridades competitivas.

Foram ouvidas as pessoas do nível estratégico (diretoria) e tático (gerentes) das representantes dessas empresas pesquisadas no Brasil, essa escolha deve-se à posição ocupada dessas empresas e a vivência no mercado, a fim de obter a sua opinião, suas concepções sobre as características das cadeias, configurações produtivas da qual fazem parte, e a influência das prioridades competitivas no desempenho dessas cadeias, e o alinhamento estratégico da cadeia de suprimentos de cada empresa. Os métodos de procedimento para coletar dados na pesquisa qualitativa foram à entrevista semiestruturada, a observação participativa, e o exame de documentos e posteriormente o cruzamento destas informações para validação das mesmas. A íntegra dos discursos não será apresentada nesse artigo devido ao grande volume de páginas e, principalmente, para impedir a possibilidade de identificação, bem como de divulgação de informações sobre as quais os informantes solicitaram sigilo. A partir da análise das cadeias de suprimentos das empresas pesquisadas, nas estratégias de operações, ferramentas utilizadas, pôde ser investigado o desempenho das cadeias e o alinhamento estratégico, quanto a dimensão tempo e diferenciação, comparando aspectos competitivos enfatizados pelas empresas.

O procedimento utilizado para a análise do alinhamento estratégico para as empresas em questão foi utilizado como insumo às notas atribuídas pelos respondentes à importância de cinco critérios de desempenho relevantes para os setores pesquisados. Foi realizado um levantamento bibliográfico para identificação destes critérios nas obras de Hines (1998), Dyer e Chu (2000), Lima (2004) e Ogden (2006). Os cinco critérios identificados são: suporte a projetos de novos produtos (área de engenharia do produto), pontualidade, capacidade de produção, rapidez no tempo de ciclo (área de produção) e preço. Aos respondentes, foi solicitado que ordenassem estes critérios em ordem decrescente de importância, atribuindo a nota 10 para o critério mais importante e a nota 1 para o menos importante. Ainda, foi solicitado que os mesmos respondentes indicassem a sua percepção. O alinhamento estratégico foi equacionado da seguinte forma: quanto menor o número obtido, mais alinhada é a estratégia da empresa com a área interna pesquisada. A fórmula para o cálculo é: as notas deveriam variar entre 1 e 5 , sendo: 1 - totalmente insatisfeito; 2 - insatisfeito; 3 - indiferente; 4 - satisfeito; 5 - totalmente satisfeito.

\section{PESQUISA DE CAMPO}

A Cisco construiu um sistema dinâmico de reabastecimento para ajudar a reduzir o estoque no fornecedor. Na média as rotações da Cisco em 2010 foram em tono de 15 v/ano, o que é bom em comparação a média da concorrência que foi de 4 v/ano. Benchmarking mundial, as rotações para commodities são em torno de 30 a 35 v/ano. Os vínculos permitiram à própria Cisco, concentrar-se no design do produto, enquanto as outras tarefas eram terceirizadas e fornecedores e fabricantes contratados. O sofisticado software de testagem automática significava que boa parte da produção podia ser terceirizada aos fornecedores sem qualquer risco de problemas de qualidade.

A empresa sempre fizera de seus serviços ao cliente, e de seu atendimento on-time de pedidos, os principais indicadores de desempenho, tanto internamente quanto ao longo de seu negócio expandido. A rede baseada na Internet permite aos clientes fazer o pedido e a configuração on-line, e aos fabricantes contratados, começar a construir sistemas 15 minutos 
após ter recebido o pedido. Fornecedores logísticos também estavam conectados ao sistema, permitindo à Cisco fornecer aos clientes, a qualquer momento, informações sobre o status de seu pedido.

A estratégia de rede facilitava o atendimento direto, o que levava a uma redução em estoques, mão-deobra e custos de remessa, significando uma economia anual de US\$12 milhões para a Cisco. Os tempos do ciclo foram encurtados ainda mais por testes on-line de protótipos dos novos sistemas dos clientes, permitindo a redução dos lead times, de semanas, para dias. Para os stakeholders, esse ambiente completamente ligado em rede permitia à Cisco monitorar a demanda e as receitas de hora em hora. Esse recurso de "proximidade virtual" não só ajudou a Cisco a tocar seu próprio negócio, mas também tornou-se uma ferramenta de marketing útil para promover seus sistemas para os clientes.

A Nike é um caso de empresa que não costura o seu tênis, mas controla competências em logística, qualidade, design, desenvolvimento de produto, testemunhos de atletas, distribuição e merchandising e manufatura dos principais componentes de seus produtos de maior valor como o Nike Air. As empresas que adotaram a idéia de terceirizar processos o fizeram visando principalmente redução de custos e deixar o balanço patrimonial menos imobilizado, contudo elas também obtiveram maior flexibilidade e acesso a tecnologias especializadas. Mais recentemente, empresas começaram internacionalizar boa parte de sua terceirização, enviando não somente a manufatura, como no caso da Nike e da HewlettPackard, mas também serviços para Índia, China, Filipinas e outros países com baixo custo laboral. As principais atividades da empresa envolvem design, pesquisa e desenvolvimento de produtos e marketing

Handy (2003, p.75) cita a NiKe como o exemplo mais conhecido de uma empresa virtual e atribui a ela o termo "Parceiros de produção", eufemismo usado para se referir à rede de fábricas de baixo custo no sudoeste da Ásia. "A Nike vende conceitos", diz Rifkin (apud HANDY, 2003, p.75), crítico social norte americano, descrevendo o fenômeno da terceirização nos estados Unidos. Embora a Nike seja a maior fabricante de calçados esportivos, ela não possui nenhuma fábrica, nenhuma máquina, nenhum equipamento ou bem imóvel significativo. O que ela possui é um sistema de comunicação que mantém todas as peças unidas. Constata-se uma busca pela flexibilidade máxima. Essas organizações "virtuais" criam uma rede de relações que Ihes permitem terceirizar a fabricação, distribuição, marketing ou qualquer outra função empresarial que a administração achar que outros especialistas podem fazer melhor ou bem mais barato.

A logística em sua cadeia de suprimentos: de sua sede em Beaverton, Oregon, a Nike opera um empreendimento virtual que abrange todo o mundo. Em seu núcleo há um conjunto de processos de negócio, projetados para combinar suas capacidades em P\&D cujo nível é o estado da arte, com uma implacável estratégia de manufatura a baixo custo. A empresa terceiriza praticamente $100 \%$ de sua produção de tênis, por exemplo, mantendo a fabricação interna de alguns componentes fundamentais de seu patenteado Nike Air System. O tênis para basquete, por exemplo, é desenhado em Oregon e no Tennessee e desenvolvido conjuntamente por técnicos asiáticos e norte-americanos em Oregon, Taiwan e Coréia do Sul. O tênis em si é manufaturado na Coréia do Sul (tamanhos para homens) e na Indonésia (tamanhos para meninos), a partir de 72 componentes fornecidos por empresas do Japão, Coréia do Sul, Taiwan, Indonésia e Estados Unidos. Além disso, a complexidade do produto significa que cada par de tênis passa por mais de 120 pares de mãos durante o processo de produção. Também significa que há risco de lead times mais longos.

A Nike não tem nenhuma fábrica. É enxuta. É forte na pesquisa e no desenvolvimento de produtos como é evidenciado na sua evolução e na escala de inovação de produtos. Produz com custos mais competitivos, onde tiver melhores condições de qualidade elevada e competitividade. Se os custos subirem, e os produtos puderem ser feitos mais baratos em outra parte (ou com melhor especificação), a Nike moverá a produção. Faz um marketing global. É a número um no seu setor. Sua logo famosa é identificada mundialmente. 


\section{CONCLUSÃO}

As empresas pesquisadas neste artigo (Nike e Cisco) apresentam cadeias de suprimentos ágeis, flexíveis e enxutas, já que se utilizam muito de terceirização dos seus produtos, fabricação em lugares mais competitivos em custos, mais rápidos, com lead times curtos, portanto a cadeia de suprimentos num nível estratégico está alinhada com a estratégia corporativa das empresas, pois esta prega rapidez, baixo custo de produção, flexibilidade, integração entre os atores participantes da cadeia, produção mais limpa, portanto alinhada com as prioridades competitivas em questão. Quanto ao alinhamento nas áreas internas das empresas, concluí-se pelos resultados obtidos nas pesquisas que Nike e Cisco os critérios de desempenho também estão alinhados com a estratégia corporativa da empresas, pois, elas focam suas competências em design, enfatizando uma prioridade quanto à área de desenvolvimento de novos produtos.

Devido às terceirizações em sua fabricação, sendo cadeias ágeis e um relacionamento colaborativo com seus parceiros, a empresa está alinhada com produção pois prioriza velocidade e rapidez, tendo como resultados custos competitivos na operação, dando possibilidade de ter um preço dos produtos inferiores aos dos concorrentes, esse alinhamento reflete positivamente na pontualidade de entrega e no pioneirismo da empresa frente aos concorrentes, tem uma capacidade de produção que atende até os imprevistos, pois é (externalizada), os parceiros se planejam e se programam para atender às demandas desse mercado extremamente competitivas, dessa forma com essa terceirização da produção traduz-se em agilidade na cadeia o produto atinge uma rapidez quanto ao lançamento de novos produtos no mercado, um tempo reduzido frente aos concorrentes em função de toda a logística com parceiros e as características da cadeia de suprimentos, dessa forma toda essa integração faz com que os custos de produção sejam mais competitivos e no final da cadeia um preço mais atrativo para os clientes, portanto a cadeia está alinhada com a estratégia global da empresa e alinhada com as áreas internas pesquisadas, gerando valor ao cliente.
Além de todos esses ganhos relatados anteriormente ambas as empresas praticam o ESI (Early Supplier Involvement) o compartilhamento de know how em desenvolvimento de projetos e produtos desde o início de sua concepção com os parceiros mais próximos da cadeia, a Cisco tem muita agilidade no tempo de resposta ao cliente em relação á entrega do pedido pois tem a venda direta de seus produtos com o cliente (online), agregando mais valor ao produto, pois não tem na cadeia elos de distribuição (representante), dessa forma é uma cadeia direta entre empresa e cliente.

\section{REFERÊNCIAS}

[1] VACHON, S.; HALLEY, A.; BEAULIEU, M. Aligning Competitive Priorities in the Supply Chain: the Role of Interactions with Suppliers. International Journal of Operations \& Production Management. V. 29, n. 4, 2009.

[2] COOPER, M. C.; LAMBERT, D. M.; PAGH, J. D. Supply chain management: more than a new name for logistics. The Internacional Journal of Logistics Management, v. 8, n. 1, p. 1-14, 1997.

[3] CHRISTOPHER, M. Logística e Gerenciamento da Cadeia de Suprimentos: criando redes que agregam valor. São Paulo: Thomson Pioneira, 2007.

[4] DONK, D. P V.; AKKERMAN, R.; VAART, T. V. D. Opportunities and realities of supply chain integration: the case of food manufacturers. British Food Journal, v. 110, n. 2, p. 218-235, 2008.

[5] BOWERSOX, D. J.; CLOSS, D. J. Logística Empresarial: o processo de Integração da Cadeia de Suprimentos. São Paulo: Atlas, 2001.

[6] CROXTON, K. L. et al. The supply chain processes. The International Journal of Logistics Management, v. 12, n. 3, p. 13-36, 2001.

[7] LAMBERT, D. M.; COOPER, M. C.; PAGH, J. D. Supply chain management: implementation issues and research opportunities. The international Journal of Logistics Management, v. 9, n. 2, p. 1-19, 1998.

[8] TUBINO, M. Planejamento e Controle da Produção. São Paulo: Atlas, 2007

[9] SKIPPER, J. B. et al. Towards a theoretical foundation of supply network interdependence and technology-enabled coordination strategies. International Journal of Physical Distribution \& Logistics Management, v. 38, n. 1, p. 39-56, 2008. 
[10] TÖYLI, J. et al. Logistics and financial performance: An analysis of 424 Finnish small and medium-sized enterprises. International Journal of Physical Distribution \& Logistics Management, v. 38, n. 1, p. 57-80, 2008.

[11] PIRES, S. R. I. Gestão da Cadeia de Suprimentos. São Paulo: Atlas, 2004.

[12] FIGUEIREDO, K. F. Gestão da Capacidade e da Demanda em Serviços Logísticos. Revista Tecnologística, v. 5, n. 66, p. 46-50, 2001.

[13] MENTZER, J. T. et al. Defining supply chain management. Journal of Business Logistics, v. 22, n. 2, p. 1-25, 2001.

[14] MORGAN, C. Supply network performance measurement: future challenges? The International Journal of Logistics Management, v. 18, n. 2, p. 255-273, 2007.

[15] CHOPRA, S.; MEINDL, P. Gerenciamento da Cadeia de Suprimentos: estratégia, planejamento e operação. São Paulo: Prentice Hall, 2003.

[16] KOH, C. E.; NAM, K. Business use of the internet: A longitudinal study from a value chain perspective. Industrial Management \& Data Systems, v. 105, n. 1, p. 82-95, 2005.

[17] NOVAES, A. G. Logística e gerenciamento da cadeia de distribuição: estratégia, operação e avaliação. Rio de Janeiro: Campus, 2004. 409 p.

[18] SIMCHI-LEVI, DAVID, KAMINSKY, PHILIP;SIMCHI-LEVI, EDITH. Cadeia de Suprimentos: Projeto e Gestão, 3a․ ed. Bookman, Porto Alegre, 2010

[19] SKINNER, W. Manufacturing - Missing Link in Corporate Strategy. Harvard Business Review, v. 47, n. 3, 1969.

[20] SLACK, N.; CHAMBERS, S.; JOHNSTON, R. Administração da Produção. 2. ed. São Paulo: Atlas, 2002.

[21] PIRES, Sílvio R. I. Formal contracts in supply chain management: a case study poms. Annual Conference Dallas, 18th, Texas, USA May 4 to May 7, 2007.

[22] Supply Chain Management. 2001. Disponível em: <http://www.numa.org.br> Acesso em: junho de 2001.

[23] GATTORNA. J. Living Supply Chain. New York: Pearson Education, 2009.

[24] JAGJIT S.S. A supply network configuration perspective on international supply chain development. International Journal of Operations \& Production Management v. 28 n. 5, pp. 386-411, 2008.

[25] HILL, T. Manufacturing strategy: text and cases. Boston, MA, Irwin, 1989.

[26] VACHON, S. Aligning competitive priorities in the supply chain: the role of interactions with suppliers. International Journal of Operations \& Production Management v. 29 n. 4, pp. 322-340, 2009.
[27] DÍAZ-GARRIDO, E.; MARTÍN-PEÑA, M. L.; GARCÍAMUIÑA, F. E. A Taxonomy of manufacturing strategies in Spanish companies. Spain International Journal of Operations \& Production Management, v. 28, n. 5, p. 455477, 2008.

[28] TAN, K. C. Supply Chain Management: Practices, concerns, and performance issues. The Journal of Supply Chain Management, p. 42-53, Winter, 2002.

[29] LUMUS, R. R.; VOKURKA, R. J.; ALBER, K. L. Strategic supply chain planning. Production and Inventory Management Journal, v. 39, p. 49-58, 1998.

[30] LAZZARINI, S. G. Estudos de caso: aplicações e limites do método. In: FARINA, E. Estudos de caso em agribusiness, São Paulo: Pioneira, 1997.

[31] YIN, R. K. Case Study Research, Design and Methods. 2. ed. London: Sage, 1994.

[32] NÓBREGA JR, J. I. C. Metodologia para análise estratégica de projetos de cadeias de abastecimento industriais. 2000. 102f. Dissertação (Mestrado em Administração) - Universidade Federal de Santa Catarina, Florianópolis, 2000.

[33] REICHHART, Andreas; HOLWEG, Matthias. Colocated supplier clusters: forms, functions and theoretical perspectives. International Journal of Operations \& Production Management, v. 28, n. 1, p. 53-78, 2008.

[34] FABBE-COSTES, Nathalie. Supply chain integration and performance: a review of the evidence. The International Journal of Logistics Management, v. 19, n. 2, p. 130-154, 2008.

[35] BUOSI, T.; CARPINETTI, L. C. B. Análise, avaliação e diagnóstico da cadeia de suprimentos: uma análise crítica sobre modelos de referências. In. Encontro Nacional de Engenharia de Produção - ENEGEP, XXII, 2002. Curitiba

[36] GARVIN, D. A. Competing on the eight dimensions of quality. Harvard Business Review, Nov./Dec., 1987.

[37] KUEHNLE, $H$. A System of models contribution to production network (PN) theory. Journal of Intelligent Manufacturing, v. 18, n. 5 October, 2007.

[38] STEVENSON, M. Supply chain flexibility: an interfirm empirical study. International Journal of Operations \& Production Management, v. 29, n. 9, p. 946-971, 2009

[39] HINES, T. Supply Chain Strategies: Customer Driven and Customer Focused, Butterworth-Heinemann, 2004.

[40] DYER, J.; CHU, W. The Determinants of Trust in Supplierautomaker Relationships in the US, Japan and Korea. Journal of International Business Studies. V. 31, n.2, 2000

[41] OGDEN J. Supply base reduction: an empirical study of critical success factors. Supply Chain Management 42(4):29 40, 2006. 
[42] Su HAYES, R. H.; PISANO, G. P. Em Busca da vantagem competitiva: produção, estratégia e tecnologia. Porto Alegre: Bookman, 2008.

[43] HEIZER, Jay; RENDER, Barry. Administração de Operações, Bens e Serviços. Rio de Janeiro, 2004

[44] HAYES, R. H.; PISANO, G. P. Em Busca da vantagem competitiva: produção, estratégia e tecnologia. Porto Alegre: Bookman, 2008.

[45] LAUGEN, T. B.; BOER, N. A. H.; FRICK, J. Best manufacturing practices: what do the best performing companies do? International Journal of Operations \& Production Management, v. 25, n. 2, p. 131-150, 2005.

[46] DEVARAJ, S.; HOLLINGWORTH, D. V.; SCHROEDER, R. G. Generic manufacturing strategies an plant performance. Journal of Operations Management, v. 22, n. 3, p. 313-333, 2004.
[47] KRAJEWSKI, Lee; LARRY, Ritzman; MANAY, Malhotra. Administração de produção e operações. 8. ed. São Paulo: Prentice Hall, 2008.

[48] CHASE, R.B., JACOBS, F.R.; AQUILANO, N.J. Administração da produção para vantagem competitiva. Porto Alegre: Bookman, 2006. 


\section{CAPÍTULO 19}

\section{MAPEAMENTO DE PROCESSOS APLICADO À ORGANIZAÇÃo DO SETOR DE PATRIMÔNIO DE UMA INSTITUIÇÃO PÚBLICA}

\section{Juliano Ferreira Lima \\ Marcio Carvalho dos Santos}

Resumo: O gerenciamento de processos torna-se uma questão muito influente no desenvolvimento organizacional de muitas empresas, principalmente as de caráter público, como as universidades. Em suma, essas instituições adotam uma administração burocrática, criando a dependência por departamentos, exigindo de seus processos máxima eficiência. Desses departamentos, destaca-se o responsável pelo gerenciamento e controle de todos os bens patrimoniais, o Setor de Patrimônio. Bens patrimoniais classificam-se como bens públicos utilizados para o desenvolvimento das atividades nas instituições, compreendidos como imóveis, móveis e semoventes. A grande questão que envolve o setor de patrimônio relaciona-se a forma de gerenciamento dos processos para entradas e saídas (processos externos) e movimentação (processos internos) de bens patrimoniais. Entendendo a influência que a estruturação de processos exerce no desenvolvimento de atividades diárias e analisando as disfunções que o setor estudado apresentava devido à falta de estruturação dos seus processos, a pesquisa tem por objetivo utilizar o mapeamento de processos externos do setor de patrimônio da Universidade Estadual do Paraná - Campus Campo Mourão com intuito de melhorar o seu desempenho organizacional. A pesquisa realizou-se por meio do acompanhamento das atividades desenvolvidas no setor, proposição de fluxos para aperfeiçoar os processos e elaboração de manual de processos do patrimônio. Com a pesquisa foi possível analisar as atividades inseridas em todos os processos externos e analisar a sua interdependência; analisar a aplicabilidade dos conceitos e ferramentas de qualidade para melhorar o desempenho de empresas prestadoras de serviços; estruturar fluxogramas para visualização gráfica dos processos desenvolvimentos do setor e acompanhar o início das melhorias ocorridas no desempenho organizacional do setor.

Palavras chave: Gestão por Processos. Qualidade nos Processos. Processos na Gestão Pública; Desempenho Organizacional. 


\section{INTRODUÇÃO}

O setor de patrimônio de qualquer instituição é o ambiente de controle dos bens patrimoniais, sendo responsável por suprir as necessidades de bens necessários para realização dos objetivos de seus clientes, controlando e protegendo os bens públicos e instruindo o seu uso racional (LELLIS, 2009).

Lellis (2009) caracteriza bens patrimoniais como sendo:

i) Bens duráveis - móveis, eletrodomésticos e veículos;

ii) Bens móveis - que podem ser deslocados sem perder sua forma;

iii) Bens imóveis - sem possibilidade de deslocamento, e;

iv) Bens semoventes - animais.

Com base nas áreas definidas pela Associação Brasileira de Engenharia de Produção - ABEPRO (2008), o artigo se insere na área de Engenharia da Qualidade devido a sua abordagem ao planejamento e controle de sistemas de gestão que utilizam gerenciamento por processos, se enquadrando na sub-área de Confiabilidade de Processos e Produtos.

O objetivo central da pesquisa caracteriza-se pelo uso do mapeamento de processos externos do setor de patrimônio da Universidade Estadual do Paraná Campus Campo Mourão com intuito de melhorar o seu desempenho organizacional.

Para o alcance do objetivo central propôs-se:

i) o acompanhamento das atividades desenvolvidas no setor de patrimônio;

ii) mapeamento dos processos externos executados pelo setor de patrimônio;

iii) proposição de fluxo para execução dos processos externos mapeados, e;

iv) Estruturação de manual de processos do patrimônio.

A problemática da pesquisa circunda os questionamentos sobre as formas com a qual o mapeamento dos processos externos pode auxiliar no desempenho organizacional do setor de patrimônio da UNESPAR - Campus Campo Mourão.

Baseando-se nos argumentos de Pereira (1998) o setor de patrimônio, uma vez inserido em instituições públicas, deve ser regido por uma administração pública burocrática, pois irá se basear em processos, como em processos para aquisição e gerenciamento de bens.

Portanto, a pesquisa justifica-se pela importância da formalização e padronização dos processos no setor de patrimônio na instituição, favorecendo o desempenho organizacional do setor além de tornar seus processos confiáveis e eficientes.

As melhorias obtidas com a aplicação do trabalho não se limitam apenas para o setor de patrimônio da UNESPAR - Campus Campo Mourão, pois trará benefícios a todos os clientes dos processos, seja pela viabilidade na melhoria do fluxo de informação ou pelo suprimento da demanda por bens.

No entanto, uma das maiores contribuições será aos alunos do curso de Engenharia de Produção Agroindustrial da UNESPAR - Campus Campo Mourão devido à temática do trabalho, pois aborda conceitos de engenharia aplicados a empresas públicas prestadoras de serviços, um objeto de estudo ainda distante do cotidiano científico do curso.

\section{TEORIA DE BASE \\ 2.1 GESTÃO PÚBLICA}

A administração de uma instituição pública de ensino superior não é feita de forma tão simplificada devido a sua estrutura administrativa. Mesmo com o surgimento de uma vertente denominada administração gerencial, que apresenta uma estrutura horizontal e caracterizada pelo alto nível de flexibilidade, muitas instituições de ensino ainda utilizam a administração burocrática (ASSUNÇÃO E MENDES, 2000; PARO, 2008).

De acordo com Assunção e Mendes (2000) e Bernardes (1988), com o uso da administração burocrática são empegados níveis de gerência seguindo uma hierarquia, assim, tem-se a necessidade de criar departamentos, burocratizando processos.

O modelo de administração burocrático apresenta três características principais, sendo elas:

i) formalidade; 
ii) impessoalidade, e;

iii) profissionalismo, de forma que o poder, ou, as regras, sejam cumpridas por normas e não pelo modo tradicional que tange os conceitos do achismo (SECCHI, 2009).

Para Secchi (2009) a administração burocrática provê processos eficientes, oferendo aos seus envolvidos tratamento igualitário em todas as atividades inseridas. Mesmo com uso da burocracia, em instituições de ensino aplica-se facilmente uma das funções administrativas propostas por Fayol, a função de controle, responsável pelo gerenciamento e verificação do planejamento para o controle de metas (LELLIS, 2009).

Essa função é visível nos setores de patrimônio de instituições públicas, pois utilizam seus processos de entradas e saídas de patrimônio para controle de suas metas, ou seja, suprimento das necessidades dos seus clientes, por meio de atribuição de responsabilidades, uso de metodologias, suprimento de recursos, dentre outras formas para efetivação de uma gestão patrimonial (LELLIS, 2009).

\subsection{GESTÃO PATRIMONIAL}

De acordo com Lellis (2009) é entendido com gestão patrimonial o gerenciamento das diretrizes de patrimônio que engloba: i) a designação de responsabilidade pelo dano causado ao bem; ii) a restrição ao uso particular de bem público; iii) a organização da documentação dos bens, como o número de patrimônio; iv) o gerenciamento da documentação de movimentação de bens, e; v) o controle de registros internos e externos devido ao fluxo de entradas e saídas de patrimônio.

Para auxiliar a gestão patrimonial dentro das instituições públicas no estado, a Secretaria de Estado da Administração por meio da Coordenadoria do Patrimônio do Estado criou o Manual de Bens Móveis do Estado do Paraná - Sistema AAB (COMPANHIA DE INFORMÁTICA DO PARANÁ - CELEPAR, 2008). móveis patrimoniais por meio:

i) da emissão de inventário do Estado;

ii) do acompanhamento dos setores na patrimônio nas instituições que utilizam o sistema, e;

iii) do acompanhamento sobre a movimentação de bens.

\subsubsection{PATRIMÔNIO PÚBLICO}

Define-se como patrimônio público o conjunto de bens e direitos, assim como valores, créditos e obrigações de conteúdo econômico, de cunho tangível e intangível, podendo ser [...] adquirido, formado, produzido, recebido, mantido ou utilizado pelas entidades de setor público [...], como instituições de ensino (LELLIS, 2009; UNIVERSIDADE ESTADUAL DO PARANÁ - UEL, 2010).

O Conselho Federal de Contabilidade (2009), pela NBC T 16.2, estrutura o patrimônio público em três grupos:

I. Ativos - controlados pela entidade com intuito de gerar benefícios econômicos futuros e serviços potenciais;

II. Passivos - obrigações presentes da entidade cujo pagamento almeja geração de benefício à entidade;

III. Patrimônio Líquido - valor residual dos ativos depois de deduzidos todos seus passivos.

Compreendido como patrimônio público, bens patrimoniais são objetos destinados ao desenvolvimento das atividades da instituição, constituído por objetos duráveis, móveis, imóveis e semoventes (LELLIS, 2009; UEL, 2010).

No Quadro 1é possível observar a estratificação dos bens seguindo sua caracterização. 
Quadro 1: Caracterização de bens patrimoniais

\begin{tabular}{|c|c|}
\hline Bens & Caracterização \\
\hline Imóveis & Terrenos; obras preliminares e complementares, e; obras civis. \\
\hline Móveis & $\begin{array}{l}\text { Instalações, Máquinas, aparelhos e equipamentos; Móveis e utensílios; Veículos; Ferramentas; Livros e acervos, e; } \\
\text { Obras de arte. }\end{array}$ \\
\hline Semoventes & Animais. \\
\hline Intangiveis & Marcas e patentes; Direito sobre recursos naturais, e; Pesquisa e desenvolvimento. \\
\hline
\end{tabular}

Fonte: UEL, 2010. Elaborado pelo autor, 2014.

\subsection{GESTÃO DE PROCESSOS}

Processo é compreendido como qualquer tipo de atividade ou conjunto de operações que apresente uma entrada (input), um método de processamento (process) e uma saída (output) (GONÇALVES, 2000; SLACK, et al., 2009).

Conforme Celepar (2008) e UEL (2010) no setor de patrimônio de instituições de ensino os processos serão caracterizados pelas atividades realizadas no setor como:

i) Processo de registros de bens patrimoniais;

ii) Processos de entradas e saídas de bens;

iii) Processo de movimentação de bens;

iv) Processo de termos de recebimento de bens, dentre outros.

Baseando-se nos argumentos de Gonçalves (2000), observa-se que em setores que controlam patrimônio público, os processos são caracterizados quanto ao fluxo de trabalho e nível organizacional, sendo burocráticos, apresentando início e fim bem definidos, atividades discretas e sequência lógica e temporal das atividades.

Torna-se importante identificar os processos a serem desenvolvidos, pois estes criam e garantem eficiência e habilidades, definindo a forma básica da organização das pessoas e demais recursos das instituições (GONÇALVES, 2000; ANJOS, REIS E SORATTO, 2002).

\subsubsection{MAPEAMENTO DE PROCESSOS}

Segundo Santos (2004) o mapeamento dos processos é uma ferramenta que tem como objetivo facilitar a identificação das atividades para a estruturação de processos, reduzindo e/ou eliminando atividades que não trazem benefício aos processos.

O emprego de ferramentas da qualidade para mapeamento dos processos proporciona muitos benefícios, visto que podem ser utilizados para implementação, monitoramento e melhoria da qualidade nos processos de organizações (NECCHI DE OLIVEIRA, JOSE DE OLIVEIRA E MAEKAWA, 2010; OLIVIRA, et al., 2010).

Das diferentes ferramentas de qualidade existentes, pode-se destacar 3 facilmente aplicadas à melhoria de processos, como: i) $5 \mathrm{~W} 1 \mathrm{H}$; ii) Ishikawa, e; iii) Fluxogramas (NECCHI DE OLIVEIRA, JOSE DE OLIVEIRA E MAEKAWA, 2010; OLIVIRA, et al., 2010; BELLUCCI JÚNIOR E MATSUDA, 2012).

O 5W1H é uma ferramenta de estruturação de planos de ação, tendo como objetivo a melhoria da qualidade, de forma a indicar o que, quem, quando, onde, por que, e principalmente, como executar suas atividades, atividades essas inseridas em processos (NECCHI DE OLIVEIRA, JOSE DE OLIVEIRA E MAEKAWA, 2010; OLIVIRA, et al., 2010).

Ishikawa caracteriza-se pela representação de [...] "opiniões a respeito de fontes de variações em processos, mas que também aplica-se à análise de 
problemas organizacionais identificando as possíveis causas que resultam em efeitos indesejáveis" (NECCHI DE OLIVEIRA, JOSE DE OLIVEIRA E MAEKAWA, 2010).

\section{E, por sua vez, fluxogramas, que caracterizam-se como} um modelo de ilustração gráfica retratando diferentes ações, possibilitando a estruturação de fluxos produtivos e a análise e organização de processos (BELLUCCI JÚNIOR E MATSUDA, 2012).

\section{REVISÃO DE LITERATURA}

Para revisão de literatura apresentada nesta pesquisa, foram revisados anais do Encontro Nacional de Engenharia de Produção - ENEGEP e Simpósio de Engenharia de Produção - SIMPEP, artigos publicados na Revista Produção e Revista Administração, dentre outros encontrados em sites de pesquisa como Portal Scielo, CAPES e Google, que estão apresentados no Quadro 2.

Quadro 2: Revisão de literatura

\begin{tabular}{|c|c|c|}
\hline Autor/Ano & Objetivos & Resultados \\
\hline Gonçalves, 2000 & $\begin{array}{l}\text { Abordar uma revisão teórica de } \\
\text { definições e aplicações do conceito } \\
\text { de processos empresariais, buscando } \\
\text { facilitar a compreensão do assunto. }\end{array}$ & $\begin{array}{l}\text { O autor apresenta definições de processos, classificando-os e } \\
\text { caracterizando-os. Aborda uma definição sobre processos não fabris, } \\
\text { relacionados a processos organizacionais. Ressalta a importância da } \\
\text { estruturação e emprego de tecnologia para o desenvolvimento de } \\
\text { processos. Por fim, o autor conclui que o entendimento claro sobre o } \\
\text { conceito de processo e a aplicação apenas pontual desse conceito na } \\
\text { administração das empresas pode limitar a obtenção de resultados. }\end{array}$ \\
\hline Santos, 2004 & $\begin{array}{l}\text { Desenvolver um modelo para identificar } \\
\text { e incorporar atividades que facilitem } \\
\text { a continuidade dos processos de } \\
\text { produção indicando o momento que } \\
\text { devem ser inseridas, para impedir ou } \\
\text { minimizar interrupções nos processos. }\end{array}$ & $\begin{array}{l}\text { A princípio identificou as atividades desenvolvidas nos processos } \\
\text { e por meio do diagrama de Ishikawa apontou as atividades que } \\
\text { podem interromper os seus fluxos. Após a descrição das atividades, } \\
\text { mapearam-se os processos com a utilização de fluxogramas e uso de } \\
\text { simbologia para elaboração de redes operacionais de processos. A } \\
\text { autora concluiu que com a aplicação da pesquisa à empresa pode } \\
\text { identificar atividades facilitadoras separando o que é intrínseco e } \\
\text { extrínseco aos processos. }\end{array}$ \\
\hline $\begin{array}{c}\text { Anjos, Reis e Soratto, } \\
2002\end{array}$ & $\begin{array}{l}\text { Apresentar uma breve revisão de } \\
\text { literatura apontando as contribuições } \\
\text { dos processos de gestão para o } \\
\text { ambiente onde são estabelecidas as } \\
\text { organizações. }\end{array}$ & $\begin{array}{l}\text { Classificou-se os processos quanto ao tipo, fazendo um comparativo } \\
\text { entre gestão por função e gestão por processos. Apresentaram- } \\
\text { se as possíveis melhorias a cerca da evolução para organizações } \\
\text { gerenciada por processos e as formas de agregar valor a esses } \\
\text { processos. Concluiu-se que o gerenciamento por processos } \\
\text { está diretamente ligado a gestão ambiental de forma com que a } \\
\text { administração do ambiente de trabalho pode influenciar a execução } \\
\text { dos seus processos. }\end{array}$ \\
\hline $\begin{array}{l}\text { Assunção e Mendes, } \\
2000\end{array}$ & $\begin{array}{l}\text { Relatareanalisaraexperiência deadoção } \\
\text { da gestão por processo na Embrapa, } \\
\text { como uma forma organizacional de } \\
\text { apoio à mudança e modernização da } \\
\text { Empresa capaz de proporcionar maior } \\
\text { flexibilidade na gestão e possibilitar } \\
\text { melhores resultados. }\end{array}$ & $\begin{array}{l}\text { A pesquisa apresentou um levantamento sobre a forma atual } \\
\text { de reestruturação de instituições públicas caracterizadas pelo } \\
\text { gerenciamento por processos. Destaca os elementos que devem ser } \\
\text { observados nos processos gerenciais e cria um modelo básico para } \\
\text { o desenvolvimento dos processos da empresa. Concluiu-se que a } \\
\text { adoção da organização por processos na empresa indica o sucesso } \\
\text { para implantar novas técnicas para gestão do setor público. }\end{array}$ \\
\hline
\end{tabular}

Elaborado pelo autor, 2014.

\section{METODOLOGIA}

A metodologia utiliza nesta pesquisa foi baseada nos estudos de Lakatos e Marconi (2003).

Quanto ao método de abordagem, utilizou-se o método quantitativo, de modo a analisar e mapear todos os processos desenvolvidos pelo setor de patrimônio da UNESPAR - Campus Campo Mourão com intuito aperfeiçoar o desempenho organizacional do setor.

A pesquisa classifica-se quanto aos fins como exploratória, pois foi necessário analisar todas as atividades inseridas em todos os tipos de processos externos desenvolvidos pelo setor; descritiva e explicativa, devido ao mapeamento dos processos externos, sendo necessário elencar cada processo 
e explicar o seu desenvolvimento, e; metodológica, devido aos modelos de fluxos que foram propostos para o desenvolvimento dos processos.

Quanto aos meios classifica-se como pesquisa de campo, pois os processos foram observados in loco durante o seu desenvolvimento; documental, pois baseou-se nos manuais de procedimentos de patrimônio de universidades e nas instruções do Sistema AAB; bibliográfica, de fonte primária e secundária, baseada em artigos e publicações com a mesma temática da pesquisa apresentada; estudo de caso, oriundo dos resultados obtidos durante estágio extracurricular na UNESPAR - Campus Campo Mourão.

Para coleta dos dados fez-se uso da observação direta intensiva do tipo não participante e aberta, possibilitando a análise e observa-se de todos os processos realizados. Para as entrevistas utilizou-se o formato estruturado, possibilitando o entendimento por operações das atividades nos processos desenvolvidos.

Para o tratamento dos dados utilizou-se quadros, necessário para descrever os processos externos e mapeá-los utilizando ferramenta $5 \mathrm{~W} 1 \mathrm{H}$; fluxogramas, viabilizando a representação gráfica dos fluxos dos processos, e; listas, referente aos dados extras como clientes dos processos, necessidades do processos e objetivos dos processos.

Os dados avaliaram-se pelo método qualitativo, descrevendo e analisando a influência dos processos externos no desempenho organizacional do setor. Para o desenvolvimento da pesquisa, foi essencial a utilização de hardware (notebook), software (Microsoft Word 2010 e Microsoft Excel 2010) e utensílios como pranchetas, caneta e papel.

\section{MAPEAMENTO DOS PROCESSOS NO SETOR DE PATRIMÔNIO DA UNIVERSIDADE ESTADUAL DO PARANÁ - CAMPUS CAMPO MOURÃO \\ 5.1 CARACTERIZAÇÃO DA EMPRESA}

Localizada na cidade de Campo Mourão, em 2012, a Empresa passou a ser denominada Universidade
Estadual do Paraná - Campus Campo Mourão UNESPAR, caracterizada como empresa pública prestadora de serviço no ramo de ensino, pesquisa e extensão (FECILCAM, 2014).

A empresa foi fundada pela Lei Municipal n²6/1972, na época denominada FUNDESCAM, e depois estadualizada em 1978 quando transformada em Faculdade Estadual de Ciências e Letras de Campo Mourão - FECILCAM (FECILCAM, 2014).

Com o tempo a FECILCAM foi desenvolvendo suas atividades e se estruturando, o que possibilitou, atualmente, a oferta de dez cursos de graduação:
i) Administração;
ii) Ciências Contábeis;
iii) Ciências Econômicas;
iv) Engenharia de Produção Agroindustrial;
v) Geografia;
vi) História; vii) Letras;
viii) Matemática;
ix) Pedagogia, e;
x) Turismo e Meio Ambiente (FECILCAM, 2014).

Após longos debates e processos, em 2012, a antiga FECILCAM é incorporada a atual UNESPAR. A instituição passa a ser caracterizada como universidade multi campi, como observado pelo Apêndice 1, tendo sete campus espalhados pelo estado, abrangendo as cidades de: i) Curitiba; ii) Campo Mourão; iii) Apucarana, iv) Paranavaí; v) Paranaguá; vi) União da Vitória, e; vii) São José dos Pinhais (UNESPAR, 2014).

\subsection{SETOR DE PATRIMÔNIO DA UNESPAR - CAMPUS CAMPO MOURÃO}

O Patrimônio trata-se de um setor inserido na seção de compras e licitações da instituição, como observado no Anexo 1, e controla o patrimônio da UNESPAR Campus Campo Mourão, sendo responsável pela incorporação, baixa e movimentação dos bens patrimoniais.

O organograma do setor pode ser observado na Figura 1. 
Figura 1: Organograma do setor de patrimônio.

\begin{tabular}{|l|}
\hline Direção de Campus \\
\hline $\begin{array}{l}\text { Divisão de Administração e Finanças } \\
\text { - Seção de Compras e Licitações } \\
\text { - Setor de Patrimônio } \\
\text { • Coordenador } \\
\text { • Auxiliar de Patrimônio }\end{array}$ \\
\hline
\end{tabular}

Elaborado pelo autor, 2014

O setor conta com apenas dois funcionários - o coordenador do setor e seu auxiliar - trabalhando em turno único de oito horas, das 08:00 às 11:30 e das 13:30 às 17:00.

\subsubsection{PROCESSOS EXTERNOS DO SETOR DE PATRIMÔNIO}

Caracterizam-se como processos externos do setor de patrimônio todos os processos de entradas e saídas de bens patrimoniais.

Esses processos são oriundos da existência de demanda nos setores/departamentos da instituição e seguem um padrão estabelecido pela AAB. Os processo de entradas e saídas podem ser observados no Quadro 3.

Quadro 3: Processos de entradas e saídas de patrimônio.

\begin{tabular}{|l|l|}
\hline PROCESSOS & \multirow{2}{*}{ CARACTERIZAÇÃO } \\
\cline { 1 - 1 } Aquisição & Saídas \\
\cline { 1 - 1 } Leilão & \multirow{2}{*}{$\begin{array}{l}\text { Furto/Roubo/ } \\
\text { Desaparecimento }\end{array}$} \\
\cline { 1 - 1 } $\begin{array}{l}\text { Permissão de uso de/para } \\
\text { terceiros }\end{array}$ & \\
\cline { 1 - 1 } Doação & \\
\cline { 1 - 1 } Permuta & \\
\cline { 1 - 1 } Comodato & \\
\cline { 1 - 1 } Fabricação & \\
\cline { 1 - 1 } Convênio & \\
\cline { 1 - 1 } Transferência & \\
\hline
\end{tabular}

Elaborado pelo autor, 2014.

Com base no Quadro 3, observa-se que, existem dez formas de inserção e retirada de bens patrimoniais dos registros de patrimônio da instituição.

Pelo processo de aquisição serão realizadas entradas de patrimônio, visto que refere-se à compra de bens. Para os processos tidos apenas como saídas caracterizam-se roubo/furto/desaparecimento e leilões. Os demais processos podem ser executados tanto para entrada quanto para saída de bens, cada um seguindo sua especificidade.

\subsection{PROBLEMÁTICA DO SETOR DE PATRIMÔNIO E O ESTUDO PROPOSTO}

O setor, em períodos anteriores ao desenvolvimento da pesquisa, enfrentou algumas disfunções não possibilitando a melhor organização das suas atividades, comprometendo o seu desempenho organizacional.

Para visualização das causas que poderiam ter resultado essas disfunções, estruturou-se um Diagrama de Ishikawa, onde foram elencadas as causas que poderiam ser atacadas de forma a auxiliar o setor a melhoras seu desempenho na execução de processos.

Escolhida a causa raiz para solução da disfunção mais relevante, estudou-se o Sistema AAB - sistema utilizado pelo setor de patrimônio da UNESPAR Campus Campo Mourão - e manuais de procedimentos de patrimônio da UEL, UNESPAR - Campus Campo Mourão e Universidade Federal de Minas Gerais para analisar quais os tipos de processos externos eram desenvolvidos nos setor.

Com base nos processos analisados, realizou-se o mapeamento dos processos utilizando a metodologia $5 \mathrm{~W} 1 \mathrm{H}$, de forma a tornar descritivo e compreensivo os processos externos designando o que, quem, quando, onde, por que e como serão executados.

Para facilitar a interpretação dos processos externos, foi proposto modelos de fluxos - utilizando fluxogramas - para cada um dos tipos de processos, de forma a agilizar o entendimento das atividades de cada um. 
Por fim, estruturou-se um Manual de Processo de Patrimônio - MPP, como forma de apontar medidas de controle e mensuração quanto à qualidade dos processos externos desenvolvidos pelo setor.

\section{RESULTADOS E DISCUSSÕES}

Buscando entender os fatores que levaram o setor de patrimônio a enfrentar algumas disfunções quanto a sua organização, estruturou-se um Diagrama de Ishikawa, como observado na Figura 2.

Figura 2: Causa que influenciam a organização do setor

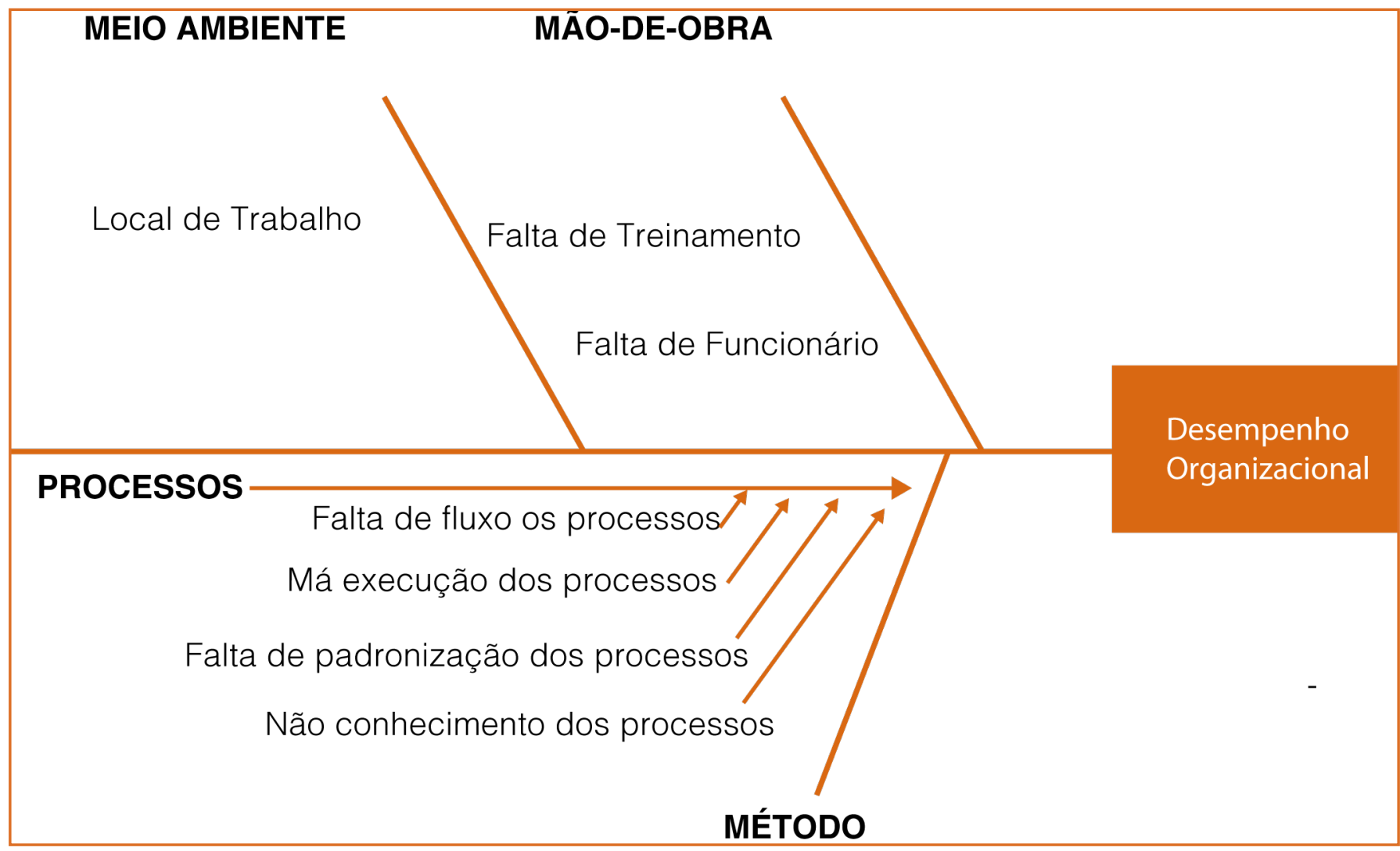

.Elaborado pelo autor, 2014.

$\mathrm{Na}$ Figura 2 observa-se as possíveis disfunções observadas no setor do patrimônio. Referente ao local de trabalho, a questão foi solucionada, pois foi inserida à seção de compras e licitações. Durante a execução da pesquisa foi inserido ao setor um colaborador após treinamento sobre as atividades desenvolvidas pelo setor. A maior disfunção, tornando-se objeto de estudo deste trabalho, compreende a não eficiência dos processos.

Fruto dessas disfunções observa-se:

i) O não gerenciamento do patrimônio de todas as localidades do campus da UNESPAR Campus Campo Mourão, visto que é composta e responsável por sede, sub-sede, Estação Cerrado, Estação Climatológica, Celin e Patronato.

ii) Pela não atualização dos bens patrimoniais da instituição, tendo sua última atualização a 11 anos atrás, no ano 2003;

iii) Baixo fluxo de informação entre os setores de patrimônio e financeiro para atualização do montante total de bens patrimoniais lançados no balancete da instituição;

iv) Não suprimento da demanda dos clientes dos processos, e principalmente;

v) Não atualização dos registros no sistema de controle patrimonial online do estado do Paraná que é fiscalizado pelo Tribunal de Contas da União. 
Quadro 4: Mapeamento dos processos

\begin{tabular}{|c|c|c|c|c|c|}
\hline What & Who & When & Where & Why & How \\
\hline O que? & Quem? & Quando? & Onde? & Porque? & Como? \\
\hline Aquisição & $\begin{array}{l}\text { Setor de } \\
\text { Patrimônio }\end{array}$ & $\begin{array}{l}\text { Solicitado } \\
\text { patrimônio } \\
\text { e este não } \\
\text { estiver } \\
\text { disponível na } \\
\text { instituição }\end{array}$ & $\begin{array}{l}\text { Seção de } \\
\text { Compras }\end{array}$ & $\begin{array}{l}\text { Para atender a } \\
\text { necessidade de algum } \\
\text { dos clientes do processo } \\
\text { de patrimônio }\end{array}$ & $\begin{array}{l}\text { Por meio de processo licitatório ou } \\
\text { processo por compra direta }\end{array}$ \\
\hline $\begin{array}{l}\text { Permissão de uso } \\
\text { de terceiros }\end{array}$ & $\begin{array}{l}\text { Responsável } \\
\text { pelo bem }\end{array}$ & $\begin{array}{l}\text { Necessário } \\
\text { para alguma } \\
\text { atividade } \\
\text { ou setor da } \\
\text { instituição }\end{array}$ & $\begin{array}{l}\text { Setor de } \\
\text { Patrimônio }\end{array}$ & $\begin{array}{l}\text { Para trazer benefício } \\
\text { com sua utilização e } \\
\text { ser incorporados às } \\
\text { atividades da instituição }\end{array}$ & $\begin{array}{l}\text { Setor de patrimônio irá firmar um } \\
\text { termo de responsabilidade para com } \\
\text { o indivíduo, tornando-se responsável } \\
\text { pelo bem, mas não detentor dos seus } \\
\text { direitos }\end{array}$ \\
\hline Doação & $\begin{array}{l}\text { Responsável } \\
\text { pelo bem }\end{array}$ & $\begin{array}{l}\text { O responsável } \\
\text { desejar se } \\
\text { desfazer do } \\
\text { bem e houver } \\
\text { o interesse } \\
\text { da instituição } \\
\text { em inseri- } \\
\text { lo ao seu } \\
\text { patrimônio }\end{array}$ & $\begin{array}{l}\text { Setor de } \\
\text { Patrimônio }\end{array}$ & $\begin{array}{l}\text { Pela necessidade ou } \\
\text { interesse do responsável } \\
\text { e/ou da instituição }\end{array}$ & $\begin{array}{l}\text { Firma-se um termo de doação, } \\
\text { tornando a instituição a detentora dos } \\
\text { diretos sobre o patrimônio }\end{array}$ \\
\hline Permuta & $\begin{array}{l}\text { Setor de } \\
\text { Patrimônio e } \\
\text { entidades }\end{array}$ & $\begin{array}{l}\text { Houver a } \\
\text { necessidade/ }\end{array}$ & $\begin{array}{l}\text { Setor de } \\
\text { Patrimônio }\end{array}$ & $\begin{array}{l}\text { Para atender a } \\
\text { necessidade de algum } \\
\text { dos clientes do processo } \\
\text { de patrimônio }\end{array}$ & $\begin{array}{l}\text { É feito um termo de recebimento do } \\
\text { bem, comprovando a troca entre } \\
\text { a instituição e alguma entidade da } \\
\text { administração pública }\end{array}$ \\
\hline Comodato & $\begin{array}{l}\text { Setor de } \\
\text { Patrimônio }\end{array}$ & $\begin{array}{l}\text { Houver } \\
\text { interesse da } \\
\text { instituição } \\
\text { pelo bem }\end{array}$ & $\begin{array}{l}\text { Setor de } \\
\text { Patrimônio }\end{array}$ & $\begin{array}{l}\text { Para atender a } \\
\text { necessidade de algum } \\
\text { dos clientes do processo } \\
\text { de patrimônio }\end{array}$ & $\begin{array}{l}\text { É firmado termo de empréstimo } \\
\text { gratuito do bem, determinando um } \\
\text { prazo para restituição do mesmo ao } \\
\text { dono }\end{array}$ \\
\hline Fabricação & $\begin{array}{l}\text { Discentes, } \\
\text { docentes e } \\
\text { agentes }\end{array}$ & $\begin{array}{l}\text { Quando feita } \\
\text { a produção/ }\end{array}$ & $\begin{array}{l}\text { Setor de } \\
\text { Patrimônio }\end{array}$ & $\begin{array}{l}\text { Para suprir a } \\
\text { necessidade de algum } \\
\text { cliente do setor ou } \\
\text { utilizar o bem oriundo da } \\
\text { sua fabricação }\end{array}$ & $\begin{array}{l}\text { Após o processo de fabricação/ } \\
\text { transformação/criação, o bem é } \\
\text { registrado e inserido como patrimônio } \\
\text { da instituição }\end{array}$ \\
\hline Convênios & $\begin{array}{l}\text { Setor de } \\
\text { Patrimônio e } \\
\text { o responsável } \\
\text { pelo convênio }\end{array}$ & $\begin{array}{l}\text { Houver a } \\
\text { necessidade/ }\end{array}$ & $\begin{array}{l}\text { Setor de } \\
\text { Patrimônio }\end{array}$ & $\begin{array}{l}\text { Para atender a } \\
\text { necessidade de } \\
\text { algum dos clientes do } \\
\text { processo de patrimônio }\end{array}$ & $\begin{array}{l}\text { Será firmado termo de doação do } \\
\text { bem entre as partes. O bem será } \\
\text { registrado e inserido como patrimônio } \\
\text { da instituição }\end{array}$ \\
\hline Leilão & $\begin{array}{l}\text { Setor de } \\
\text { Patrimônio }\end{array}$ & $\begin{array}{l}\text { Quando há } \\
\text { bem inservível } \\
\text { e haja a } \\
\text { intenção de }\end{array}$ & $\begin{array}{l}\text { Seção de } \\
\text { compras }\end{array}$ & $\begin{array}{l}\text { Para o controle dos } \\
\text { bens patrimoniais da } \\
\text { instituição }\end{array}$ & $\begin{array}{l}\text { É feito processo de leilão, como } \\
\text { estabelecido em Lei, mas limitando-se } \\
\text { apenas à leilões de automóveis }\end{array}$ \\
\hline
\end{tabular}




\begin{tabular}{|c|c|c|c|c|c|}
\hline What & Who & When & Where & Why & How \\
\hline O que? & Quem? & Quando? & Onde? & Porque? & Como? \\
\hline Transferência & $\begin{array}{l}\text { Setor de } \\
\text { Patrimônio }\end{array}$ & $\begin{array}{l}\text { Houver a } \\
\text { necessidade/ }\end{array}$ & $\begin{array}{l}\text { Setor de } \\
\text { Patrimônio }\end{array}$ & $\begin{array}{l}\text { Para atender a } \\
\text { necessidade de } \\
\text { algum dos clientes do } \\
\text { processo de patrimônio }\end{array}$ & $\begin{array}{l}\text { A transferência de bens ocorre } \\
\text { apenas entre instituições que utilizam } \\
\text { o mesmo sistema de controle de bens } \\
\text { patrimoniais. Realiza-se os termos de } \\
\text { permissão de uso de dado baixa ou } \\
\text { inserção do bem ao sistema }\end{array}$ \\
\hline $\begin{array}{l}\text { Roubo/Furto/ } \\
\text { Desaparecimento }\end{array}$ & $\begin{array}{l}\text { Setor de } \\
\text { Patrimônio }\end{array}$ & $\begin{array}{l}\text { Quando } \\
\text { houver } \\
\text { algum evento } \\
\text { característico }\end{array}$ & $\begin{array}{l}\text { Setor de } \\
\text { Patrimônio }\end{array}$ & $\begin{array}{l}\text { Para o controle dos } \\
\text { bens patrimoniais da } \\
\text { intituição }\end{array}$ & $\begin{array}{l}\text { Será identificado o bem que foi } \\
\text { furtado/roubado/desaparecido e, } \\
\text { se caso não recuperado, o número } \\
\text { do seu patrimônio será retirado dos } \\
\text { registros da instituição }\end{array}$ \\
\hline
\end{tabular}

Dos 10 processos apresentados no Quadro $3 \mathrm{e}$ mapeados no Quadro 4, sete podem ser utilizados para inserção ou retirada de bens do sistema; dois para retirada; e um para entrada.

Dos processos utilizados para saída ou entrada de bens tem-se: i) Doação; ii) Convênios; iii) Transferência; iv) Cessão de uso de terceiros; v) Comodato; vi) Fabricação/transformação/criação, e; vii) Permuta.

Para doação encaminha-se solicitação para doação de bem à instituição; se for do interesse inserir o bem à instituição, as partes firmarão termo de doação.

Para convênios firma-se também um termo de doação, mas a instituição que receberá as doações deve se adequar as especificações de cada tipo de convênio.

A transferência de bem ocorre apenas entre entidades/ instituição públicas que utilizam o mesmo sistema de gerenciamento de patrimônio, ou seja, a instituição realizará transferência de bens apenas com entidades/ instituição que utilizam o sistema AAB.

Os processos de cessão de uso de terceiros e comodato muito se assemelham, pois firmam-se termos de cessão de uso com as atribuições de responsabilidade pelo bem por período previamente determinado. No entanto, quando cedido por terceiros, este deve ser devolvido no mesmo estado e, quando feito comodato, devem-se devolver bens com a mesma característica e não necessariamente o mesmo bem;
No processo de fabricação/transformação/criação, quando fabricado ou criado o bem é apenas inserido no sistema. Na transformação, se utilizados partes de bens avariados ou inservíveis, deve-se retirar do sistema estes bens e inserir o novo, oriundo desta transformação.

A permuta pode ser realizada entre qualquer instituição ou entidades de caráter público, firmando termo de recebimento depois de realizada a troca de bens.

Dos processos de entrada tem-se: i) Leilões, e; ii) Roubos/furtos.

Leilões seguem uma sequência específica e diferente de todos os outros processos, pois é caracterizado como uma modalidade de licitação, desta forma, o processo deve seguir as regras estabelecidas pela Lei n. 8666/93. Nesta lei todos os processos para realização de leilão são detalhados, especificando o que pode ser comprado/vendido, os participantes, quais as exigências para participação, os critérios de julgamento para decisão de valor e a determinação de leiloeiros e avaliadores. Leilão é um processo apenas de saídas de bens, pois a instituição torna-se proponente de leilão e não participante.

Roubos/furtos são processos apenas de saídas, acontecem de forma indesejada, não esperada e sem planejamento da instituição.

Para inserção de bens, o processo de aquisição é responsável em realizar compras por licitação ou por 
compra direta, realizadas pela seção de compras e, quando recebidos na instituição, são encaminhados para o setor de patrimônio para finalização do processo.
Para facilitar o entendimento dos processos foram propostos fluxos para execução. Na Figura 3 é possível visualizar a forma proposta para o desenvolvimento dos processos externos.

Figura 3: Fluxograma do processo de cessão de uso de terceiro para entrada de de bens

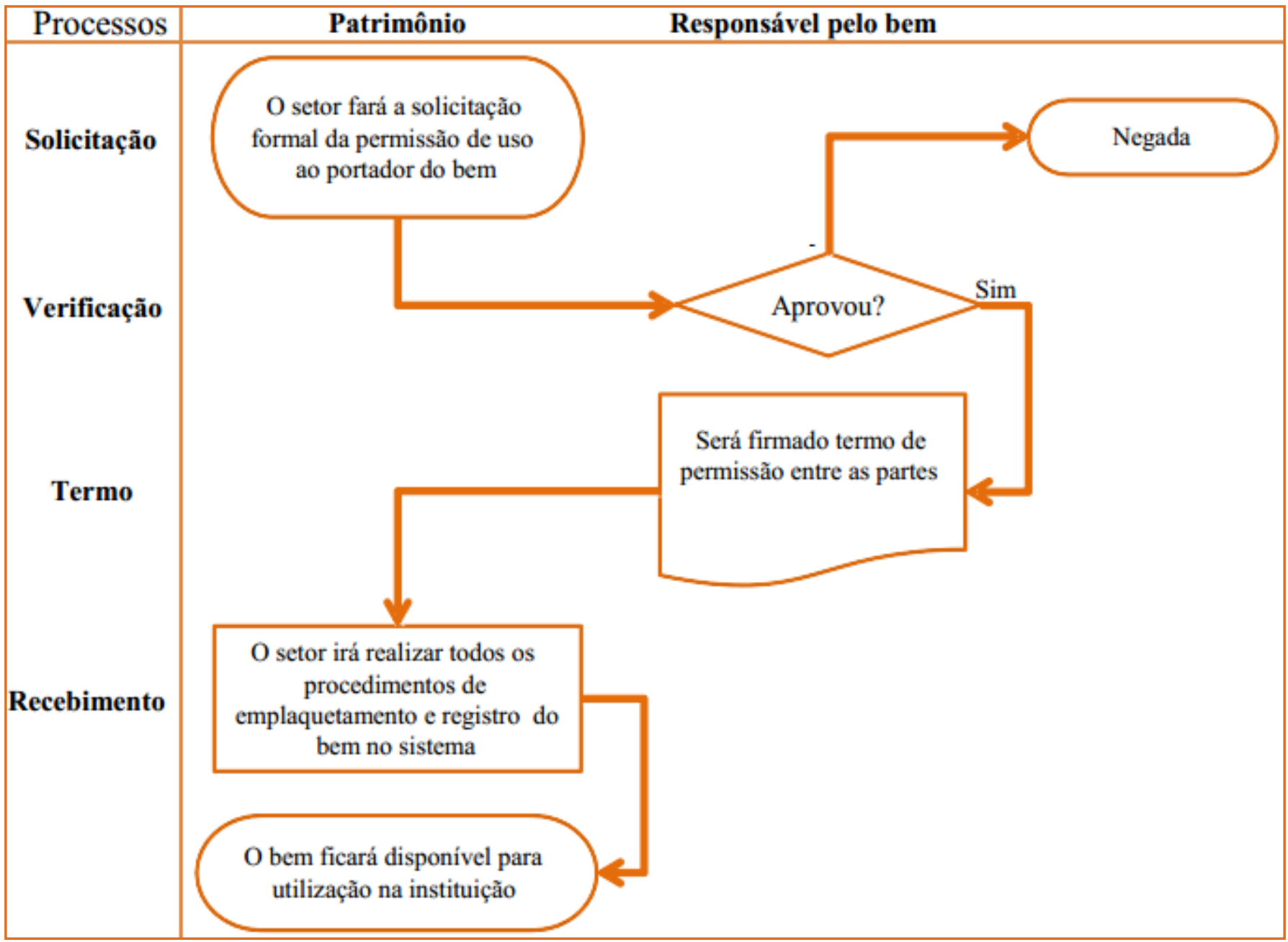

Fonte: Elaborado pelo autor, 2014.

O processo de cessão de uso de terceiros é desenvolvido tendo como envolvidos apenas o setor de patrimônio e o responsável pelo bem. Na proposta ilustrada o processo deverá seguir as seguintes atividades: i) Solicitação - compreendendo o pedido de cessão do bem ao cliente; ii) Verificação- por parte do responsável pelo bem, aceitando ou não ceder o bem; iii) Termo - tratando do cessão formal documentada entre as partes; iv) Recebimento - quando recebido o bem na instituição e encaminhado ao setor de patrimônio, onde será feito o emplaquetamento e registro do bem no sistema, ficando a disposição para uso.
O fluxograma para o processo de Cessão de uso de terceiros para saída de bens pode ser analisado no Apêndice 2.

Utilizou-se a estrutura do fluxograma apresentado na Figura 3 para todos os processos externos do patrimônio, de forma a definir as partes envolvidas e as atividades a serem desenvolvidas.

No Quadro 5, é possível analisar a designação das partes e atividades envolvidas nos processos. 
Quadro 5: Designação das partes envolvidas e atividades desenvolvidas nos processos.

\begin{tabular}{|c|c|c|c|}
\hline Processos & Partes Envolvidas & Atividades Desenvolvidas & Apêndice \\
\hline Aquisição & $\begin{array}{l}\text { Fornecedor, } \\
\text { Setor de Patrimônio; } \\
\text { Setor de Compras; } \\
\text { Financeiro. }\end{array}$ & $\begin{array}{l}\text { Solicitação do bem; } \\
\text { Verificação da disponibilidade do bem na instituição; } \\
\text { Realização do processo de compra; } \\
\text { Recebimento do bem; } \\
\text { Pagamento; } \\
\text { Entrega. }\end{array}$ & 3 \\
\hline Doação & $\begin{array}{l}\text { Responsável pelo bem; } \\
\text { Setor de Patrimônio. }\end{array}$ & $\begin{array}{l}\text { Solicitação da doação; } \\
\text { Verificação da necessidade do bem à instituição; } \\
\text { Termo de doação; } \\
\text { Recebimento do bem. }\end{array}$ & 4 e 5 \\
\hline Permuta & $\begin{array}{l}\text { Setor de Patrimônio; } \\
\text { Órgãos/Entidades/Instituições } \\
\text { Públicas. }\end{array}$ & $\begin{array}{l}\text { Solicitação da troca de bens; } \\
\text { Verificação da necessidade; } \\
\text { Termo de troca; } \\
\text { Entrega do bem. }\end{array}$ & 6 e 7 \\
\hline Comodato & $\begin{array}{l}\text { Responsável pelo bem; } \\
\text { Setor de Patrimônio. }\end{array}$ & $\begin{array}{l}\text { Solicitação da permissão de uso do bem; } \\
\text { Verificação da necessidade do bem; } \\
\text { Termo de cessão de uso; } \\
\text { Entrega do bem; } \\
\text { Fim do acordo. }\end{array}$ & 8 e 9 \\
\hline Fabricação & $\begin{array}{l}\text { Fabricante; } \\
\text { Setor de Patrimônio. }\end{array}$ & $\begin{array}{l}\text { Processo de fabricação, transformação ou criação; } \\
\text { Verificação da necessidade do bem; } \\
\text { Registro de entrada e saída de bens. }\end{array}$ & 10 \\
\hline Convênio & $\begin{array}{l}\text { Patrimônio; } \\
\text { Proponente do convênio. }\end{array}$ & $\begin{array}{l}\text { Solicitação da doação; } \\
\text { Verificação da necessidade do bem à instituição; } \\
\text { Termo de doação; } \\
\text { Recebimento do bem. }\end{array}$ & 11 e 12 \\
\hline Transferência & $\begin{array}{l}\text { Setor de Patrimônio; } \\
\text { Outra instituição. }\end{array}$ & $\begin{array}{l}\text { Solicitação do bem; } \\
\text { Verificação da necessidade; } \\
\text { Termo de transferência; } \\
\text { Entrega do bem. }\end{array}$ & 13 e 14 \\
\hline Roubo/Furtos & $\begin{array}{l}\text { Departamento da Instituição; } \\
\text { Setor de Patrimônio; } \\
\text { Comissão de patrimônio. }\end{array}$ & $\begin{array}{l}\text { Informação sobre roubo/furto; } \\
\text { Acompanhamento do boletim de ocorrência; } \\
\text { Parecer da comissão. }\end{array}$ & 15 \\
\hline
\end{tabular}

Elaborado pelo autor, 2014.

Identificados, mapeados e proposto fluxos para os processos de entradas e saídas, faz-se necessárias medidas para controlar a sua execução. Desta forma, o estudo formalizou o Manual de Processos do Patrimônio - MPP, que servirá para o controle de revisões da execução dos processos.

\section{Como observado no Apêndice 16 o MPP apresenta:}

i) Objetivos dos processos para o patrimônio justificando a aplicação dos processos;

ii) Identificação dos clientes dos processos determinando as instâncias dependentes do setor de patrimônio;

iii) Dados de entradas e saídas - caracterizando os processos de entrada e saída de bens;

iv) Objetivos numéricos - possibilitando a mensuração da qualidade dos processos;

v) Satisfação do cliente - Determinando a padronização dos processos;

vi) Registro dos processos - Norteando a forma de armazenar as informações dos processos realizados.

\section{CONSIDERAÇÕES FINAIS}

Pode-se observar, com base nas pesquisas realizadas e no estudo de caso proposto, a importância do gerenciamento dos processos para gestão pública e a influência que a não padronização pode exercer na obtenção de resultados positivos.

A metodologia, ou seja, os fluxos dos processos mapeados não foram possíveis de se aplicar devido 
ao curto tempo para o desenvolvimento, no entanto, foi transmitida aos funcionários do setor a essência do que compreende a gestão de processos.

Observou-se o início da melhoria da organização do setor. Este passou a entender os tipos de processos que podem ser executados, identificando atividades desnecessárias e facilitadoras.

Com a aplicação da pesquisa, o setor poderá analisar a necessidade de bens patrimoniais, discernindo apenas o que seja útil para suprir a demanda dos seus clientes, evitando acúmulo de bem.

No entanto, a maior contribuição da pesquisa para o setor trata-se da apresentação de métodos que podem favorecer a organização dos processos externos e internos desenvolvidos pelo setor, de forma a suprir a demanda de seus clientes, seja pela disponibilização de bens ou pelas informações que devem ser repassadas ao setor financeiro e ao Tribunal de Contas do Estado, desta forma, garantindo um padrão de qualidade para o seu desempenho organizacional.

\section{REFERÊNCIAS}

[1] ANJOS, F. A. de; REIS, H. R.; SORATTO, A. N. Gestão por processos nas organizações e sua interação com o meio ambiente. 2002. In: ENCONTRO NACIONAL DE ENGENHARIA DE PRODUÇÃO, XXII, 2002, Curitiba - PR, Anais... Curitiba, 2002. Disponível em: < http://www.abepro. org.br/biblioteca/ENEGEP2002_TR100_1026.pdf>. Acesso em: 21 out. 2014.

[2] ASSOSSICAÇÃO BRASILEIRA DE ENGENHARIA DE PRODUÇÃO - ABEPRO. Áreas e subáreas da Engenharia de Produção. 2008. Disponível: < http://www.abepro.org.br/ interna. $a s p ? p=399 \& m=424 \& s s=1 \& c=362>$. Acesso: 10 out. 2014.

[3] ASSUNÇÃO, M. A. de; MENDES, P. J. V. Mudança e gestão de processos em organização pública. 2000. In: CONGRESSO INTERNCIONAL DE CLAD SOBRE A REFORMA DO ESTADO E DA ADMINISTRAÇÃO PÚBLICA, V, 2000, República Dominicana, Anais... República Dominicana, República Dominicana, 2000. Disponível em: < http://aurelio.pro.br/qualidade/clad0038538.pdf>. Acesso em: 25 set. 2014.
[4] BELLUCCI JÚNIOR, J. A.;MATSUDA, L. M. Implantação do sistema acolhimento com classificação e avaliação de risco e uso do fluxograma analisador. 2012. CONTEXTO ENFERM, v. 21, n. 1, p. 217-225, 2012. Disponível em: < http://www.scielo.br/pdf/tce/v21n1/a25v21n1.pdf>. Acesso em: 07 nov. 2014.

[5] BERNARDES, C. Teoria geral das organizações: os fundamentos da administração integrada. São Paulo: Atlas, 1988.

[6] COMPANHIA DE INFORMÁTICA DO PARANÁ CELEPAR. AAB - bens móveis do estado do Paraná. 2005. Disponível em: < http://www.administracao.pr.gov.br/ arquivos/File/aabcmes0_resumido.pdf>. Acesso em: 20 abr. 2014

[7] CONSELHO FEDERAL DE CONTABILIDADE. Altera, inclui e exclui itens das NBC T 16.1, 16.2 e 16.6 que tratam das Normas Brasileiras de Contabilidade Técnicas aplicadas ao Setor Público e dá outras providências. Lex: Resoluções e ementas do CFC. 2009. Disponível em: < http://www.cfc.org. br/sisweb/SRE/docs/RES_1268.doc>. Acesso em: 23 set. 2014

[8] FACULDADE ESTADUAL DE CIÊNCIAS E LETRAS DE CAMPO MOURÃO - FECILCAM. Universidade Estadual do Paraná. 2014.

[9] GONÇALVES, J. E. L.; As empresas são grandes coleções de processos. 2000. REVISTA DE ADMINISTRAÇÃO DE EMPRESAS, v. 40, n. 1, p. 6-19, 2000. Disponível em: < http://www.scielo.br/pdf/rae/v40n1/v40n1a02.pdf>. Acesso em: 05 nov. 2014.

[10] LAKATOS, E.; MARCONI, M. Fundamentos da metodologia científica. 5 ed. São Paulo: Atlas, 2003.

[11] LELLIS, C. Gestão patrimonial e almoxarifado. 2009. Disponível em: <http://www.tce.es.gov. br/portais/LinkClick.aspx?fileticket=jphsuo_ zFfE\% 3D\&tabid=875\&pportali $=14$ \& mid $=1442 \&$ forcedownload=true>. Acesso em: 01 out. 2014.

[12] NECCHI DE OLIVEIRA, J. C. de; JOSE DE OLIVEIRA, O.; MAEKAWA, R. T. Um estudo sobre o grau de utilização de programas e ferramentas da qualidade em empresas industriais da região de Bauru/SP. 2010. In: ENCONTRO NACIONAL DE ENGENHARIA DE PRODUÇÃO, XXX, 2010, São Carlos - SP, Anais..., São Carlos - SP, 2010. Disponível em: < http://www.abepro.org.br/biblioteca/enegep2010_TN_ WIC_125_808_16648.pdf>. Acesso em? 07 nov. 2014.

[13] OLIVEIRA, J. A. de; et al. Um estudo sobre a utilização de sistemas, programas e ferramentas da qualidade em empresas do interior de São Paulo. 2010. REVISTA PRODUÇÃO, 2010. Disponível em: < http://www.scielo.br/ pdf/prod/2011nahead/aop_t6_0002_0302.pdf>. Acesso em: 07 nov. 2014 
[14] PARO, V. H. Gestão democrática da escola pública. 3. ed. 11. reimp. São Paulo: Ática, 2008.

[15] PEREIRA, L. C. B. Gestor do setor público: estratégia e estrutura para um novo estado. 1998. Disponível em: <http://www.vdl.ufc.br/solar/aula_link/bagp/Q_a_Z/ST_VI_ TCC_Gestao_Governamental/aula_01/imagens/04/texto_da_ aula_01.pdf>. Acesso em: 27 set. 2014.

[16] SANTOS, D. de G. Modelo de gestão de processos na construção civil para identificação de atividades facilitadoras. 2004. 219 f. Tese (Doutorado em Engenharia de Produção) - Universidade Federal de Santa Catarina, Santa Catarina. 2004. Disponível em: < https://repositorio. ufsc. br/bitstream/handle/123456789/88194/207871. pdf? sequence=1\&isAllowed=y >. Acesso em: 10 jul. 2014.
[17] SECCHI, L. Modelos organizacionais e reformas da administração pública. 2009. REVISTA DE ADMINISTRAÇÃO PÚBLICA, v. 43, n. 02, p. 347-369, 2009. Disponível em: < http://www.scielo.br/pdf/rap/v43n2/v43n2a04.pdf>. Acesso em: 23 ago. 2014

[18] SLACK, N.; et al. Administração da produção. 1. ed. 12. reimp. São Paulo: Atlas, 2009.

[19] UNIVERSIDADE ESTADUAL DO PARANÁ - UNESPAR. Apresentação. Disponível em: < http://www.unespar.edu. br/?page_id=102>. Acesso em: 4 set. 2014.

\section{APÊNDICES}

Figura 4: Relação campus/instituição da UNESPAR

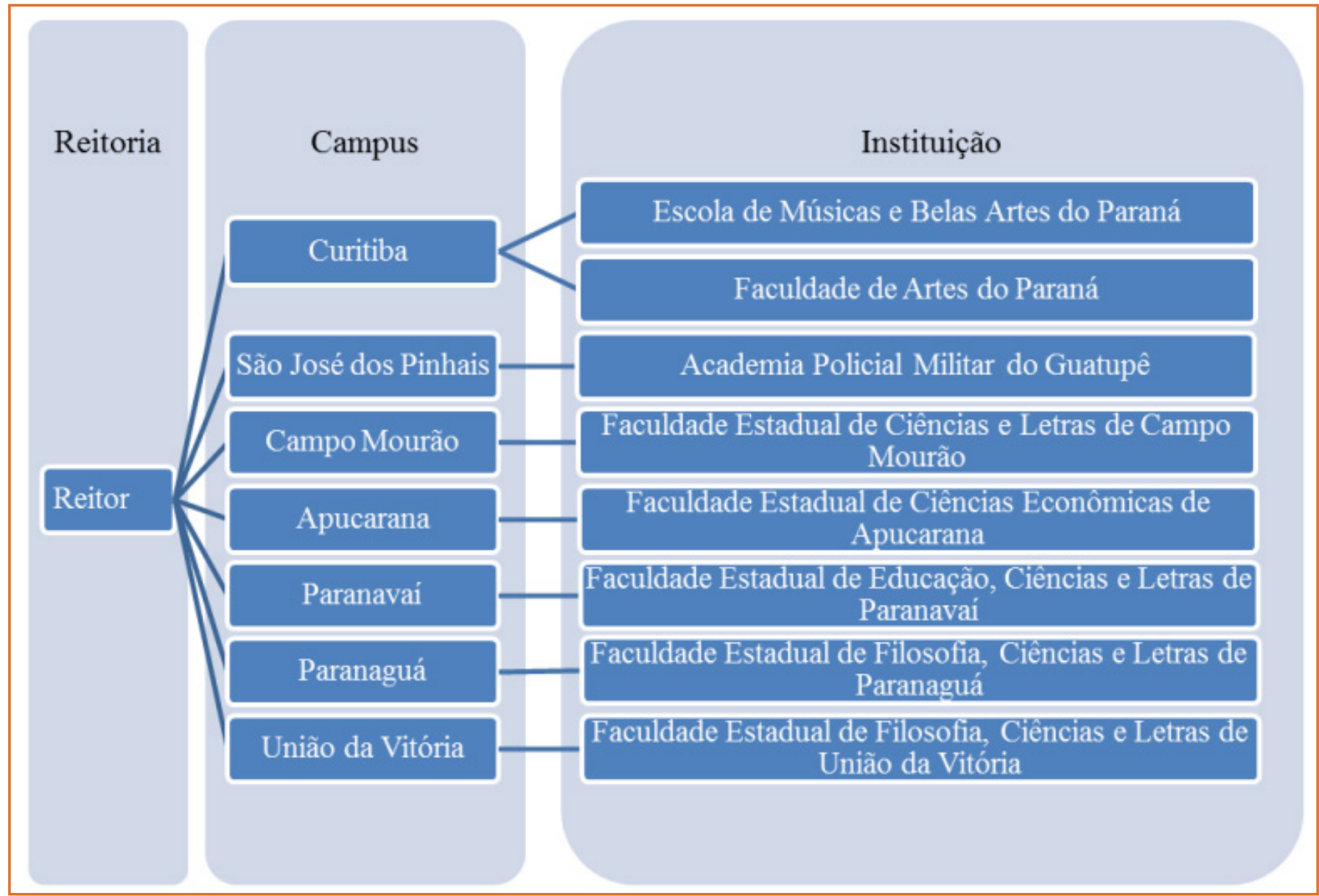

Fonte: Elaborado pelo Autor, 2014 
Figura 5: Fluxograma do processo de cessão de uso de terceiro para saída

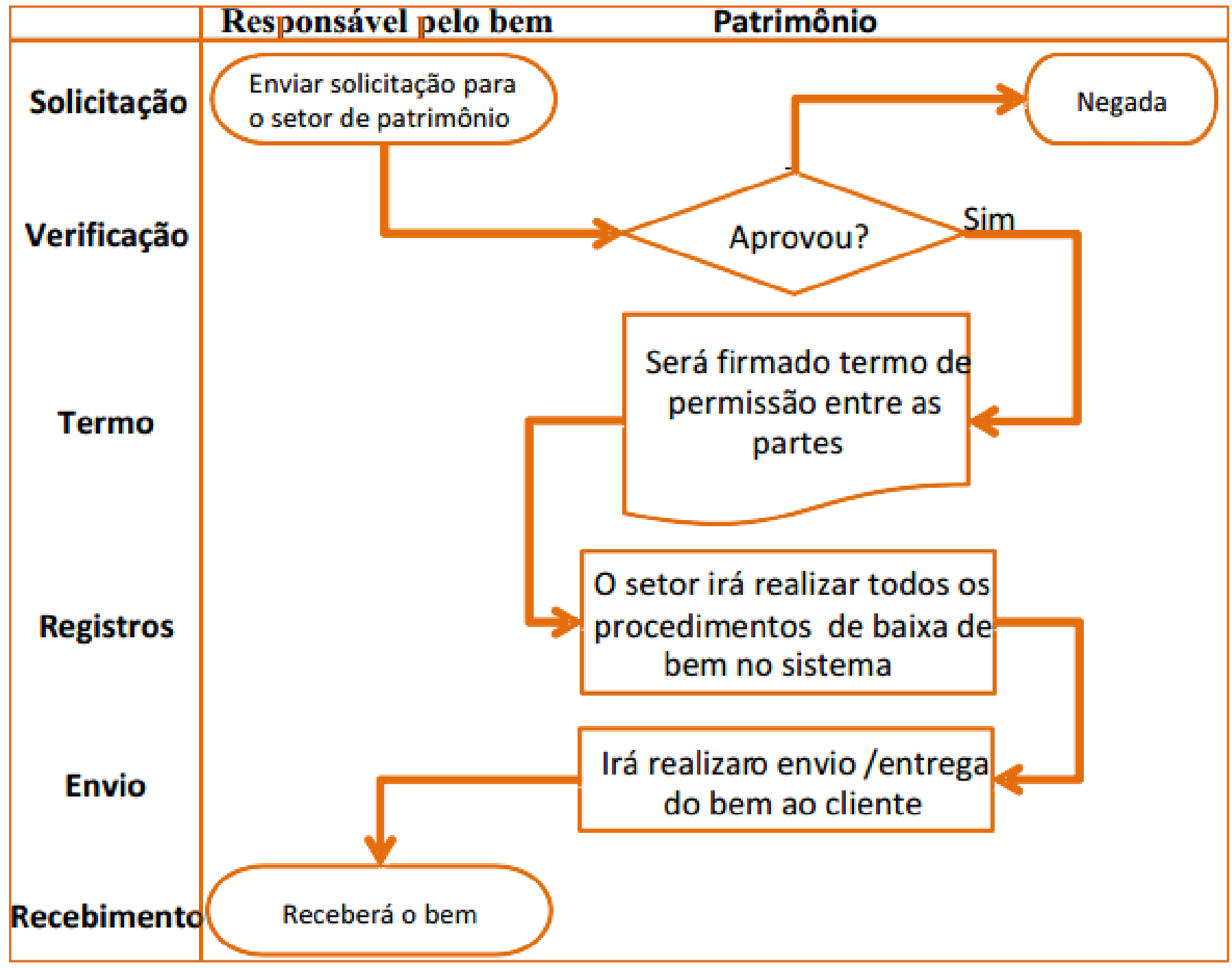

Fonte: Elaborado pelo autor, 2014. 
APÊNDICE 3

Figura 6: Fluxograma do Processo de aquisição.

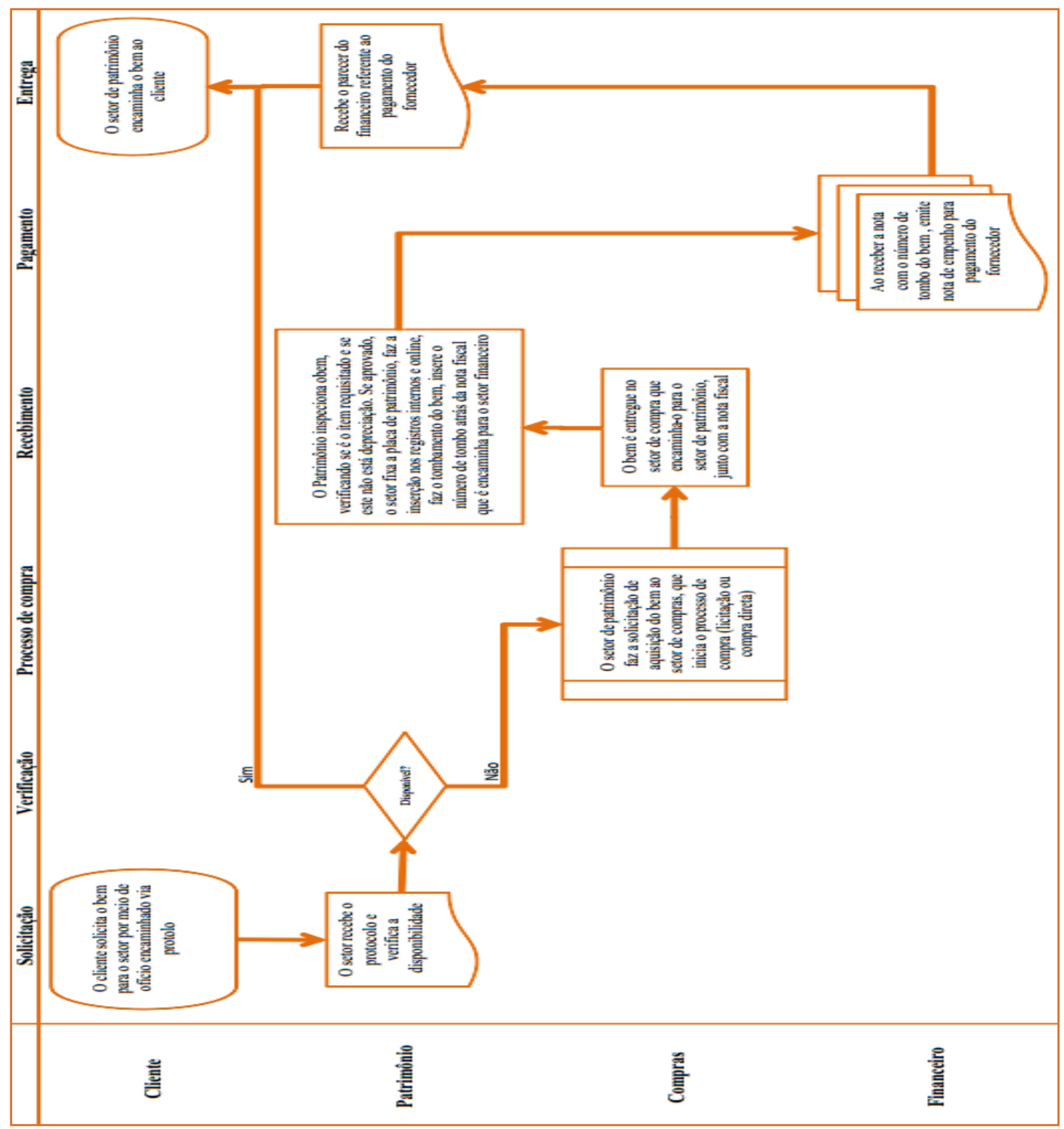

Elaborado pelo autor, 2014. 
APÊNDICE 4

Figura 7: Fluxograma do processo de doação para entrada de bens

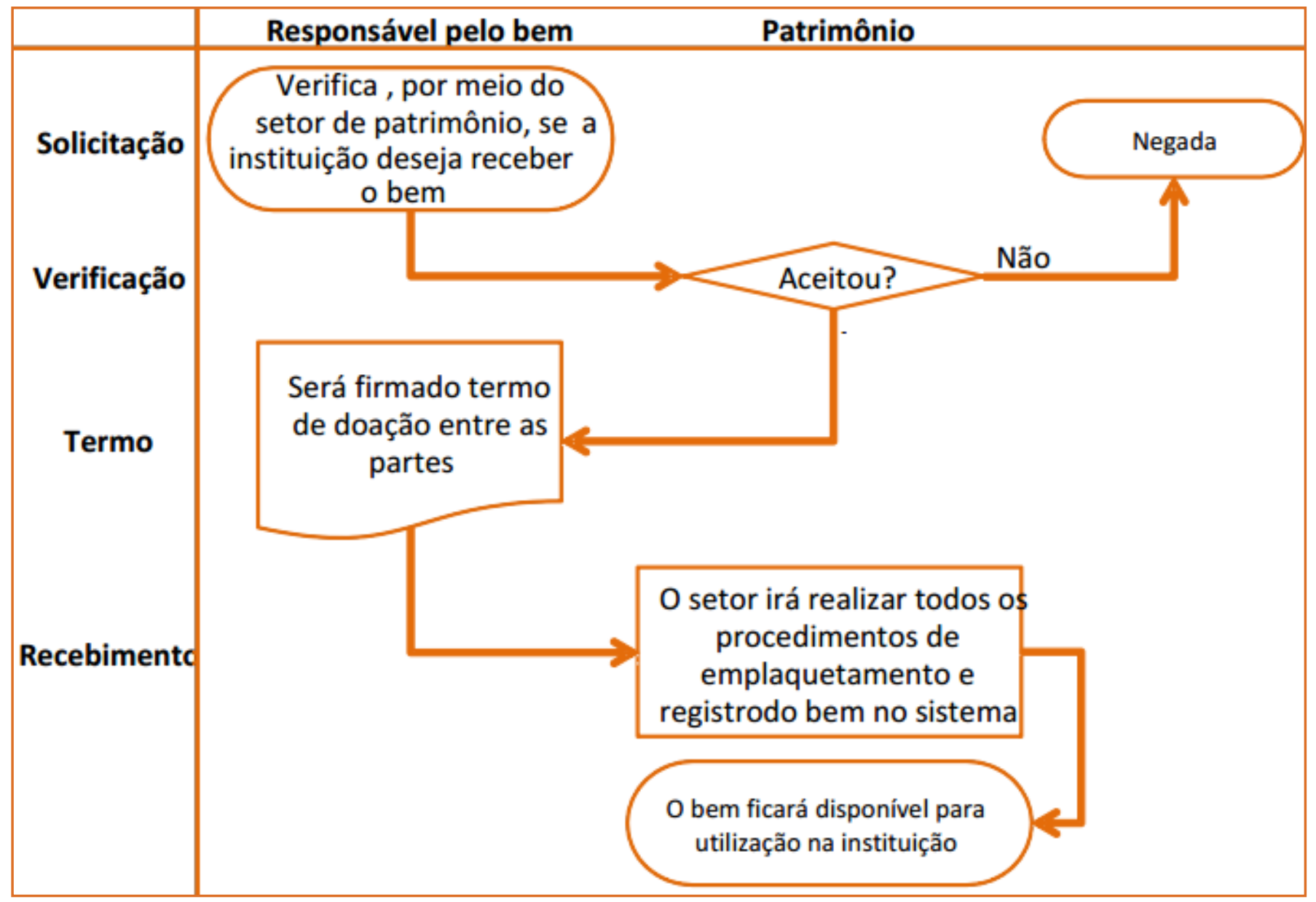

Elaborado pelo autor, 2014. 
APÊNDICE 5

Figura 8: Fluxograma do processo de doação para saída de bens

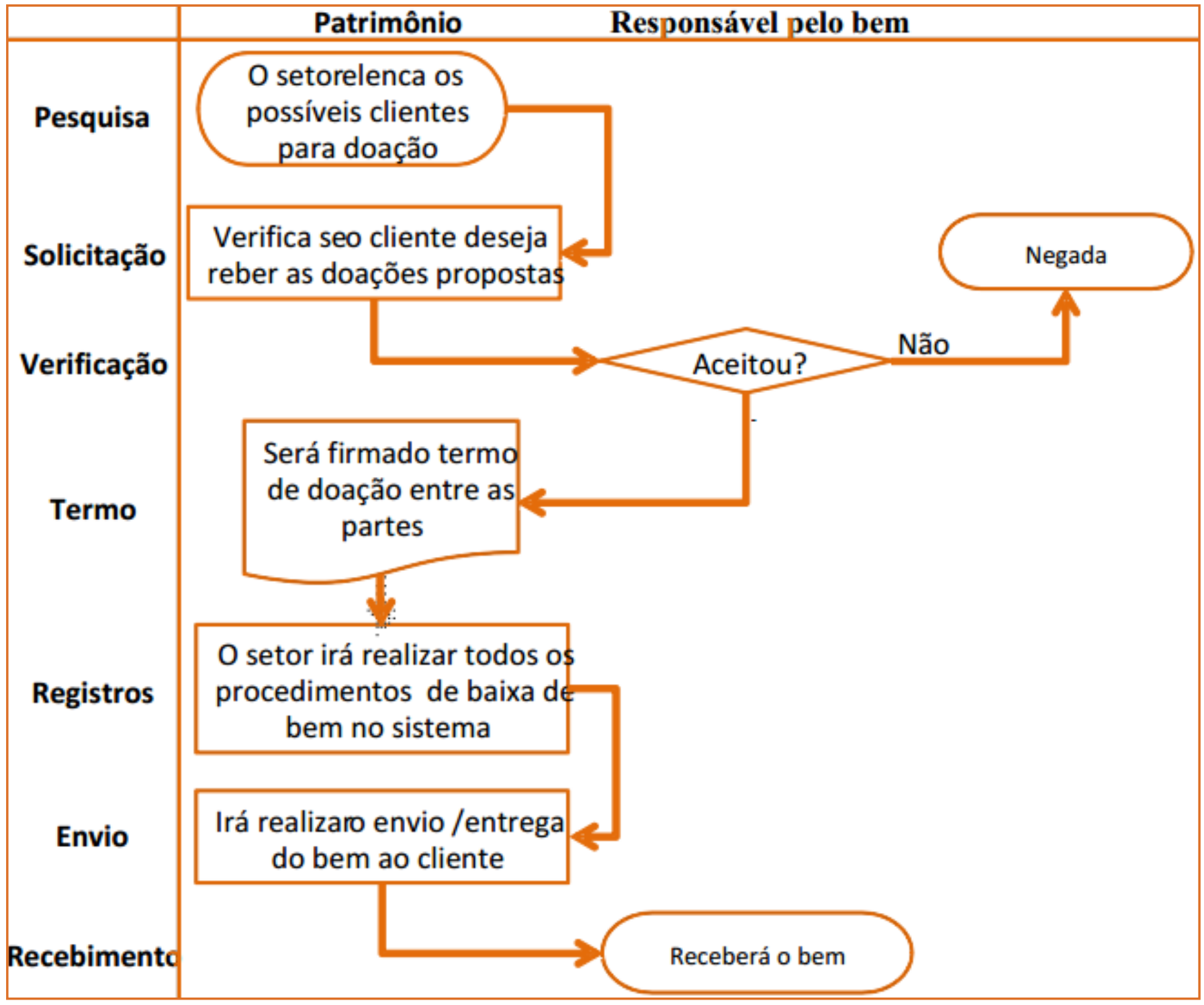

Elaborado pelo autor, 2014. 
Figura 9: Fluxograma do processo de permuta para entrada de bens.

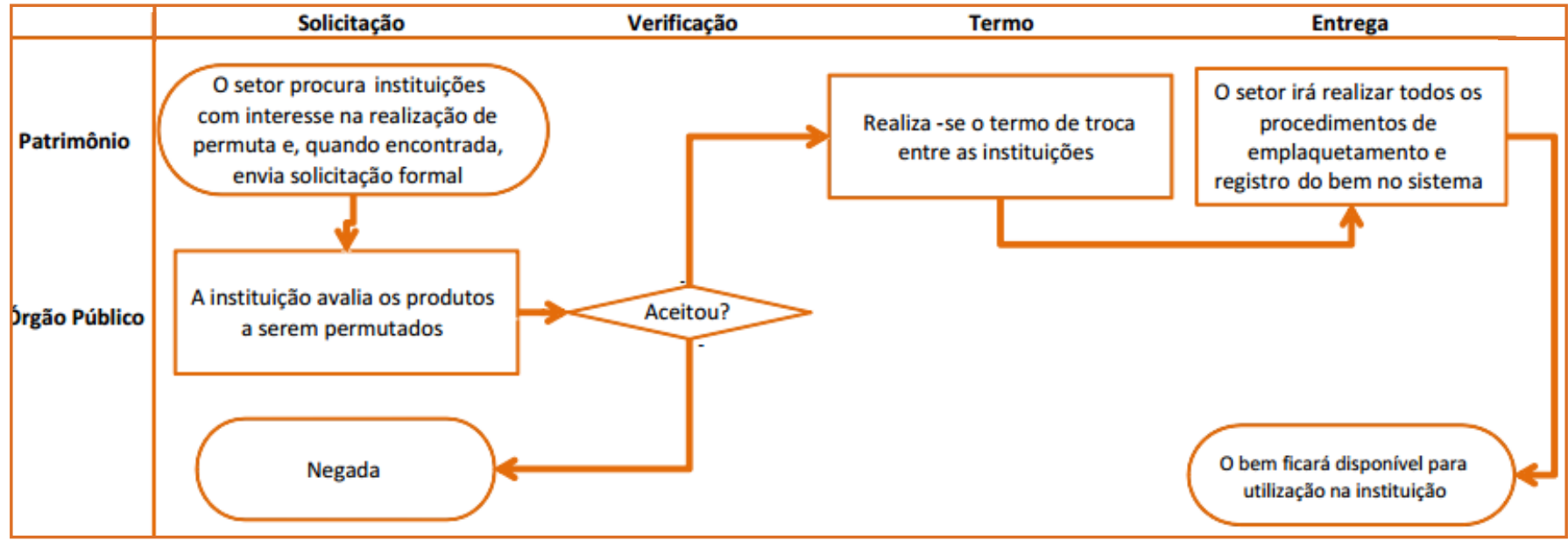

Fonte: Elaborado pelo autor, 2014.

\section{APÊNDICE 7}

Figura 10: Fluxograma do processo de permuta para saída de bens.

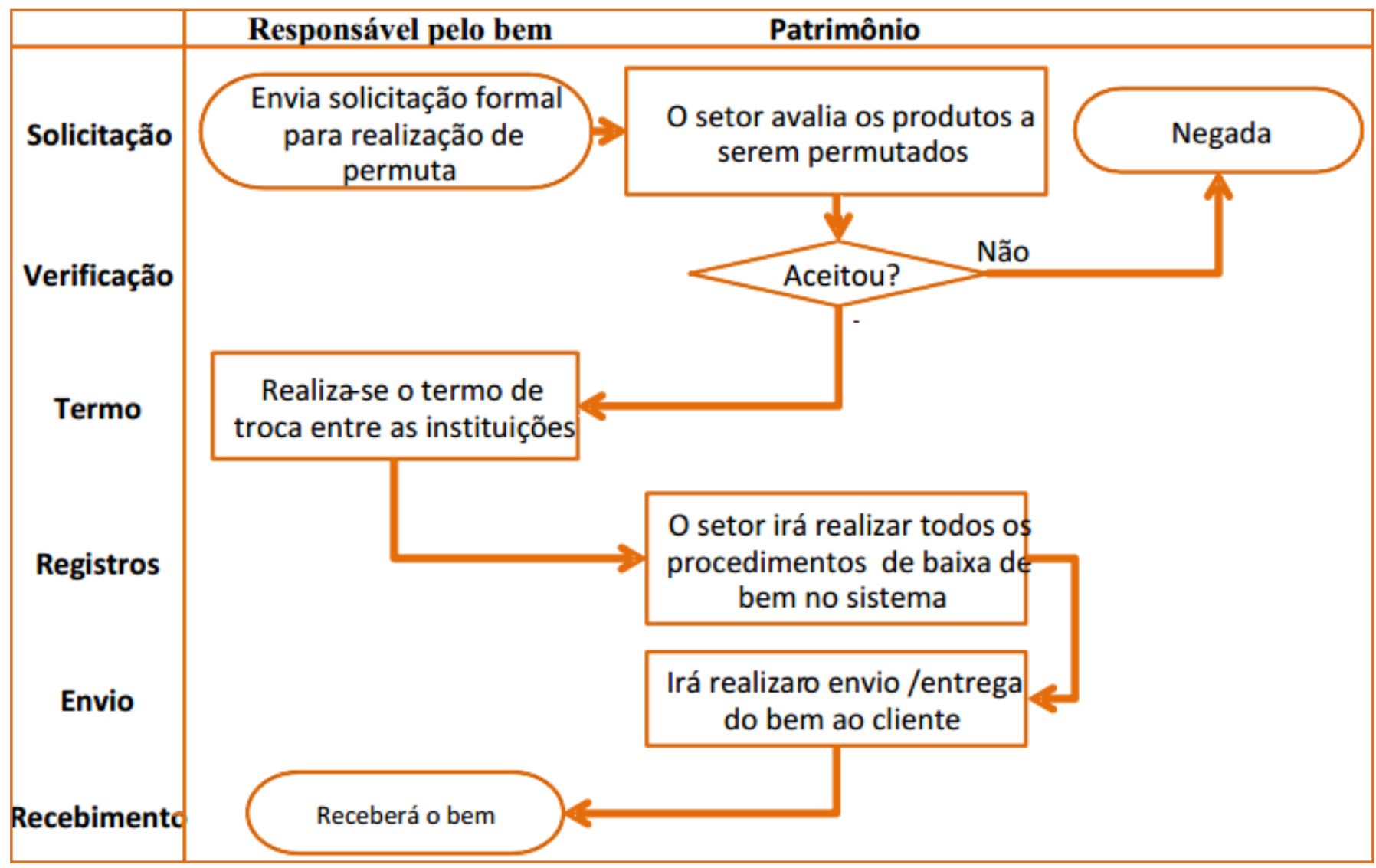

Fonte: Elaborado pelo autor, 2014. 
APÊNDICE 8

Figura 11: Fluxograma do processo de comodato para entrada de bens

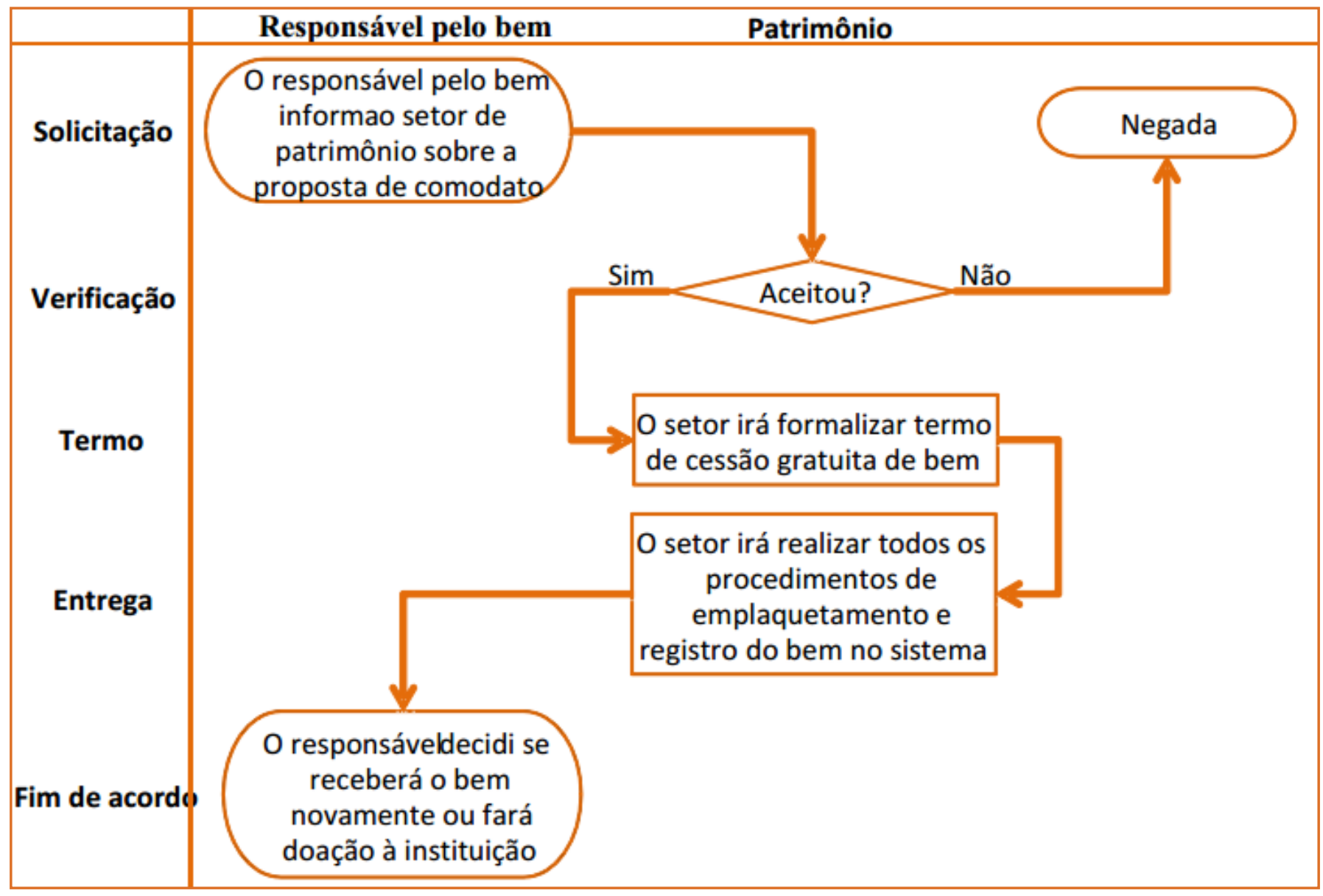

Fonte: Elaborado pelo autor, 2014. 
Figura 12: Fluxograma do processo de comodato para saída de bens.

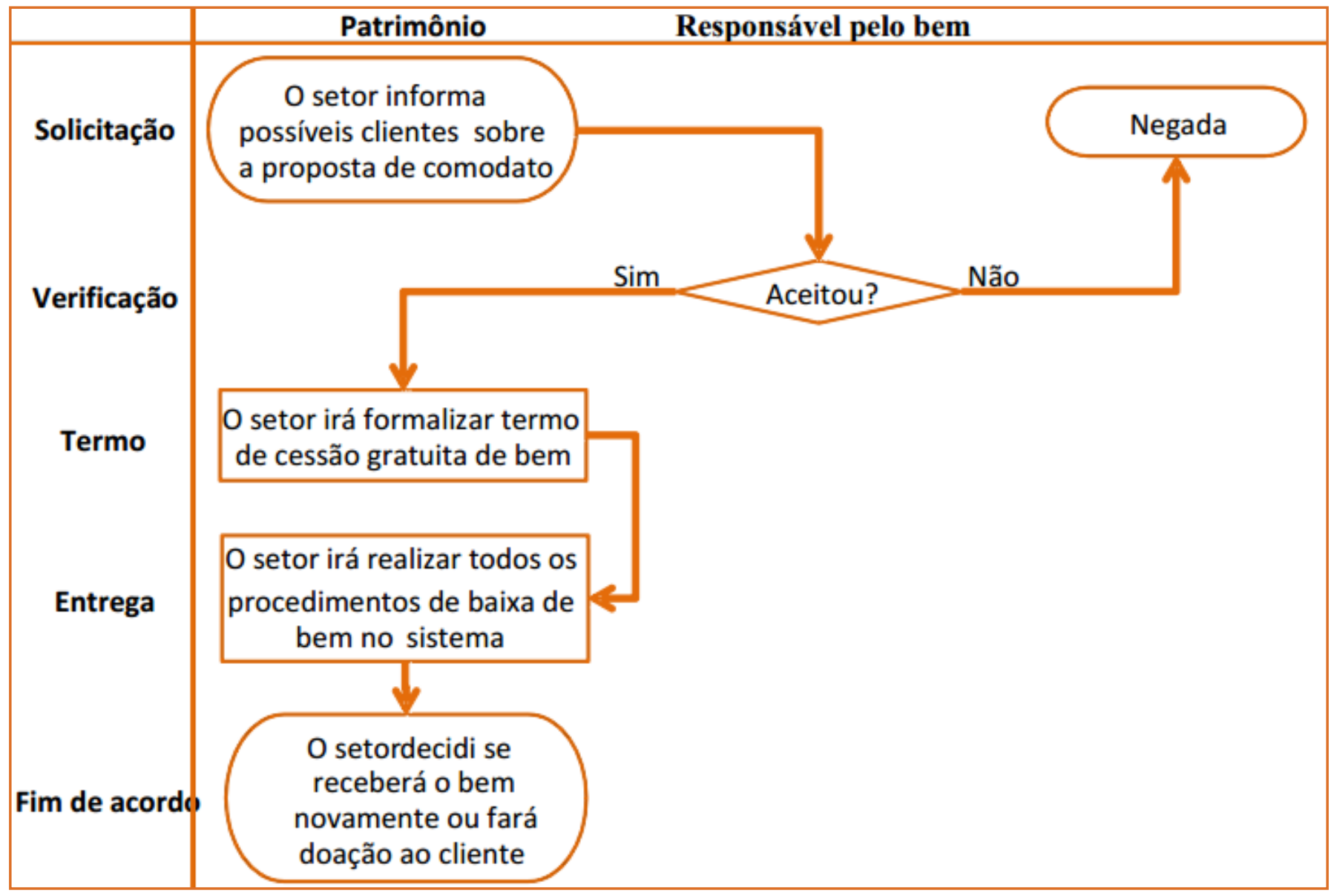

Fonte: Elaborado pelo autor, 2014.

\section{APÊNDICE 10}

Figura 13: Fluxograma do processo de fabricação para entrada e saída de bens.

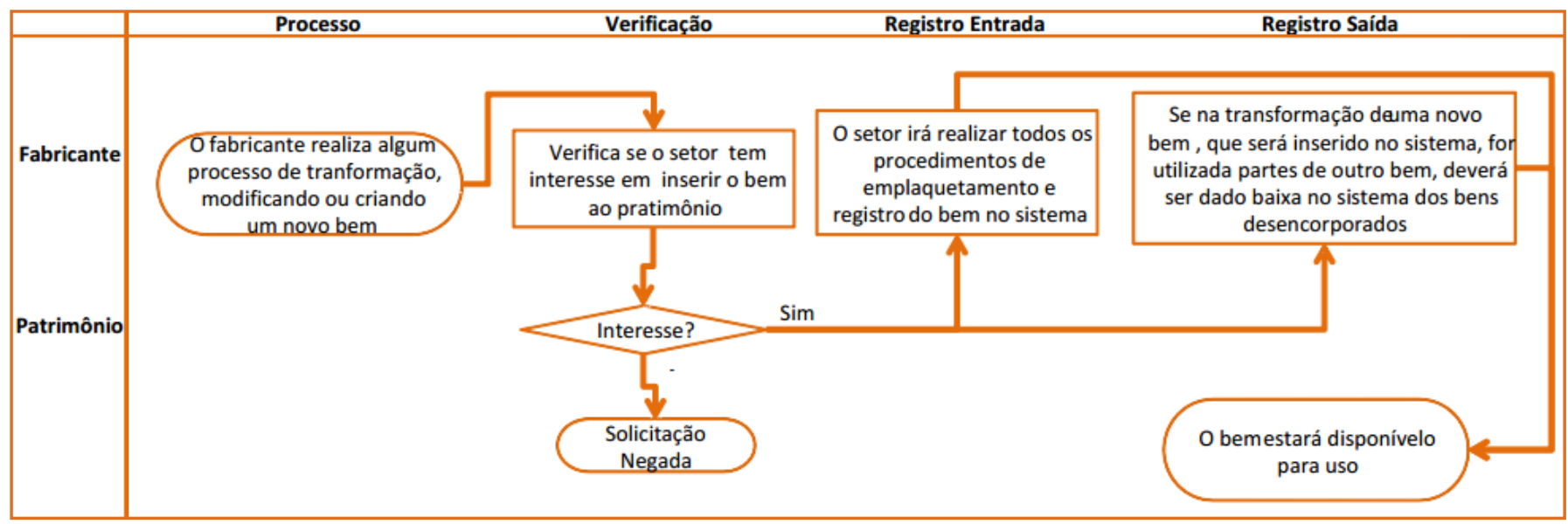

Fonte: Elaborado pelo autor, 2014. 
Figura 14: Fluxograma do processo de convênio para entrada de bens

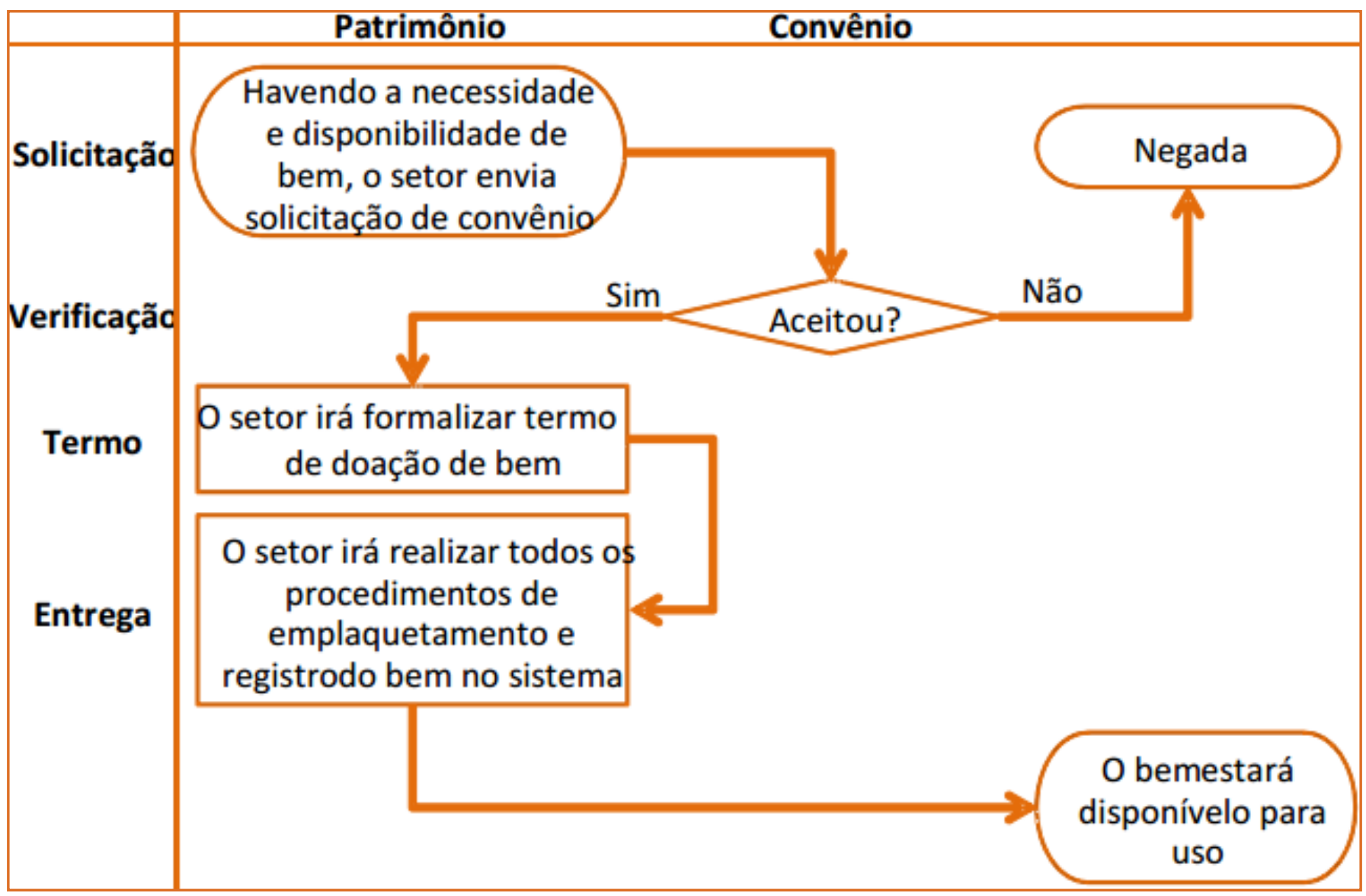

Fonte: Elaborado pelo autor, 2014. 
Figura 15: Fluxograma do processo de convênio para saída de bens.

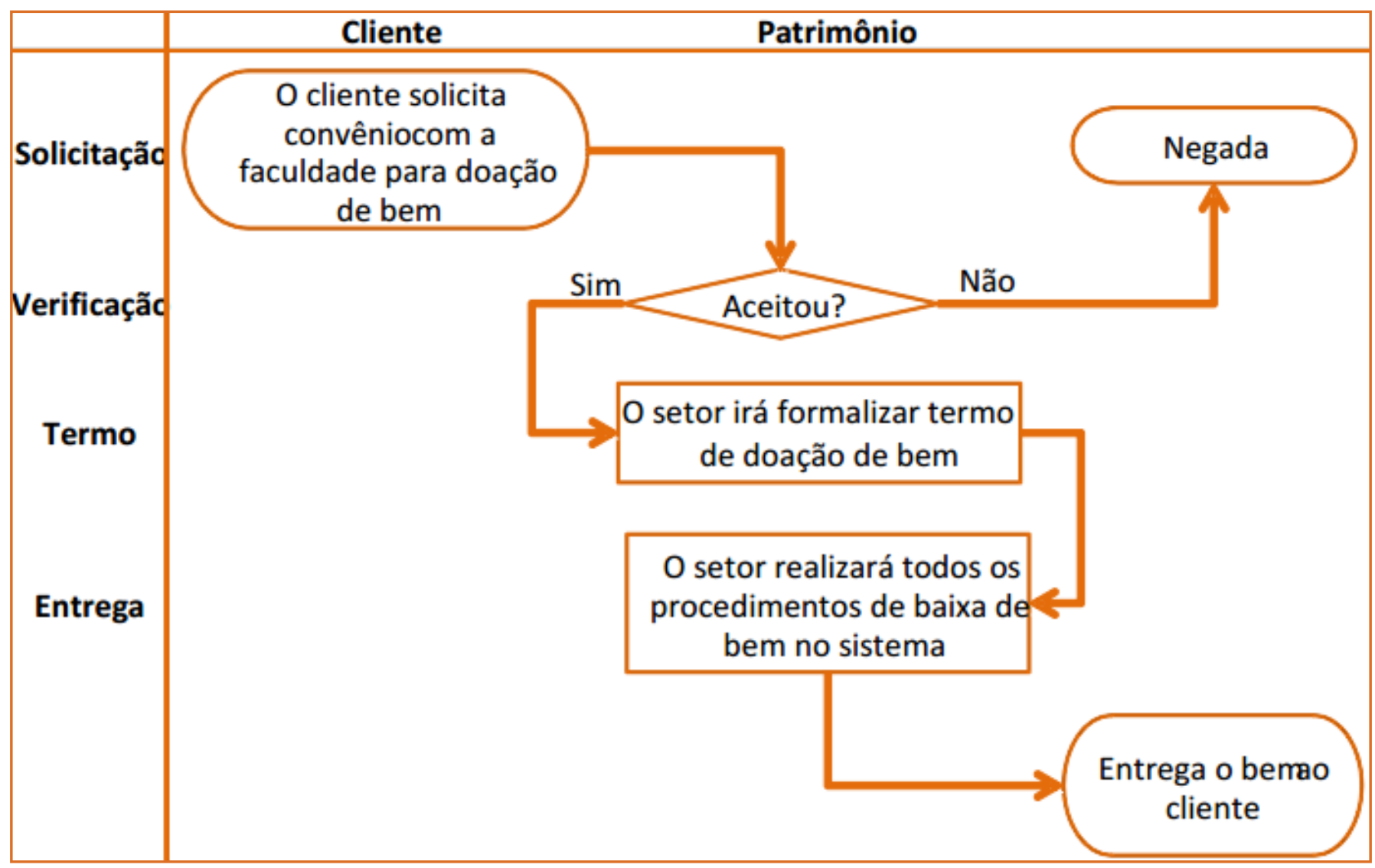

Fonte: Elaborado pelo autor, 2014. 
Fluxograma 16: Fluxograma do processo de transferência para entrada de bens.

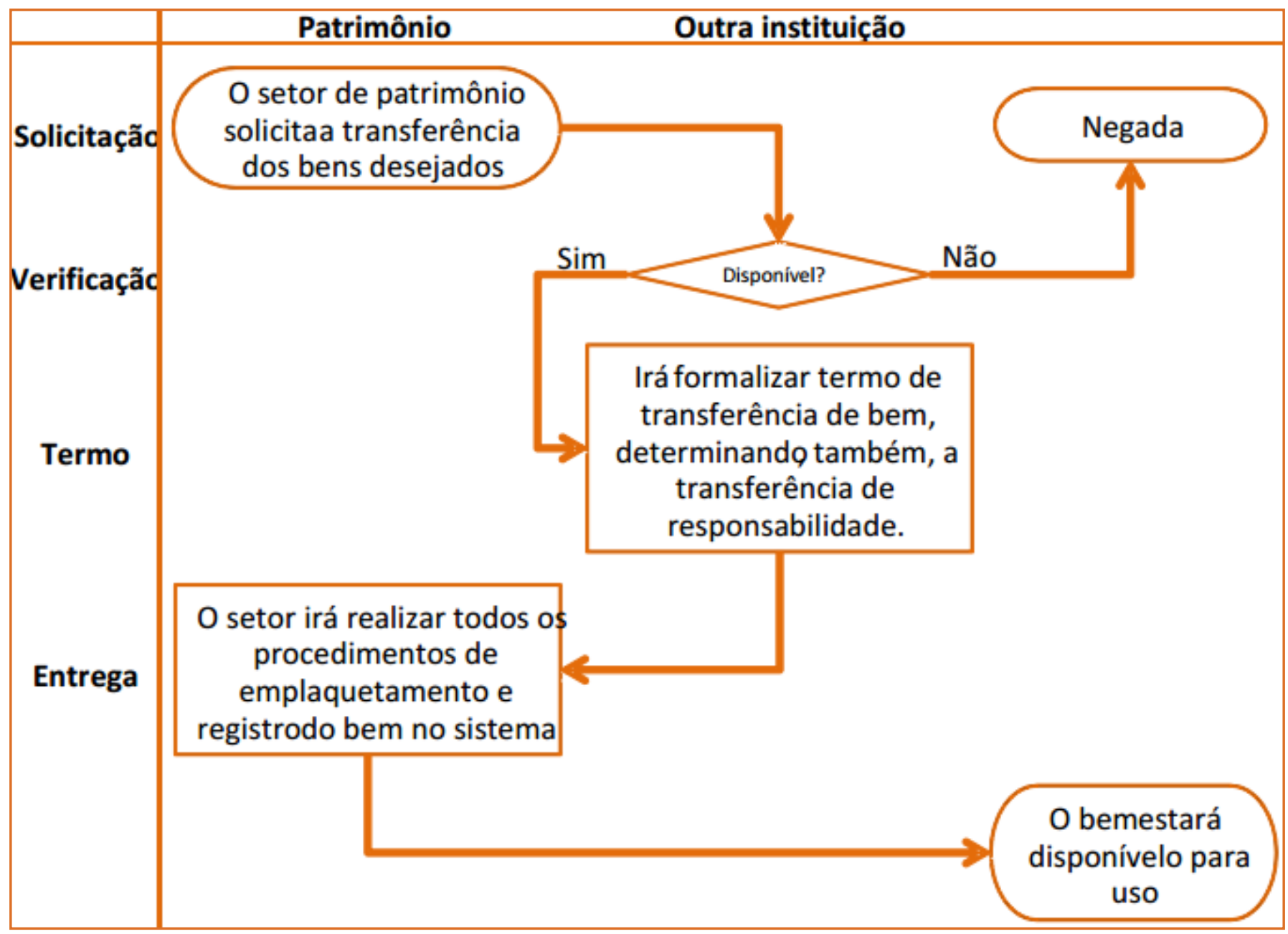

Elaborado pelo autor, 2014. 
Figura17: Fluxograma do processo de transferência para saída de bens.

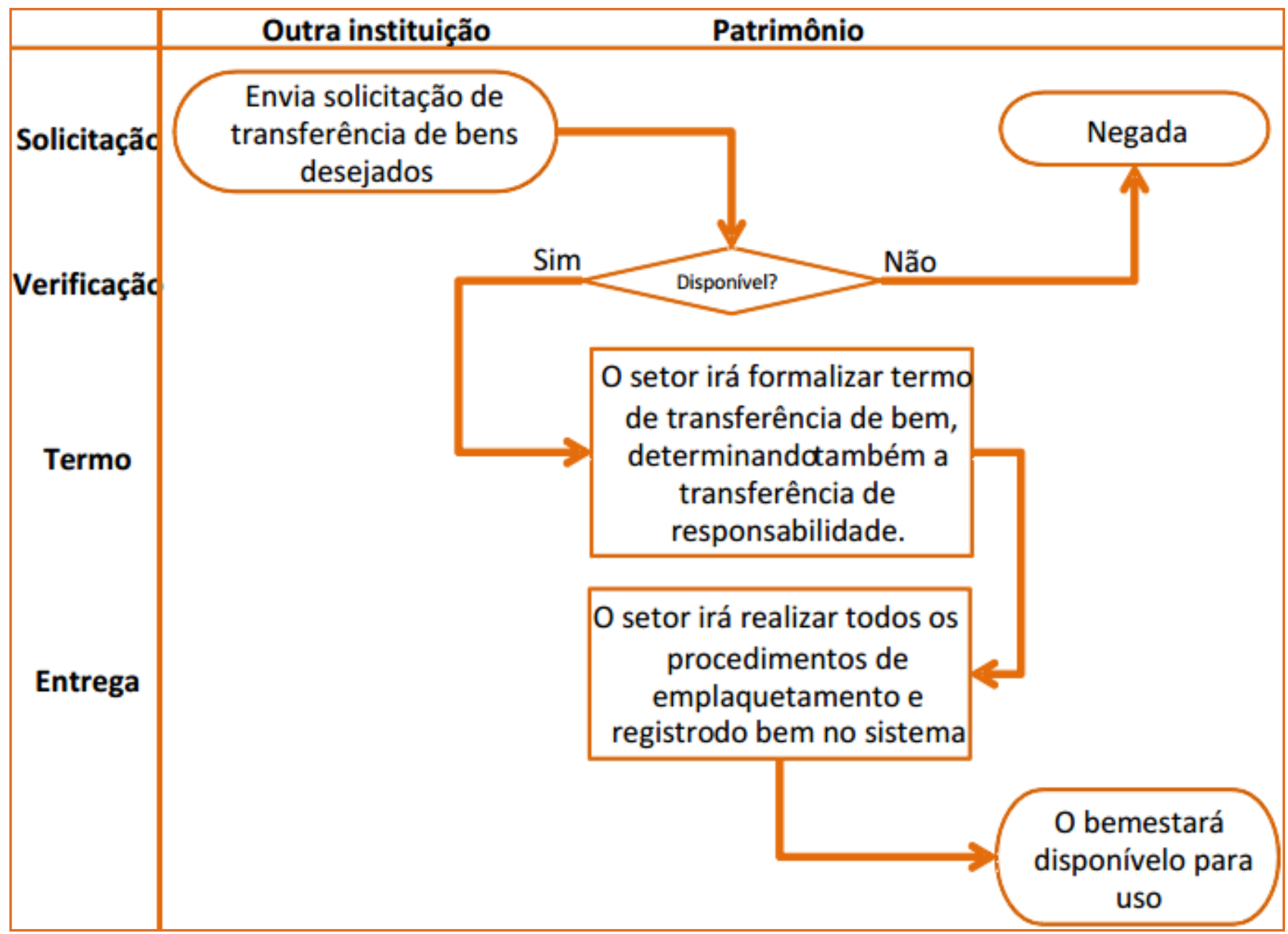

Fonte: Elaborado pelo Autor, 2014.

\section{APÊNDICE 15}

Figura 18: Fluxograma do processo de roubo/furto para saída de bens.

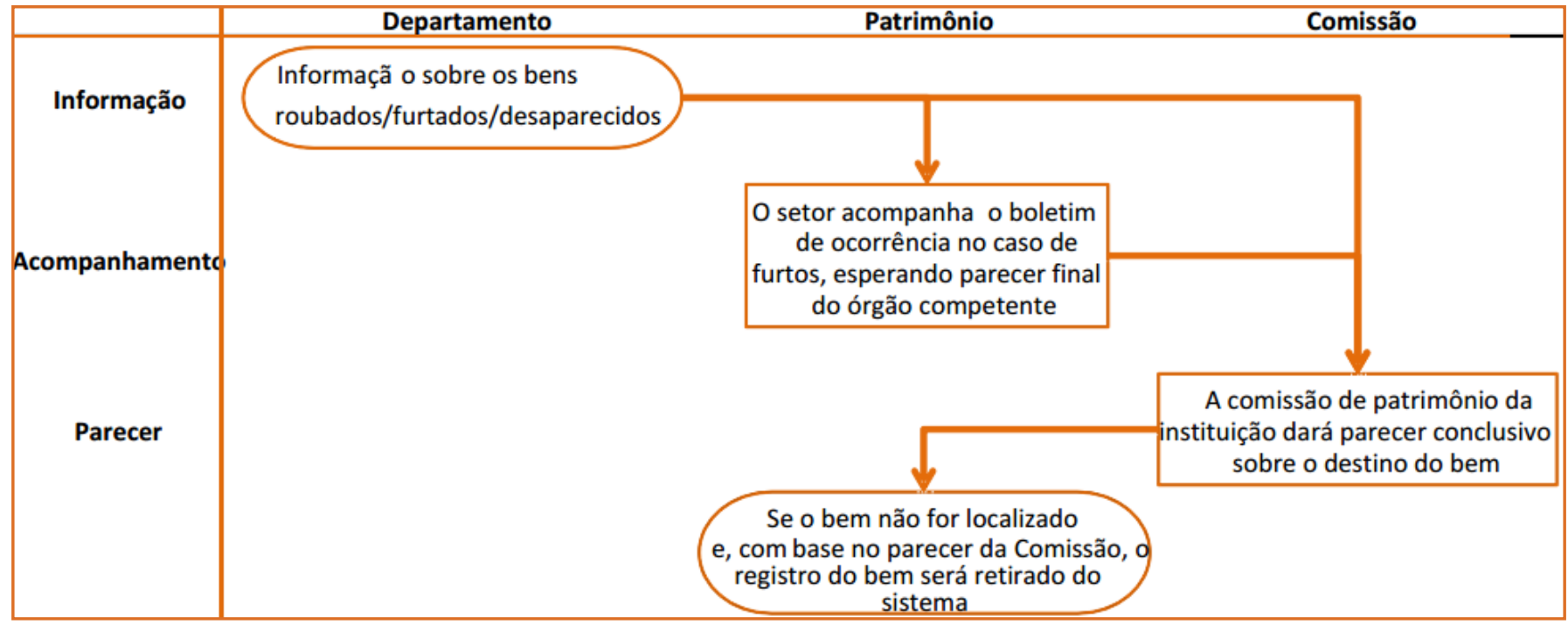


APÊNDICE 16

MANUAL DE PROCESSOS DO PATRIMÔNIO - MPP

\begin{tabular}{|c|c|c|c||}
\hline Revisão & Data & Histórico & Aprovado por \\
\hline \hline 0 & $00 / 00 / 00$ & Emissão Inicial & \\
\hline & & & \\
\hline & & & \\
\hline & & & \\
\hline & & & \\
\hline
\end{tabular}

\section{OBJETIVOS DO PROCESSO PARA O PATRIMÔMIO}

- Tornar o fluxo de informação funcional;

- Manter atualização constante dos bens patrimoniados;

- Padronizar procedimentos para movimentação de bens patrimoniados.

- Estabelecer critérios de responsabilidade pelos bens patrimoniados.

\subsection{NECESIDADES DOS CLIENTES DO PROCESSO}

- Ser atendido com rapidez e atenção;

- Receber as informações necessárias sempre que solicitadas;

- Obter as informações tratadas com qualidade satisfatória;

- Conhecer os procedimentos para movimentação do patrimônio;

- Receber o patrimônio solicitado em perfeito estado de uso;

- Manter atualizado o percentual de depreciação, conforme categoria do bem como instrui a legislação;

- Ter registro interno dos bens patrimoniados;

- Manter atualizado o sistema de patrimônio online;

- Ter solucionada dúvidas referente a responsabilidade dos bens.

\section{DADOS DE ENTRADA DO PROCESSO E SEUS FORNECEDORES}

- Aquisição;

- Permissão de uso de terceiros;

- Doação;

- Permuta;

- Comodato;

- Fabricação

- Convênios.

III DADOS DE SAÍDAS DO PROCESSO

- Leilão;

- Permissão de uso para terceiros;

- Doação;

- Permuta;

- Comodato;

- Convênios. 
IV CLIENTES DOS DADOS DE ENTRADA E SAÍDA

- Financeiro;

- Estado;

- Reitoria;

- Direção;

- Docentes;

- Agentes.

\section{$\checkmark$ COMO FAZER}

Cumprindo/Executando as orientações do Manual de Controle e Procedimentos do Patrimônio - MCPP - da Universidade Estadual do Paraná - Campus Campo Mourão.

\section{PORQUE FAZER}

Para garantir fluxo de informação satisfatório e a atualização constante de entradas e saída, cumprindo os procedimentos de movimentação dos bens patrimoniados, possibilitando a reivindicação da responsabilidade sobre o zelo dos bens a quem for transferida.

\section{SATISFAÇÃO DOS CLIENTES DO PROCESSO}

A satisfação dos clientes do processo deve ser quantificada em percentuais a partir de questionário semiestruturado respondido in loco ou por outros meios (impresso e entregue ao responsável do setor ou pela internet).

Investigar a satisfação dos clientes trimestralmente.

\section{OBJETIVO NUMÉRICO PARA A QUALIDADE DO PROCESSO}

A Qualidade do processo deve ser mensurada mensalmente, exigindo:

i) Atualização de $100 \%$ dos bens patrimoniais da instituição (ALTA);

ii) Emissão de 97\% das informações solicitadas ao setor de patrimônio (MÉDIA);

\section{REGISTRO DO PROCESSO}

Os registros dos processos do patrimônio limitam-se aos relatórios de bens incorporados à faculdade.

Desta forma, no setor de patrimônio os relatórios são armazenados por software online, ficando a disposição do governo e do setor sempre que necessário. Propõem-se também o armazenamento dos documentos impressos em pastas divididas pelo tipo de processo.

Nos departamentos/setores da faculdade, que utilizam bens patrimoniais da instituição, o relatório é armazenado em local visível, tendo em anexo o termo de responsabilidade (formal ou informal). 


\title{
CAPÍTULO 20
}

\section{UM ESTUDO COMPARATIVO DO DESEMPENHO DAS CADEIAS DE SUPRIMENTOS DA INDÚSTRIA AUTOMOBILÍSTICA: O CASO DA VOLKSWAGEN (RJ) E MERCEDES BENZ (SBC-SP)}

\author{
Délvio Venanzi \\ Orlando Roque da Silva \\ Haroldo Lhou Hasegawa \\ Arnoldo José de Hoyos Guevara
}

Resumo: Este artigo tem por objetivo compreender a rapidez e agilidade das cadeias no tocante à resposta do mercado, à introdução de novos produtos e às ferramentas na cadeia. Para tanto partiu-se de um referencial teórico focado na gestão das cadeias e na estratégia de operações para então analisar duas configurações produtivas: (Volkswagen-RJ) configuração modular e a (Mercedes Benz- SBC-SP), configuração produtiva tradicional - ambas reconhecidas no mercado de caminhões. A metodologia adotada foi o estudo de caso, pesquisa descritiva, entrevistas com profissionais do nível estratégico e tático das montadoras e parceiros, assim como fontes documentais cedido pelas montadoras.

Palavras chave: gestão da cadeia de suprimentos, prioridades competitivas, cadeias de suprimentos flexíveis, cadeias de suprimentos ágeis, condomínio industrial e consórcio modular. 


\section{INTRODUÇÃO}

Embora a implementação das práticas e filosofia da "produção enxuta" constitua um marco na indústria automobilística mundial, esta tem passado por várias transformações. De acordo com Ohno (1997), o foco da produção enxuta é a absoluta eliminação ou redução do desperdício. Segundo Salerno et al. (2003), tais transformações não se restringem ao lean manufacturing e ocorrem em três grandes áreas: reestruturação interna da produção, caracterizada pela adoção das práticas enxutas; configuração de novas relações de fornecimento, caracterizada pela formação dos blocos de comércio regionais e introdução de novos arranjos produtivos (consórcio modular e condomínio industrial); e mudanças nas atividades de projeto de produto, caracterizadas por meio das tecnologias de processo e da introdução do conceito de carro mundial. Segundo Humphrey e Salerno (2000), novos investi- mentos em mercados emergentes tornaram-se estratégicos não apenas para montadoras, mas também para os fornecedores de primeiro nível e subsidiárias de companhias transnacionais. Como conseqüência disso, as indústrias automobilísticas têm recebido modificações estruturais, tanto no que tange ao número e tamanho das empresas quanto ao padrão de relacionamento entre elas. No Brasil, com a abertura da economia, a indústria automobilística passou por uma reestruturação importante a partir de 1995, quando diversas montadoras instalaram unidades produtivas em regiões sem tradição no setor automobilístico. Nesse período, as montadoras experimentaram um processo de crescimento e investimento, enquanto que as autopeças atravessavam um período de consolidação/desnacionalização (Posthuma, 1997).

No que diz respeito às novas relações de fornecimento, Alves Filho et al. (2002) ressaltam o impacto que os investimentos realizados pelas montadoras trouxeram aos arranjos das cadeias de suprimentos e à alteração do padrão de relacionamento entre as montadoras e seus fornecedores, que resultaram num ganho e acúmulo de poder das montadoras com relação aos seus fornecedores. Essa concentração de poder, aliado à posse do comando dos investimentos, possibilitou com que as montadoras conseguissem definir a maior parte das configurações das cadeias produtivas do setor, especialmente nas ocasiões em que novas plantas estavam sendo instaladas. Frente a esta transformação, Maia e Cerra (2004a) compartilham de visão semelhante ao afirmar que, no decorrer desse período, puderam-se observar impactos significativos também nas unidades montadoras que, através da adoção de estratégias competitivas distintas, estabeleceram novos tipos de relações com fornecedores de autopeças que tiveram que adotar estratégias de operações e práticas de gestão da cadeia de suprimentos (SCM) apropriadas aos novos contextos.

Alves Filho et al. (2004), citam alguns pressupostos que contemplam, dentre outras questões, a necessidade de que as empresas que participam de uma mesma cadeia devem possuir estratégias próprias mas devidamente alinhadas com a cadeia, de modo a enfrentar a competitividade e gerar ganhos para todos os seus elos. Desta forma, considerando a importância econômica do setor automotivo do Brasil, bem como a relevância das alterações que este setor tem sofrido, duas questões podem ser formuladas: o impacto da configuração produtiva na montadora e a estratégia de operações; e o tipo de cadeia de suprimentos utilizada para responder às respostas do mercado ao qual a montadora está inserida.

\section{REFERENCIAL TEÓRICO}

\subsection{GESTÃO DA CADEIA DE SUPRIMENTOS (SUPPLY CHAIN MANAGEMENT - SCM)}

Segundo Alves Filho et al. (2004), os esforços para o desenvolvimento de abordagens para o estudo de cadeias de suprimentos são relativamente recentes. Para os autores, apenas no início da década de 90, lastreado no amplo desenvolvimento da logística, o assunto começa a ser sistematicamente tratado nas empresas ocidentais, em periódicos científicos nas áreas de Administração e Engenharia de Produção, que abordavam a difusão do novo padrão de relacionamento entre montadoras e fornecedores da indústria automobilística japonesa.

Para entender o conceito de Gestão da Cadeia de Suprimentos (SCM) é necessário antes compreender qual o objeto que será gerido por 
estas práticas. Segundo Chopra e Meindl (2003), uma cadeia de suprimentos engloba todos os estágios (clientes,varejistas, distribuidores, fabricantes e fornecedores) envolvidos direta ou indiretamente no atendimento de um pedido ao cliente. Para Lumus et al. (1998), uma cadeia de suprimentos pode ser vista como uma rede de entidades que abrange todo o fluxo de materiais e informações. Esta cadeia de empresas, enxergada como um conjunto ou de forma sistêmica, apresenta uma série de desafios que dificilmente são superados pelas práticas gerenciais tradicionais. O forte controle hierárquico, exercido anteriormente pela integração vertical, não é mais factível na situação em que empresas distintas detêm a operação de diferentes etapas do processo produtivo, acumulando competências inerentes a tais etapas e necessitando traçar estratégias para servir seus vários clientes. É neste novo contexto de relações que surge a Gestão da Cadeia de Suprimentos (SCM).
Segundo Pedroso (2002), a SCM pode ser definida como "a integração dos principais processos que gerenciam os fluxos bidirecionais de materiais e informações no âmbito intra- empresa e entre empresas participantes da cadeia de suprimentos, até atingir os consumidores finais, cujo objetivo principal é agregar valor aos acionistas e aos clientes ao longo destes processos". Este conceito atual apresentado esquematicamente na figura 1 (Pires, 1998), tem trazido interessantes contribuições para as indústrias, sobretudo a automobilística. Segundo Cooper et al. (1997) e Tan (2002), a SCM envolve a integração dos processos de negócios por meio da cadeia de suprimentos, abrangendo a coordenação de atividades e processos não apenas dentro de uma organização isolada, mas entre todas as organizações que compõem a cadeia de suprimentos. Para Pires (2001), a SCM baseia-se na idéia de que empresas devem estar estratégica e holisticamente integradas com os seus fornecedores e clientes.

Figura 1 - Representação de uma Cadeia de Suprimentos

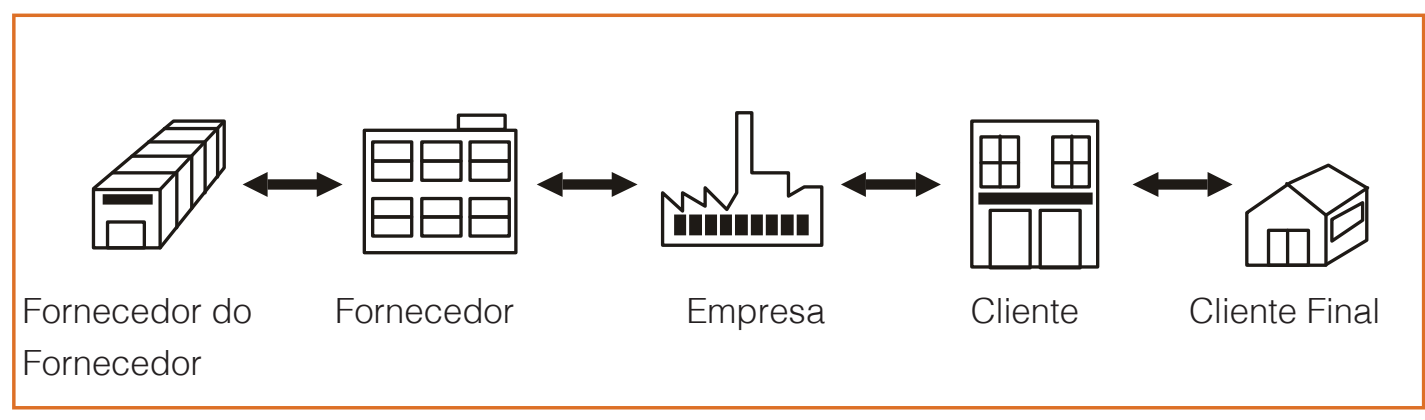

Fonte: Pires (1998)

De um ponto de vista total, SCM pode ser compreendida como uma área contemporânea, dentro do espaço da gerência do negócio, que considera a convergência de uma série de temas e de interesses de áreas tradicionais, tais como a gerência de produção, logística, compras e marketing. (PIRES; CARDOZA, 2007). Um conceito importante, no tocante da SCM, é o de outsourcing explicado por Pires (2004), como: refere-se à prática em que parte do conjunto de produtos e serviços utilizados por determinada empresa (na realização de uma cadeia produtiva) é executada por outra empresa externa, num relacionamento colaborativo e interdependente. A empresa fornecedora desenvolve e melhora continuamente a competência e a infraestrutura para atender o cliente, o qual deixa de possuí-las total ou parcialmente. O cliente, entretanto, continua mantendo estreita e colaborativa integração com o fornecedor. Isto mostra uma nova forma de relacionamento entre o cliente e fornecedor, diferente das configurações tradicionais utilizadas, as quais estabelecem uma parceria de longo prazo e necessita de total integração, abrangendo toda a estrutura das empresas. Portanto, deve ser fruto de uma decisão estratégica, baseada numa correta avaliação do desempenho e das competências do fornecedor, pois criará uma situação de grande interdependência e difícil retorno. No Brasil, isto 
é recente e difere do modo como foram utilizadas a terceirização e a subcontratação. O modelo de CM pode ser entendido como um caso radical do outsourcing bem como algumas de suas implicações o caracteriza como o estado da arte da SCM.

Embora cada empresa da cadeia tenha seus clientes diretos, a cadeia como um todo, cumulativamente, agrega valor ao produto/serviço que será entregue ao cliente final. Desta forma, o objetivo é maximizar a sinergia entre todas as partes da cadeia, a fim de atender o cliente final da maneira mais eficiente possível. Para Alves Filho et al. (2001), o objetivo é tornar os processos de negócio mais eficientes e eficazes, reduzindo custos, níveis de estoque, melhorando a qualidade e criando vantagem competitiva e valor para a cadeia de suprimentos. $\mathrm{O}$ foco na satisfação do cliente final impõe desafios de integração, visibilidade e coordenação entre todas as empresas. Flutuações na demanda final, associadas a um fluxo deficiente de informações entre as empresas, possuem seus impactos amplificados conforme se caminha a montante na cadeia (fato conhecido como efeito "chicote") (Slack et al., 2002). Embora o efeito "chicote" seja relevante e um bom exemplo didático, uma série de outros problemas pode ser originada pelas dificuldades de integração e relacionamento entre empresas. Desta forma, um dos princípios norteadores da SCM é "assegurar maior visibilidade dos eventos relacionados à satisfação da demanda, com o objetivo de minimizar os custos das operações produtivas e logísticas entre empresas, constituintes do fluxo de materiais, componentes e produtos acabados" (Christopher, 1998; Handfield e Nichols, 1999; Chopra e Meindel, 2003 apud Assumpção, 2003).

Para Ballou (1999), o aumento do interesse pelas relações de parceria deve-se ao fato de não existir mais a possibilidade de uma única empresa ter todo o controle do fluxo dos produtos ou serviços, da fonte da matéria-prima ao consumo final. As relações de parceria buscam inte- grar empresas distintas, responsáveis por diferentes etapas do processo produtivo, em um modelo de integração alternativo à hierarquia da Integração Vertical. Buscando uma definição para o conceito de parceria, Lamming apud
Slack et al. (2002) apresenta parceria como um padrão de relacionamento pautado "no compartilhamento de riscos e recompensas de tecnologia e inovação, levando à redução de custos, ao aprimoramento na entrega e na qualidade e à ampliação de vantagem competitiva".

Os relacionamentos de parceria, segundo Mchug et al. (2003), guardam alguns aspectos comuns como, por exemplo: relacionamento de longo prazo baseado em confiança mútua e em cooperação mais do que em competição; forte interesse do fornecedor pela qualidade dos produtos que são entregues; e cooperação visando o aumento de desempenho dos fornecedores. A confiança mútua, um dos requisitos para o estabelecimento de parcerias, é fortemente condicionada por outro pressuposto da SCM: as relações de longo prazo. Relações de longo prazo podem implicar ligações de confiança entre as empresas, na medida em que as transações ocorrem reiteradamente entre os diversos elos da cadeia (Maia e Cerra, 2004a). A SCM é um conceito com caráter fortemente estratégico e, conseqüentemente, as empresas necessitam acompanhar o desempenho de seus processos. Contudo, a medição de desempenho na cadeia é ainda um campo em desenvolvimento, no qual diversos autores realizam proposições enfocando aspectos específicos. Como exemplos, têm-se: enfoque em custos (Damme e Zon, 1999), eficiência na utilização de recursos, saídas/serviços aos clientes e fle- xibilidade às mudanças do ambiente (Beamon, 1999), níveis de estoque, tempo, atendimento aos pedidos, qualidade, foco no cliente, satisfação dos clientes (Ramdas e Sperkman, 2000).

\subsection{TIPOS DE CADEIAS DE SUPRIMENTO 2.2.1 CADEIAS DE SUPRIMENTOS ENXUTAS}

De acordo com Gattorna (2009), as organizações aplicam conceitos enxutos nos sistemas logísticos corporativos e no mais amplo domínio da gestão da cadeia de suprimentos. Os princípios enxutos se concentram na eliminação dos desperdícios de material, processo, tempo e informação. A cadeia enxuta é a cadeia na qual o baixo custo é alcançado assegurando-se que os clientes não sejam superatendidos. Os custos baixos são obtidos por 
meio de seus processos mais básicos, mas bemfeitos. As cadeias enxutas se os clientes não quiserem compartilhar suas projeções de demanda, naturalmente é necessário empurrar 0 produto usando as melhores previsões em um ambiente mais estável, portanto para se conseguir eficiência nessa cadeia há necessidade de colaboração dos fornecedores. Na visão de Gattorna (2009), as cadeias enxutas estão inseridas num contexto em que os clientes frequentemente compram preços e utilizam múltiplas empresas na busca pelo suprimento estável e preço mais baixo. Mas ao adotar essa postura eles podem ser impessoais ou adversativos, com o desenvolvimento de pouca lealdade. Este é um mercado caracterizado por um estilo muito transacional, no qual a informação é poder e ocorre pouco ou nenhum compartilhamento entre compradores e vendedores. Para os fornecedores, é um mercado difícil e implacável, com clientes tão sensíveis ao preço que as empresas que as empresas não têm praticamente nenhuma oportunidade de diferenciar sua proposição de valor. Para competir em tais condições, necessita ter o produtor mais barato e sustentar essa vantagem ao longo do tempo, usando todas as técnicas e estratégias disponíveis.

Para Vachon (2009), o melhor caminho para servir o mercado guiado pelo baixo custo e confiabilidade é por meio de uma configuração enxuta da cadeia de suprimentos. O foco principal está em operações eficientes que ofereçam maior volume e menor variedade, e em sua maioria que produzam bens e serviços baseados em previsões. É o ambiente operacional MTF (Make-To-Forecast - Produção Sob Previsão). Segundo Vachon (2009), clientes servidos por cadeias enxutas, beneficiar-se-ão com a produção e a logística de baixo custo, alcançadas por meio de uso de todas as sinergias, integração, sincronismo, troca de informações, compartilhamento de know-how, entre os elos e economias de escala disponíveis. Há a vantagem em prever a demanda de forma mais precisa. Essas cadeias têm como característica central a reprodução de processos padronizados. Dessa forma, as cadeias enxutas de baixo custo e confiáveis podem ser projetadas e operadas para fornecer a eficiência, a previsibilidade e o baixo custo tão almejado pelos clientes. Em ambiente operacional onde os clientes exigem altos níveis de responsividade em condições imprevisíveis às cadeias enxutas podem ser inadequadas.

\subsubsection{CADEIAS DE SUPRIMENTOS ÁGEIS}

Para Stevenson (2009), as cadeias ágeis tem como foco serem rápidas e alinharem-se com os clientes exigentes. Frequentemente, a alta responsividade requer a habilidade de prever a capacidade com precisão em vez de prever qual será o próximo produto de sucesso e estar preparado para passar para uma produção de alta prioridade quando chegar o momento. O comportamento de compra dominante dos clientes de uma cadeia ágil é de demanda e reposta rápida. São cliente que exigem do modelo de negócio uma resposta rápida para condições imprevisíveis de fornecimento e demanda. $\mathrm{Na}$ visão de Stevenson (2009), a cadeia ágil é uma cadeia de fluxo oscilante, pois a demanda tem surtos durante condições de mercado imprevisíveis e de grande variedade. As capacidades de MTO (Make-To-Order- Produção sob Encomenda) ou ATO (Assemble-to-order- Montagem sob Encomenda) são críticas por uma resposta rápida às exigências do cliente. A alta responsividade não pode ser atingida por um custo mínimo; clientes têm de fazer escolhas, caso contrário eles se tornam inadministráveis e não lucrativos. Essas cadeias respondem rapidamente e com alta prioridade, em condições imprevisíveis de suprimentos e demanda.

O sucesso dessas cadeias é o resultado de uma combinação de processos e técnicas específicos dentro de um modo de pensar do negócio voltado à responsividade. Técnicas como o fornecimento estratégico e a manufatura postergada têm um papel central nesse aspecto, pois tudo tem que estar alinhado para se obter um resultado rápido e um custo eficiente. Há também a necessidade de habilidades nas atividades enxutas em módulos e ter capacidade de reconfigurar de maneira que forneçam as respostas desejadas. Quanto aos processos que motivam e sustentam as cadeias ágeis, estes são principalmente combinações de processospadrão e modulares, pois esta é a chave para conter custos e ao mesmo tempo, atender ás urgências de 
serviços em curtos períodos. Uma outra característica importante de acordo com Stevenson (2009), nas cadeias ágeis, é fundamental desenvolver e manter um modelo de otimização de rede, pois melhoram muito a qualidade das decisões tomadas no nível executivo integradas com as empresas participantes desse processo, buscando um alinhamento entre a empresa, clientes e fornecedores.

\subsubsection{CADEIAS DE SUPRIMENTOS TOTALMENTE FLEXÍVEIS}

Jagjit (2008) define as cadeias totalmente flexíveis, as que conseguem responder com rapidez e flexibilidade situações inesperadas impostas pelo mercado. Estas são desenhadas para encontrar soluções pra os problemas com muita rapidez, independente se requer pensamentos criativos das áreas internas, comportamentos inovadores por parte da empresa e um custo elevado internamente, o negócio está disposto a encarar essa situação. Esses clientes procuram soluções inovadoras em seus produtos e a empresa tem que estar preparada com seus elos para responder rapidamente às necessidades destes clientes especiais. As cadeias são configuradas em torno dos princípios de diminuição do risco e mobilização que fornecem responsividade máxima de maneiras distintas durante períodos curtos, pois o objetivo central é atender a demandas não programadas e não planejáveis com soluções rápidas, eficazes e centradas nos clientes, que geralmente não estariam disponíveis em circunstâncias normais. Quanto ao desenho organizacional que caracteriza essa cadeia, onde o trabalho é cooperativo entre as partes, a maior ênfase é colocada em inovação e em auto-suficiência.

\subsection{ESTRATÉGIA DE OPERAÇÕES}

Segundo Hayes et al. (2004, p. 51), para os quais [...] a estratégia de operações é um conjunto de objetivos, políticas e restrições auto-impostas que conjuntamente descrevem como a organização se propõe a dirigir e desenvolver todos os recursos investidos nas operações, de forma a melhor executar (e possivelmente redefinir) sua missão.

\subsubsection{CONCEITOS E EVOLUÇÃO}

Dois artigos de Skinner $(1969,1974)$ iniciaram o desenvolvimento da teoria de estratégia de operações e diversos avanços têm emergido desde então. Skinner (1969) propôs o conceito de estratégia de operações, ligado à função da produção a estratégia competitiva. Não se realizava, até os anos 80 , um estudo detalhado da estratégia de manufatura; foi empreendido, embora este fosse atualmente insuficiente (DANGAYACH; DESHMUKH, 2001). Acredita- se que algumas organizações podem ter atribuído a importância estratégica à função da manufatura, desenvolvendo uma estratégia consistente com a estratégia empresarial, assim permitindo vantagem competitiva (DÍAZ-GARRIDO; MARTÍN-PEÑA; GARCÍA-MUIÑA, 2007). Por outro lado, a estratégia de produção foi fomentada pelas obras clássicas de Skinner (1969; 1978), as quais enfatizam que a função produção é crucial para a competitividade da empresa. Numa outra visão, Madhavan (2007) salienta que a estratégia de operações éfundamentada por duas perspectivas: processo e conteúdo. Estas duas perspectivas estão fortemente inter-relacionadas, uma vez que o processo é apto para administrar o conteúdo. Assim, sem o processo o conteúdo não se torna efetivo, por outro lado, se não houver conteúdo o processo será apenas um método incapaz de realizar qualquer coisa na organização.

O foco do conteúdo é apropriar as intenções estratégicas da manufatura preocupando-se com o que a organização almeja competir, em contraste, o processo centraliza somente em como a estratégia de produção é desenvolvida. No ambiente empresarial, estratégias são ações ou padrões de ações intencionadas para a realização dos objetivos da organização. (RIIS; JOHANSEN; WAEHRENS, 2007). Para Skinner (1969), estratégia é um conjunto de planos e políticas estabelecidas pela companhia para obter vantagens sobre seus competidores. Contudo, Hayes e Wheelwright (1984) fundamentam o termo estratégia de forma mais sistemática e conceituam que a utilização do termo "estratégia", na área de negócio, possui no mínimo cinco características: horizonte de tempo, impacto, concentração de esforços, padrões de decisões, e poder de difusão (amplo espectro). 


\subsubsection{PRIORIDADES COMPETITIVAS}

As prioridades competitivas também chamadas de objetivos de desempenho, constituem as diretrizes mestras para posicionar a manufatura perante todos os grupos sociais que tenham vínculos de interesse na organização. Skinner (1969) classificava as prioridades como sendo o retorno sobre o investimento, qualidade, serviço. Garvin (1993) fornece uma grande contribuição ao planejamento estratégico de manufatura, constatando a necessidade de uma estrutura mais dinâmica de modo a suplementar o modelo de estratégia de manufatura com percepções do planejamento de longo prazo em relação às decisões do dia a dia. Sob a ótica do planejamento estratégico, a Estratégia de Operações éuma estratégia funcional e, portanto, deve promover sustentação à estratégia competitiva. No entanto, conforme ressalta Skinner (1969), não se podem considerar "baixos custos e alta eficiência" como os objetivos de todos os sistemas produtivos, invariavelmente. Dado o fato de que os elementos que compõem o sistema produtivo devam ser concebidos para atingir determinadas tarefas, estratégias competitivas diferentes exigirão configurações distintas do projeto do sistema de produção.

A chave para o desenvolvimento de uma estratégia de produção efetiva está em compreender como criar ou agregar valor para os clientes. Especificamente, o valor é agregado através da prioridade ou das prioridades competitivas, que são selecionadas para apoiar uma estratégia de negócios. Conforme Ward e Duray (2000), a estratégia de operações atua como mediadoraentre a estratégia competitiva empreendida por uma companhia e o desempenho que esta atinge. Selecionando especificamente o enfoque da qualidade como um exemplo, os autores propõem que a estratégia competitiva de diferenciação é bem sucedida, quando apropriadamente apoiada pela qualidade das operações. Portanto, cada tipo de estratégia demanda certas tarefas da função operações, as quais são conhecidas por "prioridades competitivas" (ou objetivos de desempenho) e foram inicialmente identificadas por Skinner (1969) como sendo produtividade, serviço, qualidade e retorno sobre o investimento. A partir deste modelo que interage nas tomadas de decisões estratégicas, destaca-se a importância das prioridades competitivas dentro da empresa.

As prioridades competitivas, também denominadas objetivos de desempenho, fornecem contribuição vital para uma empresa que busca sucesso em longo prazo, possibilitando vantagem competitiva baseada em operações. Prioridades competitivas podem ser definidas como um conjunto consistente de objetivos/ metas para operações (LEONG; SNYDER; WARD, 2000), sendo aplicadas ao nível funcional, constituindo, juntamente com as questões estruturais e infraestruturais, a base para a formação de uma estratégia de operações. As prioridades competitivas se aplicam ao nível funcional, em especial a operações. Contudo, as prioridades competitivas se aplicam a toda unidade de negócios e devem ser consideradas pelas outras estratégias funcionais. (PIRES, 1995). Posteriormente, essas habilidades foram condensadas, por muitos autores, em quatro prioridades principais: custo, qualidade, desempenho e entregas e flexibilidade. Alguns autores como Leong, Snyder e Ward (2000) subdividem desempenho de entregas em velocidade de entregas e confiabilidade de entregas. O objetivo "flexibilidade" também costuma ser subdividido em flexibilidade de volume e mix de produção e acrescenta a prioridade inovação como sendo a habilidade de introdução de novos produtos e processos. Alves Filho et al. (1995) e Pires (1995) consideram um conjunto de quatro prioridades competitivas: custo, qualidade, desempenho de entregas e flexibilidade.

As prioridades competitivas usadas eram as prioridades clássicas: custo, qualidade, flexibilidade, entrega e serviço de pós-vendas, além da prioridade nova da proteção ambiental. Desde que as questões meio-ambientais são uma fonte de vantagem competitiva para empresas e a área da manufatura é o ponto crítico onde a empresa atua no impacto ambiental, diversos autores recomendam incluir a proteção ambiental na estratégia da manufatura. (BURGOS, 2001; SUM; LOW; CHEN, 2004; ZHAO et al., 2006). Observa-se que há um consenso geral entre os pesquisadores perante quatro prioridades competitivas: qualidade, rapidez, flexibilidade, custo, velocidade, confiabilidade e inovação. Não obstante, 
a literatura recente mostra que esse tema ainda não está concluído e novos estudos apresentam debates sobre o desempenho ambiental como uma nova prioridade competitiva da manufatura. (VACHON; KLASSEN, 2006).

\section{MÉTODO DE PESQUISA}

A metodologia de pesquisa adotada foi o estudo de caso, pois investiga fenômenos contemporâneos inseridos em algum contexto da vida real, quando as fronteiras entre fenômeno e contexto não são muito claras e são utilizadas múltiplas fontes de evidência. Dado em que se ambiciona verificar, empiricamente, o desempenho das cadeias de suprimentos das montadoras baseados em convergências e divergências entre a Estratégia de Operações e práticas da SCM, bem como ilustrar a dinâmica de interação existente entre ambas as áreas em empresas do segmento de caminhões. A escolha desta abordagem está em concordância com as proposições de Yin (1994), pois se deseja "investigar um fenômeno atual dentro do seu contexto real, quando as fronteiras entre o fenômeno e o contexto não são claramente definidas e utilizando-se várias fontes de evidência". A pesquisa de campo, tendo sido realizada por meio de estudos de caso, utilizouse de um método qualitativo, de pesquisa descritiva (ou exploratória), o fator decisivo que conduziu à escolha da pesquisa exploratória foi o fato do tema ser recente, importante e diferenciado na literatura. Segundo Lazzarini (1997), os métodos denominados qualitativos caracterizam-se por um foco maior na compreensão dos fatos que propriamente na sua mensuração. Eles são empregados, de acordo com Richardson (1985), em casos em que a riqueza dos detalhes é mais relevante do que as informações quantitativas. Foram conduzidas entrevistas semiestruturadas, em duas montadoras de caminhões, seguindo-se um roteiro previamente formulado a partir da revisão bibliográfica, incluindo um protocolo de pesquisa. A escolha das montadoras, deve-se principalmente aos extremos de suas configurações nas cadeias de suprimentos, os arranjos produtivos utilizados e o foco nas prioridades competitivas. do artigo, e a escolha foram profissionais do nível estratégico (diretor industrial) e tático (gerentes de produção) das montadoras, essa escolha deve-se à posição ocupada na empresa e a vivência no ramo, a fim de obter a sua opinião, suas concepções sobre as características das cadeias, configurações produtivas da qual fazem parte, e a influência das prioridades competitivas no desempenho dessas cadeias. Os métodos de procedimento para coletar dados na pesquisa qualitativa foram a entrevista semi-estruturada, a observação participativa, e o exame de documentos e posteriormente o cruzamento destas informações para validação das mesmas. A amostra utilizada foram as fábricas da VW(RJ) e MB(SBC-SP) e fornecedores parceiros de primeiro nível dessas montadoras. A íntegra dos discursos não será apresentada nesse artigo devido ao grande volume de páginas e, principalmente, para impedir a possibilidade de identificação, bem como de divulgação de informações sobre as quais os informantes solicitaram sigilo.

\section{PESQUISA DE CAMPO E ANÁLISE DOS CASOS ESTUDADOS}

As unidades de análise citadas nesta pesquisa correspondem a duas configurações produtivas: Volkswagen (VW-RJ) - configuração de Consórcio Modular (CM) - e a Mercedes Benz do Brasil (MBB unidade São Bernardo do Campo - SP), configuração produtiva tradicional - ambas reconhecidos players do mercado de caminhões e veículos comerciais. No caso do Consórcio Modular liderado pela VW, as empresas parceiras estão instaladas dentro do site da montadora no CM da VW localizado em Resende-RJ. Já no caso da MBB, os fornecedores estão logisticamente espalhados por todo o Brasil, concentrando-se mais no Sudeste de São Paulo. O mercado brasileiro de caminhões conta atualmente com os seguintes principais participantes: Agrale, Fiat, Ford, Iveco, Mercedes-Benz, Scania, Volkswagen e Volvo, divididos nos segmentos de veículos semileves, leves, médios, pesados e extrapesados, sendo que nem todas as montadoras concorrem em todos os segmentos. Na consolidação de todos os segmentos, o mercado é dominado por MBB e VW respectivamente, depois a Ford; a Scania e Volvo 
com participações em pesados. (ASSOCIAÇÃO DOS FABRICANTES DE VEÍCULOS AUTOMOTORES, 2009). Nos segmentos de leves, há a presença da Ford, a líder nesse segmento; VW e MBB se alternam na liderança do mercado, a diferença da VW é pelo seu arranjo produtivo (CM), consegue um lead time de produção inferior ao arranjo tradicional (MB), sendo mais competitiva no final da cadeia em preço do produto.

\subsection{VOLKSWAGEN -RESENDE (RJ)}

Essa fábrica possui o único arranjo produtivo (CM) - Consórcio Modular, o qual foi concebido a fim de realizar a produção num ciclo menor e com custos menores do que na configuração tradicional de montagem, permitido à montadora concentrarse na coordenação de projetos, no marketing, na qualidade, vendas e pós-vendas dos autoveículos. (PIRES, 2004). São de responsabilidade da montadora Volkswagen as áreas de: engenharia de produto; controle de qualidade; compra de suprimentos; distribuição, comercialização e logística do produto final. Para a montadora, este projeto causou uma redefinição de seu negócio, que passou a abranger somente as atividades relativas a finanças, ao projeto, à qualidade, ao desenvolvimento e à certificação de produtos e às atividades de pós-venda (PIRES, 2004).

Quando decidiu iniciar as operações com veículos comerciais no Brasil, no início da década de 80, a VW apoiou-se em parceiros mundialmente mais experiente na produção de caminhões e se beneficiou da experiência e do know-how da Chrysler no setor. Essa estratégia se repetiu em 1987 com a criação da Autolatina, quando a empresa se beneficiou da expertise em projeto e manufatura de caminhões da Ford Caminhões. Com o fim da Autolatina, as operações da VW e Ford são divididas novamente, fato que levou a VW ficar sem uma unidade produtiva para sua fábrica de caminhões, já que a fábrica do Ipiranga, onde eram montados os veículos Ford e VW, pertenciam à Ford e a ela retornou. Nessa ocasião, os caminhões com marca VW (mesmo quando o acordo Autolatina estava de pé, os veículos mantinham as marcas comerciais Ford e VW) detinham a expressiva participação de cerca de $18 \%$ do mercado de caminhões no Brasil. Isso significava que a VW necessitava, urgentemente, de uma fábrica capaz de manter a produção de caminhões no Brasil (SALERNO, 1997), caso contrário seria decretado o fim das atividades da marca VW no mercado mundial de caminhões. A opção do board mundial da empresa na época foi pela continuidade das operações no Brasil e, após longas tratativas, o local escolhido para continuar as atividades de veículos comerciais recaiu no município de Resende-RJ.

Cabe aqui destacar uma questão determinante para a escolha do local da fábrica de caminhões ter sido Resende como projeto piloto para implantação do CM, que foi o fato de o projeto de um caminhão e chassi de ônibus ser menos complexo e mais fácil de ser modularizado (dividir/quebrar em partes) do que o projeto de um automóvel. Outro ponto importante foi o fato de Resende estar afastada dos grandes sindicatos no ABC paulista, visto as alterações providas pelo $\mathrm{CM}$ no tocante à sua organização interna. O objetivo era de afastar os sindicatos de qualquer discussão sobre a configuração da organização da produção e trabalho. (VOLKSWAGEN DO BRASIL, 2007). Isto mostra uma nova forma de relacionamento entre cliente e fornecedor, diferente das tradicionalmente utilizadas, o qual estabelece uma parceria de longo prazo e necessita de total integração, abrangendo toda a estrutura das empresas. A decisão de localização, portanto, foi fruto de uma decisão estratégica, baseada numa correta avaliação do desempenho e das competências do fornecedor, pois cria uma situação de grande interdependência e difícil retorno (PIRES, 2007).

Em Resende, os principais fornecedores (fornecedores de módulos) da VW ficaram responsáveis pela montagem de partes inteiras dos caminhões, respondendo pela contratação dos subfornecedores que anteriormente se relacionavam diretamente com a montadora. Mais do que isso, eles estão fisicamente presentes na fábrica, divididos em sete módulos. Cada um destes módulos administra uma etapa da produção. À VW, por sua vez, cabe fazer a supervisão geral. (SALERNO, 2002). Um dos objetivos do CM é o repasse de atividades de montagem aos modulistas 
de forma a permitir a redução dos custos e do tempo de montagem do produto, uma vez que várias tarefas são realizadas em paralelo (PIRES, 2004). Logo, a montagem final está submetida a tarefas de dependência prévia, configurando um caminho crítico para a montagem. Porém, a vantagem da produção paralela não é a única característica responsável pela redução do tempo, mas também a forma de gerir e organizar as atividades dos modulistas.

A cadeia de suprimentos da VW, representada na figura 3, é uma cadeia flexível, ágil e enxuta, pois o arranjo de CM contribui para alcançar esses atributos. O foco estratégico está embasado nas prioridades competitivas de flexibilidade e custo e é suportado, também em função do arranjo, por diversas ferramentas de TI que unem todos os elos, a saber: EDI, ESI,VMI,CRM e e-business. De acordo com a figura 2, em função do arranjo a cadeia permite flexibilidade $\mathrm{E}$ sincronismo e diferencia-se principalmente pelas práticas e interações entre os elos participantes da cadeia. O EDI (Electronic Data Interchange), intercâmbio eletrônico de dados, permite à montadora agilidade na comunicação do programa de produção para os parceiros e estes gerenciarem os suprimentos necessários e se comunicarem com seus fornecedores de segunda camada). O ESI (Early Supplier Involvement), propicia o envolvimento do fornecedor desde o início do projeto do produto, embora não em todos os módulos, apenas em alguns. O VMI (Vendor Managed Inventory), possibilita que estoque seja gerenciado pelos parceiros, já que os mesmos estão dentro do próprio site da montadora. Ao CRM (Customer Relationship Management), cabe a gestão de relacionamento com o cliente. Esta ferramenta permite à montadora medir a satisfação dos clientes em relação á produtos e serviços. A prática do E-business (B2B, B2C) agiliza via internet os negócios realizados entre empresas fornecedoras e parceiros e parceiros e montadora, além de possibilitar a compra via site da montadora pelo cliente. A cadeia de suprimentos de Resende é flexível, ágil e enxuta, dando uma excelente condição de competitividade e produtividade para a unidade.
Figura 2 - Cadeia de Suprimentos da Volkswagen

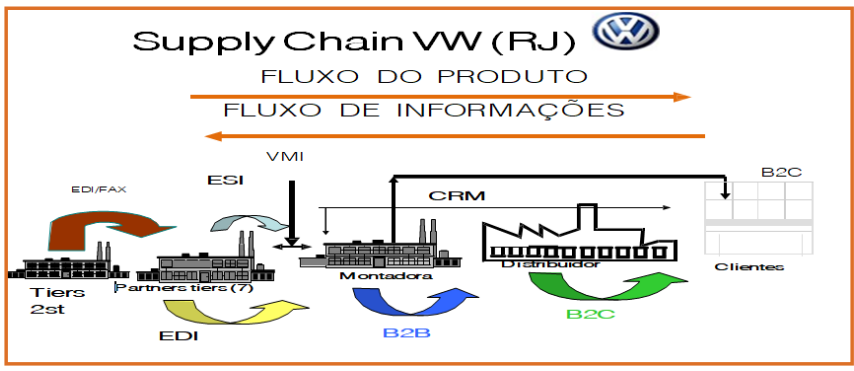

Fonte: VOLKSWAGEN DO BRASIL, 2007

\subsection{MERCEDES BENZ DO BRASIL-SÃO BERNARDO DO CAMPO -SP}

A história da MBB, no Brasil, sempre foi caracterizada por pioneirismo e vanguarda. A fábrica de São Bernardo do Campo também produz peças e agregados para veículos comerciais, como motores, câmbios e eixos. (MERCEDES BENZ DO BRASIL, 2008). A fábrica de São Bernardo do Campo produz os próprios motores para caminhões e chassis de ônibus da marca Mercedes-Benz. Além disso, exporta motores para atender outras fábricas de veículos comerciais da Daimler Chrysler em países como Argentina, México, Estados Unidos, Alemanha e Espanha. Para oferecer ao mercado soluções efetivamente adequadas, eficientes e confiáveis, a MB tem incrementado cada vez mais sua parceria com fornecedores e clientes. (MERCEDES BENZ DO BRASIL, 2008). A cadeia de suprimentos na MB é uma cadeia tradicional e, como tal, não está inserida nos tipos de cadeia (ágil, flexível e enxuta), pois o sistema produtivo da fábrica é um sistema tradicional, onde os principais fornecedores diretos estão logisticamente espalhados por todo o Brasil, de acordo com a figura 3 .

$\mathrm{Na}$ MBB, apenas existem duas práticas das ferramentas da cadeia de suprimentos, em função de ser uma operação tradicional, não há arranjo nem de condomínio industrial nem de consórcio modular. Tendo o arranjo comum, a cadeia é penalizada em termos de agilidade no tocante à informação, responsividade, e sincronismo entre os elos participantes. O EDI é utilizado para a comunicação entre montadora e fornecedores no tocante a dados de produção e estoque, já o ESI ainda é uma pratica embrionária na unidade, sendo utilizado apenas na produção de eixos. O foco estratégico da montadora 
está embasado nas prioridades competitivas de custo e qualidade, contudo, por ser uma fábrica tradicional onde o arranjo também é tradicional, esta unidade foca apenas a prioridade de custos como prioridade essencial.

Figura 3 - Cadeia de Suprimentos da Mercedes Benz do Brasil

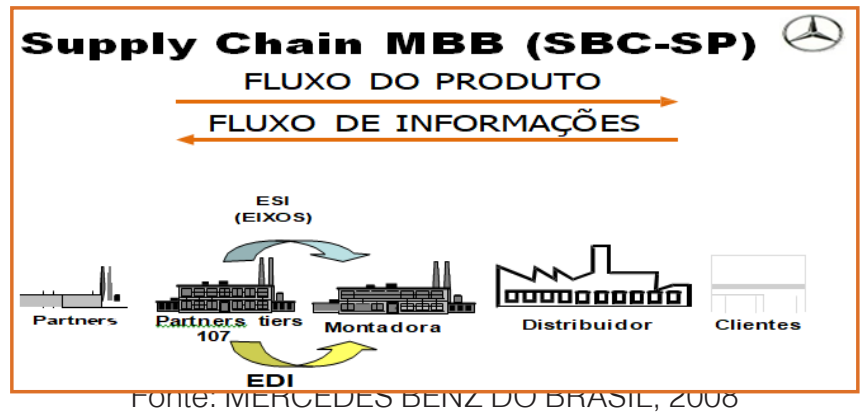

\section{CONCLUSÕES}

De acordo com a pesquisa de campo, as montadoras diferem em suas cadeias de suprimentos principalmente no tipo de arranjo produtivo adotado, no foco estratégico decorrente da estratégia de operações de cada montadora e na utilização de ferramentas de informação utilizadas na cadeia. A VW dispõe de uma cadeia ágil, flexível e enxuta, apoiada na utilização das práticas da cadeia com os elos participantes. Por isso beneficia-se de resultados mais rápidos quando os mesmos se tornam necessários. Um exemplo disso é o que ocorre, por exemplo, nas alterações do programa de produção, quando a transmissão de dados entre os níveis de fornecimento se dá através do uso do EDI e do ESI, mesmo que este último não esteja disponível em todos os módulos. Essa cadeia também proporciona vantagens em custos menores de desenvolvimento de novos produtos e no compartilhamento de know-how entre montadora e fornecedores de módulo, focados em melhorias de flexibilidade e redução de custos dos módulos. O desenvolvimento de produtos também representa um ponto de confluência entre a estratégia de operações e a gestão da cadeia de suprimentos, já que as montadoras possuem autonomia perante suas matrizes internacionais para realizar desenvolvimentos incrementais em módulos não estratégicos com seus parceiros e, como resultado de tais desenvolvimentos, buscam parcerias com os fornecedores de suas cadeias para realizar o desenvolvimento conjunto dos componentes necessários.

O VMI, estoque gerenciado pelos sete fornecedores instalados dentro do site, proporciona à montadora uma redução considerável de capital empatado nos estoques, já que os parceiros são exclusivos no fornecimento dos módulos de competência. O CRM visa gerenciar o conjunto de planos, controles, decisões e ações necessários para a gestão integral de todos os relacionamentos com os clientes, objetivando o aumento de vendas, do ciclo de vida do cliente, da lucratividade por cliente e a personalização do tratamento dado aos diferentes clientes, o que pode ser feito porque a empresa criou uma área de engenharia para produtos especiais, que projeta os produtos de acordo com as necessidades de cada cliente, o que se traduz na obtenção de uma vantagem competitiva para a VW. O E-business proporciona a flexibilidade para a montadora nos negócios entre os participantes da cadeia e fornecedores, tanto os de primeira camada, quanto os de camadas inferiores, utilizando-se da internet para essas operações.

A MBB apresenta como característica uma cadeia tradicional que não está inserida entre os tipos abordados nesse artigo (ágil, flexível e enxuta). De acordo com sua configuração produtiva mais tradicional, a velocidade, o sincronismo e a integração entre os elos da cadeia são muito prejudicados, em função de utilizarem-se apenas duas práticas de ferramentas (EDI, ESI). O EDI gerencia informações de estoque entre os fornecedores de primeira camada, pois são numerosos com a montadora e os de camada inferiores trazendo um ganho no tocante às informações para a montadora. O ESI, apesar da existência de planos na montadora para estender a prática a outros módulos, por enquanto é praticado apenas em uma única área (eixos), já que ainda se encontra em fase de adaptação e medição e análise dos resultados proporcionados. Concluindo a pesquisa e o propósito desse artigo, pode-se afirmar que as cadeias de suprimentos impactam na produtividade e resultados da montadora em função do tipo de cadeia, juntamente balizadas na estratégia de operações e prioridades competitivas apoiadas no uso de ferramentas da cadeia e o arranjo produtivo, 
trazem o diferencial para a montadora.

\section{REFERÊNCIAS}

[1] ALVES FILHO, A. G. et al. Automaker Control of the supply chain: the case of Volkswagen's engine plant in São Carlos. In: GERPISA EIGTH INTERNATIONAL COLLOQUIUM, 2000. Proceedings..., Paris, França, 2000.

[2] ALVES FILHO, A. G. et al. O consórcio modular e seus impactos na cadeia de suprimentos da fábrica de motores da VW-São Carlos, Projeto Temático, Processo FAPESP 97/13071-9. Relatório Final, 2001.

[3] _. Assembler control of the Supply Chain: The case of an engine plant in Brazil. Actes du GERPISA Groupe d' Etudes et de Recherches Permanent sur l' Industrie et les Salariés de l' Automobile, v. 33, n. 1, p. 49-60, Paris 2002.

[4] ALVES FILHO, A. G.; CERRA, A. L.; MAIA, J. L.; SACOMANO NETO, M.; BONADIO,

P. V. G. Pressupostos do Gerenciamento da Cadeia de Suprimentos: evidências de estudos sobre a indústria automobilística. Gestão \& Produção, v. 11, n. 3, p. 275-288, set-dez. 2004.

[5] ASSOCIAÇÃO DOS FABRICANTES DE VEÍCULOS AUTOMOTORES. 50 anos da

indústria automobilística brasileira. Disponível em: <http:// www.anfavea.com.br>. Acesso em: 04 ago. 2007.

[6] BALLOU, R. H. Business Logistics Management, Planning, Organizing and Controlling the Supply Chain. 4. ed. New Jersey: Prentice Hall, 1999.

[7] BEAMON, B. M. Measuring supply chain performance. International Journal of Operations and Production Management, v. 19, n. 3, p. 275-292, 1999.

[8] CHOPRA, S.; MEINDL, P. Gerenciamento da Cadeia de Suprimentos, Estratégia, Planejamento e Operação. São Paulo: Prentice Hall, 2003

[9] CHRISTOPHER, M. Logistics and Supply Chain Management, Strategies for Reducing Cost and Improving Service. 2. ed. London: Prentice Hall, 1998.

[10] COOPER, M. C.; LAMBERT, D. M.; PAGH, J. D. Supply chain management: more than a new name for logistics. International Journal of Logistics Management, v. 8, n. 1, p. $1-13,1997$

[11] DAMME, D. A. V.; ZON, F. L. A. Activity based costing and decision support. International Journal of Logistics Management, v. 10, n. 1, p. 71-82, 1999.

[12] DANGAYACH, G. S.; DESMUKH, S. G. Manufacturing Strategy: Literature review and some issues. International Journal of Operations and Production, v. 21, n. 7, p. 884-932, 2001.
[13] GARVIN, D. A. Manufacturing Strategy Planning. California Management Review, v. 35, n. 4, p. 85-106, 1993.

[14] GATTORNA. J. Living Supply Chain. New York: Pearson Education, 2006

[15] GIL, A. C. Métodos e Técnicas de Pesquisa Social. 5. ed. São Paulo: Ed. Atlas, 1999. HANDFIELD, R. B.; NICHOLS, E. L. Introduction to Supply Chain Management. Saddle River: Prentice Hall, 1999.

[16] HAYES, R. H.; PISANO, G. P.; UPTON, D. M.; WHEELWRIGHT, S. C. Operations, Strategy and Technology, Pursuing the Competitive Edge. New York: John Willey \& Sons, 2004

[17] HAYES, R.; WHEELWRIGHT, S. C. Restoring our Competitive Edge - Competing through Manufacturing. New York: John Willey \& Sons, 1984

[18] JAGJIT S.S. A supply network configuration perspective on international supply chain development. International Journal of Operations \& Production Management v. 28 n. 5, pp. 386-411, 2008.

[19] LAZZARINI, S. G. Estudos de caso: aplicações e limites do método. In: FARINA, E.

Estudos de caso em agribusiness, São Paulo: Pioneira, 1997.

[20] LEONG, G. K.; SNYDER, D. L.; WARD, P. T. Research in the process and content of manufacturing strategy. OMEGA International Journal of Management Science, v. 18, n. 2, p. 109-122, 1990

[21] LUMUS, R. R.; VOKURKA, R. J.; ALBER, K. L. Strategic supply chain planning. Production and Inventory Management Journal, v. 39, p. 49-58, 1998.

[22] MADHAVAN, B. Operation management, theory \& practice. New Delhi: Pearson Education, 2007.

[23] MAIA, J. L.; CERRA, A. L. Relacionamento entre empresas na cadeia de uma montadora de motores: uma análise a partir da Economia de Custos de Transação. In: SIMPEP - SIMPÓSIO DE ENGENHARIA DE PRODUÇÃO. 11. 2004. Anais... Bauru/SP, 2004a. Disponível em: www.simpep. feb.unesp.br

[24] MCHUG, M.; HUMPHREYS, P.; MCIVOR, R. Buyersupplier relationships and organizational health. The Journal of Supply Chain Management, p. 15-25, May, 2003.

[25] OHNO, T. O sistema Toyota de produção além da produção em larga escala , Trad. Cristina Schumacher, Artes Médicas, Porto Alegre, 145p., 1997.

[26] PEDROSO, M. C. Um estudo sobre o desenvolvimento de competências em Gestão de Cadeia de Suprimentos. Tese (Doutorado em Engenharia de Produção) - Escola Politécnica, Universidade de São Paulo. São Paulo, 2002. 
[27] PIRES, S. R. I. Managerial implications of the modular consortium in a Brazilian automotive plant. Int. Journal of Operations \& Production Management, v. 18, n. 3, p. 221232, 1998.

[28] _. Supply Chain Management. 2001. Disponível em: <http://www.numa.org.br> Acesso em: junho de 2001.

[29] PIRES, S. R. I. Gestão da cadeia de suprimentos (supply chain management): conceitos, estratégias e casos. São Paulo: Atlas, 2004.

[30] PIRES, Sílvio R. I. Formal contracts in supply chain management: a case study poms. Annual Conference Dallas, 18th, Texas, USA May 4 to May 7, 2007.

[31] POSTHUMA, A. C. Autopeças na encruzilhada: modernização desarticulada e desnacionalização. In: ARBIX, G.; ZILBOVICIUS, M. (orgs.). De JK a FHC: a reinvenção dos carros. São Paulo: Scritta, 1997.

[32] RAMDAS, D. F.; SPERKMAN, R. E. Chain or shackles: understanding what drives supply- chain performance. Interfaces, v. 30, n. 4, p. 3-31, 2000.

[33] RICHARDSON, R. J. Pesquisa Social, método e técnicas. São Paulo: Atlas, 1985. SALERNO, M. S.; MARX, R.; ZILBOVICIUS, M. A nova configuração da cadeia de fornecimento na indústria automobilística do Brasil. Revista de Administração da USP, v. 38, n. 3, p. 192-204, 2003.

[34] SKINNER, W. The Focused factory. Harvard Business Review, May./Jun., 1974.

[35] SKINNER, W. Manufacturing - Missing Link in Corporate Strategy. Harvard Business Review, v. 47, n. 3, 1969.
[36] SLACK, N.; CHAMBERS, S.; JOHNSTON, R. Administração da Produção. 2. ed. São Paulo: Atlas, 2002.

[37] TAN, K. C. Supply Chain Management: Practices, concerns, and performance issues. The Journal of Supply Chain Management, p. 42-53, Winter, 2002.

[38] VACHON, S. Aligning competitive priorities in the supply chain: the role of interactions with suppliers. International Journal of Operations \& Production Management v. 29 n. 4, pp. 322-340, 2009.

[39] VACHON, S.; KLASSEN, R. D. Green project partnership in the supply chain: the case of the package printing industry. Journal of Cleaner Production, v. 14, n. 6-7, p. 661-671, 2006.

[40] WARD, P. T.; DURAY, R. Manufacturing Strategy in Context: Environment, competitive strategy and manufacturing strategy. Journal of Operations Management, v. 18, n. 2 , p. 123-138, 2000.

[41] YIN, R. K. Case Study Research, Design and Methods. 2. ed. London: Sage, 1994. 


\title{
CAPÍTULO 21
}

\section{ANÁLISE MULTICRITÉRIO DA EVIDENGIAÇÃO AMBIENTAL DAS EMPRESAS DO IBRX-100 \\ UMA APLICAÇÃO DO MÉTODO T-ODA}

\author{
Mara Vogt \\ Larissa Degenhart \\ Nelson Hein \\ Adriana Kroenke
}

Resumo: O objetivo deste estudo foi de mensurar o grau de evidenciação ambiental das empresas brasileiras listadas no IBrX-100 da BM\&FBovespa utilizando o método de análise multicritério T-ODA. Trata-se de um estudo descritivo, documental e quantitativo. A amostra compreendeu as 97 empresas brasileiras pertencentes ao índice IBrX-100 listadas na BM\&FBovespa nos anos de 2010 a 2013. A partir dos resultados verificou-se que as empresas com maior grau de evidenciação ambiental em cada ano são: Ambev (2010), Duratex (2011), BRF Brasil Foods (2012) e a Eletrobrás (2013). Além disso, as organizações divulgaram diferentes informações nos períodos analisados, o que pode indicar seleção de informações visando a legitimação, pois as empresas tornam-se legitimadas quando demonstram que suas atividades estão de acordo com as demandas sociais. Além disso, as empresas poderão aumentar o seu grau de evidenciação se divulgarem mais informações em seus relatórios sobre suas ações ambientais, principalmente sobre o aspecto transporte.

Palavras chave: Grau de Evidenciação Ambiental, Relatório de Sustentabilidade, Relatório Anual, Empresas Brasileiras. 


\section{INTRODUÇÃO}

Nos últimos 30 anos o impacto das empresas sobre o meio ambiente tornou-se uma preocupação cada vez maior entre ambientalistas, legisladores, clientes, autoridades públicas e a sociedade em geral. Diante disso, há 15 anos as empresas começaram a evidenciar mais sobre as estratégias ambientais em função das pressões institucionais. Essas estratégias são relatadas por meio de indicadores e podem ser classificadas de acordo com o compromisso ambiental que representam (ALBERTINI, 2013).

Nossa (2002) ressalta que a preocupação com o meio ambiente e a conscientização encontra- se cada vez mais presente na sociedade. É por isso que as empresas investem em programas ambientais, pois descobrem que poluir é o mesmo que desperdiçar, não ter eficiência e não ter como competir. Afinal, a sociedade pressiona o Governo e as empresas, sobre a preservação do meio ambiente e essa pressão aumenta a partir do momento em que a poluição causada pelas atividades das organizações também for aumentar. É nesse momento que as empresas estabelecem metas para minimizar os impactos ambientais sobre as emissões de efluentes líquidos e gasosos, reciclagem de materiais, dentre outras, com vistas a legitimar suas atividades.

De acordo com Rosa et al. (2013), na década de 1990, o foco das informações ambientais apresentadas pelas empresas estava pautada na divulgação das políticas, dos objetivos, das responsabilidades profissionais e o cumprimento legal. Já na década de 2000, além dessas preocupações com a gestão e os aspectos legais, iniciaram as pesquisas relacionadas aos níveis de evidenciação, aos tipos de relatórios utilizados, os padrões de comunicação, os sistemas de gestão ambiental e as certificações. Nessa época, também foram pesquisados aspectos de desempenho ambiental, tais como os resíduos, a gestão de impactos e energia.

A partir de 2010, aumentaram consideravelmente os estudos sobre os critérios para avaliar o desempenho da empresa. Nesse período estudos passaram a analisaram a relação de causa e efeito das atividades das organizações com o meio ambiente (ROSA et al., 2013). Segundo Rosa et al. (2014), o interesse dos pesquisadores tem aumentado por aspectos relacionados ao desempenho ambiental como: água, energia, biodiversidade, emissões, efluentes, resíduos, impactos e transporte. No entanto, outros aspectos, como a certificação, os sistemas de gestão ambiental e as políticas ambientais, continuam fazendo parte dos grandes movimentos, debates sociais e políticos para o desenvolvimento sustentável.

Diante do contexto apresentado emerge a seguinte questão que norteia esta pesquisa: Qual é o grau de evidenciação ambiental das empresas brasileiras listadas no IBrX-100 da BM\&FBovespa? No intuito de responder a esta questão, o objetivo do estudo consiste em mensurar o grau de evidenciação ambiental das empresas brasileiras listadas no IBrX100 da BM\&FBovespa.

O estudo justifica-se, pois as informações contidas nos relatórios deveriam ser além de amplas, exatas e verdadeiras, visto que muitos investidores utilizam as informações contidas nos relatórios ambientais para a tomada de decisões, decidindo se devem investir ou não em determinada empresa (NOSSA, 2002).

Justifica-se ainda devido ao fato do método de análise multicritério Trade-Off Decision Analysis (T-ODA), ser inédito dentro do tema evidenciação ambiental em pesquisas realizadas em âmbito nacional e internacional e devido a escassez de estudos na área contábil envolvendo o método. Conforme Rossoni (2011), o método é relevante, visto que a história nos mostra que os processos de tomada de decisão, geralmente não levam em consideração todos os critérios que modificariam certa decisão. Ressalta ainda que os gestores normalmente seguem a sua intuição para tomar decisões e, para que uma empresa tenha sucesso é preciso considerar esses critérios e ponderá-los corretamente.

\section{EVIDENCIAÇÃO AMBIENTAL}

Até o começo do século XX houve pouca preocupação das empresas quanto a preservação e recuperação do meio ambiente. Isso porque naquela época os recursos naturais eram considerados abundantes e os gestores utilizavam esses recursos como uma fonte inesgotável 
de matéria-prima a um custo muito baixo ou até mesmo nulo. A partir do momento que os efeitos da agressão ao meio ambiente começaram a se manifestar, a sociedade começou a cobrar das organizações maior responsabilidade ambiental. O mercado selecionou as empresas que estavam comprometidas com a preservação, manutenção e recuperação da natureza, visto que as demais comprometeriam o futuro do planeta (COSTA, 2006).

Essa crescente preocupação sobre os impactos da empresa na sociedade e no meio ambiente levou o público a exigir destas um comportamento social e ambientalmente responsável (GARCÍA-SÁNCHEZ; FRÍAS-ACEITUNO; RODRÍGUEZ-DOMÍNGUEZ, 2013).

Dessa forma, para que as empresas se tornem competitivas, estas precisam evidenciar informações que sejam relevantes aos usuários para auxiliar na tomadas de decisões. Para as empresas apresentarem à sociedade seus compromissos, estas podem utilizar diversos recursos, como campanhas e divulgações em propagandas, divulgação de relatórios específicos, entre outros. Cada vez as organizações visam apresentar mais informações sobre suas atividades na buscar de se diferenciarem das demais, com relação às questões ambientais e sociais (KRESPI et al., 2012).

Nos últimos anos a evidenciação ambiental se expandiu em todo mundo de forma significativa (WANG; BERNELL, 2013). Mesmo que a evidenciação ambiental deveria ocorrer sempre, no Brasil, a legislação não obriga as empresas a divulgarem. Há uma tendência mundial na qual os investidores procuram as empresas que são socialmente responsáveis, sustentáveis e rentáveis para aplicarem os seus recursos (OLIVEIRA; MACHADO; BEUREN, 2012). Isso porque, de acordo com Meng et al. (2013), o nível de evidenciação das informações ambientais reflete o grau de responsabilidade ambiental corporativa das empresas.

Da mesma forma, Rosa et al. (2014) frisam que a evidenciação pode ser conceituada como um meio, ou então um conjunto de meios utilizados por diferentes empresas, com o intuito de expor suas práticas ambientais aos stakeholders, ao mesmo tempo que funciona como ferramenta para a tomada de decisões aos diferentes interessados por essas informações. A evidenciação ambiental é baseada na economia, desenvolvimento sustentável e informação divulgada. Serve para os investidores realizarem previsões e analisarem o desempenho ambiental da empresa.

\section{METODOLOGIA}

Diante do objetivo de mensurar o grau de evidenciação ambiental das empresas brasileiras listadas no $\mathrm{IBrX}$ 100 da BM\&FBovespa, realizou-se uma pesquisa descritiva, documental e com abordagem quantitativa.

A população da pesquisa compreende todas as empresas pertencentes ao Índice Brasil 100 (IBrX-100) listadas na BM\&FBovespa, ou seja, 100 companhias. No entanto, pelo fato das empresas Bradesco, Klabin e Oi estarem duplicadas, a amostra do estudo foi composta por 97 destas empresas listadas na Bolsa de Valores de São Paulo, pertencentes ao índice IBrX-100. Por meio do Quadro 1 são apresentadas as empresas que compõem a amostra da pesquisa. 
Quadro 1 - Amostra da pesquisa

\begin{tabular}{|c|c|c|c|}
\hline \multicolumn{4}{|l|}{ Empresas } \\
\hline Aes Tietê & CPFL Energia & Itaú Unibanco Holding & PDG Realty \\
\hline All América Latina Log. & Cyrela Realty & JBS & Petróleo Brasileiro \\
\hline Ambev & Diagnósticos da América & Klabin & Petropar \\
\hline Anhanguera Educ. Part. & Duratex & Kroton Educacional & Porto Seguro \\
\hline Arteris & Ecorodovias & Light & Qualicorp \\
\hline B2W Companhia Digital & Eletrobrás Participações & LLX Log & Raia Drogasil \\
\hline Banrisul & Eletropaulo & Localiza Rent a Car & Randon \\
\hline BM\&FBovespa & Embraer & Lojas Americanas & Rossi Residencial \\
\hline BR Malls Participações & EDP - Energias do Brasil & Lojas Renner & Sabesp \\
\hline BR Properties & Eneva & M. Dias Branco & CIA Siderúrgica \\
\hline BCO Bradesco & Equatorial Energia & Magazine Luiza & Souza Cruz \\
\hline BCO Brasil & Estácio Participações & Marcopolo & Sul América \\
\hline BCO Santander & Even & Marfrig Global Foods & Suzano Papel e Celulose \\
\hline Bradespar & Eztec & Mills & Taesa \\
\hline Braskem & Fibria Celulose & Minerva & Telefônica Brasil \\
\hline BRF-Brasil Foods & Gafisa & MMX & TIM Participações \\
\hline Brookfield Incorporações & Gerdau & MRV & Totvs \\
\hline CCR & Gerdau Metalúrgica & Multiplan & Tractebel Energia \\
\hline Cemig & Gol & Multiplus & Ultrapar Participações \\
\hline Cetip & HRT Petróleo & Natura Cosméticos & Usiminas \\
\hline CIA Hering & Hypermarcas & Odontoprev & Vale \\
\hline Cielo & Iguatemi & OGX Petróleo e Gás & Valetron \\
\hline Copasa & lochpe Maxion & $\mathrm{Ol}$ & Valid \\
\hline Copel & Itausa Investimentos Itaú & Pão de Açúcar - CBD & Weg \\
\hline Cosan & & & \\
\hline
\end{tabular}

Fonte: Dados da pesquisa.

Verificou-se em todos os relatórios divulgados pelas empresas da amostra nos anos de 2010 a 2013, seja no Relatório Anual (RA) ou no Relatório de Sustentabilidade (RS), as informações apresentadas sobre as Emissões, Efluentes, Resíduos, Produtos/ Serviços e Transportes. Os dados coletados foram inseridos em planilhas do software excel a partir da interpretação das diretrizes do GRI, na qual constam os aspectos, seus critérios e subcritérios, a descrição de cada um destes e os níveis de divulgação que foram verificados em cada relatório de cada empresa analisada.

Vale destacar que esses critérios e subcritérios apresentam diferentes escalas ordinais para expressar ordem entre os níveis, conforme o desempenho a ser medido em cada critério, o que possibilita a atribuição de até oito níveis distintos. Destaca-se que os níveis, escalas, foram criados a partir da interpretação de todas as informações apresentadas sobre cada aspecto analisado nas diretrizes do GRI (2013).

As escalas utilizadas variam entre 1 a no máximo 8, dependendo do aspecto analisado, visto que alguns dos aspectos e seus critérios e subcritérios necessitam de escalas diferenciadas entre si, pois são informações distintas. Na Figura 1 são apresentados os aspectos e a devida mensuração e descrição dos critérios e subcritérios. 
Figura 1 - Indicadores de Evidenciação Ambiental

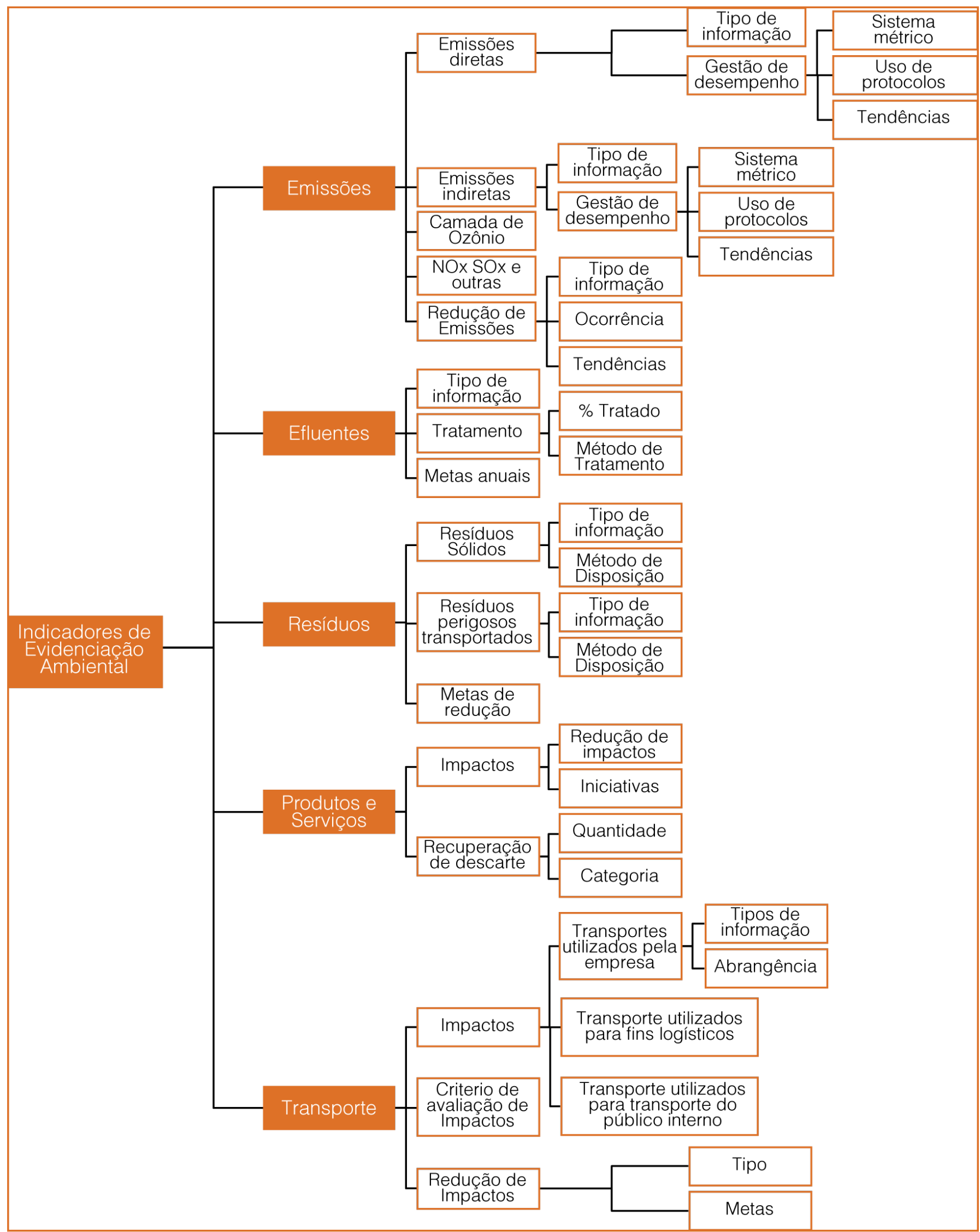

Fonte: Adaptado do GRI (2013). 
$\mathrm{Na}$ planilha eletrônica do software excel, foram preenchidos ao lado de cada critério e subcritério, seu devido nível. A análise referente aos níveis para cada empresa da amostra foi realizada em cada ano analisado e referente a cada relatório (RS e RA) de forma separada.

Depois de verificados e preenchidos todos os níveis de evidenciação das empresas sobre os aspectos analisados tanto no Relatório Anual como no Relatório de Sustentabilidade os dados foram tabulados de acordo com o nível de N1 a N8 para 1 a 8. Na sequência, foram somados os níveis dos Relatórios de Sustentabilidade com os níveis dos Relatórios Anuais de cada empresa analisada para se obter o peso, o grau de evidenciação ambiental individual, de cada ano, a partir do método T-ODA. Caso a empresa não divulgasse os seus relatórios (RS e RA), considerou-se que esta tivesse um nível de divulgação 1 (N1) para todos os critérios e subcritérios, o que é considerado um nível comprometedor de evidenciação ambiental.

\section{MÉTODOT-ODA}

No método de análise multicritério Trade-Off Decision Analysis (T-ODA) inicialmente deve- se estabelecer a importância de cada critério para comparar cada critério com os demais (MEIRELES; SANCHES, 2009). Na construção e utilização de um modelo que estabelece prioridades, fundamentado no T-ODA, temse as seguintes etapas: a especificação do objetivo da decisão; a definição de critérios para tomar decisões; a definição da função objetivo; a comparação pivô; a comparação consistente dos critérios; a ponderação consistente dos critérios; o peso relativo dos fatores; e o cálculo da função objetivo e escolha.

A ponderação dos critérios é fundamental seja qual for o método utilizado. Na etapa comparação pivô o peso dos critérios é tratado como determinístico na avaliação das alternativas. Essa ponderação dos critérios é feita por meio de uma escala Trade Off e atende algumas etapas. Inicialmente é preciso fazer uma comparação de um critério, considerado pivô, com os demais critérios analisados. Para esses outros critérios é estabelecido um peso que seja comparativo com o critério pivô (MEIRELES; SANCHES, 2009). A atribuição dos valores para as avaliações das importâncias relativas de cada critério é apresentada por Meireles e Sanches (2009) da seguinte forma, como observado no Quadro 2.

Quadro 2 - Avaliação e valor dos critérios

\begin{tabular}{|l|l|}
\hline Avaliação & Valor \\
\hline Extremamente preferida & 3.000 \\
\hline Fortemente preferida & 2.000 \\
\hline Moderadamente preferida & 1.200 \\
\hline Igualmente preferida & 1.000 \\
\hline Moderadamente inferior & 0.833 \\
\hline Fortemente inferior & 0.500 \\
\hline Extremamente inferior & 0.333 \\
\hline
\end{tabular}

Fonte: Meireles e Sanches (2009).

Como neste estudo tem-se os aspectos de acordo com as diretrizes do GRI (2013), divididos em critérios e subcritérios, é necessário fazer essa avaliação e atribuir valores a todos estes critérios e subcritérios que serão analisados. No Quadro 2 é possível visualizar que parte-se do pivô (igualmente preferida) para estabelecer a comparação com os demais critérios de forma consistente. Conforme Meireles e Sanches (2009), este quadro deve ser entendido como uma orientação e está subordinado a valores que eventualmente foram medidos ou captados de alguma maneira.

O valor dos critérios não seguiu a proposta de Meireles e Sanches (2009). Estes foram obtidos por meio de uma adaptação em que se calculou o valor da informação para cada um dos aspectos analisados (emissões, efluentes, resíduos, produtos e serviços e transporte). Como aspecto pivô utilizou-se o valor da informação calculado para emissões e os demais pesos são relativos a este aspecto. Diante disso, a partir da Tabela 1 apresentam-se os aspectos e seus respectivos pesos utilizados no presente estudo em cada ano analisado. 
Tabela 1 - Aspectos e pesos relativos

\begin{tabular}{|c|c|c|c|c|c|}
\hline \multirow{2}{*}{\multicolumn{2}{|c|}{$\begin{array}{l}\text { Aspectos } \\
2010\end{array}$}} & \multicolumn{4}{|l|}{ Pesos } \\
\hline & & 2011 & 2012 & \multicolumn{2}{|l|}{2013} \\
\hline \multicolumn{2}{|l|}{ Emissões* } & 1,0000 & 1,0000 & 1,0000 & 1,0000 \\
\hline Efluentes & 0,8962 & 0,3692 & 0,4404 & 0,4597 & \\
\hline Resíduos & 1,6406 & 1,1486 & 0,9575 & 1,3365 & \\
\hline Produtos e Serviço & 1,3132 & 0,9647 & 1,1137 & 1,9097 & \\
\hline Transporte & 0,0805 & 0,0615 & 0,0688 & 0,0598 & \\
\hline
\end{tabular}

${ }^{\star}$ ) Critério pivô

Fonte: Meireles e Sanches 2009).

Com o intuito de aclarar o método T-ODA, é apresentado um exemplo em que são tomadas oito empresas, que serão ranqueadas segundo dois grupos de perguntas. O primeiro aspecto é composto por três critérios/ subcritérios e o segundo por dois critérios/subcritérios.
Os dados são meramente ilustrativos, não possuindo qualquer relação com os valores coletados neste estudo. O modelo busca identificar 'quanto maior, melhor'.

Quadro 3 - Exemplo: Passo 1

\begin{tabular}{|l|l|l|l|l|l|l|}
\hline Empresa & Q1_A1 & Q2_A1 & Q3_A1 & 0 & 4 \\
\hline Empresa_1 & 4 & 2 & 0 & 7 & 3 \\
\hline Empresa_2 & 5 & 1 & 0 & 3 & 6 \\
\hline Empresa_3 & 6 & 3 & 1 & 6 & 7 \\
\hline Empresa_4 & 5 & 2 & 1 & 2 & 6 \\
\hline Empresa_5 & 2 & 3 & 0 & 3 & 5 \\
\hline Empresa_6 & 6 & 2 & 1 & 1 & 4 \\
\hline Empresa_7 & 5 & 1 & 0 & 5 & 3 \\
\hline Empresa_8 & 1 & 2 & & \\
\hline
\end{tabular}

Fonte: Dados da pesquisa.

Antes da inicialização do método T-ODA foi necessária uma preparação prévia dos dados para a verificação da importância de cada informação. Essa preparação seguiu a metodologia adota por Krylovas et al. (2014, p. 1124). A verificação do peso de cada informação no bloco (A1 e A2), foi obtida somando os pontos de cada coluna como pode ser visualizado no Quadro 4. 
Quadro 4 - Exemplo: Passo 2

\begin{tabular}{|l|l|l|l|l|l|l|}
\hline Empresa & Q1_A1 & Q2_A1 & Q3_A1 & Q1_A2 & Q2_A2 \\
\hline Empresa_1 & 4 & 2 & 0 & 8 & 4 \\
\hline Empresa_2 & 5 & 1 & 0 & 7 & 3 \\
\hline Empresa_3 & 6 & 3 & 0 & 3 & 6 \\
\hline Empresa_4 & 5 & 2 & 1 & 6 & 7 \\
\hline Empresa_5 & 2 & 3 & 1 & 2 & 6 \\
\hline Empresa_6 & 6 & 2 & 0 & 3 & 5 \\
\hline Empresa_7 & 5 & 1 & 1 & 1 & 4 \\
\hline Empresa_8 & 1 & 2 & 0 & 5 & 3 \\
\hline Soma & 34 & 16 & 3 & 39 & 38 \\
\hline
\end{tabular}

Fonte: Dados da pesquisa.

Os somatórios de cada coluna foram acumulados para cada aspecto, totalizando: $\sum A 1=53$ e $\sum A 2=$ 77. Em seguida as somas de cada coluna foram dividas pela soma do aspecto, obtendo-se: $w_{1,1}=$ 0,$642 ; w_{2,1}=0,302 ; w_{3,1}=0,056 ; w_{1,2}=0,506 ; w_{2,2}$ $=0,494$. A soma dos pesos de cada aspecto resulta em 1.

A seguir os dados iniciais foram unificados em dois aspectos, por meio de uma média ponderada em que os valores $w_{i, j}$ (i é a questão, j é o aspecto) foram utilizados. Após foram calculadas as variâncias de cada aspecto e por meio desta, calculado o peso de cada um dos aspectos. O método T-ODA possui critérios de peso comparativo, conforme apresentado no Quadro 16, tendo como referência o pivô. Meireles e Sanches (2009, p. 42) sustentam que ela é "orientativa e subordina-se a valores eventualmente medidos e captados de alguma forma".

Com o peso dos critérios é possível estabelecer a relação de Trade-Off (RTO) e o inverso da relação Trade-Off (iRTO) do método T-ODA.

Quadro 5 - Exemplo: Passo 3

\begin{tabular}{|l|l|l|}
\hline Empresa & A1 & A2 \\
\hline Empresa_1 & 3,169 & 6,026 \\
\hline Empresa_2 & 3,509 & 5,026 \\
\hline Empresa_3 & 4,755 & 4,481 \\
\hline Empresa_4 & 3,868 & 6,494 \\
\hline Empresa_5 & 2,245 & 3,974 \\
\hline Empresa_6 & 4,452 & 6,013 \\
\hline Empresa_7 & 3,566 & 2,241 \\
\hline Empresa_8 & 1,245 & 4,013 \\
\hline Variância & 1,316 & 1,811 \\
\hline Valor do Critério (\%) & 42,1 & 57,9 \\
\hline
\end{tabular}

Fonte: Dados da pesquisa. 
A seguir é apresentada a matriz de priorização correspondente (os valores do RTO e iRTO). Como há apenas dois aspectos estes são calculados como sendo: $\frac{0,421}{0,579}=0,727$ e $\frac{0,579}{0,421}=1,375$
Por meio destes obtém-se a comparação consistente dos aspectos conforme demonstrado no Quadro 6.

Quadro 6 - Exemplo: Passo 4

\begin{tabular}{|l|lll|l|l|}
\hline RTO/iRTO & Aspecto-1 & Aspecto-2 & \multicolumn{2}{l}{ Soma } & \multicolumn{2}{l|}{ Peso } \\
\hline Aspecto-1 & & 0,727 & 0,727 & 0,346 \\
\hline Aspecto-2 & 1,375 & & 1,375 & 0,654 \\
\hline Soma & 1,375 & 0,727 & 2,102 & 1 \\
\hline
\end{tabular}

Fonte: Dados da pesquisa.

Como o aspecto geral (quanto maior melhor) já foi estabelecido, o problema é reduzido em determinar o valor máximo da seguinte expressão:

$$
\text { Função Objetivo }=\operatorname{Max}\left\{\begin{array}{l}
E_{1}=0,346 A_{1,1}+0,654 A_{2,1} \\
E_{2}=0,346 A_{1,2}+0,654 A_{2,2} \\
E_{3}=0,346 A_{1,3}+0,654 A_{2,3} \\
E_{4}=0,346 A_{1,4}+0,654 A_{2,4} \\
E_{5}=0,346 A_{1,5}+0,654 A_{2,5} \\
E_{6}=0,346 A_{1,6}+0,654 A_{2,6} \\
E_{7}=0,346 A_{1,7}+0,654 A_{2,7} \\
E_{8}=0,346 A_{1,8}+0,654 A_{2,8}
\end{array}\right.
$$

Para resolver o sistema é necessário introduzir os aspectos com seus pesos normalizados. O exemplo tomou como pivô (valor de referência) a Empresa-1, a análise do primeiro aspecto. O resultado da análise da relação Trade-Off do primeiro aspecto ficou estabelecido de acordo com o que consta no Quadro
7

Quadro 7 - Exemplo: Passo 5

\begin{tabular}{|l|l|l|}
\hline Empresa & Aspecto & \multicolumn{1}{l|}{ Índice } \\
\hline E-1 & 3,169 & 1 \\
\hline E-2 & 3,509 & 1,107 \\
\hline E-3 & 4,755 & 1,500 \\
\hline E-4 & 3,868 & 1,220 \\
\hline E-5 & 2,245 & 0,708 \\
\hline E-6 & 4,452 & 1,405 \\
\hline E-7 & 3,566 & 1,125 \\
\hline E-8 & 1,245 & 0,393 \\
\hline
\end{tabular}

Fonte: Dados da pesquisa.

A seguir, por meio do Quadro 8 é apresentada a matriz com os valores RTO e iRTO.

Quadro 8 - Exemplo: Passo 6

\begin{tabular}{|llll|l|l|l|l|l|l|l|l|l|l|}
\hline RTO & E-1 & E-2 & E-3 & E-4 & \multicolumn{1}{l}{ E-5 } & E-6 & E-7 & Eoma & $\%$ \\
\hline E-1 & & 0,903 & 0,667 & 0,820 & 1,412 & 0,712 & 0,889 & 2,544 & 7,947 & 11,7 \\
\hline E-2 & 1,107 & & 0,738 & 0,907 & 1,564 & 0,788 & 0,984 & 2,817 & 8,905 & 13,2 \\
\hline E-3 & 1,500 & 1,355 & & 1,230 & 2,119 & 1,067 & 1,333 & 3,817 & 12,421 & 18,4 \\
\hline E-4 & 1,220 & 1,102 & 0,813 & & 1,723 & 0,868 & 1,084 & 3,104 & 9,914 & 14,6 \\
\hline E-5 & 0,708 & 0,640 & 0,472 & 0,580 & & 0,504 & 0,629 & 1,801 & 5,334 & 7,9 \\
\hline E-6 & 1,405 & 1,269 & 0,937 & 1,152 & 1,984 & & 1,249 & 3,575 & 11,571 & 17,1 \\
\hline E-7 & 1,125 & 1,016 & 0,750 & 0,922 & 1,589 & 0,801 & & 2,863 & 9,066 & 13,4 \\
\hline E-8 & 0,393 & 0,355 & 0,262 & 0,322 & 0,555 & 0,280 & 0,349 & & 2,516 & 3,7 \\
\hline
\end{tabular}

Fonte: Dados da pesquisa. 
O mesmo acontece com o segundo aspecto (A2), em que as empresas são comparadas entre si. Também a Empresa-1 é utilizada como pivô.

Quadro 9 - Exemplo: Passo 7

\begin{tabular}{|l|l|l|}
\hline Empresa & \multicolumn{1}{|l|}{ Fator } & 1 \\
\hline E-1 & 6,026 & 0,834 \\
\hline E-2 & 5,026 & 0,744 \\
\hline E-3 & 4,481 & 1,077 \\
\hline E-4 & 6,494 & 0,659 \\
\hline E-5 & 3,974 & 0,998 \\
\hline E-6 & 6,013 & 0,372 \\
\hline E-7 & 2,241 & 0,666 \\
\hline E-8 & 4,013 & \\
\hline
\end{tabular}

Fonte: Dados da pesquisa.

De similar modo é apresentada a matriz com os valores RTO e iRTO do segundo aspecto, de acordo com o Quadro 10.

Quadro 10 - Exemplo: Passo 8

\begin{tabular}{|l|l|l|l|l|l|l|l|l|l|l|l|}
\hline RTO & \multirow{2}{*}{ E-1 } & E-2 & E-3 & E-4 & E-5 & E-6 & E-7 & E-8 & Soma & \% \\
\hline E-1 & & 1,199 & 1,344 & 0,929 & 1,517 & 1,002 & 2,688 & 1,502 & & 16,2 \\
\hline E-2 & 0,834 & & 1,121 & 0,774 & 1,266 & 0,836 & 2,242 & 1,252 & 8,325 & 13,2 \\
\hline E-3 & 0,744 & 0,892 & & 0,691 & 1,129 & 0,745 & 2,000 & 1,117 & 7,318 & 11,6 \\
\hline E-4 & 1,077 & 1,291 & 1,448 & & 1,634 & 1,079 & 2,895 & 1,617 & & 17,5 \\
\hline E-5 & 0,659 & 0,790 & 0,886 & 0,612 & & 0,660 & 1,772 & 0,854 & 6,233 & 9,9 \\
\hline E-6 & 0,998 & 1,197 & 1,341 & 0,927 & 1,514 & & 2,683 & 1,498 & & 16,1 \\
\hline E-7 & 0,372 & 0,446 & 0,500 & 0,345 & 0,564 & 0,373 & & 0,559 & 3,159 & 5,0 \\
\hline E-8 & 0,666 & 0,799 & 0,896 & 0,618 & 1,170 & 0,667 & 1,790 & & 6,606 & 10,5 \\
\hline
\end{tabular}

Fonte: Dados da pesquisa.

A pontuação de cada empresa fica assim estabelecida.

$$
\text { Pontuação }=\left\{\begin{array}{c}
E_{1}=0,346 \times 11,7+0,654 \times 16,2=14,643 \\
E_{2}=0,346 \times 13,2+0,654 \times 13,2=13,2 \\
E_{3}=0,346 \times 18,4+0,654 \times 11,6=13,953 \\
E_{4}=0,346 \times 14,6+0,654 \times 17,5=16,497 \\
E_{5}=0,346 \times 7,9+0,654 \times 9,9=9,208 \\
E_{6}=0,346 \times 17,1+0,654 \times 16,1=16,446 \\
E_{7}=0,346 \times 13,4+0,654 \times 5,0=7,906 \\
E_{8}=0,346 \times 3,7+0,654 \times 10,5=8,147
\end{array}\right.
$$

A leitura do ranking é feita em ordem decrescente, assim a ordenação formada segue a sequência:
Empresa-4 (16,497 pontos), Empresa-6 (16,446 pontos), Empresa-1 (14,643 pontos), Empresa-2 (13,2 pontos), Empresa-3 (13,953 pontos), Empresa-5 (9,208 pontos), Empresa-8 (8,147 pontos) e Empresa-7 (7,906 pontos).

Este mesmo conjunto de procedimentos foi utilizado com as 97 empresas analisadas e com os cinco aspectos que apresentam diversos critérios e subcritérios. 


\section{DESCRIÇÃO E ANÁLISE DOS DADOS}

De posse dos rankings anuais, foi estabelecido um ranking geral em relação ao grau de evidenciação das empresas analisadas e o período. Para constituir esse ranking geral a partir dos rankings parciais (anuais), verificou-se a evolução das organizações durante os quatro anos analisados por meio de um sistema de pontos corridos.

$\mathrm{Na}$ Tabela 2 apresenta-se o score obtido a partir do método T-ODA e o ranking das empresas analisadas no que diz respeito à evidenciação ambiental nos quatro anos analisados e sua posição final.

Tabela 2 - Grau de evidenciação e ranking de evidenciação ambiental

\begin{tabular}{|c|c|c|c|c|c|c|c|c|c|}
\hline \multirow{2}{*}{ Empresas } & \multicolumn{2}{|l|}{2010} & \multicolumn{2}{|l|}{2011} & \multicolumn{2}{|l|}{2012} & \multicolumn{2}{|l|}{2013} & \multirow{2}{*}{$\begin{array}{l}\text { Ranking } \\
\text { final } \\
\text { Posição }\end{array}$} \\
\hline & Score & Posição & Score & Posição & Score & Posição & Score & Posição & \\
\hline Duratex & 4,0110 & 2 & 3,6753 & 1 & 2,8970 & 7 & 3,4020 & 5 & 1 \\
\hline Ecorodovias & 3,6690 & 3 & 3,0220 & 5 & 3,1233 & 4 & 3,4130 & 4 & 2 \\
\hline Energias BR & 3,6463 & 4 & 3,4816 & 3 & 2,7618 & 8 & 3,0298 & 9 & 3 \\
\hline P. Açúcar & 2,8840 & 7 & 3,0602 & 4 & 2,5780 & 10 & 3,2265 & 7 & 4 \\
\hline Copel & 3,3301 & 5 & 3,5445 & 2 & 2,5144 & 11 & 2,6049 & 11 & 5 \\
\hline Cemig & 2,1130 & 16 & 2,0971 & 18 & 2,9250 & 6 & 3,4886 & 2 & 6 \\
\hline BM\&FBovespa & 2,8048 & 9 & 2,6021 & 12 & 2,4131 & 12 & 2,7756 & 10 & 7 \\
\hline Natura & 2,1617 & 15 & 2,8144 & 9 & 2,9553 & 5 & 2,3243 & 14 & 7 \\
\hline Petrobrás & 2,7951 & 10 & 2,7532 & 10 & 2,1337 & 20 & 2,1783 & 16 & 9 \\
\hline AES Tietê & 2,8054 & 8 & 2,5774 & 13 & 2,1483 & 19 & 2,1717 & 17 & 10 \\
\hline Braskem & 1,9786 & 20 & 1,7136 & 29 & 3,2221 & 2 & 3,3818 & 6 & 10 \\
\hline Eletrobrás & 1,2503 & 41 & 2,4140 & 15 & 3,1655 & 3 & 3,8811 & 1 & 12 \\
\hline BRF - Brasil Foods & 3,2604 & 6 & 3,0056 & 6 & 3,3789 & 1 & 0 & 48 & 13 \\
\hline Even & 1,8702 & 24 & 2,6339 & 11 & 2,2560 & 14 & 2,3051 & 15 & 14 \\
\hline Copasa & 2,3085 & 14 & 2,9639 & 7 & 2,0736 & 21 & 1,1165 & 42 & 15 \\
\hline Eletropaulo & 2,4661 & 11 & 1,7516 & 27 & 1,8767 & 29 & 2,1280 & 20 & 16 \\
\hline JBS & 1,2542 & 40 & 1,4042 & 39 & 2,6958 & 9 & 3,4760 & 3 & 17 \\
\hline Klabin & 2,3863 & 12 & 2,5596 & 14 & 1,8714 & 30 & 1,6727 & 36 & 18 \\
\hline Banco Bradesco & 2,0454 & 17 & 2,0913 & 19 & 1,7117 & 36 & 2,0140 & 23 & 19 \\
\hline Vale & 1,5793 & 30 & 1,5092 & 34 & 2,1522 & 17 & 2,1445 & 19 & 20 \\
\hline CPFL Energia & 1,9108 & 22 & 1,9214 & 22 & 1,7116 & 37 & 2,0655 & 21 & 21 \\
\hline $\mathrm{CCR}$ & 1,9908 & 19 & 1,4067 & 38 & 2,1513 & 18 & 1,8427 & 31 & 22 \\
\hline Embraer & 0 & 52 & 2,2896 & 16 & 2,0563 & 22 & 2,1693 & 18 & 23 \\
\hline Souza cruz & 1,6338 & 29 & 0 & 52 & 2,2028 & 16 & 2,5975 & 12 & 24 \\
\hline Tractebel & 2,3342 & 13 & 2,1899 & 17 & 1,7835 & 33 & 0,8718 & 47 & 25 \\
\hline Ambev & 4,8399 & 1 & 2,9477 & 8 & 0 & 55 & 0 & 48 & 26 \\
\hline Lojas Renner & 1,2806 & 37 & 1,0748 & 46 & 1,9484 & 26 & 3,1769 & 8 & 27 \\
\hline Suzano Papel & 1,9430 & 21 & 1,7894 & 24 & 2,0188 & 24 & 0 & 48 & 27 \\
\hline Weg & 1,1986 & 43 & 2,0636 & 20 & 1,9595 & 25 & 1,7577 & 33 & 29 \\
\hline Fibria & 1,8705 & 23 & 1,7055 & 30 & 1,5422 & 40 & 1,8175 & 32 & 30 \\
\hline Sabesp & 1,7421 & 26 & 1,7419 & 28 & 1,3302 & 45 & 1,9630 & 27 & 31 \\
\hline Tim Participações & 1,4720 & 31 & 1,4546 & 37 & 2,3818 & 13 & 0 & 48 & 32 \\
\hline Sul América & 2,0198 & 18 & 1,8843 & 23 & 1,5138 & 41 & 0 & 48 & 33 \\
\hline
\end{tabular}




\begin{tabular}{|c|c|c|c|c|c|c|c|c|c|}
\hline \multirow{2}{*}{ Empresas } & \multicolumn{2}{|l|}{2010} & \multicolumn{2}{|l|}{2011} & \multicolumn{2}{|l|}{2012} & \multicolumn{2}{|l|}{2013} & \multirow{2}{*}{$\begin{array}{l}\text { Ranking } \\
\text { final } \\
\text { Posição }\end{array}$} \\
\hline & Score & Posição & Score & Posição & Score & Posição & Score & Posição & \\
\hline Banco do Brasil & 1,6382 & 28 & 0 & 52 & 1,8013 & 32 & 2,0054 & 25 & 34 \\
\hline Marfrig & 1,1554 & 48 & 1,0586 & 49 & 2,0257 & 23 & 2,0372 & 22 & 35 \\
\hline Porto Seguro & 1,4153 & 33 & 0 & 52 & 1,2457 & 46 & 2,4484 & 13 & 36 \\
\hline Light & 1,3814 & 35 & 0 & 52 & 1,8460 & 31 & 1,9431 & 28 & 37 \\
\hline Marcopolo & 0 & 52 & 1,7801 & 26 & 1,4614 & 42 & 1,9337 & 29 & 38 \\
\hline Itaú Unibanco & 1,4124 & 39 & 1,3382 & 44 & 1,2371 & 47 & 2,0134 & 24 & 39 \\
\hline Santander & 0 & 52 & 0 & 52 & 2,2444 & 15 & 1,7287 & 35 & 39 \\
\hline Ultrapar & 1,4598 & 32 & 1,5448 & 32 & 1,3699 & 44 & 0 & 48 & 41 \\
\hline Cosan & 0 & 52 & 0 & 52 & 1,8947 & 27 & 1,9844 & 26 & 42 \\
\hline Banrisul & 0 & 52 & 1,7849 & 25 & 1,4302 & 43 & 1,6183 & 38 & 43 \\
\hline Multiplant & 1,2767 & 38 & 2,0353 & 21 & 0,9599 & 52 & 0 & 48 & 44 \\
\hline Randon Part. & 0 & 52 & 1,6880 & 31 & 1,8936 & 28 & 0 & 48 & 44 \\
\hline Gol & 1,8121 & 25 & 1,5283 & 33 & 0 & 55 & 0 & 48 & 46 \\
\hline Oi & 0 & 52 & 0 & 52 & 1,7127 & 35 & 1,8494 & 30 & 47 \\
\hline Itausa & 1,2666 & 34 & 1,1124 & 41 & 0 & 55 & 1,0730 & 44 & 48 \\
\hline Hypermarcas & 1,1554 & 47 & 1,0798 & 45 & 1,0937 & 51 & 1,7488 & 34 & 49 \\
\hline Valetron & 1,3698 & 36 & 1,3863 & 40 & 0 & 55 & 0 & 48 & 50 \\
\hline Rossi Resid. & 1,6881 & 27 & 0 & 52 & 0 & 55 & 0 & 48 & 51 \\
\hline Telefônica Brasil & 1,1379 & 49 & 1,0507 & 50 & 1,6335 & 38 & 0,9525 & 45 & 51 \\
\hline Estácio Part. & 0 & 52 & 0 & 52 & 1,5712 & 39 & 1,3026 & 40 & 53 \\
\hline MRV & 1,1677 & 45 & 1,2082 & 42 & 1,1214 & 50 & 0 & 48 & 54 \\
\hline Cielo & 0 & 52 & 0 & 52 & 1,7824 & 34 & 0 & 48 & 55 \\
\hline Cyrela Realty & 1,1554 & 46 & 1,0586 & 48 & 0,8693 & 53 & 1,4921 & 39 & 55 \\
\hline Lojas Americanas & 1,1677 & 44 & 1,0745 & 47 & 1,1581 & 49 & 0 & 48 & 57 \\
\hline Sid nacional & 1,2299 & 42 & 1,1132 & 43 & 0 & 55 & 0 & 48 & 57 \\
\hline Valid & 0 & 52 & 1,4945 & 35 & 0 & 55 & 0 & 48 & 59 \\
\hline Minerva & 0 & 52 & 1,4888 & 36 & 0 & 55 & 0 & 48 & 60 \\
\hline Gerdau & 0 & 52 & 0 & 52 & 0 & 55 & 1,6198 & 37 & 61 \\
\hline Dasa & 0 & 52 & 0 & 52 & 0,8693 & 54 & 1,2724 & 41 & 62 \\
\hline Magazine Luiza & 0 & 52 & 0 & 52 & 1,2215 & 48 & 0 & 48 & 63 \\
\hline Taesa & 0 & 52 & 0 & 52 & 0 & 55 & 1,0940 & 43 & 64 \\
\hline ALL Amer. Lat. Log. & 1,1225 & 51 & 1,0305 & 51 & 0 & 55 & 0 & 48 & 65 \\
\hline Arteris & 0 & 52 & 0 & 52 & 0 & 55 & 0,8865 & 46 & 65 \\
\hline Gafisa & 1,1319 & 50 & 0 & 52 & 0 & 55 & 0 & 48 & 65 \\
\hline
\end{tabular}

Fonte: Dados da pesquisa.

Inicialmente destaca-se que 67 empresas das 97 apresentaram pelo menos uma informação ambiental em seus Relatórios Anuais e de Sustentabilidade. As demais, ou seja, 30 empresas obtiveram score igual a zero em todos os anos analisados, ficando com a última posição no ranking de evidenciação ambiental e, estas não foram apresentadas no ranking. Isso demonstra que um grande número de empresas não está divulgando informações suficientes sobre os aspectos ambientais em seus relatórios. 
Conforme a Tabela 2, observa-se que em relação ao resultado do método T-ODA (score) obteve-se o grau de evidenciação e destacam-se as empresas que lideraram o ranking em cada ano: Ambev (2010), Duratex (2011), BRF Brasil Foods (2012) e a Eletrobrás (2013). No ano de 2010 verificou-se o maior grau, se comparado aos demais períodos. Além disso, neste mesmo ano e em 2011, 51 empresas divulgaram informações ambientais em seus relatórios. Em 2012 foram 54 empresas que apresentaram alguma informação ambiental e no último ano, (2013), apenas 47.

Salienta-se que as empresas Duratex, Ecorodovias, Energias BR e Pão de Açúcar ficaram classificadas nas posições iniciais no ranking em todos os anos analisados, no que diz respeito ao grau de evidenciação ambiental. Estas empresas são as que mais evidenciaram informações sobre as emissões, efluentes, resíduos, produtos e serviços e transportes neste período. Das vinte empresas melhor posicionadas no ranking de cada ano, foi possível constatar que a maioria destas apenas mudava a sua colocação de um ano para o outro.

\section{CONCLUSÃO}

Conclui-se que as empresas podem aumentar o grau de evidenciação ambiental se divulgarem mais informações em seus relatórios sobre suas ações no meio ambiente, principalmente sobre o aspecto transporte, visto que poucas das empresas analisadas apresentam essa informação em seus relatórios. Dessa forma, passarão a transmitir uma imagem ainda melhor à sociedade. Destaca-se que as empresas não possuem um padrão de divulgação nos seus relatórios sobre as informações ambientais, visto que estas possuem comportamentos diferentes umas das outras e, divulgam diferentes informações de um ano para o outro, o que indica seleção de informações para a divulgação ambiental. Entende-se que o nível de divulgação é insuficiente e algumas das causas são a falta de divulgação das práticas ambientais, a ineficiência de controles e a falta de motivação para divulgação, o que representa uma lacuna de pesquisa.

\section{REFERÊNCIAS}

[1] ALBERTINI, E. A descriptive analysis of environmental disclosure: A longitudinal study of French companies. Journal of Business Ethics, v. 121, n. 2, p. 233-254, 2013.

[2] COSTA, R S. Evidenciação Contábil das Informações Ambientais: Uma Análise das Empresas do Setor de Papel e Celulose da BOVESPA. 2006. 146 f. Dissertação (Mestrado em Ciências Contábeis e Atuárias) - Pontifícia Universidade Católica de São Paulo: PUC-SP, Programa de Estudos PósGraduados em Ciências Contábeis e Financeiras, São Paulo, 2006.

[3] GARCÍA-SÁNCHEZ, I.M.; FRÍAS-ACEITUNO, J. V; RODRÍGUEZ-DOMÍNGUEZ, L. Determinants of corporate social disclosure in Spanish local governments. Journal of Cleaner Production, v. 39, p. 60-72, 2013.

[4] GRI. Global Reporting Initiative. Elaboração de relatórios de sustentabilidade. 2013. Disponível em: <https://www.globalreporting.org/languages/Portuguesebrazil/ Pages/Elaboração-de-relatórios-de- sustentabilidade.aspx>. Acesso em: 13 Set. 2014.

[5] KRESPI, N. T; UTZIG, M. J. S.; DALLABONA, L. F.; SCARPIN, J. E. Disclosure of information environmental analysis under the social aspect of companies listed on ISE. Custos e @gronegócio on line, v. 8, n. 4, p. 147-170, 2012.

[6] KRYLOVAS, A.; ZAVADSKAS, E. K.; KOSAREVA, N.; DADELO, S. New KEMIRA Method for

Determining Criteria Priority and Weights in Solving MCDM Problem. International Journal of Information Technology \& Decision Making, v. 13, n. 06, p. 1119-1133, 2014.

[7] MEIRELES, M; SANCHES, C. ST-ODA: Strategic Trade-Off Decision Analysis - Processo de tomada de decisões gerenciais multicritério subordinadas à vantagem competitiva. 1. Ed. São Paulo: FACCAMP, 2009.

[8] MENG, X. H.; ZENG, S. X.; TAM, C. M.; XU, X. D. Whether top executives' turnover influences environmental responsibility: From the perspective of environmental information disclosure. Journal of business ethics, v. 114, n. 2, p. 341-353, 2013

[9] NOSSA, V. Disclosure ambiental: uma análise do conteúdo dos relatórios ambientais de empresas do setor de papel e celulose em nível internacional. São Paulo, 2002. 249 f. Tese (Doutorado em Ciências Contabéis) - Programa de Pós-Graduação em Ciências Contabéis, Departamento de Contabilidade e Atuária, Faculdade de Economia, Administração e Contabilidade da Universidade de São Paulo, São Paulo, 2002.

[10] OLIVEIRA, A. F.; MACHADO, D. G.; BEUREN, I. M. Disclosure Ambiental de Empresas de Setores Potencialmente Poluidores Listadas no Índice de Sustentabilidade Empresarial (ISE). Revista de Gestão Social e Ambiental, v. 6, n. 1, p. 20-37 2012. 
[11] ROSA, F. S.; GUESSER, T.; HEIN, N.; PFITSCHER, E. D.; LUNKES, R. J. L. Environmental impact management of Brazilian companies: analyzing factors that influence disclosure of waste, emissions, effluents, and other impacts. Journal of Cleaner Production, p. 1-13, 2013.

[12] ROSA, F. S.; LUNKES, R. J.; HEIN, N.; VOGT, M., DEGENHART, L. Analysis of the determinants of disclosure of environmental impacts of Brazilian companies. Global Advanced Research Journals, vol. 3, n. 6, p. 249-266, 2014.

[13] ROSSONI, C. F. Decisão Multicritério - Uma pesquisa experimental para avaliação da percepção dos gestores de MPE acerca do modelo de tomada de decisão multicritério T-ODA quanto à sua aplicabilidade. 2011 . 241

f. Dissertação (Mestrado em Administração)-Faculdade Campo Limpo Paulista - FACCAMP, Programa de Mestrado em Administração, Campo Limpo Paulista, 2011.
[14] VILLIERS, C.; LOW, M.; SAMKIN, G. The institutionalisation of mining company sustainability disclosures. Journal of Cleaner Production, p. 1-8, 2014.

[15] WANG, H.; BERNELL, D. Environmental Disclosure in China: An Examination of the Green Securities Policy. The Journal of Environment \& Development, v. 22, n. 4, p. 339369, 2013 


$$
\text { Alutary }
$$




\section{Hélcio Martins Tristão (Organizador)}

Possui graduação em Cîencias Êconômicas pelo Centro Universitário de Franca (1985), especialização em gestão, contabilidade e recursos humanos, mestrado em Administração pelo Centro Universitário de Franca (2000), doutorado em Engenharia de Produção pelo Programa de Pós-graduação do Departamento de Engenharia da Universidade Federal de São Carlos - UFSCAR (2013), membro do Grupo de Pesquisas em Qualidade -GEPEQUFSCAR. É professor titular do Centro Universitário de Franca. Tem experiência na área de Administração, com ênfase em Administração Geral atuando principalmente nos temas: teorias administrativas, cluster, cadeia produtiva, cooperação, estratégia empresarial, inovação e aprendizagem organizacional.

\section{Adriana Kroenke}

Possui graduação em Matemática (2007), mestrado em Ciências Contábeis (2009) pela Universidade Regional de Blumenau e doutorado pelo Programa de Métodos Numéricos e Engenharia da Universidade Federal do Paraná (2014). Professora do Departamento de Matemática da Universidade Regional de Blumenau desde 2010. Atualmente é professora permanente do Programa de Pós-Graduação em Administração e do Programa de PósGraduação em Ciências Contábeis da Universidade Regional de Blumenau. Suas pesquisas concentram-se na área de Análise Multivariada de Dados, Análise Decisória Multicritério e Avaliação de Desempenho. Integrante do grupo de estudos MULTIVAR.

\section{Adriana Simas da Silva}

Graduada em Administração pela Universidade do Estado do Amazonas (2012) e em Engenharia de Produção pela Universidade Federal do Amazonas (2013), com MBA em Lean Manufacturing pela Fundação Centro de Análise, Pesquisa e Inovação Tecnológica - FUCAPI (2016) e Mestrado em Engenharia de Produção pela Universidade Federal do Amazonas (2017). Atualmente é Administradora na Secretaria de Saúde do Estado do Amazonas. Tem experiência em organizações da Administração Pública e Privada, atuando principalmente nas seguintes áreas: gestão de processos, gestão ambiental, mensuração de desempenho organizacional e políticas públicas de saúde e de meio ambiente.

\section{Aldérico Silvio Gulini}

Possui formação em Sistemas de Informação pela ETT (Escola Técnica Tupy), Graduação em Ciências Econômicas pela Universidade da Região de Joinville - (UNIVILLE), Especialização em Engenharia de Produção pela Universidade do Estado de Santa Catarina(UDESC) e Mestre em Engenharia de Produção pela UNISOCIESC. É professor de Graduação e Pós Graduação nas áreas de Sistemas de Informação, Segurança da Informação, Gestão de Materiais e Patrimônio, Planejamento Logístico, Gestão de Transportes, Gestão de Escopo de Projetos e Estratégia de TI e também atua como analista de sistemas e Negócio em uma grande Companhia de Tecnologia a empresas de Médio e Grande Porte. 


\section{Alessandro Márcio Martins Dias}

Sócio Diretor da AMD Corretora Seguros. Mestre em Administração, pela Fundação Pedro Leopoldo, em 2016. MBA em Gestão de Pequenas e Médias Empresas, pelo Centro Universitário UNA, em 2010. Pós-Graduado Latu Sensu em Gestão de Projetos, pela Fundação Dom Cabral - FDC, em 2005. Graduado em Engenharia de Produção, pela Universidade Federal de Ouro Preto - UFOP, em 2003. Técnico em Meio Ambiente, pelo Centro Federal de Educação Tecnológica de Ouro Preto - CEFET / OP, em 2002. PMP, filiado ao PMI-MG, com experiência na gestão de projetos industriais e de negócio realizando atividades de planejamento, engenharia, implantação, segurança do trabalho, qualidade e meio ambiente. Membro do Conselho Fiscal da AMEPRO (Associação Mineira de Engenharia de Produção)

\section{Alexandre Checoli Choueiri}

Possui graduação em Engenharia de Produção pela Universidade Estadual de Maringá (2016) e, atualmente, é mestrando em Pesquisa Operacional pela Universidade Federal do Paraná (UFPR). Suas principais áreas de pesquisa são: Problemas de Otimização Combinatorial.

\section{Alice Dantas de Medeiros}

Mestre em Administração pela UFRN, Especialista em Formação Docente para o Ensino Superior, Graduada em Administração. No UNIFACEX, coordena os cursos de graduação em Administração e o de especialização em Gestão Estratégica de Pessoas. Professora no ensino superior há 15 anos. Tem experiência como docente nas áreas de Administração Geral, Estágio Supervisionado, Empreendedorismo e Recursos Humanos.

\section{André Luiz Nunes Zogahib}

Possui graduação em Administração de empresas / Comércio Exterior pelo Centro Universitário de Ensino Superior do Amazonas (2004), graduação em Administração Pública pela Universidade do Estado do Amazonas (2005), mestrado em Administração Pública pela Fundação Getúlio Vargas (2008) e doutorado em Administração pela Universidade Federal de Minas Gerais (2014). Atualmente é professor adjunto da Universidade do Estado do Amazonas. Tem experiência na área de Administração Pública e privada, atuando principalmente nos seguintes temas: políticas públicas, planejamento governamental, desenvolvimento regional; segurança pública, comércio exterior e mercadologia.

\section{Ariel Muniky dos Santos Brito}

Graduada em Engenharia de Produção na Universidade Federal do Amazonas (UFAM). 


\section{Arnoldo José de Hoyos Guevara}

Possui graduação em Engenharia Química e Matemáticas pela Universidade de Nuevo Leon México (1961), tem mestrado em Engenharia Nuclear do PRNC na Universidade de Puerto Rico - USA (1965), doutorado em Estatística - University of California - Berkekley USA (1970), e fez pos-doutorado na Universidade de Oxford - UK ( 1985 ). É representante no Brasil da World Future Society (www.wfs.org), e do Projeto Milênio (www.millennium-project.org) rede internacional de pesquisadores que analisa prospectivamente o futuro em relação a 15 grandes desafios globais, e publica seu informe State of The Future (http://www.millenniumproject.org/millennium/publications.html )

\section{Bruno Henrique da Silva}

Bruno Henrique da Silva possui graduação em Matemática pela Universidade Tuiuti do Paraná (2012), especialização em Metodologia do Ensino da Matemática pela Universidade Leonardo da Vinci (2015) e mestrado em Engenharia de Produção pela Universidade Federal do Paraná (2016).

\section{Camila Maira Viana Gonçalves}

Graduada em Engenharia de Produção pela Universidade Federal de Mato Grosso do Sul (2016). Participou de curso de formação para Black Belts. Atualmente (2017) trabalha como gestora no setor de varejo.

\section{Carina Lorenzon}

Graduada em Engenharia de Produção pela Universidade Federal de Mato Grosso do Sul (2016). Participou de curso de formação para Black Belts. Atualmente (2017) trabalha como gestora no setor de varejo.

\section{Carlos Rodrigues Silva}

Professor da Universidade Federal de Mato Grosso/UFMS, no Câmpus de Paranaíba/CPAR. Doutor em Administração pela Universidade Nove de Julho. Mestre em Administração pela Universidade Estadual de Maringá (UEM). Graduado em Administração pela Universidade Federal de Mato Grosso do Sul (1995). Tem experiência na área de Administração, com ênfase em Estratégia de Sistemas Produtivos. Atua na Pesquisa da Gestão e Inovação de Cadeias Produtivas. Ênfase em Cadeias Produtivas do Agronegócio, com destaque para as Cadeias Produtivas da Carne Bovina e do Leite.

\section{Cassius Tadeu Scarpin}

Doutor (2012) e Mestre (2007) em Pesquisa Operacional pelo Programa de Pós-Graduação em Métodos Numéricos em Engenharia, área de concentração: Programação Matemática, na Universidade Federal do Paraná. Engenheiro de Produção (2010) e Licenciado em Matemática (2002) pela mesma universidade. Atualmente ocupa o cargo de Professor Adjunto no Departamento Administração Geral e Aplicada (DAGA) da Universidade Federal do Paraná (UFPR). Possui experiência na área de Engenharia de Produção, Gestão de Operações e Logística, com particular interesse em Pesquisa Operacional e Logística. 


\section{Cleder Marcos Schenekemberg}

Aluno de Doutorado em Métodos Numéricos em Engenharia - UFPR. Possui Mestrado em Métodos Numéricos em Engenharia/Programação Matemática pela Universidade Federal do Paraná (2015) e Licenciatura em Matemática pela Universidade do Estado de Santa Catarina (2012). Atua principalmente nas áreas de Pesquisa Operacional e Matemática Discreta e Combinatória.

\section{Cristiane Mallmann Huppes}

Professora DE da Universidade Federal da Grande Dourados (UFGD). Mestre em Contabilidade pela Universidade Federal do Paraná - UFPR, Especialista em Contabilidade Gerencial e Ensino Superior, Graduada em Ciências Contábeis pela Universidade Regional do Noroeste do Estado do Rio Grande do Sul - UNIJUÍ.

\section{Dalmarino Setti}

Possui graduação em Engenharia de Materiais pela Universidade Estadual de Ponta Grossa(1996), mestrado em Engenharia e Ciência de Materiais pela Universidade Estadual de Ponta Grossa(2003) e doutorado em Engenharia de Produção pela Universidade Federal do Rio Grande do Sul(2010). Atualmente é professor titular da Universidade Tecnológica Federal do Paraná e Revisor de periódico da International Journal of Engineering Management and Economics (IJEME). Tem experiência na área de Engenharia de Materiais e Metalúrgica. Atuando principalmente nos seguintes temas:Fundição de metais, seleção de processos, decisão multicritério discreta.

\section{Dayron Antonio Álvarez Rodríguez}

É mestre em Engenharia de Automação e Sistemas pela Universidade Federal de Santa Catarina e tem graduação em Engenharia de Controle e Instrumentação do Politécnico Colombiano Jaime Isaza Cadavid. Suas principais áreas de interesse são o controle de processos, projetos de automação com CLP e o desenvolvimento de Hardware e Firmware com foco em inovação. Trabalha como coordenador de Pesquisa \& Desenvolvimento na ONIX Tecnologia do Brasil.

\section{Deidson Vitorio Kurpel}

Possui licenciatura em Matemática pela Universidade Tecnológica Federal do Paraná, Campus Pato Branco (2012) e mestrado em Ciências pelo Programa de Pós-Graduação em Métodos Numéricos em Engenharia da Universidade Federal do Paraná (2015). Possui interesse nas áreas de Matemática Discreta e Combinatória e Programação Linear, Mista e Dinâmica. Atualmente cursa o doutorado no Programa de Pós-Graduação em Métodos Numéricos em Engenharia (PPGMNE) na Universidade Federal do Paraná. 


\section{Délvio Venanzi}

Possui Doutorado em Educação - Universidade de Sorocaba (2016), graduação em Engenharia Elétrica pela Universidade de Mogi das Cruzes (1986),Mestrado em Administração de Empresas pelo Centro Universitário Santana (SP) (2000) e Mestrado em Engenharia de Produção pela Universidade Estadual Paulista Júlio de Mesquita Filho (2008). Atualmente é professor titular da Universidade de Sorocaba e Coordenador do Curso de Engenharia de Produção. Professor de Logística e Supply Chain da Faculdade de Tecnologia de Sorocaba (FATEC). Professor de MBA do IAT/FACENS, Professor Convidado na Especialização em Engenharia de Produção UNESP-Sorocaba

\section{Dhiego Troquez}

Bacharel em Ciências Contábeis pela Universidade Federal da Grande Dourados - UFGD Profissão: Técnico Administrativo no Instituto de Previdência Social dos Servidores do Município de Dourados/MS - PreviD

\section{Djosete Santos da Costa}

Djosete Santos da Costa - CRA-RN 2073 é Administrador, Responsável Técnico pela RH Ser Consultoria Empresarial junto ao CRA/RN, Especialista em Gestão Universitária e Mestre em Engenharia da Produção. Foi Diretor de Curso de Administração e da Escola de Gestão e Negócios da Universidade Potiguar e Diretor Geral das Faculdades FPB/UNIPB (Instituições pertencentes a Laureate International Universities). Atualmente é Professor do Centro Universitário UNIFACEX onde leciona nos Curso de Administração e Logística e no curso de Pós Graduação em Gestão Estratégica de Pessoas, Diretor Administrativo Financeiro da LJ Alliance Corretora de Seguros e Diretor Executivo da RH Ser Consultoria Empresarial.

\section{Eder de Andrade Santos Falcao}

Graduando em Engenharia de Produção na Universidade Estadual de Santa Cruz. Estagiário de Engenharia de Processos na Barry Callebaut, Ilhéus-BA. Bolsista do programa Ciência Sem Fronteiras. Formação em Black-Belt Lean Six Sigma pela Voitto, MG.

\section{Eliseu Afonso Soares}

Bacharel em Administração pela Universidade Federal do Mato Grosso do Sul(UFMS). Servidor público na área de Segurança Pública do Estado de Mato Grosso do Sul.

\section{Eloni dos Santos Perin}

Mestre em Ciência, Gestão e Tecnologia da Informação pela Universidade Federal do Paraná (2017). Professora em SEED- Paraná 


\section{Fabiane Avanzi Rezende}

Graduada em Engenharia de Produção Agroindustrial na Universidade Estadual do Paraná Campus Campo Mourão. Foi integrante do Programa de Iniciação Científica - Pesquisadora Bolsista pela Fundação Araucária e Assessora de Gestão de Pessoas da Otimiza Empresa Júnior

\section{Fernanda Maria de Oliveira Firmino}

Formada em Administração de Empresa pelo Centro Universitário - FACEX (UNIFACEX) 2016. Tem experiência na área administrativa no seguimento indústria têxtil. Atualmente é assistente administrativo da empresa Vicunha Têxtil e está cursando pós-graduação em Administração Financeira.

\section{Flavio Trojan}

Pós-doutorado na Universidade Federal de Pernambuco - PPGEP (2016) pelo Projeto PROCAD-2013, Doutor em Engenharia de Produção pela UFPE - Universidade Federal de Pernambuco - PPGEP (2012). Mestre em Engenharia de Produção pela UTFPR - PPGEP (2006), Especialização em Gestão Industrial pelo CEFET-PR (2004), Graduação em Ciências Econômicas pela Universidade Estadual de Ponta Grossa- UEPG (2001), Graduação em Tecnologia Eletrônica (Automação Industrial) pelo CEFET-PR (2003). É Professor na graduação da UTFPR nos cursos superiores de Engenharia Eletrônica e Tecnologia em Automação Industrial. Professor permanente no Programa de pós-graduação em Engenharia de Produção(PPGEP - Campus Ponta Grossa) e professor permanente no Programa de pósgraduação em Engenharia de Produção e Sistemas (PPGEPS - Campus Pato Branco). Tem experiência na área de Engenharia de Produção com os temas: Pesquisa Operacional, Apoio a Decisão e Decisão Multicritério e Engenharia Elétrica, com ênfase em Automação Industrial.

\section{Gabriela Borges Silveira}

Bacharel em Ciências Contábeis pela Universidade Federal da Grande Dourados (UFGD). Atualmente é aluna regular do programa de pós-graduação em Contabilidade (Mestrado) da Universidade Federal de Santa Catarina (UFSC).

\section{Gleison de Sousa Amorim}

Possui graduação em Logística pelo Instituto Blumenauense de Ensino Superior - IBES SOCIESC. MBA em Coaching e especialização em Gestão de Operações Logísticas - GOL pela UNIASSELVI - FAMEBLU. Mestre em engenharia de produção na UNISOCIESC Joinville. Professor universitário. Tem experiência em Logística Empresarial e Engenharia de Tráfego, Logística de transporte, distribuição, armazenagem, compras e materiais e Manutenção Produtiva Total (TPM) avançado. Publicou artigos em eventos nacionais e internacionais em assuntos relacionados a engenharia, coaching e gestão da cadeia de suprimentos e logística. 


\section{Gustavo da Costa Rodrigues}

Possui graduação em Engenharia de Produção (2017) e Sistemas de Informação (2016). Tem experiência na área de Gestão da Produção, Simulação de Sistemas, Gestão de Processos, Sistemas de Gestão da Informação e Governança de Tecnologia da Informação.

\section{Haroldo Lhou Hasegawa}

Possui graduação em Engenharia de Materiais pela Universidade Federal de São Carlos (2000), mestrado em Ciência e Engenharia dos Materiais pela Universidade Federal de São Carlos (2004) e doutorado em Programa de Pós Graduação em Ciência e Engenharia de Materiais pela Universidade Federal de São Carlos (2007) também é especialista em Engenharia de Produção pelo Curso de Especialização em Engenharia de Produção pela UNESP (2010). Atualmente é professor Adjunto-A da Universidade Federal de Itajubá. Possui experiência industrial no Brasil e no Exterior (Japão). Atualmente desenvolve estudos e pesquisas envolvendo a área de Engenharia de Materiais e Metalúrgica, com ênfase em Processos de Fabricação e Conformação, atuando principalmente nos seguintes temas: reciclagem, reutilização, material cerâmico, siderurgia, e também em Engenharia de Produção na área de Gestão Estratégica Organizacional em industrias atuando nos temas de Lean Manufacturing, Supply Chain e Produção Mais Limpa.

\section{Ieda Isabella de Lira Souza}

Doutora em Administração pela Universidade Federal do Rio Grande do Norte (UFRN), na área de Políticas e Gestão Pública, possui mestrado em Administração pela UFRN na área de Gestão Organizacional e graduação em Administração pela Faculdade do Vale do Ipojuca (2005). Tem experiência na área de Gestão Organizacional e Pública. Atualmente é professora e coordenadora adjunta da graduação do curso de Administração do Centro Universitário - FACEX (UNIFACEX), e ministra aulas na pós-graduação de diversos cursos.

\section{Isabela Costa Nery}

Graduada em Engenharia de Produção pela Universidade do Estado do Amapá (2017). Atuou na Fundação Getúlio Vargas - FGV (2016) e como professora de Língua Estrangeira pelo Instituto de Idiomas Yázigi do Grupo Pearson Education (2014-2015). Possui experiência em Iniciação Científica na área de Legislação Ambiental (2016) , com artigos científicos publicados em Pesquisa Operacional, Gestão da Qualidade e Gestão da Produção. Atuando principalmente nos seguintes temas: Gestão de Projetos em Rede PERT/CPM, aplicações de Matriz de Decisão, Teoria das Filas e Programação Linear.

\section{Jose Americo Fernandes de Souza}

Graduando em Engenharia de Produção pela Universidade Estadual de Santa Cruz, Bahia. Anteriormente, Conselheiro Fiscal do CAEP e assessor Administrativo Financeiro da Optimus Engenharia Jr. Com ampla experiência na pesquisa cientifica. Atualmente, faz parte do grupo de pesquisa Mondelez, com estudo sobre a viabilidade do cacau, no intuito de fortalecer a identidade e economia regional. Além de dedicado, comprometido e sensato. 


\section{José Cícero Melo}

Bacharel em Administração pela Universidade Federal do Mato Grosso do Sul(UFMS). Administrador da Serv Festa e Fábrica de Gelo Nossa Senhora Aparecida. Experiência em comércio e pequenas empresas. Também Técnico Ambiental pelo Instituto Profissionalizante de Iturama (IEP).

\section{José Eduardo Pécora Junior}

Professor do Departamento de Adminstração Geral e Aplicada da UFPR, possui doutorado em Administração de Empresas (2008), pelo departamento de operações e sistemas de decisão na Université Laval no Canadá, mestrado em Matemática Aplicada e Computacional pela Universidade Estadual de Campinas (2002) e Bacharelado em Matemática Aplicada e Computacional pela Universidade Estadual de Campinas (1998). Tem experiência na área de Pesquisa Operacional, com ênfase em Matemática Discreta e Combinatória.

\section{Jovenilson Rocha de Oliveira}

Graduando em Engenharia de Produção pela Universidade Estadual de Santa Cruz, Bahia. Atualmente, faz parte do grupo Olam Cocoa, na função de estagiário da produção. Anteriormente, foi diretor de Gestão de Pessoas na Optimus Engenharia Júnior, onde constatou a importância do trabalho em grupo e o gerenciamento de habilidades interpessoais. Dedicado, persistente e altruísta, busca envolver-se em problemas demandados pela sociedade, fazendo da engenharia uma ponte para a construção de um mundo melhor.

\section{Juliano Ferreira Lima}

Graduado em Engenharia de Produção Agroindustrial pela Universidade Estadual do Paraná - Campus Campo Mourão. Pós graduando em Engenharia de Produção pelo Centro Universitário Internacional (UNINTER). Acadêmico de Iniciação Científica em 2012/2013 financiado pelo CNPq e em 2013/2014 financiado pela Fundação Araucária. Atualmente atuo como Analista de Qualidade em uma indústria de resistência elétrica, sendo responsável pela Gestão de Qualidade da empresa e apoio a Gestão de Processos, gerido pela ISO 9001:2015

\section{Julio Elias Normey-rico}

Possui graduação em Ingenieria Electronica Universidad Nacional de La Plata, mestrado em Engenharia Elétrica pela Universidade Federal de Santa Catarina e doutorado em Robotica Automatica y Electronica Universidad de Sevilla. É professor titular da Universidade Federal de Santa Catarina, pesquisador $1 \mathrm{~B}$ do CNPq, Coordenador do programa de formação de recursos humanos da Agencia Nacional do Petróleo (PRH 34 ANP) e Editor Associado da revista Control Engineering Practice. Atua na área de Controle de Processos, principalmente em controle de sistemas com atraso e controle preditivo, com aplicações com aplicações em diversos setores da indústria. Mantém projetos de cooperação internacional com universidades da Europa e América Latina, além de projetos de cooperação com o setor produtivo. 


\section{Kamila Taira Paschoal Alves Corrêa}

Formada em Engenharia de Produção pela Universidade Federal de Mato Grosso do Sul (2016). Pós-graduada em Engenharia de Segurança do Trabalho pela Universidade Cândido Mendes(2017). Participou de curso de formação para Black Belts. Tem experiência na área de Gestão de Produtos, Logística e Varejo. Atualmente é Gestora de Produtos no setor do varejo.

\section{Kazuo Hatakeyama}

Ph.D., "Design of Manufacturing Processes", UK. M.Sc., "Planning of Engineering Courses", USA e PG Dipl., "Management and Manufacturing Technology", Scotland. PosDoc. "Management of Higher Education"; "Innovation Policy", England e "Information, Production and Systems, Japan. Chefiou a DEP do CEPED nos projetos de equipamentos para pesquisas e produção industrial. Chefiou o DEMEC do CENTEC. Coordenou o Colegiado de EMEC da UFBA; o Mestrado em EP da UTFPR; projetos de intercâmbio de graduação na Alemanha, PQI e Pro-engenharia para a formação de doutores e mestres. Elaborou projetos de APCN de doutorado em engenharia de produção e industrial. Ministrou disciplinas de tecnologia e engenharia dos cursos de graduação, pós-graduação e especialização. Orientou alunos dos cursos de graduação, de especialização, de mestrado e co-orientou os de doutorado em tecnologia e engenharia. Publicou artigos em eventos nacionais e internacionais em assuntos relacionados a engenharia e formação de recursos humanos nas áreas tecnológicas.

\section{Kellen Dayelle Endller}

Graduada em Engenharia Química pela Universidade Estadual do Oeste do Estado do Paraná (2012) e em Engenharia de Produção pela Pontifícia Universidade Católica do Paraná (2013). Atualmente é mestranda de Engenharia de Produção pela Universidade Federal do Paraná (UFPR),. Suas principais áreas de pesquisas são: Pesquisa Operacional e Engenharia de Operações e Processos da Produção.

\section{Larissa Degenhart}

Doutoranda em Ciências Contábeis e Administração pela Fundação Universidade Regional de Blumenau - FURB (2016). Mestre em Ciências Contábeis pela Fundação Universidade Regional de Blumenau - FURB (2015). Graduada em Ciências Contábeis pela FAl Faculdades de Itapiranga - SC (2012). Já atuou em escritório de contabilidade e como professora de ensino superior. Possui experiência nas disciplinas de Mercado de Capitais e Ética e Responsabilidade Social. Atualmente é Bolsista CAPES CNPQ vinculado ao Programa de Pós-Graduação em Ciências Contábeis da FURB de Blumenau. 


\section{Leandro Aparecido Leite}

Economista pela Universidade Estadual do Centro-Oeste - UNICENTRO (2006) e Mestre em Engenharia de Produção pela Universidade Federal do Amazonas - UFAM (2012). Possui experiência na indústria em controladoria e gestão de custos, com destaque para a atuação na multinacional sul-coreana Samsung Electronics de 2010 a 2014, na qual liderou quatro projetos Six Sigma com ganho financeiro de 39,7 milhões de dólares. Foi professor substituto da Universidade Federal do Amazonas (UFAM) de 2013 a 2014, e professor de carreira na mesma de 2014 a 2017. Atualmente mora no Canada com interesse sobre o setor aeroespacial.

\section{Leticia Fernanda Pires Alves}

Mestranda do Programa de Pós-Graduação em Engenharia de Produção e Sistema (PPGEPS) na Universidade Tecnológica Federal do Paraná - UTFPR Campus Pato Branco. Engenheira de Produção Agroindustrial formada pela Universidade Estadual do Paraná - UNESPAR Campus Campo Mourão. Participou da Empresa Júnior de Engenharia de Produção, Otimiza Empesa Júnior, e foi Membro Dirigente do Crea-Jr. Participou de projetos de Iniciação Científica financiados pelo Conselho Nacional de Desenvolvimento Científico e Tecnológico.

\section{Letícia Lange de Macedo}

Formada em Engenharia de Produção pela Universidade Federal de Mato Grosso do Sul (2016). Certificada como auditora interna da Norma ISO 9001:2015. Participou de curso de formação para Black Belts. Tem experiência nas áreas de Gestão de Estoque, Cadeia de Suprimentos, Sistema de Gestão da Qualidade. Atualmente é Gestora de Aquisição no segmento de nutrição animal.

\section{Loreine Gabriele Martins da Silva Oliveira}

Formada em Engenharia de Produção pela Universidade Federal de Mato Grosso do Sul (2016). Participou de curso de formação para Black Belts. Tem experiência na área de Gestão de Produtos e Logística. Atualmente é Gestora de Produtos no setor do varejo.

\section{Luis Phillippe do Carmo Moreira}

Graduando em Engenharia de Produção, pela Faculdade de Engenharia de Minas Gerais FEAMIG. Técnico em Mecânica Industrial, pelo SENAI - ACR Centro de Formação Profissional, em 2007. Experiência de 10 anos no segmento Automotivo em diversas frentes de trabalho como: Suprimentos / Compras, Engenharia de Desenvolvimento de Produtos e Processos / Engenharia de Manufatura. 


\section{Mara Vogt}

Doutoranda em Ciências Contábeis e Administração pela Fundação Universidade Regional de Blumenau (FURB), Mestre em Ciências Contábeis pela Fundação Universidade Regional de Blumenau (FURB) e Bacharel em Ciências Contábeis pela FAI Faculdades de Itapiranga. Já atuou em escritório de contabilidade, consultorias e como professora de ensino superior. Atualmente Bolsista CAPES vinculada ao Programa de Pós-Graduação em Ciências Contábeis da Fundação Universidade Regional de Blumenau. Tem experiência em Teoria da Contabilidade, Laboratório Contábil e Consultoria em Empresa Júnior.

\section{Marcelo Gonçalves Trentin}

Possui graduação em Engenharia Elétrica (1995) e mestrado em Métodos Numéricos em Engenharia pela Universidade Federal do Paraná (2002) e Doutorado em Engenharia de Produção pela Universidade Federal do Rio Grande do Sul - UFRGS (2010). Atualmente é professor do Programa de Pós-Graduação em Engenharia de Produção e Sistemas (PPGEPS) e dos Cursos de Engenharia Mecânica, Engenharia Elétrica e Tecnologia em Manutenção Industrial da Universidade Tecnológica Federal do Paraná, Campus Pato Branco. Tem desenvolvido trabalhos de pesquisa na área da Eng. de Produção com ênfase em Simulação de Processos, Programação da Produção, atuando principalmente com métodos quantitativos para a solução de problemas, previsão de demanda e estatística aplicada. Atualmente é um dos coordenadores e professor do curso de Especialização em Engenharia de Produção da UTFPR-PB.

\section{Marcio Carvalho dos Santos}

Possui graduação em Engenharia Química pela Universidade Estadual de Maringá (1996) e Doutorado em Química pela Universidade Estadual de Maringá. Atualmente é professor efetivo da Faculdade Estadual de Ciências e Letras de Campo Mourão no Departamento de Engenharia de Produção. Tem experiência na área de Engenharia Química, com ênfase em Operações de Separação e Mistura, atuando principalmente nos seguintes temas: efluentes industriais, alimentos, metais pesados, water hyacinth e biological filter. Atua na area de projetos industriais, layout e projetos de instalações industriais.

\section{Maria Teresinha Arns Steiner}

Maria Teresinha Arns Steiner possui Pós-Doutorado pelo ITA (2005) e Pós-Doutorado pelo IST de Lisboa (2014). Atuou na Universidade Federal do Paraná de 1978 a 2010. Desde 2011 vem atuando na PUCPR, no Programa de Pós-Graduação em Engenharia de Produção e Sistemas (PPGEPS). Tem experiência na área de Engenharia de Produção, sub-área de Pesquisa Operacional. 


\section{Matheus Bazo do Nascimento}

Mestre em Engenharia de Produção pela Universidade Federal do Paraná, na área de Pesquisa Operacional (2017). Possui graduação em Engenharia de Produção pela Universidade Federal do Paraná (2014). Tem experiência na área de Engenharia de Produção, com ênfase em Engenharia de Produção. Participou de projetos de Extensão e Iniciação Tecnológica no Grupo de Tecnologia Aplicada à Otimização (GTAO), vinculado ao CNPq, nas áreas de Logística, Pesquisa Operacional (PO) e Planejamento e Controle da Produção (PCP).

\section{Mayesk Alves Rocha}

Discente do curso de engenharia de produção pela Universidade Estadual de Santa Cruz ( UESC). Atualmente, participa do projeto de iniciação científica como o tema: inovação e sustentabilidade no setor cervejeiro e também, voluntário do programa de extensão: caminhão com ciência.

\section{Meire Ramalho de Oliveira}

Possui graduação em Engenharia de Produção Química (2006), mestrado em Ciência, Tecnologia Sociedade (2012) e doutorado em Engenharia de Produção (2015) na área de Gestão de Tecnologia Inovação, todos pela Universidade Federal de São Carlos (UFSCar). Já trabalhou no Setor de Transferência de Tecnologia da Agência de Inovação da UFSCar, e também como docente na Universidade Estadual de Santa Cruz (UESC) no Departamento de Ciências Exatas e Tecnológicas (DCET). Atualmente atua como professora de Engenharia de Produção na Universidade Federal de Goias (UFG).

\section{Myller Augusto Santos Gomes}

Mestrado em Gestão de Políticas Públicas pela Universidade do Vale do Itajaí, Brasil(2013) Professor da Universidade Estadual do Centro-Oeste, Brasil

\section{Nathália Cristina Ortiz da Silva}

Possui graduação em Matemática pela Universidade Estadual de Maringá (2009) e mestrado pelo Programa de Pós-Graduação em Métodos Numéricos em Engenharia pela Universidade Federal do Paraná (2016). Atualmente, cursa o doutorado no Programa de Pós-Graduação em Métodos Numéricos em Engenharia pela Universidade Federal do Paraná. Possui experiência profissional como professora da Universidade Estadual de Maringá (2010 - 2014) e da Faculdade de Araucária (2015-2016). Atua, principalmente, na área de Pesquisa Operacional, com os seguintes temas: Planejamento e Controle de Produção (PCP) e Processos de Produção. 


\section{Nelson Hein}

Graduado em Ciências (1987) e em Matemática (1988) pela Universidade Regional de Blumenau - FURB, especialista em Ensino de Ciências / Matemática pela Universidade Regional de Blumenau (1990). Mestrado (1994) e Doutorado (1998) em Engenharia de Produção pela Universidade Federal de Santa Catarina (UFSC). Possui Pós-Doutorado pelo IMPA - Associação Instituto Nacional de Matemática Pura e Aplicada (2003) e pela Anderson School of Management da Universidade do Novo México (EUA), concluído em 2011. É professor do Departamento de Matemática da Universidade Regional de Blumenau desde 1989. Atualmente é professor permanente no Programa de Pós-Graduação em Ciências Contábeis (PPGCC) da Universidade Regional de Blumenau. Tem experiência na área de Matemática Aplicada, atuando principalmente nos seguintes temas: análise estatística multivariada e análise decisória multicritério. Coordena o grupo de Estudos MULTIVAR.

\section{Orlando Roque da Silva}

Professor Titular de Inovação Tecnológica no Centro Universitário das Faculdades Metropolitanas Unidas e professor de Engenharia de Produção na Faccamp. Graduado em Administração pelo Centro Universitário SantAnna, mestre em Administração pela Pontifícia Universidade Católica de São Paulo e doutor em Engenharia de Produção pela Universidade Metodista de Piracicaba. Foi professor do programa de mestrado e doutorado em engenharia de produção da Unimep, atualmente é coordenador do Programa de Mestrado Acadêmico em Administração no Centro Universitário das Faculdades Metropolitanas Unidas.

\section{Rafael Leandro da Silva}

Metalúrgico pela empresa Vallourec Soluções Tubulares - desde 2010. Técnico em Metalurgia pela escola técnica e profissionalizante - GAMA em 2009. Graduado em Engenharia de Produção com ênfase em Meio Ambiente pela Faculdade de Engenharia de Minas Gerais - FEAMIG em 2016.

\section{Rafaela Costa de Azevedo}

Possui graduação em Administração pelo CENTRO UNIVERSITÁRIO FACEX (2016). Atualmente é gerente de Unidade na Empresa Paulident - Parnamirim/RN. Tem experiência na área de Relacionamento com Cliente e de Estratégia de Negócios e está cursando pósgraduação em Consultoria Empresarial.

\section{Rayane Carla Scheffer}

Graduada em Engenharia de Produção Agroindustrial na Universidade Estadual do Paraná Campus Campo Mourão. 


\section{Renato Tonello}

Mestre em Engenharia de Produção e Sistemas (UTFPR - Campus Pato Branco). Especialista em Métodos de Melhoria da Produtividade (2011) (UTFPR - Campus Pato Branco). Bacharel em Administração (2010) (UTFPR - Campus Pato Branco). Exerce o cargo de Administrador na Superintendência de Compras e Licitações da Universidade Federal da Fronteira Sul (Chapecó - SC). Áreas de interesse: Comportamento do consumidor, Gestão da Qualidade, Estatística aplicada a negócios.

\section{Robson Benedito Farias}

Bacharel em Ciências Contábeis pela Universidade Federal da Grande Dourados, (UFGD) 2015. Atualmente é aluno do mestrado do Programa Pós Graduação em Contabilidade da Universidade Federal de Santa Catarina (UFSC).

\section{Rodolfo César Costa Flesch}

Professor adjunto do Departamento de Automação e Sistemas, do Programa de Pós-graduação em Engenharia Mecânica e do Programa de Pós-graduação em Engenharia de Automação e Sistemas da Universidade Federal de Santa Catarina. É doutor e mestre em Engenharia de Automação e Sistemas e tem graduação em Engenharia de Controle e Automação e em Administração Empresarial. Suas principais áreas de interesse são controle de processos (processos com atraso e controle preditivo baseado em modelo), instrumentação e automação da medição. Mantém projetos de cooperação internacional com universidades da Europa e Ásia, além de projetos de cooperação com o setor produtivo. É bolsista de produtividade em pesquisa do CNPq.

\section{Rony Peterson da Rocha}

Doutor e Mestre em Engenharia Química pelo Programa de Pós Graduação em Engenharia Química da UEM - Universidade Estadual de Maringá. Especialista em Gestão Ambiental e Especialista em MBA Gestão Empresarial pela UNESPAR Campus de Campo Mourão. Graduado em Engenharia de Produção Agroindustrial pela UNESPAR. Atualmente é Professor e Coordenador do Curso de Engenharia de Produção Agroindustrial da UNESPAR Campus de Campo Mourão. Pesquisador do Grupo de Estudos e Pesquisas em Processos e Gestão de Operações (GEPPGO).

\section{Shirley Suellen Thesari}

Possui mestrado em Engenharia de Produção e Sistemas pela Universidade Tecnológica Federal do Paraná (UTFPR) e graduação em Administração pela Faculdade de Pato Branco. Atualmente é servidor público na Universidade Tecnológica Federal do Paraná, Campus Pato Branco. Tem experiência na área de Administração. Áreas de interesse: Administração, Pesquisa Operacional, Apoio a Decisão, Decisão Multicritério e Empreendedorismo. 


\section{Talita Mariana Pinho Schimidt}

Mestre em Pesquisa Operacional (2017) pelo Programa de Pós Graduação em Engenharia de Produção (PPGEP) da Universidade Federal do Paraná (UFPR) e é aluna do Grupo de Tecnologia Aplicada à Otimização (GTAO), vinculado ao Departamento de Administração Geral e Aplicada (DAGA) do Setor de Ciências Sociais Aplicadas da Universidade Federal do Paraná (UFPR). Engenheira Química (2014) pela Universidade Estadual do Oeste do Paraná (UNIOESTE). Atualmente cursa Doutorado em Métodos Numéricos em Engenharia na Universidade Federal do Paraná e suas pesquisas se concentram nas áreas: Pesquisa Operacional, Planejamento e Controle da Produção (PCP) e Programação Inteira Mista (PIM).

\section{Tamires Heidemann}

Possui Graduação em Administração pela Sociedade Educacional Santo Antônio (INESA) e está cursando MBA em Liderança Estratégica na Sociedade Educacional Santo Antônio (INESA). Atua como Analista de compras em uma Empresa comercial do ramo Alimentício.

\section{Tulio Arnold Aguiar de Oliveira}

Graduado em Engenharia de Produção pela Universidade do Estado do Amapá - UEAP (2017). Foi bolsista de Iniciação Científica com pesquisa voltada à Logística Reversa. Desenvolveu Artigos Científicos publicados nas áreas de Gestão de Projetos (Rede PERT/CPM), Gestão da Produção (Logística Reversa, Filosofia LEAN), Gestão da Qualidade (SERVQUAL, Ferramentas da Qualidade) e Pesquisa Operacional (Programação Linear, Teoria das Filas, Matriz de Decisão). Experiência Profissional na Companhia de Eletricidade do Amapá - CEA (2009 - 2010) e na Secretaria de Estado da Infraestrutura do Amapá - SEINF (2014 - 2015).

\section{Vinnicyus Branco de Morais Santos}

Técnico em segurança do trabalho com ênfase em meio ambiente, pela - 2008. Graduação em Engenharia de produção, pela FEAMIG - 2015. Pós-graduacao Latu Sensu em Engenharia de Segurança do Trabalho, pela Una - 2016 
Agência Brasileira do ISBN ISBN 978-85-93729-33-1

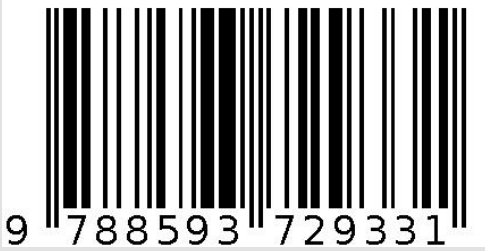

